\title{
Organización tecnológica y biogeografía humana en La Payunia, sur de la provincia de Mendoza
}

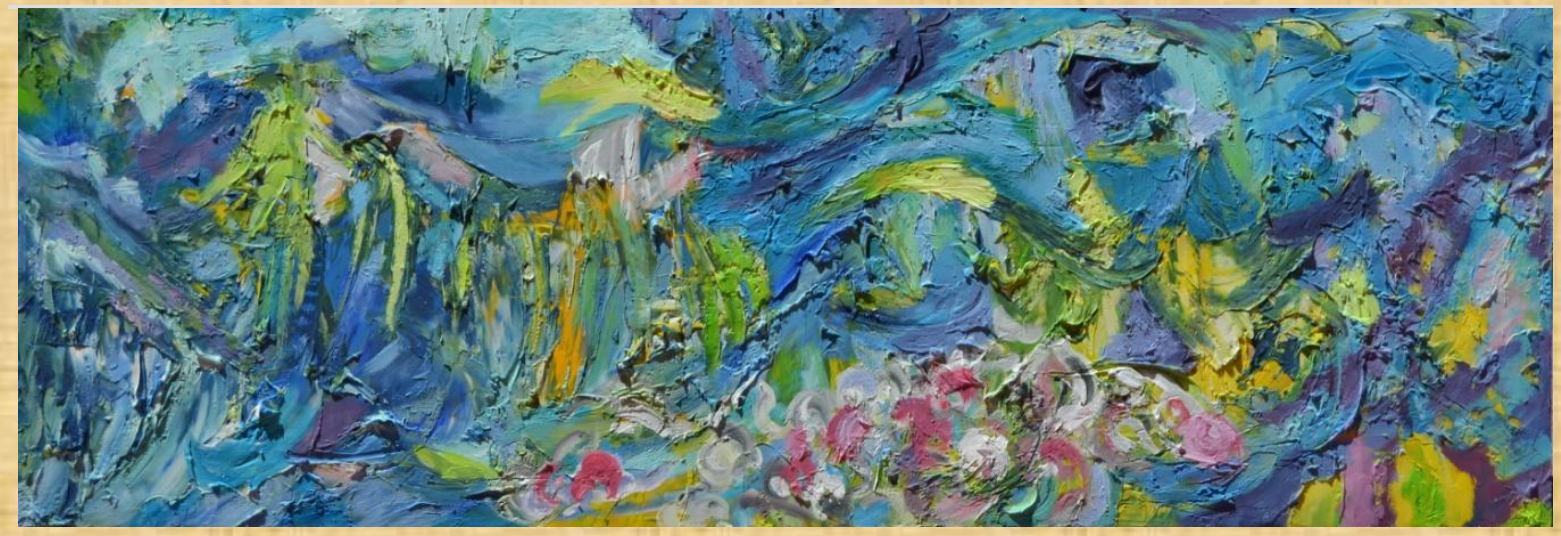

\section{Lic. María Laura Salgán}

Trabajo de Tesis para optar al título de Doctor en Ciencias Naturales.

\author{
Director: Adolfo F. Gil
}

Co-director: Luciano R. Prates

Facultad de Ciencias Naturales y Museo.

Universidad Nacional de La Plata.

AÑO 2012 
A mis padres y hermanas por apoyarme en forma incondicional. A Hugo y Fidel por compartir y ser motor de mi vida. 


\section{AGRADECIMIENTOS}

La realización de este trabajo de tesis fue posible gracias al apoyo y colaboración de muchas personas e instituciones. A todas y cada una de ellas quiero expresarles un profundo agradecimiento.

En primer lugar quisiera agradecer a Adolfo Gil y Gustavo Neme, quienes impulsaron en más de una ocasión mi formación profesional y brindaron su amistad en los momentos más difíciles.

Agradezco muy especialmente a los directores de este trabajo, Adolfo Gil y Luciano Prates, que con sus consejos, comentarios y discusiones, facilitaron y alentaron la culminación de este trabajo. También a mi director de proyecto, Gustavo Neme, cuyas discusiones y aportes invalorables, enriquecieron y ayudaron a cumplir los objetivos propuestos. Especialmente quiero agradecer a Walter Bertotto, del Departamento de Geología de la Universidad Nacional de La Pampa, quién realizó los cortes delgados y descripción de las rocas, por su generosidad y predisposición a mis permanentes consultas. A Mirta Garrido (UNSur) y Viviana Martínez (UNLPam), que colaboraron con el análisis y corrección de los análisis petrográficos, y muy especialmente a Eduardo Llambías, por las charlas, los conocimientos compartidos e interés permanente por los trabajos realizados.

A josé Ruzzante, director del International Center for Earth Sciences (ICES), por facilitarme el espacio e instrumental de trabajo en Malargüe. A Nidia Barbero, Ana Rosa Castaño Gañan, Amalia Ramires y Adalgisa Scotti, quienes compartieron mates y jornadas de trabajo.

A la Municipalidad de Malargüe y al Centro Regional de Investigación y Desarrollo Cultural (CRIDC), por colaborar en las distintas las instancias de trabajo. A la Dirección de Recursos Naturales, seccional Sur (Malargüe, Mendoza), en especial al guardaparque Martín Palma. 
Muy especialmente quiero agradecer a Miguel Giardina, quien despertó nuestro interés por la arqueológica cuyana y brindó a mi familia y a mí un lugar donde llegar. A Patricia Madrid, quién guio mis primeros pasos por la tecnología lítica y despertó mi interés en las rocas. A mis compañeros de trabajo, Nuria Sugrañes, Clara Otaola, Fernando Franchetti, Salvador Paulides, Carina Llano, Mariana Monti y Myriam Ayala, por las discusiones, charlas y mates compartidos en las jornadas de trabajo. Todos ellos colaboraron directamente en las distintas etapas de trabajo. En particular quiero agradecer a la familia Gil-Guinot, Mari Giardina, Cecilia Pérez Winter, Analía Forasiepi, Nuria Sugrañes y Clara Otaola, por facilitar mi estadía en San Rafael y brindarme su valiosa amistad.

A Fernando Franchetti, por darle arte y color a la portada de esta tesis (Obra: Lo Convenido). A Clara Otaola y Nuria Sugrañes, por su colaboración en edición y bibliografía. A Rolando Poblete por su permanente colaboración en cartografía y por los mapas realizados.

A Valeria Cortegoso, Víctor Durán, Ramiro Barberena y Raven Garvey, por responder siempre de forma generosa a mis consultas. A Paz Pompei, por colaborar y compartir tareas de campo. También a los liticólogos del norte, Silvina Castro y Gustavo Lucero, por las discusiones y cursos compartidos.

A mis padres Florencia Cabrera y Juan Domingo Salgán, mis hermanas Claudia, Fernanda y Lucia, también a mis cuñados, sobrinos y primos, que a pesar de la distancia y ausencias, siempre tuvieron palabras de aliento y apoyo en cada una de las etapas de mi formación. A mis compañeras y amigas Elina Albarrán, Nuria Sugrañes, Clara Otaola, Catalina Peña, Gabriela Ameri, Mariana Pereyra León, Romina Beltaco, Liliana Scelso e Inés Mucci por aguantarme. A Ernesto Ovando, Analía Navarro, Gabriela Díaz, Andrés Risi, Ana Rosa Cataño Gañan y Rut Lecitra, por brindarnos su colaboración y amistad en Malargüe.

Por último, a mi compañero y colega Hugo Tucker y a mi hijo Fidel Tucker, por el apoyo permanente y por brindarme toda la contención y el afecto necesarios para empezar cada día. 


\section{RESUMEN}

En este trabajo de tesis se presentan los resultados obtenidos a partir del estudio de la organización de la tecnología de los grupos cazadores recolectores que en el Holoceno tardío ocuparon los ambientes áridos y semiáridos de La Payunia, sur de la provincia de Mendoza (Argentina). Se propuso como objetivos de esta investigación, avanzar en el conocimiento de la estructura regional, el modo de aprovisionamiento y utilización de los recursos líticos y la circulación de las materias primas en la región durante el Holoceno tardío.

Los trabajos realizados involucran diferentes escalas de análisis; se realizaron prospecciones superficiales, se relevaron fuentes de aprovisionamiento, se analizaron los conjuntos líticos de sitios estratigráficos y de colecciones previas. También se realizaron estudios petrográficos y geoquímicos de rocas potencialmente útiles y piezas arqueológicas, que permitieron caracterizar las fuentes disponibles en la región y diferenciarlas de las extra-regionales. La integración de estas líneas de evidencia permitió dar cuenta de las distintas estrategias tecnológicas adoptadas por los grupos que ocuparon el área.

Las hipótesis propuestas apuntan a conocer las estrategias tecnológicas adoptadas en el aprovisionamiento y uso de los recursos locales y no locales y, los posibles cambios ocurridos en la última mitad del Holoceno tardío final.

El trabajo consistió en el análisis de materiales superficiales y estratigráficos de tres sectores de La Payunia: norte, central y sur. Estos fueron definidos con fines netamente heurísticos y teniendo en cuenta diferencias geológicas y de disponibilidad de agua. Los conjuntos líticos se analizaron desde una perspectiva tecnológica, orientada al estudio de las trayectorias productivas de los recursos líticos. Los estudios petrográficos y geoquímicos, permitieron la integración de las fuentes de aprovisionamiento a las 
trayectorias de producción y facilitaron la formulación de la base regional de recursos líticos.

Los resultados muestran diferencias espaciales y temporales en las estrategias tecnológicas adoptadas en el aprovisionamiento, uso y circulación de rocas locales y no locales. Desde un punto de vista espacial, las diferencias más notorias muestran que las materias primas más frecuentemente utilizadas habrían sido de acceso local inmediato y uso expeditivo, mientras que las rocas que le siguen en frecuencia, habrían sido obtenidas por medio de acceso directo e indirecto y de uso mayormente conservado. También se observaron diferencias en cuanto a la procedencia de los artefactos de obsidiana registrados en cada sector, que indican una direccionalidad de transporte extra regional oeste-este y una circulación intra regional sur-norte. Desde una perspectiva temporal, las variaciones muestran un incremento en la frecuencia e intensidad de uso de los recursos locales y no locales en los últimos ca. 1.000 años AP, así como un incremento en la tasa de descarte de los artefactos y la incorporación en este último periodo de artefactos de obsidiana procedentes de fuentes distantes. Este cambio podría ser el resultado de una disminución de la movilidad y al afianzamiento de redes de intercambio intergrupal. Estas tendencias permitieron discutir las expectativas planteadas en torno al modelo biogeográfico de poblamiento, sugiriendo una ocupación previa de la región (ca. 2.000 años AP) y evidenciar un proceso de intensificación en la producción tecnológica para el bloque temporal tardío (últimos ca. 1.000 años AP).

En términos generales estas variaciones han sido interpretadas como la coexistencia de estrategias de "aprovisionamiento incluido" de materia primas locales, el "aprovisionamiento directo" de larga distancia de recursos no locales y, la incorporación por medio de intercambio de rocas no locales de forma frecuente en últimos ca. 1.000 años. La discusión de los resultados permitió elaborar un modelo de circulación de materias primas, con implicancias en los rangos de acción y patrones de movilidad de los grupos cazadores recolectores que ocuparon La Payunia. 


\section{ABSTRACT}

In this thesis, it is presented the results of technological organization in arid and semi arid landscapes of La Payunia region, located in Southern Mendoza (Argentina). The main objectives of this dissertation is the improvement in the knowledge of the regional lithic resource structure, the procurement and utilization of lithic resources and also understand the circulation of raw materials in the region during the late Holocene.

The activities done for this purposes implied different analytical scales, which included superficial surveys and the study of different quarries and lithic collections from this region. Petrography and geochemical analyses of the quarries and archaeological lithic materials had been also made, which allowed the characterization of the rocks available in this region and discern those that become from extra regional areas. The integration of these lines of evidences helped to understand the different technological strategies adopted for the procurement and use of lithic material.

The hypothesis proposed here, point to the knowledge of the technological strategies adopted in the procurement and use of local and non local resources and to assess the existence of changes occurred during the last half of the late Holocene.

The work carried out in this thesis consisted in the analysis of superficial and stratigraphic materials coming from three places of La Payunia: north, central and south. These places were defined heuristically and taking into account geological differences and the difference in water availability. The lithic assemblages had been analyzed from a technological perspective, oriented to the study of the production trajectories of lithic resources. The petrography and geochemical studies allowed the integration of the study of lithic quarries and the production trajectories and also facilitated the formulation of the lithic resources regional base.

In general terms, this variations had been interpreted as a coexistence of procurement strategies for local raw materials, the direct procurement of long distance resources (non locals) and the exchange of non local rocks during the last 1000 years BP. 
The discussion of these results allowed the elaboration of a model of raw materials circulation with implications in the home ranges and mobility patterns of the hunter gatherers populations who lived in La Payunia.

The results presented here, showed spatial and temporal differences in procurement strategies and the use of local and non local rocks, and in the way they circulate among people. In spatial terms, the most notable differences are that the more common raw materials are those from immediate local access with an expedient utilization, followed by those rocks obtained by direct or indirect access, which shows a conservative use. Differences in provenance of obsidian artifacts registered in each sector were also observed, which denote an extra regional transport in west-east direction and an intra regional circulation in north-south direction. Within a temporal perspective, the most significant variations were the increase in the frequency and intensity in the use of both kind of resources (local and non local) during the last 1000 years B.P and the increase in the rate of artifact discard and the incorporation of obsidian artifacts from distant sources. These differences may be due to a diminution of the mobility and the entrenchment of social networks. In one hand, these tendencies allowed the discussion of the expectations previously proposed within the human biogeography model, and on the other hand previous occupation of this region ( $c a$. 2000 years BP) and the existence of a lithic intensification process in the last 1000 years BP is suggested. 


\section{INDICE GENERAL}

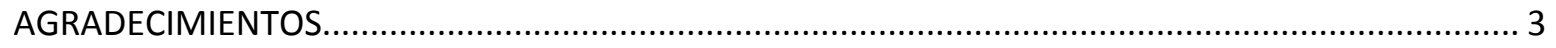

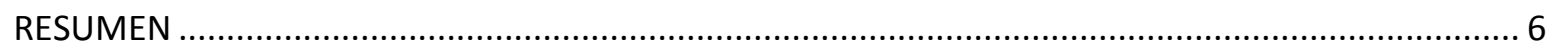

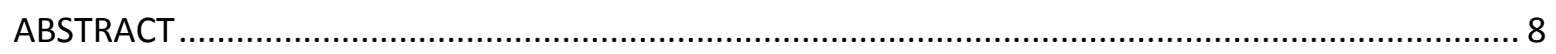

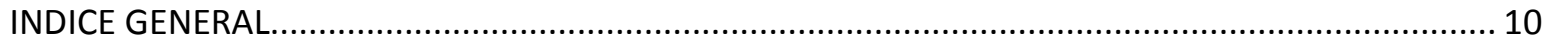

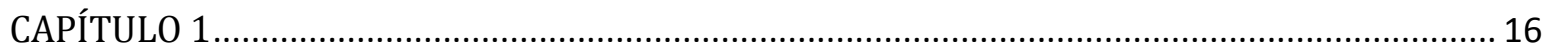

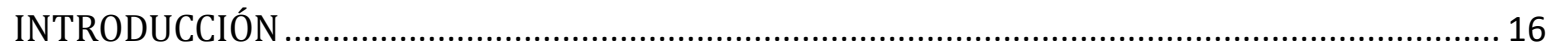

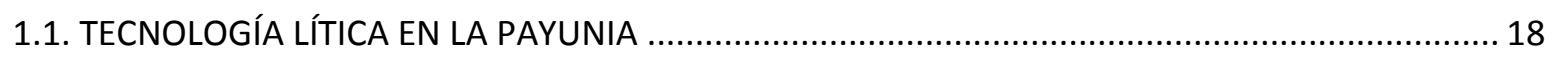

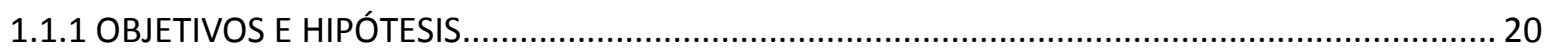

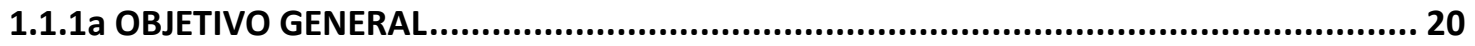

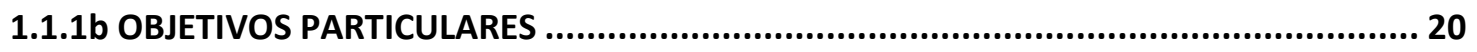

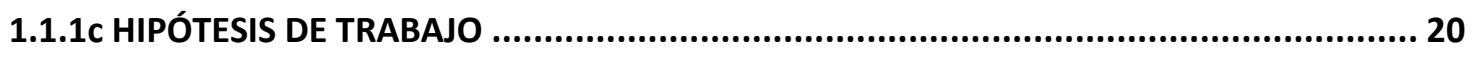

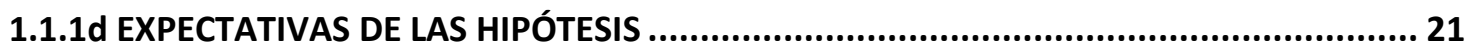

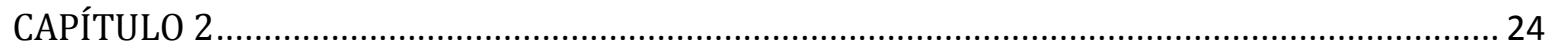

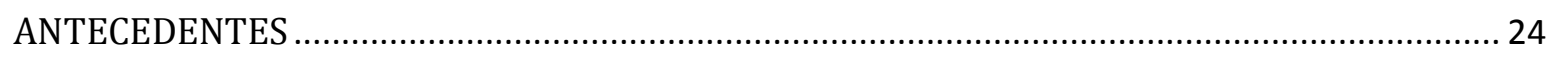

2.1 OCUPACIÓN HUMANA EN LA PAYUNIA: CONTEXTOS E IMPLICANCIAS ............................ 24

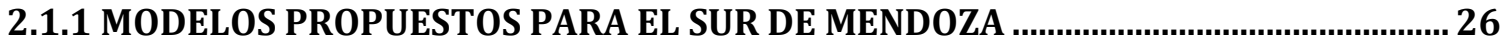

2.1.2 LA PAYUNIA EN EL CONTEXTO NORDPATAGÓNICO _................................................. 29

2.1.3 PERSPECTIVAS BIOGEOGRÁFICAS: NUEVOS MARCOS PARA VIEJOS PROBLEMAS

2.2 PROBLEMAS A DISCUTIR EN LA ARQUEOLOGÍA DE LA PAYUNIA .............................. 35

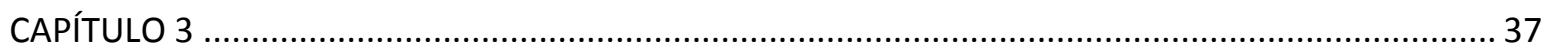

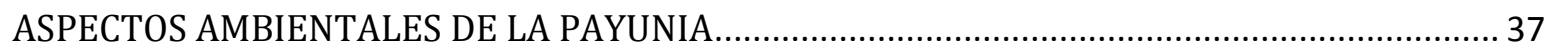

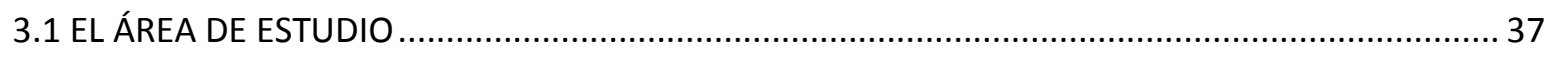

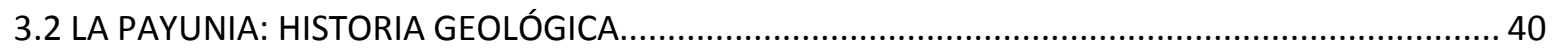

3.2.1 SECUENCIAS Y CARACTERÍSTICAS GEOLÓGICAS DE LA PAYUNIA............................ 44

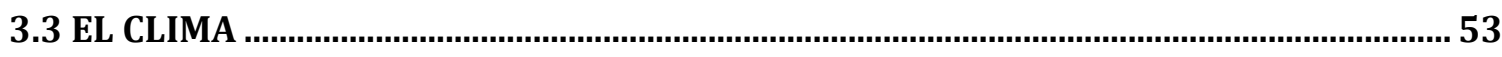

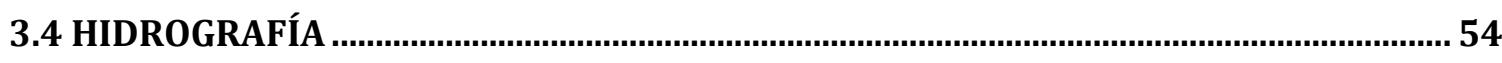

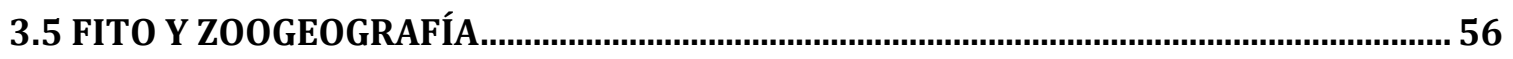


3.6 GEOMORFOLOGÍA 58

3.7 PALEOAMBIENTE, HOLOCENO TARDÍO Y DISPONIBILIDAD DE ROCAS EN EL CAMPO VOLCÁNICO LA PAYUNIA 61

CAPÍTULO 4 65

APROXIMACIONES TEÓRICAS PARA EL ESTUDIO DE LA TECNOLOGÍA ................................... 65

4.1 MARCO TEÓRICO GENERAL 65

4.2 EL ESTUDIO ARQUEOLÓGICO DE LA TECNOLOGÍA LÍTICA: LA ORGANIZACIÓN DE

LA TECNOLOGÍA. 66

4.2.1 ESTRATEGIAS TECNOLÓGICAS Y LOS APORTES DE LA ETNOARQUEOLOGÍA 68

4.2.2 AMPLIANDO CONCEPTOS. ORGANIZACIÓN TECNOLÓGICA, ETNOARQUEOLOGÍA Y ARQUEOLOGÍA. 73

4.2.3 APROVISIONAMIENTO Y DESCARTE: EXTREMOS EN LA ORGANIZACIÓN TECNOLÓGICA 80

4.2.3.1 MATERIAS PRIMAS NO LOCALES Y ESTRATEGIAS DE APROVISIONAMIENTO DE RECURSOS LÍTICOS 87

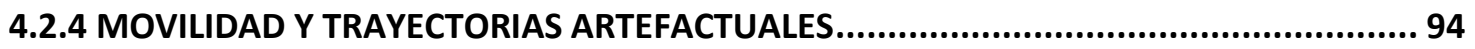

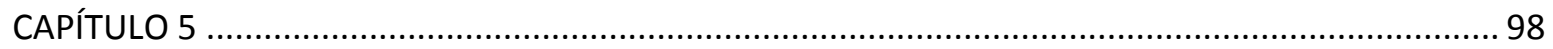

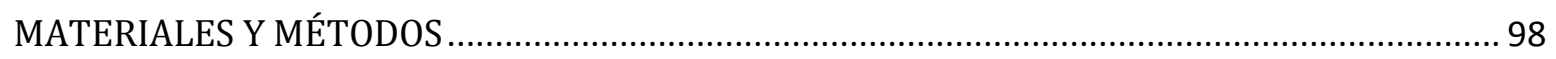

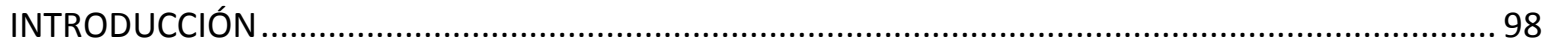

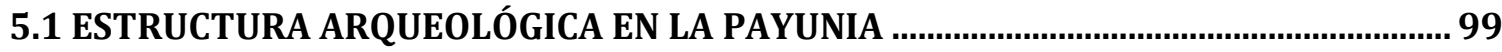

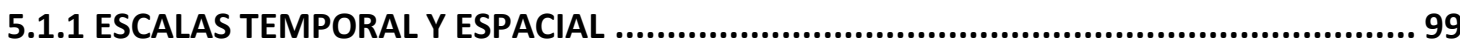

5.1.2 LA UNIDAD DE ANÁLISIS ARQUEOLÓGICO...................................................... 100

5.1.3 ESTRUCTURA ESPACIAL: SUPERFICIAL Y ESTRATIGRÁFICA .................................. 101

5.1.4 BASE REGIONAL DE RECURSOS LÍTICOS......................................................... 106

5.2 ANALISIS ARTEFACTUAL

5.2.1DESCRIPCIÓN DE LOS CONJUNTOS LÍTICOS ..................................................... 109

5.2.2 VARIABLES CONSIDERADAS EN EL ANÁLISIS DE LOS ARTEFACTOS LÍTICOS .............. 111

5.2.3 DETERMINACIÓN DE LAS MATERIAS PRIMAS..........................................................116

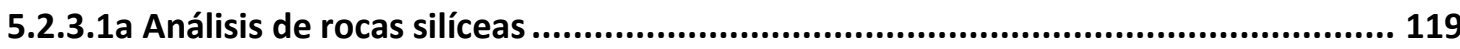

5.3 ÍNDICES Y ESTADÍSTICOS PARA EL TRATAMIENTO DE LOS DATOS .......................... 123

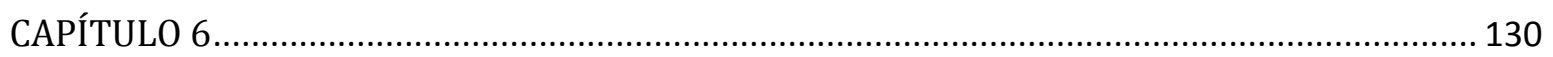

BASE REGIONAL DE RECURSOS LÍTICOS EN LA PAYUNIA...................................................... 130

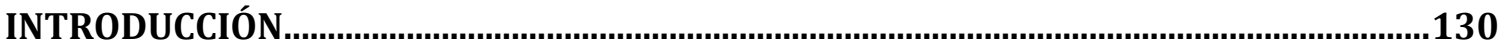


6.1 GEOLOGÍA Y LITOLOGÍA EN LA PAYUNIA

6.1.1 SECTOR NORTE: SIERRAS DE PALAUCO Y AGUA ESCONDIDA..................................131

6.1.2 SECTOR CENTRAL: CAMPO VOLCÁNICO DE LA PAYUNIA ......................................136

6.1.3 SECTOR SUR: SIERRAS CARA CURA Y DE REYES, CAÑADÓN AMARILLO Y SIERRAS

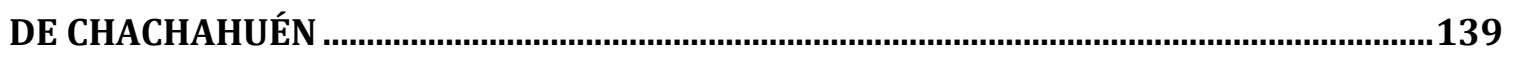

6.2 RECURSOS LÍTICOS EN LA PAYUNIA ..................................................................145

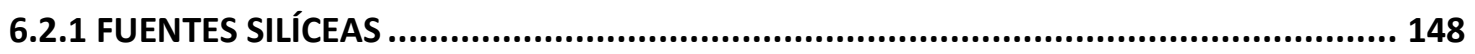

6.2.1a AGUA ESCONDIDA (SECTOR NORTE): LOCALIDAD LA PELIGROSA (LP)................... 149

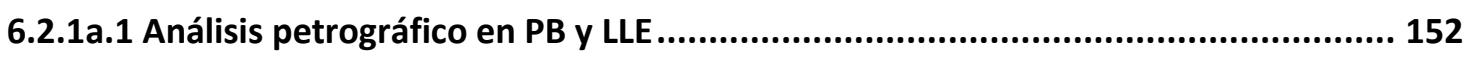

6.2.1b CAÑADÓN AMARILLO (SECTOR SUR): LOCALIDAD AGUA DE Pérez (APE) Y

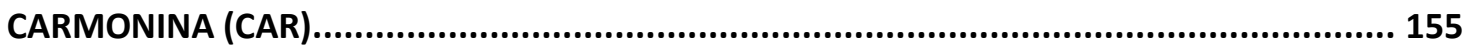

6.2.1b.1 Análisis petrográfico en APE-C y Pista .............................................................. 157

6.3 DISPONIBILIDAD DE ROCAS EN LA PAYUNIA...........................................................160

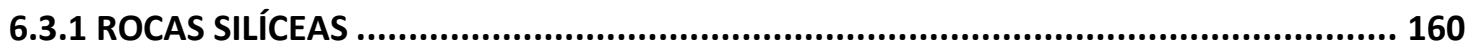

6.3.2 OBSIDIANA .............................................................................................................162

6.3.3 OTRAS MATERIAS PRIMAS ..................................................................................... 165

6.4 CONSIDERACIONES GENERALES DE LA BASE REGIONAL DE RECURSOS LÍTICOS ........... 166

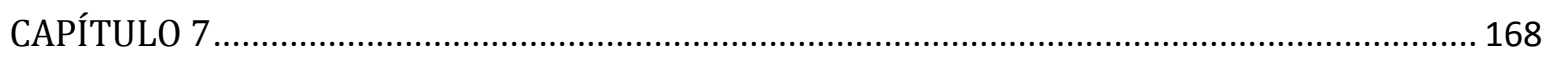

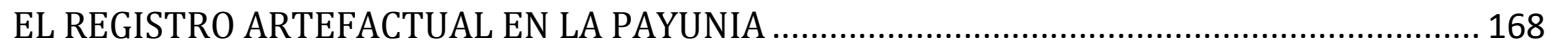

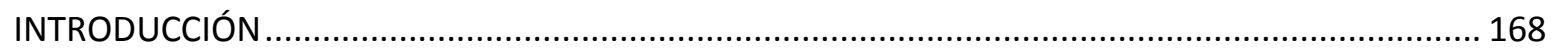

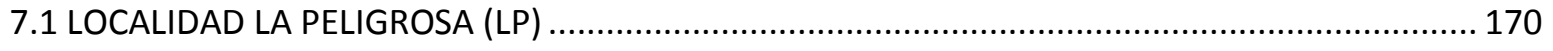

7.1.1a LA PELIGROSA 2 (LP-2) ..............................................................................172

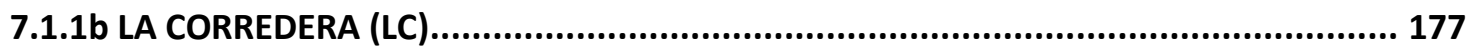

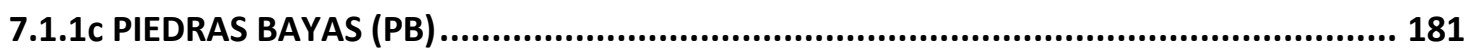

7.1.1d LA LEONA (LLE) …….................................................................................................. 184

7.1.1e LA PELIGROSA TRANSECTA 2 (LPT2) ........................................................................ 186

7.1.2 ANÁLISIS TECNOLÓGICO DE LA LOCALIDAD LA PELIGROSA ..................................187

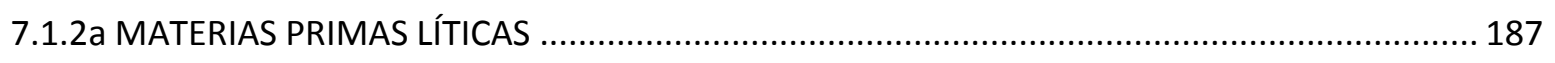

7.1.2b ESTRUCTURA TECNOLÓGICA EN LA PELIGROSA ................................................. 191

7.1.3 CONSIDERACIONES GENERALES DE LA LOCALIDAD LA PELIGROSA .....................210

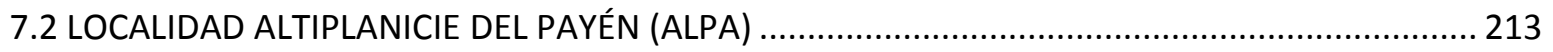

7.2.2 ANÁLISIS TECNOLÓGICO DE LA LOCALIDAD ALTIPLANICIE DEL PAYÉN (ALPA) 


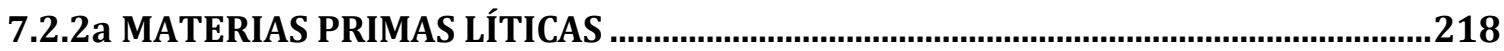

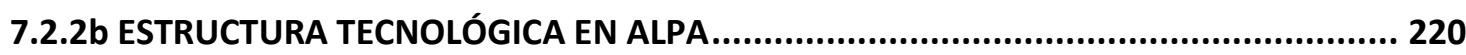

7.2.3 CONSIDERACIONES GENERALES DE LA LOCALIDAD ALPA …..............................232

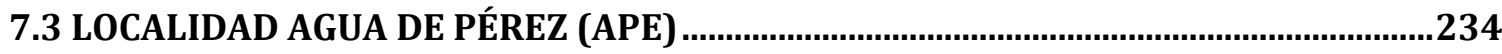

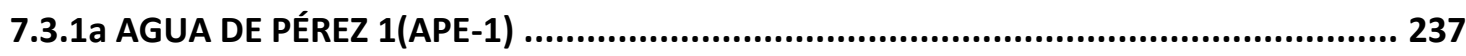

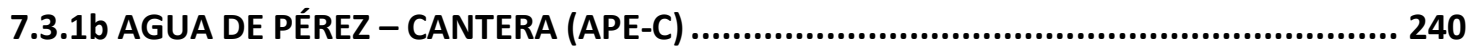

7.3.2 ANÁLISIS TECNOLÓGICO DE LA LOCALIDAD AGUA DE PÉREZ ............................246

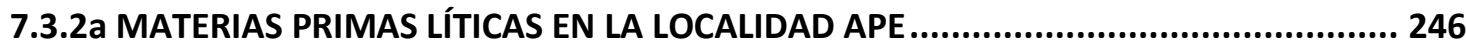

7.3.2b ESTRUCTURA TECNOLÓGICA EN AGUA DE PÉREZ (APE) ..................................... 248

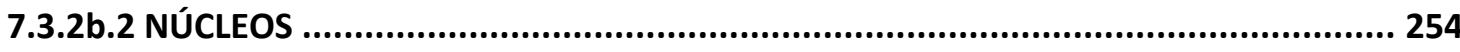

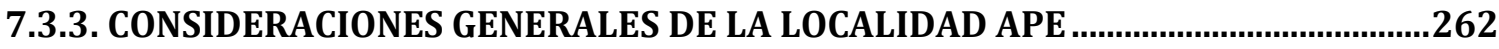

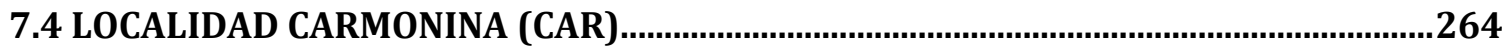

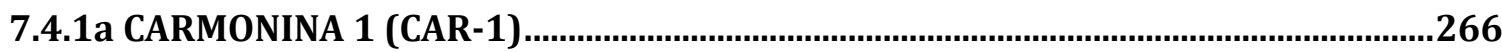

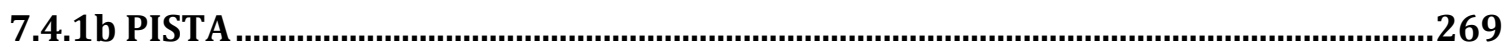

7.4.2 ANÁLISIS TECNOLÓGICO DE LA LOCALIDAD CARMONINA ..................................273

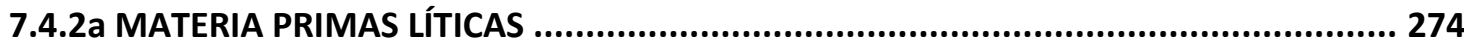

7.4.2b ESTRUCTURA TECNOLÓGICA EN CARMONINA................................................... 276

7.4.3 CONSIDERACIONES GENERALES DE LA LOCALIDAD CARMONINA........................292

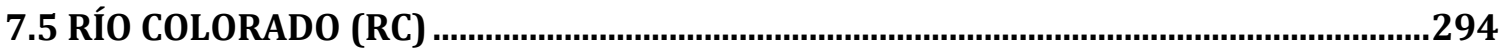

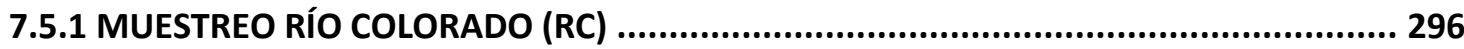

7.5.2 ANÁLISIS TECNOLÓGICO DE LA LOCALIDAD RÍO COLORADO ................................299

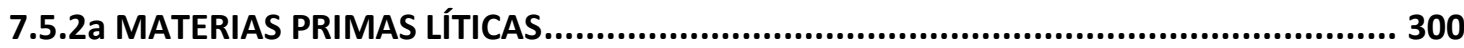

7.5.2b ESTRUCTURA TECNOLÓGICA EN RÍO COLORADO ................................................. 301

7.5.3 CONSIDERACIONES GENERALES DE LA LOCALIDAD RÍO COLORADO ….................313

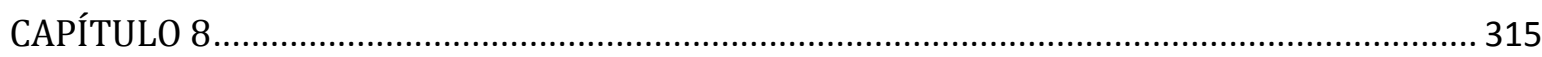

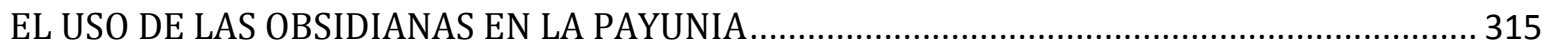

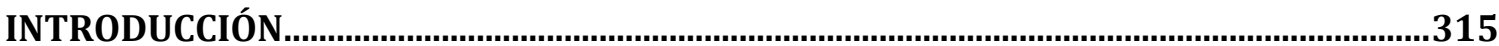

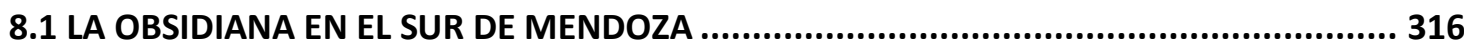

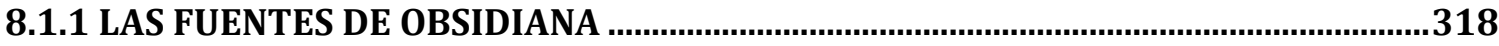

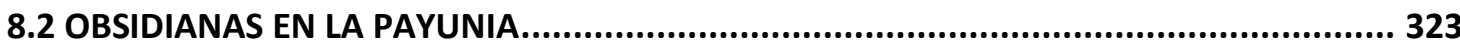

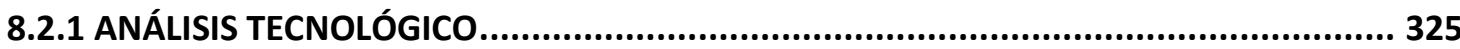


8.2.2 TENDENCIAS ESPACIALES EN EL APROVISIONAMIENTO DE OBSIDIANA EN LA PAYUNIA

CAPÍTULO 9 348

TENDENCIAS EN EL APROVISIONMIENTO Y USO DE MATERIAS PRIMAS LÍTICAS EN LA

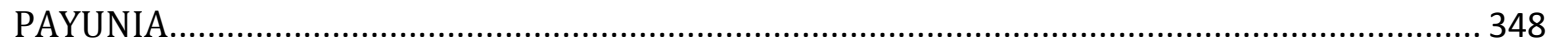

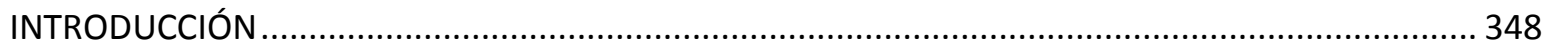

9.1 TENDENCIAS ESPACIALES EN EL APROVISIONAMIENTO Y USO DE RECURSOS

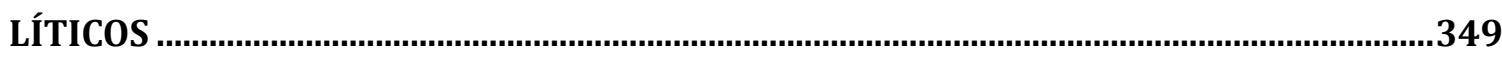

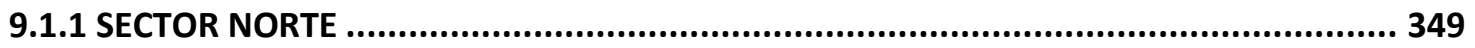

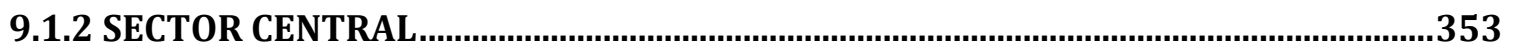

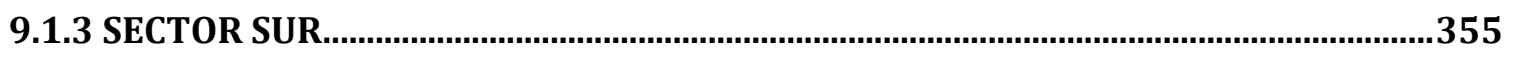

9.1.4 CONSIDERACIONES GENERALES DE LAS TENDENCIAS ESPACIALES EN LA

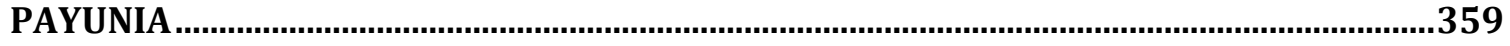

9.2 TENDENCIAS TEMPORALES EN EL USO DE LOS RECURSOS LÍTICOS........................363

9.2.1 CONSIDERACIONES GENERALES DE TENDENCIAS TEMPORALES EN LA PAYUNIA 370

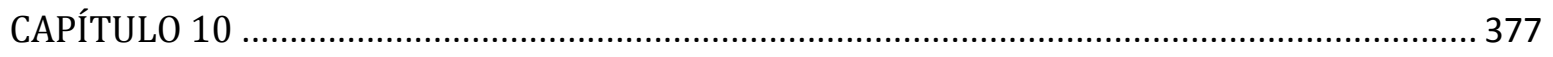

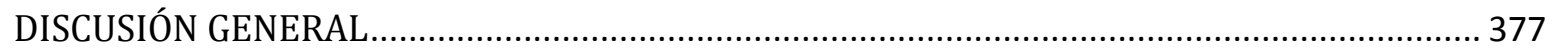

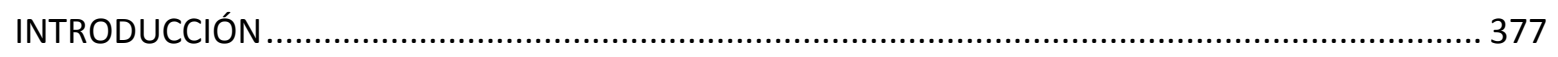

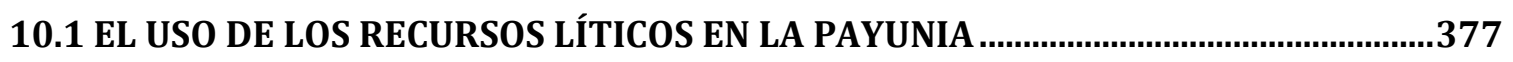

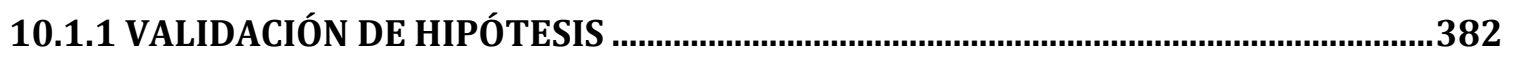

10.1.2 UN MODELO PARA EL APROVISIONAMIENTO DE RECURSOS LÍTICOS EN LA

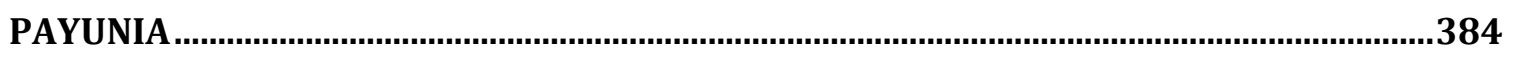

10.2 LA PAYUNIA EN EL CONTEXTO DEL SUR DE MENDOZA ...........................................387

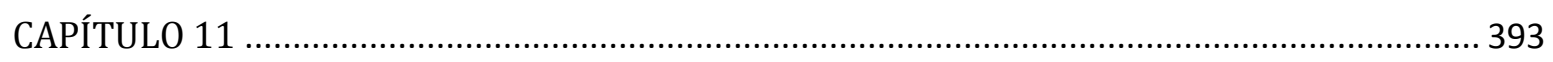

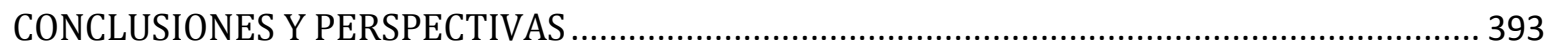

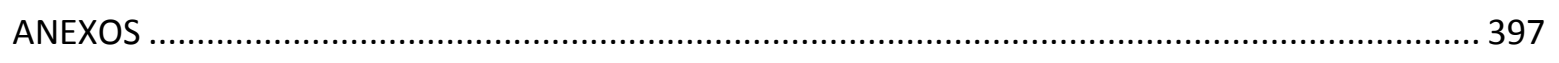

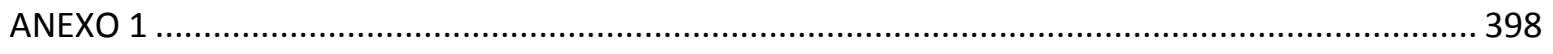

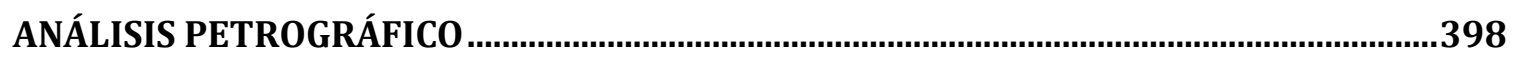

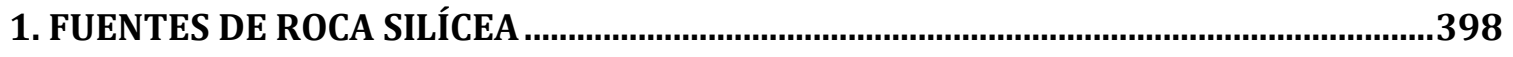

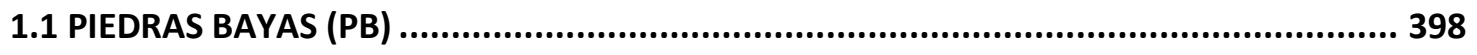

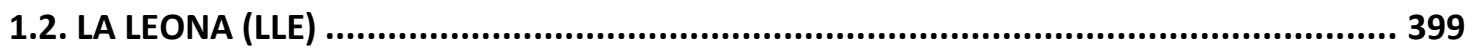

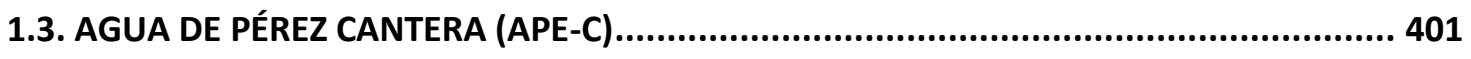

1.4 DESCRIPCIÓN GENERAL DE LAS MUESTRAS........................................................ 402 


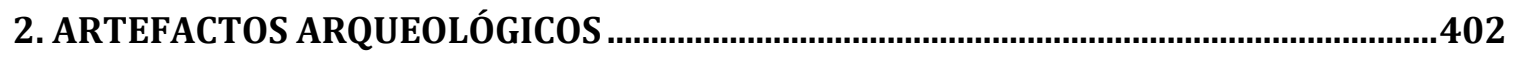

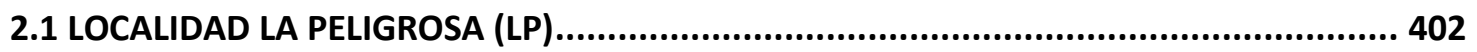

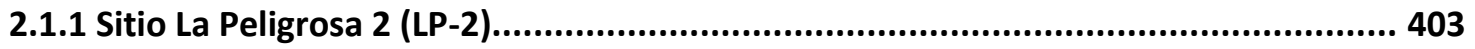

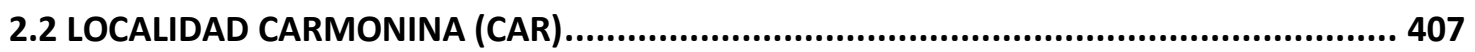

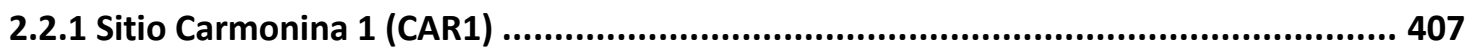

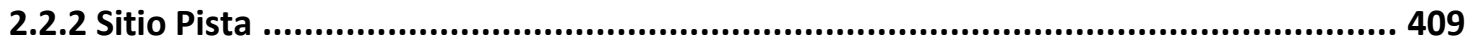

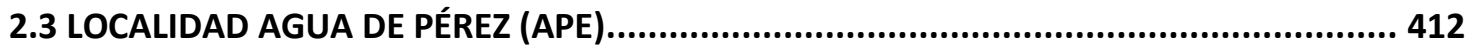

2.3.1 Sitio Agua de Pérez 1 (APE-1) .......................................................................... 412

2.4 DESCRIPCIÓN GENERAL DE LAS MUESTRAS......................................................... 413

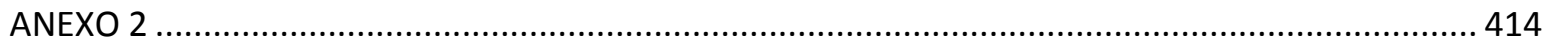

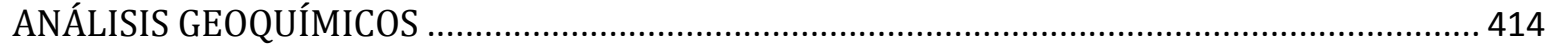

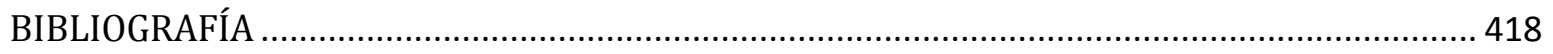




\section{CAPÍTULO 1}

\section{INTRODUCCIÓN}

Los materiales líticos en el sur de Mendoza han sido recurrentemente informados desde los primeros estudios arqueológicos en la región (entre otros, Rusconi 1961-62; Semper y Lagiglia 1968; Agüero Blanch 1971). Sin embargo, la importancia de la tecnología lítica en los modelos planteados para comprender los procesos socioculturales de la región ha sido variable y generalmente subvalorada. Los primeros trabajos que incorporan este material en su marco explicativo usaron los cambios en la morfología de los instrumentos, y en especial de las puntas de proyectil, como marcadores estilísticos, étnicos, y temporales de secuencias culturales regionales (Gambier 1976, 1979, 1980, 1985; Lagiglia 1997a, 2002). Estos avances enfocaron en la historia cultural, donde los

instrumentos fueron utilizados para definir unidades de análisis que permitieran reconocer estilos formales, sensibles a procesos étnicos, a modo de "fósil guía" (Gambier 1985; Lagiglia 1997a). Una perspectiva alternativa se generó con la adopción de marcos ecológicos y evolutivos en la década de 1990, que indagaron sobre regularidades en la explotación, uso y descarte de recursos líticos, y los integraron en el estudio de los modos de subsistencia de las sociedades humanas del sur mendocino (Durán 2000; Gil 2002, 2006; Gil y Neme 2002; Neme 2002a, 2007; Pérez Winter 2008, 2010; Bonnat 2009, 2011). El trabajo de Durán (2000) plantea una situación ecléctica al definir conjuntos en base a estilos morfológicos líticos y cerámicos, pero considerando la variabilidad funcional y el marco ambiental, así como distintas escalas espaciales de análisis. Posteriormente se incorpora a la tecnología como una respuesta adaptativa a las condiciones del ambiente natural y social (Gil 2000, 2006; Neme 2001, 2007; Durán et al. 2004; Gil y Neme 2006; Neme y Gil 2008, 2009). En este marco los trabajos compilados por Gil y Neme (2002) 
generaron tendencias e interrogantes que orientaron los estudios líticos realizados en la última década.

Entre los aportes se destacan los esfuerzos por definir la base de recursos líticos (Durán et al. 2004; Campos et al. 2006; Gil y Neme 2006; Salgán y Pérez Winter 20082009) y conocer aspectos relacionados con la disponibilidad, el acceso a los recursos, transporte e implicancias para el estudio de la movilidad de las poblaciones humanas (Pérez Winter 2010; Bonnat 2011; Gil et al. 2011). El conocimiento de las bases regionales se vio enriquecido con los estudios geoquímicos sobre obsidiana (Durán et al. 2004; Giesso et al. 2011a; Barberena et al. 2011). Esto permitió abordar aspectos espaciales y temporales sobre la circulación de esta materia prima, la incorporación de las canteras dentro de los circuitos de movilidad, la producción y la colonización de nuevas áreas (Giesso et al. 2011a, 2011b; Gil et al. 2011; Salgán et al. 2012), que incorporan la perspectiva organizacional de la tecnología lítica (sensu Nelson 1991). Se abordaron tópicos como: el hiatus ocupacional o vacío arqueológico propuesto para el Holoceno medio (p.ej. Garvey 2008a, 2008b; Neme y Gil 2009; Pérez Winter 2009a, 2009b, 2010), los procesos de intensificación en regiones de altura para momentos tardíos (Bonnat 2011) y el uso de recursos líticos en la cuenca media del río Grande en el Holoceno mediotardío (Campos et al. 2006). En La Payunia, trabajos recientes incorporan desde ésta perspectiva el registro tecnológico como variable para entender el proceso de ocupación de ambientes áridos, y discutir la intensidad y el modo de uso de los distintos espacios desde estudios distribucionales (Gil y Neme 2006).

Este trabajo de tesis busca profundizar los estudios relativos a la tecnológica lítica de La Payunia. En particular, en la forma en que las poblaciones cazadoras recolectoras organizaron su tecnología en ambientes áridos y semiáridos, a partir del estudio de los modos de aprovisionamiento y utilización de los recursos líticos. Para ello se integra y genera información referente a la base regional de recursos líticos, haciendo especial hincapié en el registro arqueológico del Área El Payén (ver definición en Gil 2006) correspondiente al Holoceno tardío. 
Para el abordaje de las formas de aprovisionamiento y utilización de recursos en La Payunia, comenzamos con la caracterización de la estructura regional de recursos líticos, la distribución y accesibilidad de las materias primas aptas para la talla, la descripción petrográfica y/o geoquímica de las canteras identificadas así como de las actividades de reducción llevadas a cabo en las fuentes de abastecimiento. Esta información sumada al estudio de la distribución de artefactos en el espacio y estratigrafía, nos permite discutir los posibles rangos de acción de las poblaciones, la intensidad de ocupación de los diferentes espacios y las posibles actividades específicas realizadas en los emplazamientos ubicados en los distintos ambientes que comprenden la región bajo estudio.

La presente tesis incluye once capítulos, las referencias bibliográficas y dos anexos. En los primeros cuatro capítulos se presentan los objetivos y los estudios previos que dan marco a la presente investigación. La perspectiva metodológica adoptada para abordar el problema de estudio se detalla en el capítulo cinco.

En el capítulo seis se integra la información geológica y los estudios geoquímicos para definir la base regional de recursos líticos de La Payunia. El registro arqueológico de La Payunia y los análisis tecnológicos realizados en el marco de esta investigación, se describen en los capítulos siete y ocho.

La integración de los resultados obtenidos e información previa regional y macro regional del registro arqueológico, se discuten en los capítulos nueve y diez. Finalmente, en el capítulo once se presentan las conclusiones y perspectivas en los estudios líticos de La Payunia.

\subsection{TECNOLOGÍA LÍTICA EN LA PAYUNIA}

La Payunia ha sido propuesta como un área con abundante disponibilidad de materias primas -mayoritariamente silíceas-, distribuidas de forma presumiblemente homogénea a través del espacio regional (Durán 1997; Gil 2000, 2006). Por lo cual, la 
escasez de materias primas en la región, nunca fue considerada un problema. Diferentes autores plantean que las poblaciones humanas no utilizan indistintamente las rocas próximas, sino que algunos seleccionan para realizar sus tareas las materias primas que prefieren (Gould 1980; Franco 2004). A su vez, la selección depende de otros factores, como la situación en que se encuentran las materias primas, el conocimiento que se tiene del área, la utilidad y duración esperada del material lítico y otras decisiones de orden no económico (p.ej. el valor simbólico; Gould 1980). La abundante disponibilidad de materias primas podría ser engañosa, dado que no todas cuentan con la calidad o características buscadas. Incluso pueden existir situaciones donde a pesar de la mencionada abundancia, aquellas que reunieran las condiciones buscadas estuvieran presentes en muy poca cantidad o en lugares específicos, o que simplemente no estuvieran en el área. Del mismo modo, las características del paisaje podrían imponer restricciones en el uso de determinadas fuentes o privilegiar el uso de aquellas cuyas características o aptitudes para la talla sean inferiores (Gould 1980; Franco 2002a).

En esta tesis se analiza la variabilidad de los recursos líticos, con el objeto de generar información relevante sobre su estructura regional. Se espera que ésta investigación permita comparar distintas áreas en términos de disponibilidad y accesibilidad, así como jerarquizarlas de acuerdo con las características espaciales. Esta información, sumada a la distribución de los artefactos en el espacio regional y al análisis de la organización de la tecnología, posibilita discutir las formas de acceso y rangos de acción de las poblaciones que transitaron y ocuparon La Payunia en el Holoceno tardío.

Desde el punto de vista metodológico, se optó por una metodología de muestreo distribucional que permita conocer y discutir las estrategias de movilidad y uso del espacio implementado por las poblaciones cazadoras recolectoras, y como éstas se articulan con la disponibilidad de recursos (Belardi 2005). Se analizan las actividades de aprovisionamiento llevadas a cabo en las fuentes primarias de recursos líticos, la distribución de las actividades en el espacio, las trayectorias tecnológicas y la selección de materias primas para la confección de las diferentes clases artefactuales. En este marco, la presente tesis explora la sensibilidad de diferentes métodos de análisis petrográficos y 
geoquímicos, que permita identificar y discutir, la selección o uso diferencial de las fuentes de recursos líticos disponibles a nivel regional.

\subsubsection{OBJETIVOS E HIPÓTESIS}

\subsection{1a OBJETIVO GENERAL}

El objetivo general de esta tesis es contribuir al conocimiento de la adaptación humana en regiones de ambientes áridos-semiáridos, mediante el estudio de la tecnología lítica. Se apunta a la comprensión de: 1) la organización tecnológica de los grupos cazadores recolectores que ocuparon ambientes áridos-semiáridos; 2) los modos de obtención y utilización de las materias primas líticas en los diferentes espacios de la región; y 3) los patrones de circulación y las formas de utilización del espacio por las poblaciones humanas.

\subsection{1b OBJETIVOS PARTICULARES}

1) Conocer la variabilidad tecnológica de los conjuntos de artefactos líticos procedentes del área; 2) reconstruir los patrones de circulación de las diferentes materias primas utilizadas para la confección de los artefactos líticos y determinar su modo de obtención; 3) determinar el papel que diferentes sectores del espacio cumplieron como fuentes potenciales de aprovisionamiento lítico; 4) analizar las estrategias de utilización de las materias primas líticas en relación con su modo de obtención; 5) contribuir a la construcción de un esquema general de la estructura regional de recursos líticos y; 6) contribuir en la contrastación de los modelos propuestos para la región.

\subsection{1c HIPÓTESIS DE TRABAJO}


H.1- El aprovisionamiento de materias primas líticas en áreas con recursos hídricos inestables y heterogéneamente distribuidos, se realizó de modo inclusivo con otras actividades de subsistencia.

H.2- Las materias primas locales fueron obtenidas y utilizadas de un modo distinto al de las materias primas exóticas.

H.3- Las materias primas exóticas son escasas; y solo aparecen como instrumentos con filos agotados y/o fracturados, desechos de formatización y reactivación de filos.

H.4- Las materias primas exóticas registran un incremento en su uso como resultado de un aumento en la demografía y en las relaciones de intercambio, durante la ocupación efectiva del espacio.

\subsection{1d EXPECTATIVAS DE LAS HIPÓTESIS}

Investigaciones previas en La Payunia proponen que la región habría sido ocupada en forma efectiva durante el Holoceno tardío como parte de un proceso de intensificación, definido arqueológicamente en regiones vecinas (Gil, 2000, 2006; Neme 2002, 2007, 2009). En este sentido, la ocupación de La Payunia respondería a la necesidad de utilizar nuevos hábitat como parte de un proceso macro regional que implicó cambios en la movilidad y el desarrollo de redes sociales amplias que favorecieron el intercambio y/o circulación de bienes, entre otros (Gil 2006). La existencia de dichas redes estaría arqueológicamente evidenciada en determinados items, entre los que se mencionan cerámicas alóctonas, placas gravadas y cultígenos (Gil 2006). Gamble (1993) destaca la importancia de la distribución de los recursos para entender las relaciones entre grupos. En regiones áridas y semiáridas las poblaciones deben utilizar amplios territorios, a veces superponiéndose con otros y estableciendo alianzas sociales que permitan el intercambio o el acceso a recursos lejanos (Gamble 1990, 1993; Madryk 1993; Yellen 1977). El intercambio es considerado como un mecanismo para enfrentar el riesgo y la 
incertidumbre, en situaciones de estrés. En los casos en que los recursos líticos son abundantes y ubicuos, se espera que reflejen el rango mínimo de acción de los grupos humanos (Binford 1979; Franco 2004).

A partir de estos postulados y en relación a la Hipótesis 1, se espera: a) un predominio en el uso de fuentes de aprovisionamiento locales cercanas o de inmediata vecindad (Gould 1980); b) las áreas de explotación, procesamientos, utilización y descarte se encuentren próximas en el espacio, el cual puede ser atribuido al rango de acción mínimo de las poblaciones (Ingbar 1994); c) que los conjuntos artefactuales recuperados presenten una alta frecuencia de rocas locales, en las que estén representadas todas las etapas de reducción; d) posean altos porcentaje de corteza; e) que los artefactos formatizados presenten una amplia variabilidad en tamaño. En instrumentos, se espera: a) alta variabilidad de tipos, baja frecuencias de fractura y evidencias de alteración térmica (esto último en los casos que sea necesario mejorar la calidad o características de las materias primas) y; b) una baja frecuencia de artefactos formatizados de modo bifacial en materia prima local y predominio de artefactos con rastros complementarios.

En desechos de talla se espera: a) una amplia variabilidad de tipos, aunque prevalezcan las etapas finales de formatización; b) la presencia de núcleos poco estandarizados, en su mayoría no agotados; c) variación de los tamaños, con mayor frecuencia de mediano pequeños y grandes; y d) escasa densidad en negativos de lascado. En áreas de ocupación recurrente, se esperan tamaños de desechos pequeños-muy pequeños relacionados con procesos post-depositacionales. En caso de pisoteo, se espera que los desechos estén en su mayoría fragmentados, vinculado con mayor cantidad de personas en el sitio.

En materias primas exóticas (Hipótesis 2), se espera: a) que el modo de obtención y uso sea distinto al de las materias primas locales; b) predominen las etapas finales de manufactura y alta especificad funcional; c) sean frecuentes los tamaños pequeños a muy pequeños, y exhiban baja reserva de corteza. En instrumentos, se espera: a) que los mismos presenten baja variabilidad de tipos de artefactos formatizados y remanentes de corteza, debido a una maximización de los recursos que ingresa como nódulos o núcleos y; 
b) presenten rastros de utilización de las fracturas. En desechos de talla: a) predominen las etapas finales de formatización -sobre todo lascas de reactivación de filos -; b) posean una alta intensidad de uso; c) no se registren núcleos y, en caso de estar presentes, estén muy agotados y con alta frecuencia de negativos de extracción.

Las Hipótesis 3 y 4 , plantean lo esperado en momentos de ocupación efectiva del espacio o fase de estabilización (en el sentido de Borrero 1994-1995; Gil 2006). Fase para la que se espera: a) se incrementen las evidencias de intercambio como respuesta a un aumento en la densidad demográfica y a un afianzamiento en las relaciones de intercambio; b) un aumento en las frecuencias de materias primas exóticas en los niveles superiores de los sitios; c) una mayor proporción de artefactos formatizados vinculados a estadías más largas en el lugar, como son los raspadores y/ instrumentos de molienda.

En resumen, se espera que los conjuntos artefactuales de La Payunia exhiban modos diferentes de aprovisionamiento y uso de los recursos líticos, según su distancia y disponibilidad. En este sentido, los recursos líticos locales de calidad para la talla habrían sido de uso predominante en la región, mientras que los exóticos o no locales de calidad excelente, estarían destinados a la manufactura de instrumental específico. La procedencia de los recursos no locales permitiría establecer el rango de acción mínimo de las poblaciones humanas para mediados del Holoceno tardío. En lo temporal, si bien no es posible un estudio diacrónico que permita comparar distintos bloques del Holoceno, es posible contrastar parte de las implicancias esperadas para fines del Holoceno tardío, tales como disminución de los rangos de movilidad, territorial y un aumento en las relaciones de intercambio intergrupal. 


\section{CAPÍTULO 2}

\section{ANTECEDENTES}

\subsection{OCUPACIÓN HUMANA EN LA PAYUNIA: CONTEXTOS E IMPLICANCIAS}

Los primeros estudios arqueológicos llevados a cabo en el sur de Cuyo plantearon controversias en torno al vínculo de La Payunia con las regiones colindantes, lo que llevó a que sea definida por distintos autores como parte de una unidad espacial de análisis distinta. Como ejemplo de esto tenemos los primeros trabajos de Lagiglia (1974, 1977b), que incluyen la región en una sub-área denominada Nordpatagonia Mendocina-Neuquina, que abarca el territorio correspondiente al sur mendocino, el oeste pampeano y el norte de Neuquén (Lagiglia 1974, 1977b). Schobinger (1975) por su parte, diferencia los procesos culturales observados en el norte cuyano e incluye el sector sur de la provincia en el área cultural patagónica. Asimismo Gambier (1985), al excavar sitios de los valles cordilleranos de los ríos Diamante y Grande, propone la ocupación del sur de Mendoza por poblaciones con características asimilables a las tradiciones culturales desarrolladas en el sector norte de Cuyo. Los postulados de Schobinger (1975), Gambier (1985) y Lagiglia $(1999,2002)$ se plantean sobre la base de presencia-ausencia de determinados rasgos de la cultura material, siendo el movimiento de las poblaciones el principal motor de cambio en las secuencias culturales.

Se reconocen en la región sur de Mendoza, al menos dos etapas contrastantes en la producción de conocimientos arqueológicos (Gil 2006; Neme 2007). La primera corresponde a principios de siglo XX, y se caracteriza por la comunicación de hallazgos fortuitos (Rusconi 1961-1962; Agüero Blanch 1965, 1971). Hacia mediados de siglo XX, la incorporación de investigadores diplomados potencia el desarrollo de trabajos de excavación sistemáticos y análisis detallado, dando inicio a una segunda etapa (Lagiglia 
1975, 2002; Gambier 1985; Durán 2000; Gil 2002, 2006; Neme 2002a, 2007). A partir de ese momento se diferencian los aportes de distintas corrientes teóricas, las cuales van a signar el modo de ver y entender el pasado. En la década de 1960, la influencia de la escuela histórico-cultural (Politis 1988), hace pie en la región con los trabajos de Semper y Lagiglia (1968), Lagiglia (1968a, 1970a, 1970b, 1977a), Schobinger (1975) y Gambier (1985). A mediados de la década de 1990, la incorporación de estudios desarrollados desde modelos ecológicos, así como estudios interdisciplinares abocados a entender el pasado humano, priorizan el abordaje regional para la discusión de problemas puntuales. Este nuevo escenario lleva a conformar una base de datos que permite replantear y discutir postulados y modelos generados para el sur de Mendoza. Ejemplo de ello son los trabajos referentes al uso de la fauna (Gil y Neme 2002; Giardina 2007, 2012), las reconstrucciones paleoambientales de los últimos 10.000 años AP (Zárate et al. 2010, Paz et al. 2010), la dieta humana y dispersión de la agricultura (Gil et al. 2005, Novellino y Gil 2007; Llano 2007, 2011), el impacto de los cambios ambientales en las poblaciones humanas (Gil et al. 2005; Durán y Mikkan 2009; Gil y Neme 2010) la movilidad y los rangos de acción de las poblaciones a partir del estudios geoquímico sobre obsidiana (Durán et al. 2004; Giesso et al. 2011; Barberena et al. 2011; Cortegoso et al. 2012; Salgán et al. 2012b), entre otros. Asimismo, en los últimos años se incorporan líneas de investigación que centran sus objetivos en entender los cambios tecnológicos registrados en el Holoceno y cómo éstos pueden ayudar a comprender los patrones sociales y/o económicos de las poblaciones humanas (Pérez Winter 2008; Sugrañes 2009, 2011; Bonnat 2009, 2011; Paulides 2011; Salgán et al. 2008-09; Salgán et al. 2011; Salgán et al. 2012a). Estas son perspectivas que desde la organización de la tecnología, hacen foco en estudios particulares para dar cuenta de procesos regionales. 


\subsubsection{MODELOS PROPUESTOS PARA EL SUR DE MENDOZA}

Antes de profundizar sobre las características del registro arqueológico del sur mendocino es importante detenernos a explorar en detalle las distintas posturas referidas a la movilidad de las poblaciones humanas en el área. En primer lugar, debe señalarse que hasta avanzada la década de 1980, los trabajos arqueológicos apuntaban a dar cuenta de los modos de ocupación y explotación del medio (Schobinger 1975; Lagiglia 1977a y b, 1999; Gambier 1980, 1985), incorporando en sus modelos los distintos ambientes. En los trabajos pioneros de Lagiglia $(1977,1997)$ y Gambier $(1985,1987)$, se generaron secuencias regionales a partir de excavaciones y registros en sitios particulares. Estos autores plantean una movilidad de tipo trashumante en ambas vertientes cordilleranas, para los distintos momentos del Holoceno (Schobinger 1975; Lagiglia 1977a y b; Gambier 1985, 1987), donde el cordón montañoso andino es el eje vertebral de sus planteos; y la planicie oriental extra cordillerana, sólo es incorporada como una opción de desplazamiento.

En el modelo de Gambier (1985) prevalecen los movimientos estacionales desde tierras bajas a tierras altas y viceversa, a los que suma posibles movimientos menores a la llanura oriental en época invernal con el fin de aprovechar sus recursos faunísticos. Según el autor, estos grupos convergen en tierras altas durante el verano para la época de cacería y serían portadores de tradiciones similares. Lagiglia (1997a), por su parte, sostiene que los grupos se desplazaban en una zona amplia que abarca la vertiente chilena de la cordillera hasta las Ilanuras próximas al Nihuil (sureste de San Rafael). La movilidad y uso de los diferentes ambientes, estaría organizada por circuitos paralelos, uno de cada lado de la cordillera, es decir: costa - valles intermedios - cordillera (en la margen chilena) y valles interandinos - piedemonte oriental - llanuras vecinas (en Argentina). Este modo de desplazamiento sería frecuente luego del retroceso de los glaciares ocurrido alrededor de los 9.000 años AP (Zárate 2002), prevaleciendo en momentos previos una circulación en sentido predominante norte-sur (Lagiglia 1997a). 
El modelo propuesto por Durán (1997, 2000), presenta similitudes en algunos aspectos al formulado por Gambier y Lagiglia, ya que implica desplazamientos estacionales en ambas vertientes de la cordillera con momentos de fusión y fisión de los grupos. En sus trabajos busca contrastar el modelo propuesto con indicadores de estacionalidad, a partir de un detallado estudio de aleros y cuevas en ambas márgenes del río Grande. Contrario a los planteos previos sostiene que los distintos ambientes pudieron ser alternativas en un amplio circuito de explotación plurianual de un área muy extensa, donde no se desplazaba necesariamente todo el grupo (Durán 2002). Para los últimos 2.000 años, el autor propone que habrían tenido lugar procesos de diferenciación social entre los grupos ubicados en ambas márgenes del río Grande. Lo que explica el registro de rasgos culturales diferentes y una diferenciación cronológica en la incorporación de la tecnología cerámica, la cual se registra en la margen izquierda del río con un desfasaje de aproximado de 500 años. Entre los rasgos culturales el autor menciona diferencias en tamaño y morfología de puntas de proyectil de obsidiana, que se presentan con módulo espeso y tamaño grande en la margen izquierda del río (sitio Alero Puesto Carrasco) y delgadas medianas a pequeñas en la margen derecha (sitio Cañada de Cachi) (Durán 1997:389). Morfologías que posteriormente coexisten en ambos márgenes, junto con la incorporación de la cerámica.

Para el oeste pampeano, Berón (2004) plantea que hacia el Holoceno tardío las poblaciones que ocupaban el valle del Curacó, realizaban incursiones logísticas de largas distancias en busca de recursos no disponibles localmente. Con posterioridad a los 1.000 años AP, el aumento demográfico, el establecimiento de diferencias étnicas y la permanencia de circuitos de movilidad macro regional, habrían facilitado las interrelaciones y sistemas de alianza entre grupos. Gil $(2000,2006)$ propone que La Payunia no fue colonizada hasta tanto las poblaciones necesitaron o pudieron explotar ambientes marginales. Plantea que los cambios arqueológicos observados en las regiones vecinas, contemporáneos a la ocupación efectiva de La Payunia podrían estar señalando modificaciones en la relación hombre-ambiente que permitieron y/o requirieron utilizar hábitats marginales. Más precisamente, en el mismo período en que se establecen los 
primeros campamentos en La Payunia -hacia los 1.000-1.200 años AP, Neme (2007) detecta las primeras ocupaciones de altura en el Alto Valle del Atuel. Asimismo, se registra la introducción de cultígenos, tecnología cerámica y otros bienes considerados de intercambio (Lagiglia 1997a y b). Neme (2001, 2007) postula que las regiones de altura fueron ocupadas en el Holoceno temprano por poblaciones altamente móviles que explotaban amplias áreas entre piedemonte y los 2200-2500 msnm. En el Holoceno tardío, procesos de intensificación influidos por un postulado crecimiento en la densidad de población, llevó a los grupos humanos a incorporar en los últimos 2.000 años AP, espacios considerados hasta entonces marginales. Posteriores procesos de regionalización, podrían reflejar una disminución en la movilidad y un incremento en la territorialidad. Este patrón definido por Neme (1999) como intensificación en las regiones de altura, se manifestaría en La Payunia como la colonización y ocupación de nuevos hábitats (Gil 2006). El autor plantea que las poblaciones que ocuparon efectivamente La Payunia, mantenían un sistema de baja movilidad residencial, en el marco de las cuales podrían ser frecuentes los mecanismos de interacción intersocietal de tipo buffer (sensu Spielman 1986). Los mecanismos buffer se desarrollan para enfrentar la escasez de alimentos periódica y localizada, e implica que un grupo accede a los alimentos disponibles en otros territorios. De forma que pueden darse relaciones competitivas o mutualistas, que incluyen la dispersión poblacional y el intercambio intersocietal (Spielman 1986, citado en Gil 2006). El contraste ambiental dado entre La Payunia y las regiones vecinas, pudo llevar a establecer una relación de interacción con poblaciones productoras de alimentos, lo cual permitiría dar cuenta de la presencia de cultígenos en el registro arqueológico regional y la falta de indicadores arqueológicos de su producción local (Gil 2006). Sin embargo, los elementos de intercambio intergrupales registrados en La Payunia, más que indicar mecanismos de subsistencia alternativos, señalarían la existencia de redes de alianza que no implicaron necesariamente una importancia en la dieta.

Como alternativa al planteo de Gil, Borrero (2002) sostiene que las poblaciones humanas estarían incorporando a la región de La Payunia en circuitos de subsistencia. El autor considera que la región pudo formar parte de zonas de ampliación de los rangos de 
acción de poblaciones, antes que colonizada y ocupada como resultado de un proceso de saturación del espacio disponible. A su vez relativiza el proceso de intensificación planteado por Neme (2002) para regiones de altura y cuyos correlatos implican la ocupación de zonas hasta entonces evitadas - como La Payunia- (Borrero 2002).

Los modelos de movilidad expuestos para el sur de Mendoza hasta avanzada la década de 1990, coinciden en la idea de que la planicie oriental se incorpora como una opción estacional más dentro de un patrón de movilidad de tipo trashumante. La cual se habría mantenido sin cambios relevantes a través de todo el Holoceno. Para la última mitad del Holoceno tardío, Durán (2000) plantea al río Grande como límite interétnico, por lo cual espera encontrar diferencias en ambas márgenes. La presencia de distintos ítems foráneos, como son los tipos cerámicos en áreas distantes, ha llevado a distintos autores a pensar en un aumento de la movilidad y de los rangos de acción de los grupos (Lagiglia 1997a, Durán 2000; Berón 2004), así como la existencia de amplias redes de alianza intergrupal (Gil 2006; Neme 2007).

\subsubsection{LA PAYUNIA EN EL CONTEXTO NORDPATAGÓNICO}

Neme $(2001,2007)$ propone evaluar, para el valle alto del río Atuel, la adaptación humana en ambientes de altura y en especial en los Andes meridionales. El modelo propuesto por el autor explica los cambios en el registro, que explica como parte de un proceso de intensificación regional, donde el aumento en la presión demográfica pudo ser uno de los causantes principales de dicho proceso (Neme 2002; 2009). Realiza un estudio diacrónicos de los distintos pisos altitudinales del valle, en los cuales diferencia tres grupos de sitios, los ubicados entre los 1400 y 1800 msnm (sitio Ojo de Agua y distribuciones superficiales de arroyo La Manga); entre los 1800 y 2500 msnm (Arroyo Malo 1, Arroyo Malo 3, Cueva Arroyo Colorado); y entre los 2500 y 3600 msnm (Los Peuquenes y El Indígeno). Propone que las regiones de altura han sido ocupadas hace al menos unos 8.900 años (sitios Arroyo Malo 3), por grupos cazadores recolectores 
altamente móviles que explotaban amplias áreas hasta los 2200-2500 msnm (Neme 2007). Un proceso gradual de crecimiento demográfico en la región, habría llevado a las poblaciones a explotar en forma más intensiva estos ambientes sobre la base de la incorporación de nuevas estrategias de aprovechamiento de los recursos y cambios en los hábitos de consumo. Esto habría ocurrido hacia ca. 2.000 años AP y el autor lo define como un proceso de intensificación en el uso de los recursos. Entre los principales correlatos o indicadores arqueológicos de dicho proceso Neme (2007) menciona: reducción de la movilidad, uso frecuente de estructuras habitacionales, mayor reocupación de los sitios, presencia de una estrategia tecnológica expeditiva, aumento en el número de instrumentos de molienda, incorporación de innovaciones tecnológicas como la cerámica y la colonización de nuevos hábitats, entre otros. Este período de intensificación habría estado acompañado por un proceso de regionalización en toda la zona de Cuyo y Chile central. Evidenciado por la aparición de estilos cerámicos particulares, tales como Viluco, Agrelo y Nihuil, en Argentina (Canals Frau 1956; Lagiglia 1977a) y Bato, Llolleo y Aconcagua Salmón en Chile (Falabella y Stehberg 1989; Durán y Planella 1989). Tendencias que son interpretadas como consecuencia de una disminución en el grado de movilidad y un incremento en la territorialidad. Neme plantea que la aparición de diferentes adornos personales como el tembetá, cuentas de collar y ornamentos de moluscos en las diversas áreas del sur de Mendoza, parecerían indicar que el proceso de regionalización estuvo acompañado por una creciente diferenciación social (Neme 2002). Los trabajos realizados por Neme en los sectores de altura tienen implicancias importantes para La Payunia principalmente porque su propuesta involucra un proceso gradual de intensificación en el uso de recursos y un aumento en la demografía, que pudieron llevar -como plantean Neme y Gil (2008)- a la ocupación de áreas marginales como la región estudiada en ésta tesis (Gil 2002, 2006; Neme 2002a).

Borrero (2002) en sus comentarios críticos a la puesta al día de los trabajos arqueológicos realizados en el sur de Mendoza, cuestiona los planteos de Neme (2002a), por considerar que el registro referente a un aumento demográfico acompañado de un uso intensivo de los recursos, no es contundente en esta región. Del mismo modo, al 
analizar la ocupación de La Payunia, sostiene que la lenta incorporación de la región al ámbito de influencia antrópica, inclusive posterior a la incorporación efectiva de algunos sectores de altura, invita a explorar la idea de un uso logístico de la región desde otros centros. Como fue señalado, considera que La Payunia pudo haber sido incorporada en circuitos de subsistencia, como resultado de una ampliación de rangos de movilidad antes que como respuesta a una saturación del espacio disponible.

Posteriormente a estos planteos y en un intento de integrar la variabilidad arqueológica de los distintos sectores del sur de Mendoza, Neme y Gil (2008) conjugan la información regional disponible de índole arqueológica y paleoambiental, para dar cuenta desde una perspectiva biogeográfica. Abordan no sólo los procesos de colonización del paisaje regional sino también el uso de determinados recursos distribuidos de una forma heterogénea en el contexto ambiental. Los autores analizan y discuten los contextos usados para caracterizar la ocupación humana del sur mendocino (Neme y Gil 2008). Sostienen que la exploración, colonización y ocupación efectiva del territorio no parece haber ocurrido en forma homogénea, dado que las tendencias radiocarbónica no tienen un comportamiento lineal sino que están distribuidas de una forma heterogénea tanto espacial como temporalmente. Asimismo cuestionan la interpretación de los registros asignados a ocupaciones del Pleistoceno final/Holoceno temprano en el valle extra cordillerano del río Atuel y ponen en discusión la continuidad temporal de dicho registros durante el resto del Holoceno (Lagiglia1977a y b; Gil y Neme 2010). Suman información relevante referente al registro en cordillera que señalaría un aumento en la densidad y diversidad de ocupaciones a lo largo del Holoceno temprano. Así señalan que hacia fines del Holoceno temprano y principios del Holoceno medio, las ocupaciones humanas se consolidan con un registro más visible y extendido, ocupando ya no sólo los valles extra cordilleranos, sino también el piedemonte y los valles intermedios de cordillera. Situación que cambia hacia mediados del Holoceno medio, cuando los sitios ocupados se restringen a los valles intermedios de cordillera (Neme y Gil 2009). Neme y Gil (2008) consideran como posible causa de la falta de registro durante este período, la creciente aridez con la consiguiente disminución de la biomasa más acentuada aun en zonas de la planicie 
oriental. En el Holoceno tardío, unos 4.000 años AP, se registra un nuevo proceso de colonización de los ambientes, que en un primer momento se restringe a valles intermedios de cordillera, piedemonte y cauces extra cordilleranos (Neme y Gil 2009, 2010). Hacia los ca. 1.500-2.000 años AP, la ocupación humana se extiende hacia los espacios caracterizados como de mayor marginalidad regional, entre los que incluye La Payunia y las áreas más altas de cordillera (por encima de los 3000 msnm) (Neme 2007; Neme y Gil 2008).

\subsubsection{PERSPECTIVAS BIOGEOGRÁFICAS: NUEVOS MARCOS PARA VIEJOS PROBLEMAS}

El modelo propuesto por Neme y Gil (2008) sostiene que la ocupación del sur de Mendoza estaría estrechamente ligada a la estructura ambiental de cada uno de los ecosistemas representados en la región (Gil 2000; Neme 2002a). Siguiendo lo propuesto por el modelo de Borrero (1989-90, 1994-1995), la propuesta de estos autores está claramente enmarcada en un marco biogeográfico en sentido amplio del término (Barberena 2008). Así parten de jerarquizar los sectores según la disponibilidad de agua, productividad primaria y accesibilidad a los recursos. Con relación a esa jerarquía desarrollan expectativas sobre cómo habrían sido colonizados los distintos ambientes de la región.

En este sentido es pertinente a esta tesis profundizar sobre La Payunia. Gil (2000) propone subdividir la región en dos amplias áreas, según rasgos geomorfológicos y ambientales: Área El Nevado (en adelante AEN) y Área El Payén (en adelante AEP). El agua es un factor crítico pero diferencialmente disponible en AEN respecto a AEP que llevó a proponer como hipótesis central de su trabajo que la colonización, asentamiento y uso del espacio estuvo regido por el factor agua (Gil 2000). Esto se fundamentó en Taylor (1964) quién mostró que en estas áreas el asentamiento y movilidad residencial están regidos más por el agua que por la disponibilidad de recursos alimenticios. Respecto a la colonización humana y partiendo del supuesto de la jerarquía ambiental, plantea que las 
áreas con recursos hídricos estables y homogéneamente distribuidos, deberían ser colonizados y ocupados efectivamente (en el sentido de Borrero 1999) antes que aquellas con recursos hídricos poco abundante, inestable y heterogéneamente distribuido (Gil 2006:34). En consecuencia, el AEN habría sido colonizado antes que el AEP y sus ocupaciones serían más prolongadas y/o frecuentes.

A partir de las mismas investigaciones Gil propone ordenar la evidencia arqueológica regional referente al poblamiento humano en Contextos. Dichos contextos son planteados como unidades de análisis, construidas con el objetivo de acotar la variabilidad temporal y espacial en la organización de los sistemas. El registro arqueológico de cada contexto reflejaría algunas de las etapas definidas por Borrero para Patagonia (Borrero 1989-90, 1994-95), de modo que no sólo tiene un sentido cronológico sino también en términos arqueológicos, biogeográficos y ecológicos. En base a esto plantea un Contexto $A$, temporalmente acotado en $c a$. 7.600 años AP y vinculado a las primeras evidencias de ocupación humana a inicios de Holoceno medio, en el abrigo Cueva Delerma (Gil 2000). Estas evidencias presentan una débil asociación entre la muestra fechada y los restos materiales. El autor postula que este registro correspondería posiblemente a la exploración de la región o al uso efímero por "viajeros". Posteriormente el registro arqueológico se reanuda en ambas áreas ca. 2.000 años AP, con los registros de Cueva Ponontrehue (AEN) y el alero La Corredera (AEP). Este período de aproximadamente 5.000 años que incluye parte del Holoceno medio y Holoceno tardío sin información arqueológica, es considerado un "hiatus arqueológico regional" (Gil 2000; Neme y Gil 2008). El registro arqueológico definido en La Corredera para el Holoceno tardío, es planteado como una nueva fase de exploración y/o colonización de la región. Esta es definida como Contexto $B$ y abarca el lapso temporal ubicado entre los 2.000 años AP y los 1.000-1.200 años AP. Se suman aquí los registros de niveles inferiores de los sitios Agua de La Mula y Agua de los Caballos 1 (AEN). Según plantea Gil (2002), Schobinger (1978) otorga a los petroglifos registrados en el sur de Mendoza cronologías contemporáneas a este contexto. 
Hacia finales de Holoceno tardío, entre los 1.200-1.000 años AP y los 250 años AP, Gil (2000) registra en La Payunia las primeras ocupaciones que evidencian para un mismo sitio, actividades múltiples. Esto último junto con una mayor densidad de materiales en el depósito arqueológico, la incorporación de nueva tecnología (como son el uso de arco y flecha y la cerámica) y de plantas domésticas (p.ej. maíz) (Gil 2000). De modo que tiende a reflejar una mayor estabilidad y frecuencia de uso que en fechas anteriores. Todo esto corresponde al Contexto $C$, que se caracterizaría por una etapa de ocupación efectiva de la región (Borrero 1994-1995). Es de destacar para esta fase el registro de elementos de molienda, básicamente en el AEN, así como restos de moluscos marinos y cerámicas no locales provenientes de Chile. En este contexto se incluyen los registros de los sitios Agua de los Caballos 1, Puesto Ortubia 1, Cueva Zanjón del Buitre, Los Leones 3 y 5, y posiblemente La Peligrosa 1. Para el Contexto D, Gil (2000) observa cambios en la organización tecnológica, la subsistencia y, posiblemente, la movilidad. Entre dichos cambios destaca, un notorio aumento en la importancia de materias primas como la obsidiana y la incorporación de fauna euroasiática (Capra hircus y Ovis aries). El autor cuestiona si esta última fase corresponde a una etapa de ocupación efectiva con cambios en la organización del sistema preexistente (en el sentido de Borrero 1994-1995), o si cabría tratarla como una ocupación efectiva con saturación del espacio. Concluye que las dos regiones de La Payunia fueron colonizadas y ocupadas recientemente, hacia mediados del Holoceno tardío (1.200-1.000 años A.P.) Considera que los registros previos a esta fecha no corresponderían a una colonización de la región, y deben ser considerados con cautela dado que en ellos la señal arqueológica es muy débil.

La cronología tardía del poblamiento documentado en La Payunia es entendida en un marco espacial mayor, como consecuencia de su jerarquía ambiental marginal respecto de regiones vecinas (Neme y Gil 2008). Si bien Gil (2006) esperaba encontrar diferencias en la colonización/ocupación efectiva entre AEN y AEP, concluye que los datos no son concordantes con tales expectativas. Aún así las ocupaciones efectivas muestran mayor estabilidad e intensidad de uso de las bases residenciales en AEN, en comparación a los registros de AEP, y generalmente están asociadas con fuentes permanentes de agua. La 
Payunia estaría caracterizada por un sistema de baja movilidad residencial, notorio en el registro de AEN y en menor medida en AEP. Gil (2002) define esto último como una tendencia preliminar, ya en AEN los trabajos de campo han sido realizados con mayor intensidad que en AEP y, como consecuencia de ello el número de sitios y de muestras fechadas es también diferente.

\subsection{PROBLEMAS A DISCUTIR EN LA ARQUEOLOGÍA DE LA PAYUNIA}

Como se puede apreciar a partir de la breve revisión de los antecedentes y modelos disponibles para La Payunia, los estudios llevados a cabo en los últimos veinte años han permitido caracterizar el modo en que las poblaciones ocuparon la región, desde una perspectiva biogeográfica (Gil 2000; Neme 2001; Neme y Gil 2008). Aún así hay varios temas que permanecen como interrogantes sin responder. Uno de ellos es el marcado aumento en las frecuencias de uso de materias primas exóticas o no locales, como la obsidiana, en los distintos sectores del sur de Mendoza (Lagiglia 1997a; Gambier 1985; Durán 2000; Neme y Gil 2008). En La Payunia y el valle medio de río Grande fueron identificadas fuentes primarias de rocas silíceas aptas para la talla (Gil 2000; Durán y Altamira 2001), las cuales aparecen con frecuencia en el registro arqueológico regional. Sin embargo no se dispone todavía de estudios orientados a determinar la conformación de la base regional de recursos líticos y la disponibilidad de esta materia prima a nivel local. Tampoco se ha abordado sistemáticamente la determinación de la ubicuidad o utilidad de los recursos líticos mencionado por distintos autores como local ni las estrategias tecnológicas mediante las cuales fueron aprovechados. En relación a esto último, cabe explorar cuáles fueron los cambios en la organización tecnológica que Ilevaron a la explotación y/o uso frecuente de rocas no locales. El avance en el estudio de la distribución de los recursos líticos en el espacio regional, de las estrategias de su explotación y selección permitirá discutir con un mayor grado de resolución procesos más 
generales como los rangos de acción y los modos de interacción de las poblaciones en los últimos 2.000 años AP.

Otro aspecto relevante a discutir, es el proceso de intensificación (Neme 2001, 2007), vinculado en La Payunia con la colonización y ocupación efectiva del espacio (Gil 2000, 2006). Como se mencionó antes, Borrero (2002) cuestiona este modelo y propone uno alternativo para el sur mendocino. Ambos modelos implican modos de uso y aprovisionamiento del recurso lítico $y$, por lo tanto, pueden ser contrastados desde el estudio de la organización de la tecnología. En este sentido, los estudios llevados a cabo en el sur de Mendoza han permitido generar modelos explicativos generales con expectativas arqueológicas concretas, las cuales pueden ser contrastadas a partir de abordajes particulares, como es la base regional de recursos líticos y las secuencias de producción. El aporte principal de esta tesis al estudio de la región, es por ende contribuir en estos últimos dos puntos. 


\section{CAPÍTULO 3}

\section{ASPECTOS AMBIENTALES DE LA PAYUNIA}

\subsection{EL ÁREA DE ESTUDIO}

La Payunia, se encuentra ubicada en el extremos sureste de la Provincia de Mendoza, entre las coordenada $36^{\circ}-37^{\circ} 20^{\prime}$ L.S. y $69^{\circ} 40^{\prime}-68^{\circ} 1^{\prime}$ ' L.O (Figura 3.1) Cubre un área aproximada de $30.000 \mathrm{Km}^{2}$, limita al norte con el campo volcánico Llancanelo, hacia el oeste y sur con los ríos Grande y Colorado -respectivamente-, y al este con la provincia de La Pampa. Gran parte del área corresponde a la unidad geomorfológica Faja deprimida central y el sur de la Depresión de los Huarpes (Llambías et al. 2010), sector de mayor actividad volcánica cuaternaria. Esto imprime a la región un paisaje volcánico particular, compuesto por rocas basáltico olivínicas, que mantiene gran parte de sus formas intactas debido a lo reciente de sus formaciones (Llambías 2008, 2009). La región carece de cauces hídricos permanentes y significativos (González Díaz 1972), por lo cual el factor hídrico ha sido considerado un limitante importante para la ocupación humana (Groeber 1933; Capitanelli 1972; Gil 2006).

Las características geológicas, morfológicas y las dimensiones de La Payunia, han llevado a varios autores a considerarla, como una unidad morfoestructural independiente (Abraham 2000; Capitanelli 2005). Capitanelli (1972, 2005) distingue en la misma, cinco áreas o subregiones morfoclimáticas diferentes: Huayquerías en el sector oeste-suroeste; mesetas volcánicas, volcanes, macizo antiguo con volcanes sobrepuestos en el sector central y norte; y llanura ondulada con volcanes aislados al este (Figura 3.2). El rasgo común entre dichas subregiones es la falta de drenaje, la existencia de cuencas cerradas o depresiones salinas, los frecuentes médanos entre los que afloran las coladas basálticas y los suelos desnudos o con muy escasa vegetación (Capitanelli 2005). La meso región de La 
Payunia, ocupa una superficie que excede en extensión el área de estudio de esta tesis. El recorte de área de estudio propuesto, se basa en la delimitación regional postulada en estudios previos, que se plantea tuvieron significancia desde el punto de vista biogeográfico (Gil 2000, 2006). Es por ello, que dados los rasgos particulares que integran esta amplia superficie, se presenta una caracterización general de la región. 


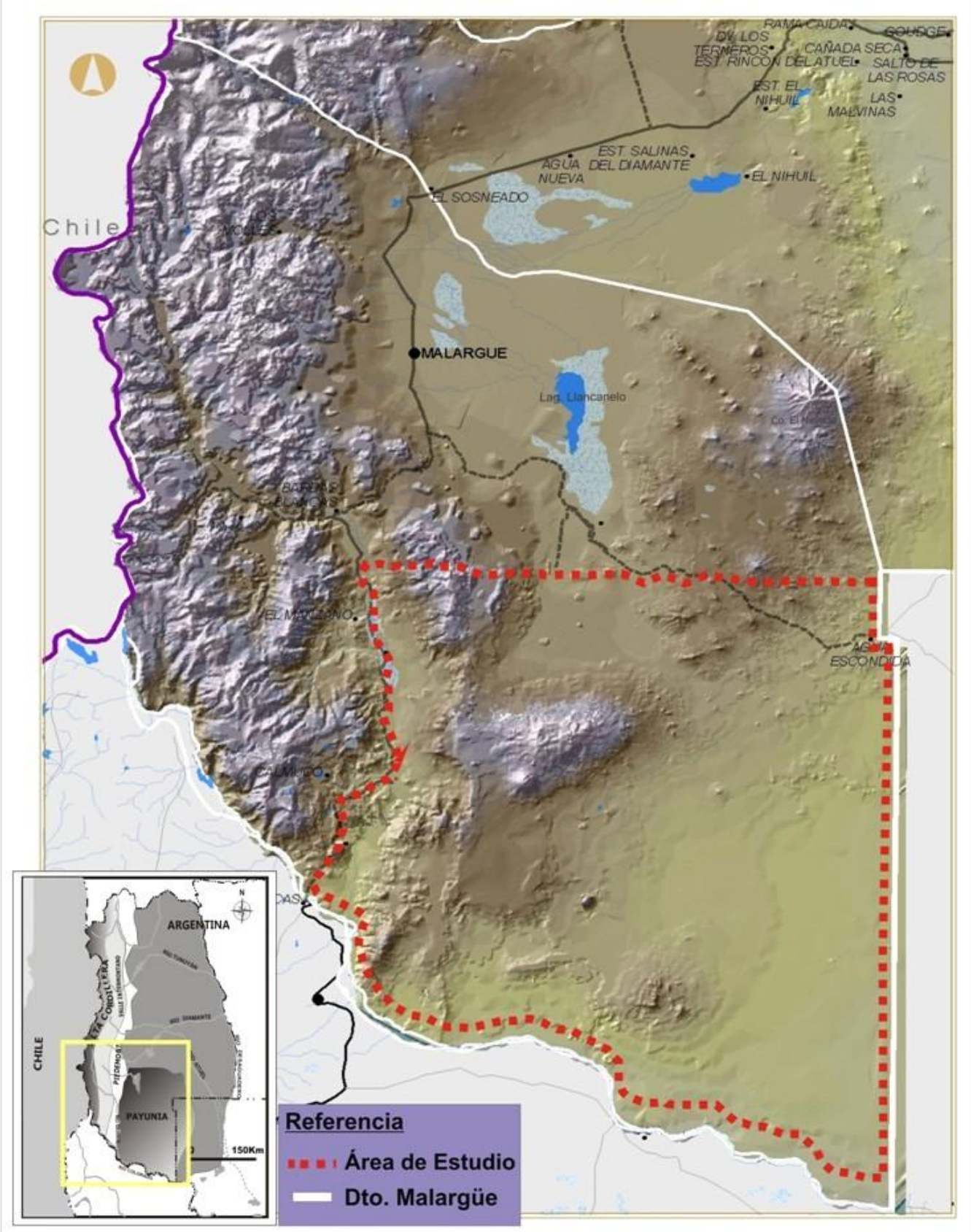

Figura 3.1. Ubicación de La Payunia (Departamento de Malargüe, sur de Mendoza). 


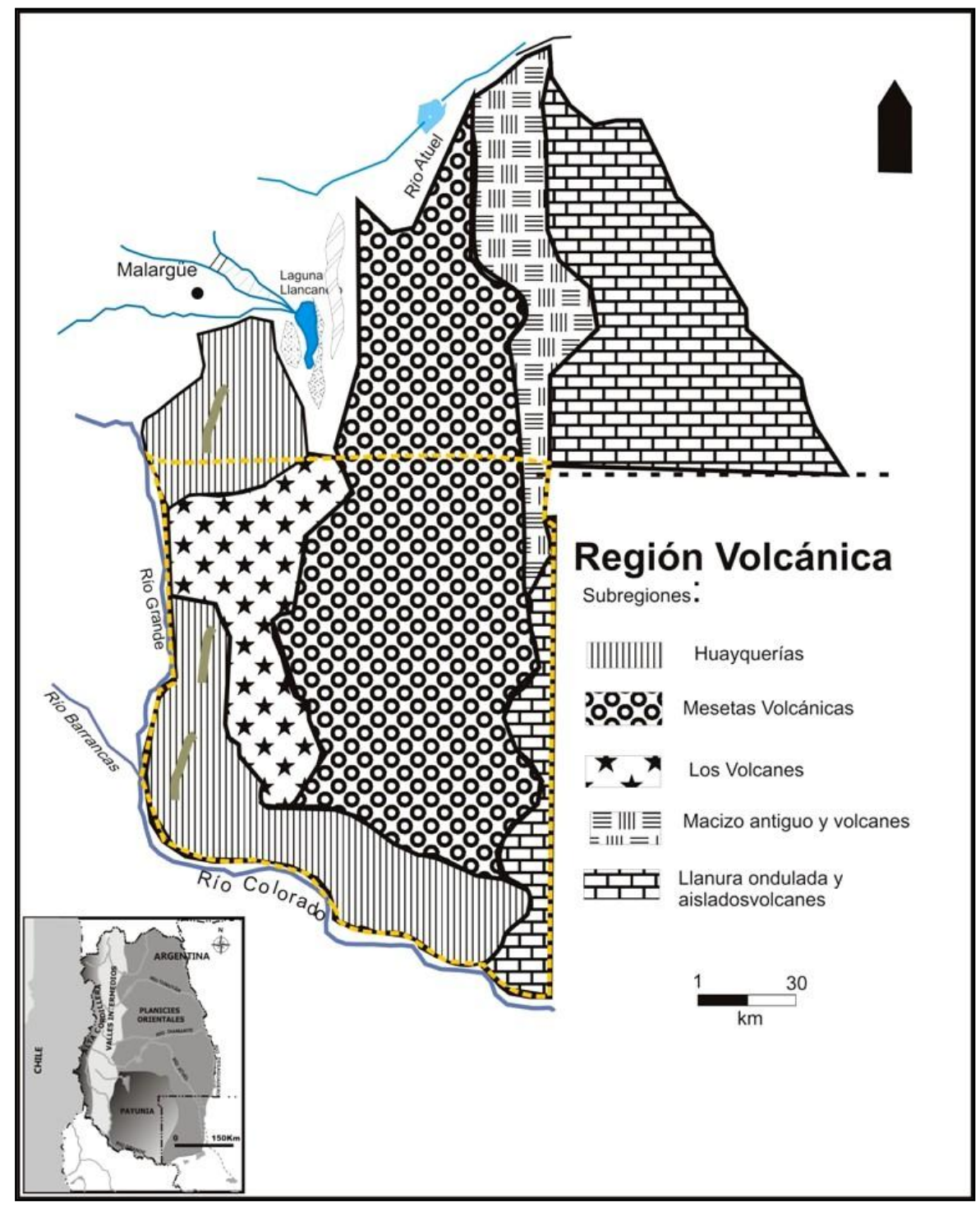

Figura 3.2 Subregiones geomorfológicas de La Payunia. Tomada de Capitanelli (2005). En línea punteada amarilla se resalta el área de estudio.

\subsection{LA PAYUNIA: HISTORIA GEOLÓGICA}

La Payunia forma parte de una extensa región volcánica también denominada Payenia o Patagonia mendocina (Polanski 1954; González Díaz y Furqué 1993; Llambías 2008). Se encuentra ubicada al este de la cordillera de Los Andes, en la faja llamada de 
retroarco andino (Llambías et al. 2010). La actividad volcánica de retroarco se encuentra al sur del segmento de subducción plana Pampeana (Ramos 2009) y continúa sin interrupción hasta alcanzar el extremo sur de Sudamérica. En esta amplia región se pueden distinguir geológicamente dos grandes segmentos: el de Payenia, entre $33^{\circ} 40^{\prime} \mathrm{S}$ y $38^{\circ} \mathrm{S}$ y el de Patagonia, que se extiende entre los $40^{\circ} \mathrm{S}$ y los $52^{\circ} \mathrm{S}$ (Llambías 2008) (Figura 3.3). En ambos, los basaltos olivínicos son dominantes. Una diferencia notable es que en La Payunia la actividad volcánica afectó sólo el borde occidental del antepaís, mientras que en Patagonia el mayor desarrollo está en el antepaís (Llambías et al. 2010). Otra diferencia importante es que en la primera, la actividad volcánica dominante es cuaternaria mientras que en Patagonia, ésta tiene pobre desarrollo (Llambías et al. 2010).

De acuerdo a los límites provinciales abarca el sector sureste de la provincia de Mendoza y noreste de la provincia de Neuquén (Llambías et al. 2010; Ramos y Folguera 2011). Está limitada al norte por el río Diamante y se extiende hasta el campo volcánico Auca Mahuida (Neuquén) (Figura 3.4). Al oeste limita con el río Grande y hacia el este supera al límite provincial, cubriendo el extremo suroeste de la provincia de La Pampa. La región también es conocida como Provincia Basáltica de Payenia (Llambías et al. 2010), Distrito Volcánico Payenia (Llambías 2009; Ramos y Folguera 2011), Provincia Basáltica Andino-Cuyana (Bermúdez y Delpino 1990; Bermúdez et al. 1993) y/o Complejo Efusivo Neógeno (Bettini et al. 1979). Se caracteriza por la presencia casi exclusiva de rocas de origen volcánico de composición basáltica. Este vulcanismo se ha desarrollado durante los últimos cinco millones de años (Ma) y ha continuado hasta hace poco menos de 7.000 años (Llambías 2009). Abarca aproximadamente unos $40.000 \mathrm{~km}^{2}$ (Ramos y Folguera 2011), con un volumen volcánico estimado de $8.387 \mathrm{~km}^{3}$ eruptado, en más de 800 centros volcánicos (Ramos y Folguera 2011). Los volcanes son en su mayoría conos de origen monogenético, destacándose en el paisaje los volcanes poligenéticos. Las coladas de lava basáltica imprimen a la zona un paisaje mesetiforme con sobreimposición de aparatos volcánicos (Polanski 1954). En un sentido norte-sur, se reconocen: el volcán Diamante, El Nevado, Payún Matrú, Payún Liso, Chachahuén y Auca Mahuida (Figura 3.4). Todos estos volcanes poligenéticos son de edad cenozoica y se formaron en posición de retroarco, 
aunque varios de ellos tienen rasgos químicos similares al arco volcánico (Kay et al. 2004; Ramos y Folguera 2005, 2011; Llambías et al. 2010).

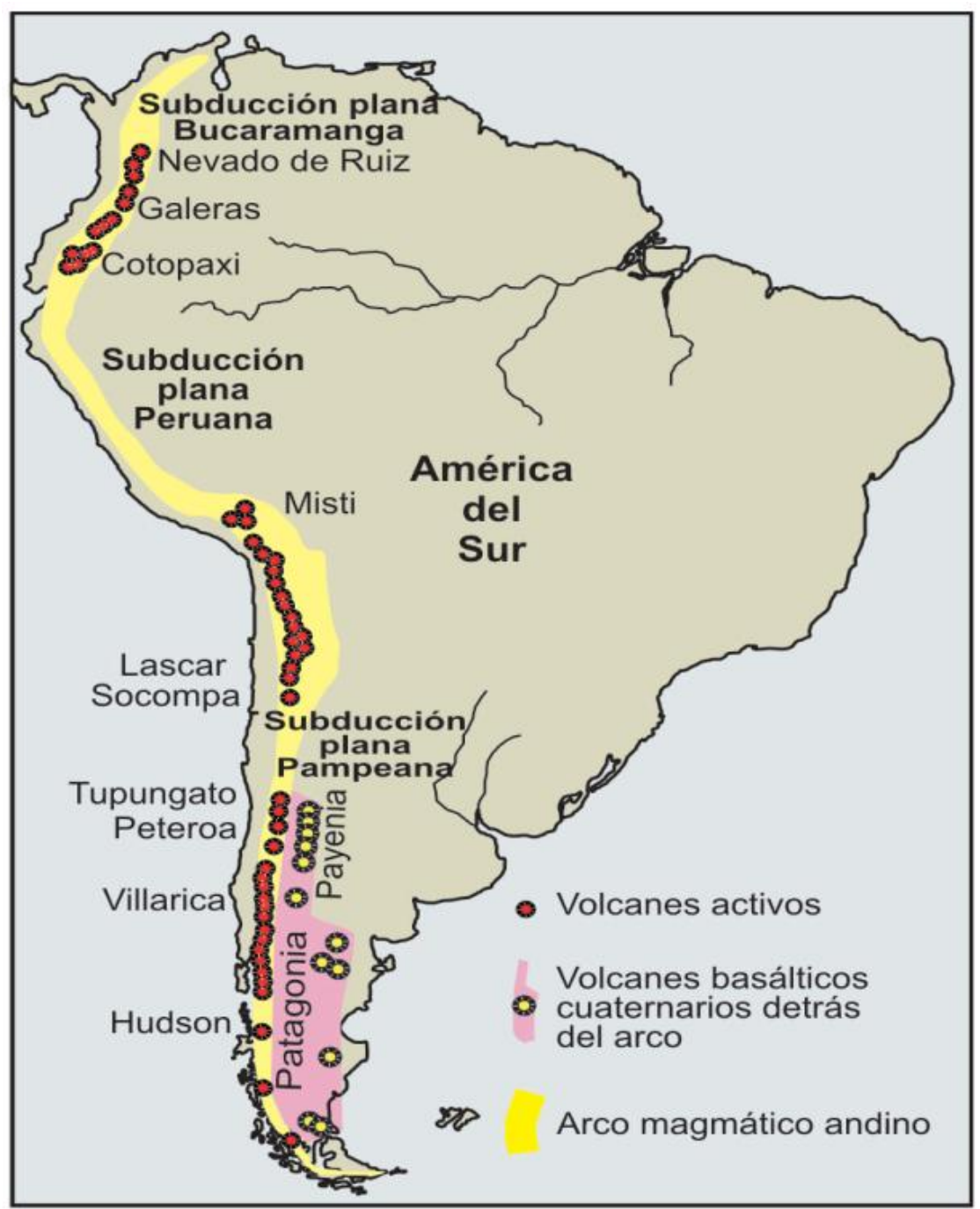

Figura 3.3 Volcanismo activo de cordillera de los Andes y el volcanismo cuaternario tardío de la región situada detrás del arco, entre las cuales se encuentra la provincia volcánica de Payenia (Polanski 1954) y la de Patagonia (Tomada de Llambías et al. 2010). 


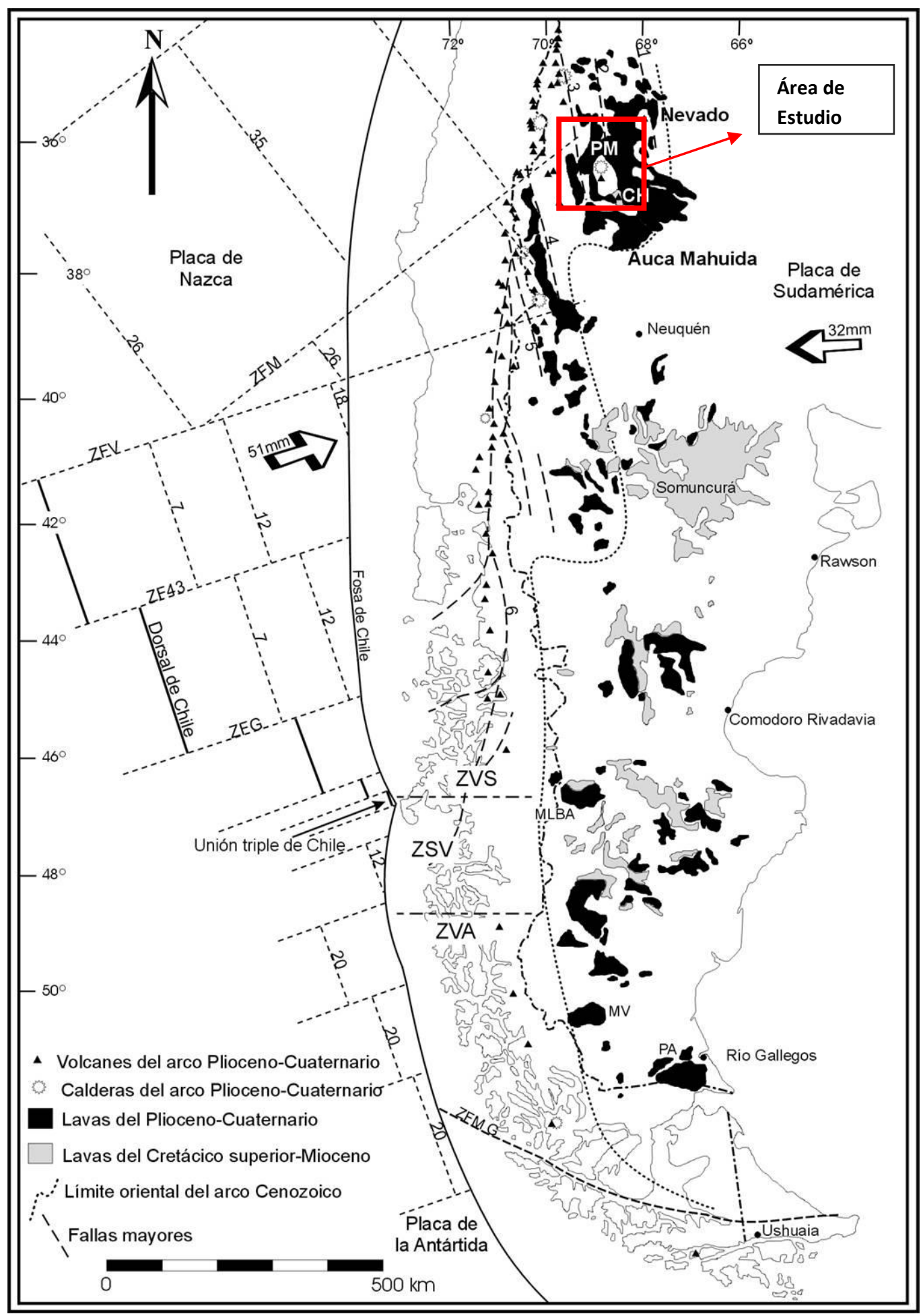

Figura 3.4 Distribución de volcanismo basáltico cenozoico (Tomada y modificada de Stern et al. 1990), Bertotto (2000) y Llambías (2003). En el cuadro rojo se indica el área de estudio de esta tesis. Referencia: PM: Payún Matrú; CH: Chachahuén; ZVA: Zona Volcánica Austral; ZVS: Zona Volcánica Sur; ZSV: Zona Sin Volcanismo. Los números indican la edad puntual en millones de años (Ma) de la placa oceánica. 


\subsubsection{SECUENCIAS Y CARACTERÍSTICAS GEOLÓGICAS DE LA PAYUNIA}

El Distrito Volcánico Payunia (Llambías 2009) o Provincia Basáltica Payenia (Llambías et al. 2010; Ramos y Folguera 2011), es una asociación de retroarco con dos picos de actividad ígnea. El más antiguo en el Mioceno inferior (23 Ma) y el más joven en el Plioceno superior-Holoceno (ca. $5 \mathrm{Ma}$ ). El volcanismo en La Payunia posee dos episodios diferenciados en edad, composición y afinidad tectónica (Kay et al. 2006). El primer episodio ocurrió durante el Mioceno-Plioceno tardío y está representado por los volcanes Chachahuén, Plateado y Nevado, asignados al volcanismo de arco (Kay et al. 2004; Kay et al. 2006). El segundo episodio se produjo en el Plioceno final-Cuaternario con afinidad intraplaca y vulcanismo basáltico, muy extendido en el Campo Volcánico de Llancanelo y el Campo Volcánico Payún Matrú. En este episodio se originaron los volcanes Payún Matrú, Payún Liso y Auca Mahuida (Kay et al. 2006a).

La mayor densidad de volcanes se encuentra en la faja deprimida central con sentido norte-sur, conocida como Depresión central o Faja deprimida central y depresión de los Huarpes (Llambías 2009; Llambías et al. 2010). Comenzó su desarrollo en el Mioceno superior, cuando la actividad ígnea formó un amplio plateau basálticoandesítico, de más de $23.000 \mathrm{~km}^{2}$ de extensión (Llambías et al. 2010). Sus afloramientos se distribuyen al pie de la actual cadena andina y abarca: el sur de Mendoza y el norte de Neuquén (Figura 3.5), dando lugar a la formación del plateau volcánico de Palao-Co o Palauco, hoy cubierto en gran parte por el vulcanismo Cuaternario (Llambías et al. 2010). En ese momento, se formaron centros eruptivos como el Plateado, Pelado, Peceño, Chorreado y Sierra Chorreada, entre otros. A este evento siguió una época de actividad nula, en la cual el ángulo de subducción se hizo más somero (entre 8 y $5 \mathrm{Ma}$ ). Ramos (2009) denominó a esta época de subducción plana de Payenia. En el Plioceno (5 Ma), el ángulo de subducción vuelve a inclinarse, dando comienzo al segundo pico de actividad ígnea, que labró la actual morfología de la depresión central registrándose una disminución de la altura de la cordillera andina (Llambías et al. 2010). En los últimos 
14.000 años la actividad volcánica tuvo una menor dispersión areal que la registrada en el Pleistoceno, ya que se encuentra únicamente en la región del Payún Matrú (Llambías et al. 2010).

El efecto de la actividad volcánica de retroarco en Payenia sobrepasa la denominada faja central deprimida y se expande a otras unidades morfoestructurales. De modo que en el extremo norte y noreste afectó al Bloque de San Rafael. También modificó el borde oriental de la faja plegada de Malargüe, donde penetra a lo largo de los corredores oeste-noroeste alterando al río Salado y La Pasarela (río Grande), aunque con volumen reducido (Llambías et al. 2010).

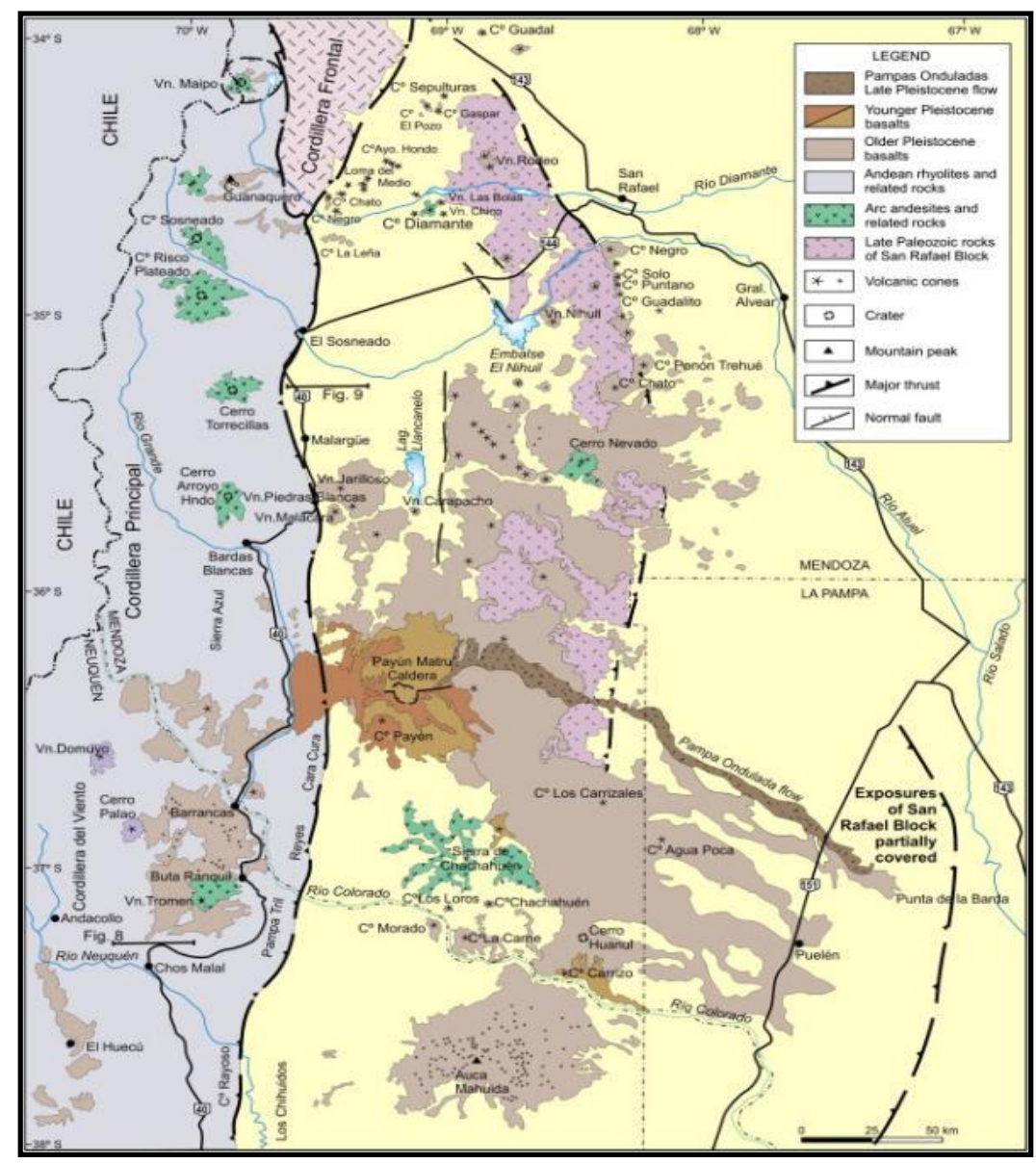

Figura 3.5 Distrito volcánico Payenia. Extensión, secuencias volcánicas y principales características geológicas. Figura tomada de Ramos y Folguera (2011). 
En la región la composición dominante de los volcanes de retroarco es basalto olivínica, y en su gran mayoría corresponden a volcanes de tipo monogenéticos (Llambías et al. 2010; Ramos y Folguera 2011). La alineación de estos conos permite inferir que muchas de las erupciones son de tipo fisural, con rumbos frecuentes oeste-este y noroeste-sureste, oblicuos al eje de la cordillera. Ejemplo de ello es la falla La Carbonilla, ubicada a ambos flancos del Payún Matrú. La misma está constituida por alrededor de 200 conos de escoria que se distribuyen en una faja este-oeste de $14 \mathrm{~km}$ de ancho, que habrían sido formados hace $c a$. 7.000 años, según dataciones radiométricas realizadas por Germa et al. (2010) (Figura 3.6).

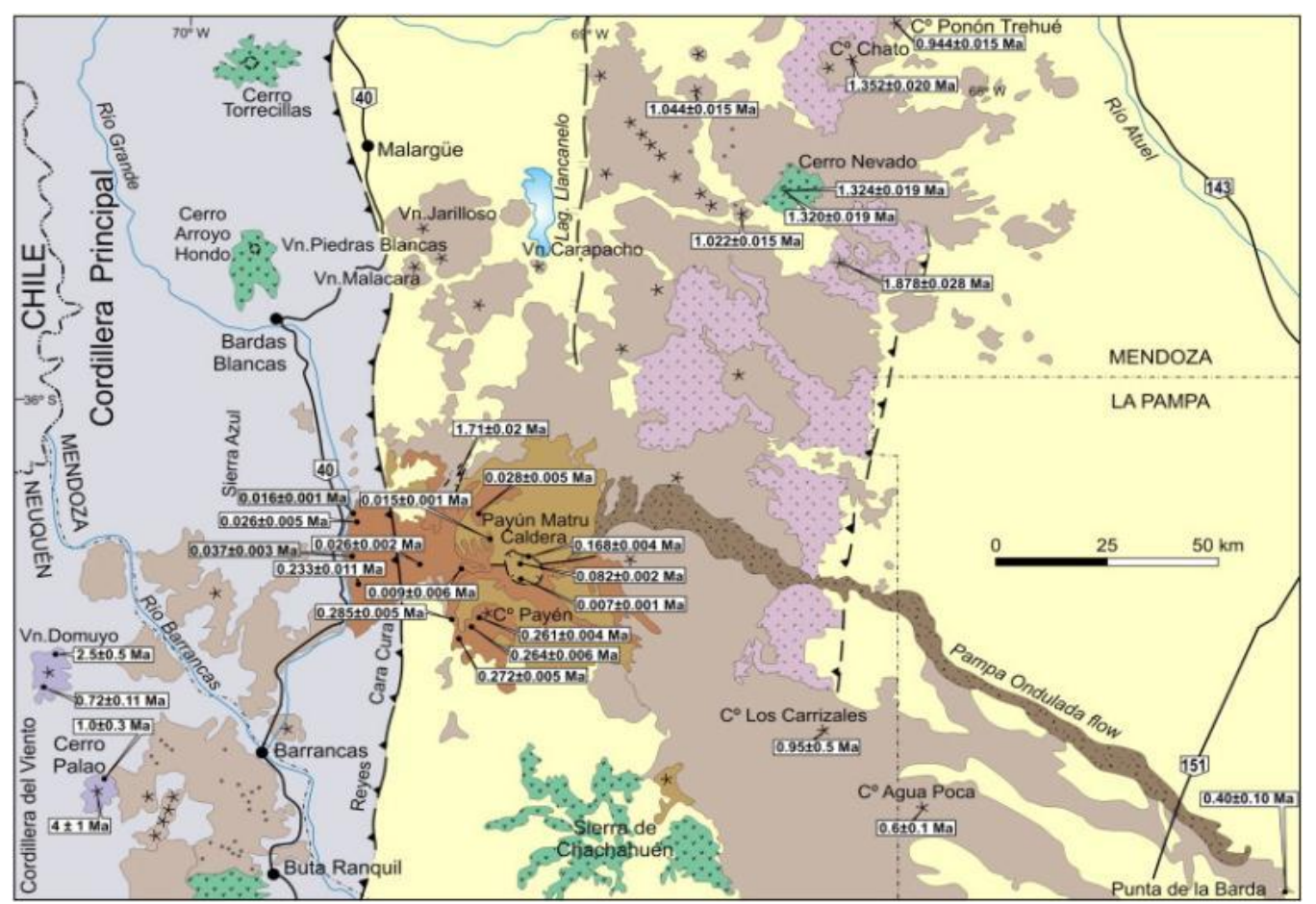

Figura 3.6. Cronología de los centros volcánicos. Figura tomada de Ramos y Folguera (2011).

Los volcanes poligenéticos en cambio, son escasos y de gran tamaño. Se encuentran en la faja deprimida central y antepaís, y no se los ha reconocido en la faja plegada de Malargüe. Entre ellos se destacan los volcanes Diamante (2.300 msnm), Payún Matrú (3.680 msnm), Payún Liso (3.715 msnm) y Auca Mahuida (2.258msnm), 
distribuidos a lo largo de la depresión central; mientras que El Nevado (3.833 msnm) es el único que se encuentra en el antepaís (Llambías et al. 2010). De éstos el primero en desarrollarse es El Nevado hace ca. 1.320 Ma (Pleistoceno). Está constituido por andesitas, traquitas dacitas, riolitas y traquiandesitas basálticas alcalinas. Es seguido por el volcán Diamante a los ca. 0.43 Ma (Gudnason et al. 2012), ubicado en el límite entre el antepaís y la depresión central, compuesto por basanitas, basaltos y andesitas traquibasálticas (Folguera 2009; Llambías et al. 2010). Posteriormente el volcanismo se concentró en la depresión central (Llambías et al. 2010) o campo volcánico Payún Matrú (Ramos y Folguera 2011), con erupciones en el Payún Liso (con edades radiométricas entre los ca. 0.272 y $0.261 \mathrm{Ma}$ ) y Payún Matrú (Figura 3.6). Este último con actividad desde ca. 0.233 Ma, la formación de la caldera entre los ca. 168 ka (miles de años) y 82 ka, seguidos por erupciones holocénicas (ca. 7.000 años) e incluso históricas (Germa et al. 2010; Llambías et al. 2010; Ramos y Folguera 2011). El Payún Matrú (y el campo basáltico adyacente) es de composición geoquímica alcalina y es el que muestra mayor variedad litológica, desde basalto hasta traquita vítrea. Esto se debe a que sus erupciones de dieron tanto por diferenciación magmática (Llambías 1966), como por mezcla de magmas (Hernando et al. 2008, 2012).

En el extremo sur de la depresión central se encuentra el escudo basáltico Auca Mahuida, correspondiente al Pleistoceno (1.7 a $0.88 \mathrm{Ma}$ ), compuesto por traquibasaltos, traquiandesitas basálticas y traquiandesitas. Por último, se encuentran las erupciones del Volcán Tromen, en el cual la actividad más joven tuvo lugar a los ca. $0.2 \mathrm{Ma}$, reportando incluso erupciones históricas (Figura 3.7). Auca Mahuida se encuentra alineado con los volcanes Tromen y Domuyo conformando un cinturón volcánico con orientación noroeste oblicuo a los Andes, cuyo límite coincide con el lineamiento Cortaderas ${ }^{1}$ y la orientación de los ríos Barrancas y Colorado.

Otro volcán poligenético presente en la depresión central es el volcán Chachahuén, compuesto por rocas calcoalcalinas, como andesitas y basaltos de alto potasio con anfíbol

\footnotetext{
${ }^{1}$ El lineamiento Cortaderas marca un área de cambio en la actividad magmática y características composicionales de las rocas volcánicas entre el sur de Mendoza y norte de Neuquén (Llambías et al. 2010).
} 
(Figura 3.6). Chachahuén (7 y $5 \mathrm{Ma}$ ), presenta características geoquímicas similares al volcanismo de arco cordillerano, esto fue tomado como evidencia de un período de subducción plana (Kay et al. 2006b; Hernando et al. 2012).

Al pie de los Andes, en la faja plagada y corrida de Malargüe, también se desarrolla actividad volcánica de retroarco. Las localidades más importantes son el cauce medio del río Grande y el río Salado. En ambas hay numerosos conos monogenéticos, muchos de ellos con efusión de lavas y la edad estimada por Marcchetti et al. (2006), para el Pleistoceno superior. En el río Salado se han reconocido dos grupos de volcanes, el de la Niña Encantada y el del Infiernillo. En el cauce medio del río Grande, las lavas endicaron el río formando La Pasarela y al este del mismo, en el sector de Los Volcanes, la composición de la lava es basalto olivínico y han sido datadas en ca. $41 \mathrm{Ka}$ (Marcchetti et al. 2006; Llambías et al. 2010).

Llambías et al. (2010) relacionan el elevado gradiente geotérmico presente en el área de Payún Matrú, con la segmentación de la depresión central que separa la cuenca Cenozoica de Los Huarpes al norte, del segmento sur sin acumulación sedimentaria de esta edad; siendo el único signo visible en superficie de esta segmentación, la falla La Carbonilla. Una postura alternativa es la de Ramos y Folguera (2011) que han explicado esta anomalía geotérmica como resultado de un proceso de adelgazamiento y estiramiento cortical en conjunción con inyección de astenósfera caliente. 


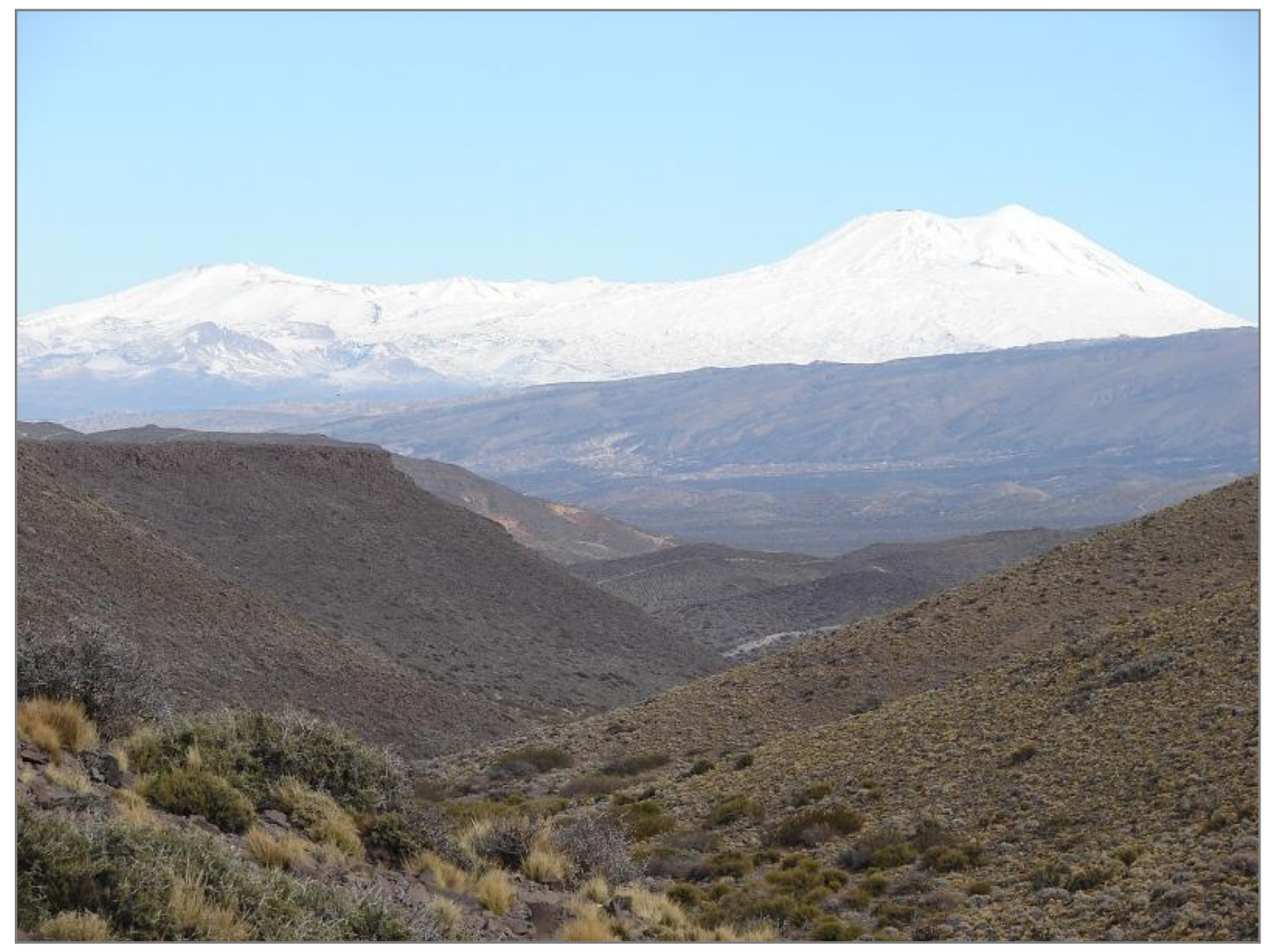

Figura 3.7. Volcán Tromen, visto desde Cañadón Amarillo (sur de La Payunia).

Ramos y Folguera (2011), en base a la información geológica disponible subdividen La Payunia en tres segmentos: norte, central y sur (Figura 3.8). El segmento norte está caracterizado por centros monogenéticos aislados, entre los que se destacan los ubicados próximos al río Diamante, tales como el Cerro Guadal (ca. 0,530 y 0,529 Ma) al norte, y el campo volcánico Las Bolas (ca. 0,505) y el volcán Chico (ca. 1,164Ma) al sur. En este segmento también se incluye el volcán Diamante con actividad entre 0,43 y 0,06 Ma, además de otros cerros monogenéticos que limitan el bloque de San Rafael como: Cerro Negro (ca. 0,801 Ma), Cerro Solo (ca. 0,750 Ma), volcán Puntano (ca. 1,78 Ma) y Cerro Guadalito (ca. 0,805 Ma) y los volcanes holocénicos ubicados a lo largo del río Salado (e.g. Hoyada, Lagunita, Loma Negra y Hoyo Negro). 


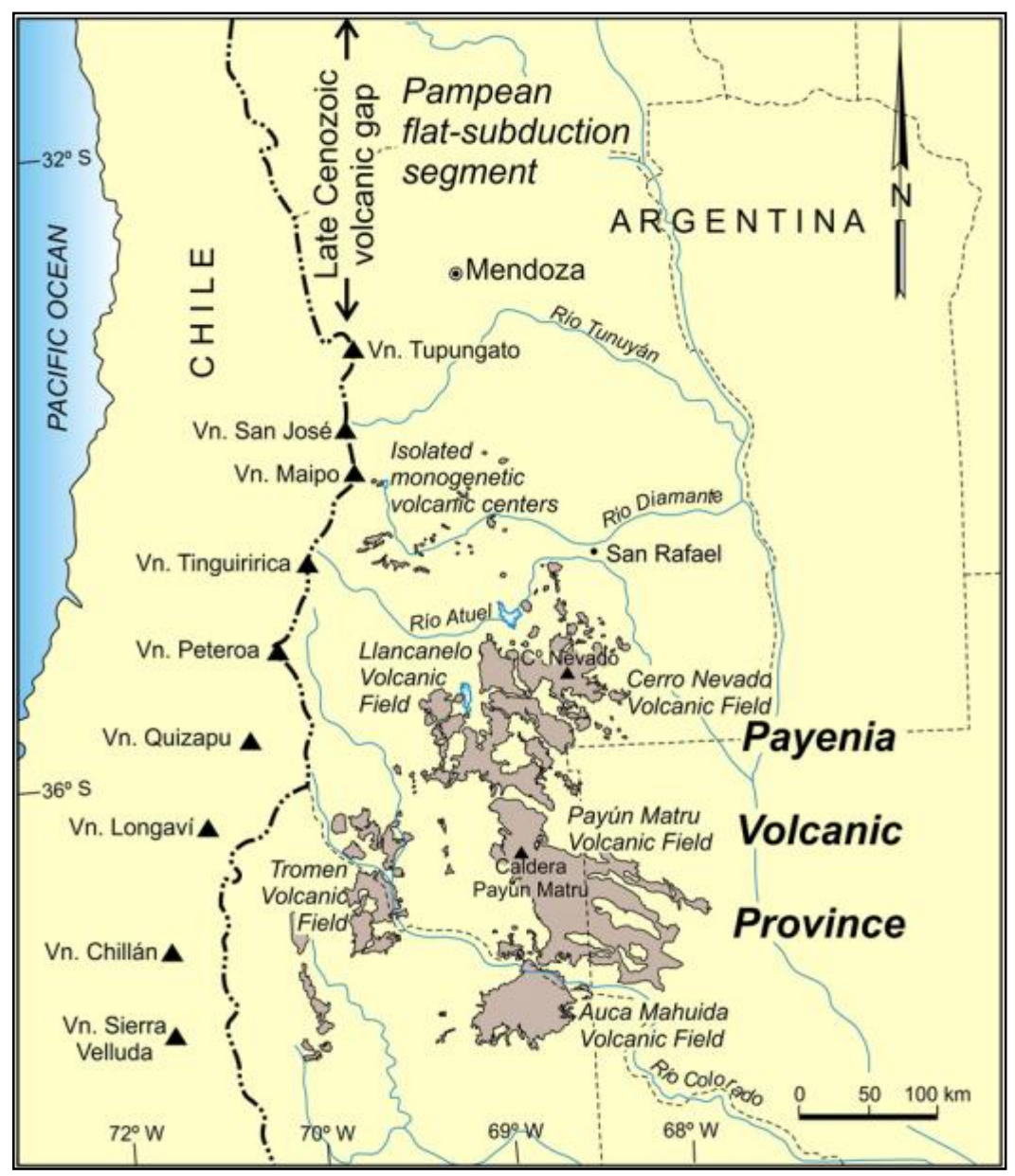

Figura 3.8. Detalle de los campos volcánicos. Figura tomada de Ramos y Folguera (2011).

El segmento central es el que concentra mayor actividad volcánica, y se caracteriza por sus extensas coladas de lava. Abarca el área de la depresión central y los autores la dividen en tres campos volcánicos: Cerro Nevado, Llancanelo y Payún Matrú. En los tres campos, se destaca la presencia de conos monogenéticos (Figuras 3.8). El campo volcánico Cerro Nevado, es caracterizado por el volcán homónimo, que corresponde a un estratovolcán desarrollado sobre antiguas coladas basálticas (rango entre ca. 1,83 Ma y 1,71 Ma). El campo volcánico Llancanelo es caracterizado por su alta densidad de conos monogenéticos. Algunos de los centros volcánicos monogenéticos muestran características freatomagmáticas, con indicadores de una importante interacción magmaagua en la construcción de los edificios volcánicos, ejemplo de ello son los volcanes Jarilloso, Carapacho y Malacara (Risso et al. 2008). Relacionado a esto, estudios recientes 
(Violante et al. 2010) confirman que la superficie de la laguna Llancanelo era mucho más extensa en el momento que se produjeron dichas erupciones. Este campo volcánico podría corresponder al Pleistoceno tardío (Linares y González 1990) y llegar incluso a tiempos históricos (Risso et al.2008). Llambías et al. (2010), sostienen que el volcanismo monogénetico hidromagmático del campo volcánico de Llancanelo estaría asociado con niveles de agua subterránea que percolaban hacia donde hoy se encuentra la laguna e interactuaron con el magma ascendente a través de las fracturas principales de la zona de rumbo noroeste-sureste y/o este-oeste. Existiera o no la laguna Llancanelo al momento de la erupciones, sus aguas no se involucraron en el hidrovolcanismo, ya que el nivel de fragmentación del magma era mucho más profundo, como es el caso del volcán Carapacho (Risso et al. 2008).

El campo volcánico Payún Matrú por su parte, es el que presenta mayor actividad volcánica cuaternaria. Se desarrolla sobre un plateau basáltico miocénico (ca. 1,71 Ma) (Quidelleur et al. 2009) con flujos de basaltos que recorren decenas de kilómetros, concentrando en este área más de la mitad del volumen eruptado en La Payunia (Figura 3.6). En este campo se destacan los estratovolcanes Payún Matrú y Payún Liso, además de los numerosos conos monogenéticos. Las erupciones se habrían originado a lo largo de una gran fisura de dirección este-oeste denominada Carbonilla, la cual habría estado activa desde el Cuaternario temprano hasta el Holoceno (Pasquarè et al. 2008). Pasquarè et al. (2008) sostiene que la actividad del complejo volcánico Payún Matrú, probablemente comenzó durante el Cuaternario temprano, con la efusión de lavas basálticas y conos de escoria representativas de la parte basal. Este producto en parte corresponde a la Formación Alto Morado de González Díaz (1972b) y en parte a los Basaltos III y IV de Groeber (1946). La etapa reciente de actividad volcánica en el sector oriental, está probada por las edades correspondientes al Holoceno de algunos conos de ceniza de Grupo El Rengo (Ingbar y Risso 2001). Germa et al. (2010) sostienen que la caldera del Payún Matrú se habría formado hace aproximadamente 100 ka y que las últimas lavas de traquita vítrea corresponden al Holoceno, igual que los basaltos fisurales a ambos lados del volcán. En este campo se encuentran extensas coladas de lava 
basálticas que hacia el oeste traspasan el río Grande (datadas en ca. 0,233 Ma) (Quidelleur et al. 2009) y hacia el este recorren cientos de kilómetros, como el flujo de lava Pampas Onduladas que llega a superar los 180 km (Figura 3.6), siendo uno de los flujos más largos conocidos (Pasquarè et al. 2008). El Payún Liso es contemporáneo a las erupciones tempranas del Payún Matrú y previo a la formación de la caldera de éste último (Hernando et al. 2012). Tal como lo indica la cobertura parcial de su vertiente norte por ignimbrita de la Formación Portezuelo, fechadas entre ca. 26 y 28 ka (Germa et al. 2010). Payún Liso tiene un volumen estimado de $40 \mathrm{~km}^{3}$ y su morfología es diferente a la de Payún Matrú, dado que cuenta con una forma cónica de las pendientes pronunciadas y un respiradero central claramente definido, es un típico estratovolcán (Hernando et al. 2012).

Por último en el segmento sur, Ramos y Folguera (2011) reconocen dos campos volcánicos para el Cuaternario, el Auca Mahuida y el Tromen. El campo volcánico Auca Mahuida posee varios pequeños volcanes basálticos, tales como: Cerro Morado, La Carne, Carrizo, y muchos otros conos monogenéticos y flujos de lava que se encuentran a lo largo del valle del río Colorado. El volcán Auca Mahuida, ha sido datado por Kay et al. (2006) entre ca. 1.78 y $1.39 \mathrm{Ma}$. El campo volcánico Tromen, también desarrolló un extenso plateau basáltico con edades en el rango de ca. 1.8 y 1.6 Ma. Está conformado por conos monogenéticos y por el estratovolcán Tromen, datados en el rango de ca. 2.27 Ma y 40 ka (Folguera et al. 2008).

En esta breve caracterización de la secuencia geológica del área, se resalta que el volcanismo de retroarco correspondiente al Pleistoceno tardío-Holoceno temprano se encuentra solamente en la región de Payún Matrú, en el valle del río Salado y en el Tromen. En Payún Matrú, la juventud de las últimas erupciones del volcán homónimo no permite descartar que la cámara magmática se haya homogeneizado térmicamente, aunque no se observan en superficie indicios de actividad post-eruptiva (Llambías et al. 2010). La actividad más reciente y contemporánea a las poblaciones humanas en el sur de Mendoza, se documenta entre los ca. 10.000 y 7.000 años (Germa et al. 2010), con erupciones efusivas y estrombolianas en la falla Carbonilla, conos monogenéticos del área de Los Volcanes y en el volcán Payún Matrú, con flujos de traquita vítrea (Germa et al. 
2010). Los recientes estudios de Durán y Mikkan (2009) confirman y profundizan esta información.

\subsection{EL CLIMA}

El clima en La Payunia es frío y árido, y depende de la acción del anticiclón del Pacífico (Capitanelli 1972; González Díaz y Furqué 1993; Abraham 2000). La temperatura media anual e interanual se estima en $12,7^{\circ} \mathrm{C}$, según la estación meteorológica del Aeródromo-Malargüe (875060-SAMM, años 1967-2011); con una temperatura media máxima de $20,4^{\circ} \mathrm{C}$ y una mínima de $4,5^{\circ} \mathrm{C}$. Para la estación sur más cercana, ubicada al norte de la provincia de Neuquén (Chosmalal), Dalmasso (2010) menciona una temperatura media anual de $13,4^{\circ} \mathrm{C}$ (periodo 1951-60), registrando una máxima absoluta en los meses de enero y febrero $\left(39,5^{\circ} \mathrm{C}\right)$ y la mínima absoluta en el mes de junio de $11,3^{\circ} \mathrm{C}$. Los vientos constituyen un factor importante del clima en la región, poseen una dirección predominante del cuadrante oeste-noroeste y noreste (Abraham 2000). Son secos y cálidos, originados por la bajada adiabática de masas de aire de dirección oeste a este desde el océano Pacífico (Dalmasso 2010). Esto hace al invierno, una estación bastante benigna desde el punto de vista térmico, razón por la cual ciertos parajes tienen afluencia de personas en las estaciones frías (Capitanelli 2005: 398) y los puesteros locales prefieran estas latitudes para la construcción de puestos de invernada.

El suelo es arenoso, muy permeable y de rocas efusivas de alta porosidad (Abraham 2000). Las precipitaciones anuales promedio son entre los 200 a $250 \mathrm{~mm}$, con variaciones estacionales e interanuales y con déficit hídrico entre los meses de octubre y enero (Mares et al. 1985; Abraham 2000). La región presenta variaciones altitudinales que van de 1450 a 2000 msnm. Carretero (2006) destaca la similitud bioclimática a partir de los 1600 msnm, entre los cerros Auca Mahuida, Chachahuén y Payún Matrú pertenecientes todos al bioclima semiárido superior y que se presentan como islas separadas por el bioclima árido (Figura 3.9). Capitanelli (2005) sostiene que la disparidad 
de altitudes genera zonas térmicas particulares, como ocurre en las subregiones Altiplanicie del Payún y Huayquerías (Capitanelli 1972, 2005). La primera llena de depresiones y cuencas cerradas y sin cauces de agua permanentes, y la segunda con numerosos ríos secos y pequeñas vertientes que favorecen pequeñas vegas.

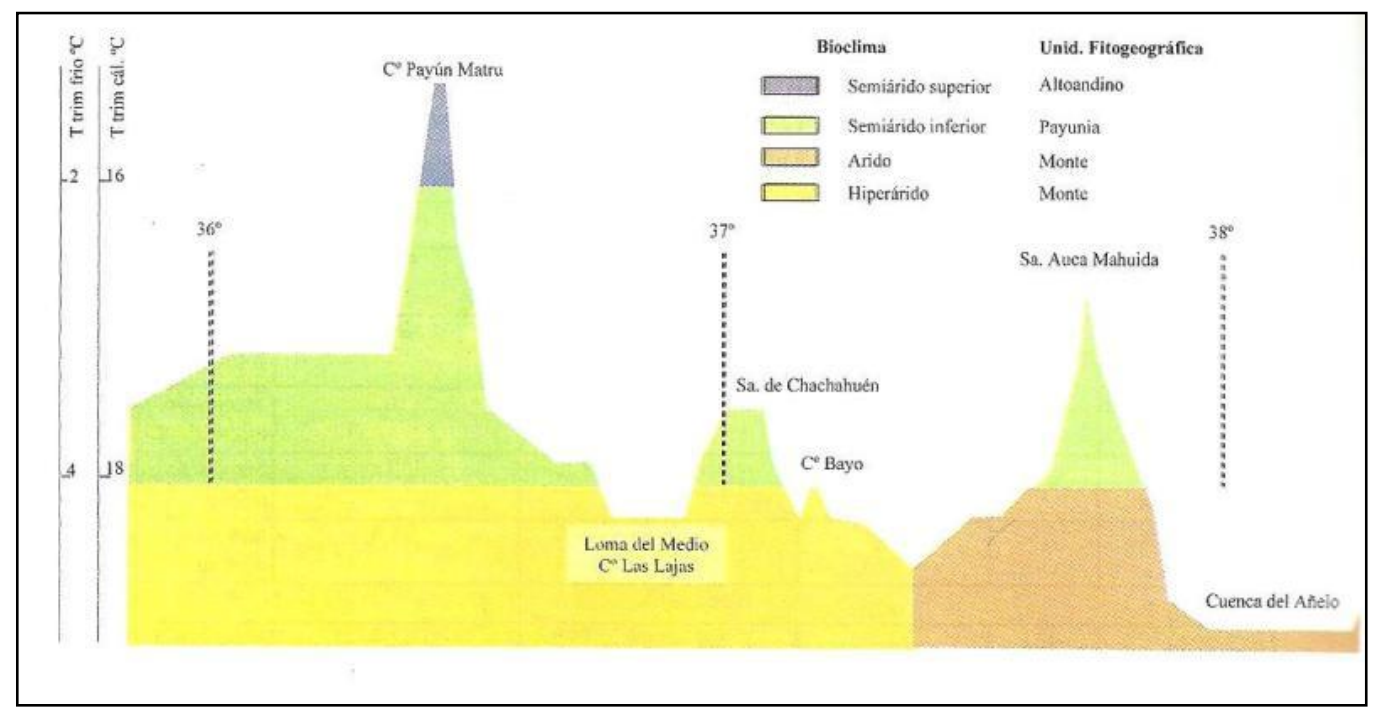

Figura 3.9. Bioclima y su vinculación con unidades fitogeográficas en La Payunia. Se destacan las variacion es entre el sur de Mendoza y norte de Neuquén. Figura tomada de Carretero (2006).

\subsection{HIDROGRAFÍA}

La Payunia carece de cauces de agua permanentes. Sólo en el sector suroeste o subregión Huayquerías (sensu Capitanelli 2005), posee ríos efímeros y pequeñas vertientes, que labran sus recorridos en zanjones o cañadones que conducen al río Colorado, direccionadas en sentido norte-sur. La Altiplanicie del Payún, con una altitud entre los 2.000 y 1.700 msnm., posee un suelo poroso (tobas y basaltos) y un relieve que declina en sentido norte-sur, que facilita la infiltración de las aguas de lluvia que surgen por debajo del basalto en los bordes de esta amplia meseta (Groeber 1933; Capitanelli 2005). Ejemplo de ello son las vertientes de Agua de Pérez, Agua del Altar, Agua de Reyes y Agua del Diablo (Groeber 1933). Groeber (1933) menciona que estas aguas son en 
general malas para el consumo, dado que surgen de capas con alto contenido en yeso, y solo algunas nacen de las formaciones Cretácicas donde apoyan los basaltos cenozoicos (Agua de Pérez y la del Altar).

Llambías (2009) sostiene que las ignimbritas depositadas por la erupción del Payún Matrú que conforma gran parte de la Altiplanicie, son las únicas rocas que hoy permiten el almacenamiento de agua de lluvia. Estas se acumulan en grietas, jagüeles o barreales considerados "aguas del tiempo", cuya ubicación es conocida por los pobladores locales, que la utilizan para el consumo personal y de animales (Llambías 2009) (Figura 3.10). La caldera del Payún Matrú también alberga una laguna de dimensiones variables, que permanece congelada en invierno y llega a secarse en épocas de escasa lluvias. Se encuentra cercana a los $3.000 \mathrm{msnm}$, es de agua dulce y de calidad para el consumo humano.

En la Altiplanicie del Payún dos largos ríos secos cruzan de norte a sur; uno viene de ambos lados del escorial situado al oeste del Payún Liso y pasa por Agua de Pérez; y el otro nace en el faldeo de este cerro y se dirige hacia Agua del Diablo, ambos se unen en el Cañadón Amarillo (Groeber 1933). Este Cañadón en conjunto con otros cauces secos (Aguada Arenosa, Pichanal y Agua del Mercado, entre otros), constituyen una planicie aluvial discontinua que forma parte del sistema de subcuenca de la cuenca del río Colorado. Estos cauces desaguan en el río el exceso de agua durante las lluvias y en muchos casos sus valles han desarrollado una planicie aluvial poco estable. Si bien el valle del río no forma parte del área de estudio propuesta para esta tesis, seguramente jugó un rol muy importante para las poblaciones en el pasado. 


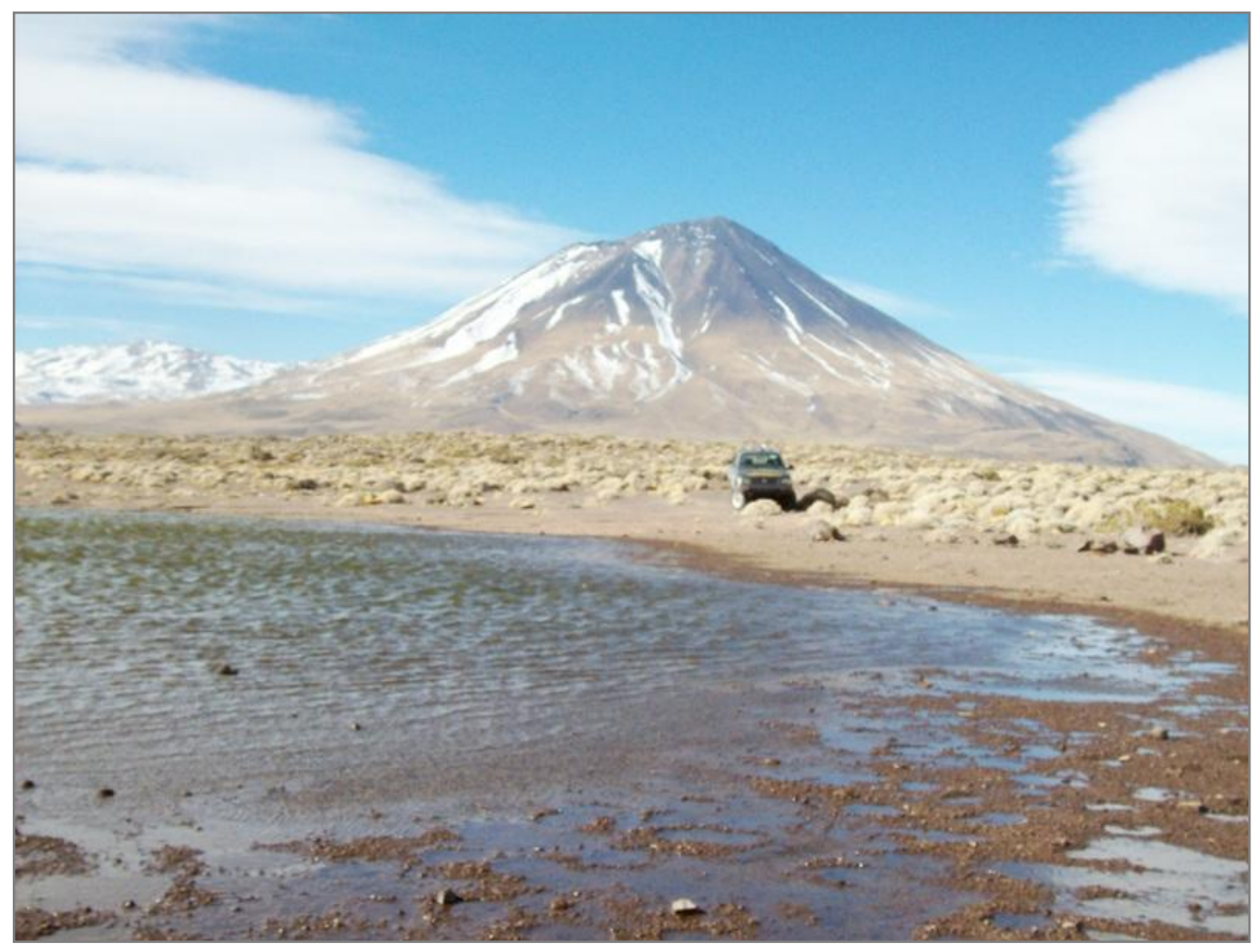

Figura 3.10. Agua del tiempo o jagüel ubicado en Altiplanicie del Payén.

\subsection{FITO Y ZOOGEOGRAFÍA}

Desde el punto de vista fitogeográfico, la región pertenece a la Provincia del Monte y Patagónica, Distrito La Payunia (Abraham 2000). El límite entre ambas provincias es altitudinal, debido a que el Monte está restringido a las altitudes menores a los 1.500 msnm (Dalmasso 2010). La transición Monte-Patagonia es relativamente gradual a altitudes intermedias. Por lo tanto, algunas áreas pueden considerarse como ecotonos. Sin embargo, la mayor parte de las discontinuidades altitudinales en el área son relativamente abruptas y, por ende, las áreas ecotonales son poco extensas (León et al. 1998). Se distinguen seis unidades de asociaciones vegetales: los matorrales patagónicos y pastizales de La Payunia; los matorrales de Monte; los pastizales psamófilos; y las comunidades de suelos salinos o vegetación saxícola (Carretero 2006). Carretero (2006) plantea en base al análisis integrado de la información florística y mesológica (geología, 
tipo de suelo y clima), que La Payunia o Distrito Volcánico Payenia, debe ser considerada una provincia fitogeográfica particular, dentro del Dominio Andino-Patagónico (Figura 3.11). Las especies más abundantes en las Ilanuras con estepas son Neosparton aphyllum o Stipa sp. (pastizales de coirón), acompañados de otros elementos xéricos, cubriendo grandes extensiones (Roig et al. 2000). Las coladas basálticas presentan elementos saxícolas y psamófilos, debido a la acción permanente del viento que va cubriendo las grietas de las rocas. Los conos volcánicos, presentan en sus cumbres elementos andinos de plantas en cojín o pastizales de Poa durifolia. Roig et al. (2000), recalcan que La Payunia es la región de Mendoza con mayor cantidad de endemismos, entre los que destacan Prosopis castellanosii, Condalia megacarpa, Schinus roigii, Argylia robusta, Stipa malalhuensis, etc. En la región también se menciona la presencia de colimamil (Adesmia pinifolia), jarilla (Larrea sp.), molle (Schinus sp.), chirriadera (Chuquiraga hystrix) y solupe (Ephedra ochreata), entre otros.

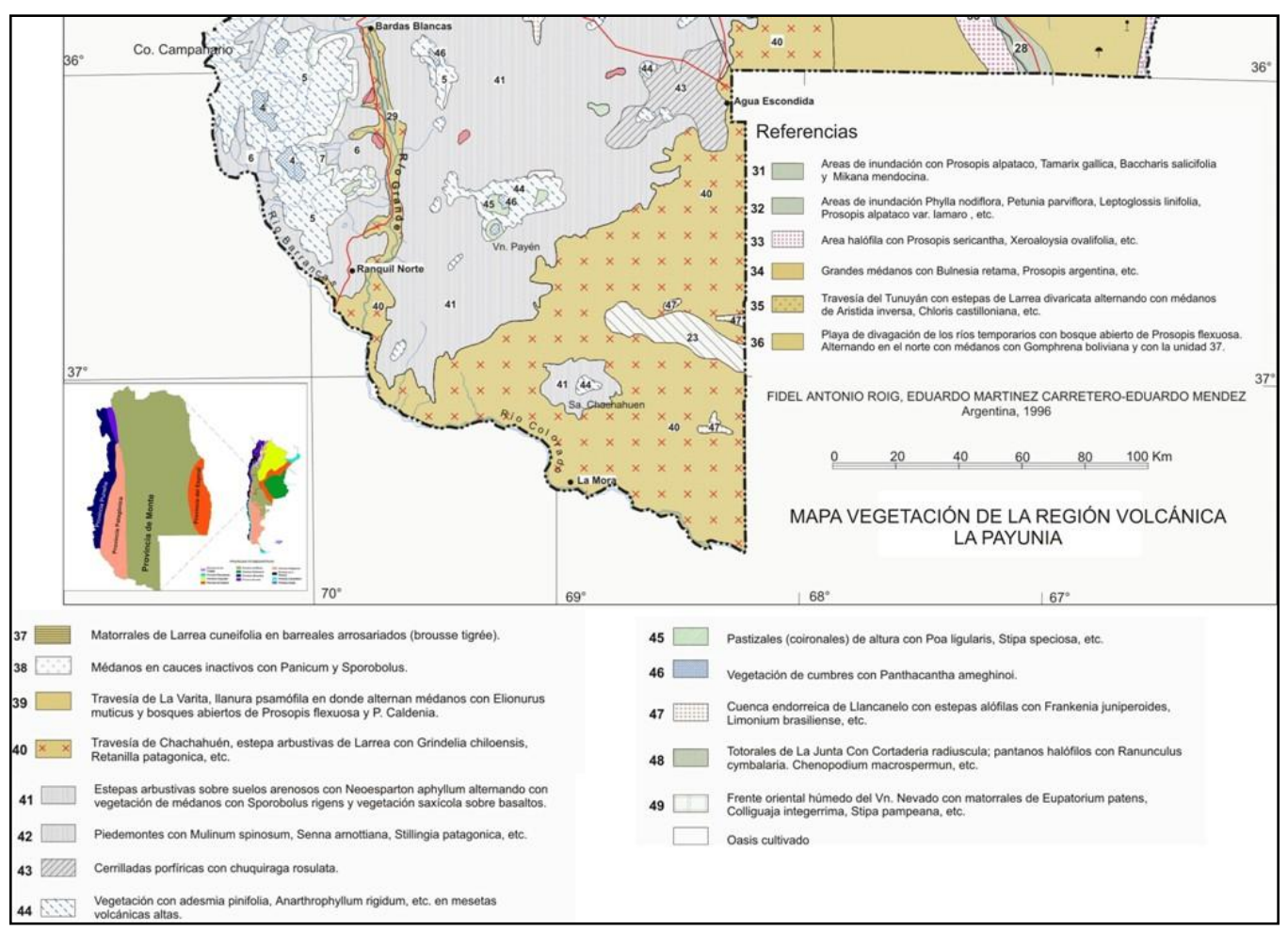

Figura 3.11. Vegetación de La Payunia. Figura tomada y modificada de Roig et al. (2000). 
En cuanto al aspecto zoogeográficos, la región alberga dos grandes grupos faunísticos: la Fauna de Montaña y la Fauna de Estepa Patagónica (Roig 1972). Entre las especies se mencionan: el guanaco (Lama guanicoe), el puma (Felis concolor) y el gato montés (Felis sp.), los chiñes o zorrinos (Conepatus sp.), el zorro gris y colorado (Dusicyon sp.), el chinchillón (Lagidium viscacia), el tuco-tuco (Ctenomys mendocinus), el cuis (Microcavia australis), el peludo (Chaetophractus villosus), el piche (Zaedius pichiy), el choique o ñandú (Pterocnemia pennata) y las tortugas (Candia et al. 1993).

\subsection{GEOMORFOLOGÍA}

Los procesos endógenos en La Payunia han generado un paisaje con relieve volcánico, en el cual se reconocen geoformas intactas tales como: conos volcánicos (elevaciones que sobresalen en los campos lávicos); ventanas lávicas convexas (áreas sin cubrir por las coladas cenozoicas que permiten que afloren asomos de formaciones más antiguas); y planicies de ignimbrita tobácea (especie de manto de ignimbrita genéticamente relacionado con la erupción del Payún Matrú que desencadenó la formación de la caldera, dando un aspecto actual de relieve chato).

Entre los procesos exógenos se destaca la presencia de geoformas vinculadas a procesos eólicos, tales como médanos y mantos de arena. Estos se extienden en particular al este y al sur-sureste de la región, donde existen mantos de arena suelta, delgada, amorfa y móvil, que cubre parcialmente las vulcanitas. Las acumulaciones son importantes en la zona de Agua Escondida, al este de las sierras de Palauco, Cara Cura y de Reyes y en todo el sector ubicado al sur de la Altiplanicie del Payún, denominado Huayquerías o tierras malas (bad lands). Como se mencionó anteriormente, Huayquerías es un relieve de alta densidad de drenajes y divisorias de agua no muy elevadas pero agudas, generadas por cauces efímeros. Siendo típica la existencia de cañadones, zanjones y cárcavas de escasa profundidad (González Díaz y Furqué 1993), que facilitan la formación de dunas y mantos de arena en los laterales de los cauces. La arena proviene en su mayoría de la deflación de las planicies aluviales y parte de la erosión de las areniscas del Grupo 
Neuquén, lo que le da coloración rojiza a estas geoformas (Narciso et al. 2001b). Al estesureste de La Payunia, se encuentran numerosos salitrales, formados por lo general en cuencas centrípetas que no poseen una red de drenaje definida. En estas cubetas se depositan evaporitas que alcanzan escaso espesor, tal es el caso del salitral de Afuera, salitral Redondo y salitral de los Carrizales, los mismos poseen mayor extensión en la provincia de La Pampa (Narciso et al. 2001b)

La acción de los vientos también produce formas particulares en las ignimbritas que conforman parte de la Altiplanicie del Payún. Los yardangs son depresiones alargadas de unos $30 \mathrm{~m}$ de longitud separadas por paredes verticales de entre 3 y $4 \mathrm{~m}$ (Llambías 1966, 2008, Inbar y Risso 2001), esculpidas como olas que indican la dirección de los vientos. Los yardangs son aprovechados hoy por los habitantes rurales para la construcción de "reales" o campamentos de uso estacional y para la construcción de corrales de animales (Figura 3.12). Otro rasgo típico de erosión eólica puede observarse en las formaciones rocosas y en los artefactos líticos superficiales. Se evidencia la presencia de ventifactos tales como clastos con picaduras, corroídos por golpeteo de clastos tamaño arena y barniz del desierto. Esta acción erosiva genera a su vez un rasgo de mayor escala denominado Pavimento del Desierto, que corresponde a una superficie cubierta por clastos de tamaño grava y bloque, con empaquetamiento cerrado, generada a partir de la remoción de materiales finos. Esta cobertura clástica protege de la erosión a los materiales que se encuentran por debajo (PRC 2009). 


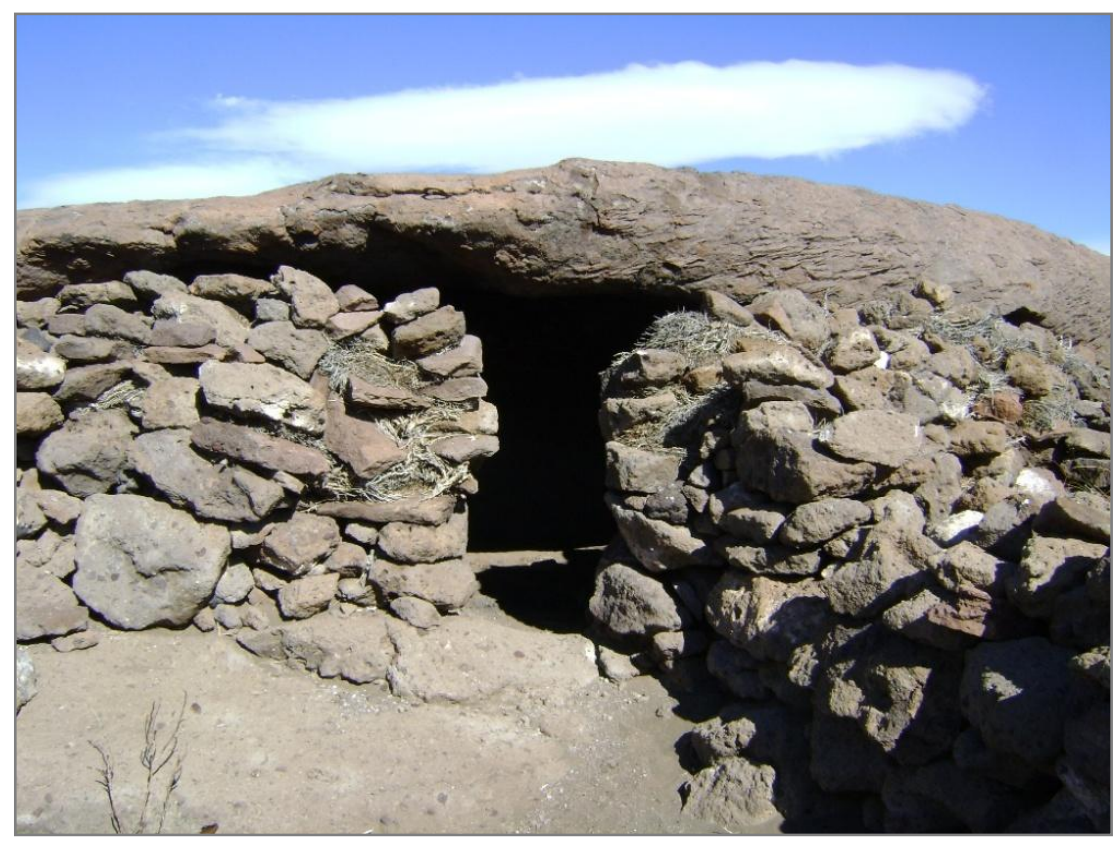

Figura 3.12. Real o puesto transitorio construido en yardangs, Altiplanicie del Payén (Puesto Mira).

Los procesos de remoción en masa o deslizamientos son otros de los factores exógenos de importancia en el sector sur. Ejemplo de ellos son depósitos aflorantes bordeando la Altiplanicie del Payún, Loma del Medio y la Cañada de los Cruceros (Narciso et al. 2001a). En la rampa que baja de la Altiplanicie del Payún a Cañadón Amarillo, se observan areniscas y arcillas cretácicas expuestas por la erosión de la cubierta de basalto miocénica (Groeber 1933: 30), siendo clara la secuencia de degradación del borde de meseta. El perfil longitudinal de estos valles ubicados al pie de la Altiplanicie es escalonado a causa de la erosión lateral, que presenta en los tramos medios escarpas laterales empinadas y de gran altura (aproximadamente $40 \mathrm{~m}$ de altura), con evidencias de remoción en masa y caída de bloques. Estos cauces poseen diseño de meandros encajonados con curvas apretadas y en ocasiones con estrangulamiento y canales.

Por último cabe mencionar la presencia de pedimentos y pedimentos cubiertos en el sur, el sector donde se encuentra Cañadón Amarillo o Huayquerías. Los pedimentos corresponden a superficies de erosión activa, con pendiente moderada originada por sistemas fluviales que bajan de zonas altas, generando retroceso de las mismas. Presentan 
en general superficies desnudas, exponiendo afloramientos antiguos. En algunos casos están cubiertos por una delgada capa de aluvio, debido a que además de ser superficies de erosión, también lo son de transporte fluvial. El pedimento cubierto, por su parte, conforma amplias superficies inclinadas de norte a sur, denominadas altiplanicies

centrales. Éstas se encuentran separadas por cañadones de diversa importancia. Probablemente en el pasado conformaban unidades amplias, pero la erosión retrocedente las separó por cañadones, en áreas de distinto tamaño. Descienden de nivel desde aproximadamente los $1100 \mathrm{~m}$ hasta los $800 \mathrm{~m}$, terminan poco antes del río Colorado y separan los ríos efímeros que cortan la zona (PRC 2009).

\subsection{PALEOAMBIENTE, HOLOCENO TARDÍO Y DISPONIBILIDAD DE ROCAS EN EL CAMPO VOLCÁNICO LA PAYUNIA}

Resultado de la acción de agentes geomorfológicos exógenos (ver apartado 3.4), especialmente a partir del Pleistoceno, el paisaje continuó modificándose, fundamentalmente por erosión. En el sector sur, la acción fluvial labró los valles del área. El resto de las geoformas, tanto de erosión como de acumulación, son el resultado de las condiciones energéticas y climáticas que condicionan los procesos geomorfológicos. En los trabajos realizados por Gil $(2000,2002,2006)$ se plantea la escasez de estudios que contemplen los cambios ambientales de los últimos 12.000 años (Gil 2006), situación que no ha cambiado sustancialmente. En sus trabajos se retoman investigaciones de regiones vecinas, que permiten plantear tendencias generales, válidas para el sudeste mendocino (Gil 2002; 2006; Zárate 2002). El autor plantea que desde el Pleistoceno hasta el Holoceno medio se desarrolló un cambio en el patrón de las precipitaciones, de principalmente invernales a veraniegas, lo que significó un periodo de extrema aridez (Markgraf 1993). Entre los 5.000 y los 3.000 años AP, existió un avance glaciario en el área de cordillera, disminuyendo la temperatura media e incrementándose, al menos en cordillera, las precipitaciones invernales. Esta tendencia pudo haber afectado los cauces fluviales de las Planicies Orientales ya que dependen de las precipitaciones cordilleranas. Para inicios del 
Holoceno tardío, entre los 4.000 y 3.000 años AP, es cuando se establece el actual patrón climático en el sur de Mendoza (Gil 2006:44 y referencias allí citadas).

Estudios recientes amplían y discuten la información paleoambiental de Mendoza a partir de múltiples indicadores o proxy (Zárate et al. 2010). Si bien centran su atención en el piedemonte y las llanuras ubicados en distintos marcos geológicos de la región central y norte de Mendoza, tales como la cuenca del río Desaguadero, el Valle de Uco, el piedemonte del Bloque de San Rafael y la cuenca del Atuel, incorporan nuevas tendencias que ayudan a entender la evolución de las geoformas principales que integran los diferentes paisajes; y permiten reconstruir la fisonomía general de los ambientes en los que vivieron los grupos humanos (Zárate et al. 2010). Los autores plantean condiciones de aridez regional durante el Máximo de la Última Glaciación (entre ca. 25.000 años AP y los 10.000 años AP), situación extensible a todo el centro de Argentina. Estas condiciones habrían sido lo suficientemente extremas como para determinar una cubierta vegetal muy escasa y posibilitar el desarrollo de extensos campos de dunas (Tripaldi 2010). Alrededor de los 10.000 años hay evidencias de un mejoramiento ambiental respecto de momentos previos, con presencia de vegetación de Monte desde ca. 12.000 años AP.

Para el Holoceno medio (ca. 8.000 - 4.000 años AP) se sostiene un incremento de la aridez, hipótesis propuesta por Markgraf (1983) que no ha podido ser contrastada con los nuevos indicadores, dado lo discontinuo y poco accesible del registro sedimentario para este bloque temporal. En los últimos 4.000 años, se configuraron las condiciones climáticas y la distribución actual de formaciones vegetales (entre ca. 4.000 y 3.000 años AP) (Páez et al. 2010). En base a estudios polínicos Páez et al. (2010), indican que el Holoceno tardío fue un intervalo de gran variabilidad climática, muy influenciado por los eventos de El Niño, según lo evidencian registros de alta resolución de otras regiones. También se reconoce para este periodo y en los $c a$. 500-400 años AP, un incremento de taxa Andino-Patagónicos en las cuencas fluviales del Valle de Uco (Páez et al. 2010), que postulan podrían vincularse con un mayor aporte fluvial de las cabeceras o con fluctuaciones de la vegetación de montaña hacia las planicies probablemente asociadas a un descenso de la temperatura. 
Teniendo en cuenta el registro arqueológico de Mendoza, Zárate et al. (2010) sostienen que los grupos humanos tempranos, posteriores al Máximo de la Última Glaciación, pudieron haber encontrado condiciones más favorables de ocupación en las inmediaciones de los cursos de agua permanentes alimentados por deshielos de altura y ambientes de cordillera con disponibilidad de agua. Esto se debe, a que el paisaje de piedemonte mendocino hacia fines del Pleistoceno se comportó como un desierto de escasa cobertura vegetal y médanos activos. A esto último se suma, que los registros de mejoramiento ambiental respecto a momentos previos mayormente áridos se dan alrededor de los ca. 10.000 años AP. Los autores destacan la falta de registro arqueológico en estos ambientes fluviales y posibles problemas de visibilidad. En este sentido, advierten que los sistemas fluviales analizados, presentan superficies topográficas aterrazadas correspondientes al Holoceno medio tardío y Holoceno tardío, es decir, que corresponden a edades posteriores a los 4.000 años AP. El registro arqueológico del Holoceno medio está localizado básicamente en aleros, y sólo en trabajos recientes se han encontrado registros del final de este periodo en sitios a cielo abiertos de cordillera (sitio Arroyo El Desecho) y piedemonte (sitio El Chancho) (Zárate et al. 2010). No obstante, para el Holoceno tardío en el piedemonte y planicie oriental, muchos de los sitios reportados son de superficie o corresponden a sitios someros en estratigrafía (Gil y Neme 2010), siendo ignoradas otras geoformas no asociadas a cursos de agua como las dunas (Zárate et al. 2010). De la misma forma en La Payunia, en especial en el área noreste (Agua Escondida) y en el sector sur (Cañadón Amarillo), resta evaluar la potencialidad de estas geoformas. Ejemplo de su potencial puede ser el registro de la localidad arqueológica La Carmonina (Salgán 2011; Gil et al. 2011), ubicada en el sector medio de Cañadón Amarillo.

Entre los factores naturales que pudieron haber modificado la estructura de los recursos en el pasado, se mencionan los incendios (Gil 2006). Lamentablemente no existen estudios sistemáticos ni registros actuales, salvo los referidos por Gil (2006), correspondientes a General Alvear (sur de Mendoza). El autor indica como causa principal de los mismos, a las descargas eléctricas. Los incendios serían frecuentes sólo en periodos de sequía (primavera-verano) y su amplitud estaría determinada por el viento y la 
topografía (Gil 2006 y referencias allí citadas). Cabe también considerar el efecto de las crecientes del río Colorado, tales como la documentada en 1914 (Groeber 1933). Esta creciente afectó fundamentalmente los ríos Barrancas y Colorado, y arrasó con anchos valles fértiles cultivados, puestos y sembradíos (Groeber 1933:7), favoreciendo la formación de médanos y la erosión de los valles secos.

En resumen, lo benigno de los inviernos, la falta de lluvias en verano y lo extremo del ambiente plantea la posibilidad de que La Payunia sea más favorable para su ocupación en los meses de otoño e invierno, sobre todo porque durante esos momentos del año no es posible acceder ni ocupar la cordillera. La información presentada en este capítulo es de utilidad para la construcción de una base de recursos líticos. Se destaca la necesidad de caracterizar las rocas silíceas disponibles en los diferentes sectores, con el objeto de evaluar la potencialidad de las herramientas geoquímicas, ya sea para la determinación de procedencia o para generar tendencias sobre su génesis y poder relacionarlos con áreas de procedencia. 


\section{CAPÍTULO 4}

\section{APROXIMACIONES TEÓRICAS PARA EL ESTUDIO DE LA TECNOLOGÍA}

\subsection{MARCO TEÓRICO GENERAL}

En esta investigación se emplean principios derivados de modelos ecológicos. Desde esta perspectiva se han adoptado y propuesto distintos modelos para comprender el comportamiento de las poblaciones en el pasado. Estos se conocen en general como modelos de optimización (Bettinger 1991; Wintherhaldet y Smith 1992). Entre ellos se destacan, en primer lugar, los derivados de la micro-economía con un desarrollo previo e independiente de su aplicación en arqueología (cf. Charnov 1976; Metcalfe y Barlow 1992) $y$, en segundo lugar, los modelos provenientes de estudios etnográficos y etnoarqueológicos, así como de teorías o principios abstractos ( $c f$. Bettinger 1991). Entre estos últimos se destacan los modelos propuestos por Binford (1979, 1980, 1988), Gould (1979, 1980), Gould y Saggers (1985), Bettinger (1991, 2001); Bettinger y Baumhoff (1992), Kelly (1988, 1992, 1995), Kuhn (1994, 2004) y Bratingham y Kuhn (2001), entre otros. Los modelos de optimización en general han sido cuestionados por presentar problemas en el estudio de las poblaciones humanas; fundamentalmente por la falta de control de variables, la extrema simplificación de los modelos y la mecanización del comportamiento humano (Mithen 1998; Ingold 2000). No obstante y teniendo en cuenta estas limitantes, proveen un marco simple y sistemático para analizar la depredación humana, para generar hipótesis y contrastar diferentes aspectos de la vida de los individuos. Representan una forma de abordar el registro arqueológico, que permite 
transformar situaciones o principios abstractos y complejos en hechos empíricos simples y accesibles (Winterhalder y Smith 2000).

Las materias primas líticas son consideradas un recurso, al igual que los de subsistencia (Bamforth 1986). Bousman (1993) destaca que el costo de producción tecnológico debe ser considerado a la hora de establecer qué tan óptimas son las estrategias de búsqueda y procesamiento de los recursos bióticos con fines dietarios. Se deben considerar los costos de producción de distintas alternativas tecnológicas, estimando la inversión de trabajo en tiempo y energía (Jeske 1989; Jochim 1989; Bousman 1993; Ugan et al. 2003; Bettinger et al. 2006). El comportamiento tecnológico es flexible y existen distintas soluciones o alternativas posibles. Por este motivo es necesario dar cuenta de la variabilidad de los conjuntos tecnológicos y entender por qué se priorizaron determinadas opciones (Bousman 1993; Lanata y Borrero 1994; Franco 2002).

\subsection{EL ESTUDIO ARQUEOLÓGICO DE LA TECNOLOGÍA LÍTICA: LA ORGANIZACIÓN DE LA TECNOLOGÍA}

La tecnología puede ser definida como todo conjunto integrado de materia, comportamiento y conocimiento para usar y crear productos, que se trasmite generacionalmente (Schiffer y Skibo 1987). Las actividades son intencionales y actúan sobre la materia (Lemonier 1992), siendo su objetivo la resolución de problemas creados por el medio social y/o natural de un grupo (Torrence 1989; Nelson 1991). La tecnología lítica utiliza técnicas extractivas y cada acción resulta en la reducción de una masa lítica. Existen dos formas generales de trabajar las rocas: la talla (por percusión y/o presión) y el picado, abrasión y pulido. El resultado de todo proceso de reducción antrópica de una masa lítica son los artefactos, los cuales pueden ser diferenciados en núcleos, desechos e instrumentos.

Los artefactos y sus propiedades (dimensión formal, espacial, frecuencia y relacional) constituyen la expresión material de la tecnología lítica (Rathje y Schiffer 1982). 
Para su estudio arqueológico en esta tesis, se adopta la propuesta denominada organización de la tecnología (Binford 1979; Torrence 1989; Nelson 1991). Este enfoque propone estudiar la selección e integración de estrategias vinculadas a la manufactura, uso, transporte y descarte de instrumentos y demás elementos necesarios para su producción y mantenimiento (Nelson 1991:397).

Las estrategias tecnológicas son entendidas como planes en los que se vinculan intereses sociales y económicos de un grupo con las condiciones ambientales de un momento dado (Nelson 1991). La clave de este enfoque es, por tanto, relacionar los artefactos con una variedad de parámetros económicos y sociales que permiten realizar inferencias relacionadas con la dinámica de las culturas pasadas (Carr 1994). Las formas de los artefactos y la composición de los conjuntos son, entonces, una consecuencia de las estrategias tecnológicas. En la toma de decisiones, las poblaciones priorizan estrategias tecnológicas que dan como resultado determinados diseños de los artefactos, y éstos constituyen una vía de entrada al problema. De este modo, los conjuntos son una fuente de información sobre temas vinculados a la movilidad, las estrategias sociales, la subsistencia, el riesgo y otros aspectos del comportamiento humano (Shott 1986; Nelson 1991; Amick 1994; Bousman 1993; Carr 1994; Beck et al. 2002), más que un indicador estático de tipos y frecuencias de actividades.

La perspectiva organizativa de la tecnología pone énfasis en el rol dinámico de la tecnología en los sistemas culturales, haciendo hincapié en el análisis de la variabilidad dentro y entre conjuntos artefactuales (Carr 1994). Una de las metas principales es reconstruir los patrones de movilidad y asentamiento, y la manera en que éstos determinan necesidades artefactuales y el acceso a las materias primas. Si bien son muchas las variables o parámetros culturales relevantes a la hora de analizar las decisiones tecnológicas y la trayectoria de los artefactos, no necesariamente todas poseen el mismo peso o son analizadas de manera simultánea (Sassaman 1994). Este último punto, entendido como un problema de equifinalidad, ha sido objeto de críticas ( $c f$. Beck Kelly 2008). Sin embargo, se plantea que puede ser superado a través de la utilización de distintas líneas de evidencias (Bradbury y Carr 1995; Franco 2002a), del uso de una 
perspectiva comparativa (Torrence 1994) y de una consideración adecuada de la estructura de recursos (sensu Ericson 1984).

\subsubsection{ESTRATEGIAS TECNOLÓGICAS Y LOS APORTES DE LA ETNOARQUEOLOGÍA}

En el marco de la organización de la tecnología, las estrategias son vistas como planes que facilitan el uso humano del ambiente (Nelson 1991). Las operaciones tecnológicas están constituidas por actividades y por puntos de elección, al tomar decisiones sobre qué hacer y cómo (Bleed 1997). Las decisiones o elecciones tecnológicas en la producción y el uso de herramientas de piedra, implican la puesta en práctica de las estrategias que resulten más adecuadas (funcional, material y socialmente) ante una situación particular (Torrence 1989; Carr 1994). Así, se espera que tengan mayor persistencia en el tiempo las elecciones que resultaron efectivas y/o flexibles para enfrentar nuevas situaciones (Carr 1994). Estas decisiones pueden ser modeladas como problemas de optimización (Torrence 1989; Nelson 1991; Surovell 2009). Las diferencias observadas entre las elecciones consideradas "óptimas" y cada conjunto arqueológico particular, requieren generar hipótesis para explicar alternativamente las decisiones materializadas en cada registro. Es decir, "los análisis de optimalidad plantean una referencia contra la cual evaluar la casuística arqueológica (Bettinger 1991, Foley 1985) y no expresan una creencia en que solamente se alcanzaron soluciones ideales en el pasado...." (Borrero 1993:17). El rechazo de las hipótesis que expliquen los patrones materiales considerando factores físico-tecnológicos o de deficiencia funcional constituye una forma de identificar las características del registro arqueológico que deben ser explicadas por factores no tecnológicos (Lemonier 1992).

El concepto de estrategias tecnológicas cuenta con un extenso desarrollo en los estudios de organización de la tecnología lítica. La integración de datos etnográficos, etnoarqueológicos y experimentales ha permitido construir modelos teóricos para explicar los comportamientos y actividades que generaron los conjuntos arqueológicos (cf. Gould 
1971, 1978, 1980; Binford 1978, 1979, 1980; Hayden 1979; Gould y Saggers 1985; Bleed 1986; Nami 1986, 1992, 2003; Shott 1989; Kuhn 2004, entre otros). Uno de los primeros antecedentes, y quizás de mayor vigencia, son los trabajos de Binford $(1973,1977,1979)$. Este investigador inspirado en parte por sus observaciones etnoarqueológicas entre los Nunamiut, propuso distinciones teóricas que resultaron de sumo interés para el estudio de las sociedades cazadoras recolectoras en general y de la tecnología lítica en particular. Entre éstos se destacan las estrategias de asentamientos-subsistencia collectors y foragers; las estrategias de utilización de recursos líticos conservada (curation) y expeditiva (expediency), y las estrategias de aprovisionamiento lítico incidental (embedded) y directa (Binford 1977, 1979, 1980). Conceptos que cuentan con amplio tratamiento en la literatura arqueológica y de las cuales sólo se hará breve referencia (Bamforth 1986; Bleed 1986; Nelson 1991; Bousman 1993; Shott 1996; Escola 2000; Odell 2003; Franco 2004; Charlin 2009, entre otros).

La primera distinción de Binford (1980) se sintetiza en dos estrategias ideales de acuerdo a los patrones de movilidad y subsistencia implicados. La estrategia collectors estaría representada por grupos con baja movilidad residencial y una elevada movilidad logística, es decir grupos cuyos viajes son realizados con fines específicos por grupos de tareas formados para tal fin. Estas partidas especiales están formadas por algunos integrantes del grupo que salen desde el campamento base o lugar de residencia hacia campamentos temporarios localizados en las cercanías del recurso a explotar. Cuando el aprovisionamiento $\mathrm{u}$ objetivo del viaje se ha cumplido, se emprende el regreso a la base residencial (Binford 1980). La estrategia foragers conlleva el desplazamiento de la base residencial. Las sociedades que aplican esta estrategia exhiben una mayor movilidad residencial que las logísticas. La explotación de los recursos se realiza diariamente sobre un radio máximo desde la base residencial (Binford 1980).

Las estrategias de utilización de recursos líticos son definidas como planes que responden a las condiciones materiales y temporales percibidas por los individuos. Una estrategia expeditiva es aquella que minimiza la inversión energética dado que el tiempo y lugar de uso son altamente predecibles. La aplicación de una estrategia expeditiva implica 
planificación, ya que prevé la disponibilidad de tiempo y materiales suficientes para llevar adelante una actividad específica (Binford 1979; Nelson 1991). Nelson (1991) menciona tres condiciones necesarias para que la expeditividad tenga lugar: 1) disponibilidad de materiales (artefactos o materia prima) en las inmediaciones del locus de actividad; 2) disponibilidad de tiempo para la preparación de instrumentos, y 3) reocupación del lugar a lo largo del tiempo, para permitir su aprovisionamiento. La expeditividad ha sido señalada como la estrategia priorizada en grupos con baja movilidad residencial, es decir, con el aumento del sedentarismo (cf. Parry y Kelly 1987).

La estrategia conservada, por su parte, es definida como la manufactura de herramientas con anticipación al uso cuando se prevén condiciones inadecuadas en tiempo y/o materiales para su preparación in situ. Se caracteriza por el cuidado de los instrumentos, que puede incluir además de la manufactura y uso, el transporte, su reactivación y almacenamiento. La conservación mitiga la incongruencia en la disponibilidad de tiempo y materiales para la realización de una actividad, permitiendo maximizar el tiempo a ser empleado en el desarrollo de esta última (Binford 1979; Nelson 1991).

Binford (1977) sostiene que la estrategia conservada es la priorizada por los grupos con movilidad logística mientras que la expeditiva es más frecuente entre los foragers. Si la estrategia priorizada es la expeditividad, se espera que los instrumentos y sus desechos de formatización y uso se encuentren espacialmente asociados. En este caso, la tasa de descarte de instrumentos es directamente proporcional a su frecuencia de uso. En cambio, si la estrategia priorizada ha sido la conservación, la tasa de descarte de los instrumentos decrecerá conforme se incremente su vida útil. Dada la manufactura con anticipación al uso del instrumental y el posterior transporte al locus de actividad, es poco probable que el instrumento y sus desechos estén asociados espacialmente en el registro arqueológico. Nelson (1991) propone una tercera estrategia de utilización de recursos líticos, la oportunista. Esta estrategia se diferencia de la expeditiva por ser una respuesta tecnológica inmediata a una situación inesperada. En este caso se espera que los conjuntos producidos se caractericen por: 1) menor inversión de trabajo en la 
formatización; 2) manufactura, uso y descarte se encuentren el mismo lugar, y 3) menor calidad en las materias primas utilizadas. Este último punto condicionado por la disponibilidad local inmediata. La aplicación de cada estrategia tecnológica tiene consecuencias sobre la estructura de los conjuntos artefactuales. Para Nelson (1991) la implementación de diferentes estrategias tecnológicas posee consecuencias formales que pueden ser abordadas a través del estudio de los diseños artefactuales. Estos hacen referencia a las formas de los utensilios y la composición de los conjuntos instrumentales. En su trabajo considera cinco variables de diseño: confiabilidad, facilidad de mantenimiento, flexibilidad, versatilidad y transportabilidad o facilidad de transporte (Nelson 1991). Cada una de ellas se adecúa a estrategias tecnológicas particulares de cazadores recolectores.

Por último, Binford $(1979,1980)$ diferencia dos tipos de estrategias de aprovisionamiento lítico según los costos implicados: aprovisionamiento incidental o incluido y estrategias de aprovisionamiento directo (Binford 1979). El primero de los casos, alude a la obtención de materias primas en el desarrollo de otras tareas, principalmente de subsistencia. Mientras que por aprovisionamiento directo, se refiere a los movimientos de una población en el ambiente con el propósito exclusivo de obtener materias primas. En el caso de los Nunamiut, el aprovisionamiento directo se da solamente cuando no se pudieron obtener recursos de manera incidental (Binford 1979). Por este motivo, el autor sostiene que las proporciones de materias primas recuperadas en un sitio son básicamente una función de la escala del hábitat que está siendo explotado y no implica costo alguno, o los mismos serían muy bajos. Numerosos autores, como más adelante se detalla, discuten este último punto (Gould y Saggers 1985; Bamforth 1991; Franco 2004). Binford también define tres tipos de equipo instrumental: equipamiento personal (personal gear), equipamiento espacial (caches que incluye el site furniture, household gear, insurance gear y seasonal gear) y el equipamiento situacional (situational gear) (Binford 1979). Estos responden a distintas necesidades y estrategias de aprovisionamiento. En el equipamiento personal y espacial los instrumentos son manufacturados con anticipación al uso y previendo necesidades futuras, por lo que no 
son afectados por limitaciones de tiempo y se espera sean manufacturadas en las mejores materias primas disponibles regionalmente. En tanto que en el equipamiento situacional, al responder a necesidades y contingencias no previstas, es manufacturado sobre las materias primas disponibles en forma inmediata. De esta forma, “...these materials may be naturally occurring, cached, scavenged, or recycled personal gear" (Binford 1979: 267). De acuerdo con estas características también se registran diferencias en la calidad de las rocas utilizadas en la manufactura de equipos. Debido a que es probable que el equipamiento personal y espacial sea manufacturado sobre materias primas de mejor calidad que el equipamiento situacional, por los mismos factores antes señalados. Características que también se extienden al diseño de los instrumentos, las formas de enmangue, las técnicas de reducción, el número de episodios o etapas de manufactura, los lugares donde la misma es realizada, las tasa de reactivación y reciclaje, entre otras (Binford 1979; Binford y Stone 1985).

Las propuestas de Binford han puesto énfasis principalmente en la organización de la tecnología en relación con el sistema de asentamiento-subsistencia de los grupos humanos. Los estudios tecnológicos que siguieron se focalizaron en la reconstrucción de patrones de movilidad y asentamiento prehistóricos. No obstante, su aplicación en la investigación arqueológica promovió diversas discusiones (cf. Gould 1978, 1980; Gould y Saggers 1985; Bamforth 1986) y nuevos modelos (cf. Nelson 1991; Bettinger 1991; Andrefsky 1994; Kuhn 1994, 2004), que pueden resumirse en el debate de dos grandes temas. En primer lugar, la injerencia de la demografía, los patrones de movilidad y subsistencia en la organización tecnológica y en los costos de abastecimiento de rocas (cf. Kelly 1988; Bettinger 1989, 1991, 2001; Andrefsky 1994; Brantingham 2003, 2006; Kuhn 1992, 1995, 2004); y en segundo lugar, en el tratamiento de las características y aspectos implicados en la estrategia tecnológica de conservación de los artefactos y sobre cómo medirla (cf. Parry y Kelly 1987; Bamforth 1986, 1991; Odell 1996; Shott 1986). Estos tópicos serán retomados más adelante en el presente capítulo con el objeto de enmarcar los estudios llevados a cabo en La Payunia. 


\subsubsection{AMPLIANDO CONCEPTOS. ORGANIZACIÓN TECNOLÓGICA, ETNOARQUEOLOGÍA Y ARQUEOLOGÍA}

La etnografía y la etnoarqueología aportan un panorama único de la variabilidad de los fenómenos sociales como la organización de la territorialidad, la movilidad y la interacción entre poblaciones (David y Kramer 2001). Desde sus primeros antecedentes se observa un marcado interés por el estudio de las estrategias de adquisición, transporte, consumo y/o uso y descarte de recursos (Binford 1977, 1979, 1980; Gould 1968, 1977, 1980; Yellen 1977; Hayden 1978, 1979; O'Connel et al. 1988; O'Connel y Marshall 1989; Stout 2002). Sin embargo, el énfasis en esta clase de estudios comenzó cuando la mayoría de las poblaciones ya no utilizaban los materiales líticos como parte de su vida diaria (Metcalfe y Barlow 1992; Johnson 1984), y se basó en estudios replicativos aislados (Elston 1989; Kelly 1994). A pesar de ello, la etnoarqueología ha demostrado ser una fuente valiosa de información que ayuda a mejorar los métodos y procedimientos de la inferencia arqueológica, y particularmente el razonamiento analógico, teniendo en cuenta las limitaciones que posee (Borrero 1991; Politis 2002; Lane 2008).

En los conceptos de Binford $(1977,1979,1980)$, mencionados en el apartado anterior, cobra relevancia la relación entre la estructura ambiental, la movilidad y los recursos. Sin embargo, diferentes estudios etnoarqueológicos y arqueológicos sobre tecnología han señalado que la movilidad no siempre puede explicar completamente los patrones de producción, uso y descarte de los artefactos (Bamfoth 1986, 1991; Torrence 1989; Andrefsky 1994, entre otros) y que otros factores intervienen en la configuración de la tecnología adoptada. En este sentido Gould $(1978,1979,1980)$ y Gould y Saggers (1985) observan en el desierto de Australia, que factores distintos a la subsistencia ejercen influencia en la organización tecnológica. Gould $(1979,1980)$ sugiere que parte del aprovisionamiento de material lítico en los aborígenes australianos está influenciado por la proximidad a los centros ceremoniales o sitios sagrados, destacando el hecho de que los

recursos líticos pueden ser seleccionados por su carga ideológica (Gould 1980: 228). Gould y Saggers (1985) plantean que las propiedades utilitarias de las rocas son un factor de 
peso en la selección del recurso líticos "... Western Desert Aborigines made spacial effort to visit lithic sources, (...) in order to obtain raw material that was known to have superior technical properties" (Gould y Saggers 1985: 120). Patrón que también observan en los contextos arqueológicos de Ranger East y Puntutjarpa (Gould y Saggers 1985). En el alero Ranger East las rocas exóticas o no locales (disponibles más allá de los 40 km de radio del sitio) son las más utilizadas en la manufactura de hachas líticas, a pesar de disponer de materias primas locales abundantes y accesibles. Los estudios experimentales de las cualidades físicas de las rocas y de la utilidad de los filos, tanto en materias primas locales como exóticas, demostraron que estas últimas eran más eficientes para el trabajo de la madera (función de uso para la cual cuentan con evidencias etnográficas y de microscopía). Por el contrario en el alero Puntutjarpa, las rocas locales son las que cuentan con estas cualidades utilitarias y son las más representadas en el sitio. En consecuencia, en ambos contextos el factor tecnológico es el que parece influir en la elección y distribución de las materias primas, a pesar de ser contrastante la representación de los tipos de materias primas en el espacio. Los autores señalan que las propiedades utilitarias de los recursos líticos deben ser consideradas a la hora de explicar la relación entre los artefactos arqueológicos, la fuente de procedencia de las rocas utilizadas y los costos asociados en su obtención.

Por su parte, Stout (2002) da cuenta de la planificación y tiempo que implican las actividades de aprovisionamiento entre los productores de hachas líticas en Irian Jaya, Indonesia. El aprovisionamiento de rocas se lleva a cabo a través de la conformación de grupos de tareas. Dado que las actividades de aprovisionamiento se extienden por varios días, se construyen viviendas en las cercanías de las canteras (Stout 2002). Asociado a las áreas de aprovisionamiento hay espacios donde se concentran actividades de procesamiento de materia primas líticas, generando áreas de actividades y descarte diferenciales en el espacio regional. Estos estudios, más allá de sus objetivos puntuales, generan información de utilidad para entender y generar expectativas referentes a la organización tecnológica. 
Son numerosos los estudios que sostienen que el lugar de uso de los artefactos no se corresponde con el lugar de descarte. Binford (1979) postula tipos de descartes diferentes para cazadores recolectores collector y forager. Así mientras los primeros descartan sus instrumentos en su lugar de uso, los forager los trasladan y usan en sucesivos lugares. En caso de que necesiten repararlos, los trasladan al campamento base, lo que hace que el lugar de descarte no corresponda al lugar de uso. Estas expectativas llevaron a planteos donde se asociaba de formas directas a estrategias de asentamiento y de carácter tecnológicas -del modo collector/expeditividad y forager/conservación(Bamforth 1986; Torrence 1989; Bousman 1993; Andrefsky 1994; Carr 1994; Escola 2004). Andrefsky (1994), sostiene que el modo en que se utilizan las materias primas líticas depende más de la abundancia y calidad de las rocas disponibles en el ambiente, que del grado de movilidad residencial de los grupos. Según este autor la influencia de los patrones de asentamiento es sólo indirecta. Utilizando datos etnográficos, evalúa la incidencia de las estrategias de asentamiento y la calidad y abundancia de las materias primas líticas disponibles en los conjuntos. Para ello define dos tipos de instrumentos, que representan puntos extremos de un continuum de formatización. Por un lado, los instrumentos formales son aquellos en cuya manufactura se ha invertido un esfuerzo adicional, ya sea a través de múltiples episodios de reactivación y/o enmangue, o en su formatización como instrumento terminado. Por otro lado, los instrumentos informales, caracterizados por una baja inversión de esfuerzo en su confección. En su estudio concluye que aún cuando la estrategia de movilidad implementada por los grupos humanos sea la misma, la calidad y la abundancia de las materias primas pueden estructurar la producción lítica. De acuerdo con sus observaciones plantea un modelo de producción artefactual basado en dos expectativas: 1) cuando las materias primas disponibles (sin importar su abundancia) son de mala calidad, en los conjuntos líticos predominan los instrumentos informales elaborados sobre materia prima no local; 2) cuando las materias primas son de buena calidad pero son escasas en el paisaje, se prioriza la manufactura de instrumentos formales; por último, 3) si las materias primas 
son de buena calidad y abundantes, se producen instrumentos tanto formales como informales (Andrefsky 1994).

Según Barton (2008), para explicar la estructura del registro lítico de los grupos cazadores recolectores (etnográficos y arqueológicos), es necesario evaluar el riesgo que se buscó reducir a través de la tecnología lítica en distintos aspectos de la subsistencia. En su ejemplo encuentra que los instrumentos manufacturados para la adquisición de alimentos son predominantemente informales. A partir de una evaluación ecológica, el autor sostiene que en la obtención de alimentos (principalmente plantas y pequeños animales) el riesgo asociado es bajo, puesto que los recursos son abundantes y fáciles de obtener. Por el contrario, observa que aquellos artefactos líticos manufacturados para intercambios regionales son predominantemente formales (bifaces, instrumentos sobre hojas, presencia de estandarización). El objetivo del intercambio de esos bienes es reproducir las relaciones sociales que permiten el acceso a recursos y la libre circulación en el espacio. Esto significa que en el mantenimiento de la libre circulación en la región (a través de la reproducción de las redes sociales) se asegura la subsistencia del grupo, por lo que el riesgo asociado es alto. Por lo tanto, el riesgo es el factor con mayor poder explicativo sobre las variaciones formales observadas en los artefactos (Barton 2008).

En torno a la aplicación dicotómica de los pares collector/expeditivos y forager/conservación, Escola (2004) realiza una revisión crítica de la aplicación del concepto de expeditividad en los estudios arqueológicos. Como observa en su trabajo, esta aplicación ha llevado a utilizar del mismo modo los conceptos de informalidad y formalidad en los instrumentos (sensu Andrefsky 1994). Los instrumentos informales -en contraposición con los formales- son generalmente atribuidos en la bibliografía a la aplicación de una estrategia expeditiva. Pero como plantea Escola (2004) a partir de su experiencia como talladora, gran parte del repertorio instrumental considerado formal (instrumentos unifaciales de retoque marginal: como cuchillos, raederas, muescas, denticulados) no requieren de mucha destreza e inversión de trabajo para su manufactura. Por lo tanto, son también esperables en conjuntos producidos en el marco de una estrategia expeditiva, lo que sugiere la necesidad de ampliar el espectro de 
instrumentos esperados en un contexto donde ésta ha sido la estrategia priorizada (Escola 2004). Considera que la inversión de trabajo debe ser entendida en términos de las técnicas de reducción involucradas en la producción de determinadas formas base, la evidencia de cierta estandarización de los soportes, tamaño o módulo, y técnicas de retoque implementadas en la formatización y regularización final de los instrumentos (Escola 2004).

La escasez de materia prima y su vinculación con las estrategias tecnológicas, han sido otras de las líneas de debate en la literatura. Bamforth $(1986,1991)$ analiza distintos indicadores de una estrategia tecnológica de conservación de artefactos (tales como diseños para usos múltiples, transporte de artefactos, mantenimiento y reciclaje) y señala que lo mismos son adaptaciones a distintas circunstancias y no son eficientes en todos los contextos. Propone que el mantenimiento y reciclaje, son dos de los componentes necesarios para una estrategia conservada $y$, se dan en función de la distancia a las fuentes de aprovisionamiento: cuanto mayor es esta distancia, mayores serán los índices de mantenimiento y reciclado. Morrow y Jefferies (1989), sostienen que el único modo de aprovisionamiento que no implica costos es el incluido en actividades de subsistencia (Binford 1979). En el intercambio de rocas con otros grupos, los costos son medidos según el valor del objeto o servicio intercambiado y; en los casos en que su adquisición se realiza a través de viajes especiales hacia las fuentes, los costos se miden según el tiempo y energía invertidos en el viaje. Estas diferencias hacen que algunas sean consideradas "costosas" y otras "no costosas" (Jeske 1989) y los grupos cazadores recolectores habrían maximizado las materias primas líticas más costosas (Bamforth 1986; McAnany 1988; Jeske 1989; Andrefsky 1994). Nelson (1991) advierte que en la definición de la conservación, no hay que confundir estrategia tecnológica con diseño de los artefactos. Pensar a los utensilios conservados como activos para una diversidad de tareas (versátiles) y plausibles de ser reciclados para otras cuando ya no son útiles para la finalidad que habían sido creados (flexibles), es confundir respuestas o estrategias para utilizar el ambiente con una estrategia tecnológica orientada a la preparación de materias primas en previsión de condiciones (materiales, tiempo o instalaciones) (Nelson 1991). 
En un esfuerzo por clarificar la ambigüedad del concepto de conservación, Odell (1996) propone restringir el uso del término para referirse a una estrategia relacionada con la existencia de situaciones de riesgo o estrés temporal derivado de los patrones de movilidad de un grupo (ya sea forager y/o collector), y denominar economía de materias primas, a aquellas estrategias que buscan mitigar la escasa disponibilidad de rocas en el paisaje (Odell 1996). De modo que el mantenimiento y reciclaje de instrumentos son una respuesta común a ambos tipos de comportamiento, sin estar asociados exclusivamente con la organización de la movilidad. En el caso de comportamientos que privilegian la economía de materias primas, el autor incorpora indicadores adicionales tales como: explotación de núcleos de tamaño pequeño, presencia de tecnología bipolar, alto grado de fragmentación de instrumentos y alta intensidad de uso de los instrumentos; esto último medido por el desgaste del instrumental hasta el agotamiento y por el uso de fracturas como filos activos (Odell 1996). Este investigador destaca a su vez, que la aplicabilidad del término conservación no se restringe a estrategias de movilidad logística, siendo en todos los casos su unidad de análisis el conjunto arqueológico. Shott (1996), por el contrario, plantea que la conservación debe analizarse a nivel del artefacto ya que ésta puede ser medida en función de su utilidad, asumiendo que la utilidad declina con el uso.

Sobre esta base se han propuesto diferentes métodos para cuantificar la conservación. Se han realizado estudios experimentales, y desarrollado modelos matemáticos que proponen diferentes ecuaciones como medidas de conservación. La mayoría de estos modelos intentan estimar la utilidad perdida por el artefacto (producto de los sucesivos usos y reavivado a los que estuvo sujeto), en relación con la utilidad máxima y potencial. Así, algunos se basan en la predicción de la masa o volumen perdido por el artefacto a partir de la estimación de la masa original (Dibble 1987, 1998; Debble y Pelcin 1995; Pelcin 1998; Eren et al. 2005). Otros se basan en la relación entre variables directamente observables como la razón entre espesor del filo retocado y el espesor de la forma base (Kuhn 1990; Hiscock y Clarkson 2005 a y b), la invasión o cobertura del retoque del filo sobre la superficie del artefacto (Clarkson 2002), la longitud del filo retocado y su curvatura, y la proporción retocada del perímetro del artefacto (Hiscock y 
Attenbrow 2002), entre otros. Siguiendo las propuestas de Bamforth (1986), Odell (1996) y aplicaciones de estos marcos en Patagonia Meridional (cf. Franco 2002a, 2004; Charlin 2007, 2009), los conceptos considerados para el estudio de las estrategias tecnológicas son: las variaciones en la disponibilidad de materias primas líticas a nivel regional, la distancia a la fuente de aprovisionamiento como medida adecuada para estimar los costos de aprovisionamiento, las estrategias de obtención implementadas y el modo de utilización de los diferentes tipos de rocas.

En referencia a las estrategias tecnológicas y modo de utilización de las materias primas, un concepto que cobra relevancia en el sur de Mendoza, es el llamado proceso de intensificación (Neme 2007, Capítulo 2). En el noroeste argentino, estudios referentes a la tecnología y utilización de artefactos de molienda (Babot 2004, 2006), analizan los correlatos e indicadores de estos procesos en las tecnologías de producción. Según Babot (2004, 2006), el concepto de intensificación es central para entender el cambio en los sistemas de producción. Entendidos estos últimos como todas las acciones de manufactura, construcción o creación llevadas a cabo por el hombre (Morrison 1994). Los indicadores desde la tecnología, remiten a decisiones tecnológicas dirigidas a aumentar la eficiencia de la tarea y posibilitar una mayor intensidad de uso, a los fines de un aprovechamiento de tiempo, trabajo y rendimiento de los recursos disponibles. La intensificación en la producción se refiere a un incremento en el rendimiento productivo por unidad de tierra o de mano de obra (labor) o de alguna otra cantidad fija (Morrison 1994; Babot 2006). Este incremento puede llevarse a cabo de diferentes maneras, la variable constante puede ser la tierra en referencia al alimento producido, la oferta de recursos de un espacio dado de actividades para la caza y recolección, el trabajo cuando se estudia la producción -uso de tecnofacturas (Babot 2006), a lo que agregamos como variable constante la roca en relación a la intensidad de uso de ese recurso lítico. También se ha hecho referencia a la intensificación tecnológica, cuando es esta última la que se modifica -mediante la utilización de artefactos y técnicas más eficientes- para aumentar el rendimiento obtenido por unidad de tierra o de mano de obra (Morrison 1994, 1995; Babot 2006). Morrison (1994) menciona que la noción de intensificación conlleva una 
dimensión temporal implícita a lo largo de la cual deben establecerse tendencias del proceso. Para Babot (2006) la intensificación de las practicas productivas se refieren a: la inversión de tiempo y trabajo puesta en la construcción y mantenimiento de los elementos materiales, y la dedicada a la organización de la mano de obra; y al esfuerzo de preparación y realización de la tarea en sí, más su frecuencia. Los cuales son factibles de ser abordados desde indicadores tecnológicos y de uso.

\subsubsection{APROVISIONAMIENTO Y DESCARTE: EXTREMOS EN LA ORGANIZACIÓN TECNOLÓGICA}

El concepto de organización de la tecnología hace hincapié en las estrategias o planes que orientan el comportamiento tecnológico. El continuum de comportamiento incluye desde la necesidad o decisión inicial de encuentro del recurso lítico, la obtención, confección, transporte, uso, mantenimiento y el reciclado y/o descarte final de los artefactos. Si bien cada etapa debe ser considerada para poder dar cuenta de la variabilidad en el comportamiento tecnológico, son escasos los estudios líticos que centran su atención en las primeras etapas de la trayectoria o historia vida de los artefactos (Schiffer 1972, 1976). No obstante, varios investigadores sostienen que para entender la relación entre las áreas de abastecimiento o canteras y las estrategias de obtención de recursos líticos, se requiere de la integración de información referente a la disponibilidad de recursos en el ambiente y de las áreas donde se emplaza cada cantera en particular, con aquella referida al transporte, uso y descarte final de la materia prima en el espacio regional amplio (cf. Binford 1980; Ericson 1984; Elston 1992; Bousman 1993). La cantera juega aquí un rol esencial para entender las estrategias de obtención de las materias primas, a la vez que aporta información complementaria a la obtenida en la región. Esta última información actúa como una medida proxy para entender las estrategias de obtención de recursos o "gestión integral" (management end) de los mismos, fuera de las áreas primarias de abastecimiento (Carr y Boszhardt 2010:132). 
Por disponibilidad de recursos líticos se entiende la presencia-ausencia de clases particulares de materias primas, mientras que accesibilidad hace referencia a la facilidad relativa con la que pueden ser obtenidos. En relación a los costos de obtención, Binford (1979) plantea que no habría costos asociados al aprovisionamiento sino sólo costos bajos relacionados con la manufactura y reparación. Esto se debe a que las materias primas normalmente se obtendrían como parte del desarrollo de otras tareas o a través de mecanismos sociales y, raramente, se harían viajes con el único propósito de obtener materias primas para los instrumentos. Por este motivo, Binford sostiene que las proporciones de distintas materias primas en un sitio son representativas de la escala del hábitat que está siendo explotado. En este sentido, Ingbar (1994) ha modelado el efecto que la movilidad y la tasa de reemplazo de instrumentos tienen sobre el porcentaje de materias primas en el registro arqueológico, y concluye que son reflejo del rango de acción mínimo del grupo. Estudios etnográficos, etnoarqueológicos y arqueológicos discuten este último punto (Gould 1980; Gould y Saggers 1985; Kelly 1995; Bousman 1993; Stout 2002), que mida el rango mínimo o máximo de un grupo humano no autoriza a creer que el aprovisionamiento lítico es dependiente de las actividades de subsistencia. Sólo podría serlo en ambientes en los que fuera abundante y ubicuo.

El aprovisionamiento lítico también se espera que varíe en relación con la clase de artefactos a manufacturar, y con su papel en el sistema tecnológico (Binford 1979; Nelson 1991; Kuhn 1994, 2004). La calidad de la materia prima es tenida en cuenta, especialmente para el caso del equipamiento personal o de individuos y de actividades. Sobre esta base, Aragón y Franco (1997) proponen diferenciar los recursos líticos disponibles en el espacio regional, según una escala nominal, de rocas según atributos macroscópicos en rocas de calidad excelente, muy bueno, bueno y regular (capítulo 5). De igual manera, los recursos líticos pueden ser adquiridos a partir de fuentes de aprovisionamiento lítico primarias o secundarias. Según Nami (1992), las fuentes primarias son aquellas en las que el material aparece en forma de mantos o filones, mientras que en las secundarias el material fue transportado por un agente natural ( $p . e j$. cauce de agua, un glaciar u otros agentes geomorfológicos). Las materias primas también han sido 
diferenciadas en función de la distancia entre su fuente y el locus donde fueron descartadas, en materias primas de origen local y no local o exóticas (Gould y Saggers 1985; Gamble 1993; Borrero 1994-95; Bayón y Flegenheimer 2004).

En este marco, conocer la estructura regional de recursos líticos (sensu Ericson 1984), es fundamental para evaluar costos de aprovisionamiento y estrategias de obtención, así como para entender la utilización de los diferentes tipos de rocas según su abundancia relativa. En términos ecológicos, esto significa caracterizar la disponibilidad (extensión de fuentes potenciales, tamaño de los nódulos, calidad para la talla, litologías, etc.) distribución y accesibilidad (exposición superficial, localización en el paisaje) de las materias primas (Nelson 1991; Franco 2002a). Esta caracterización del paisaje en términos de disponibilidad de rocas es la contraparte del estudio arqueológico que permite discutir decisiones humanas sobre la economía de las materias primas. Una de las variables más comúnmente utilizada para explicar y discutir el origen de la distribución espacial y características composicionales de los conjuntos líticos ha sido la distancia a la fuente de aprovisionamiento (Renfrew 1977; Torrence 1984; Meltzer 1989; Beck et al. 2002; Brantingham 2003; Kuhn 2004). Renfrew (1977) estudió los patrones de distribución espacial de los artefactos para entender los mecanismos de circulación de bienes. De acuerdo con este autor, cuando la disponibilidad de un bien es puntual en el paisaje, su distribución espacial es más frecuente en sectores cercanos a la fuente de aprovisionamiento de materia prima (ley de decrecimiento monotónico, Renfrew 1977). Conforme nos alejamos del punto de origen del recurso, la frecuencia disminuye debido a los costos de transporte implicados. Este patrón se denomina curva de fall-off y puede adoptar tres formas (distribución de Pareto, Gaussiana o Exponencial). La forma de la curva y su inclinación son utilizadas para discutir y distinguir las modalidades de aprovisionamiento que dieron origen a un conjunto artefactual (directo o por intercambio). Renfrew señala que en algunos casos, como sucede con el modelo denominado random walk or flight que implica un gran número de transacciones al azar, se genera una curva gaussiana. Por lo tanto un número de eventos no coordinados produce también un patrón coherente y cuantificable como una curva de caída. Éste y 
otros estudios, han destacado la equifinalidad observada en los patrones resultantes de las modalidades de aprovisionamiento (Renfrew 1977; Meltzer 1989; Brantingham 2003). Ingbar (1994) sostiene que es necesario entender cómo se organizaba la tecnología para poder interpretar las variaciones en la proporción de fuentes utilizadas.

Junto con la caída registrada en la frecuencia, conforme aumenta la distancia a la fuente, existe un decrecimiento en el tamaño de los artefactos (Hiscock 2001). Byrne (1980) trata el tema específicamente en núcleos y sostiene que la utilidad potencial de un artefacto está directamente relacionada al abastecimiento o disponibilidad de materia prima. El umbral de descarte es circunstancial, es decir, la tolerancia de tamaños reducidos aumenta con la distancia a la fuente de aprovisionamiento. En este último caso, se plantea que el descarte estará dado por la pérdida completa de los atributos necesarios para el desempeño funcional del artefacto.

Todos estos modelos son construcciones heurísticas que, como se mencionó antes, permiten un acercamiento al problema de investigación. No existe ninguna asunción indeleble, en el sentido de que la curva de fall-off o sus variantes, constituyen el universo explicativo para la distribución de rocas de una fuente única. De hecho constituye una forma de evaluar no sólo nuestras expectativas en relación al registro bajo análisis, sino también cuando éstas no se ajustan. Siguiendo esta línea, Brantingham (2003) a partir de un modelo que simula el movimiento al azar de las poblaciones en un ambiente uniforme, demuestra que la riqueza, la frecuencia y la intensidad de la reducción de las materias primas en relación con la distancia a la fuente, sigue los mismos patrones que los supuestos de optimización. Por consiguiente, sostiene que el tipo y abundancia de las materias primas en el ambiente, parecería no jugar un rol tan importante en la organización de la movilidad y las estrategias de aprovisionamiento. Señala además que si consideramos la incidencia de los procesos de formación de sitio, especialmente el carácter promediado del registro arqueológico, es difícil aislar los eventos discretos de aprovisionamiento; el resultado sería un patrón agregado del comportamiento de obtención de rocas indistinguible de un patrón neutral. La ausencia de planeamiento y manejo del riesgo podría ser una estrategia más adaptativa que las alternativas más 
complejas. Es posible que la optimización se dé en otros aspectos del forrajeo que no incluyen el aprovisionamiento y transporte de materias primas, conclusión que apoya lo sostenido por Binford (1979) en cuanto a la inclusión del aprovisionamiento de rocas en el marco del desarrollo de otras actividades de forrajeo. Si bien los supuestos del modelo neutral de Brantingham pueden no aceptarse como válidos, dado que es poco probable que una estrategia de forrajeo se encuentre librada al azar, sus propuestas advierten sobre los límites de nuestras interpretaciones. Para revertir situaciones de equifinalidad, los supuestos del modelo podrían ser modificados independientemente, para testear qué variables son las que producen diferentes resultados y su correlato en el registro arqueológico (cf. Renfrew 1977; Borrero 1989; Bradbury y Carr 1995; Franco 2002a). En este sentido, la simulación de situaciones de escasez y sus correlatos arqueológicos han constituido un tema de debate en los modelos tecnológicos. Para la Puna, el Centro Occidente Argentino y Patagonia, las obsidianas constituyen uno de estos casos ejemplo, en donde el registro agregado no alcanza a borrar el patrón de una utilización diferencial de estas rocas, probablemente producto de la economía de las mismas debido a su escasez y de su excelente calidad para la talla (cf. Escola 2003; Stern y Franco 2004; Durán et al. 2004; Bellelli et al. 2006; Escola et al. 2007; Elías 2007; Franco 2004; Charlin 2009; Giesso et al. 2011a; Barberena et al. 2011; Cortegoso et al. 2012).

Para el estudio del aprovisionamiento lítico, Wilson (2007) propone un gravity model que consideran múltiples factores como determinantes de la utilización de una fuente de materias primas: 1) geológicos o geográficos (calidad de la materia prima, tamaño de los nódulos disponibles, la facilidad de extracción, abundancia de nódulos utilizables, extensión areal, facilidad de acceso a la fuente); y 2) humanos (distancia a la fuente, presencia de otros recursos deseados en el área, la necesidad de llevar alimentos, el nivel de fatiga de los individuos, tiempo disponible, organización social, estrategia de movilidad, estrategia de aprovisionamiento e intercambio, límites territoriales, tabúes, etc.). Utilizando los límites geológicos y geográficos, Wilson (2007) propone una ecuación para calcular el valor del atractivo (atractiveness value) de cada fuente $\mathrm{y}$, con ello establecer un ranking de las fuentes disponibles. La comparación posterior de la 
jerarquización basada en el valor del atractivo, la participación de las materias primas de las distintas fuentes en los conjuntos artefactuales y la distancia entre los loci arqueológicos y los lugares de aprovisionamiento, puede resultar informativa sobre las causas que orientaron las decisiones materializadas en la selección y uso de las fuentes líticas.

En relación a las formas de realizar el aprovisionamiento, Kuhn (2004) plantea que el aprovisionamiento directo tiene costos que varían de acuerdo con la distancia de transferencia. Este autor sostiene que la distancia a la fuente es sólo un marco de referencia para la investigación, puesto que los costos en la obtención varían significativamente de acuerdo a cómo se haya realizado el aprovisionamiento. Para discutir esto, utiliza el concepto de aprovisionamiento tecnológico y propone tres estrategias (provisioning strategies), que producen cambios en la trayectoria o historia de vida de los artefactos desde la fuente de aprovisionamiento hasta su depositación en el contexto arqueológico: 1) aprovisionamiento de lugares (almacenamiento de artefactos y/o materia prima en sectores del paisaje donde se prevén futuras actividades); 2) aprovisionamiento de los individuos (equipamiento personal o toolkit); y 3) aprovisionamiento de las actividades (manufactura in situ de instrumentos para el desarrollo de una actividad imprevista). Las dos primeras estrategias son planificadas puesto que anticipan una necesidad, mientras que la última es una respuesta situacional, no planificada. Kuhn (2004) enfatiza que no es esperable que un grupo humano aplique una sola de estas estrategias, sino que se valga de cada una de ellas de acuerdo a las condiciones que enfrenta (distribución y calidad de materias primas, movilidad residencial, planificación de actividades y tipo de tarea).

Las diferentes estrategias planteadas enfrentan la resolución de un mismo problema: el aprovisionamiento. Cada una de ellas está constreñida por diferentes factores, lo que permite derivar expectativas arqueológicas para los conjuntos artefactuales resultantes de ellas (Kuhn 2004). El aprovisionamiento de lugares conlleva el transporte de materias primas bajo diferentes formas (nódulos, núcleos, formas base, instrumentos terminados) a espacios recurrentemente ocupados. Con el tiempo este lugar 
en el paisaje puede devenir en espacio equipado, lo que permite disminuir la intensidad de reducción y reactivación de los recursos líticos disponibles. El aprovisionamiento de individuos por su parte, será constreñido por el peso del conjunto de herramientas personales o toolkit, puesto que debe cumplir con el requisito de ser transportable. En este tipo de estrategias, se espera que se maximice el uso del material transportado, por lo que es esperable que el equipamiento de individuos este integrado por instrumentos terminados y que éstos sean intensamente reactivados y reformatizados. En la selección de las materias primas empleadas para equipar a los individuos se priorizarían aquellas de las mejores calidades para la talla que permitan maximizar la utilidad por unidad de peso, aún cuando su costo de obtención sea elevado (Kuhn 2004). En el caso del aprovisionamiento de actividades, se espera que los conjuntos producidos registren una mínima inversión en su manufactura y que en las materias primas estén representados los recursos inmediatamente disponibles.

Kuhn (2004) menciona algunos casos como ejemplos de las limitaciones implicadas en la utilización exclusiva de la distancia a la fuente de aprovisionamiento en los estudios arqueológicos. Cuando la movilidad residencial es muy elevada y el tiempo de residencia es muy breve, la estrategia priorizada es el aprovisionamiento de los individuos. En este caso, el grado de reducción observado en un artefacto depende más de la ruta de los movimientos realizados por el individuo portador y/o el tiempo de uso, que de la distancia efectivamente registrada entre el lugar de descarte y la fuente (Kuhn 2004). El estudio de las ocupaciones paleolíticas en Turquía, mostró que a pesar de la utilización de las mismas fuentes a lo largo de miles de años de ocupación, los conjuntos presentan diferencias en su composición. Este contexto estable (mismo locus, mismas fuentes disponibles) no permite defender que las variaciones observadas sean efecto de distancias variables a las fuentes. Pero sí pueden ser explicadas como consecuencia de la implementación diacrónica de distintas estrategias de aprovisionamiento, derivadas de condiciones organizacionales diferentes de los grupos humanos en el tiempo. En un trabajo previo Kuhn (1994) plantea que en poblaciones móviles el diseño de los artefactos que forman parte del mobile toolkit (Kuhn 1994) o el personal gear propuesto por Binford (1979), está 
influenciado principalmente por dos factores: la portabilidad y la utilidad potencial de los artefactos. En este sentido el autor sostiene que altos niveles de movilidad condicionan la cantidad y variedad de artefactos que los grupos humanos pueden cargar cuando se desplazan. Si las herramientas móviles tienden a maximizar la durabilidad y la versatilidad funcional, y simultáneamente minimizar el peso, entonces la mejor estrategia es transportar muchas herramientas de lasca pequeñas. Su propuesta es concordante con la existencia de muchas herramientas de lasca en conjuntos correspondiente a cazadores con alta movilidad (p.ej. Frison y Bradley 1980; Frison y Stanford 1982; Kelly y Todd 1988).

Otras variables que deben ser consideradas al evaluar los factores que condicionan el grado de reducción de los artefactos son, entonces, la intensidad y duración de las ocupaciones. Barton (2008) ha observado en los conjuntos localizados en las llanuras de arena y cerca de manantiales del desierto australiano que -aún cuando materias primas adecuadas están disponibles a $1 \mathrm{~km}$ de los loci estudiados- los núcleos exhiben un elevado grado de reducción. En este caso Barton (2008) sostiene que la distancia a la fuente no habría sido el factor determinante en la intensidad de reducción, sino la menor movilidad residencial (mayor duración de ocupaciones) implicada en la producción de los conjuntos.

\subsubsection{MATERIAS PRIMAS NO LOCALES Y ESTRATEGIAS DE APROVISIONAMIENTO DE RECURSOS LÍTICOS}

La disponibilidad de materias primas es concebida como una propiedad natural del espacio geográfico. Los recursos líticos ocurren en concentraciones localizadas e involucran costos de búsqueda, de aprovisionamiento y de procesamiento (Hayden 1989; Bousman 1993; Franco 2002a). La disponibilidad de rocas en el paisaje regional es, por lo tanto, el principal constreñimiento a abordar en el estudio de la variabilidad tecnológica (Bamforth 1986; Andrefsky 1994, 1991; Kuhn 1994, 1995; Nelson 1991; Surovell 2009). Para la clasificación de recursos según su disponibilidad local o no local, se han utilizado distintos parámetros de distancia (Geneste 1988; Gould 1980; Meltzer 1989). Meltzer 
(1989) sobre la base de información etnográfica de distintos autores (entre otros Binford 1980 y Kelly 1983) y teniendo en cuenta los trabajos de Gould (1980: 145) y Gould y Saggers (1985: 119), considera los $40 \mathrm{~km}$ como límite entre materia prima local y no local. Meltzer introduce el término inmediata vecindad, para referirse a la materia prima disponible cercana del lugar de utilización y/o descarte.

La distancia a la que los artefactos o materias primas son transportados, constituyen un punto de partida para el análisis. En esta tesis, se emplean las categorías de Meltzer (1989) y se consideran también las modificaciones de Civalero y Franco (2001). Estas autoras consideran tres rangos de distancias, que se corresponden a recursos inmediatamente disponibles (distancia menor a $5 \mathrm{~km}$ ), local (distante entre 5 y $40 \mathrm{~km}$ ) y no local (distancia mayor a $40 \mathrm{~km}$ ). Los recursos locales a su vez, son diferenciados en local cercanos $(5-30 \mathrm{~km})$ y local lejanos $(30-40 \mathrm{~km})$.

Las materias primas exóticas o no locales, son generalmente relacionadas a acceso indirecto u otro mecanismo de obtención que involucre la transferencia de bienes, como el intercambio entre grupos, la migración o la conquista, entre otros (Meltzer 1989). Implica la presencia de intermediarios entre la fuente de materia prima y el consumidor (Ericson 1984; McAnany 1989). Meltzer (1989) sostiene que la adquisición indirecta de recursos, incluye no sólo materias primas y artefactos líticos, sino también otros recursos utilitarios y no-utilitarios. La información etnográfica disponible referida a redes de intercambio, comúnmente se ha centrado en las relaciones sociales involucradas más que en los correlatos materiales de esas transacciones, que a su vez involucraban generalmente bienes no-utilitarios. Si bien considera que es una operación difícil de definir en términos de reglas, propósitos o bienes que involucra, es posible distinguir su rol según determinadas circunstancias, entre las que menciona: mantener lazos entre grupos; permitir aprovisionarse de artefactos no disponibles en el territorio de explotación del grupo; como reaseguro económico para momentos de estrés de recursos; sostener un sistema de "mutualismo" entre grupos vecinos que necesitan complementar sus dietas o iniciar o reforzar relaciones sociales (Meltzer 1989:20 y referencias incluidas). 
Para Meltzer, ésta última es la función más general del intercambio, aunque sus correlatos pueden ser escasos o difusos.

Meltzer (1989) discute los correlatos materiales de cuatro variables que comúnmente se consideran para diferenciar el aprovisionamiento directo del indirecto: 1) la presencia-ausencia de materias primas exóticas, 2) la cantidad y el tipo de artefactos manufacturados en materias primas exóticas, 3) la uniformidad estilística y, 4) la secuencia de reducción de los artefactos. De este modo, el autor concluye que en la mayoría de los casos el aprovisionamiento directo e indirecto generan los mismos productos materiales, produciéndose problemas de equifinalidad (Meltzer 1989: 27-29). Solamente en dos circunstancias particulares es posible desechar un mecanismo de adquisición en favor de otro: cuando los conjuntos están compuestos exclusivamente de rocas exóticas, que refleja el intercambio como un medio para la adquisición de rocas; y cuando están presentes atributos estilísticos exóticos, donde se espera que reflejen una adquisición directa de rocas (Meltzer 1989: 30). El autor advierte sin embargo, que estas variables son dificultosas de interpretar en registro arqueológico y que es de esperar que se den combinaciones difíciles de segregar. Las propuestas y expectativas desarrolladas por Meltzer (1989) están planteadas para una escala de abordaje de sitio, es decir, que hacen referencia a conjuntos artefactuales correspondientes al mismo episodio de depositación. Franco $(2002 a, 2004)$ y Charlin $(2007,2009)$ en Patagonia, proponen incorporar a la propuesta de Meltzer variables e indicadores cuantitativos que permitan un abordaje a escala regional y con las características promediadas del registro arqueológico. Para el intercambio de materias primas en grupos cazadores recolectores, Franco (2002a, 2007) propone dos alternativas: 1) el intercambio de instrumentos terminados y 2) el intercambio de nódulos o núcleos. Para el primer caso se espera que solamente algunas clases de instrumentos se encuentren representadas sobre materias primas exóticas y, para el segundo caso se espera la presencia de nódulos o núcleos en materia prima exótica en lugares específicos del paisaje y curvas de decaimiento de la frecuencia o falloff (Renferw 1977) a partir de estos puntos. Así las expectativas son: un decaimiento en la frecuencia y tamaño de los artefactos y un incremento en el ángulo de descarte de los 
instrumentos, evidencias de reactivación e incremento en el grado de explotación de los núcleos (Franco 2002). Por otro lado, espera que las materias primas no locales se incrementen a través del tiempo, y "...que durante el momento de "ocupación efectiva del espacio" aumenten las evidencias de intercambio simplemente porque la densidad demográfica es mayor." (Franco 2002a:34).

Otro modelo para dar cuenta del aprovisionamiento de recursos exóticos, es el propuesto por Whallon (2006). Este considera la escala espacial de las redes de intercambio en relación con las características ambientales inter-regionales. Plantea que estas son el resultado de dos tipos de movilidad que, a diferencia de la movilidad residencial y logística, no se encuentran relacionados con la búsqueda y procesamiento de los recursos de subsistencia sino con razones sociales e informativas. Denomina network mobility a la primera, e informational mobility a la segunda, caracterizados por movimientos para recolectar y actualizar la información sobre la disponibilidad de recursos en el ambiente (Whallon 2006: 262). La extensión de ambas redes depende de la variabilidad de los recursos. En éste modelo la amplitud de la escala espacial de análisis permite evaluar la escala de homogeneidad ambiental, que es el principal factor determinante de las redes (Figura 4.1). La distribución de los bienes exóticos, es considerado un indicador de su existencia y amplitud. 


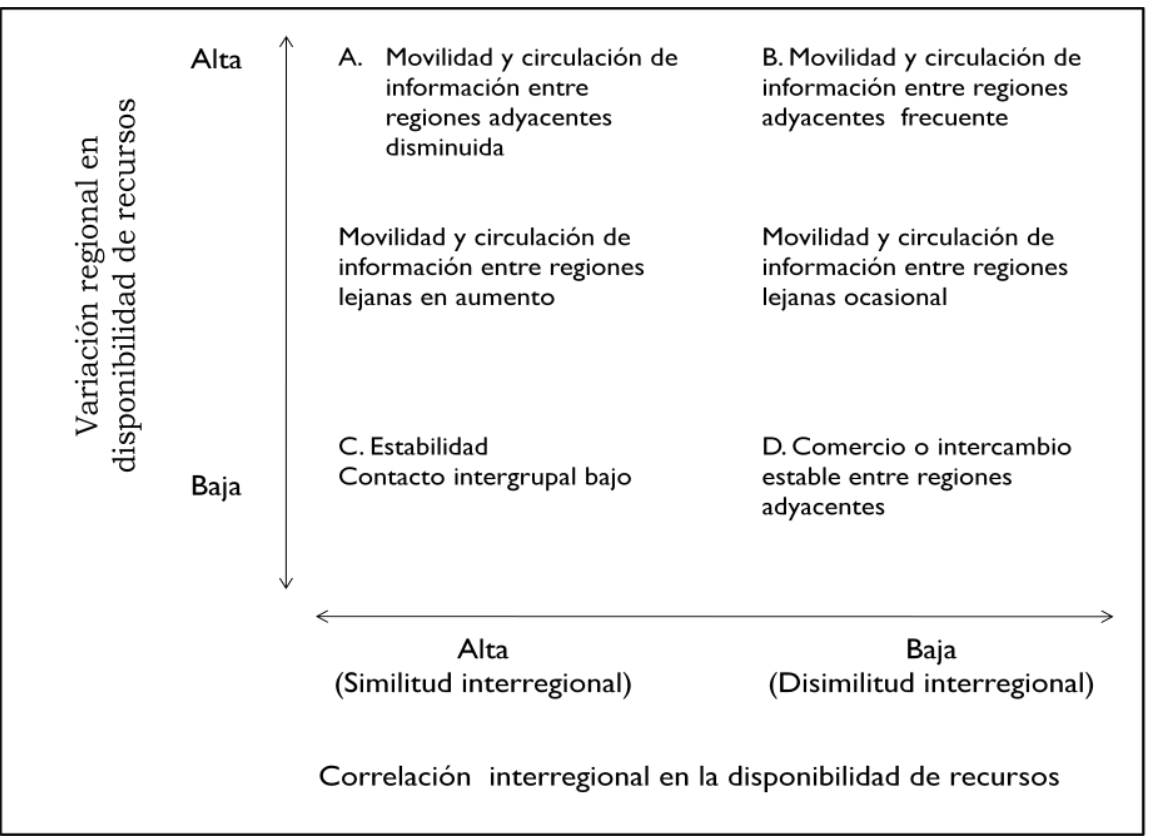

Figura 4.1. Relación entre las redes de intercambio y las características ambientales inter-regionales según Whallon (2006: 264).

La dirección de los movimientos producto de las redes de información, sería transversal a los patrones de movilidad relacionados con las actividades de subsistencia (Whallon 2006). El modelo espacial propuesto distingue la movilidad entre regiones adyacentes y entre regiones geográficas lejanas, así como entre bandas mínimas y bandas máximas o regionales. Bajo ciertas condiciones, como un uso poco intensivo del espacio en el largo plazo, se puede esperar que estas alternativas sean identificables. En relación a las materias primas líticas, el autor plantea que entre los grupos locales circulan rocas dentro de los límites de una banda regional (contacto y movilidad entre regiones adyacentes, ca. $200 \mathrm{~km}$ aproximadamente). Los contactos de mayor escala (más de 300 km) involucran la interacción y movilidad entre bandas máximas, y son sugeridos por la distribución de otro tipo de bienes, como los suntuarios. El modelo asume que a mayor homogeneidad ambiental en una escala espacial amplia, menor network mobility e informational mobility entre regiones adyacentes y mayor entre regiones geográficamente lejanas. 


\subsubsection{1a Distancia y rangos de acción}

Los rangos de acción, la distancia a la fuente y el modo acceso a los recursos, son conceptos que permiten realizar inferencias relativas a la territorialidad (Foley 1981a y b; Kuhn 2004). Los estudios referidos a trayectorias tecnológicas han demostrado ser un indicador confiable de distancia a la fuente abastecimiento e intensidad de uso de recursos (Kuhn 2004). Del mismo modo, el uso de herramientas petrográficas y geoquímicas en los estudios de procedencia han permitido ajustar las interpretaciones e indagar sobre temas vinculados a temporalidad, direccionalidad de migraciones e intercambio a grandes distancias.

Jones et al. (2003) en un esfuerzo por entender como se desplazaban las poblaciones en la región de la Gran Cuenca de Estados Unidos, analizan el uso de fuentes líticas de obsidiana y dacita para estimar la escala geográfica o territorio de movilidad de las poblaciones tempranas. Los autores analizan los estadios de producción lítica e ilustran la secuencia de cada fuente explotada. Las materias primas mejor representadas en los conjuntos -sobre todo las utilitarias- son un buen estimativo del rango de acción mínimo, por lo tanto, es fundamental conocer la proveniencia de los recursos líticos y la distribución de etapas de manufactura y mantenimiento de herramientas en el espacio. En este marco, los primeros estadios de producción se encuentran cerca de la fuente geológica y, movimientos alejados de la fuente, generan un incremento en los eventos de uso de las herramientas. Estos patrones sirven de indicadores de dirección de los movimientos, de la extensión del rango total de territorio y de barreras de transporte tanto a escala espacial amplia (Jones et al. 2003) como en aquellas de distribución acotada (Jones et al. 2012).

Custer et al. (1983), esbozan dos estrategias de adquisición de recursos líticos relacionados con las poblaciones móviles. La primera, se denomina de abastecimiento cíclico, e implica el uso repetido de una fuente lítica por parte de una misma población, que retorna periódicamente a abastecerse en su ciclo anual/estacional de 
desplazamiento. En esta estrategia se espera, que se evite o no sea frecuente el abastecimiento de rocas disponible en otras localidades (Figura 4.2A). La segunda estrategia implica el abastecimiento serial, y se refiere a situaciones en las que una población explota a lo largo de su ciclo anual dos o más fuentes de recursos líticos situados en diferentes puntos del espacio (Figura 4.2B). Dichas fuentes serían visitadas en el curso de sus actividades de subsistencia, lo que es similar a la estrategia de abastecimiento incluida (embedded) propuesta por Binford (1979). Carr (1995) retoma estos planteos para evaluar el uso de canteras de chert de distinta calidad, para la manufactura de piezas bifaciales (puntas de proyectil) en Winsconsin (EEUU). Sostiene que la estrategia de aprovisionamiento serial, es común en las materias primas disponibles en espacios cercanos a los ocupados en su ciclo anual y las mismas se encuentran sobrerrepresentadas. En las estrategias de abastecimiento cíclico, por su parte, una fuente es explotada para la formatización de artefactos particulares, como los bifaciales (particularmente puntas de proyectil). Mientras que las rocas transportadas, suelen presentan frecuencias cercanas al $25 \%$. y requiere retornar a la cantera para abastecerse en su ciclo de desplazamiento, por lo que se espera que ésta fuente se encuentre muy representada (90\%) entre estos tipos de artefactos.

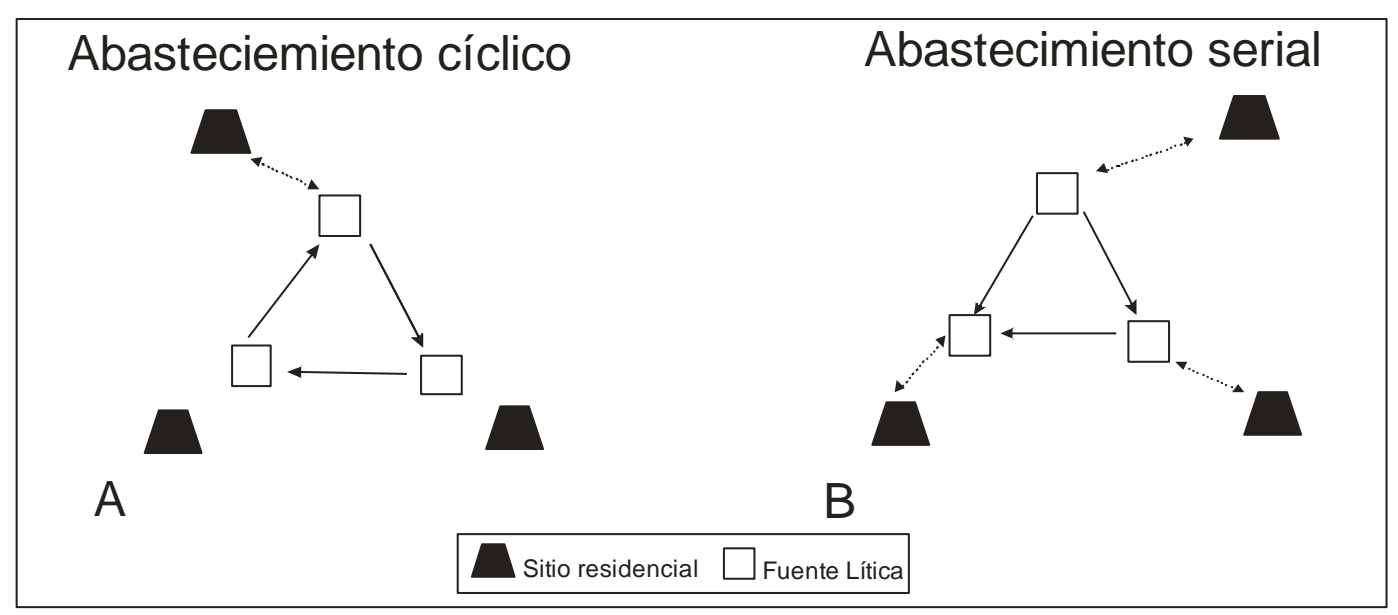

Figura 4.2 Estrategias de abastecimiento de recursos líticos (A) cíclico y (B) serial Tomada de Carr (1995). 
Trabajos recientes en arqueología argentina, constituyen antecedentes de interacción o vinculaciones entre ambientes que presentan diferencias en la disponibilidad de recursos (Berón 2004, 2006; Barros y Messineo 2004; Bonomo 2005; Escola 2004; Borrero y Barberena 2006; Charlin 2007, 2009; Barberena 2008; Hermo 2008; Giesso et al. 2011a; Barberena et al. 2011). Los mismos utilizan variables diversas que permitan ajustar sus interpretaciones referentes a interacción entre ambientes. Entre las variables comúnmente abordadas cabe mencionar: el consumo de recursos bióticos procedentes de la costa vs. interior, transporte de elementos marinos (moluscos y restos óseos de mamíferos marinos), la distribución de restos humanos con valores de isotópos estables que indiquen el consumo de recursos de subsistencia, los recursos arqueofaunístico y el traslado de materias primas de procedencia conocida, entre otros.

En el sur de Mendoza la presencia de cañas colihue y tipos cerámicos procedentes de Chile, ha llevado a plantear interacciones a larga distancia en especial en el sector andino (Gambier 1985; Lagiglia 1999; Durán 2000). Tendencia también observada en La Pampa por Berón (2004). Estudios recientes sobre obsidiana (Durán et al. 2004; Giesso et al. 2011a) analizan por medio de estudios geoquímicos la distribución espacial y temporal de distintas fuentes de abastecimiento detectadas. Barberena et al. (2011) en el norte de Neuquén analiza la distribución de la señal geoquímica de la fuente Cerro Huenul y plantea diferentes hipótesis que dan cuenta de su distribución y posible traslado por medio de intercambio. Entre los temas vigentes de discusión en la región, se encuentra el proceso de intensificación regional, propuesto para regiones de altura por Neme (2007). Este autor si bien genera expectativas referentes a la tecnología lítica, centra sus estudios en indicadores de subsistencia. Estos puntos serán retomados para el análisis de la organización tecnológica en La Payunia.

\subsubsection{MOVILIDAD Y TRAYECTORIAS ARTEFACTUALES}

En los estudios líticos es importante dar cuenta de la variabilidad y entender por qué se priorizaron unas opciones sobre otras (Franco 2004). Para ello, distintos factores 
han sido analizados, entre ellos, el grado de movilidad de un grupo, la disponibilidad de materias primas líticas, la estrategia de tecnología y el tiempo disponible para realizar las tareas de subsistencia (entre otros Binford 1979, 1980; Bamforth 1986; Parry y Kelly 1987; Torrence 1989; Nelson 1991; Odell 1996). Asimismo para comprender la variación la disponibilidad de rocas en el ambiente (Ericson 1984) que si bien pudo haber variado en el pasado, constituye un punto de partida básico. En poblaciones cazadoras recolectoras la movilidad puede ser definida como su desplazamiento en un ciclo anual. Si bien el grado de movilidad de los grupos no basta para dar cuenta de la adopción de una determinada estrategia tecnológica, influye en forma variable en la organización de la tecnología lítica (Carr 1994). Un alto grado de movilidad puede impactar en la tecnología lítica imponiendo costos de transporte, restringiendo el tiempo que puede ser dedicado a la manufactura de instrumentos, del mismo modo puede tener efectos positivos en la adquisición de materias primas. En cambio, una movilidad baja puede restringir el acceso a fuentes de materias primas y otros recursos, potenciando quizás formas de acceso indirecto o el intercambio entre poblaciones (Lurie 1989; Kuhn 2004).

El hecho de que los recursos se encuentren distribuidos en el espacio, hace que no haya puntos específicos que provean todos los recursos necesarios para la población. La movilidad es considerada como una estrategia básica empleada por los cazadores recolectores para prevenir el riesgo o mitigar su impacto (Belardi 2005) y sus cambios afectan distintos aspectos de la vida de las poblaciones (Kelly 1992). La jerarquía de un determinado espacio va a estar dictada la presencia de materiales arqueológicos. De ahí, la importancia de los estudios que enfaticen en las variaciones en la distribución de los artefactos como el resultado de la acción de las poblaciones humanas dentro de un ecosistema (Foley 1981a; Belardi y Borrero 1999).

Una forma de abordar las variaciones en la distribución del componente tecnológico, en términos de objetos, sus atributos y relaciones espaciales, es a partir del estudio de las trayectorias artefactuales o sistema de producción lítica (sensu Ericson 1984). Ericson (1984) define a los sistemas de producción lítica como todas las actividades y localizaciones sincrónicas implicadas en la utilización y modificación de una fuente o un 
material lítico específico para la manufactura y uso de artefactos en un sistema social. Constituye, por tanto, un nexo entre las actividades de producción lítica, los productos de esas actividades (útiles obtenidos, desechos y elementos utilizados en la modificación de la masa lítica como percutores, arena, agua, etc.) y los distintos locus en donde se llevaron a cabo las actividades de producción. Requiere por lo tanto del manejo de las fuentes de abastecimiento de las materias primas y de la manera en que las actividades de producción se presentan en el espacio. Para Ericson (1984) la producción lítica es el proceso de modificación material orientado a la obtención de un objeto particular que incluye todas las etapas seguidas hasta la consecución de un artefacto o instrumento determinado. Su análisis comienza en las canteras y su denominación varía con la medida en que todo el proceso de producción se desarrolla dentro o fuera de un área específica. Así el autor denomina sistemas de producción lítica terminales a los procesos de producción que se dan en un área específica; sistemas secuenciales a los procesos cuyas etapas están representadas en áreas diferenciales; y sistemas de producción irregulares a los que tienen lugar cuando las actividades se encuentran dispersas en una gran área.

La reducción lítica es un proceso continuo en el cual las relaciones entre los atributos de los productos y los procesos de producción son predecibles (Ingbar et al. 1989; Shott 1996). La secuencia de reducción procede a través de varias etapas, aunque la manufactura y el mantenimiento no pueden ser tan fácilmente discriminados en el continuum (Elston 1992). Son numerosos los desarrollos en arqueología referidos a trayectorias artefactuales (Binford y Quimby 1963; Shiffer 1972, 1976; Collins 1975; Kordehoff 1987; Aschero 1988; Henry 1989; Bradbury y Carr 1999; Beck et al. 2002 Cortegoso 2005; Surovell 2009) y en los que se destaca la necesidad de definir las etapas o estadios de reducción de forma explícita. Una manera simple de abordar las características estructurales y organizativas en los conjuntos artefactuales, es a través de la delineación de trayectorias de producción. Estas son entendidas como modelos particulares que abordan la relación entre disponibilidad de recursos líticos, las secuencias de producción y la distribución espacial de las actividades productivas (Koldehoff 1987). Así se definen etapas amplias como: abastecimiento, selección de materias primas y 
obtención de formas base, manufactura, mantenimiento y reactivación de herramientas, descarte y posible reclamación. El uso de variables cuantitativas basadas en estudios experimentales en el sentido de Ingbar et al. (1989), si bien no están exentas de problemas, permiten generar expectativas a una escala de trabajo amplia. Asimismo facilitan el manejo de gran cantidad de información, que es segregada en base a medidas cuantitativas y no a definiciones ambiguas o con matices poco claros de clasificación (Hiscock 2001). 


\section{CAPÍTULO 5}

\section{MATERIALES Y MÉTODOS}

\section{INTRODUCCIÓN}

En este capítulo se presentan los aspectos metodológicos que guían la investigación, desde el relevamiento de campo hasta el procesamiento de los datos. El capítulo consta de dos partes. En la primera se presenta la escala temporal y espacial de trabajo, la unidad de análisis arqueológico, las estrategias de relevamiento adoptadas en el área de estudio y las aplicadas en sectores del espacio con fuentes primarias de recursos líticos. En la segunda parte se profundiza el enfoque tecnológico para el abordaje de las estrategias de abastecimiento de materas primas líticas detallando las variables y atributos de los artefactos considerados así como los estudios petrográficos y geoquímicos seleccionados para el análisis de procedencia y caracterización de las materias primas líticas. Luego se describe la forma de procesamiento de los datos.

Las evidencias consideradas para el análisis en esta tesis se organizan en dos grandes conjuntos: evidencias sobre la intensidad de uso del espacio y evidencias sobre la utilización y distancias de transporte de materias primas líticas. Las primeras se refieren a intensidad de uso humano de ambientes y selección de lugares en el espacio (Belardi 2005). La segunda permite discutir la disponibilidad, accesibilidad y utilización de recursos líticos (sensu Ericson 1984) a partir del análisis de la organización de la tecnológica lítica (Nelson 1991; Carr 1994; Franco 2004; Cortegoso 2005). Las líneas metodológicas y el tratamiento integrado de los conjuntos de evidencias serán utilizados para cumplir los objetivos y contrastar las hipótesis propuestas en esta tesis. 


\subsection{ESTRUCTURA ARQUEOLÓGICA EN LA PAYUNIA}

\subsubsection{ESCALAS TEMPORAL Y ESPACIAL}

La arqueología de La Payunia cuenta con un conjunto de fechas radiocarbónicas que llevaron a proponer una ocupación tardía de la región (capítulo 2, Gil 2000). Sin embargo, los fechados obtenidos en Cueva Delerma (localizada en el reborde oriental del área de estudio) y Gruta El Manzano (en el vecino vale occidental del río Grande), correspondientes a los inicios del Holoceno medio (Gil 2000, 2006; Durán 2000; Neme et al. 2011), permiten reconsiderar esta propuesta a la luz de los conceptos de "cuenta corta" y "cuenta larga" (Borrero et al. 1992). El primero hace referencia a los fechados radiocarbónicos conocidos, mientras que el segundo se refiere a la fecha máxima teórica esperable. En el caso particular de La Payunia, la cuenta corta hace referencia a los últimos ca. 1200 años AP, mientras que la cuenta larga puede ser en planteada para inicios del Holoceno medio, es decir, en los últimos 7600 años.

En cuanto a la escala espacial de trabajo, la perspectiva adoptada en La Payunia es regional. Esta perspectiva incluye escalas menores, como la localidad, la unidad de recolección superficial, la unidad de excavación y los hallazgos aislados. La micro escala (Dincauze 2000: 199) incluye al sitio arqueológico, con una amplitud espacial máxima de 1 $\mathrm{km}^{2}$. La localidad arqueológica corresponde a la meso escala (Dincauze 2000:199) y abarca $10 \mathrm{~km}^{2}$. Incluye un conjunto determinado de sitios o distribuciones arqueológicas así como distintos rasgos geomorfológicos del paisaje como planicies y ríos, cuencas fluviales, campos de dunas, flujos de lava y volcanes. La meso escala puede agrupar diferentes localidades arqueológicas. Puede delimitar espacios de entre $10 \mathrm{~km}^{2}$ y $10 \mathrm{~km}^{4}$ (Dincauze 2000) y responde a criterios geográficos, geológicos o geomorfológicos. En el caso del La Payunia, corresponde a los sectores norte, central y sur, en los cuales priman los criterios geográficos y geomorfológicos. La macro escala corresponde al sur de Mendoza. Estas unidades son recortes espaciales sin significado funcional, útiles para explorar en distinta resolución la estructura arqueológica. Se trata de observar en cada escala el 
comportamiento de las variables en términos de densidad, diversidad y composición artefactual. Así se reconocen diferencias dentro del ambiente, por ejemplo, a partir de cotas o de características geomorfológicas, ambientales e hidrológicas particulares como son la Altiplanicie de Payén y el río Colorado, entre otros. La escala mayor a la regional, involucra distintas regiones y su interrelación -establecida y ejemplificada en arqueología sobre la base de la circulación de bienes e individuos, como los artefactos confeccionados sobre obsidiana y la señal isotópica obtenida a partir del estudio de dietas humanas (Belardi 2005; Gil et al. 2006; Novellino y Gil 2007; Neme y Gil 2008), entre otros.

El enfoque distribucional permite analizar y discutir el registro arqueológico desde distintas escalas espaciales (Belardi 2005): 1) la ubicación de los artefactos dentro de la transecta, 2) la ubicación de la transecta dentro de un ambiente determinado o localidad, 3) la ubicación del ambiente dentro del sector de la región y, 4) la ubicación de la región dentro del contexto macro regional (Dincauze 2000).

\subsubsection{LA UNIDAD DE ANÁLISIS ARQUEOLÓGICO}

En los estudios distribucionales la unidad de análisis es el artefacto (Thomas 1975; Foley 1981 a y b; Dunnell y Dancey 1983; Binford 1975; Borrero y Nami 1996; Belardi 2005). Por lo tanto los relevamientos se centralizan en la toma de información sobre los artefactos. La variable seleccionada fue la clase artefactual, siguiendo los lineamientos propuestos por Aschero $(1975,1983)$ y Aschero y Hocsman (2004). Las categorías empleadas fueron las más abarcativas (Hiscock 2001), relacionadas con la intensidad de uso y el grado de reducción de los artefactos (este punto se desarrolla en el apartado siguiente). Dado que uno de los objetivos es estudiar la distribución espacial del registro arqueológico, se tuvieron en cuenta tanto los artefactos enteros como fracturados.

Se consideraron tres unidades de análisis distribucional, que constituyen medidas de variación en la densidad de los artefactos. La primera hace referencia a los artefactos aislados, que se presentan solos en un espacio delimitado por un área de 20 metros de 
diámetro (ca. $300 \mathrm{~m}^{2}$ de superficie; 0,003 artefacto/ $/ \mathrm{m}^{2}$ ); le siguen las concentraciones, cuando se encuentran entre 2 y 24 artefactos (hasta 0,08 artefacto $\mathrm{m}^{2}$ ), y los sitios cuando hay 25 o más artefactos en la superficie mencionada (Borrero y Nami 1996; Belardi 2005). Las categorías "concentraciones" y "artefactos aislados" corresponden a lo que usualmente se llaman "no-sitios" (Thomas 1975; Foley 1981b).

En lo que respecta al contexto regional, y como se mencionó anteriormente, se ejemplificará a partir de los estudios disponibles de distribuciones de obsidianas (Durán et al. 2004; Giesso et al. 2011a; Barberena et al. 2011; Salgán et al. 2011) en relación a otros aspecto de la organización humana (Gil 2000, 2006; Novellino et al. 2004; Gil et al. 2006; Novellino y Gil 2007).

\subsubsection{ESTRUCTURA ESPACIAL: SUPERFICIAL Y ESTRATIGRÁFICA}

El registro arqueológico es un continuum, donde se otorga igual importancia al material recolectado de superficie en diferentes sectores del espacio que al registrado en estratigrafía, obtenido a través de sondeos en localizaciones específicas (Belardi et al. 1992). Así, la distribución superficial de los artefactos líticos se compara con su distribución estratigráfica, integrando diferentes niveles de escala espacial (Franco 2004; Belardi 2005; Gil y Neme 2006).

Para el relevamiento superficial se realizaron recolecciones sistemáticas y asistemáticas. Las primeras se diseñaron según rectas lineales dirigidas y otras al azar, siguiendo rumbos de brújula y GPS. En todos los casos se siguió la metodología propuesta por Neme (2002a), en la cual las líneas de muestreo son subdivididas en unidades de observación y recolección. En las transectas se asumió una cobertura de un metro a cada lado por individuo y los materiales de cada unidad fueron levantados y embolsados con los datos correspondientes a la localidad, transecta y unidad. La superficie de muestreo fue variable, dependiendo de la cantidad de personas, el tiempo y la accesibilidad al área, entre otros. Por ello se especifica en cada localidad la superficie muestreada. Esta variable 
permitió calcular la densidad de hallazgos superficiales recuperados en las diferentes localidades (número total de hallazgos/superficie en metros cuadros prospectados o $\mathrm{n} / \mathrm{m}^{2}$ ). Durante el relevamiento de las transectas se registraron las características generales del paisaje y otras variables consideradas relevantes para la evaluación de los procesos de formación del registro arqueológico (ver criterios en Gil y Neme 2006). Los principales elementos del paisaje relevados fueron: pendiente, visibilidad, vegetación y presencia de rasgos importantes como alteraciones antrópicas modernas (p.ej. caminos y corrales) o cauces de agua (Gil y Neme 2006). Por su parte, las recolecciones asistemáticas tuvieron como objetivo obtener información sobre aspectos puntuales de relevancia para la investigación, por ejemplo la selección de artefactos de obsidiana. En todos los casos la visibilidad fue establecida como una estimación del porcentaje de la cobertura vegetal en un metro cuadrado y determinando la existencia de variaciones de una unidad de muestreo a otra. Las categorías adoptadas fueron, en el caso de visibilidad: $100 \%$ óptima, $80 \%$ muy buena, $60 \%$ buena, $40 \%$ regular, $20 \%$ mala y $0 \%$ nula (Neme 2002). En la variable pendiente se consideró: $90^{\circ}$ abrupta, $70^{\circ}$ pronunciada, $50^{\circ}$ regular, $30^{\circ}$ suave, $10^{\circ}$ muy suave y $0^{\circ}$ nula (Gil y Neme 2006).

Una de las prioridades para esta investigación fue que en las muestras arqueológicas estudiadas estén representados los diferentes ambientes que conforman la región. De este modo, se definieron tres sectores en los cuales se incluyeron las localidades arqueológicas: en el sector norte, se definió la localidad La Peligrosa (LP); en el sector central (APE), Carmonina (CAR) y Río Colorado (RC) (Figura 5.1). En cada localidad se realizaron muestreos superficiales y/o estratigráficos, cuyos resultados se comparan por sector y entre sí a fin de discutir la estructura arqueológica regional e insertarla en la problemática macro regional. En el capítulo 4, se detallan los muestreos llevados a cabo en cada localidad (Tabla 5.1).

En las fuentes recursos líticos identificadas, con el fin de obtener información tecnológica detallada de las actividades de producción, se definieron las áreas de mayor concentración de material superficial y se aplicó un muestreo aleatorio simple proporcional al tamaño de los conjuntos. Los límites de estas áreas se establecieron en 
función de la ausencia de material superficial, mediante la definición de track de GPS y un medidor de distancia Metro-Láser. Esta información permitió segmentar los conjuntos en cuadrantes de un metro cuadrado, a los cuales se otorgó números consecutivos. Una vez numerados, se generaron números al azar por medio del programa Random (www.random.org/integers), teniendo en cuenta el total de celdas de cada conjunto. Se solicitó al programa generar cinco números al azar, sin descartar la posibilidad de reposición de los elementos. Debido a los tamaños dispares de los conjuntos, se optó por realizar una unidad de muestreo cada $300 \mathrm{~m}^{2}$, en los cuadrantes cuya numeración coincidía con los números generados por el programa. En todas las canteras se tomaron muestras de mano para su caracterización petrográfica intra fuente y con el objeto de analizar posibles diferencias entre fuentes.

Durante el relevamiento estratigráfico se realizaron sondeos y excavaciones amplias. Los sondeos se llevaron a cabo con el objeto de monitorear el comportamiento de los materiales en estratigrafía y tuvieron un tamaño de $50 \times 50 \mathrm{~cm}$. La profundidad de excavación fue variable, dependieron de la presencia o ausencia de material arqueológico y de la aparición de "sellos" estratigráficos, tales como mantos de roca. En los sondeos se siguieron niveles artificiales de $10 \mathrm{~cm}$, respetando posibles cambios estratigráficos y, en todos los casos, se describieron las modificaciones en la matriz sedimentaria. Tanto los hallazgos como los niveles de excavación fueron remitidos al nivel de artificial de referencia. Los hallazgos macroscópicos fueron medidos en forma tridimensional al centímetro y los sedimentos extraídos se tamizaron en mallas de $1 \mathrm{~mm}$. Los materiales recuperados fueron embolsados y debidamente rotulados. Los fragmentos de carbón fueron conservados por separado para evitar su contaminación por contacto con otros elementos. En los sitios que disponían de edades radiocarbónicas, se calculó la tasa de depositación temporal de los artefactos, siguiendo lo propuesto por Gil (2006).

Las áreas para los muestreos estratigráficos fueron seleccionadas por presentar concentración superficial de materiales arqueológicos y por encontrarse asociadas con recursos hídricos actuales o con fuentes de materia prima apta para la talla. Una parte importante de los muestreos de campo se llevó a cabo en el marco de estudios de 
impacto ambiental y rescate arqueológico, lo que facilitó el acceso a sectores del área que no contaban con estudios previos.

\begin{tabular}{|c|c|c|c|}
\hline SECTOR & $\begin{array}{c}\text { LOCALIDAD } \\
\text { ARQUEOLÓGICA }\end{array}$ & MUESTREO ESTRATIGRÁFICO & MUESTREO SUPERFICIAL \\
\hline \multirow{4}{*}{ NORTE } & \multirow{4}{*}{ 1-La Peligrosa (LP) } & La Corredera (LC) & Piedras Bayas (PB) \\
\hline & & \multirow{3}{*}{$\begin{array}{l}\text { La Peligrosa-2 } \\
\qquad \text { (LP-2) }\end{array}$} & La Leona (LLE) \\
\hline & & & \\
\hline & & & $\begin{array}{c}\text { La Peligrosa Transecta } 2 \\
\text { (LPTR2) }\end{array}$ \\
\hline CENTRAL & $\begin{array}{l}\text { 2-Altiplanicie del } \\
\text { Payén (ALPA) }\end{array}$ & Jagüel Avelino (JAV) & ALPA-Este \\
\hline \multirow{4}{*}{ SUR } & $\begin{array}{l}\text { 3-Agua de Pérez } \\
\text { (APE) }\end{array}$ & Agua de Pérez-1 (APE-1) & $\begin{array}{l}\text { Agua de Pérez- Cantera } \\
\qquad \text { (APE-C) }\end{array}$ \\
\hline & \multirow[t]{2}{*}{ 4-Carmonina (CAR) } & Carmonina-1 (CAR-1) & \multirow[t]{2}{*}{ Pista } \\
\hline & & Sondeo Pista & \\
\hline & 5-Río Colorado (RC) & Agua Arenosa 1 & PRC- Gasoducto \\
\hline
\end{tabular}

Tabla 5.1. Relevamiento superficial y estratigráfico realizado en La Payunia. 


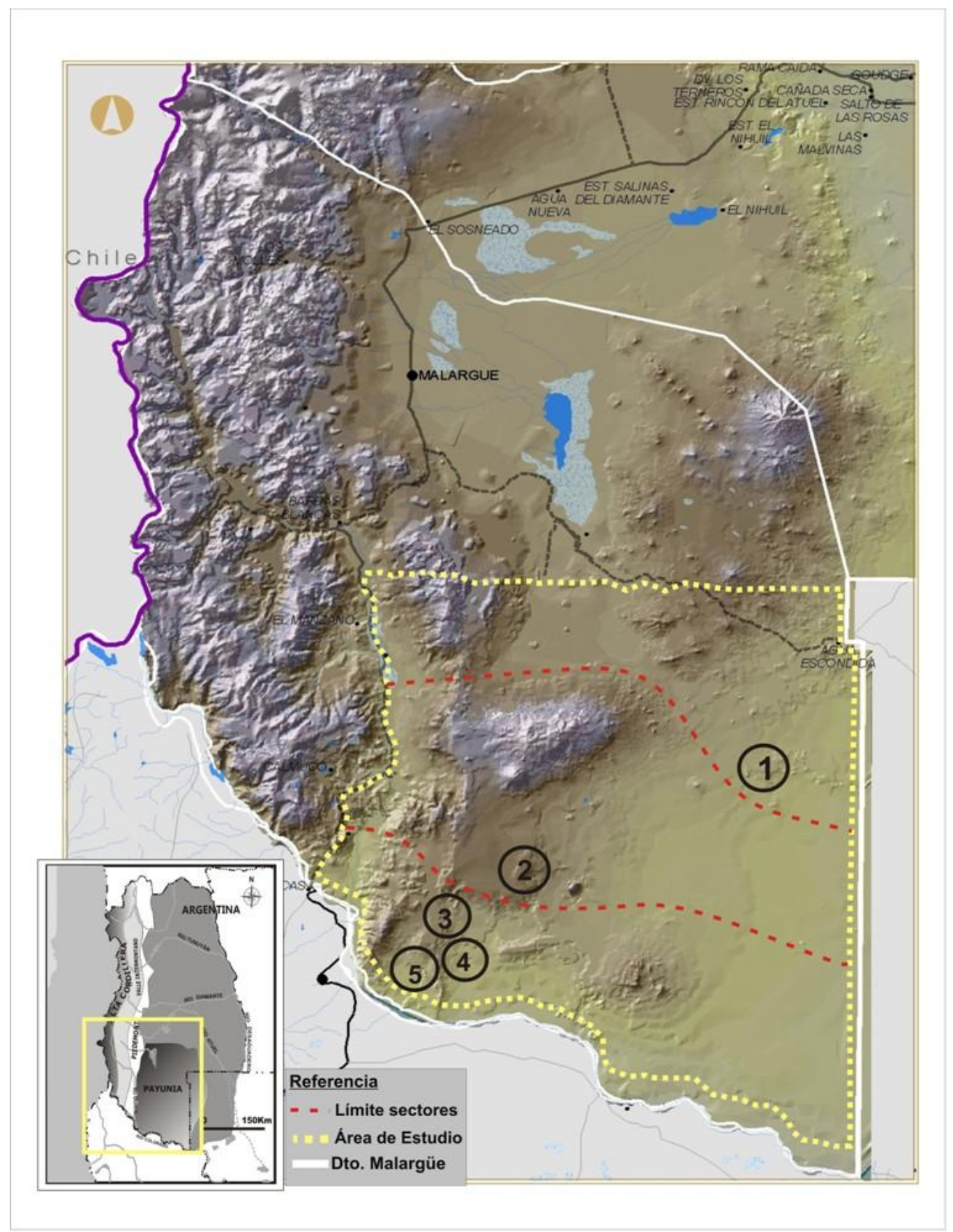

Figura 6.1. Sectores y localidades arqueológicas incluidas en la tesis. Con línea punteada se indica los límites de cada sector y con círculos continuos las localidades arqueológicas definidas. Referencias: 1: La Peligrosa; 2: Altiplanicie del Payén; 3: Agua de Pérez; 4: Carmonina; 5: Río Colorado. 


\subsubsection{BASE REGIONAL DE RECURSOS LÍTICOS}

La determinación de la abundancia, variabilidad y calidad de los recursos líticos es uno de los pasos principales en el estudio de la tecnología lítica. A través de esto se pueden realizar inferencias sobre el modo aprovisionamiento y uso materias primas, entre ellas: qué actividades extractivas y/o de formatización se emplearon en cada sitio de aprovisionamiento, las trayectorias que pudieron seguir esas rocas en el paisaje y los distintos usos a los cuales fueron destinados hasta su descarte y posible reciclaje.

Como se planteó antes, el Área El Payén está caracterizada por la abundancia de rocas con diferente utilidad para la confección de instrumentos y preparación de pigmentos minerales (Durán 1992; 2000; Gambier 1985; Gil 2000, 2006). Esta tesis se centra en las rocas aptas para la talla.

Debido a la amplitud del área aquí se intenta un esquema parcial de distribución, entendido como un paso en la construcción de la base regional de los recursos (Berón y Curtoni 1998). Para ello se efectuaron análisis en detalle de localidades con características contrastantes, a fin de profundizar los conocimientos sobre la estructura lítica de la región y aplicarlos a la resolución de los problemas que se desprenden del análisis de los conjuntos líticos. En el planteo metodológico se siguió lo postulado por diferentes investigadores (Ericson 1984; Nami 1992; Bayón et al. 1999; Franco y Borrero 1999; Escola 2003). En ese marco la propuesta comprendió:

a) Análisis de la bibliografía geológica y geomorfológica del área de estudio, así como de las descripciones de campo llevadas a cabo en las prospecciones y relevamientos superficiales (Groeber 1933; González Díaz 1972; Llambías 1966, 2009; Narciso et al. 2001a y b; Zárate 2002; Bertotto et al. 2009; Llambías et al. 2010; Ramos y Folguera 2011; Zárate et al. 2010, entre otros);

b) Ubicación por medio de un Sistema de Información Geográfica (SIG) de afloramientos de rocas aptas para la talla, de fuentes mencionadas en trabajos previos y las registradas en el marco de esta investigación; 
c) Caracterización litológica de los conjuntos artefactuales relevados (ver punto 2 .3, en este capítulo);

d) Evaluación de la disponibilidad (abundancia y calidad, sensu Andrefsky 1994) y accesibilidad local de rocas;

e) Análisis petrográfico de las fuentes de rocas y aplicación de modelos que permitan ajustar la descripción de estas fuentes (ver punto 2 .3, en este capítulo);

f) Extensión areal y oferta de materias primas (Wilson 2007) se consideraron las categorías de tamaño: pequeño (menor a $10 \mathrm{~m}$ de diámetro), medio (entre 10 a $50 \mathrm{~m}$ de diámetro), extenso (entre 50 y 100 m de diámetro) y, muy extenso (más de 100 m de diámetro).

g) Accesibilidad hace referencia a la localización de la fuente en el paisaje y/o facilidad en que pueden ser obtenidos los recursos en el ciclo anual. Se consideraron las categorías: anual (disponibles las cuatro estaciones del año) y estacional (cuando presenta restricciones geográficas o climáticas en una o varias estaciones del año).

h) Distribución de la materia prima en la fuente, se considera las categorías: concentrado, disperso y aislados (sensu Nami 1992).

i) Calidad para la talla (Franco y Aragón 1997).

j) Distancia a las fuentes de agua, para lo cual se consideró local a una distancia menor a los $5 \mathrm{~km}$ lineales.

k) Análisis geoquímico por medio de la técnica de fluorescencia de rayos $X$ (XRF) de artefactos de obsidiana recuperados en los relevamientos estratigráficos y superficiales y de los afloramientos de esta roca localizados en el área (ver apartado siguiente).

En cuanto a la utilización de SIG se empleó un mosaico de imágenes del satélite Landsat 7 con siete bandas de $30 \mathrm{~m}$ de resolución más una banda pancromática de $15 \mathrm{~m}$, que se utilizó para analizar la distribución de los artefactos en los distintos sectores del paisaje (patrones de distribución de artefactos, áreas de densidad y frecuencia artefactual, visualizar porcentajes de muestreo sin hallazgos, distancias entre muestreos con hallazgos 
y formas distribucionales) y desarrollar la cartografía. Las imágenes fueron facilitadas por la Dirección de Catastro de la Municipalidad de Malargüe; y de fuentes de acceso libre (http://glcf.umiacs.umd.edu/siteMap.shtml; http://www.ign.gob.ar; ;http://www.mineria.g

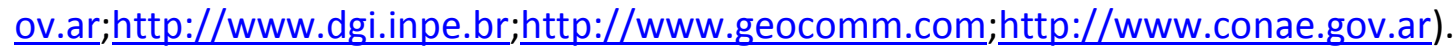

En relación al relevamiento de las fuentes primarias de recursos líticos se utilizaron dos procedimientos de muestreo: líneas de transecta y muestreos probabilísticos de áreas de cantera. Teniendo en cuenta las características geológicas de la región el trabajo se concentró en tres fuentes principales: Piedras Bayas, La Leona y Aguada de Pérez-Cantera, que se encuentran asociadas a recursos considerados críticos (Gil 2006) y poseen amplia disponibilidad (Andrefsky 1994) y accesibilidad (Bamforth 1992). Esto les otorga un tamaño expuesto de afloramiento de buena calidad que habría posibilitado un uso continuo en el tiempo. En el estado actual de conocimiento de la región, sólo las fuentes seleccionadas reúnen las características antes descriptas. Pista, ALPA y RC, poseen disponibilidad de nódulos silíceos, dispuesto en forma dispersa en el ambiente, y pueden ser considerados áreas potenciales de aprovisionamiento. Se espera que los estudios tecnológicos propuestos, aporten información relevante en este sentido.

Se describieron las características generales de las fuentes, siguiendo lo propuesto por Nami (1992), en cuanto a: materia prima, forma de presentación (afloramiento, bloque, nódulo, guijarro, etc.), forma de distribución (aislada, dispersa o concentrada) y características petrográficas. Los muestreos superficiales se centraron en la fuente primaria LLE y APE-C, y en el caso de PB se utilizó la información previa disponible en Gil (2000, 2006). En LLE se empleó la estrategia de muestreo tradicional, siguiendo líneas de transecta.

Para evaluar la acción de los procesos geomorfológicos y/o enterramiento en cada unidad de muestreo, se describieron las variables de pendiente y visibilidad, se determinó la presencia de cárcavas y se definió el sector de la geoforma muestreada. Se tomaron muestras de mano representativas de la variación macroscópica observada en cada una a los fines de avanzar en la caracterización petrográfica y litológica de las fuentes. 


\subsection{ANALISIS ARTEFACTUAL}

\subsubsection{DESCRIPCIÓN DE LOS CONJUNTOS LÍTICOS}

El análisis de los artefactos líticos se llevó a cabo desde una perspectiva tecnológica que apunta a la descripción de la variabilidad de los artefactos a partir de atributos directamente observables, sin referencia a aspectos funcionales, a la predisposición mental de la forma o el objetivo del artesano (Hiscock 2001; Odell 2003). Siguiendo la propuesta general de Hiscock (2001), una clasificación tecnológica materialista es un sistema de análisis donde se establecen divisiones o categorías conforme a intereses particulares de investigación, destacando rasgos relativos a la producción de los artefactos y su uso, como fenómenos separados. Las categorías de análisis adoptadas son mutuamente excluyentes. El análisis de la variabilidad no se restringe a la comparación entre clases, o dentro de una clase, como suele suceder en los análisis tipológicos, ya que las clases o tipos desde esta perspectiva dejan de constituir la unidad de análisis. Por el contrario, se enfatiza la variación de los individuos dentro del total de la población (Hiscock 2001). Este enfoque considera al artefacto como resultado de su historia de vida, adoptando una perspectiva "backward-looking" (Hiscock 2001). Interesan las variaciones en diferentes atributos de los artefactos, por ejemplo, a medida que aumenta la distancia a la fuente de aprovisionamiento de materia prima lítica. Dichas variaciones en la forma de los artefactos se evalúan en relación a la secuencia de producción y los factores que inciden en la manufactura, uso y reactivación de los artefactos, así como la disponibilidad y propiedades de las materias primas líticas, el tipo de enmangue y los costos de transporte, entre otros (Hiscock 2001).

En nuestro caso en particular, el diseño de planillas para la descripción de la variedad de artefactos líticos se centró en los grupos tecnológicos, considerados clases artefactuales (sensu Aschero y Hocsman 2004): I. Núcleos, II. Desechos de talla, III. Artefactos formatizados y, IV. Artefactos no formatizados con rastros complementarios. 
Las variables descriptivas y los índices de tamaño corresponden a las propuestas de Aschero $(1975,1983)$, asimismo se han incorporado propuestas de otros autores (Ingbar et al. 1989; Shott 1989; Hayden y Hutchings 1989, Andrefsky 1998; Odell 2003; Franco 2004; Cortegoso 2005; Charlin 2007). Dentro de cada clase se diferenciaron los artefactos según la energía invertida durante su manufactura. Así, la clase Artefactos manufacturados se subdivide en: a. Artefactos de formatización bifacial, ya que la reducción y adelgazamiento bifacial de una forma-base implica un mayor tiempo de trabajo que producir un artefacto con el sólo retoque de sus bordes (Escola 2000; Aschero y Hocsman 2004) y b. Artefactos de formatización unifacial. En cuanto a los artefactos sin formatización con rastros complementarios, estos son comúnmente definidos como filos, superficies o puntas activas, cuyo origen puede estar vinculado al uso del útil, a la presión ejercida sobre los bordes durante la aprehensión, a la preparación de plataformas para retoque o extracción, o bien a efectos producidos por factores post-depositacionales (Aschero 1983:20). Aquí se consideró sólo aquellos casos de filos y/o puntas activas con retalla y/o muescas continuas, y se descartaron los casos con rastros aislados o atribuidos a posibles factores post-depositacionales.

En la arqueología argentina la mayoría de los estudios líticos utilizan la tipología propuesta por Aschero (1975, 1983) (Flegenheimer y Bellelli 2007). La misma considera variables que dan cuenta de las técnicas de talla, otras que hacen referencia al grado de reducción de los artefactos y otras relacionadas principalmente con aspectos funcionales. Si bien estas variables son de utilidad en esta investigación, no resulta operativa la definición de "grupos tipológicos". Es más pertinente para los objetivos de esta tesis considerar las variables en forma independiente, ya que muchas de ellas se encuentran relacionadas con el grado de reducción de los artefactos y varían, por ejemplo, en relación con la distancia a la fuente de aprovisionamiento de materia prima. Dado que el interés reside en la trayectoria artefactual e historia de vida de los artefactos, nuestra atención está puesta en la variabilidad sobre determinadas dimensiones y atributos, considerados como indicadores de reducción e intensidad de uso de las rocas. Aquí la variación morfológica es entendida como un continuum más que como discontinuidades entre tipos 
morfológicamente distintos (cf. Dibble 1987, Hiscock y Attenbrow 2002, 2005, entre otros). Por ello interesa la comparación del modo en que fueron explotados los artefactos según la materia prima líticas sobre la que se encuentran manufacturados y como estas se distribuyen en el espacio regional. Numerosos estudios etnográficos y etnoarqueológicos (Binford 1979, 1980; Gould 1980; Hayden 1979, 1998) ponen en relieve las dificultades para el estudio de la variabilidad artefactual desde enfoques tipológicos (para una discusión de este punto ver Charlin 2007). Estudios recientes en las Sierras Centrales (Sario 2010) y Patagonia (Charlin 2007; Hermo 2008) abordaron desde diferentes marcos, estudios tecnológicos orientados a superar los problemas asociados con las clasificaciones tipológicas. En todos los casos, la denominación de los artefactos formatizados según la clasificación morfológica-funcional de Aschero es utilizada de un modo descriptivo (no analítico), ya que es útil como una forma de sintetizar la información (Charlin 2007) o para la comunicación entre colegas.

\subsubsection{VARIABLES CONSIDERADAS EN EL ANÁLISIS DE LOS ARTEFACTOS LÍTICOS}

Se presentan las variables que han sido consideradas en todas las clases artefactuales, las cuales hacen referencia a la identificación de la pieza, los atributos de las materias primas y las variables métricas, para continuar con las medidas específicas que han sido descriptas por clase artefactual. Para el tratamiento de los datos, los atributos fueron volcados a una única planilla de datos.

\section{1. $\quad$ Atributos de identificación de la pieza}

-Número de pieza.

-Sitio o área.

-Unidad de muestreo.

- Muestreo: superficial o estratigráfico.

2. $\quad$ Atributos de la materia prima 
-Materia prima: según determinación petrográfica (macroscópica y microscópica).

-Color: categorías cromáticas generales según la observación macroscópica.

-Translucidez: translucido y opaco.

-Calidad para la talla: mala, regular, buena, muy buena y excelente (sensu Aragón y Franco 1997).

-Presencia de alteraciones en la superficie externa: pátina; ventificación; rodamiento; hoyuelos; craquelado; alteración del color por acción térmica; sustancias adheridas.

-Presencia de alteraciones en la matriz: fracturas internas; inclusiones minerales e impurezas; geodas internas.

\section{3. $\quad$ Atributos de los artefactos}

-Reserva de corteza: en rangos de $25 \%$ de reserva de corteza en la cara dorsal de los artefactos. Los rangos indican: 0\%: ausencia; $25 \%$ : entre 0,1 y $25 \%$; $50 \%$ : entre 26 y $50 \%$; 75\%: entre 51 y $75 \%$; y $100 \%$ : entre 76 y $100 \%$ de cara dorsal) (Franco 2002a). Este indicador se considera un atributo estimado, dado que hay numerosos factores que influyen sobre él (Sullivan y Rozen 1985).

-Estado de fragmentación: entero o fracturado.

-Tamaño: se tomaron las medidas de largos, ancho y espesor en artefactos enteros y fragmentados. Esto permitió estimar el volumen de las piezas y el módulo de tamaño (sensu Aschero 1975, 1983). Muy Pequeño (MP): 0-20; Pequeño (P): 21-40; Mediano Pequeño (MEP): 41-60; Mediano Grande (MEG): 6180; Grande (G): 80-120; Muy Grande (MG): 121-160; Grandísimo (GD): >161.

-Peso: mediante el uso de balanza digital, valores en gramo con error de 0,1 gr.. Esta variable permite inferir con mayor precisión la realidad volumétrica de la producción lítica (Geneste 1990).

\subsection{2a NÚCLEOS}


-Designación morfológica de los núcleos: siguiendo la propuesta de Aschero (1975, 1983).

- Medidas de longitud, ancho y espesor máximo: medidos en $\mathrm{mm}$ con calibre digital según eje morfológico (sensu Aschero 1975, 1983).

-Forma base: lasca, nódulo, rodado, indiferenciado.

-Característica de los negativos de lascado: regular, irregular.

- Cantidad de negativos de lascado en la cara dorsal (Ingbar et al. 1994).

-Cantidad de plataformas de percusión (Aschero 1975, 1983).

-Grado de explotación: agotado, no agotado (Franco 2002a).

- Longitud y ancho de la extracción máxima y mínima (Prates 2008).

\subsection{2b DESECHOS DE TALLA}

-Caracteres básicos de la forma-base: siguiendo a Aschero $(1975,1983)$.

-Clase de desecho: siguiendo a Aschero (1975, 1983).

-Estado de conservación: siguiendo a Hiscock (2002) se diferencian las categorías: entero y fragmentado. Los fragmentados se diferencian en: fragmentos; fragmentos transversales proximales, distales o mediales; fragmentos marginales y fragmentos no diferenciados.

-Longitud, ancho y espesor máximo: medidos en $\mathrm{mm}$ con calibre digital de acuerdo al eje tecnológico (sensu Aschero1975, 1983). En los casos de lascas fragmentadas también se tomaron estas medidas para calcular el área y así poder aplicar el modelo de Ingbar et al. (1989).

-Forma del talón: natural o cortical, liso, diedro, filiforme, puntiforme y facetado siguiendo a Aschero $(1975,1983)$. 
-Cantidad mínima de extracciones en la cara dorsal: número mínimo de formasbase extraídas previamente de una lasca (Ingbar et al. 1989).

-Atributos de la cara ventral: siguiendo a Aschero $(1975,1983)$.

-Presencia de rastros complementarios: siguiendo a Aschero $(1975,1983)$.

\subsubsection{ARTEFACTOS FORMATIZADOS}

Esta clase comprende artefactos de filo y puntas-herramientas y puede ser subdividida en dos grande grupos: artefactos de formatización unifacial (en adelante AF Unifacial) y artefactos de formatización bifacial (en adelante AF Bifacial). Las variables consideradas para ambos grupos se detallan a continuación, seguido de las descriptas para en cada uno de estos grupos en particular.

En el estudio de los artefactos formatizados y/o con rastros complementarios se consideraron dos unidades de análisis: el artefacto y el filo y/o punta formatizada y/o con rastros complementarios. Por cada pieza se registraron variables de los artefactos como un todo y se relevaron variables sobre cada uno de los filos y/o puntas formatizados y/o con rastros complementarios. Cabe señalar que si bien los artefactos formatizados y sin formatización con rastros complementarios constituyen diferentes clases (Aschero y Hocsman 2004), en esta tesis y siguiendo lo propuesto por Charlin para Patagonia (2007), se les otorga la misma importancia, sin diferenciar entre filos principales y complementarios.

\subsection{2c.1 Artefactos de formatización unifacial (AF Unifacial):}

-Forma-base (sensu Aschero 1975, 1983).

-Número de filos y/o puntas formatizados y/o con rastros complementarios. 
- Número de dorsos formatizados (sensu Aschero 1975, 1983).

-Forma del filo (sensu Aschero 1975, 1983).

-Sección transversal de la pieza (Aschero 1975, 1983).

-Atributos del filo y/o punta formatizada: extensión relativa del filo respecto del borde de la pieza (sensu Aschero 1975, 1983); largo, ancho y espesor máximo del filo o punta: medidos en $\mathrm{mm}$ con calibre digital y en el caso de filos con un grado de concavidad o convexidad alto, el largo fue medido con cinta métrica flexible, con el fin de disminuir el error de medición de las curvadas de los filos (Cardillo y Charlin 2007).

-Presencia-ausencia de reactivación: siguiendo lo propuesto por Aschero (1975, 1983) y Franco (1994).

-Longitud, ancho y espesor máximo: medidos en $\mathrm{mm}$ de calibre digital de acuerdo al eje tecnológico (ET) para evaluar el tamaño de la forma-base y por eje morfológico (Aschero 1983) en los casos que no fue posible identificar el ET y para evaluar el grado de reducción del instrumento (cf. Dibble 1984, 1987; Franco 1994; Hiscock y Attenbrow 2002, 2003; Kuhn 2004; Bousman 2005).

-Peso: en gramos en balanza digital.

\subsection{2c.2 Artefactos de formatización bifacial (AF Bifacial):}

-Clase: preformas bifaciales, bifaces y puntas de proyectil (sensu Aschero 1975, 1983; Aschero y Hocsman 2004).

-Largo, ancho y espesor máximo: medidos en mm con calibre digital según eje morfológico (EM) (Aschero 1975, 1983).

-Peso en gramos: en balanza digital. Para puntas de proyectil enteras esta medida evita la redundancia en las medidas de tamaño, dado que las medidas métricas de largo y espesor de las puntas se utilizan para el cálculo del índice de reactivación (Iriarte 1995). 
-Forma perimetral del limbo: siguiendo a Aschero $(1975,1983)$.

-Atributos morfológicos de la base: siguiendo a Aschero $(1975,1983)$.

\subsection{2c.3 Artefactos sin formatización con rastros complementarios (ASF $\mathrm{RC})$ :}

Las variables medidas en esta clase artefactual son las mismas que las señaladas para los artefactos de formatización unifacial, excepto aquellas correspondientes a la descripción del filo (forma del filo, sección transversal, ancho y espesor del filo) y a la presencia de reactivación.

\subsubsection{DETERMINACIÓN DE LAS MATERIAS PRIMAS}

La determinación de las materias primas y el conocimiento de la base regional de recursos líticos, son pilares para entender las estrategias de aprovisionamiento y utilización de los recursos líticos (Ericson 1984; Nami 1992; Bayón et al. 1996, 2006; Escola 2003; Berón 2004, 2006; Franco 2004; Cortegoso 2005, entre otros). Las características macroscópicas de los artefactos proveen una aproximación a las materias primas presentes en los conjuntos arqueológicos y permite generar expectativas sobre las rocas que podrían estar disponibles en el espacio regional y aquellas que no, así como definir la representatividad de cada tipo (Odell 2003). Las formaciones geológicas generalmente presentan alta variabilidad interna y atributos macroscópicos poco específicos. Por ello son fuertes las advertencias sobre las debilidades de vincular el registro lítico con su procedencia a partir de propiedades macroscópicas (Hoard et al. 1993; Odell 2003). En ensta tesis se realizaron tres instancias de análisis de recursos líticos: la identificación petrográfica a nivel macroscópico, seguido de su caracterización microscópica y/o los análisis geoquímicos. 


\subsubsection{ARTEFACTOS, MUESTRAS DE MANO Y CORTES PETROGRÁFICOS DE ROCAS SILÍCEAS}

En las rocas silíceas, su escasa sensibilidad a métodos geoquímicos y petrográficos las ubica entre los recursos más problemáticos para la determinación de procedencia (Luedke 1992; Hoard et al. 1993; Aragón y Franco 1997). Sin embargo, es común encontrar en la bibliografía arqueológica referencias a divisiones de tipos de rocas silíceas que responden a características macroscópicas, como por ejemplo a texturas de la rocas (cf. calcedonia), inclusión de minerales (dendritas ferromagnesianas) o variedades en color y granulometría. Ciertamente esto puede responder a numerosos factores, entre ellos la selección de rocas en la fuente por parte de los grupos humanos (Flegenheimer y Bayón 1999), la elección de determinadas fuentes en el espacio regional (vinculado a factores como menor distancia, facilidad de acceso, etc.) o el uso de recursos vinculados a factores simbólicos (Gould 1980; Gould y Saggers 1985). En todos los casos, se requiere de una exhaustiva caracterización de las materias primas disponibles en el espacio regional y de aquellas presentes en los conjuntos arqueológicos. Trabajos como los de Luedtke (1978, 1992), Hoard et al. (1993), Church (1994) y Risso (2004) representan esfuerzos por diferenciar fuentes silíceas y superar los problemas asociados a determinaciones macroscópicas. En Argentina los antecedentes se reducen a los trabajos realizados por Franco y Aragón (1997), Berón (2004), Barros y Messineo (2004) y Hermo (2009), quienes por medio de estudios petrográficos y/o geoquímicos buscan ajustar la caracterización de las rocas silíceas. Tomando estos estudios de base, se optó por un abordaje que explora la aplicación de modelos geológicos para el abordaje de formaciones silíceas.

En cada fuente analizada se tomaron muestras de mano del afloramiento superficial. En la selección de muestras se tuvo en cuenta la variedad en color, textura y brillo observados (definidas según Tarbuck y Lutgens 1992) y, de modo exploratorio, se tomaron en cuenta los caracteres utilizados en la literatura arqueológica para discriminar fuentes de procedencia, entre las que se mencionan, inclusiones minerales, translucidez, granulometría, y alteraciones de la matriz como presencia de geodas internas (Franco 
2002a; Barros y Messineo 2004; Cortegoso 2005; Bayón et al. 2006). Posteriormente, se seleccionaron las muestras de mano más disímiles dentro de cada fuente primaria, para ser caracterizadas petrográficamente. Asimismo, en los sitios estratigráficos y siguiendo los mismo parámetros mencionados para las fuentes, se seleccionaron artefactos para su caracterización petrográfica. Esta tarea fue diseñada conjuntamente al geólogo Walter G. Berttoto (Universidad Nacional de La Pampa).

En las fuentes y áreas de disponibilidad de rocas silíceas, se seleccionaron 31 muestras, de los cuales 10 corresponden a PB, 6 a LLE, 5 a APE-C y 10 a PISTA. En los sitios estratigráficos, por su parte, se escogieron 15 artefactos, de ellos 7 proceden de LP-2, 5 de CAR-1 y 3 del sitio APE-1. Todas las muestras fueron procesadas para cortes delgados , conservando en los casos que fue posible un remanente de roca. Para la definición del color se tuvieron en cuenta categorías cromáticas generales a partir de la observación macroscópica; la textura es definida como la disposición espacial de los componentes o grupos de minerales idénticos de una roca, la textura puede ser: afanítica (cristales no observables a simple vista, para observarlos es necesario la ayuda de un microscopio); vítrea o amorfa (sin estructura cristalina); fanerítica o de grano grueso (estructura cristalina observable en forma macroscópica). El brillo es el aspecto o la calidad de la luz reflejada definido de la superficie de un mineral, entre los que se destaca brillo vítreo, sedoso, terroso, etc. En el laboratorio se fragmentaron las muestras, y se destinó un fragmento de $12 \mathrm{~cm}^{2}$ aproximadamente para el corte delgado, y un fragmento para la caracterización macroscópica (cuando el tamaño de la muestra lo permitió). Para la realización de los cortes petrográficos se preseleccionó la cara en la cual se realizaría el corte para luego enviarlas a la Universidad del Sur (Provincia de Buenos Aires). Se realizaron 46 cortes delgados.

Los cortes fueron analizados con la colaboración del Dr. Walter Bertotto (Universidad Nacional de La Pampa) y la Dra. Mirta Garrido (Universidad Nacional del Sur). Las muestras de mano fueron observadas con una lupa Leica MZ 9s y el estudio petrográfico de los cortes delgados se realizó mediante un microscopio petrográfico Nikon (Universidad Nacional La Pampa) y un microscopio de trasmisión Leica DMLP con objetivos 
de 5, 10, 20, 50, y 100X (para la descripción de los cortes y muestras de mano ver ANEXO 2).

\subsubsection{1a Análisis de rocas silíceas}

Estudios geológicos destacan la importancia de las texturas de cuarzo hidrotermal para determinar el contenido y mineralización de metales nobles de interés económico actual, como son el oro, la plata y el cobre, entre otros (Echavarría 1997; Garduglio et. al 2007). El modelo propuesto por Buchanan (1981) permite establecer los niveles o zonaciones verticales dentro del sistema hidrotermal en tres categorías, según el origen y ambiente de formación (Echavarría 1997). En base a una clasificación descriptiva que tiene en cuenta el tamaño, forma y relaciones entre los componentes del agregado cristalino, Buchanan (1981) agrupa las texturas en: texturas de crecimiento primario, de reemplazo y de recristalización.

Este modelo fue desarrollado para el estudio de venas de cuarzo formadas en grietas de rocas volcánicas intermedias a básicas, que permiten establecer niveles o zonaciones verticales dentro de un sistema hidrotermal. El modelo genera una tendencia referida al nivel expuesto en superficie de la estructura vetiforme, a partir de la descripción de tamaño, forma y relaciones entre los componentes del agregado cristalino. La base de la clasificación es descriptiva. El autor agrupa las texturas observadas en microscopio petrográfico en tres categorías mayores sobre la base de su origen y ambiente de formación, en: texturas de crecimiento primario, texturas de reemplazo y texturas de recristalización (Echavarría 1997).

Los estudios hasta aquí descriptos permiten caracterizar la superficie expuesta del sistema de veta en su conjunto. Desde el punto de vista arqueológico esta información permite diferenciar un conjunto de características texturales de otros a nivel microscópico. Desde el análisis macroscópico las diferencias observadas son poco diagnósticas por el hecho de presentar cada afloramiento una amplia variabilidad interna. En el caso de las rocas silíceas diagenéticas, estas presentan líneas de crecimiento 
continuo que se disponen en paralelo o concéntricas. Las silicificaciones o reemplazos poseen características similares a las descriptas para las correspondientes a origen hidrotermal, sin embargo la forma de disposición del afloramiento y la combinación de tipos texturales ayuda a diferenciar entre una y otra variedad.

\subsubsection{ESTUDIOS GEOQUÍMICOS SOBRE OBSIDIANA}

En la región sur del centro oeste argentino, proyectos vinculados a la detección y caracterización geoquímica de las fuentes de obsidiana han permitido la detección de al menos siete fuentes (Seelenfreud et al. 1996; Durán et al. 2004; Barberena et al. 2011; Giesso et al. 2011a). Las muestras analizadas, fueron seleccionadas con el objeto de caracterizar la mayor variabilidad macroscópica regional (Giesso et al. 2011a; Salgán et al. 2012). De acuerdo a los objetivos planteados en esta tesis y a los fines de discutir modos de obtención, patrones de movilidad y circulación de bienes. Se procesaron 98 especímenes por INAAA $(n=4)$ y XRF $(n=94)$ cuyos resultados se presentan el capítulo IX. El análisis tecno-morfológicos de las piezas líticas, se profundizaron a posteriori del análisis geoquímico, razón por la cual cuatro de las muestras analizadas por medio de métodos destructivos (INAA), solo pudieron ser diferenciadas a nivel de clase tecnológica (4\%). Las muestras fueron procesadas en el Missouri University Research Reactor (MURR; Glascock et al. 1998) y en la Facultad de Filosofía y Letras (Universidad Nacional de Cuyo) siguiendo la metodología para INAA (Durán et al. 2004) y para XRF (Giesso et al. 2011a).

Varios métodos geoquímicos han sido utilizados para determinar la procedencia de obsidiana arqueológica. Los tres más usados son el de análisis instrumental de activación de neutrones (INAA), el de fluorescencia de rayos (XRF) y el de espectrometría de emisión atómica con plasma acoplado inductivamente (LA-ICP-MS). Cada uno posee ventajas y desventajas (Shackley 1998, 2007; Barberena et al. 2011). INAA ofrece excelente sensibilidad, mayor precisión para un número mayor de elementos traza, y puede ser utilizado para analizar muestras muy pequeñas (hasta 5 miligramos). Sin embargo es una 
técnica destructiva, requiere de mayor tiempo de preparación de las muestras y es más costosa. En la región norte y centro andina, ha sido el método utilizado para la caracterización de las fuentes de obsidiana (Durán et al. 2004; Elías et al. 2007; Elías y Escola 2010; Giesso et al. 2010), mientras que en la región patagónica el método más utilizado ha sido LA-ICP-MS (Stern y Franco 2000; Stern 2004; Gómez Otero y Stern 2005). Este último, más conocido por su sigla resumida ICP, es una técnica destructiva, intermedia entre INAA y XRF en relación a la precisión y cantidad de elementos traza que identifica. Por su parte, XRF ofrece buena sensibilidad e información para los elementos traza (Rb, Sr, Y, Zr y Nb) reconocidos para discriminar fuentes de obsidiana (Shackley 1998, 2007). Es un método no destructivo, que implica una menor inversión de tiempo y costo. Sobre esta base y habiendo evaluado la consistencia de los resultados de las fuentes entre INAA y XRF, las muestras arqueológicas fueron analizadas por esta última técnica (Glascock 2010) aunque las fuentes se procesaron previamente por INAA (Durán et al. 2004; Giesso et al. 2011a; Cortegoso et al. 2012).

Los valores de consenso para la calibración de las fuentes de obsidiana fueron previamente determinados en el MURR (utilizando INAA y XRF). Los rangos de concentración de las muestras de referencia abarcan todo el rango de concentración probable de obsidiana procedente de distintas fuentes en el mundo (Glascock 2010). Los INAA fueron realizados en el MURR (Missouri University Research Reactor) y constituyen un conjunto de procedimientos que consisten de dos irradiaciones y tres conteos de rayos gamma. Los procedimientos se inician con una irradiación corta a través del sistema de irradiación en tubos neumáticos. Las muestras se irradian en secuencia, dos por vez, durante cinco segundos con un flujo neutrónico $\left(8 \times 10^{13} \mathrm{n} \mathrm{cm}^{-2} \mathrm{~s}^{-1}\right)$. El conteo de 720 segundos produce un espectro de rayos gama que contiene picos para los elementos de vida corta: aluminio (Al), bario (Ba), calcio (Ca), diprosio (Dy), potasio (K), manganeso (Mn), sodio (Na), titanio (Ti), y vanadio (V). Las muestras de $200 \mathrm{mg}$ se irradian durante 24 horas con un flujo neutrónico de $5 \times 10^{13} \mathrm{n} \mathrm{cm}^{-2} \mathrm{~s}^{-1}$. Esta irradiación larga es análoga a la irradiación única utilizada en la mayoría de los laboratorios. Después de la irradiación larga, se dejan las muestras durante siete días y luego se cuenta la irradiación durante 
2.000 segundos (el "conteo medio") en un detector de germanio de alta resolución acoplado a un cambiador automático de muestras. El conteo medio produce determinaciones de siete elementos de vida media, específicamente arsénico (As), lantano (La), lutecio (Lu), neodimio ( $\mathrm{Nd})$, samario $(\mathrm{Sm})$, uranio $(\mathrm{U})$, e iterbio $(\mathrm{Yb})$. Después de unas tres o cuatro semanas adicionales, se hace un conteo final de 9.000 segundos para cada muestra. La última medición produce datos de 17 elementos de vida media larga: cerio (Ce), cobalto (Co), cromio ( $\mathrm{Cr}$ ), cesio (Cs), europio (Eu), hierro (Fe), hafnio (Hf), níquel ( $\mathrm{Ni})$, rubidio $(\mathrm{Rb})$, antimonio $(\mathrm{Sb})$, escandio $(\mathrm{Sc})$, estroncio $(\mathrm{Sr})$, tantalio $(\mathrm{Ta})$, terbio (Tb), torio (Th), zinc (Zn), y circonio (Zr) (Giesso et al. 2011a; Cortegoso et al. 2012).

La mayor parte de los artefactos presentados en esta tesis (96\%) se analizaron utilizando un espectrómetro de fluorescencia de rayos $\mathrm{X}$ portátiles del MURR (Elva-X y Bruker) en la Universidad Nacional de Cuyo (Mendoza). El Elva-X es un espectrómetro portátil de fluorescencia de rayos $X$ por energía dispersa. El instrumento consiste de un generador de rayos $X$, un detector de rayos $X$ y un analizador de canales múltiples (MCA). El detector es un diodo de estado sólido con un área de $30 \mathrm{~mm}^{2}$ y una resolución de 180 eV a 5,9 KeV (a 1.000 cuentas por segundo). El espectrómetro Elva-X no requiere refrigeración con nitrógeno líquido del detector de estado sólido. Los análisis fueron conducidos con $35 \mathrm{kV}$ con una corriente de $45 \mu \mathrm{A}$ y tiempo de operación de 400 segundos. Las concentraciones se calcularon en partes por millón utilizando el programa ElvaX Regression, basado en el modelo de regresión cuadrática de una serie de muestras de obsidiana de referencia caracterizadas previamente por fluorescencia de rayos $\mathrm{X}$ y activación neutrónica. El análisis permite la cuantificación de 11 elementos: potasio (K), titanio (Ti), manganeso $(\mathrm{Mn})$, hierro $(\mathrm{Fe})$, zinc $(\mathrm{Zn})$, galio $(\mathrm{Ga})$, rubidio $(\mathrm{Rb})$, estroncio $(\mathrm{Sr})$, itrio $(\mathrm{Y})$, circonio $(\mathrm{Zr})$ y niobio $(\mathrm{Nb})$. El equipo proyecta una curva de distribución de elementos en la pantalla que permite comparar con las muestras de fuentes previamente preparadas y realizar una identificación visual muy rápida. Este equipo permite procesar entre 70 y 80 muestras diarias y no es destructivo.

El espectrómetro portátil Bruker Trace III-V permite cuantificar la presencia de 13 elementos, los 11 elementos mencionados para el Elva-X más el plomo ( $\mathrm{Pb}$ ) y torio (Th). Al 
igual que el Elva-X, este equipo proyecta una curva de distribución de elementos en la pantalla que permite comparar con las muestras de fuentes previamente preparadas y realizar una identificación visual muy rápida. La diferencia es que el equipo Bruker permite procesar entre 100 y 120 muestras diarias. La devolución de los picos obtenidos u operaciones matemáticas de las tendencias se realiza mediante el paquete del análisis espectral Bruker, que permitió la medición de trece elementos en la mayoría de las muestras ( $\mathrm{K}, \mathrm{Ti}, \mathrm{Mn}, \mathrm{Fe}, \mathrm{Zn}, \mathrm{Ga}, \mathrm{Rb}, \mathrm{Sr}, \mathrm{Y}, \mathrm{Zr}, \mathrm{Nb}, \mathrm{Pb}$ y Th). El instrumento fue calibrado usando datos de composición de muestras de origen bien caracterizados en la colección de referencia de obsidiana del MURR. La determinación de las fuentes desconocidas es un tema problemático, ya que se necesitan por lo menos 5 a 10 muestras de cada fuente para determinar su rango de distribución química. Por el momento sólo una, que llamamos Desconocida A se puede definir basada en la presencia en sitios arqueológicos exclusivamente. Material de esa fuente se encontró en sitios del Río Grande (Cañada de Cachi y Cueva de Luna), en sitios cordilleranos (El Indígeno), y en La Peligrosa. Por el momento no se ha determinado si proviene de una fuente nueva o de una sub fuente de alguna de las estudiadas (Giesso et al. 2011a; Cortegoso et al. 2012).

\section{3 ÍNDICES Y ESTADÍSTICOS PARA EL TRATAMIENTO DE LOS DATOS}

La media geométrica ha sido la medida de tamaño calculada para todas las clases artefactuales, ya que es el estadístico más utilizado para medidas lineales, como longitud, ancho y espesor. El mismo se basa en la $n$-ésima raíz del producto de $n$ variables (Jungers et al. 1995). Su ventaja radica en que el valor obtenido es el resultado del cálculo de un centroide que resume las distancias entre las $n$ variables.

Para el análisis de la diversidad tanto de las clases de roca explotadas para la manufactura de artefactos, como de las medidas de reducción de las materias primas en los diferentes sitios arqueológicos, se implementó el índice de diversidad (Jones y Leonard 1989; Lanata 1996; Belardi 2005). El concepto de diversidad, como herramienta analítica, 
nos posibilita caracterizar la estructura de una población o muestra ya que es una medida de la variabilidad (Jones y Leonard 1989). La diversidad presenta dos dimensiones: la riqueza, que nos permite dar cuenta del número de categorías o clases representadas en una muestra, y la homogeneidad, que nos indica cómo se distribuyen las cantidades por categoría (Jones y Leonard 1989). Por tratarse de una medida compuesta, en nuestro análisis consideramos los tres tipos de índices que, por encontrarse correlacionados, nos permiten caracterizar de forma más precisa las muestras que estamos comparando. Dichos índices son el de Shannon-Wiener, el de Simpson y el de Dominancia. El primero considera la relación entre el número de individuos y de clases; por consiguiente es una medida simultánea de la riqueza y homogeneidad (cf. Shott 1989). Los valores más elevados del índice indican que la mayoría de las clases se encuentran representadas por pocos o cantidades similares de individuos (es decir, tienen una distribución homogénea), en tanto que los valores bajos sugieren que pocas clases se encuentran representadas por muchos individuos (la distribución es asimétrica ya que se encuentra dominada por una o pocas clases) (cf. Krebs 1989; Hammer et al. 2004; Kintigh 1989; Shott 1986; Grayson 1989; Gotelli y Graves 1996). Este índice cuenta con la ventaja de ser sensible a la frecuencia de ítems en las clases menos representadas (Shott 1989). Los resultados obtenidos a través del índice de Shannon-Wiener pueden ser complementados por los índices de Simpson y dominancia. Dichos índices varían entre 0 y 1, según la uniformidad o asimetría en la distribución de cantidades entre clases, respectivamente. Para la comparación de la diversidad entre muestras se utilizan dos procedimientos de randomización: el boostrapping y la permutación (Hammer et al. 2004). Ambas son técnicas de re-muestreo al azar, con y sin reemplazo, respectivamente. Se considera a la distribución muestreal como si fuera la verdadera distribución poblacional y a través del re-muestreo de la misma se genera la distribución teórica. Cada una de las $n$ observaciones originales tiene igual probabilidad de ser seleccionada. El procedimiento de muestreo se repite varias veces, generalmente seleccionando 1000 muestras de tamaño $n$ y a partir de estas muestras se estiman los parámetros, que constituyen la distribución teórica comparativa. 
Para no sobreestimar la muestra analizada y explorar procesos de formación de los conjuntos, se tuvieron en cuenta los conteos e índices propuestos por Hiscock (2002), análogos a los utilizados en estudios tafonómico para materiales óseos. Estos son, NAS (Number of Artefactual Specimens): número total de artefactos recuperados, ya sean enteros o fragmentados; NFS (Number of Flake Specimens): número de especímenes identificados como lascas, ya sean enteras o fragmentadas; MNF (Minimum Number of Flakes): estimación del números mínimo de lascas necesario para dar cuenta de las lascas completas y fragmentadas presentes en un conjunto (Hiscock 2002). El índice MNF (número mínimo de lascas) se calcula utilizando la fórmula $\mathrm{MNF}=\mathrm{C}+\mathrm{T}+\mathrm{L}$, donde $\mathrm{C}$ son todas las lascas completas; T es la categoría más numerosa de fragmentos transversales (excluyendo los mediales), es decir, los proximales o los distales. L es el número de fragmentos longitudinales dados por $\mathbf{L}=\mathbf{C L}+\mathbf{B L}$, donde $\mathbf{C L}$ es el número mayor de fragmentos longitudinales, ya sean izquierdos o derechos sin fractura transversal (que posean inicio y terminación de la fractura); y BL es el mayor de las cuatro categorías relevantes de fragmentos longitudinales fracturados transversalmente (derecho/proximal, izquierdo/proximal, derecho/distal, izquierdo/distal). Para aumentar la precisión del MNF, el mismo se calcula para cada materia prima. Esto produce valores mayores ya que un fragmento distal de basalto y otro proximal de sílice contarían como dos lascas diferentes, mientras que si no se discrimina por materia prima, ambos fragmentos darían cuenta de una sola lasca (Hiscock 2002: 255). Asimismo, es importante controlar que la fragmentación no se produzca sobre alguna materia prima en particular, ya que puede responder a las características inherentes de la roca y/o su resistencia tanto a procesos de manufactura como tafonómicos. Para ajustar la estimación de la abundancia original de todos los artefactos que integran los conjuntos bajo análisis, se utiliza el MNA (Minimum Number of Artefacts). El mismo es el resultado de la sumatoria del MNF y los instrumentos y núcleos enteros. Los núcleos e instrumentos fragmentados son considerados "fragmentos no diferenciados", es decir, que los fragmentos sólo son considerados en el conteo de NAS. El índice de fragmentación de cada localidad es la razón entre el NAS y el MNA obtenido (Hiscock 2002; Borrazo 2010). 
Para el tratamiento de los conjuntos se tuvieron en cuenta los índices propuestos por Ericson (1984), que tienen la función particular de generar información referente a los estadios de producción de una materia prima en particular. Entre ellos se mencionan: índice de corteza (desechos primarios y secundarios de descortezamiento / $\mathrm{n}$ total de desechos); índice de producción (desechos de talla / instrumentos); índice de bifacialidad (instrumentos bifaciales / $\mathrm{n}$ total instrumentos). Para analizar la reducción de las distintas clases artefactuales, se utilizaron los índices derivados de estudios experimentales, con el objetivo de evaluar diferencias y similitudes entre distintas técnicas de manufactura y a medida que avanza el proceso de reducción (Amick y Mauldin 1989). Muchos de ellos centran su atención en los desechos de talla, en tanto son los artefactos comúnmente más numerosos del registro arqueológico (Shott 1994, 1996; Sullivan y Rozen 1985; Ingbar et al. 1989; Bradbury y Carr 1995, entre otros). Estos estudios mostraron algunas constantes en la variación de determinados atributos sobre los desechos de talla a medida que aumenta la reducción, tales como la disminución del tamaño y el incremento en la cantidad de negativos de lascada en la cara dorsal de la lasca (Ingbar et al. 1989). A través del modelo de estos investigadores señalan que la densidad de negativos de lascados (100 $x$ cantidad de negativos de lascado en la cara dorsal/área de la lasca) es la medida que más se ajusta al proceso de reducción. En consecuencia, es adoptada para calcular el grado de reducción de los desechos de talla. El área o superficie de la lasca es calculada a través del largo (en $\mathrm{mm}$ ) por el ancho (en $\mathrm{mm}$ ) según el eje tecnológico. El resultado expresa la cantidad de extracciones (negativos de lascado) por $\mathrm{mm}^{2}$ (sintetizado como e/ $\mathrm{mm}^{2}$ ). Dado que la densidad es una medida relativa al tamaño, es posible calcularla sobre lascas fragmentadas, lo cual resulta necesario en las materias primas de representación minoritarias, como las obsidianas.

Una medida similar ha sido aplicada a los núcleos con el objetivo de evaluar su utilidad residual al momento del descarte, es decir, si los mismos se desecharon con utilidad potencial o cuando se encontraban agotados. Esto nos permite comparar la explotación de las distintas clases de materias primas líticas, como así también la utilización de los diferentes espacios del campo volcánico. Al igual que los desechos de 
talla, se calcula la razón entre el número mínimo de extracciones (formas-base) realizadas sobre el núcleo y el volumen del mismo (como medida de tamaño, en $\mathrm{mm}^{3}$ ). Debido a la unidad de medida del volumen, el número mínimo de extracciones es multiplicado por 1000, para evitar un número excesivo de decimales (Charlin 2007). El resultado expresa la cantidad de extracciones (negativos de lascado) por $\mathrm{mm}^{3}\left(\mathrm{e} / \mathrm{mm}^{3}\right)$.

Este índice de reducción también es aplicado de manera exploratoria para estimar la secuencia de manufactura representada en los diferentes conjuntos. Se parte de la idea de que todo proceso de reducción involucra una disminución en el tamaño de la pieza y en la intensidad de los lascados. Para este análisis solo se tienen en cuenta los artefactos enteros. Se propone trabajar con las categorías amplias detalladas antes y en base a conceptos abarcativos, como son los de sistema producción lítica (sensu Ericson 1984), historia de vida (sensu Schiffer 1972, 1976) y trayectorias de producción (Koldehoff 1987). El sistema de producción puede ser definido como “(...) todas las actividades y localizaciones sincrónicas implicadas en la utilización y modificación de una fuente o un material lítico específico para la manufactura y uso de los artefactos líticos en un sistema social" (Ericson 1984; traducción propia). Constituye por tanto, un nexo entre las actividades de producción lítica, los productos de esas actividades (útiles obtenidos, desechos y elementos utilizados en la modificación de la masa lítica como percutores, arena, agua, etc.) y los locus en donde se llevaron a cabo, en un análisis particularizado por fuentes o materias primas específicas. Si bien para Ericson (1984) la producción lítica es un proceso de modificación del material orientado a la obtención de un objeto particular que incluye todas las etapas seguidas hasta la consecución de un instrumento determinado, en este trabajo se amplía para tomar en consideración los procesos ocurridos posteriormente como son el mantenimiento, la reutilización o reuso, descarte, almacenaje y transporte; así como procesos posteriores que forman parte de la historia de vida de un artefacto como pueden ser la reclamación y la perturbación (Schiffer 1972). Una manera simple de abordar las características estructurales y organizativas en los conjuntos artefactuales, es a través de la delineación de trayectorias de producción. Estas son entendidas como modelos particulares que apuntan a clarificar la relación entre 
disponibilidad de recursos líticos, las secuencias de producción y la distribución espacial de las actividades productivas (Koldehoff 1987). Para ello se consideran atributos tecnomorfológicos (Aschero 1975, 1983), que permiten analizar las etapas de reducción representadas en los diferentes locus. La trayectoria se inicia en las fuentes de aprovisionamiento, donde se consideran las actividades productivas representadas (tales como: testeo y selección de nódulos; descortezamiento primario y preparación de núcleos para su transportes; manufactura de formas base o extracción de lascas y/o manufactura de artefactos). En caso de locus distintos a las fuentes, se considera el modo de ingreso de la materia prima (ya sea como nódulos, núcleos preparados y/o formas base para la manufactura de instrumentos), las etapas de formatización y mantenimiento de filos y el estado de descarte del instrumental. Para el análisis de etapas de manufactura, se consideran los desechos talla. En este sentido, las primeras etapas de manufactura o descortezamiento están representadas por las lascas externas, que corresponden a desechos de talla enteros que presentan en su cara dorsal entre el $100 \%$ y $75 \%$ de reserva corteza (lascas primarias y secundarias, respectivamente), sumado a las lascas nodulares o de reactivación de núcleo (lascas de flanco de núcleo, de dorso natural y tableta de núcleo). Le siguen las lascas internas, que pueden definirse como desechos de talla que no poseen corteza y presentan en su cara dorsal negativos de lascados previos (lascas angulares y de arista). Por último, se consideran las lascas de formatización de filo, cuya morfología, tamaño y características tecnológicas son atribuidos a las últimas etapas de manufactura (lascas de adelgazamiento bifacial, lascas planas y lascas de reactivación de filo). En instrumentos se analiza los modos de manufactura frecuentes e inversión de trabajo (Escola 2000), el estado de descarte, el grado de reducción en artefactos unifaciales (Kuhn 1990) e índice de rejuvenecimiento en puntas de proyectil (Iriarte 1995).

El índice geométrico de reducción propuesto por Kuhn (1990) es de utilidad como indicador de reducción para instrumentos unifaciales. Se basa en un modelo geométrico sobre la sección transversal de la forma-base. El mismo constituye un indicador de la frecuencia o intensidad de reactivación de un filo y por lo tanto de la vida útil del instrumento. En dicho índice se considera la razón entre el espesor máximo del filo 
retocado $(t)$ y el espesor máximo de la forma-base $(T)$. Esta medida cuenta con la ventaja de ser independiente del tipo de reducción implementada y del tamaño original de la forma-base. Si bien ha habido debate en cuanto a la confiabilidad de dicha medida por la incidencia de distintos factores asociados con la forma de la forma-base del instrumento, las experimentaciones realizadas por Hiscock y Clarkson (2005a y b) han demostrado que las variaciones en la sección transversal de la forma-base ("the flatflake problem") no ejercen una influencia significativa sobre el cálculo del índice. Si bien el índice geométrico fue propuesto originalmente para calcular el grado de reducción en las raederas, es aplicable a otras clases de instrumentos de filo unifacial. El requisito que debe cumplir el artefacto para una adecuada aplicación del índice es que la forma-base sea una lasca, dado que el modelo se basa sobre la forma triangular de la lasca en sección transversal. Esta forma geométrica, considerada "típica" de las lascas, implica que el punto de mayor espesor se localiza hacia el centro de la pieza; por consiguiente, a medida que la reducción del artefacto avanza a través de sucesivas reactivaciones, los negativos de lascado del filo se aproximan al centro del artefacto, lo que se traduce en un incremento del espesor del filo (t), hasta que alcanza el espesor máximo de la forma-base (T). De esta forma, la tasa de t/T adquiere valores entre 0 y 1 a medida que avanza la reducción [(t/T)/n]. El índice geométrico no es aplicable a los filos naturales con rastros complementarios.

En las puntas de proyectil se ha considerado como índice de reducción el índice de rejuvenecimiento propuesto por Iriarte (1995), el cual se calcula mediante la razón entre el largo y el espesor del artefacto. Iriarte (1995) considera que esta última variable métrica es la menos afectada por la reactivación, siendo el largo la dimensión que muestra las mayores variaciones. De este modo el índice resulta inversamente proporcional al rejuvenecimiento, en otras palabras, a mayor rejuvenecimiento menor será el valor del índice y viceversa. Para el tratamiento estadístico de los datos se utilizó en software PAST 2.07 (http://folk.uio.no/ohammer/past) (Hammer et al. 2011). 


\section{CAPÍTULO 6}

\section{BASE REGIONAL DE RECURSOS LÍTICOS EN LA PAYUNIA}

\section{INTRODUCCIÓN}

Este capítulo aborda la distribución, disponibilidad, abundancia y accesibilidad de las materias primas. Para ello se analiza, en primer lugar, la disponibilidad de rocas aptas para la talla a partir de estudios geológicos y arqueológicos previos. Luego se define un mapa potencial de rocas disponibles. Y por último, se integra dicha información el análisis petrográfico y geoquímico de fuentes de rocas y herramientas líticas para discutir el modo de uso de las rocas en La Payunia por parte de las poblaciones humanas.

\subsection{GEOLOGÍA Y LITOLOGÍA EN LA PAYUNIA}

A partir de los antecedentes geológicos disponibles para La Payunia (capítulo IV), se optó por dividir la región en tres sectores (figura 6.1), denominados según su localización y antigüedad de las formaciones allí expuestas en: norte, central y sur (Capítulo III). El sector norte incluye las sierras de Palauco y Agua Escondida y comprende un área donde afloran formaciones antiguas correspondientes al Bloque de San Rafael y al Grupo Palauco. El sector central está conformado por la Altiplanicie del Payún Matrú y la parte este de la planicie de degradación de la meseta de La Matancilla. Este sector se encuentra cubierto por materiales producto del volcanismo actual, donde se destacan los volcanes Payún Liso y Payún Matrú. Por último en el sector sur, se encuentran las sierras de Cara Cura y de Reyes, el Cañadón Amarillo y las sierras de Chachahuén. A continuación se detalla la litología y recursos líticos presentes en cada sector. 


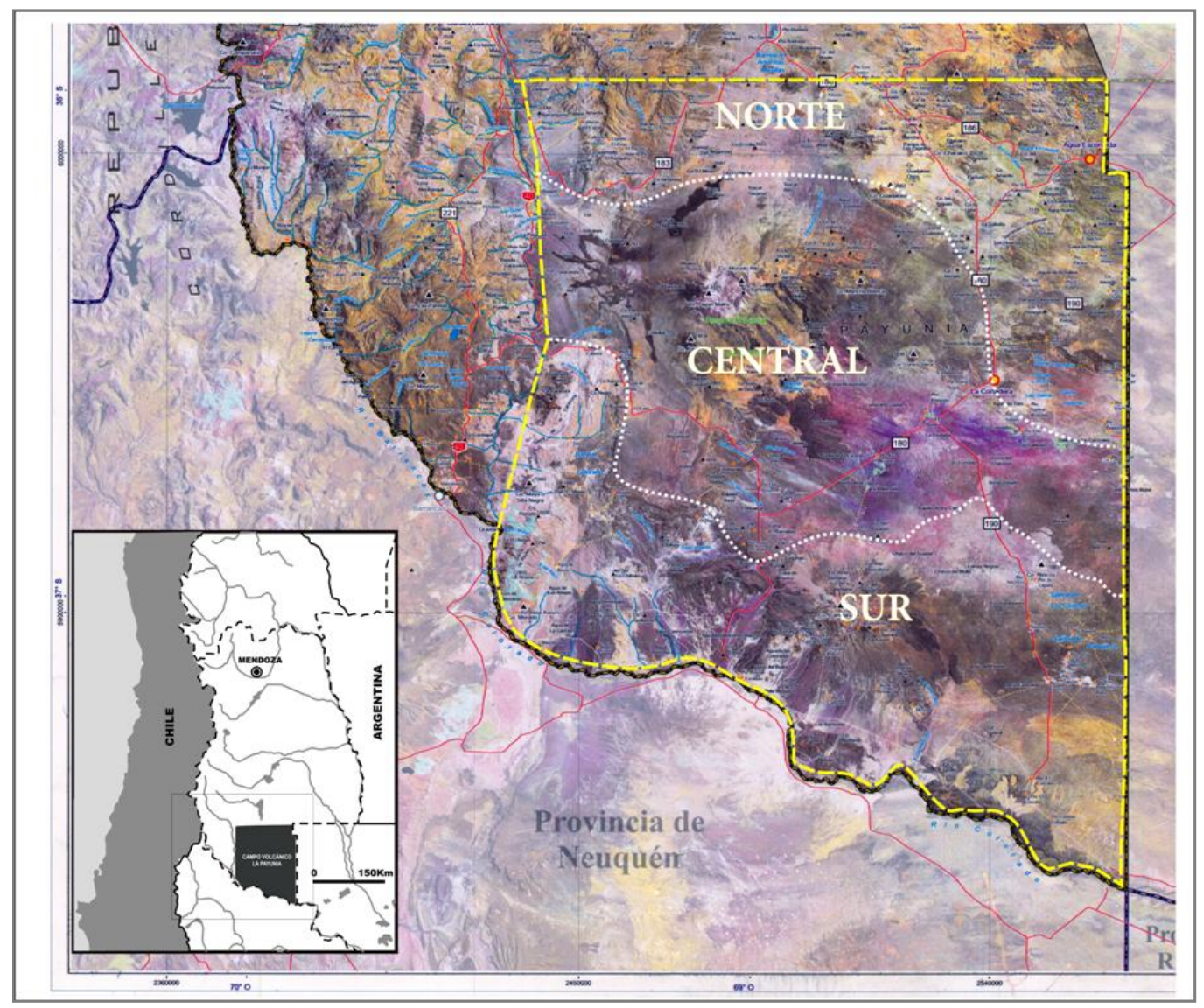

Figura 6.1 Sectores de La Payunia. Imagen LANSAT gentileza de la Dirección de Catastro de la Municipalidad de Malargüe.

\subsubsection{SECTOR NORTE: SIERRAS DE PALAUCO Y AGUA ESCONDIDA}

En base a la información geológica disponible (Groeber 1933; Narciso et al. 2001a y b), se reconocen dos estructuras de paisajes contrastantes: las sierras de Palauco (al oeste) y el área de Agua Escondida (al este), ambas comprenden parte del límite entre las unidades de volcanismo Cenozoico de retroacro y del antepaís o Bloque de San Rafael. Las sierras de Palauco, se ubican al noreste del cauce medio del río Grande (Figura 6.2). Están conformadas por un cordón serrano con orientación norte-sur, con frente occidental empinado y oriental más distendido, con alturas de hasta los 2800 msnm (Narciso et al. 2001a). Este cordón es un anticlinal que se continúa hacia el sur en las sierras de Cara Cura 
y de Reyes, y en él afloran formaciones Mesozoicas y Cenozoicas. Su litología está mayoritariamente compuesta por coladas de basalto olivínico (Grupo Palauco, Mioceno medio), pero también se pueden encontrar brechas, aglomerados y tobas. Estas coladas se caracterizan por una textura porfírica formada por fenocristales de feldespatos y mafitos en una pasta traquítica (Santamaría 1997, citado por Narciso et al. 2001a). En los sectores altos de las sierras se observan suelos rojizos y friables del Grupo Neuquén. En el centro este se encuentran basaltos olivínicos, aglomerados y tobas con alto porcentaje de fenocristales (Formación Chapúa). Éstos forman una meseta de 2.000 msnm, alternada por depósitos de gravas, arenas y limos de erosión eólica actual, que separa las sierras de la planicie este. Los basaltos se continúan al sur de Agua Escondida, donde afloran en proximidades de rocas de más antigüedad, correspondientes al Bloque de San Rafael o basamento cristalino.

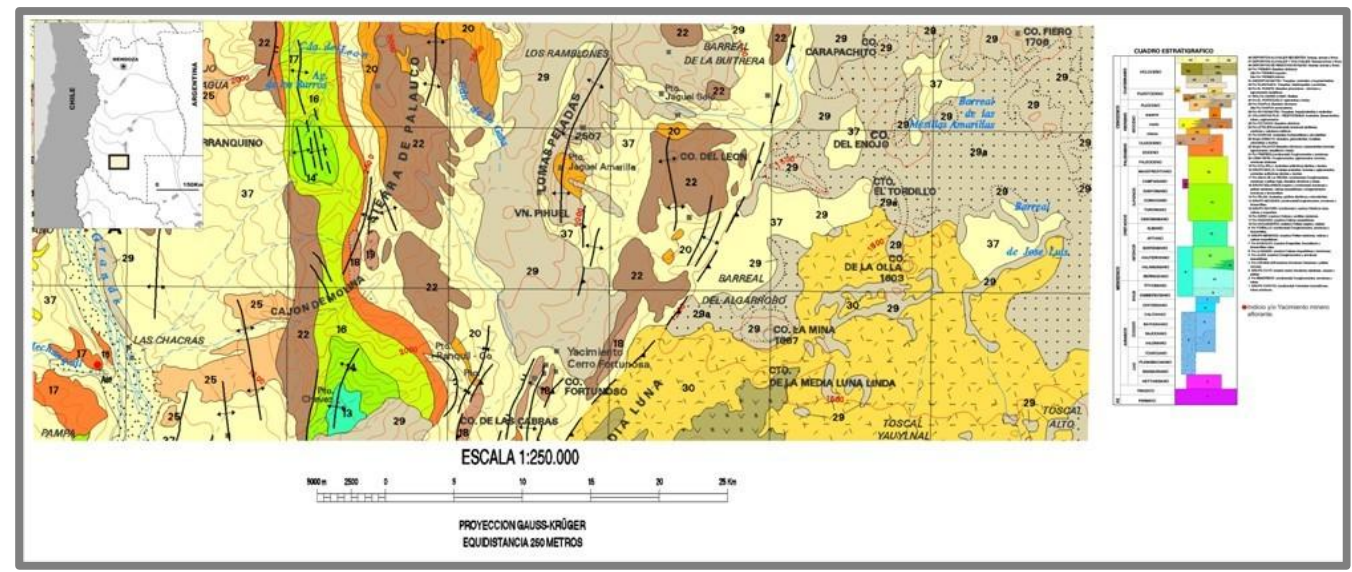

Figura 6.2. Sierras de Palauco (sector norte). Detalle de hoja geológica (Narciso et al. 2001a).

En Agua Escondida, las estructuras que forman el Bloque de San Rafael, presentan mayor diversidad de tipos de rocas, muchas de ellas importantes por sus aptitudes para la talla y para su explotación actual (Figura 6.3). Se destacan afloramientos de granitos, riolitas y dacitas Paleozoicas (en particular Formación Piedras de Afilar, Agua de los Burros y Grupo El Portillo), areniscas con cementación silícea (Formación Agua Escondida), así como de cuarzo hidrotermal y silicificaciones alojadas en rocas del Grupo El Portillo y de la 
formación Choique Mahuida (Narciso et al. 2001a; Rubinstein y Gargiulo 2005). Tanto el granito como el cuarzo hidrotermal son explotados por la industria minera desde la década de 1940, lo que podría haber afectado la persistencia de rastros arqueológicos sobre su explotación prehispánica. En el caso particular de las rocas aptas para la talla, como es el cuarzo, se conocen cuatro canteras de extracción actual ubicadas próximas a la localidad Agua Escondida y asociadas al Grupo El Portillo: Cantera Germán, Tres Alejandro, La Olivia y Piedras Blancas (Narciso et al. 2001a). Las tres primeras se encuentran al norte de Agua Escondida en el límite con el Área El Nevado (sensu Gil 2000). Piedras Blancas se encuentra al suroeste del paraje Agua Escondida. En las últimas décadas, exploraciones mineras documentaron vetas de cuarzo hidrotermal al sureste de Agua Escondida (Área El Nevado) en la zona denominada El Pantanito (Rubinstein y Gargiulo 2005; Gargiulo et al. 2007; Mugas Lobos et al. 2010). Dichas vetas están asociadas a yacimientos de oro diseminado en rocas correspondientes al Bloque de San Rafael, Grupo Choiyoi (Delendatti 2005). La cantera Germán, consiste en un afloramiento de cuarzo de forma irregular, de unos $25 \mathrm{~m}$. de ancho por $30 \mathrm{~m}$. de largo. El cuarzo es lechoso a hialino, con algunos "nidos" de molibdenita. Tres Alejandro es un lentejón aproximadamente 300 m. de longitud y $8 \mathrm{~m}$. de espesor de cuarzo quebradizo color óxido. También se mencionan para el área venillas de cuarzo que contienen fluorita y manganeso, en una roca de caja de composición riolítica. La Olivia, es otra manifestación de cuarzo de $50 \mathrm{~m}$. aproximadamente, con venillas de fluorita, cuarzo en cristales, óxido de hierro y material alterado de arcillas. Por último Piedras Blancas, es un lentejón de cuarzo alojado en riolita alterada. El cuarzo presenta relictos de pórfido alterado y brechado, e inclusiones de pirita, malaquita y azurita, entre otros (Figura 6.4), lo que favorece se presente en una importante variedad de colores, desde el pardo al rojizo. 


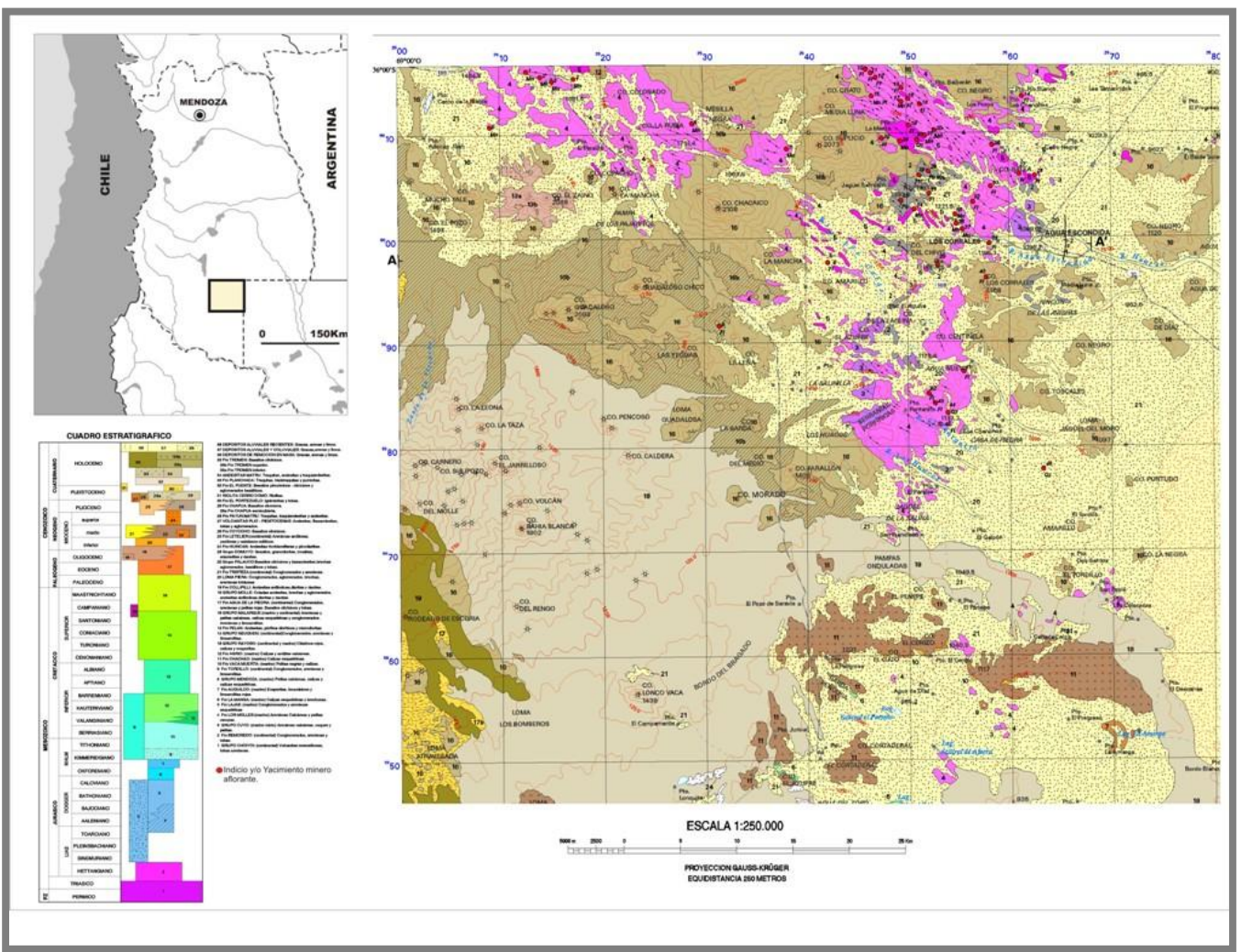

Figura 6.3. Agua Escondida (sector norte). Detalle de la hoja geológica Agua Escondida (Narciso et al. 2001a). En color rosa se destacan las formaciones de roca Paleozoicas; en tonos marrones se representan los basaltos Cuaternarios; y los puntos rojos señalan yacimientos de minerales aflorantes. 


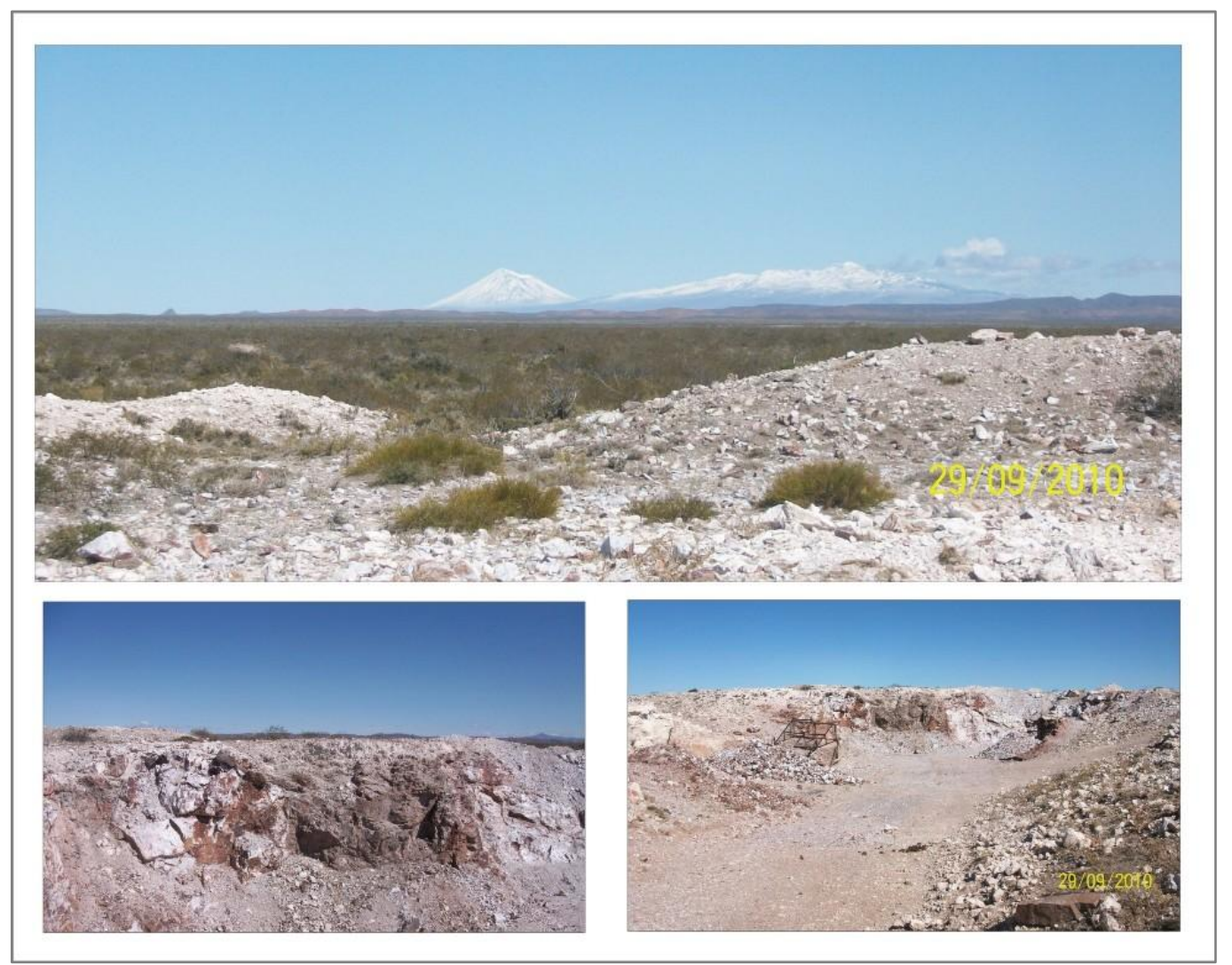

Figura 6.4. Cantera actual de extracción de cuarzo Piedras Blancas, Agua Escondida.

Otra área con disponibilidad de roca silícea es el Cerro El Zaino, ubicado al oeste de Agua Escondida y en el límite este de la Reserva Provincial La Payunia, donde Candía et al. (1993) han documentado nódulos de ágatas. El cerro está conformado por asomos de rocas volcánicas de la formación homónima, compuesta principalmente por andesitas (Narciso et al. 2001b). Gil (2006) documentó filones de rocas silíceas cercanas al puesto La Peligrosa, cerca de la Ruta Provincial N 180, que denominó cantera Piedras Bayas. Piedras Bayas es un afloramiento primario de cuarzo criptocristalino que se presenta a modo de filón y en el cual se observan signos de extracción antrópica. Se encuentran en asomos de basalto del Grupo Palauco. En el área, dichos asomos constituyen lomadas bajas, en los cuales se han localizado recientemente otros filones en Cerro La Leona. Por otra parte, Narciso et al. (2011a) mencionan que desarrollan, en el contacto con los basaltos, un nivel de nódulos silíceos formando lentes de sílice criptocristalina color blanquecino y roja de 
origen diagenético. En esta área hemos ampliado los estudios cuyos resultados serán presentados más adelante.

Sobre esta base, Agua Escondida presenta amplia disponibilidad de rocas silíceas. En su génesis se puede reconocer al menos tres variedades: nódulos silíceos de origen diagenético precipitado en oquedades rocosas, silicificaciones o reemplazos de rocas sedimentarias y las vetas de cuarzo hidrotermal. Es de destacar el hecho de todos los afloramientos de rocas silíceas mencionadas, así como las formaciones potenciales de contenerlas, se encuentran todas en el extremo noreste de la región y se continúa al norte en el Área El Nevado. Continuando hacia el este, estas formaciones se encuentran cubiertas por depósitos aluviales y coluviales actuales (Narciso et al. 2001a) (Figura 6.3).

\subsubsection{SECTOR CENTRAL: CAMPO VOLCÁNICO DE LA PAYUNIA}

Este sector esta compuesto básicamente por el Campo Volcánico de La Payunia. Se caracteriza por un paisaje netamente volcánico, modelado por erupciones efusivas, cuyos

conos basálticos y coladas conforman una vasta llanura denominada Altiplanicie del Payún. Esta llanura posee una altitud aproximada de entre 2.000 y 1.700 msnm, con una leve inclinación en sentido noreste-suroeste, en cuyo paisaje se destacan los volcanes Payún Matrú y Payún Liso. La Altiplanicie está compuesta de basalto olivínico del Grupo Palauco y parcialmente cubierta por ignimbritas y tobas de la formación El Portezuelo. Al pie del volcán Payún Matrú, se encuentran basaltos piroxénico-olivínicos de tipo vesicular y pasta afanítica (Formación El Puente); bordeando la caldera aparecen traquitas, traquibasaltos y obsidiana (Formación La Planchada) correspondiente a los últimos eventos volcánicos de Payún Matrú (Groeber 1937; Narciso et al. 2001a; Llambías 2008) (Figura 6.5). 


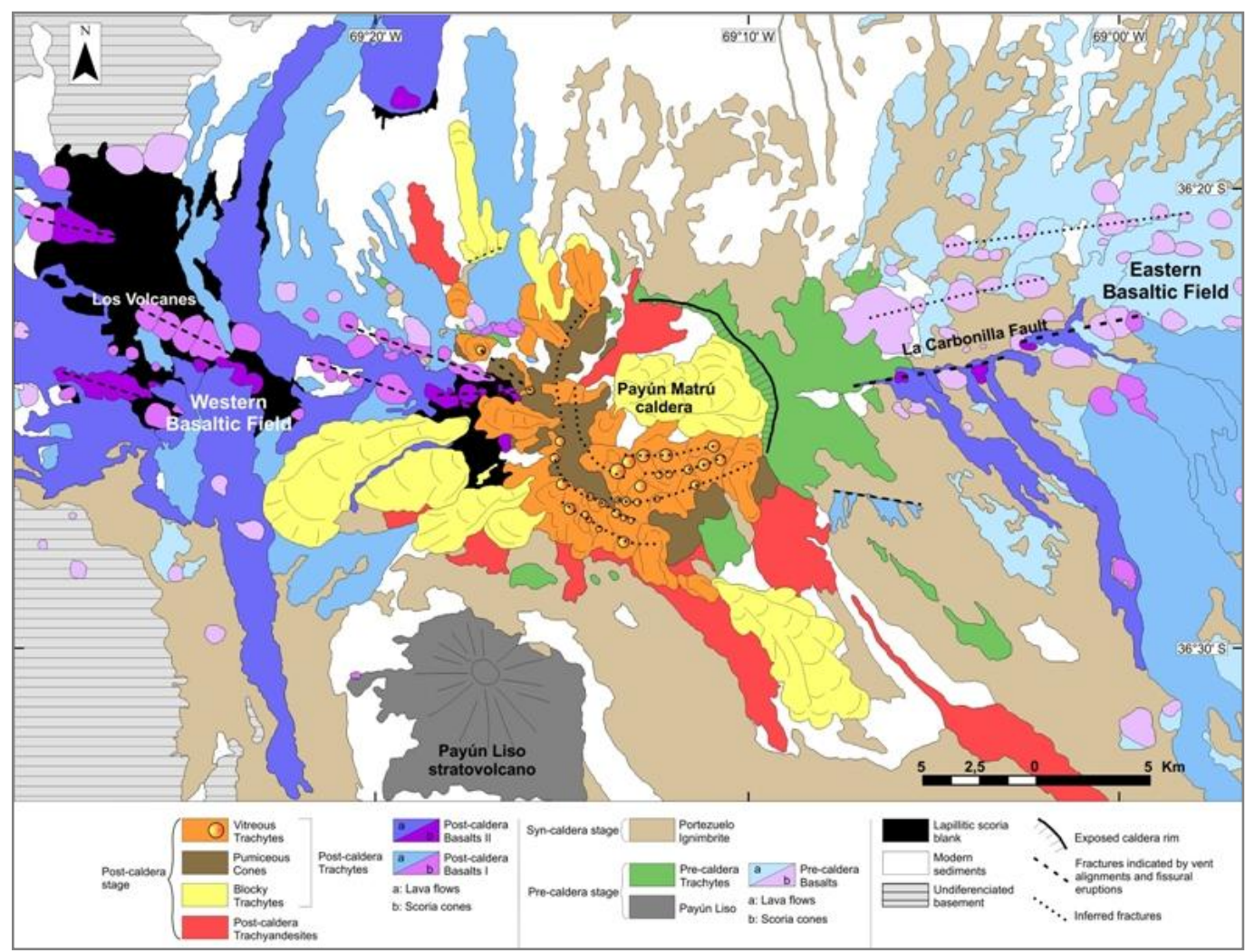

Figura 6.5 Mapa geológico del Campo Volcánico La Payunia. Figura tomada de Hernando et al. (2012).

En Payún Matrú, Llambías (2008) denomina volcanismo central al circunscripto a la actividad del volcán y volcanismo adventicio, al representado por los conos volcánicos basálticos asociados en su gran mayoría a la falla La Carbonilla. Producto del primero resultan las traquitas vítreas, y del volcanismo adventicio las efusiones de basalto olivínico ubicado en el este y oeste del Payún Matrú (figura 6.5). La zona formada por basalto olivínico ubicada al oeste se denomina Los Volcanes y las coladas generadas en este sector llegan hasta el río Grande (Formación Tromen) (Figura 6.6. Dentro del sector de Los Volcanes se encuentra el campo llamado Pampas Negras, debido a la cubierta de lapilli, ceniza basáltica gruesa y bombas basálticas, que abarca una superficie aproximada de 30 $\mathrm{km}^{2}$ (Figura 6.7). Las bombas basálticas son en general de grano muy fino y presentan buenas características para la talla. El volcán Payún Liso comprende principalmente lavas con pequeñas rocas piroclásticas. Las lavas son traquíticas a traquiandesitas (Hernando et 
al. 2012). En prospecciones recientes, se detectó la existencia de bloques de obsidiana en las proximidades del cráter del volcán Payún Liso (36³0'24”'L.S-69¹7'27'"L.O; Figura 6.5; Tucker 2010, comunicación personal). Aunque, cerca de los aparatos volcánicos es factible la formación de cuarzo hidrotermal vinculado a los eventos volcánicos Cenozoicos, aún no han sido documentados afloramientos de este tipo (Figura 6.8). González Díaz (1979) menciona para los pedimentos que descienden de la Altiplanicie hacia el este, en la zona denominada La Matancilla, la presencia de nódulos de sílice criptocristalina asociados con asomos de la Formación Loncoche. El autor sostiene que su origen debe asociarse a fenómenos secundarios conectados con emisiones de basalto, que dieron lugar a la depositación de sílice (González Díaz 1979:28). Gil y Neme (2006) mencionan una amplia disponibilidad de nódulos silíceos, en el área sur-sureste de la Altiplanicie del Payún. La variabilidad de tamaños y frecuencia de hallazgo los lleva a plantear la posibilidad de que existan fuentes de rocas silíceas cercanas. Para los fines de esta tesis, también se ampliaron los muestreos en el área.

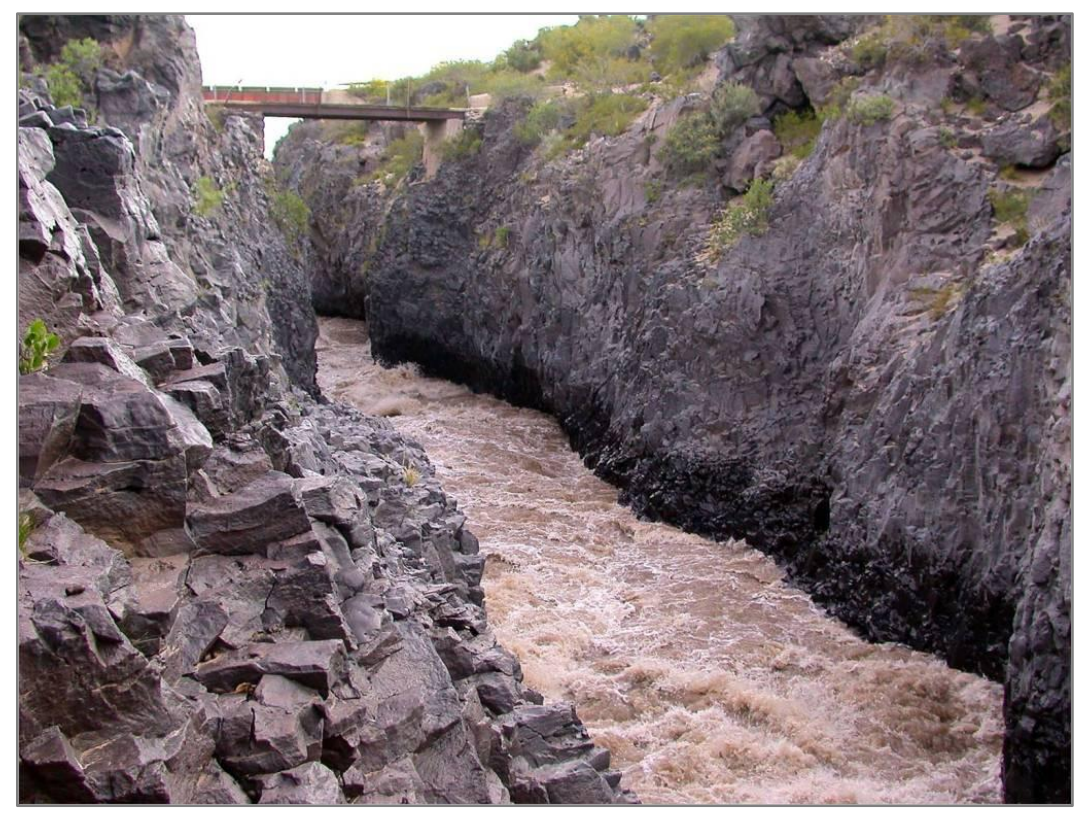

Figura 6.6. Cauce bajo del rio Grande, La Pasarela. 

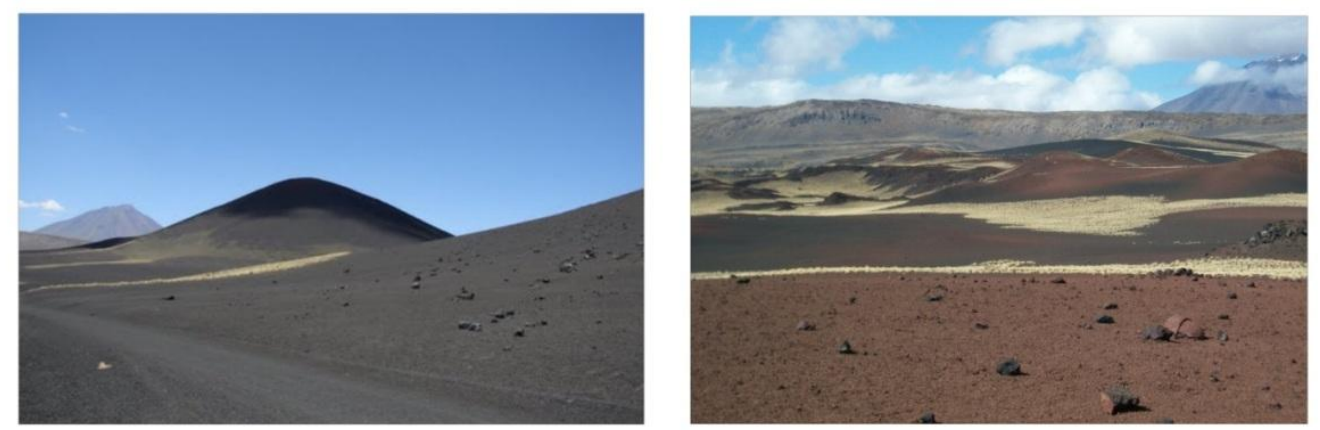

Figura 6.7. Pampas Negras y Los Volcanes, vista oeste (izquierda) y noroeste (derecha). Se observan las bombas de basalto dispersas.

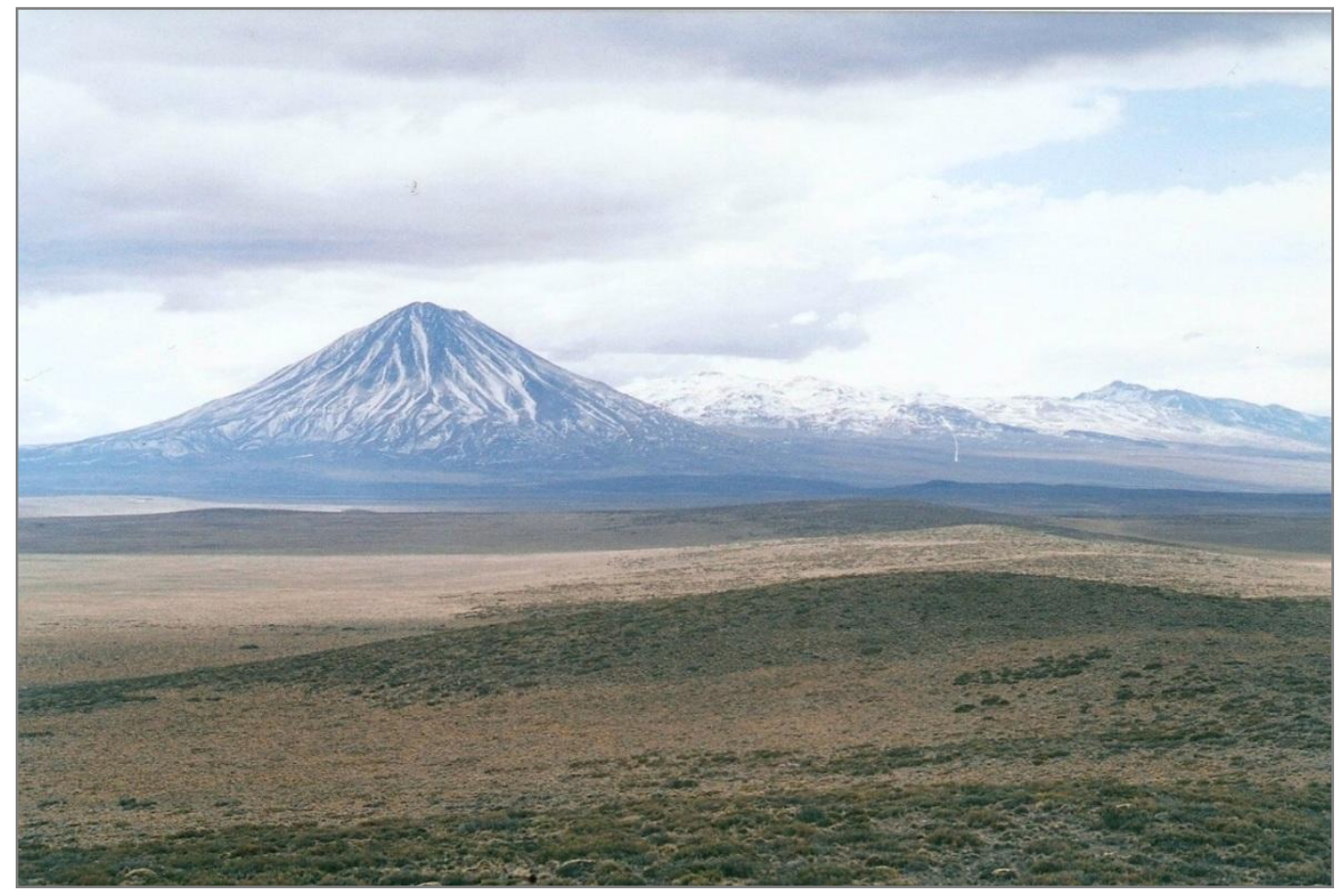

Figura 6.8. Área sureste del Campo Volcánico La Payunia. Se observa la planicie sureste de la Altiplanicie del Payún y se destacan los volcanes Payún Liso (izquierda) y Payún Matrú (derecha).

\subsubsection{SECTOR SUR: SIERRAS CARA CURA Y DE REYES, CAÑADÓN AMARILLO Y SIERRAS DE CHACHAHUÉN}

El sector sur de La Payunia se encuentra al este del río Grande, limitado por el cordón serrano de Cara Cura y de Reyes al oeste y el complejo de volcanes sierras de 
Chachahuén al este. En el área centro-sur se encuentran bajadas de agua temporarias que han socavado cañadones en las rocas y suelos prexistentes con sentido norte-sur. Este área la hemos denominado Cañadón Amarillo, en alusión a uno de los cauces secos. El cordón serrano Cara Cura y de Reyes es un anticlinal de sentido norte-sur, que continúa la alineación de las sierras de Palauco (sector norte) y es interrumpido en el sector central por las coladas basálticas de Los Volcanes. Las sierras se encuentran recortadas por ríos secos que corren en sentido este-oeste y labran pendientes empinadas. El río Seco del empedrado separa las sierras de Cara Cura de la sierra de Reyes, constituyendo un paso natural que conecta el río Grande con el sector sur de La Payunia. La altura del cordón serrano no supera los 2200 msnm, y al igual que en las sierras de Palauco, la inclinación de la pendiente es suave hacia el este y brusca hacia el oeste. En este cordón aflora todo el Mesozoico (Groeber 1933) y al occidente parte del Paleozoico (Figura6.9). Este cordón se conoce como Cordillera del Viento (Groeber 1933), y aún no ha sido explorada en detalle. Groeber $(1933,1947)$ menciona que en las sierras de Cara Cura, en el río seco Agua de la Tosca, se encuentra una capa de 10 a $15 \mathrm{~m}$. de yeso rico en concreciones de calcedonia (Groeber 1947:355). En esta misma sierra pero en la depresión que forma el volcán El Jinete y el río seco del Altar, el autor menciona la presencia de “...conglomerados duros, formados por rodados de tamaño hasta de un puño, de porfiritas y de cuarzo y de bancos de arcilla colorada." (Groeber 1933:16). La existencia de capas antiguas expuestas (Formación Choiyoi, Paleozoica) hacen suponer la presencia de cuarzo hidrotermal, similar al descripto para las mismas formaciones en Agua Escondida (Figura 6.10). 


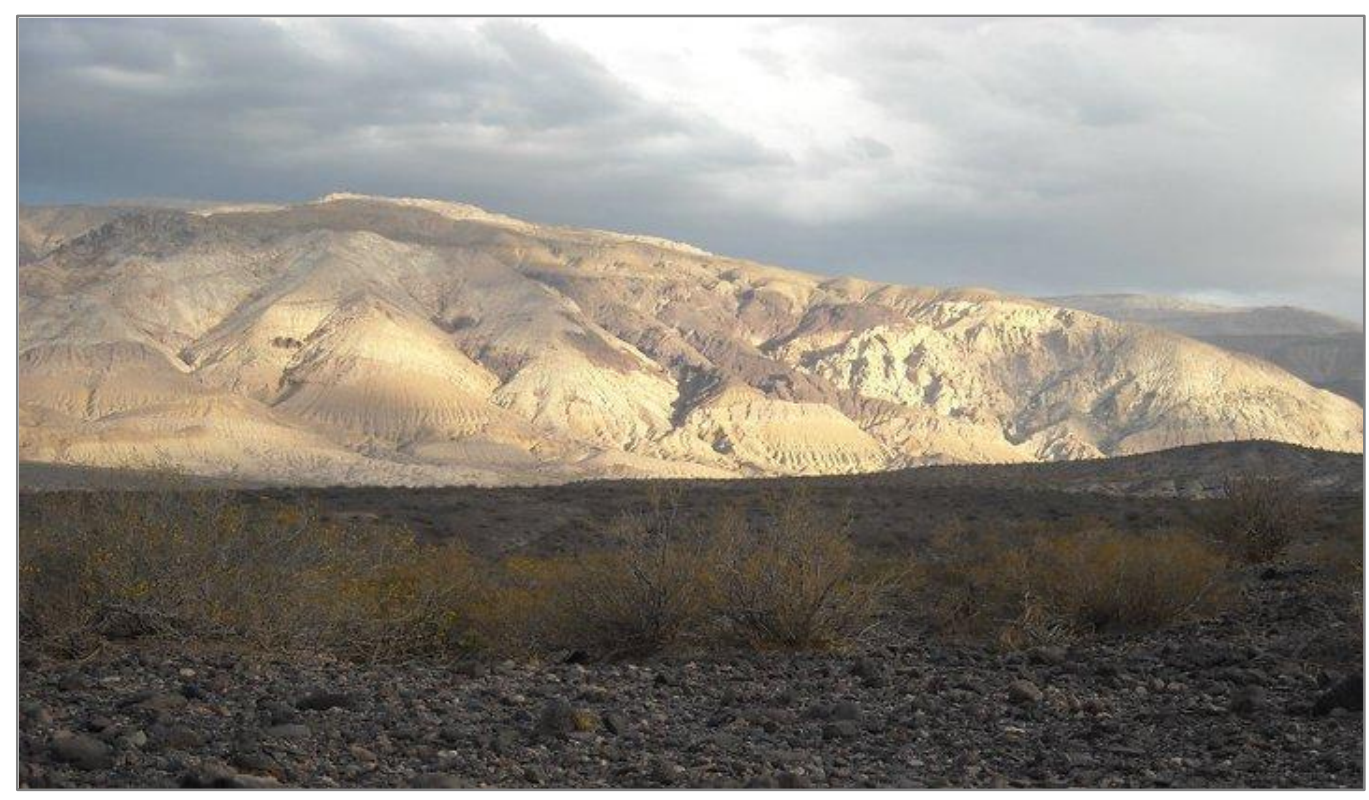

Figura 6.9. Sierra de Reyes, vista desde el este.

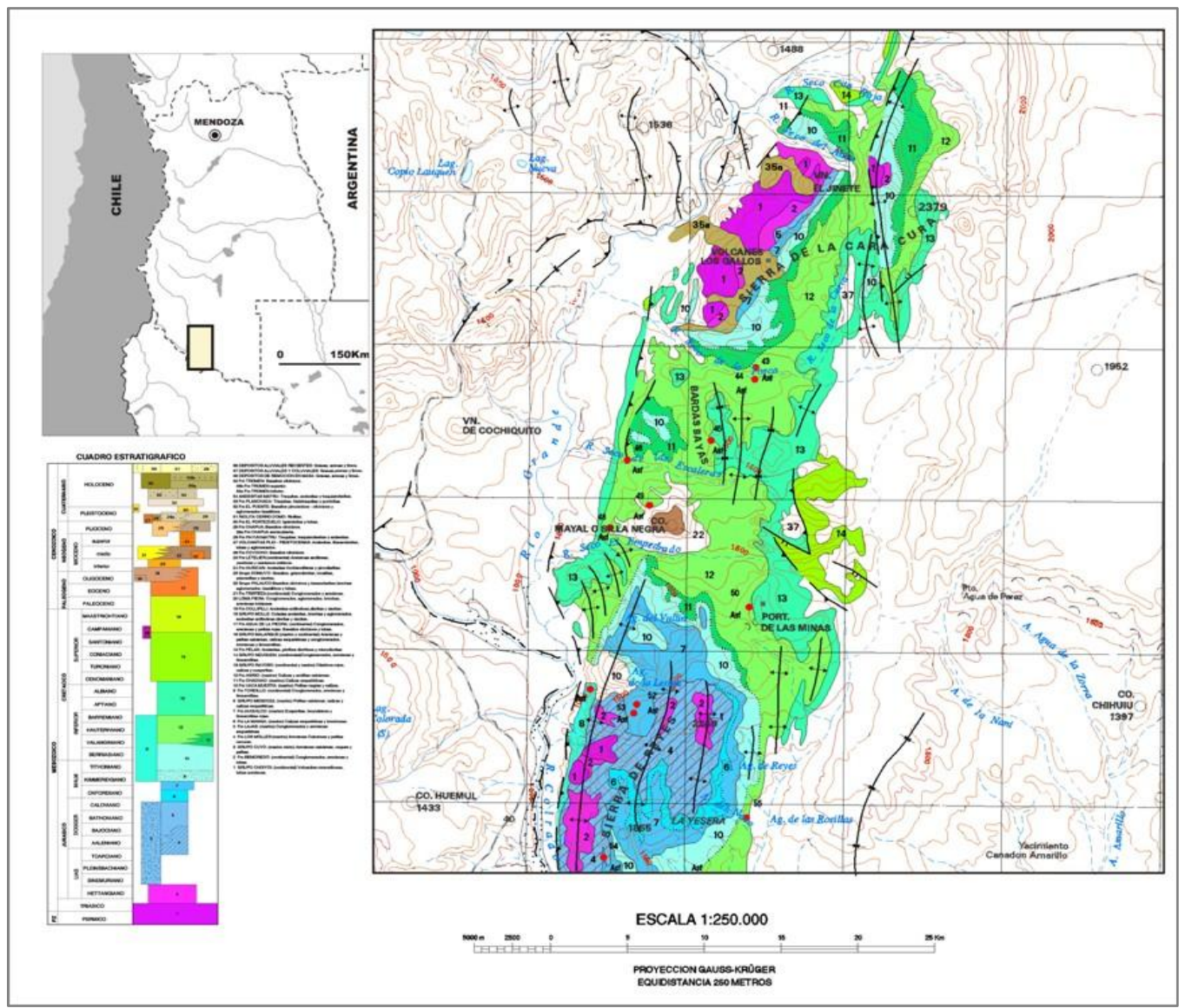

Figura 6.10. Hoja Geológica del área Sierra de Reyes (Narciso et al. 2001b). 
En Cañadón Amarillo, los valles secos de sentido norte-sur están expuestos a la acción de los factores exógenos que facilitan los desplazamientos o remoción en masa (Figura 6.11). Estos generan una amplia rampa irregular de entre 200 y $300 \mathrm{~m}$. de altitud, que dejan expuestas rocas mesozoicas y terciarias. Entre las rocas aflorantes se destacan las areniscas, arcilitas y fangolitas del Grupo Neuquén y las areniscas del Grupo Malargüe. Éstas se encuentran alternadas y en parte sepultadas por gravas y limos modernos. González Díaz (1979) menciona para estas formaciones la presencia de nódulos silíceos, como las localizadas en Agua de Pérez (Salgán y Pérez Winter 2008-09) y Pista (Salgán 2011). La fuente APE-C se encuentra en la geoforma de deslizamientos inactivos de remoción en masa (figura 6.12). Asimismo, a en ambos lados del Cañadón Amarillo se encuentran basaltos olivínicos Terciarios de la Formación Coyocho, expuestos a procesos de deslizamiento o remoción en masa (Capítulo 3). Estos basaltos conforman plataformas elevadas que se destacan en el paisaje, como Loma del Medio y Pampas del Carrizalito.

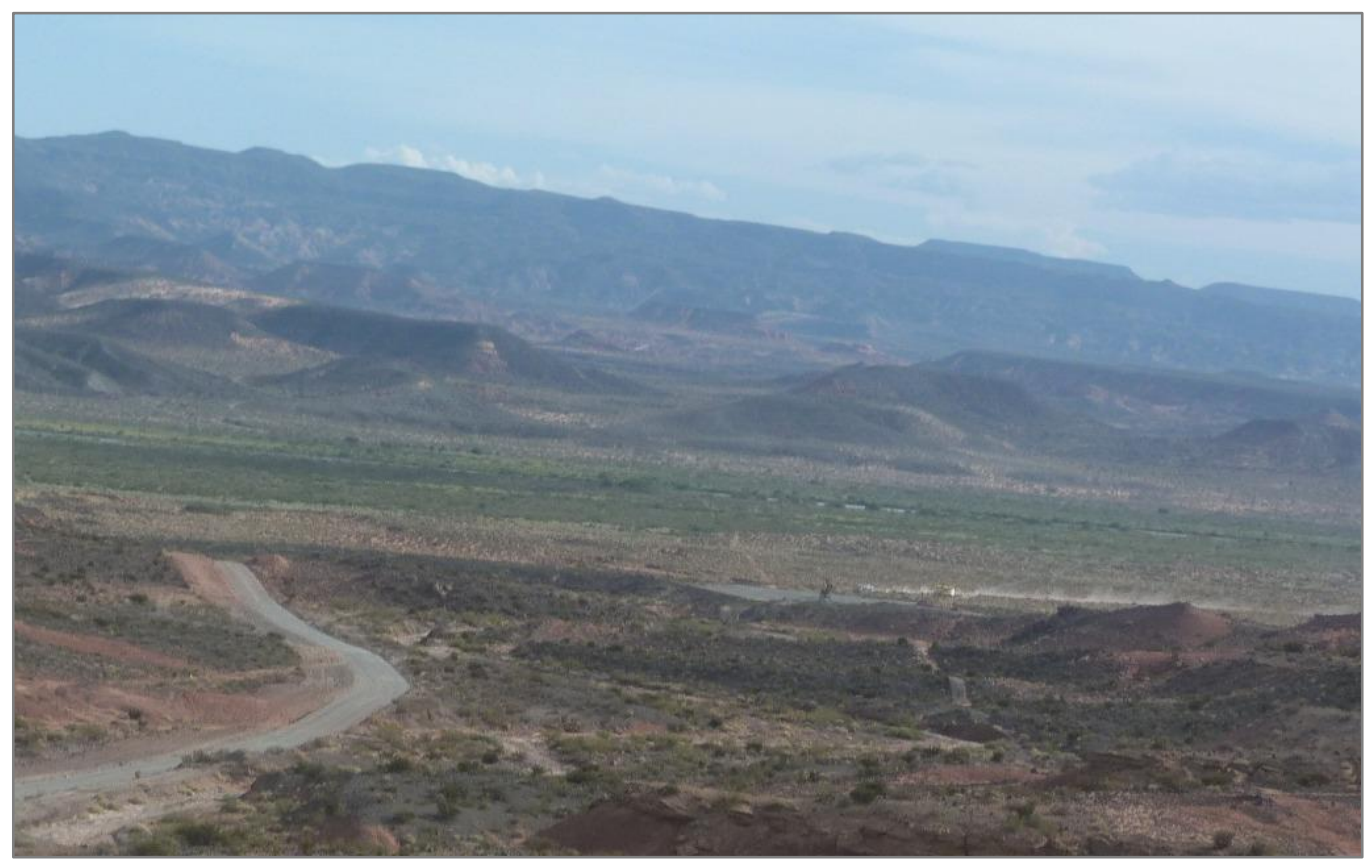

Figura 6.11 Vista de Cañadón Amarillo. 


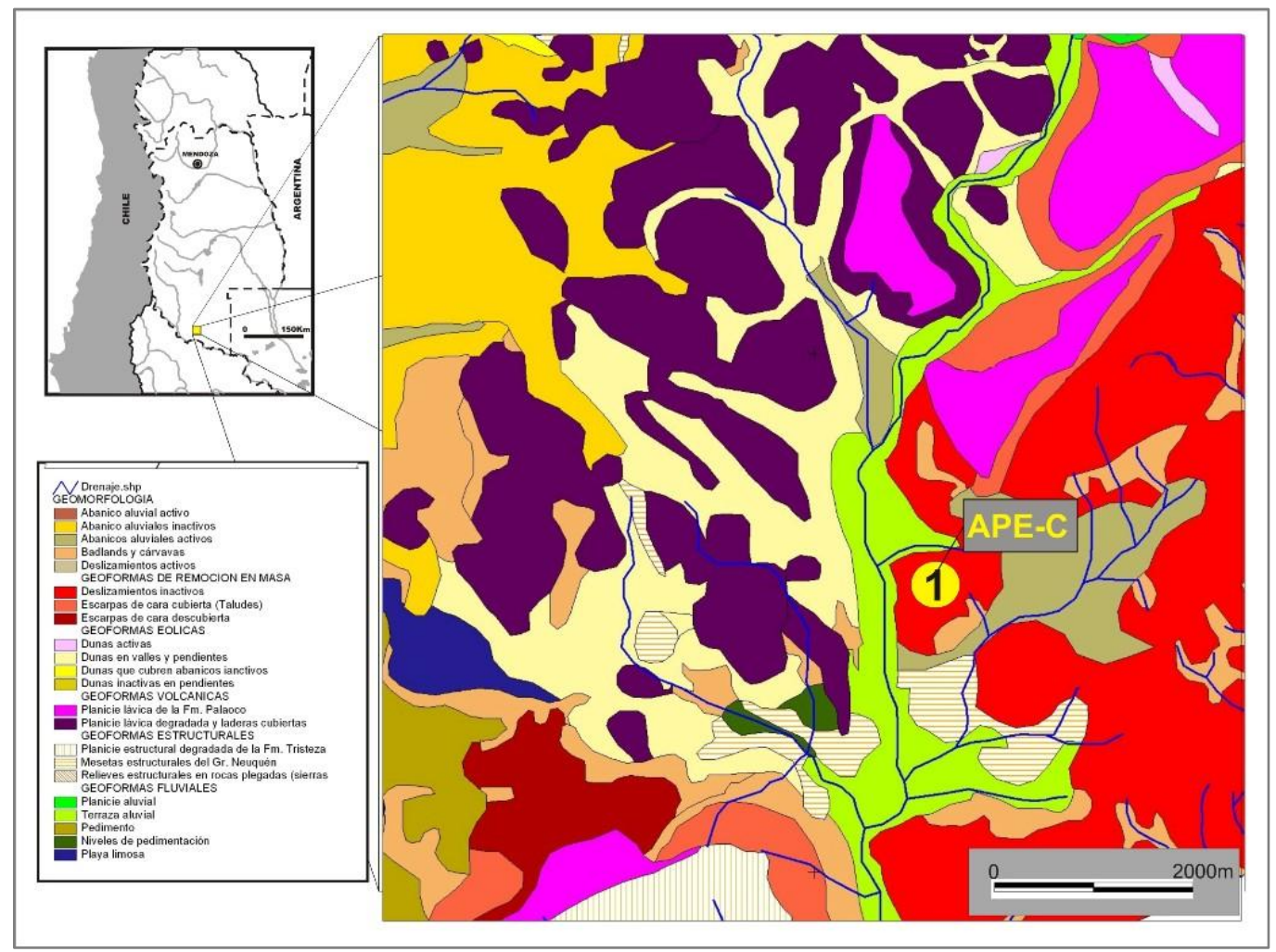

Figura 6.12. Mapa geomorfológico de localidad Agua de Pérez, con el número uno se indica la ubicación de la cantera APE-C (Imagen modificada de PRC 2009).

Las sierras de Chachahuén, ubicadas al sureste de La Payunia, pertenecen a una serie de volcanes y coladas sobreimpuestas, donde se encuentra el volcán homónimo. Corresponden a eventos volcánicos miocénicos, compuestos por andesitas y basaltos de composición intermedia y depósitos aluviales holocénicos (Narciso et al. 2001b; Kay et al. 2004). La andesita es en general de color gris a castaño rojizo y presenta alvéolos que pueden estar cubiertos por calcita. Entre las facies volcánicas se encuentran aglomerados y areniscas volcánicas de color castaño rojizo, factibles de formar silicificaciones. El terreno se encuentra cubierto por depósitos aluviales, que poseen una inclinación gradual de altitud en sentido oeste-este que va de los 1000 a 500 msnm (Figura 6.13). En las sierras hay una mina actual de extracción de cuarzo, y de ágatas (CUEMECO 2010) (Figura 6.14). Cerca del volcán Chachahuén, sobre depósitos de la terraza del río Colorado, se encuentra el volcán Los Loros. Éste presenta una compleja historia eruptiva, pero en su actividad póstuma generó ignimbritas de pequeño volumen y flujos lávicos de traquita 
vítrea (Llambías et al. 2010), que podrían presentar buenas aptitudes para la talla. Otra fuente potencial de aprovisionamiento de basaltos y rocas volcánicas, son los rodados del cauce del río Colorado, en cuya planicie de inundación se observa amplia disponibilidad de nódulos grandes y aptos para la talla (Figura 6.15).

En el sector sur habría recursos líticos aptos para la talla en los tres subsectores del paisaje o geoformas diferenciadas. En las sierras de Reyes y Cara Cura los nódulos silíceos localizados en los cauces secos de Agua de la Tosca, cerro El Jinete y en río Seco del Altar, expuestos por meteorización de la roca encajante y transportados en épocas de lluvia. En Cañadón Amarillo, se esperan encontrar nódulos silíceos, asociado a asomos mesozoicos expuestos por procesos de remoción en masa, así como formaciones de sílice diagenético. Asimismo en las sierras de Chachahuén, también se esperan encontrar nódulos silíceos de origen diagenético y silicificaciones o reemplazos de rocas, como los anteriormente mencionados.

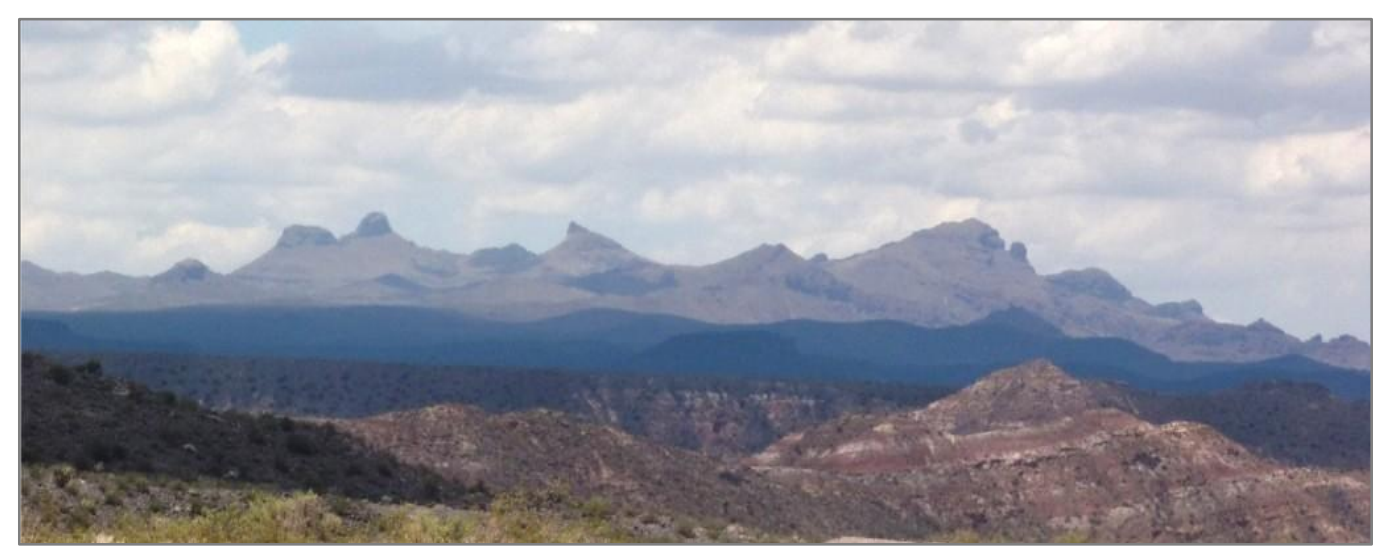

Figura 6.13. Sierras de Chachahuén, vista desde Cañadón Amarillo. 


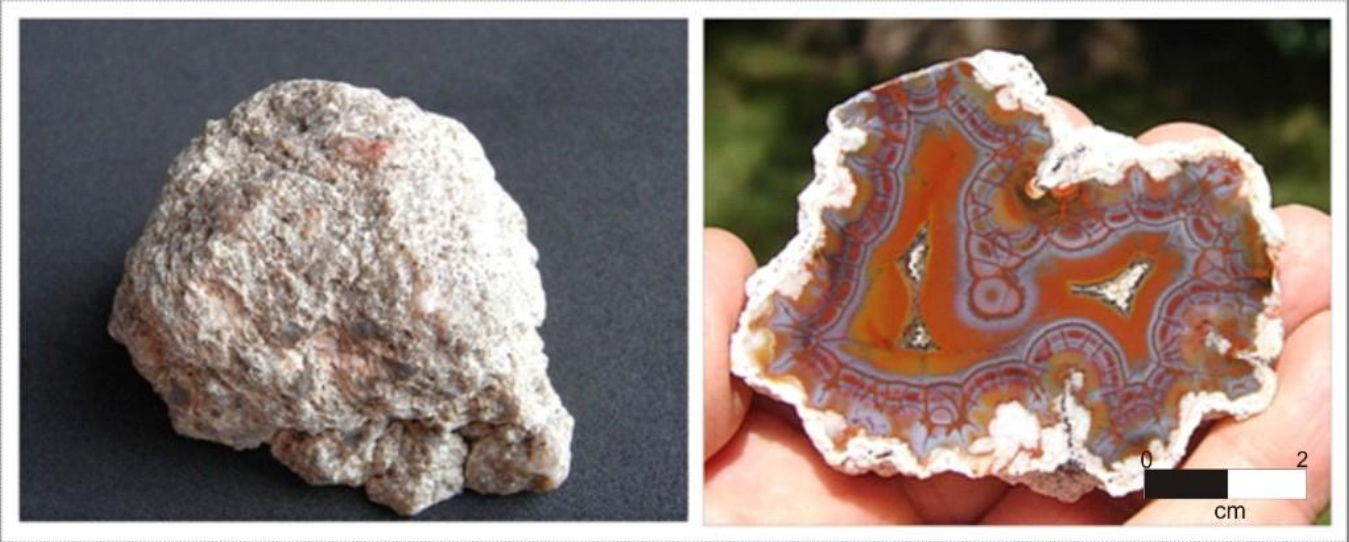

Figura 6.14. Nódulos de ágata de canteras actuales en sierra de Chachahuén (CUEMECO 2009).

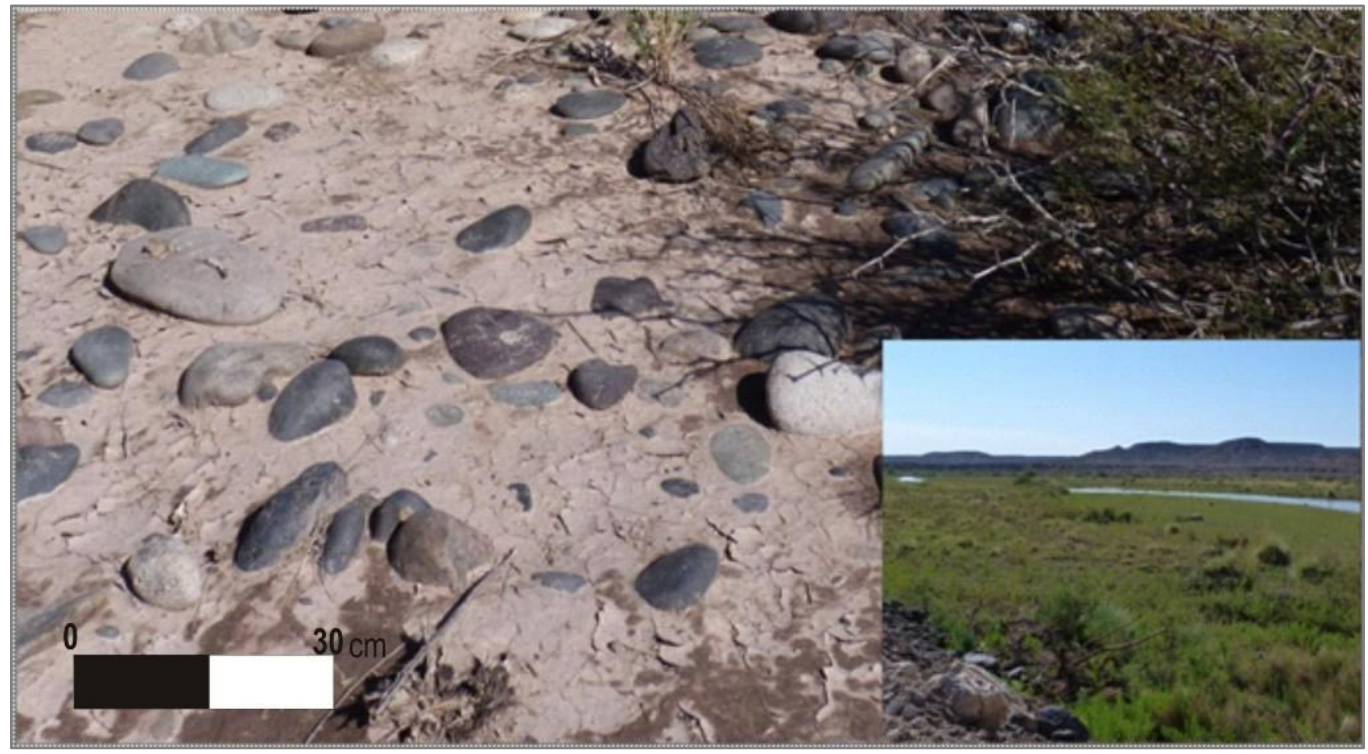

Figura 6.15. Rodados de basalto y otras rocas ígneas en el río Colorado.

\subsection{RECURSOS LÍTICOS EN LA PAYUNIA}

En las distintas geoformas se espera encontrar rocas aptas para la talla en La Payunia, asociadas a determinadas unidades geológicas. En Agua Escondida, encontramos rocas Paleozoicas (Grupo Choiyoi, Grupo El Portillo) en las que son frecuentes las vetas hidrotermales (Narciso et al. 2001b). En asomos del Mioceno-Plioceno (Grupo Palauco y 
Formación El Zaino) se localizaron afloramientos de rocas silíceas cuya génesis parece estar asociada a procesos de silicificación de rocas previas y precipitación química de sílice en nódulos. En la Altiplanicie del Payún, el volcanismo de retroarco forma un amplio manto que recubre el terreno, cuyas rocas no presentan en general buenas aptitudes para la talla. Por último en el sector sur, es posible encontrar rocas silíceas en los tres paisajes diferenciados (sierras Cara-Cura y de Reyes, Cañadón Amarillo y sierras de Chachahuén).

En Agua Escondida y en el Sector Sur es alta la probabilidad de ocurrencia de rocas silíceas, que pueden presentarse como chert (silicificación de capas o nódulos sedimentarios) o como vetas de cuarzo hidrotermal, asociados con antiguos eventos volcánicos. En Sector Central, la Altiplanicie del Payún hay traquitas vítreas (obsidiana) con muchas impurezas asociadas a los estratovolcanes (Llambías et al. 2010; Ramos y Folguera 2011; Hernando et al. 2012). Los basaltos, presentan en general mala calidad para la talla, con excepción de las bombas basálticas del área Los Volcanes. Las rocas silíceas, son frecuentes en el área sureste en el borde de degradación de meseta, en forma de nódulos asociados a formaciones Mesozoicas, expuestos por meteorización y eventos de remoción en masa. Sin embargo, hay que destacar no se conocen áreas de disponibilidad concentrada como las mencionadas para el Sector Norte.

En la tabla 6.1 se resumen las expectativas de rocas con aptitudes para la talla, para cada sector. Se detalla el tipo de materia prima, el relieve y la unidad geológica, en los casos en que dicha información se encontraba disponible. Con esta información de base se llevó a cabo un mapa que destaca áreas potenciales de hallazgo (Figura 6.16). 


\begin{tabular}{|c|c|c|c|c|c|c|c|}
\hline $\begin{array}{l}\text { 응 } \\
\text { ㅆّㅇ }\end{array}$ & ÁREA & $\begin{array}{c}\text { FUENTES/ } \\
\text { ÁREA }\end{array}$ & $\begin{array}{l}\text { MATERIA } \\
\text { PRIMA }\end{array}$ & $\begin{array}{c}\text { UNIDAD } \\
\text { GEOLÓGICA }\end{array}$ & LITOLOGÍA & EDAD & REFERENCIAS \\
\hline \multirow{5}{*}{$\begin{array}{l}\text { 山्, } \\
\text { ợ } \\
\text { 을 }\end{array}$} & \multirow{5}{*}{$\begin{array}{c}\text { AGUA } \\
\text { ESCONDIDA }\end{array}$} & $\begin{array}{c}\text { El Zaino-Mucho } \\
\text { Vale }\end{array}$ & Ágata & $\begin{array}{c}\text { Formación El } \\
\text { Zaino }\end{array}$ & Andesita & $\begin{array}{c}\text { Plioceno } \\
\text { (Cenozoico, } \\
\text { Terciario) }\end{array}$ & $\begin{array}{l}\text { Candia et al. 1993; } \\
\text { Narciso et al. 2001a }\end{array}$ \\
\hline & & Piedras Bayas & $\begin{array}{l}\text { Cuarzo } \\
\text { criptocrista- } \\
\text { lino, } \\
\text { cristalino y } \\
\text { ópalo }\end{array}$ & $\begin{array}{c}\text { Formación } \\
\text { Loncoche/ } \\
\text { Grupo Palauco }\end{array}$ & $\begin{array}{l}\text { Areniscas, calizas } \\
\text { y pelitas /Basalto } \\
\text { olivínico. }\end{array}$ & $\begin{array}{c}\text { Cretácico } \\
\text { Superior; } \\
\text { Mioceno } \\
\text { (Mesozoico / } \\
\text { Cenozoico, } \\
\text { Terciario) }\end{array}$ & $\begin{array}{l}\text { Gil 2002, 2006; } \\
\text { Narciso et al. 2001a }\end{array}$ \\
\hline & & La Leona & $\begin{array}{l}\text { Cuarzo } \\
\text { criptocrista- } \\
\text { lino y } \\
\text { cristalino }\end{array}$ & $\begin{array}{c}\text { Formación } \\
\text { Loncoche/ } \\
\text { Grupo Palauco }\end{array}$ & $\begin{array}{l}\text { Areniscas, calizas } \\
\text { y pelitas / Basalto } \\
\text { olivínico, tobas, } \\
\text { Conglomerados }\end{array}$ & $\begin{array}{c}\text { Mio-Plioceno } \\
\text { (Cenozoico, } \\
\text { Terciario) }\end{array}$ & $\begin{array}{l}\text { Gil 2002, 2006; } \\
\text { Narciso et al. 2001a }\end{array}$ \\
\hline & & Minas de cuarzo & Cuarzo & $\begin{array}{l}\text { Grupo Choiyoi / } \\
\text { El Portillo }\end{array}$ & $\begin{array}{l}\text { Intrusivos } \\
\text { graníticos y } \\
\text { riolíticos }\end{array}$ & $\begin{array}{l}\text { Paleozoico, } \\
\text { Permo- } \\
\text { Triasico }\end{array}$ & Narciso et al. 2001a \\
\hline & & Piedras Blancas & Cuarzo & $\begin{array}{c}\text { Grupo Choiyoi / } \\
\text { El Portillo }\end{array}$ & Riolita alterada & $\begin{array}{l}\text { Permo- } \\
\text { Triásico }\end{array}$ & Narciso et al. 2001a \\
\hline \multirow{4}{*}{ 崖 } & \multirow{4}{*}{$\begin{array}{l}\text { ALTIPLANICIE } \\
\text { DEL PAYÚN }\end{array}$} & $\begin{array}{c}{ }^{*} \text { Caldera Payún } \\
\text { Matrú }\end{array}$ & $\begin{array}{l}\text { Traquita } \\
\text { vitrea }\end{array}$ & $\begin{array}{l}\text { Unidades post- } \\
\text { caldera }\end{array}$ & Traquita vítrea & $\begin{array}{c}\text { Pleistoceno } \\
\text { sup-Holoceno } \\
\text { temprano } \\
\text { (Cenozoico, } \\
\text { Cuaternario) }\end{array}$ & $\begin{array}{l}\text { Llambías 2008; } \\
2009\end{array}$ \\
\hline & & $\begin{array}{l}\text { *Cráter Payún } \\
\text { Liso }\end{array}$ & $\begin{array}{l}\text { Traquita } \\
\text { vitrea }\end{array}$ & No determinado & Traquita & 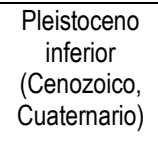 & $\begin{array}{c}\text { Narciso et al. } \\
\text { 2001a; Llambías et } \\
\text { al. } 2010\end{array}$ \\
\hline & & *Los Volcanes & Basalto & $\begin{array}{l}\text { Formación } \\
\text { Tromen }\end{array}$ & Basalto olivínico & $\begin{array}{c}\text { Holoceno } \\
\text { temprano } \\
\text { (Cenozoico, } \\
\text { Cuaternario) }\end{array}$ & $\begin{array}{c}\text { Narciso et al. } \\
\text { 2001a; Llambías et } \\
\text { al. } 2010\end{array}$ \\
\hline & & La Matancilla & $\begin{array}{l}\text { Nódulos } \\
\text { silíceos }\end{array}$ & $\begin{array}{c}\text { Grupo Neuquén } \\
\text { y Grupo } \\
\text { Malargüe }\end{array}$ & $\begin{array}{c}\text { Conglomerados, } \\
\text { areniscas y } \\
\text { limoarcilitas }\end{array}$ & $\begin{array}{c}\text { Cretácico } \\
\text { Superior } \\
\text { (Mesozoico) }\end{array}$ & $\begin{array}{c}\text { González Díaz } \\
\text { (1979) }\end{array}$ \\
\hline \multirow{6}{*}{ 号 } & \multirow{2}{*}{$\begin{array}{l}\text { SIERRA CARA } \\
\text { CURA Y REYES }\end{array}$} & ${ }^{*}$ Agua del Altar & Cuarzo & No determinado & No determinado & $\begin{array}{c}\text { No } \\
\text { determinado }\end{array}$ & Groeber 1947 \\
\hline & & $\begin{array}{c}\text { *Agua de la } \\
\text { Tosca }\end{array}$ & Cuarzo & No determinado & No determinado & $\begin{array}{c}\text { No } \\
\text { determinado }\end{array}$ & Groeber 1933 \\
\hline & \multirow{3}{*}{$\begin{array}{l}\text { CAÑADON } \\
\text { AMARILLO }\end{array}$} & \multirow{2}{*}{ Agua de Pérez } & \multirow{2}{*}{$\begin{array}{l}\text { Cuarzo } \\
\text { criptocrista- } \\
\text { lino y } \\
\text { cristalino }\end{array}$} & $\begin{array}{c}\text { Formación } \\
\text { Coyocho }\end{array}$ & Basalto Olivínico & $\begin{array}{c}\text { Plioceno } \\
\text { (Cenozoico, } \\
\text { Terciario) }\end{array}$ & Narciso et al. 2001b \\
\hline & & & & Grupo Neuquén & $\begin{array}{l}\text { Conglomerados, } \\
\text { areniscas y } \\
\text { limoarcilitas }\end{array}$ & $\begin{array}{c}\text { Cretácico } \\
\text { superior } \\
\text { (Mesozoico) }\end{array}$ & Narciso et al. 2001b \\
\hline & & Pista & $\begin{array}{l}\text { Cuarzo } \\
\text { criptocrista- } \\
\text { lino y } \\
\text { cristalino }\end{array}$ & $\begin{array}{l}\text { Amígdalas en } \\
\text { basalto }\end{array}$ & No determinado & $\begin{array}{c}\text { No } \\
\text { determinado }\end{array}$ & $\begin{array}{l}\text { Gil y Neme 2010?; } \\
\text { Salgán } 2011\end{array}$ \\
\hline & CHACHAHUÉN & $\begin{array}{l}\text { Sierras de } \\
\text { Chachahuén }\end{array}$ & $\begin{array}{l}\text { Ágatas y } \\
\text { cuarzo }\end{array}$ & $\begin{array}{l}\text { Formación } \\
\text { Chachahuén }\end{array}$ & $\begin{array}{c}\text { Andesitas } \\
\text { hornblendiferas y } \\
\text { basaltos }\end{array}$ & $\begin{array}{l}\text { Plioceno } \\
\text { (Cenozoico, } \\
\text { Terciario) }\end{array}$ & $\begin{array}{c}\text { Narciso et al. } \\
2001 \mathrm{~b} ; \text { Linares et al. } \\
2010\end{array}$ \\
\hline
\end{tabular}


Tabla 6.1. Expectativas de materias primas en cada sector. La litología y la edad se refiere a las rocas que contienen a la materia prima silícea o venillas silíceas. $\left({ }^{*}\right)$ Fuentes potenciales. En negrita se señalan las fuentes conocidas.

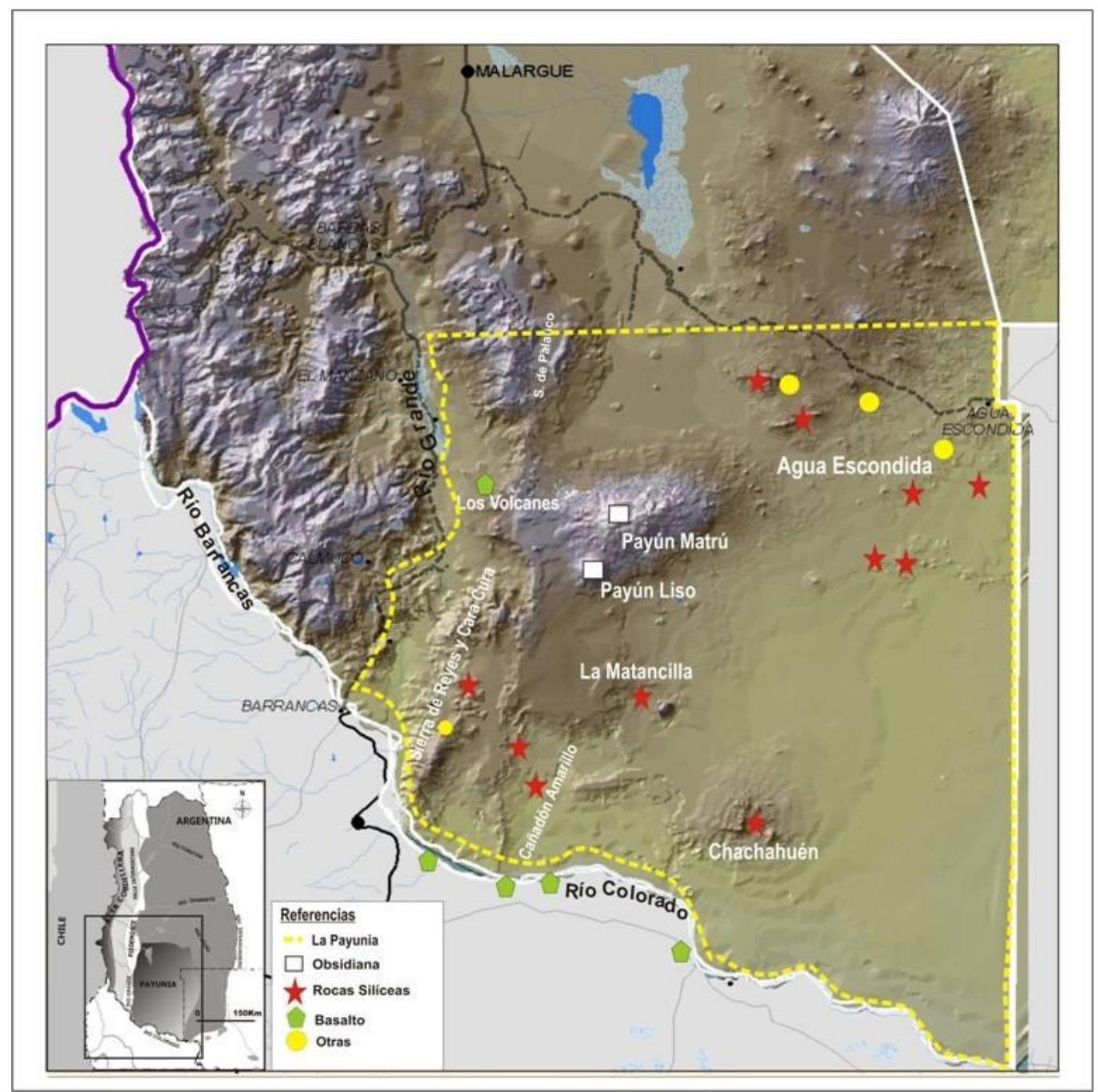

Figura 6.16. Distribución de rocas con aptitudes para la talla.

\subsubsection{FUENTES SILÍCEAS}

En las cinco localidades arqueológicas analizadas, se detectaron fuentes primarias de roca silícea (Capítulo 7). En LP (Piedras Bayas y La Leona) y en APE (Agua de PérezCantera), las fuentes primarias de roca silícea se presentan como afloramientos 
dispuestos en forma de filón de superficie variable y distribución espacial concentrada. En CAR (PISTA), ALPA y RC, hay disponibilidad de nódulos silíceos de distribución dispersa (Pista) y aislada (ALPA y RC), sin estar incluidos en ninguna unidad. La génesis de los nódulos puede estar asociada a la formación de acreciones en oquedades y grietas, y por el momento son consideradas potenciales, dada la ausencia de estudios sistemático que permitan sostener que los mismos habrían sido utilizados.

\subsection{1a AGUA ESCONDIDA (SECTOR NORTE): LOCALIDAD LA PELIGROSA (LP)}

En la localidad LP, para la que ya se conocía la existencia de la fuente primaria Piedras Bayas (PB), se llevaron a cabo muestreos en otros puntos. Se realizaron dos prospecciones, una en dirección oeste hacia el cerro La Leona (LLE) y otra en dirección este, denominada La Peligrosa Transecta 2 (LPT2) (Capítulo VI.1). En el relevamiento se detectó un afloramiento en el cerro La Leona, distante entre 3 y 4 km de PB.

PB es un afloramiento subcircular en planta de unos $3200 \mathrm{~m}^{2}$ primario de una roca completamente silicificada dispuesta en forma de filón, en el que se observan signos de extracción antrópica (Gil 2000, 2006). Los muestreos recientes permitieron determinar que los estratos que contienen rocas silíceas se encuentran en asomos de basalto del Grupo Palauco. Estos asomos constituyen una serie de lomadas de escasa altitud (entre 200 y 250 m.), que se continúan en el cerro La Leona. Narciso et al. (2011a) menciona que en el contacto de los basaltos Palauco con rocas sedimentarias de la formación Loncoche se desarrolla un nivel de nódulos silíceos, que forman lentes de sílice criptocristalina de color blanquecino y rojo, de origen diagenético. En los relevamientos se observó que la roca silicificada presenta oquedades subesféricas a irregulares de hasta $2 \mathrm{~cm}$, parcialmente rellenas con calcedonia bandeada y cuarzo cristalino hacia el centro (Figura 6.17). La roca silicificada presenta fracturas rellenas con una brecha formada por ópalo negro y clastos de la roca silicificada. En algunos sectores el ópalo es rojo a rosado. Las 
fracturas superan los $28 \mathrm{~m}$ de longitud y $30 \mathrm{~m}$ ancho. El diseño de las fracturas es irregular, con variaciones en la orientación, en algunos casos tortuoso (Figura 6.18).

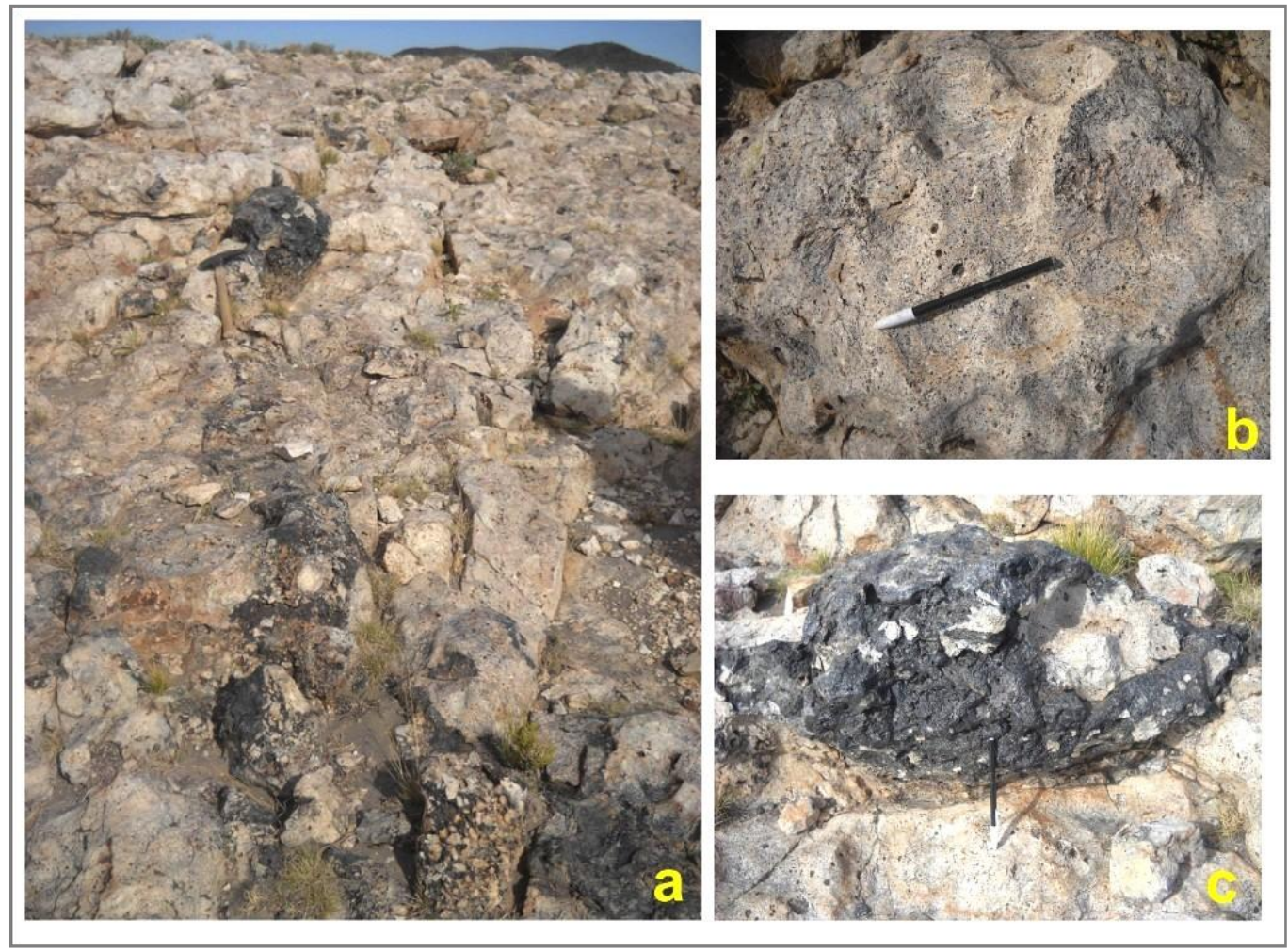

Figura 6.17. Cantera Piedras Bayas. (a) Fractura con oquedades; (b) alteraciones de la corteza; (c) ópalo negro.

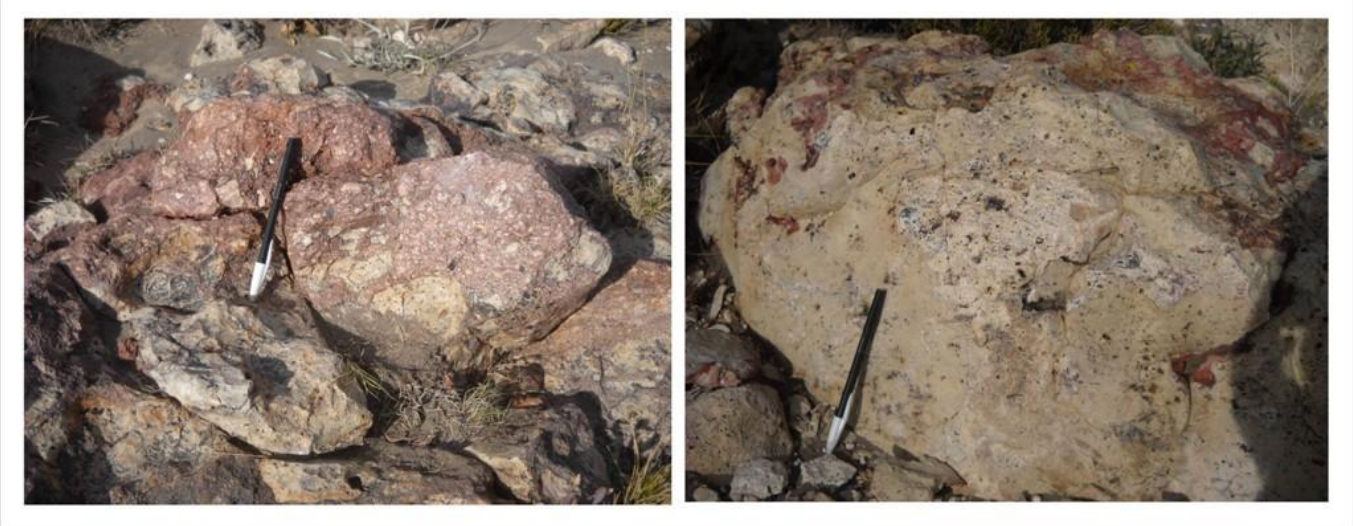

Figura 6.18. Rocas silíceas en Piedras Bayas. Derecha: fractura rellena con ópalo rojo y clastos; Izquierda: variante de la anterior con matriz de roca silicificada color pardo. 
La fuente LLE es de menores dimensiones que Piedras Bayas. Se presenta a modo de filón continuo, es de color pardo, marrón y negro, sin oquedades en superficie y matriz cristalina homogénea (Figura 6.19). La matriz de roca se encuentra reemplazada principalmente por ópalo con presencia de minerales opacos y en algunos casos venillas de calcedonia. En un primer abordaje, las diferencias en color, homogeneidad de la matriz y dimensiones del afloramiento, nos llevó a pensar que respondían a una génesis diferencial.

En ambas fuentes de roca silícea se tomaron muestras de mano, que fueron procesadas por el Dr. Walter Bertotto en el Laboratorio de Geología de la Universidad de La Pampa. Las muestras fueron seleccionadas de modo tal que sean representativas de las diferencias macroscópicas observadas (color, brillo, textura, homogeneidad de la pasta). En Piedras Bayas se seleccionaron 10 muestras y en La Leona 6 (Anexo 1). 


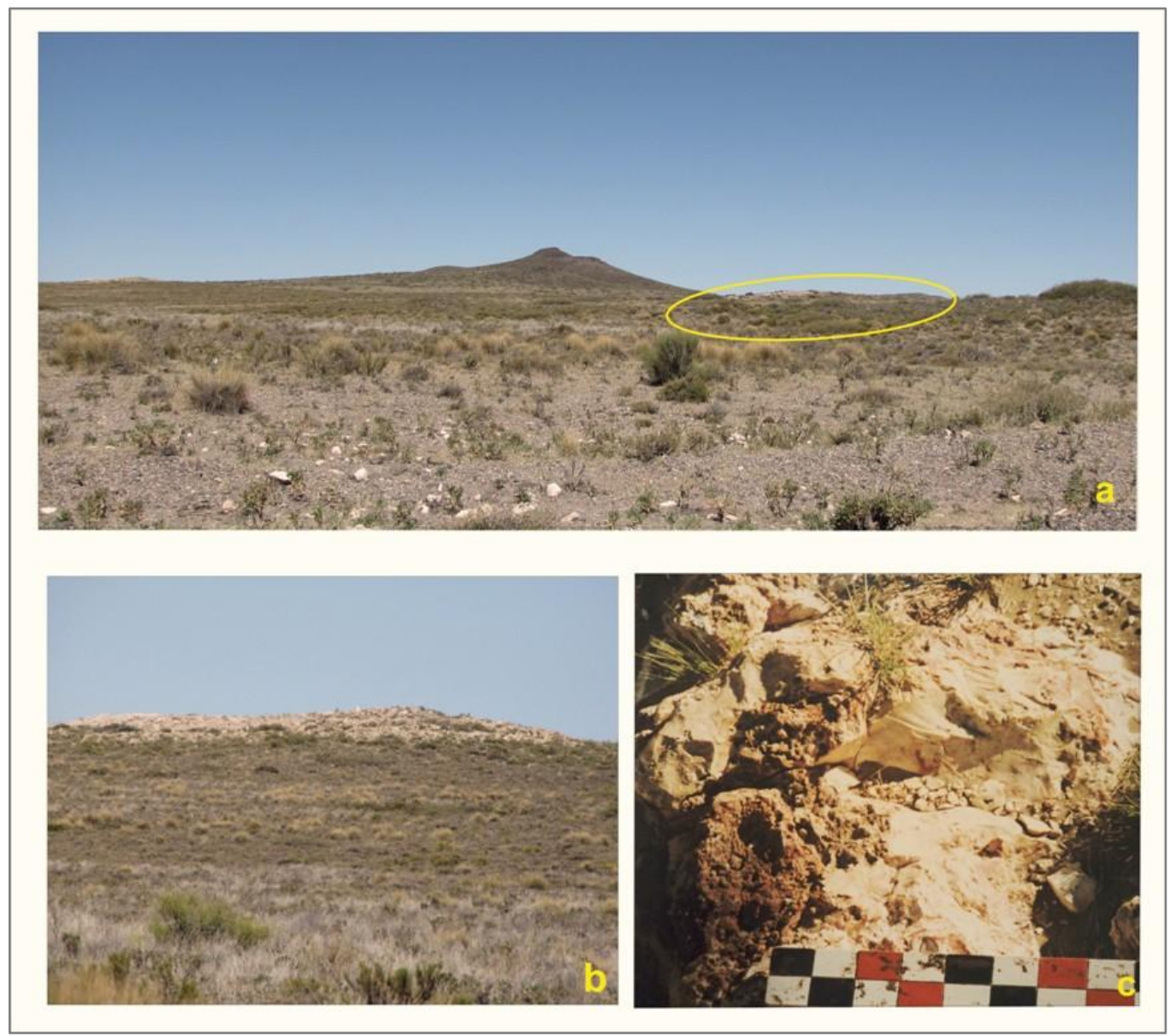

Figura 6.19. Vista del afloramiento La Leona (a). Se destaca el filón expuesto (b) y sectores canteados por talla antrópica (c).

\subsection{1a.1 Análisis petrográfico en PB y LLE}

Los estudios petrográficos se realizaron en dos etapas. En la primera se realizó una descripción macroscópica de las muestras y en la segunda se seleccionaron algunas muestras para ser procesadas y caracterizadas por microscopía de polarización. El objetivo en todos los casos fue caracterizar las fuentes a fin de determinar la procedencia de las materias primas de los artefactos. En La Peligrosa, ambas fuentes fueron caracterizadas como rocas silicificadas, cuya génesis se vincula al remplazo de rocas prexistentes. En PB (muestras LP12 a LP21) se trata de roca silicificada con textura de brecha (clastos y cemento) (Figura 6.20). Los clastos son de ópalo o remplazados por ópalo y cemento de 
calcedonia (cuarzo microcristalino). La calcedonia adquiere en algunos sectores textura fibrosa y costriforme. Además se observan cavidades sub-circulares a irregulares rellenas por calcedonia y cuarzo.

LLE (muestras LP6 a LP11) fue caracterizada como una cantera de roca silicificada, donde posiblemente la roca original haya sido una volcanoclástica con cristaloclastos de cuarzo. Presenta diversidad de colores y texturas, que van del pardo traslúcido, al blanco y negro. En los cortes delgados se pudieron observar vesículas rellenas de calcedonia de grano fino, fibrosa y cuarzo en el centro (Figura 6.21 y 6.22). La matriz de la roca se encuentra reemplazada principalmente por ópalo con presencia de minerales opacos y en algunos casos venillas de calcedonia. Si bien los cortes delgados de ambas fuentes permitieron definir algunas características particulares de cada una, éstas no pueden ser consideradas de distinta procedencia debido a que las precipitaciones de sílice en un ambiente similar generan texturas semejantes (Bertotto 2012).

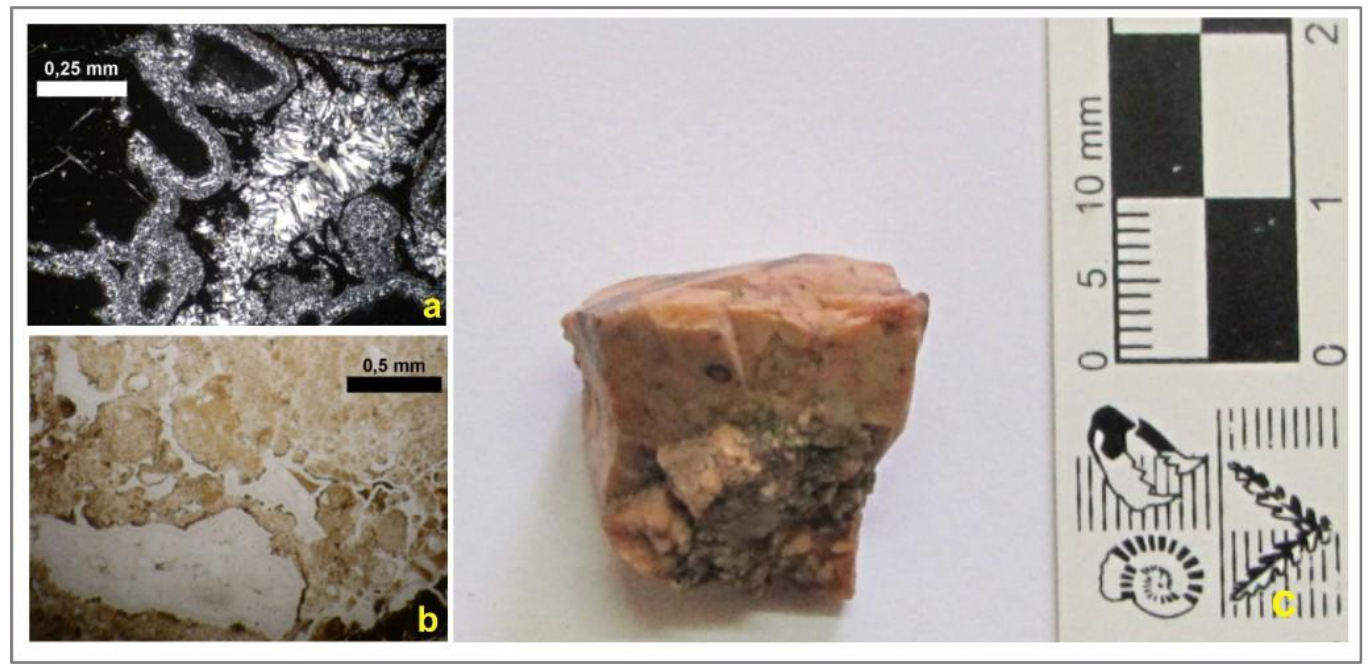

Figura 6.20. Roca silícea de PB (LP16). Muestra de cuarzo microcristalino (c) y vista de corte delgado en luz polarizada (a) y luz natural (b). Se observa textura llameante y venillas de cuarzo de recristalización. 


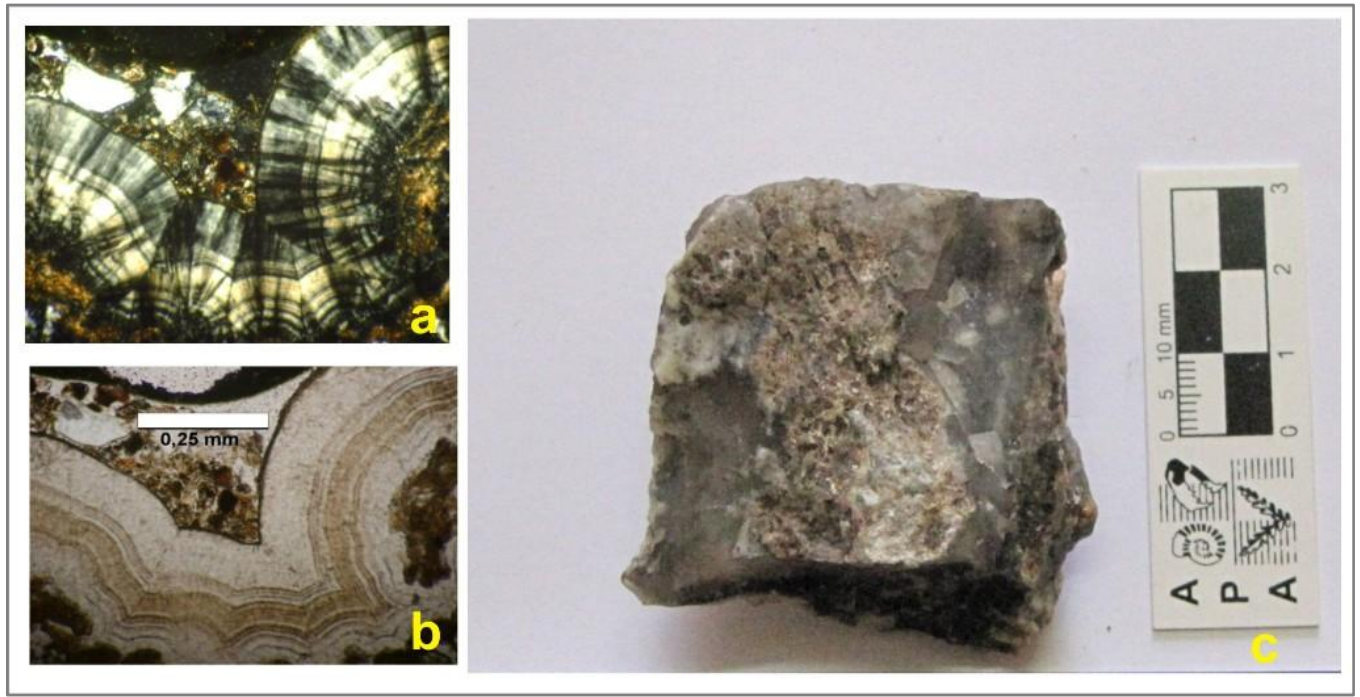

Figura 6.21. Roca silícea de LLE (LP10). Muestra de cuarzo microcristalino (c) y vista de corte delgado en luz polarizada (a) y luz natural (b). Se observa textura costriforme coloforme formada por bandas de precipitación de sílice.

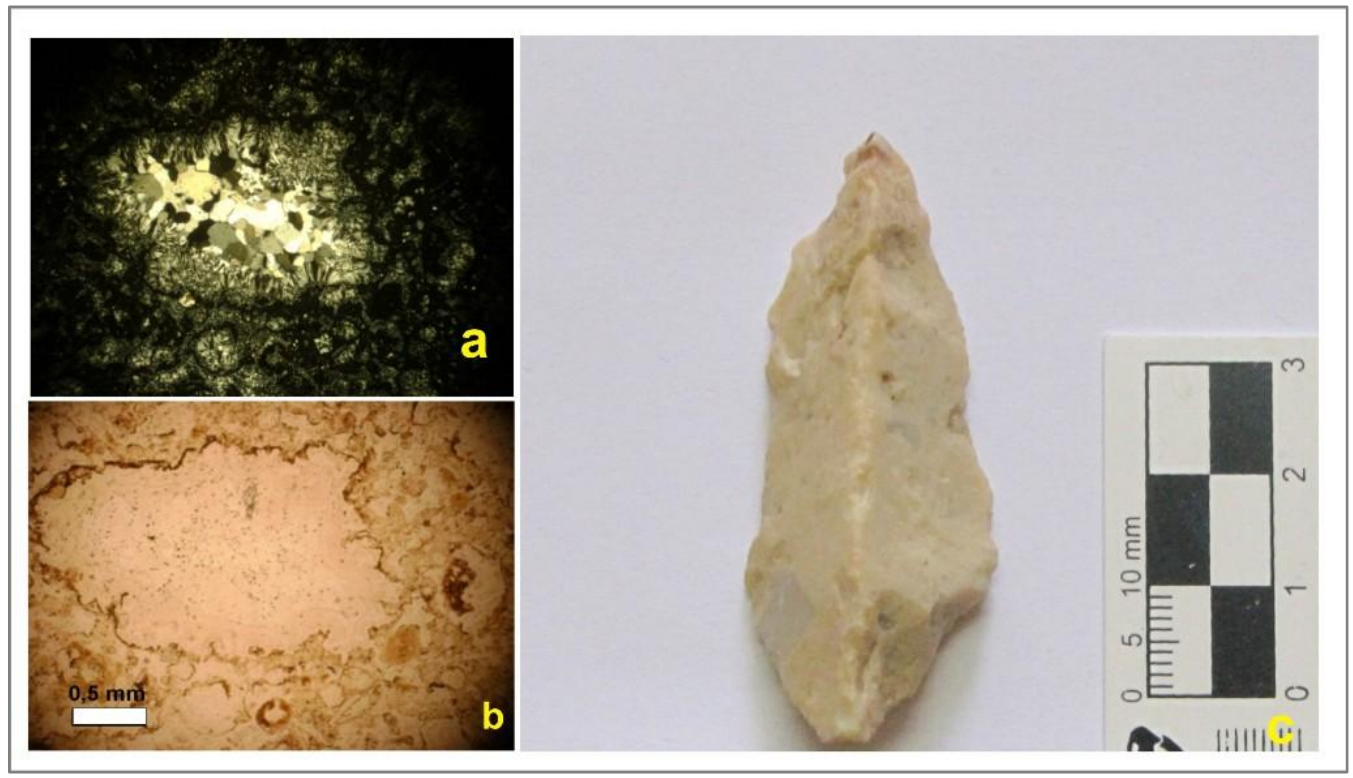

Figura 6.22. Muestra de cuarzo microcristalino (muestra LP7) (c) y vista de corte delgado en luz polarizada (a) y luz natural (b). Se observa agregado de granos esferoidales de cuarzo y concentraciones de impurezas, así como orificios rellenos con cuarzo calcedónico de grano grueso 


\subsection{1b CAÑADÓN AMARILLO (SECTOR SUR): LOCALIDAD AGUA DE Pérez (APE) Y CARMONINA (CAR)}

En Cañadón Amarillo los muestreos de fuentes se centraron en Agua de PérezCantera (APE-C) y en PISTA, de las localidades Agua de Pérez (APE) y Carmonina (CAR) respectivamente. En APE, se realizaron dos prospecciones, una en Agua de Pérez y otra en el área Payún sur. En la figura 6.11 se observa que la fuente se encuentra asociada a geoformas de remoción en masa inactivas, que cubren un área importante en el cañadón. Las remociones en masa facilitan el asomo de formaciones antiguas, en las cuales se encuentran las silicificaciones. La cantera APE-C se encuentra en la cima y faldeo de una lomada baja, que posee una diferencia de nivel respecto al terreno no mayor a los $300 \mathrm{~m}$ (Figura 6.23). Se dispone a modo de filón lineal intermitente en roca de caja basáltica (Figura 6.24). La materia prima es de color blanco, gris, violáceo y negro. Presenta una matriz cristalina homogénea, sin alteraciones ni oquedades. Se seleccionaron cinco muestras de mano para su procesamiento y análisis petrográfico.

En Pista, se realizaron dos transectas lineales continuas, que corren en sentido noroeste-sureste y cubren gran parte la plataforma elevada ubicada al oeste de cañadón. Se ubica a una distancia aproximada de $3 \mathrm{~km}$ del sitio Carmonina-1. Aquí se encuentran disponibles nódulos silíceos aislados, de tamaño grande y dispersos en el pedimento basáltico (Figura 6.25). Su génesis está vinculada con procesos de precipitación y acreción de material silíceo diagenético, en oquedades de formaciones antiguas (Formación Neuquén y Grupo Malargüe). Dichos nódulos habrían sido expuestos como resultado de la acción de agentes meteorológicos y geomorfológicos. En Pista se seleccionaron cuatro muestras para corte delgado. 


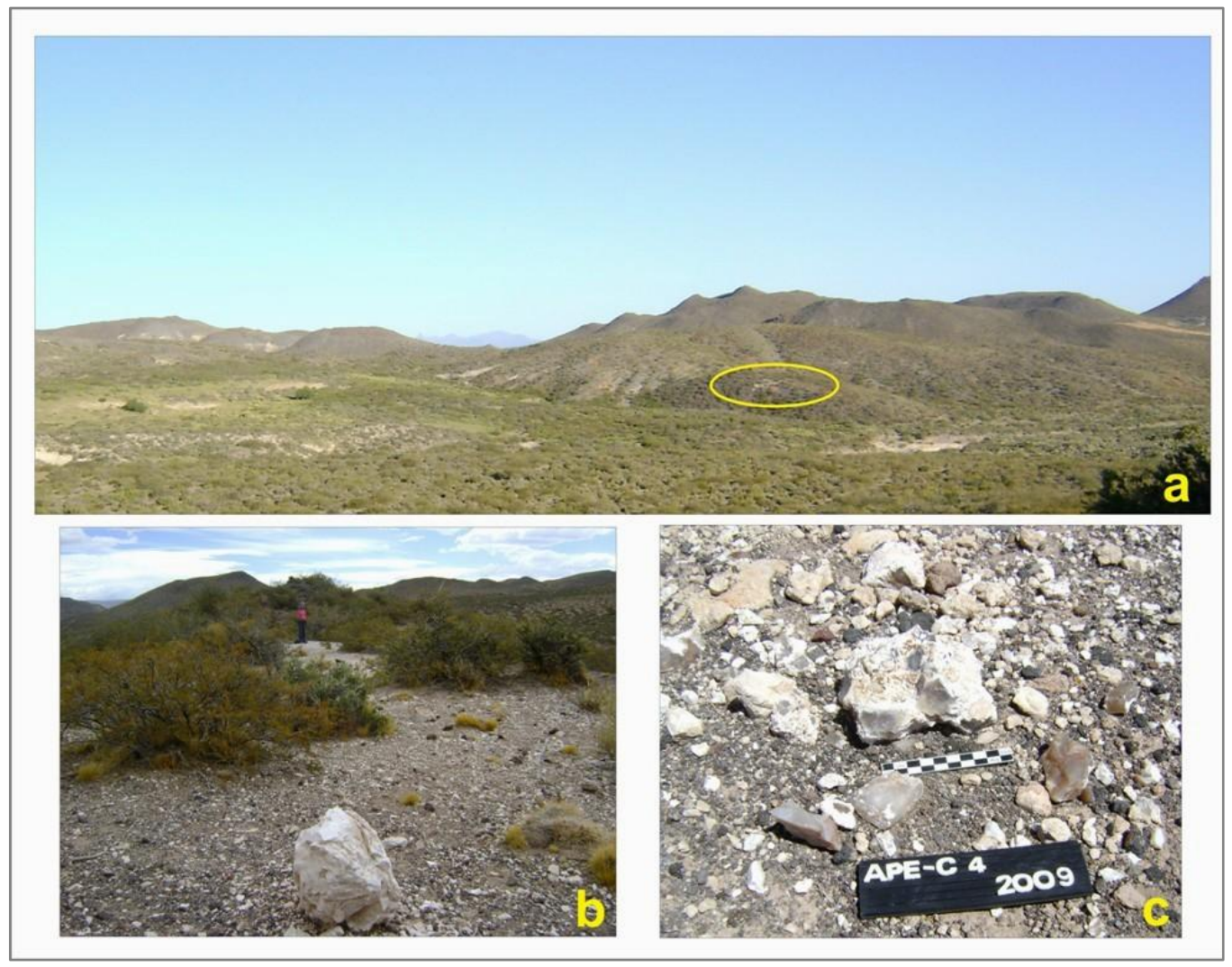

Figura 6.23. Vista de APE-C (a y b). Detalle de artefactos superficiales en APE-C (c).

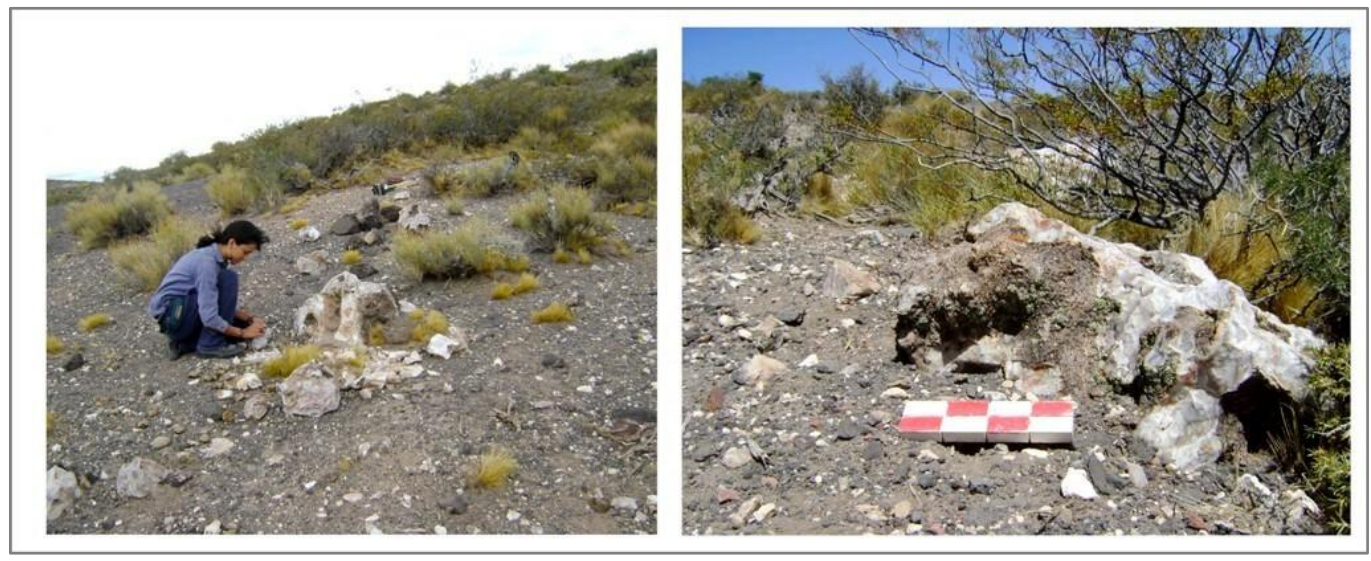

Figura 6.24. Filones de roca silícea expuestos en APE-C. 


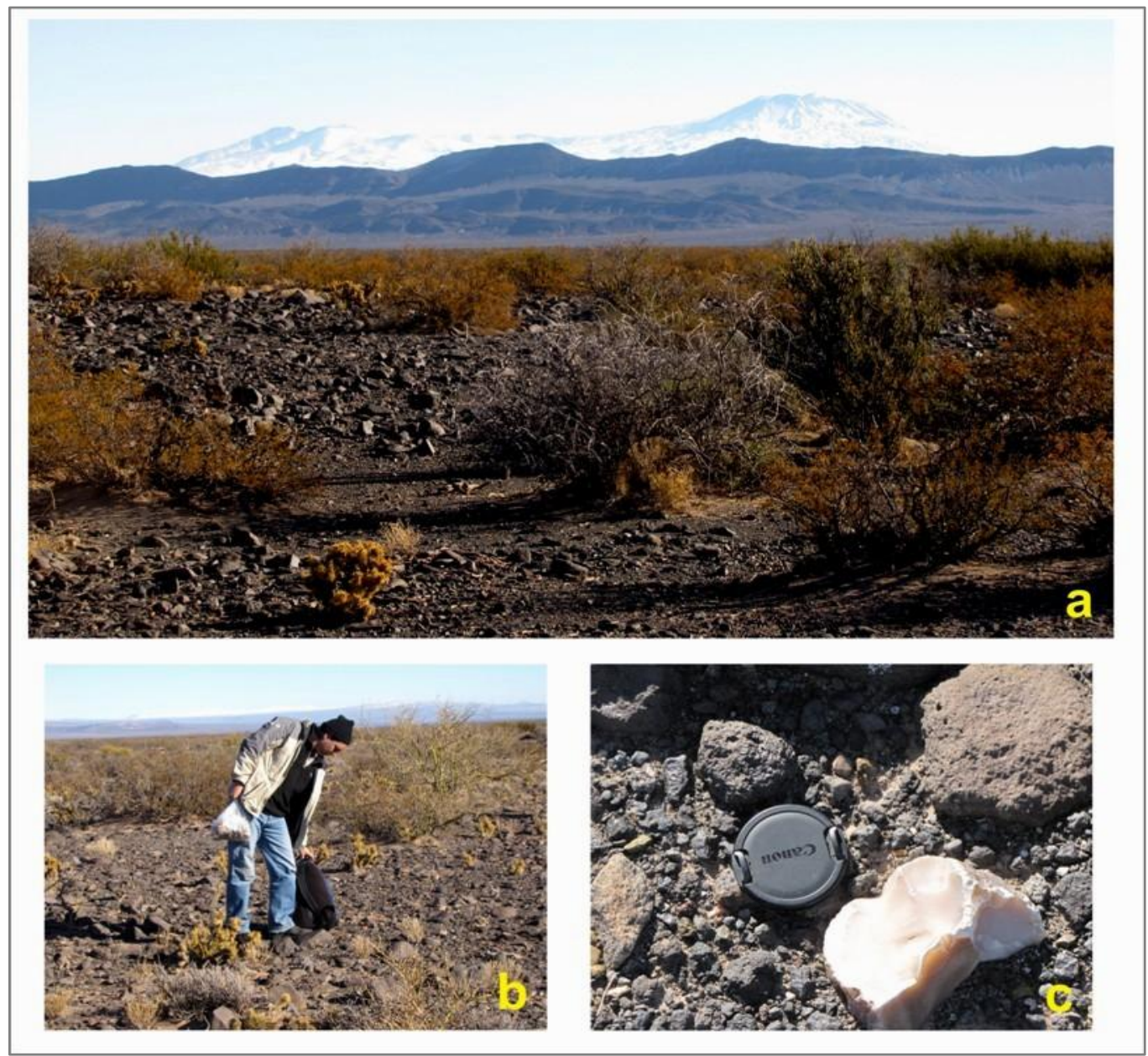

Figura 6.25. Vista de PISTA (a y b). Se observan nódulos silíceos sub-redondeados (c).

\subsection{1b.1 Análisis petrográfico en APE-C y Pista}

El análisis petrográfico de las muestras de mano de APE-C (muestras APE 1 a APE5), permitió diferenciar dos posibles génesis. Por un lado se reconocieron texturas costriformes de relleno de veta (muestras APE 1 y APE2) (Figura 6.26), compuestas de calcedonia más ópalo. El segundo grupo (muestras APEN3, APEN4 y APEN5) se corresponde con una roca silicificada con textura de brecha, compuesta por clastos o fragmentos de roca más cemento (Figura 6.27). Los clastos de roca son de ópalo o reemplazados por ópalo y el cemento es de calcedonia de grano fino y de disposición fibrosa. Los nódulos silíceos de Pista (muestras Pista17 a Pista20), corresponden a 
calcedonia masiva, brechada en algunos sectores y cementado por ópalo. Se encuentra atravesada por venillas rellenas de calcedonia de grano grueso y presenta minerales opacos con el margen oxidado. Posee bandas donde se desarrollan agregados de granos esferoidales contorneados con "impurezas", lo cual indica precipitación a partir de gel silíceo, de origen diagenético (Figura 6.28). La materia prima es de color blanco, pardo y negro, $y$, en algunos casos con inclusiones minerales.

Sobre estos resultados se pueden distinguir tres lugares de formación geológica en el área de Cañadón Amarillo; dos registradas en APE-C y una en Pista. Esta última posee variaciones texturales diferentes a las antes descriptas; sin embargo pueden estar presentes en todo el cañadón Amarillo. Del mismo modo los nódulos silíceos de origen diagenético son mencionados para el área de La Matancilla en el sector central (González Diaz 1972). En APE-C, se observaron texturas de posible origen hidrotermal, las vetas presentan variaciones texturales en sentido vertical, que permiten discriminar el nivel expuesto de la misma (Buchanan 1981; Echavarría 1997). Metodología que podría ser de utilidad para el estudio de procedencia (Salgán et al. 2010). La caracterización y determinación de variedad de tipos de génesis, es uno de los primeros pasos necesarios para posteriores estudios geoquímicos (Lyon et al. 2003).

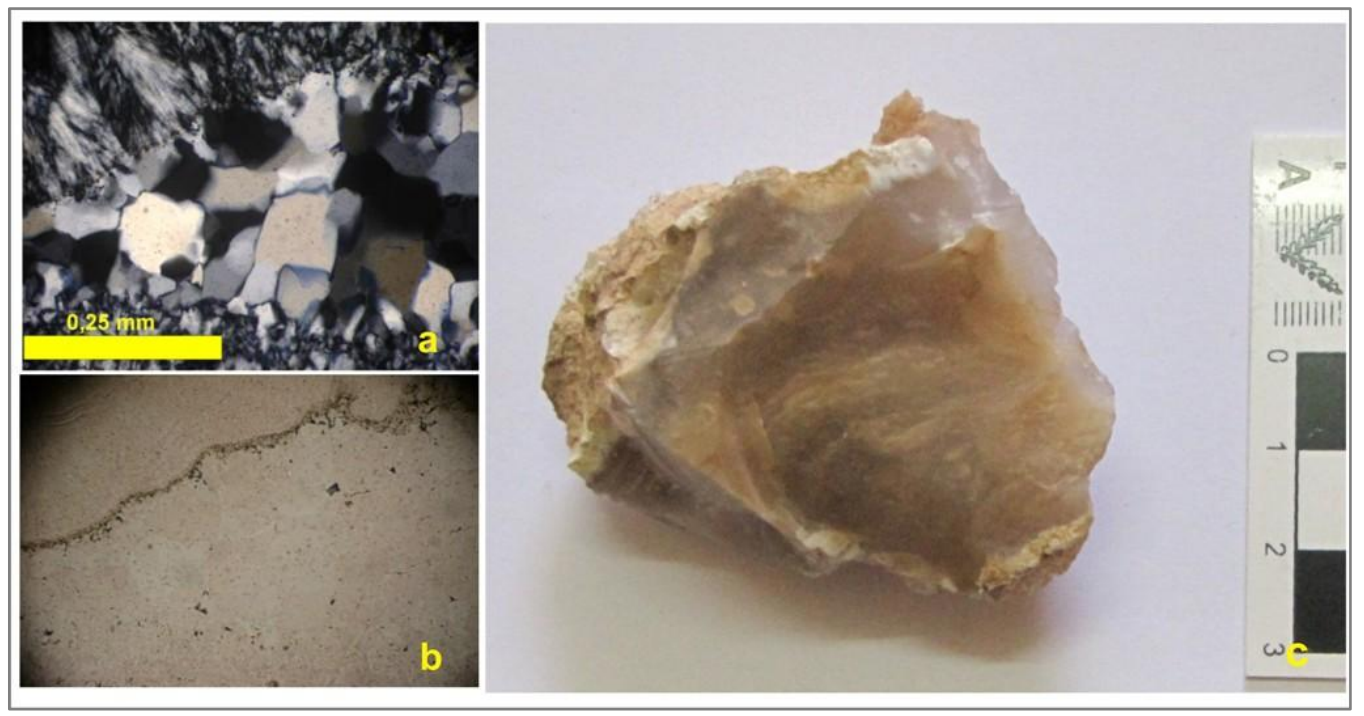

Figura 6.26. Roca silícea de APE (APE1). Muestra de cuarzo microcristalino (c) y vista de corte delgado en luz polarizada (a) y luz natural (b). Se observa textura plumosa y en mosaico; bandas de calcedonia y venillas de cuarzo. 


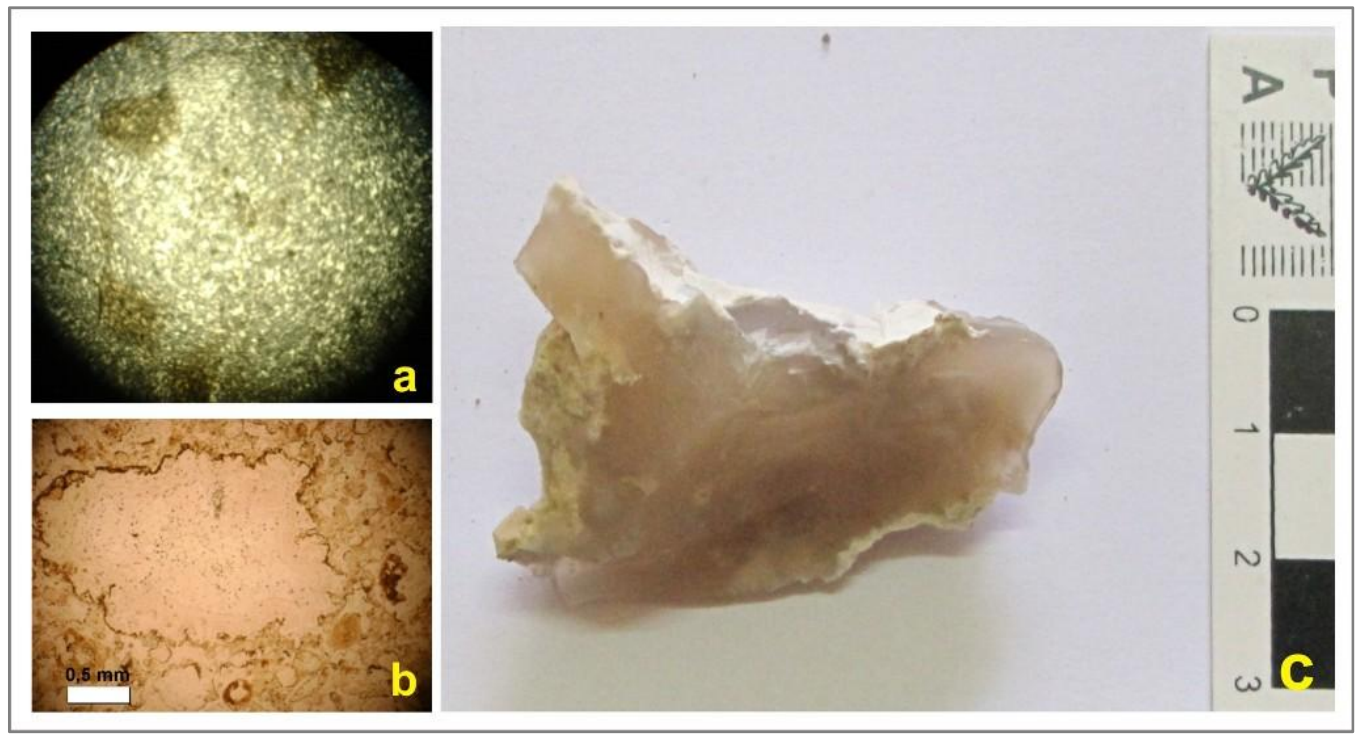

Figura 6.27. Roca silícea de APE (APE4). Muestra de mano de cuarzo microcristalino (c) y vista de corte delgado en luz polarizada (a) y luz natural (b). Se observan textura en mosaico, huecos relleno de cuarzo de grano grueso.

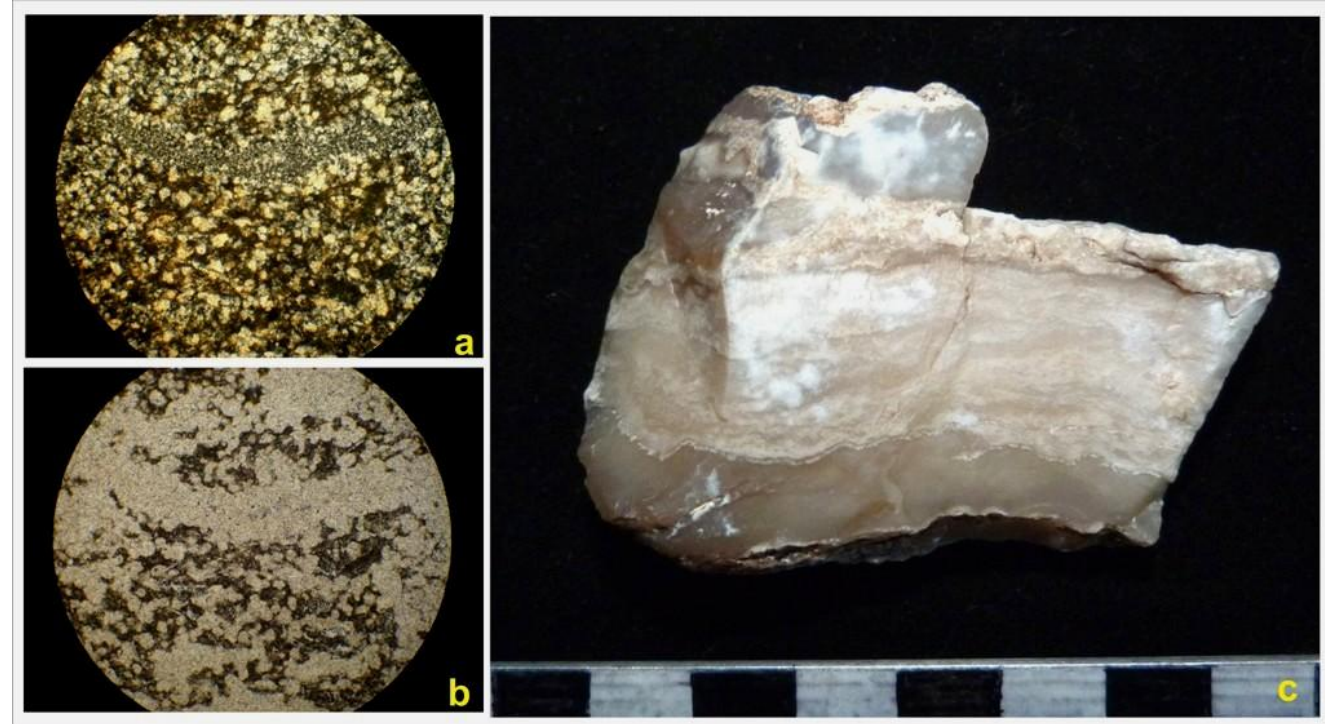

Figura 6.28. Roca silícea de PISTA (PistaTR2N3.4). 1. Muestra de mano de cuarzo microcristalino de textura bandeada costriforme (c) y vista de corte delgado en luz polarizada 63x (a) y luz natural 63x (b). Se observa calcedonia en mosaico y bandas de agregado de granos esferoidales con impurezas. 


\subsection{DISPONIBILIDAD DE ROCAS EN LA PAYUNIA}

En este apartado se analiza la disponibilidad, distribución y accesibilidad de rocas en La Payunia. En primer lugar se analizan las rocas silíceas, luego la obsidiana y otras materias primas con aptitudes para la talla disponibles en el espacio regional.

\subsubsection{ROCAS SILÍCEAS}

La denominación rocas silíceas hace referencia a materias primas de fractura concoidea con alto contenido en sílice $\left(\mathrm{SiO}_{2}\right)$. Está conformada por cuarzo, calcedonia, jaspe, ópalo y chert, de génesis asociada a múltiples procesos (Dana 1960). En La Payunia esta materia prima es considerada abundante y de distribución relativamente homogénea (Durán 2000; Gil 2000, 2006). Sin embargo los estudios realizados permiten segregar el amplio espacio regional según su disponibilidad, así como discutir los enunciados planteados en estudios previos.

La disponibilidad de materias primas se puede definirse como la presenciaausencia de clases particulares de recursos líticos en un espacio geográfico. Para su análisis se consideran aquí cuatro variables cualitativas: a) tamaño, b) accesibilidad, c) distribución de las rocas y d) calidad para la talla (Tabla 6.2).

Como se desprende de los apartados previos, el área de Agua Escondida ubicada en el sector norte, es la que presenta mayor disponibilidad y abundancia de rocas silíceas, seguida por el área de Cañadón Amarillo en el sector sur. El área de menor disponibilidad estaría representada por el sector central o Altiplanicie del Payén, donde solo se han registrado nódulos silíceos aislados. En cada sector, se pueden observar diferencias en cuanto a la distribución y calidad para la talla. En Agua Escondida si bien ambas fuentes presentan una distribución concentrada y accesibilidad anual, no presentan igual disponibilidad de materias primas y calidad para la talla. En relación a las fuentes de agua, si bien LLE no está asociada a una fuente hídrica (Figura 6.29), la misma se encuentra a 
una distancia no mayor a los $3 \mathrm{~km}$, por lo cual no puede considerarse ausente. En el área central, las variables analizadas presentan los rangos más bajos. La disponibilidad es escasa, se encuentra en forma aislada y su calidad es regular. En Cañadón Amarillo, las fuentes documentadas presentan distintas características, siendo APE-C la fuente con mejor disponibilidad y calidad para la talla de rocas, además de contar con recursos hídricos cercano. Por el contrario, Pista, posee una distribución dispersa en el espacio, su calidad para la talla es menor y no dispone de aguadas o vertientes cercanas.

\begin{tabular}{|c|c|c|c|c|c|c|}
\hline Sector & Fuente & Extensión & Distribución & Accesibilidad & Calidad & R. Hídrico \\
\hline $\begin{array}{c}\text { Agua Escondida } \\
\text { (Sector norte) }\end{array}$ & PB & Muy Extenso & Concentrada & Anual & Buena & vertiente \\
\cline { 2 - 7 } & LLE & Medio & Concentrada & Anual & Muy buena & vertiente \\
\hline $\begin{array}{c}\text { Altiplanicie del Payún } \\
\text { (Sector central) }\end{array}$ & ALPA-E & Pequeño & Aislada & Anual & Regular & Jagüel \\
\hline $\begin{array}{c}\text { Cañadón Amarillo } \\
\text { (Sector sur) }\end{array}$ & APE-C & Extenso & Concentrada & Anual & Muy buena & vertiente \\
\cline { 2 - 7 } & PISTA & Escasa & Dispersa & Anual & Buena & - \\
\hline
\end{tabular}

Tabla 6.2. Rocas silíceas en La Payunia; caracterización de sus fuentes.

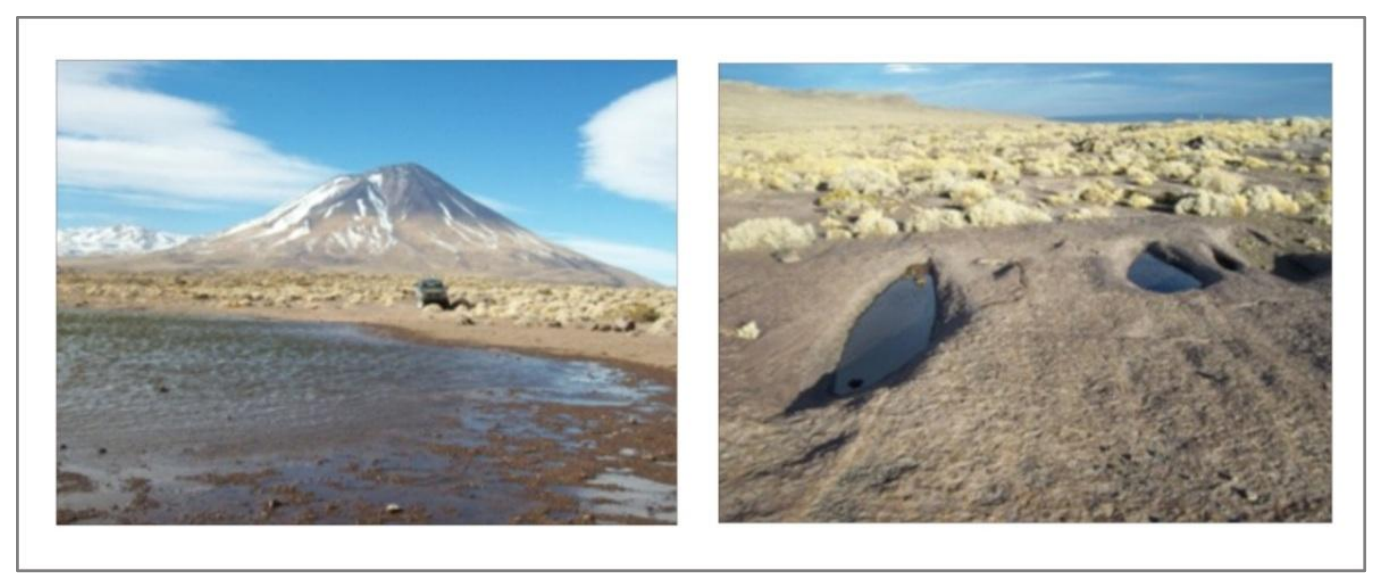

Figura 6.29 Recursos hídricos en la Altiplanicie de Payén. En las dos imágenes muestran variedad de "aguas del tiempo" o jagüel, presentes en el sector central. 
La distancia que separa los sitios arqueológicos analizados para esta tesis y las fuentes de roca registradas, en la mayoría de los casos es menor a los $5 \mathrm{~km}$, por lo cual deben considerarse como recursos inmediatamente disponible (Civalero y Franco 2003)(Tabla 6.3). Sólo en el caso de RC (8,5 km lineales) la distancia es mayor, aunque igualmente debe considerarse como un recurso local cercano (5-30 km).

\begin{tabular}{|c|c|c|c|c|c|c|c|}
\hline 谷 & 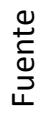 & LP-1 & LC & ALPA & APE-1 & CAR-1 & $\mathrm{RC}$ \\
\hline \multirow{2}{*}{$\begin{array}{l}\text { w } \\
\text { o } \\
\text { o }\end{array}$} & $\mathscr{a}$ & Local (5km) & Local $(5 \mathrm{~km})$ & $\begin{array}{l}\text { No local } \\
(40 \mathrm{~km})\end{array}$ & $\begin{array}{l}\text { No local } \\
(40 \mathrm{~km})\end{array}$ & $\begin{array}{l}\text { No local } \\
(40 \mathrm{~km})\end{array}$ & $\begin{array}{l}\text { No local } \\
(40 \mathrm{~km})\end{array}$ \\
\hline & بّ & Local $(5 \mathrm{~km})$ & Local $(5 \mathrm{~km})$ & $\begin{array}{l}\text { No local } \\
(40 \mathrm{~km})\end{array}$ & $\begin{array}{l}\text { No local } \\
(40 \mathrm{~km})\end{array}$ & $\begin{array}{l}\text { No local } \\
(40 \mathrm{~km})\end{array}$ & $\begin{array}{l}\text { No local } \\
(40 \mathrm{~km})\end{array}$ \\
\hline 岕 & $\stackrel{\nwarrow}{\varrho}$ & $\begin{array}{l}\text { No local } \\
(40 \mathrm{~km})\end{array}$ & $\begin{array}{l}\text { No local } \\
(40 \mathrm{~km})\end{array}$ & Local (5km) & $\begin{array}{c}\text { Local } \\
(10-40 \mathrm{~km})\end{array}$ & $\begin{array}{c}\text { Local } \\
(10-40 \mathrm{~km})\end{array}$ & $\begin{array}{l}\text { No local } \\
(40 \mathrm{~km})\end{array}$ \\
\hline \multirow{2}{*}{ 号 } & 晏 & $\begin{array}{l}\text { No local } \\
(40 \mathrm{~km})\end{array}$ & $\begin{array}{l}\text { No local } \\
(40 \mathrm{~km})\end{array}$ & $\begin{array}{l}\text { Local (10- } \\
40 \mathrm{~km})\end{array}$ & $\begin{array}{l}\text { Local } \\
(5 \mathrm{~km})\end{array}$ & $\begin{array}{l}\text { Local (10- } \\
40 \mathrm{~km})\end{array}$ & $\begin{array}{c}\text { Local } \\
(10-40 \mathrm{~km})\end{array}$ \\
\hline & $\frac{5}{\frac{n}{a}}$ & $\begin{array}{l}\text { No local } \\
(40 \mathrm{~km})\end{array}$ & $\begin{array}{l}\text { No local } \\
(40 \mathrm{~km})\end{array}$ & $\begin{array}{c}\text { Local } \\
(10-40 \mathrm{~km})\end{array}$ & $\begin{array}{c}\text { Local } \\
(10-40 \mathrm{~km})\end{array}$ & Local (5km) & $\begin{array}{l}\text { Local } \\
(10 \mathrm{~km})\end{array}$ \\
\hline
\end{tabular}

Tabla 6.3 Distancia entre las fuentes de rocas silíceas y los sitios arqueológicos en La Payunia.

\subsubsection{OBSIDIANA}

En La Payunia la presencia de obsidiana, aunque necesita ser confirmada y caracterizada, se circunscribe a los volcanes del sector central: Payún Matrú y Payún Liso (en adelante PM y PL, respectivamente) (González Díaz 1972; Llambías et al. 2010). En el complejo volcánico Payún Matrú habría buena disponibilidad de esta materia prima, de 
accesibilidad anual, pero los sectores que pudimos constatar presentan calidad regular a mala, dado el alto contenido de fenocristales en su matriz (Figura 6.30). Sin embargo, aún no ha podido ser caracterizada en forma geoquímica. En trabajos previos Payún Matrú, fue caracterizada a partir de un fragmento entregado por un tercero, y propuesta como fuente (Durán et al. 2004; Giesso et al. 2011a; Cortegoso et al. 2012). Si bien no se descarta la existencia de una fuente asociada a Payún Matrú, por el momento se considera una fuente potencial hasta tanto se pueda corroborar o no su existencia.

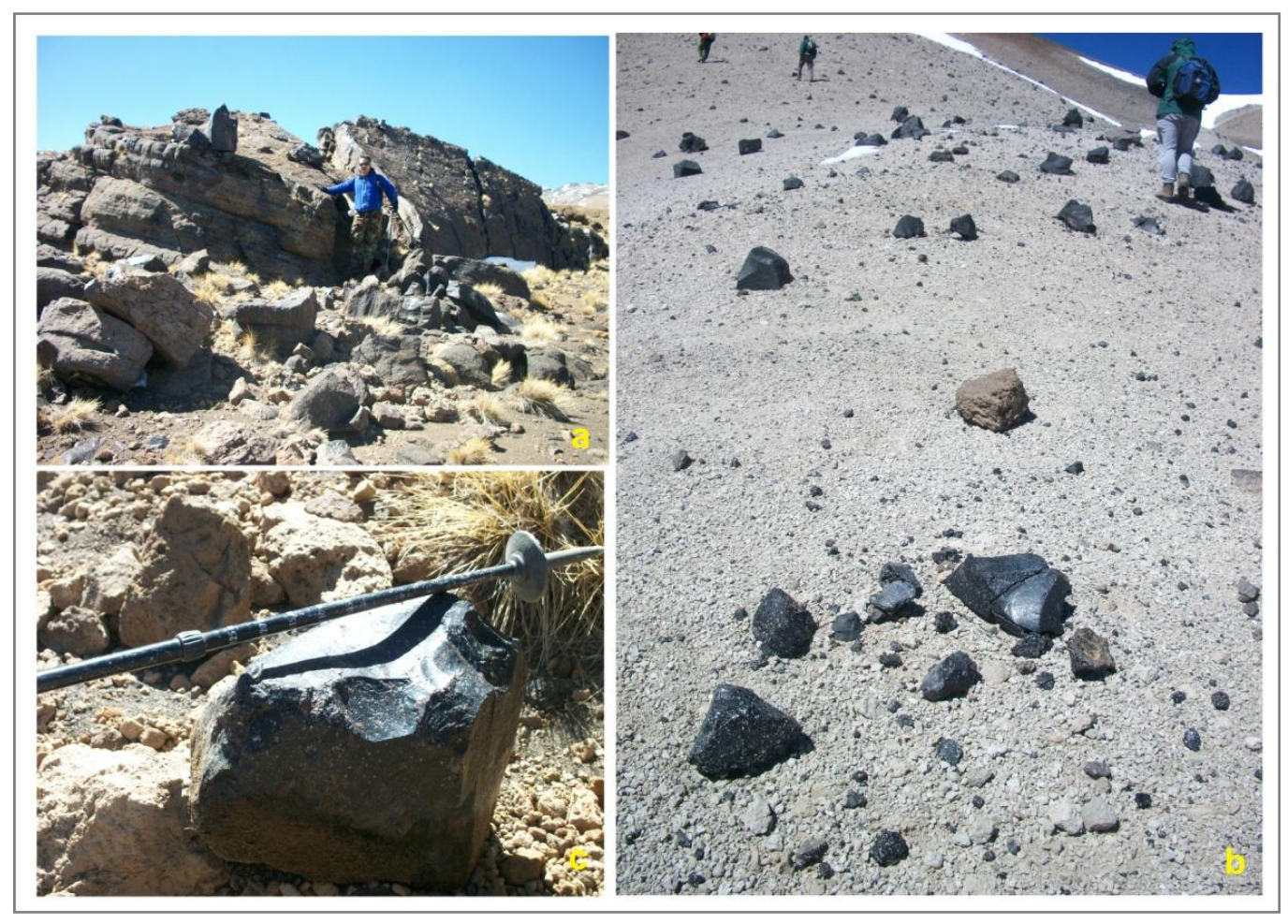

Figura 6.30. Traquita vítrea ubicada en el borde noroeste de la caldera del Volcán Payún Matrú (Fotos: Amalia Ramires)

En Payún Liso y en el marco de ésta investigación, se detectaron filones de traquita vítrea en la cima del estratovolcán, a una altura aproximada a los 3.760 msnm. Presenta una disponibilidad escasa, distribución concentrada, accesibilidad sólo en las estaciones de primavera-verano y calidad para la talla buena a regular. La roca tiene una matriz homogénea, con intrusiones aisladas. Las muestras de mano obtenidas (Figura 6.31) 
fueron procesadas por medio de la técnica de Fluorescencia de Rayos X, indicando una señal química hasta entonces desconocida (Glascock 2011). Resta mejorar los muestreos para definir su señal química y evaluar si corresponde a una de las fuentes documentadas como desconocidas para el sur de Mendoza (Giesso et al. 2011a).

En la tabla 6.4, se observan las distancias entre las fuentes potenciales de obsidiana y los sitios analizados, que supera los $40 \mathrm{~km}$. Por lo tanto, si se confirma su uso, estas materias primas deberían considerarse no local, con excepción quizás del ALPA respecto a PL.

\begin{tabular}{|c|c|c|c|c|c|c|c|}
\hline 克 & 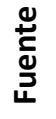 & LP & LC & ALPA & APE-1 & CAR-1 & RC \\
\hline \multirow{2}{*}{ 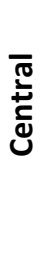 } & $\sum_{a}$ & $\begin{array}{l}\text { No local } \\
(40 \mathrm{~km})\end{array}$ & $\begin{array}{l}\text { No local } \\
(40 \mathrm{~km})\end{array}$ & Local (40km) & $\begin{array}{l}\text { No local } \\
(40 \mathrm{~km})\end{array}$ & $\begin{array}{l}\text { No local } \\
(40 \mathrm{~km})\end{array}$ & $\begin{array}{l}\text { No local } \\
(40 \mathrm{~km})\end{array}$ \\
\hline & $\vec{a}$ & $\begin{array}{l}\text { No local } \\
(40 \mathrm{~km})\end{array}$ & $\begin{array}{l}\text { No local } \\
(40 \mathrm{~km})\end{array}$ & $\begin{array}{c}\text { Local (30- } \\
40 \mathrm{~km})\end{array}$ & $\begin{array}{c}\text { Local (30- } \\
40 \mathrm{~km})\end{array}$ & $\begin{array}{l}\text { No local } \\
(40 \mathrm{~km})\end{array}$ & $\begin{array}{l}\text { No local } \\
(40 \mathrm{~km})\end{array}$ \\
\hline
\end{tabular}

Tabla 6.4. Distancia lineal a fuentes potenciales de obsidiana en La Payunia. Referencias: $D K M$ : distancia aproximada en kilómetros lineales; PM: Payún Matrú; PL: Payún Liso; EL: Cerro El Loro. 


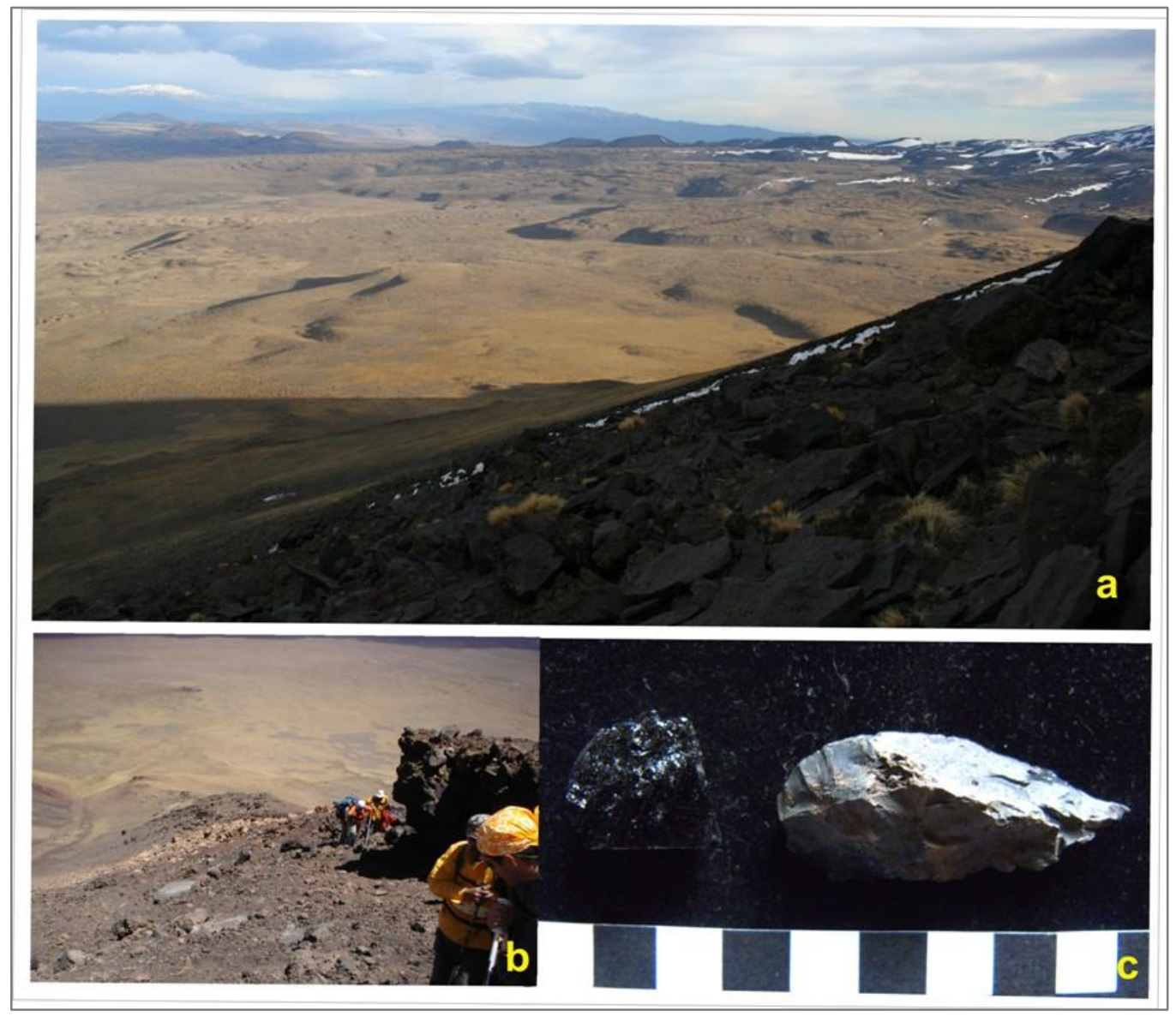

Figura 6.31. Obsidiana Payún Liso ( $\mathrm{a}$ y b) y muestra de mano(b), procesada por medio de fluorescencia de rayos X (XRF) (Fotos: Rolando Poblete).

\subsubsection{OTRAS MATERIAS PRIMAS}

En esta categoría general, se incluyen las rocas minoritarias en el registro arqueológico; tales como el basalto y la riolita. En la región hay amplia disponibilidad de basalto, no obstante este material no presenta en general buenas características para la talla. Es vesicular de estructura porfírica y con cantidad variable de fenocristales. Una excepción se presenta en el área de Los Volcanes, donde algunas bombas basálticas presentan pasta homogénea y textura afanítica. Estos basaltos son escasos, de distribución aislada, accesibilidad anual y calidad para la talla buena. En el área la única 
fuente de agua es el río Grande. La distancia a los sitios es en la mayoría de los casos superior a los $50 \mathrm{~km}$.

Las riolitas, presentan amplia disponibilidad en el sector norte, en Agua Escondida. Pese a esto, no se ha documentado la existencia de fuentes de buena calidad. Su presencia en el registro arqueológico está vinculada en la mayoría de los casos a percutores o fragmentos naturales sin claras evidencias de uso y/o formatización.

\subsection{CONSIDERACIONES GENERALES DE LA BASE REGIONAL DE RECURSOS LÍTICOS}

A partir del análisis de la disponibilidad de recursos líticos en La Payunia, discutida en este capítulo se puede plantear que en la región se reconocen dos espacios con amplia disponibilidad de recursos líticos de buena a muy buena calidad para la talla: el sector norte (Agua Escondida) y el sector sur (Cañadón Amarillo); y un área con recursos de menor calidad y disponible en forma aislada, que corresponde a la Altiplanicie del Payén o sector central.

Agua Escondida presenta amplia disponibilidad de rocas silíceas, en cuya génesis se puede reconocer al menos tres variedades: nódulos silíceos de origen diagenético precipitado en oquedades rocosas, silicificaciones o reemplazos de rocas sedimentarias y las vetas de cuarzo hidrotermal. Todos los afloramientos de rocas silíceas mencionadas, así como las formaciones potenciales de contenerlas, se encuentran en el extremo noreste de la región y se continúa al norte en el Área El Nevado. En el extremo hacia el este, estas formaciones se encuentran cubiertas por depósitos actuales, y no poseen visibilidad. En Cañadón Amarillo, se encuentran rocas silíceas del mismo origen que en sector norte, pero los procesos geomorfológicos actuantes en el sector sur y el relieve accidentado, dificultan su visibilidad. Los basaltos disponibles en el río Colorado, poseen amplia disponibilidad y fácil acceso, aunque resta aún evaluar de modo sistemático sus aptitudes para la talla. En Sector Central, hay traquitas vítreas (obsidiana) con muchas 
impurezas asociadas a los estratovolcanes y basaltos, pero ambas materias primas presentan en mala calidad para la talla, con excepción de las bombas basálticas del área Los Volcanes. En sureste del sector, en el área de La Matancilla, se encuentran en forma aislada nódulos silíceos, expuestos por meteorización y eventos de remoción en masa. 


\section{CAPÍTULO 7}

\section{EL REGISTRO ARTEFACTUAL EN LA PAYUNIA}

\section{INTRODUCCIÓN}

En este capítulo se presentan los resultados del análisis de los conjuntos artefactuales del Área El Payén (Figura 7.1). Para la organización de la información se consideraron cinco localidades arqueológicas incluyendo en cada una los distintos tipos de hallazgos (concentraciones y artefactos aislados) recuperados mediante relevamientos superficiales (sistemáticos y asistemáticos) y estratigráficos. Dichas localidades fueron definidas tomando en cuenta áreas circulares de $10 \mathrm{~km}$ de diámetro. Estas son las localidades de La Peligrosa (sector norte), Altiplanicie del Payún (sector central), Agua de Pérez, La Carmonina y Río Colorado (sector sur). Al presentar cada una de ellas se detalla la información ordenada de acuerdo a los sitios y las unidades de relevamiento. Para cada localidad se describen las características generales, los rasgos geológicos y geomorfológicos, y las distribuciones arqueológicas. 


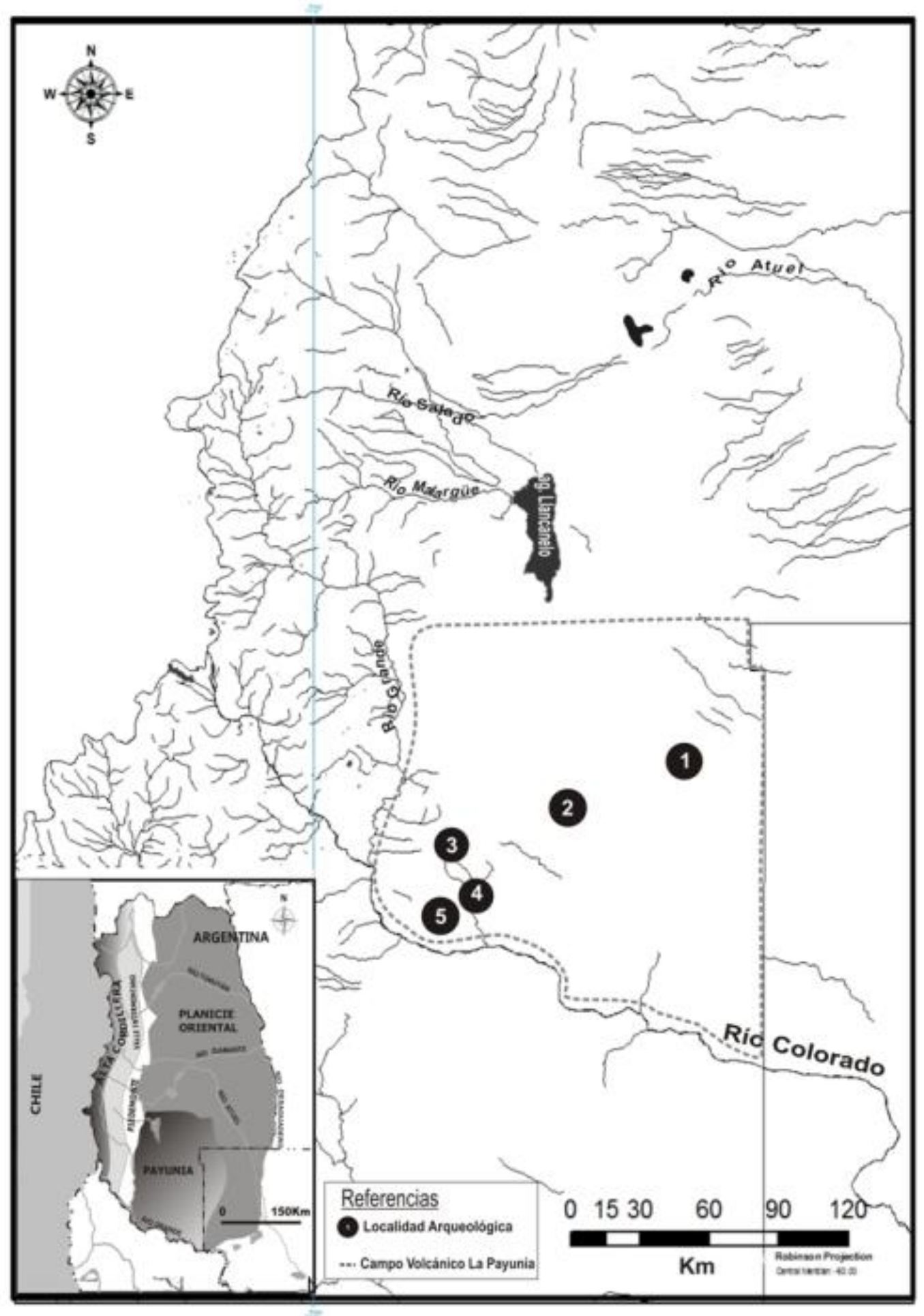

Figura 7.1 Localidades arqueológicas de La Payunia. Referencia: 1: La Peligrosa; 2: Altiplanicie del Payén 3: Aguada de Pérez; 4: Carmonina; 5: Río Colorado. 


\subsection{LOCALIDAD LA PELIGROSA (LP)}

La localidad arqueológica La Peligrosa (en adelante LP) se ubica en el sector norte de la región en estudio (Figura 7.2). En ella se encuentra el puesto homónimo perteneciente a la familia Cerna, que tienen una aguada natural endicada intencionalmente para uso ganadero. Los primeros estudios arqueológicos sistemáticos de la localidad fueron realizados en la década de 1990 (Gil 2002, 2006) y luego continuaron a principios del presente siglo. En la primera campaña (1997-1998), se excavaron y relevaron los sitios La Corredera, La Peligrosa 2 Sondeo Z-98, La Peligrosa 1 (Alero) y la cantera de roca silícea Piedras Bayas (Gil 2006). En la segunda campaña (2002-2003) se realizó la excavación de una unidad A-1 en el sitio La Peligrosa 2, el relevamiento superficial de distintas geoformas de la localidad y de la fuente de rocas silíceas La Leona.

Los sitios La Corredera y La Peligrosa 1 (Alero) se encuentran en abrigos rocosos, mientras que los restantes se emplazan a cielo abierto. Gil (2006) analizó el registro arqueológico recuperado en la primera campaña, lo que sirvió de base para proponer una cronología de ocupación desde ca. 2000 años AP, con evidencias de ocupaciones efímeras (La Corredera) y campamentos de actividades múltiples (Sondeo Z-98 en La Peligrosa 2 que equivocadamente en Gil (2006) figura como La Peligrosa 1). Se documentó la presencia de representaciones rupestres significativamente meteorizadas en La Peligrosa 1 (Alero) y de filones rocosos con signos de explotación (Piedras Bayas). El investigador destaca que la asociación de recursos considerados críticos, tales como agua, refugio y rocas aptas para la talla, es poco habitual en la región y conformaría una co-ocurrencia clave para explicar ocupación humana aquí. 


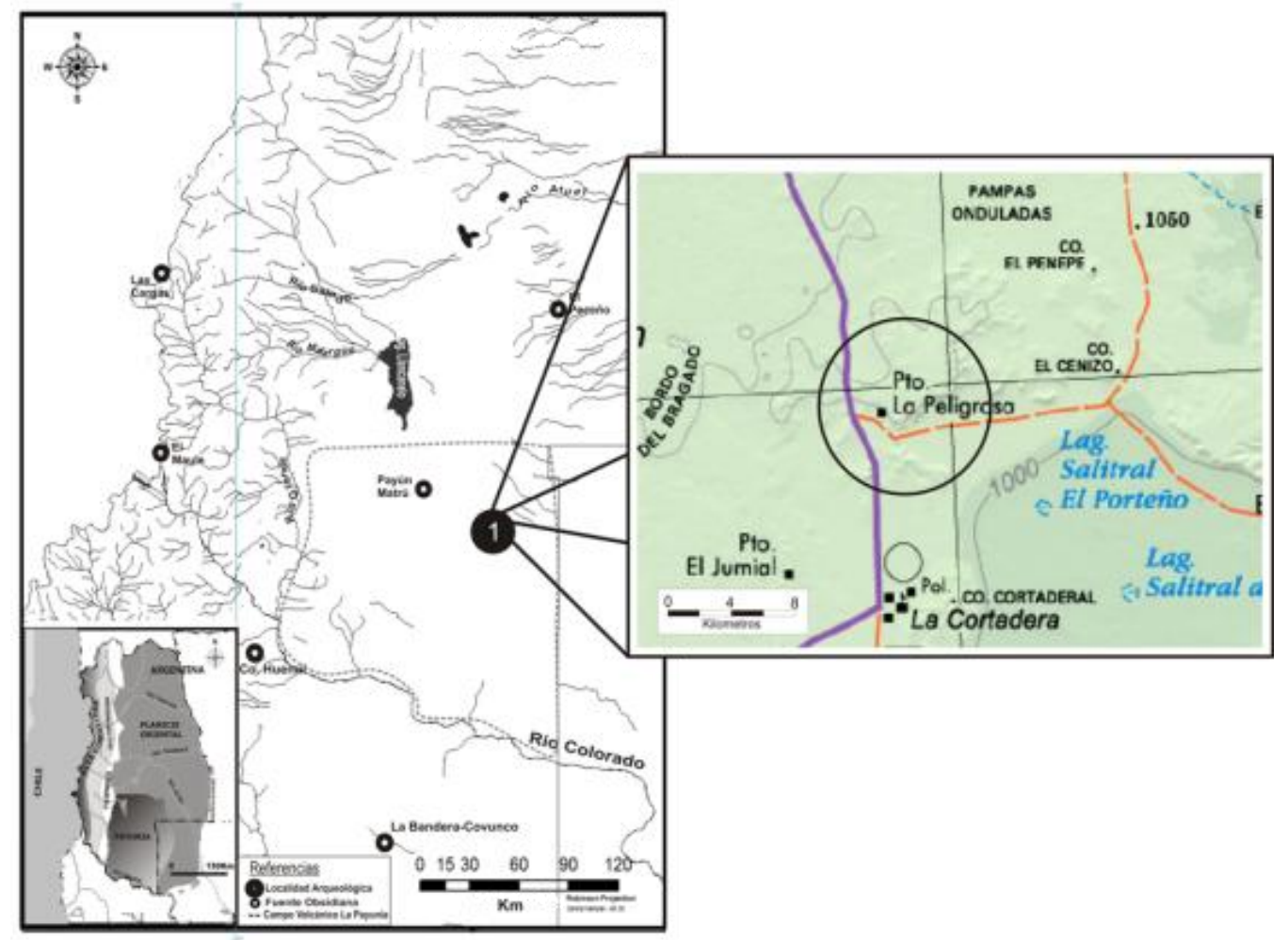

Figura 7.2. Ubicación localidad arqueológica La Peligrosa.

La Peligrosa se encuentra en el límite entre las provincias fitogeográficas de Patagónica y Monte (Cabrera 1976, citado por Gil 2006). Se localiza en un bajo formado por una ventana lávica convexa, cubierto en parte por depósitos eólicos, donde afloran asomos de basalto olivínico del Grupo Palauco. Estos asomos forman una serie de cerros que no superan los 1.200 msnm, entre los que se encuentran El Cenizo, El Gato y Barda Pencosa. En el puesto La Peligrosa, Co. El Azufre y salitral de La Salina, la cubierta basáltica preservó relictos de la Formación Loncoche, en cuyo contacto con los basaltos desarrolla un nivel de nódulos silíceos formando lentes de sílice criptocristalino color blanquecino y rojo de origen diagenético (Narciso et al. 2001a). Un nivel de nódulos silíceo también ha sido documentado en Cerro La Leona, distante aproximadamente $3 \mathrm{~km}$ al oeste del puesto La Peligrosa (Figura 7.3).

Para esta tesis se analizaron los conjuntos de los sitios estratigráficos La Corredera, La Peligrosa 2 (cuadrícula A1) y las distribuciones superficiales de artefactos de la fuente 
La Leona. En la fuente Piedras Bayas se realizó un muestreo de rocas con el objeto de caracterizar petrográficamente la fuente y se empleó información distribucional previa (Gil 2006).

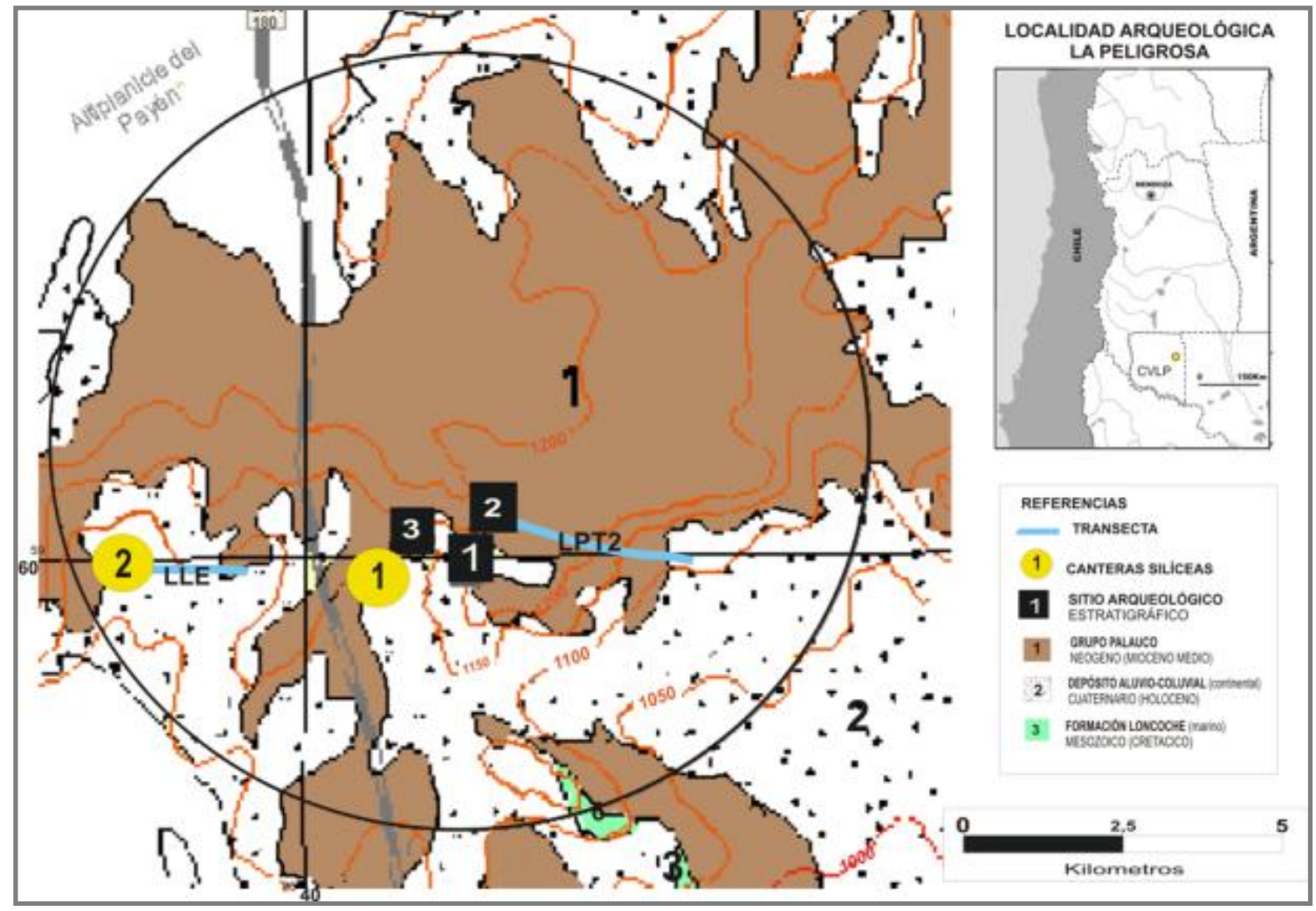

Figura 7.3. Ubicación de los sitios analizados en la localidad arqueológica La Peligrosa. Referencias: en círculos amarillos se indican las fuentes de rocas silíceas: 1: Piedras Bayas, 2: La Leona. Cuadros negros indican los sitios excavados: 1: La Peligrosa-2; 2: La Peligrosa-1; 3: La Corredera; y con traza celeste los muestreos lineales: LLE: transecta La Leona; LPT2: La Peligrosa Transecta 2. Figura modificada de Narciso et al. (2001b).

\subsection{1a LA PELIGROSA 2 (LP-2)}

El sitio estratigráfico La Peligrosa 2 (en adelante LP-2), se encuentra entre las coordenadas: $36^{\circ} 31^{\prime} 00^{\prime \prime}$ L. S.- 68³1'37' L. O. (1.140 msnm), próximo a la mencionada vertiente y al puesto homónimo. Se excavaron dos unidades a cielo abierto, una de $1 \mathrm{~m}^{2}$ denominada Sondeo Z-98 (Gil 2006) y otra de $4 \mathrm{~m}^{2}$, denominada Cuadrícula A-1. En ambas 
se registraron artefactos líticos y restos faunísticos, vegetales y cerámicos. En trabajos previos se le atribuyó una cronología estimada de entre 1000 y 1500 años AP (Gil 2006) ajustada posteriormente con fechas radiocarbónicas (Giardina 2010).

La unidad A1 de LP-2 se excavó por niveles artificiales de $5 \mathrm{~cm}$ llegando a una profundidad de $70 \mathrm{~cm}$, y respetando la inclinación natural del terreno. La matriz sedimentaria es arenosa con clastos de tamaño mediano y pequeño y se diferencian dos unidades separada entre ellas por una unidad intermedia o de transición (Figura 7.4). La unidad superior, denominada unidad $A$, es básicamente arenosa y abarca los cuatro primeros niveles de la excavación (niveles 0 a 4). La unidad inferior, denominada unidad $B$, incluye los niveles 5 y 14. La cronología del sitio fue definida a partir de dos fechados sobre carbón vegetal, una de $400 \pm 70$ años AP (LP-1474) del nivel 3 (unidad A) y otra de $640 \pm 70$ años AP (LP-1513) del nivel 7 (unidad B). En esta unidad se registraron 7906 piezas líticas, pero para esta tesis se analizaron 1743 procedentes del sector NE de la excavación. Se calculó una tasa de depositación temporal de artefactos de 2,73 artefactos por año y $\mathrm{m}^{2}$. Las clases artefactuales representadas en la muestra analizada son 6 (Tabla 7.1). El conjunto está integrado en un $57 \%(n=997)$ por artefactos enteros, $38 \%(n=656)$ de artefactos fragmentados y el 6\% $(n=99)$ restante por fragmentos no diferenciados. En materias primas, el 94,2\% ( $n=939)$ de los artefactos enteros son de rocas silíceas, el 5,6\% $(n=56)$ de obsidiana y el $0,2 \%(n=2)$ restante por basalto (Tabla 7.2). De los artefactos fracturados, el $91 \%(n=597)$ corresponde a rocas silíceas, el 8,5\% ( $n=57)$ a artefactos de obsidiana y el $0,5 \%(n=2)$ restante a riolita. 


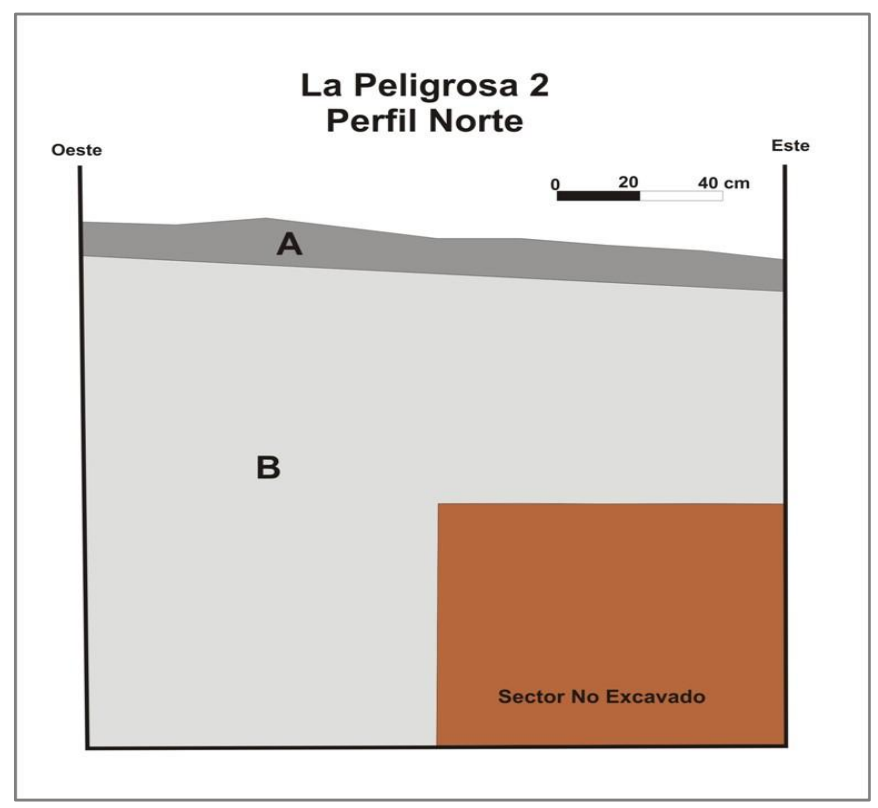

Figura 7.4. Perfil estratigráfico de LP-2.

\begin{tabular}{|c|c|c|c|c|c|c|c|c|}
\hline \multirow[b]{2}{*}{ NIVEL } & \multicolumn{7}{|c|}{ Artefactos } & \multirow[t]{2}{*}{ Total } \\
\hline & $\begin{array}{c}\text { AF } \\
\text { Bifacial }\end{array}$ & $\begin{array}{c}\text { AF } \\
\text { Unifacial }\end{array}$ & ASF RC & DT & Núcleo & Percutor & ND & \\
\hline 0 & 3 & - & - & 83 & - & - & 9 & 95 \\
\hline 1 & 1 & 1 & - & 329 & - & - & 15 & 346 \\
\hline 2 & 1 & 2 & 1 & 271 & - & - & 18 & 293 \\
\hline 3 & 1 & 1 & 1 & 224 & - & - & 4 & 231 \\
\hline 4 & - & 1 & - & 139 & - & - & 11 & 151 \\
\hline 5 & 2 & - & 1 & 25 & - & - & 5 & 33 \\
\hline 6 & - & - & - & 149 & - & 1 & - & 150 \\
\hline 7 & - & 1 & - & 123 & 1 & - & 7 & 132 \\
\hline 8 & - & - & - & 95 & - & - & 5 & 100 \\
\hline 9 & - & - & - & 61 & - & - & 6 & 67 \\
\hline 10 & - & - & - & 52 & - & - & 5 & 57 \\
\hline 11 & - & - & - & 40 & - & - & 3 & 43 \\
\hline 12 & - & - & - & 27 & - & - & 4 & 31 \\
\hline 13 & - & - & - & 14 & - & - & 1 & 15 \\
\hline 14 & - & - & - & 3 & - & - & - & 3 \\
\hline Total & 8 & 6 & 3 & 1635 & 1 & 1 & 93 & 1747 \\
\hline Total \% & $0,50 \%$ & $0,30 \%$ & $0,20 \%$ & $93,60 \%$ & $0,10 \%$ & $0,10 \%$ & $5,30 \%$ & $100 \%$ \\
\hline
\end{tabular}

Tabla 7.1. Clases artefactuales de LP-2. 


\begin{tabular}{|c|c|c|c|c|c|}
\hline Nivel & BAS & OBS & RIO & SIL & Total \\
\hline 0 & - & $18(18,9 \%)$ & - & $77(81,1 \%)$ & $95(100 \%)$ \\
\hline 1 & - & $28(8,1 \%)$ & - & $318(91,9 \%)$ & $346(100 \%)$ \\
\hline 2 & $1(0,3 \%)$ & $11(3,8 \%)$ & - & $281(95,9 \%)$ & $293(100 \%)$ \\
\hline 3 & $1(0,4 \%)$ & $10(4,3 \%)$ & - & $220(95,2 \%)$ & $231(100 \%)$ \\
\hline 4 & - & $16(10,6 \%)$ & - & $135(89,4 \%)$ & $151(100 \%)$ \\
\hline 5 & - & $2(6,1 \%)$ & - & $31(93,9)$ & $33(100 \%)$ \\
\hline 6 & - & $13(8,7 \%)$ & $1(0,7 \%)$ & $136(90,7)$ & $150(100 \%)$ \\
\hline 7 & - & $4(3 \%)$ & - & $128(97 \%)$ & $132(100 \%)$ \\
\hline 8 & - & $7(7 \%)$ & - & $93(93 \%)$ & $100(100 \%)$ \\
\hline 9 & - & $9(13,4 \%)$ & - & $58(86,6 \%)$ & $67(100 \%)$ \\
\hline 10 & - & $3(5,3 \%)$ & - & $54(94,7 \%)$ & $57(100 \%)$ \\
\hline 11 & - & $2(4,7 \%)$ & $1(2,3 \%)$ & $40(93 \%)$ & $43(100 \%)$ \\
\hline 12 & - & $2(6,5 \%)$ & - & $29(93,5 \%)$ & $31(100 \%)$ \\
\hline 13 & - & - & - & $15(100 \%)$ & $15(100 \%)$ \\
\hline 14 & $2(0,1 \%)$ & $125(7,2 \%)$ & $2(0,1 \%)$ & $1618(92,6 \%)$ & $3(100 \%)$ \\
\hline Total & -21747 \\
\hline
\end{tabular}

Tabla 7.2. Distribución y frecuencia de materias primas por nivel de excavación en LP-2. La diferencia en color de las files señala las dos unidades litológicas antes descriptas.

En las figura 7.5 se detalla la proporción relativa de artefactos en cada nivel. Se observan dos picos de abundancia, uno en los niveles superiores de A y otro en los superiores de B. Las rocas silíceas son las más abundantes, superando en todos los niveles el $80 \%$ del total (Figura 7.6), se observa una disminución en la densidad de artefactos de sílice en los niveles superiores (niveles 1 y 2). La obsidiana sigue en importancia, con frecuencias que van de $0,7 \%$ a $10,4 \%$ del total, mientras que la riolita y basaltos son las menos representadas. Se observa un leve aumento en la frecuencia de obsidiana en la Unidad A respecto a la B (Tabla 7.3). También se destaca la ausencia de riolita en la Unidad A y de basalto en la Unidad B. En la tabla 7.4, se presentan las clases artefactuales registrándose desechos de talla, percutores, núcleos, artefactos de formatización unifacial, bifacial y otros elementos no identificados. Se destaca una mayor frecuencia de artefactos formatizados en la Unidad A (bifacial, unifacial y rastros complementarios), mientras que en la B solo hay artefactos de formatización unifacial. Esta última unidad es la que registra núcleo $(n=1)$ y un percutor $(n=1)$. 


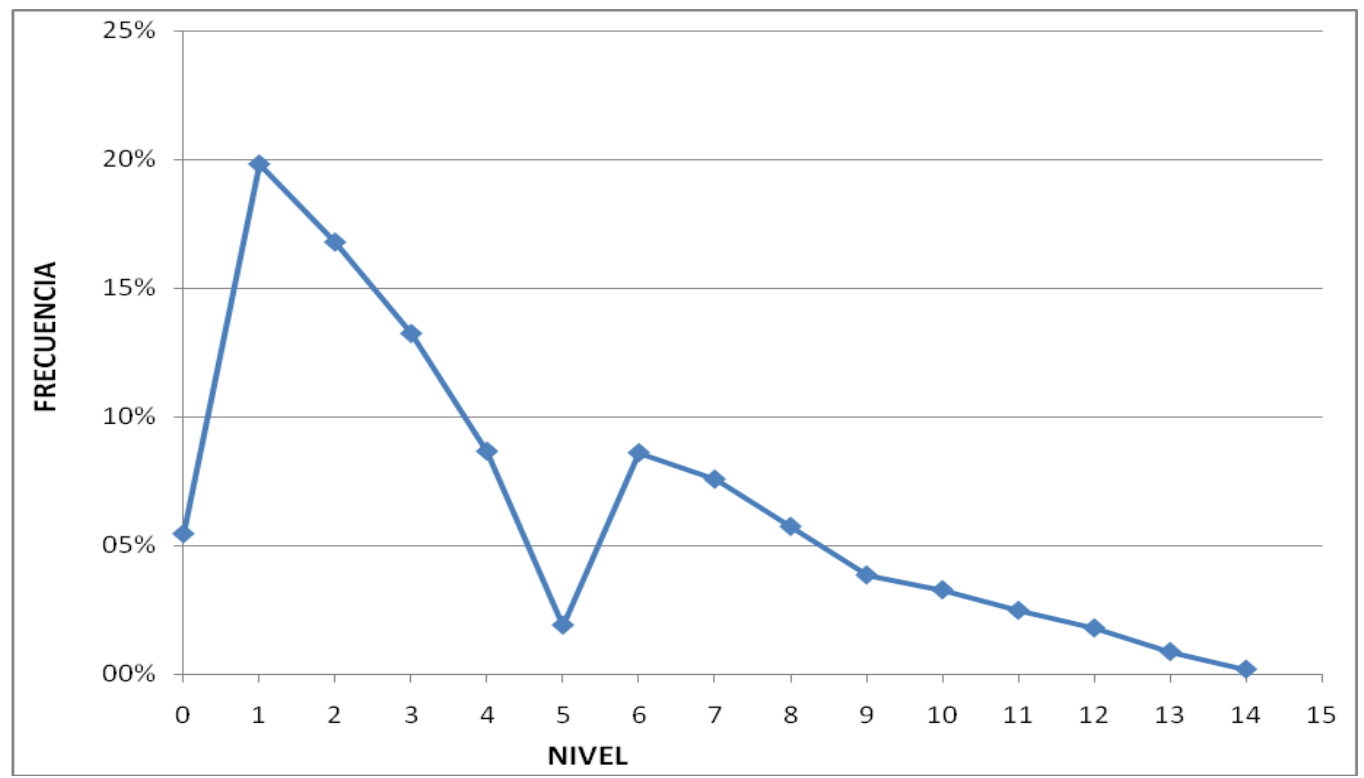

Figura 7.5. Frecuencia de artefactos en LP-2.

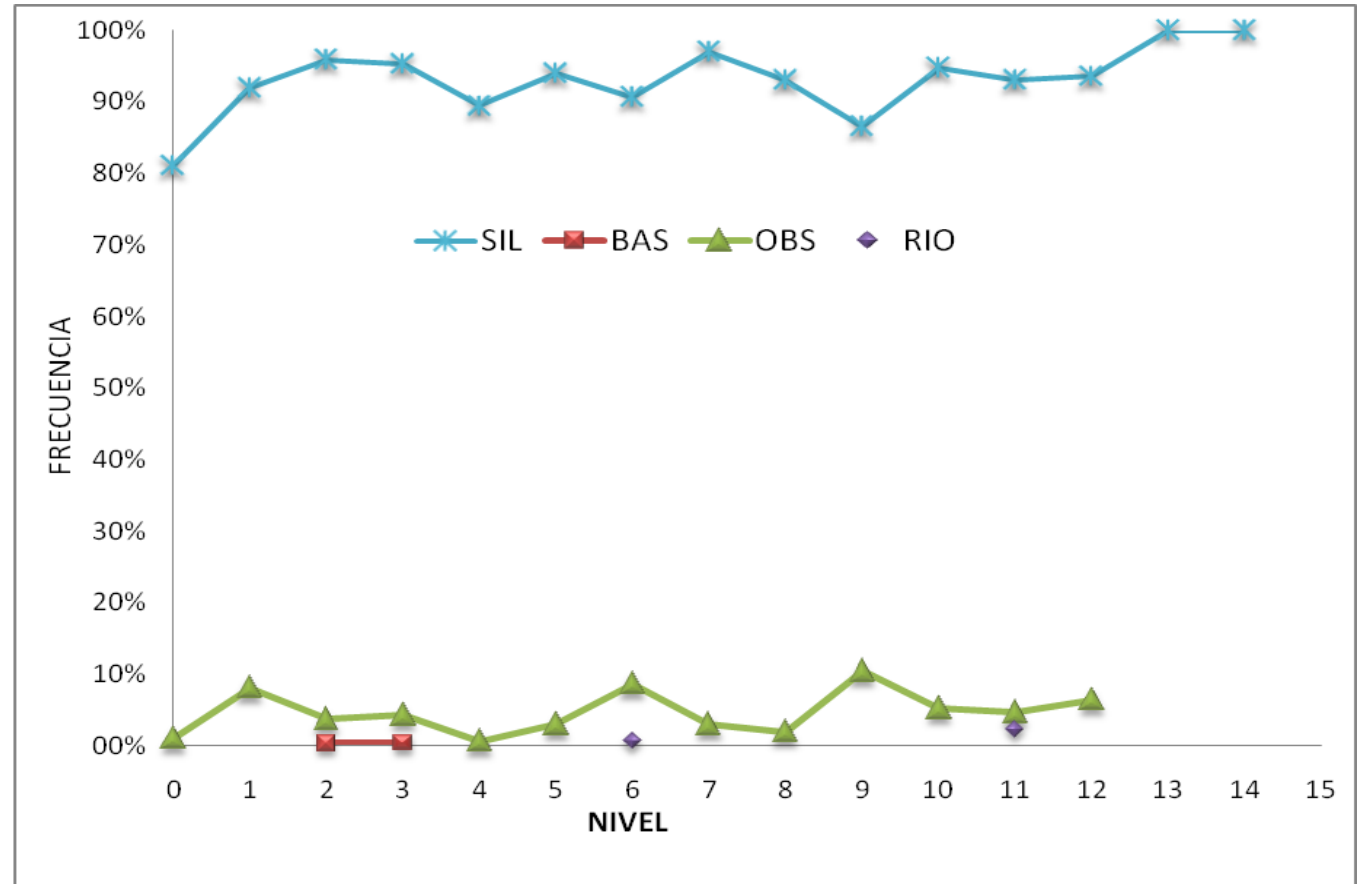

Figura 7.6. Frecuencia de materias primas por nivel de excavación en LP-2. 


\begin{tabular}{|c|c|c|c|c|c|}
\hline Unidad & BAS & OBS & RIO & SIL & Total \\
\hline A (nivel 1-4) & $0,17 \%(2)$ & $7,40 \%(85)$ & - & $92,43 \%(1062)$ & $100 \%(1149)$ \\
\hline B (nivel 5-14) & - & $6,69 \%(40)$ & $0,33 \%(2)$ & $92,98 \%(556)$ & $100 \%(598)$ \\
\hline
\end{tabular}

Tabla 7.3. Frecuencia de materias primas en bloque temporal. Entre paréntesis se indica el número de artefactos.

\begin{tabular}{|c|c|c|c|c|c|c|c|c|}
\hline Unidad & $\begin{array}{c}\text { AF } \\
\text { Bifacial }\end{array}$ & $\begin{array}{c}\text { AF } \\
\text { Unifacial }\end{array}$ & ASF RC & DT & Núcleo & Percutor & ND & Total \\
\hline A (niveles 1-4) & $0,70 \%(8)$ & $0,44 \%(5)$ & $0,26 \%(3)$ & $93,21 \%(1071)$ & - & - & $5,40 \%(62)$ & $65,7 \%(1149)$ \\
\hline B (niveles 5-14) & - & $0,17 \%(1)$ & - & $94,31 \%(564)$ & $0,17 \%(1)$ & $0,17 \%(1)$ & $5,18 \%(31)$ & $34,2 \%(598)$ \\
\hline
\end{tabular}

Tabla 7.4. Frecuencia de clase artefactual por unidad estratigráfica. Entre paréntesis se indica el número de artefactos.

\subsection{1b LA CORREDERA (LC)}

La Corredera es un abrigo rocoso localizado en las coordenadas $36^{\circ} 31^{\prime} 29^{\prime \prime}$ LS y $68^{\circ} 32^{\prime} 05^{\prime \prime}$ LO a los $1.160 \mathrm{msnm}$ (Figura7.8). El abrigo posee una abertura de $36 \mathrm{~m}$ orientada hacia al este y una profundidad máxima de ca. $8 \mathrm{~m}$ (Figura 7.9) y se formó en la Formación sedimentaria Puesto Barros (González Díaz 1972); A pesar de la amplitud de la cueva, la superficie excavable es muy reducida debido a los derrumbes de su techo. En el sitio se excavó un área de $2 \times 2 \mathrm{~m}$, denominada A-1 que fue dividida en cuatro sectores $1 \times$ $1 \mathrm{~m}$. El trabajo se realizó siguiendo niveles artificiales de $5 \mathrm{~cm}$ hasta alcanzar las capas estériles (nivel 11, $55 \mathrm{~cm}$ ); en dos sectores se continuó el sondeo para verificar el comportamiento de los sedimentos más profundos (nivel 14, $70 \mathrm{~cm}$ ) (Gil 2006). 


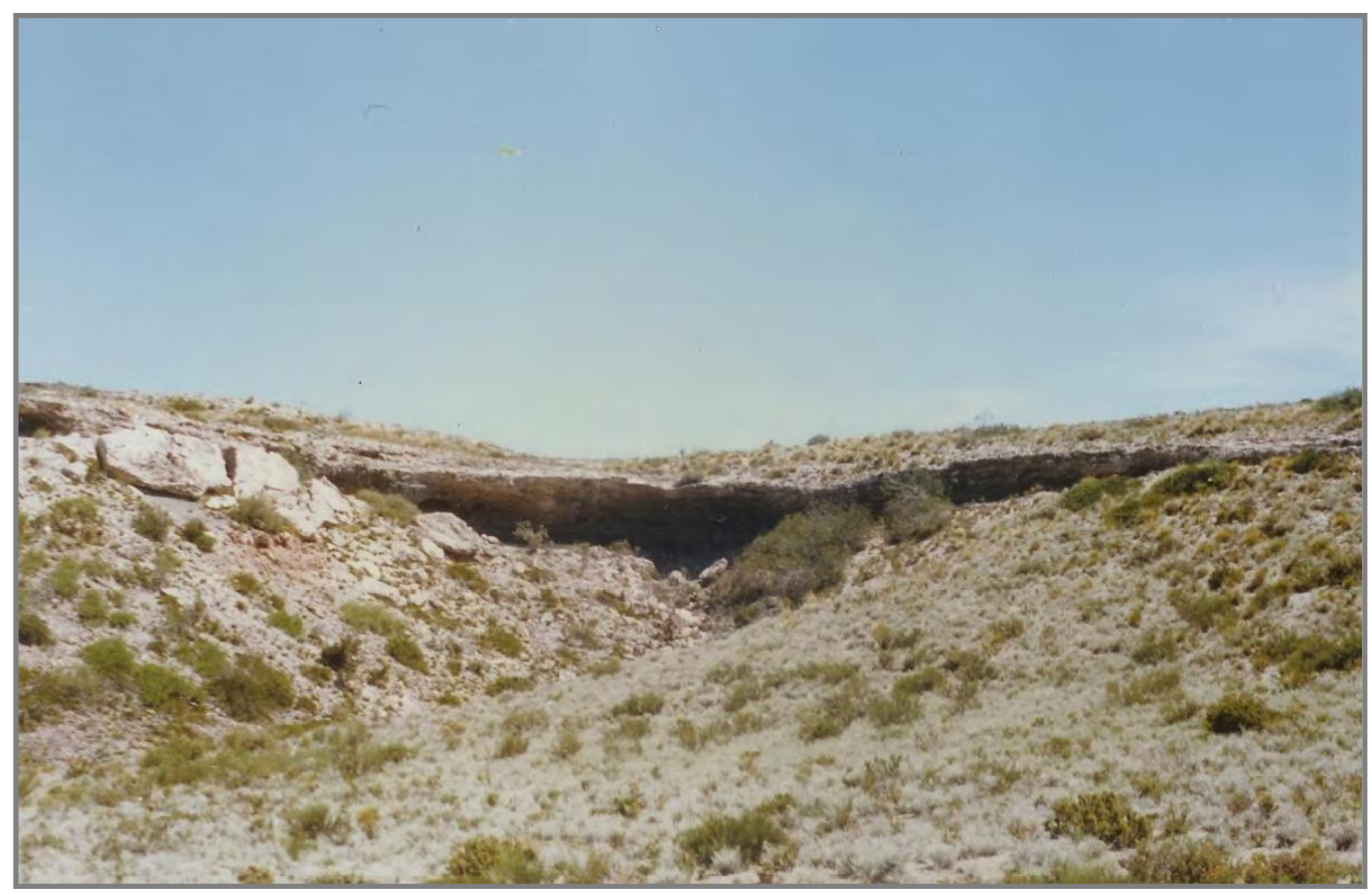

Figura 7.8. Abrigo rocoso La Corredera.

La estratigrafía de LC (Figura 7.10) consta de una capa superior de guano de ovicáprido (Unidad A), seguida por una de sedimento arenoso que incluye clastos y guano de la capa superior (Unidad B). La unidades C y E son posibles rellenos de pozos. Posiblemente producto del relleno de una perturbación antrópica postdepositacional, inferida por la presencia de sedimentos arenosos mezclados con guano (Gil 2006). El sedimento de los niveles inferiores es arenoso y no contiene guano (Unidad D) (Gil 2006). Se recuperaron restos de fauna y carbón en todas las extracciones y una camada vegetal, interpretada como de construcción humana. No se registraron fragmentos cerámicos (Gil 2006). 


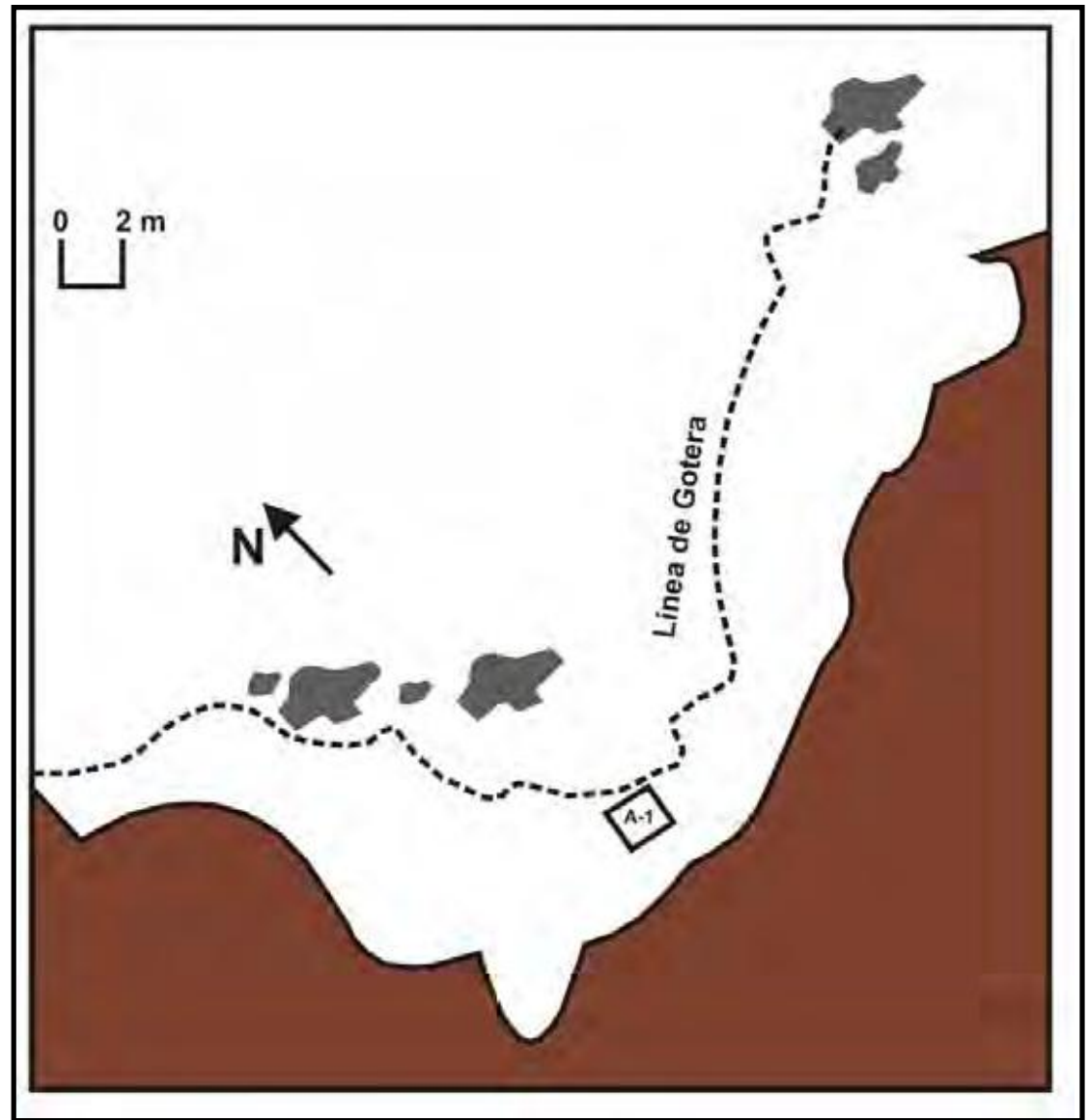

Figura 7.9. Planta del sitio La Corredera. Tomada de Gil (2006).

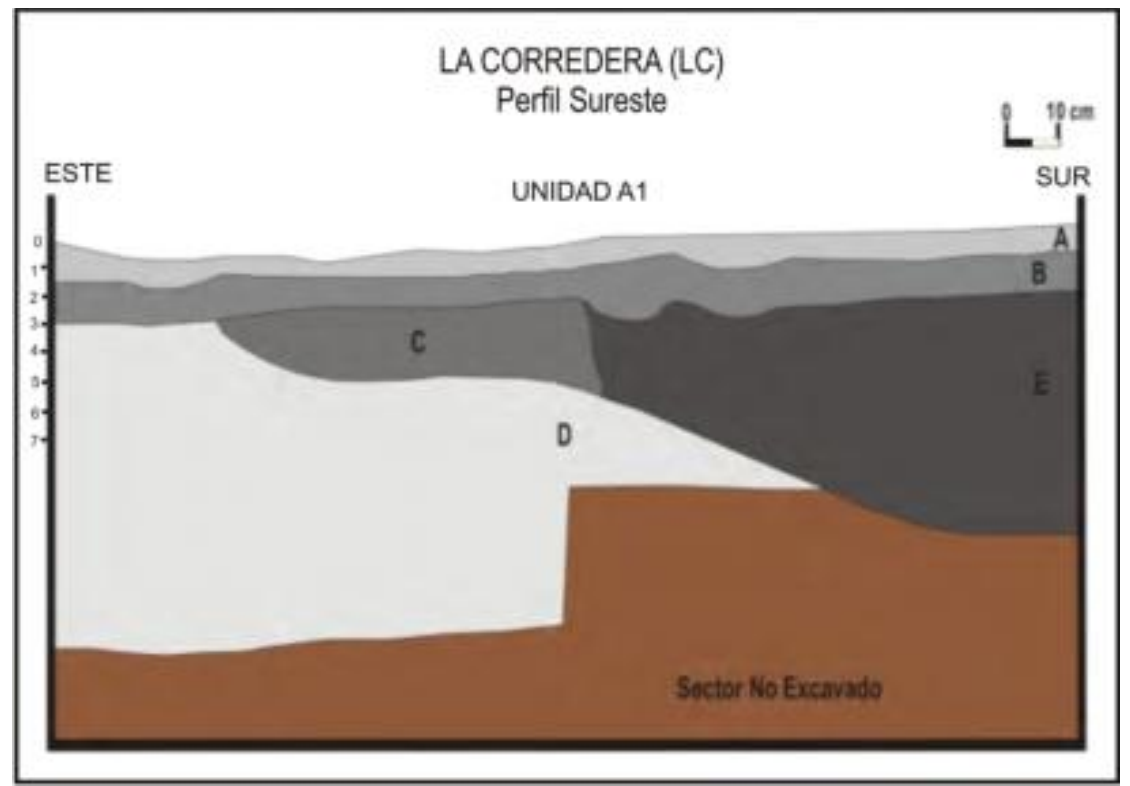

Figura 7.10. Estratigrafía del sitio La Corredera, perfil sureste. Tomada de Gil (2006). 
La cronología del sitio ha sido determinada mediante ${ }^{14} \mathrm{C}$ sobre una muestra de carbón proveniente del nivel 7, con el resultado de $1930 \pm 50$ años AP (LP-1012). Esta datación proviene de los niveles inferiores asociados con material arqueológico y correspondería a las primeras ocupaciones humanas del abrigo (Gil 2006). La baja depositación de restos y la escasa diversidad de clases de materiales recuperadas llevaron a proponer que el registro fue resultado de ocupaciones efímeras. Los materiales no reflejan actividades de subsistencia (Gil 2006; Giardina 2010), pero se destacan las actividades de talla en las etapas medias u finales de la cadena de producción y asociada quizás a la explotación de la cantera cercana denominada Piedras Bayas (Gil 2006).

Para el análisis de los artefacto líticos se consideró el total de muestra recuperada $(n=35)$. En la tabla 7.5 se detallan las clases artefactuales registradas $(n=1)$, las frecuencias por unidad estratigráfica y nivel de excavación. Los artefactos, en su mayoría desechos de talla, se presentan enteros en un $60 \%(n=21)$, mientras los fracturados $(28 \%, n=10)$ e indeterminados $(11,4 \%, n=4)$ son minoritarios. La totalidad de la muestra corresponde a rocas silíceas. En la figura 7.11, se presenta la distribución del registro lítico según unidades estratigráficas, denotando diferencias marcadas en las frecuencias de las unidades $\mathrm{D}$ y $E$.

\begin{tabular}{|c|c|c|}
\hline \multirow{2}{*}{ Unidad Estratigráfica } & \multicolumn{2}{|c|}{ Artefactos } \\
\cline { 2 - 3 } & DT & ND \\
\hline A & 1 & - \\
\hline B & 2 & - \\
\hline C & 1 & 3 \\
\hline D & 22 & 1 \\
\hline E & 5 & $4(11,4 \%)$ \\
\hline Total & $31(88,6 \%)$ & - \\
\hline
\end{tabular}

Tabla 7.5. Abundancia de artefactos y clases artefactuales por nivel de excavación en LC. 


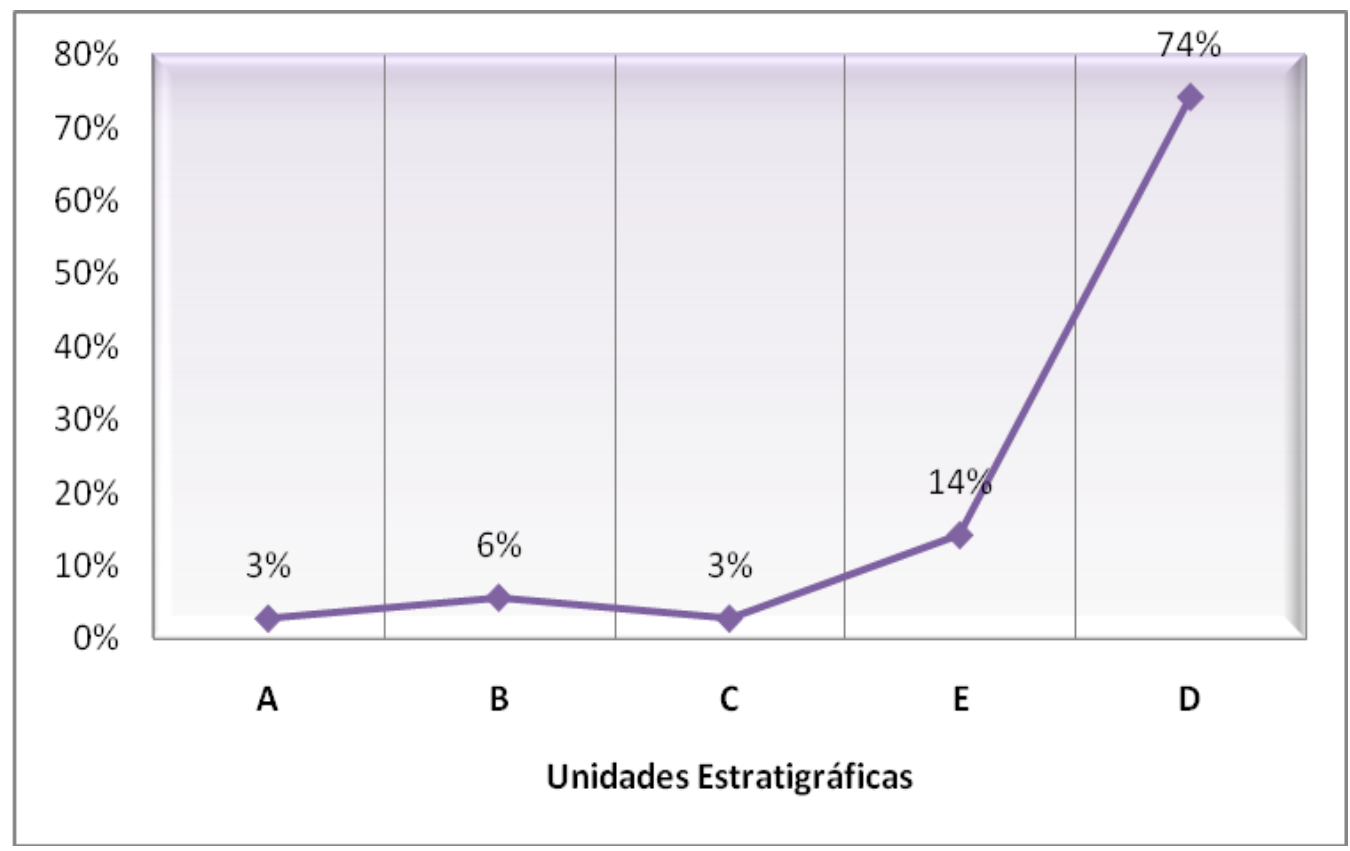

Figura 7.11. Frecuencia de artefactos de roca silícea por unidad estratigráfica.

\subsection{1c PIEDRAS BAYAS (PB)}

Piedras Bayas, se encuentra aproximadamente en las coordenadas a $36^{\circ} 31^{\prime} 27^{\prime \prime} \mathrm{L}$. S y $68^{\circ} 32^{\prime} 21^{\prime \prime}$ L. O, por encima del puesto de la familia Cerna (Figura 7.12). Es una amplia distribución superficial de rocas silíceas talladas. La roca silícea es de origen sedimentario (Narciso et al. 2011a; Bertotto 2012) y se dispone a modo de filones discontinuos, dado que en parte se encuentra sepultado bajo sedimentos actuales. Dichos filones posee una superficie expuesta que varía entre los 6.838 y los $861 \mathrm{~m}^{2}$ (Gil 2006). Los primeros trabajos en el sitio fueron efectuados en el año 1998 (Gil 2006). Se identificaron y relevaron 9 filones rocosos aflorantes con signos de explotación humana. También se relevaron los materiales líticos superficiales distribuidos entre esos filones, abordando un área aproximada de $1 \mathrm{~km}^{2}$. El muestreo superficial se diseñó con cinco transectas (Tabla 7.6) de modo tal que vincule los filones con los puntos del espacio con mayor concentración de hallazgos, entre los que se destaca los sitios La Corredera y LP-2, la vertiente de agua cercana al puesto y los sectores de uso antrópico actual (puesto y corrales de animales). 
Gil (2006) observó que en el registro superficial predominan los productos de talla y desechos no diferenciados o misceláneas, artefactos cuyas densidades son altas en las proximidades del filón y disminuyen en los sectores alejados, demarcando áreas de mayor concentración (Figura 7.13). La información superficial analizada por Gil (2006) es retomada en esta tesis.

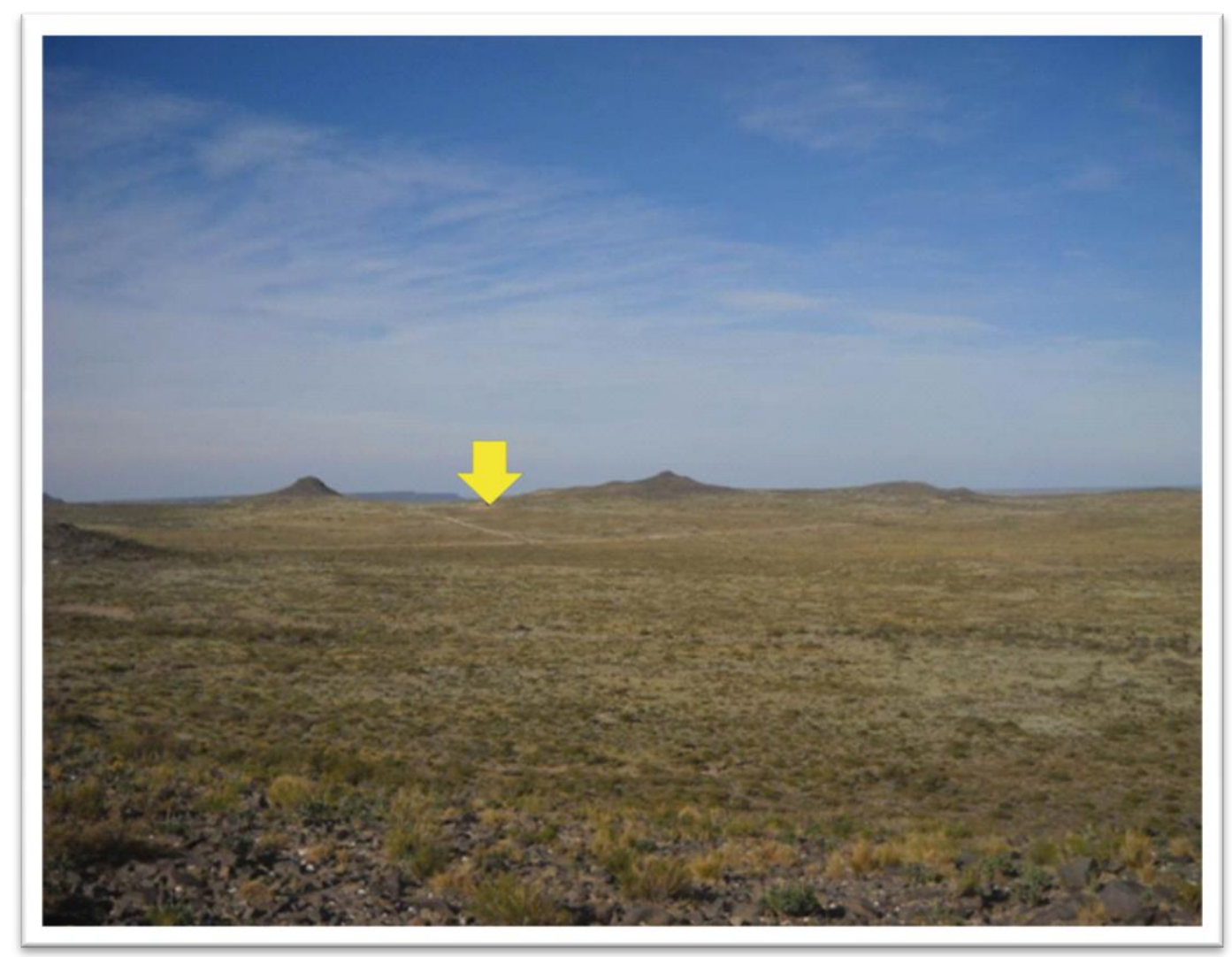

Figura 7.12. Vista de la localidad La Peligrosa; la flecha señala el afloramiento Piedras Bayas (Foto: Walter Bertotto). 


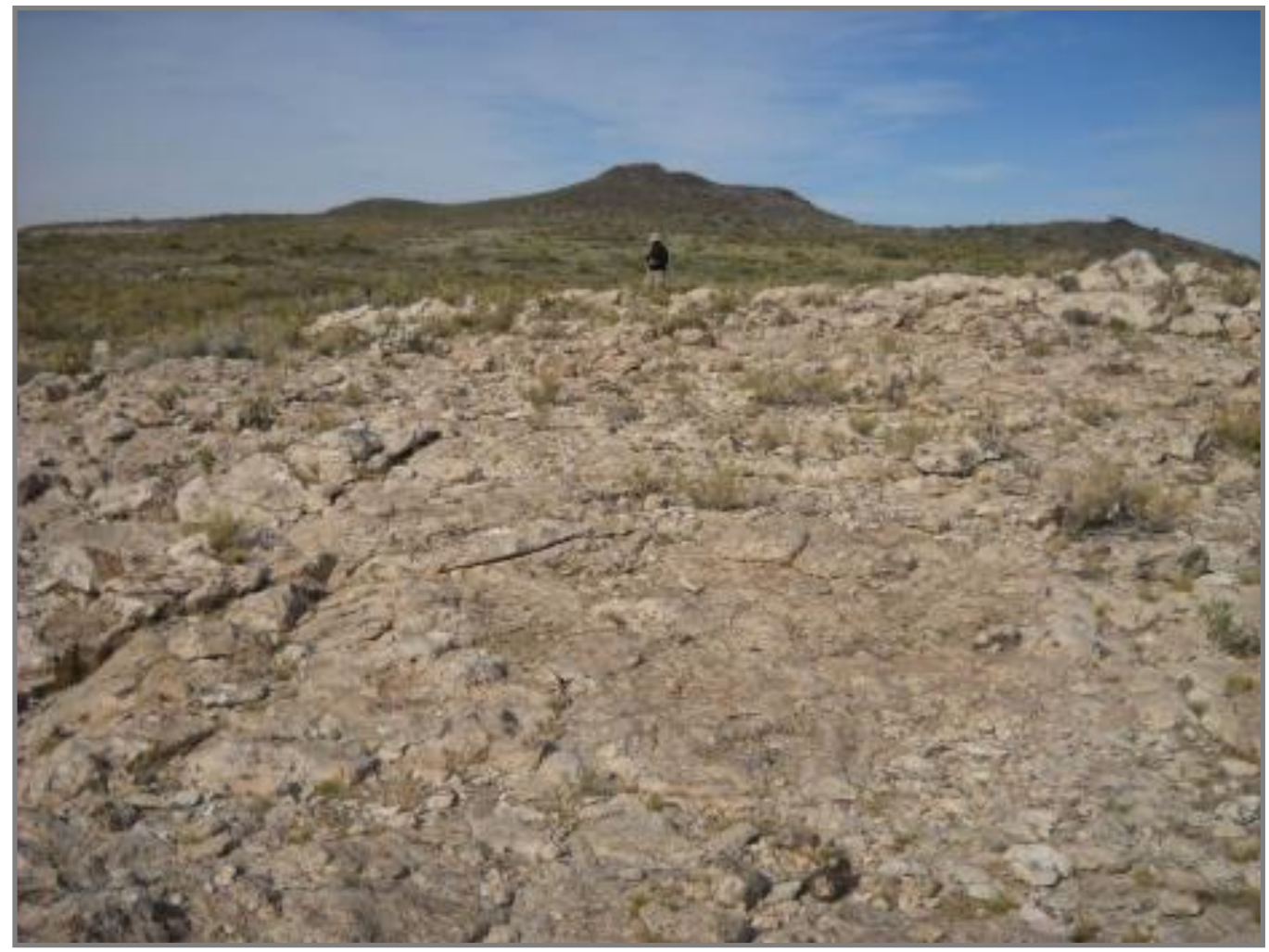

Figura 7.13. Fuente primaria Piedras Bayas (Foto: Walter Bertotto).

En cada unidad se recolectó la totalidad de los materiales superficiales, con excepción de los de gran tamaño que fueron cuantificados y descriptos in situ (Tabla 7.6). El tamaño de las unidades de muestreo fue de $2 \times 2 \mathrm{~m}$, excepto en la transecta LC-Puesto que siguió unidades de $4 \mathrm{~m}$. x $270 \mathrm{~m}$. El número total de muestreos realizados en la transecta es de 304, abarcando una superficie aproximada de $1.535 \mathrm{~m}^{2}$; en 145 de ellos no se realizaron hallazgos. Los artefactos recolectados en las transectas realizadas en la cantera PB suman $n=1323$, lo que permite calcular una densidad máxima de 0,86155 y una mínima de 1,89432. En la tabla 7.7 se detallan las frecuencias de clases artefactuales identificadas en PB. Para el análisis tecnológico de los artefactos (Tabla 7.7), se tuvieron en cuenta las clases artefactuales, la materia prima y la abundancia. La información obtenida será útil para discutir estadios de manufactura presentes en áreas de cantera y analizar cómo se distribuyen las mismas en el espacio regional.

Las condiciones de visibilidad varían entre muy buenas (59\%) y buenas (23\%). La pendiente del terreno es suave en el $66 \%$ de las unidades y regular en el $18 \%$, siendo poco 
frecuentes las pendientes nulas (14\%) y pronunciadas (2\%). En las cercanías del puesto y la vertiente de agua, se observan cárcavas de escurrimiento de agua.

\begin{tabular}{|c|c|c|c|c|c|c|c|c|c|}
\hline 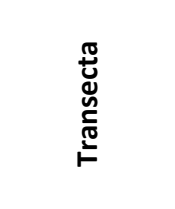 & 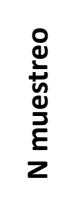 & 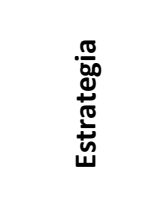 & 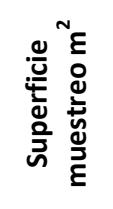 & 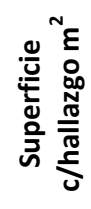 & 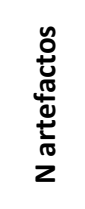 & 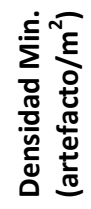 & 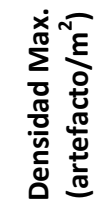 & 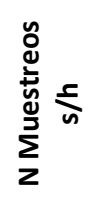 & $\begin{array}{l}\text { N } \\
\frac{0}{\partial} \\
\frac{0}{\alpha}\end{array}$ \\
\hline PB6-LC & 95 & $1 \times 1(50 \%)$ & 380 & 184 & 118 & 0,64 & 0,31 & 49 & 4 \\
\hline PB6-PB7 & 70 & $1 \times 2(33 \%)$ & 280 & 232 & 1162 & 5,01 & 4,15 & 12 & 3 \\
\hline PB6-Vert. & 80 & $1 \times 4(20 \%)$ & 320 & 156 & 11 & 0,07 & 0,034 & 41 & 1 \\
\hline Vert.-Puesto & 12 & $1 \times 4(20 \%)$ & 48 & 40 & 24 & 0,60 & 0,5 & 4 & 2 \\
\hline LC-Puesto & 47 & $\begin{array}{c}\text { Continuo } \\
(100 \%)\end{array}$ & 507,6 & 86,4 & 8 & 0,09 & 0,0001 & 39 & 1 \\
\hline Total & 304 & - & 1535,6 & 698,4 & 1323 & 1,89 & 0,86 & 145 & 4 \\
\hline
\end{tabular}

Tabla 7.6. Transectas de Piedras Bayas. Referencias: N: número de ítem; Min.: mínimo; Máx.:máximo; s/h: sin hallazgos.

\begin{tabular}{|c|c|c|c|c|c|c|}
\hline \multirow{2}{*}{ Transecta } & \multicolumn{5}{|c|}{ Artefactos } & Total \\
\cline { 2 - 7 } & INST & DT & Núcleo & Percutor & ND & - \\
\hline PB6-LC & 2 & 135 & 3 & 1 & 116 & 257 \\
\hline PB6-PB7 & 6 & 1156 & 6 & - & 432 & 3600 \\
\hline PB6-Vert. & - & 11 & - & - & 1 & 445 \\
\hline Vert.-Puesto & 1 & 23 & - & - & - & 25 \\
\hline LC-Puesto & - & 8 & - & 1 & 2983 & 4335 \\
\hline Total & 9 & 1333 & 9 & & & 8 \\
\hline
\end{tabular}

Tabla 7.7. Clases artefactuales por transecta en Piedras Bayas.

\subsection{1d LA LEONA (LLE)}

El sitio La Leona es una cantera taller y se encuentra al oeste de la Ruta Provincial $\mathrm{N}^{\circ} 180$, aproximadamente a los $36^{\circ} 31^{\prime} 33^{\prime \prime}$ L. S y $68^{\circ} 33^{\prime} 52 \mathrm{~L}$. O. Es un afloramiento de rocas silíceas que, al igual que el sitio Piedras Bayas, está asociado con asomos basálticos del Grupo Palauco (Figura 7.14). Se encuentra a ca. $3 \mathrm{~km}$ al suroeste de PB. En los trabajos de campo del año 2002-2003 se realizó un estudio superficial con unidades de muestreo de 
$200 \times 25$ m. El muestreo se inició próximo a la ruta provincial y tuvo una extensión aproximada de $2 \mathrm{~km}$.

En la tabla 7.8 se presenta la información relevada en LLE. La roca silícea es la única materia prima registrada. Los artefactos corresponden en un $98 \%(n=53)$ a desechos de talla y en un $2 \%(n=1)$ a núcleos. Los desechos se presentan enteros en un $91 \%(n=49)$ y el $9 \%(n=5)$ restante fracturado. Las condiciones de visibilidad son muy buenas (98\%) y buenas (2\%), con una pendiente suave (95\%) y, en menor medida, nula (5\%). En la tabla 7.9, se detallan las frecuencias de clases artefactuales.

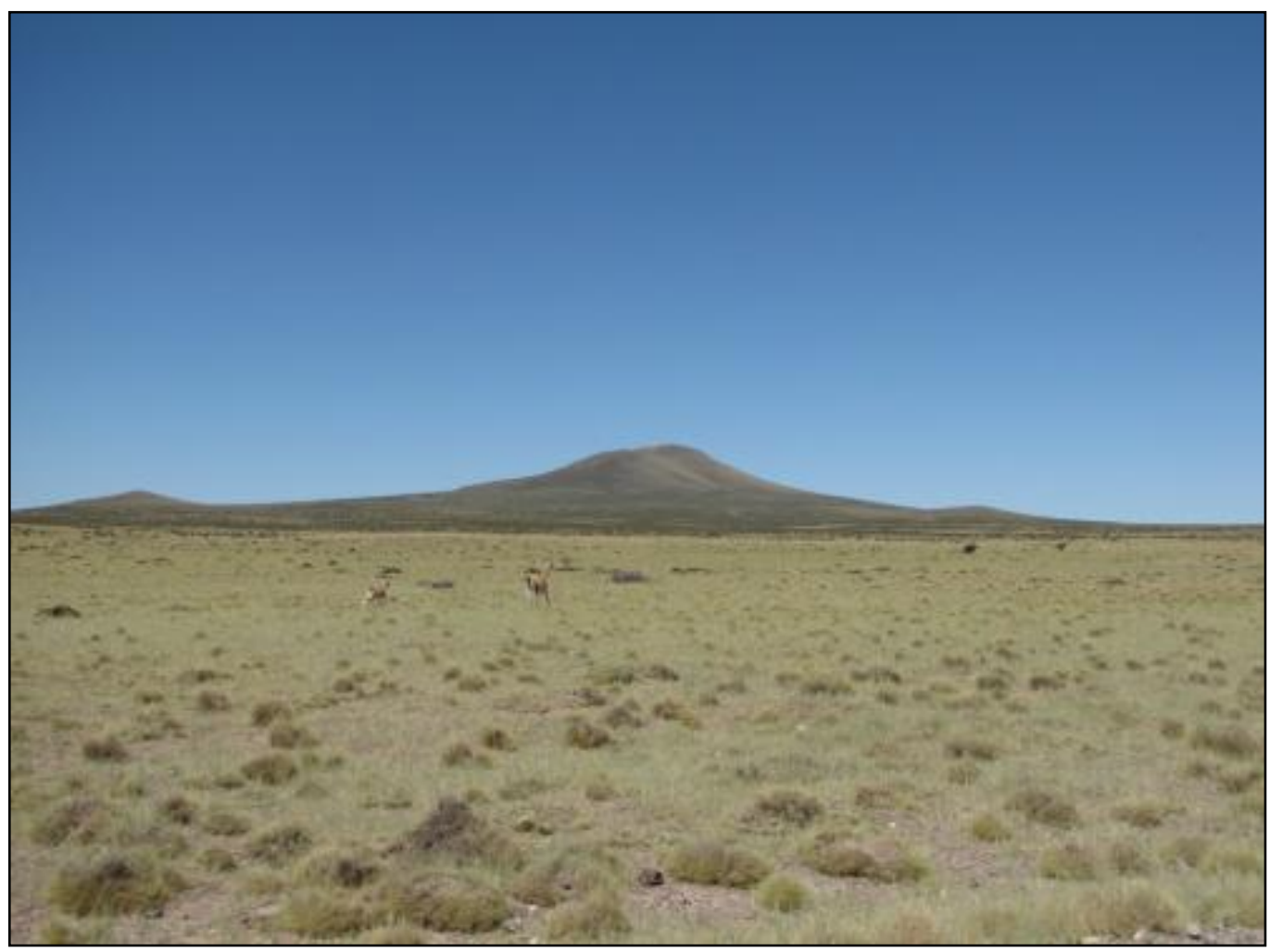

Figura 7.14. Vista del Cerro La Leona desde Ruta Provincial 180.

\begin{tabular}{|c|c|c|c|c|c|c|c|c|c|}
\hline Transecta & $\begin{array}{c}\mathbf{N} \\
\text { muestreos }\end{array}$ & Estrategia & $\begin{array}{c}\text { Superficie } \\
\text { muestreo } \\
\mathbf{m}^{\mathbf{2}}\end{array}$ & $\begin{array}{c}\text { Superfi } \\
\text { cie } \\
\text { c/halla } \\
\text { zgo } \mathbf{~ m}^{2}\end{array}$ & $\mathbf{N}$ & $\begin{array}{c}\text { Densida } \\
\mathbf{d} \text { Max. }\end{array}$ & $\begin{array}{c}\text { Densid } \\
\text { ad } \\
\text { Min. }\end{array}$ & $\begin{array}{c}\text { Muestres } \\
\text { s/ hallazgo } \\
\text { hal }\end{array}$ & Riqueza \\
\hline LLE & 7 & $\begin{array}{c}\text { Continuo } \\
(100 \%)\end{array}$ & 19000 & 4000 & $\begin{array}{c}5 \\
4\end{array}$ & 0,00284 & 2000 & 5 & 2 \\
\hline
\end{tabular}

Tabla 7.8. Muestreo superficial en La Leona. 


\begin{tabular}{|c|c|c|c|c|}
\hline \multirow{2}{*}{ LLE } & \multirow{2}{*}{ Superficie en $\mathbf{~ m}^{2}$} & \multicolumn{2}{|c|}{ Artefactos } & \multirow{2}{*}{ Densidad } \\
\cline { 3 - 4 } & & DT & Núcleo & \\
\hline 1 & 7400 & - & - & - \\
\hline 2 & 2400 & - & - & - \\
\hline 3 & 2000 & 53 & - & 0,0265 \\
\hline 4 & 3000 & - & - & - \\
\hline 5 & 2000 & - & 1 & 0,0005 \\
\hline 6 & 1000 & - & - & - \\
\hline 7 & 1200 & - & - & - \\
\hline Total & 19000 & 53 & 1 & 0,00284 \\
\hline
\end{tabular}

Tabla 7.9. Transecta LLE. Superficie por unidad de muestreo y clases artefactuales identificadas en LLE.

\subsection{1e LA PELIGROSA TRANSECTA 2 (LPT2)}

La transecta LPT2 se ubica al este de la localidad entre las coordenadas $68^{\circ} 31^{\prime} 39^{\prime \prime}$ $68^{\circ} 28^{\prime} 46^{\prime \prime}$ y $36^{\circ} 31^{\prime} 10^{\prime \prime} 36^{\circ} 31^{\prime} 4^{\prime \prime}$, cubriendo un área total de $46.000 \mathrm{~m}^{2}$. En el muestreo superficial intensivo se diseñó un muestreo por unidades. La transecta cubre una superficie de 4,2 km de largo por $10 \mathrm{~m}$ de ancho. Se recuperó un total de 36 artefactos en 6 unidades de muestreo. La densidad artefactual máxima obtenida es de 0,00078, mientras que la mínima es de 0,002. La riqueza o número de clases presentes en el área es de 2, representada en ambos casos por instrumentos (Tabla 7.10). La materia prima registrada en todas las unidades es la roca silícea.

La visibilidad de la cantera LPT2 es predominantemente buena (98\%) a regular (8\%), en éste sitio se observó la presencia de numerosas cárcavas y un río seco en la unidad de muestreo número 7 (unidad 7). La pendiente del terreno es nula en el $50 \%$ de las unidades, seguida por pendientes suaves $(33 \%)$ y regulares $(17 \%)$.

\begin{tabular}{|c|c|c|c|c|c|c|}
\hline LPT2 & $\begin{array}{c}\text { Superficie } \\
\mathbf{m}^{\mathbf{2}}\end{array}$ & $\begin{array}{c}\text { AF } \\
\text { Bifacial }\end{array}$ & ASF RC & DT & Total & Densidad \\
\hline $\mathbf{1}$ & 5390 & 1 & 2 & 13 & 16 & 0,002968 \\
\hline $\mathbf{2}$ & 2500 & - & - & - & - & - \\
\hline
\end{tabular}




\begin{tabular}{|c|c|c|c|c|c|c|}
\hline $\mathbf{3}$ & 2520 & 1 & 1 & 3 & 5 & 0,001984 \\
\hline $\mathbf{4}$ & 3080 & - & - & - & - & - \\
\hline $\mathbf{5}$ & 3620 & - & - & - & - & - \\
\hline $\mathbf{6}$ & 3830 & - & - & - & - & - \\
\hline $\mathbf{7}$ & 4820 & - & - & - & - & - \\
\hline $\mathbf{8}$ & 4080 & - & - & - & - & - \\
\hline $\mathbf{9}$ & 410 & - & 1 & - & 1 & 0,002439 \\
\hline $\mathbf{1 0}$ & 4610 & - & - & 12 & 12 & 0,002603 \\
\hline $\mathbf{1 1}$ & 7540 & - & - & 1 & 1 & 0,000132 \\
\hline $\mathbf{1 2}$ & 3600 & - & - & 1 & 1 & 0,000277 \\
\hline Total & 46000 & 2 & 4 & 30 & 36 & 0,000782 \\
\hline
\end{tabular}

Tabla 7.10. Distribución de artefactos por unidad de muestreo en LPT2.

\subsubsection{ANÁLISIS TECNOLÓGICO DE LA LOCALIDAD LA PELIGROSA}

En la localidad La Peligrosa, Gil (2006) analizó los artefactos líticos de sitios LP-2 (Sondeo Z-98), LP-1 (Alero), LC y PB. Aquí se retoman los estudios disponibles (sitio LC) y se amplía la información tecnológica con el análisis de los conjuntos de LP-2 (cuadrícula A1), LLE y LPT2. En el caso de PB se considera en otra sección la información superficial obtenida en estudios previos (Gil 2006). El total de la muestra analizada es de $n=1875$ artefactos líticos.

\subsection{2a MATERIAS PRIMAS LÍTICAS}

La materia prima más frecuente en la localidad es la roca silícea $(93,1 \%, n=1744)$, le siguen en importancia la obsidiana $(6,7 \%, n=125)$, la riolita $(0,1 \%, n=2)$ y el basalto $(0,1 \%$, $\mathrm{n}=2$ ). La mayor diversidad de rocas se encuentra en el sitio LP-2, donde se registran las cuatro materias primas, mientras que en los sitios restantes sólo se han documentado artefactos confeccionados sobre rocas silíceas. De modo que la distribución de las rocas no es homogénea entre sitios, así como tampoco en LP-2. Al considerar la distribución interna en éste último sitio, se observa que las rocas silíceas son las más frecuentemente 
explotadas, seguidas por las obsidianas y en menor frecuencia las riolitas y los basaltos. En la localidad predomina la calidad para la talla muy buena $(43,4 \%)$ y buena $(19 \%)$, seguida por la excelente $(6,8 \%)$ y la regular $(4,1 \%)$ (Tabla 7.11$)$.

\begin{tabular}{|c|c|c|c|c|c|c|c|c|}
\hline & SITIO & MP & $\mathbf{R}$ & B & MB & $E$ & SD & Total \\
\hline \multirow{5}{*}{ 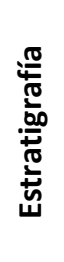 } & LC & SIL & - & - & - & - & 35 (100\%) & 35 \\
\hline & \multirow{4}{*}{ LP-2 } & BAS & $1(50 \%)$ & $1(50,0 \%)$ & - & - & - & 2 \\
\hline & & OBS & - & - & $5(4 \%)$ & $120(96,0 \%)$ & - & 125 \\
\hline & & RIO & $1(50 \%)$ & - & - & - & $1(50 \%)$ & 2 \\
\hline & & SIL & $72(4,4 \%)$ & $333(20,5 \%)$ & $742(45,9 \%)$ & $7(0,4 \%)$ & $465(28,7 \%)$ & 1619 \\
\hline \multirow{3}{*}{ 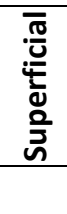 } & LLE & SIL & $2(3,7 \%)$ & $18(33,3 \%)$ & $34(62,9 \%)$ & - & - & 54 \\
\hline & LPT2 & SIL & $1(2,8 \%)$ & $6(16,7 \%)$ & $29(80,6 \%)$ & - & - & 36 \\
\hline & \multicolumn{2}{|c|}{ Total } & $76(4,1 \%)$ & $356(19,0 \%)$ & $810(43,2 \%)$ & $127(6,8 \%)$ & $502(26,8 \%)$ & 1872 \\
\hline
\end{tabular}

Tabla 7.11. Materias primas y calidad para la talla en LP. Referencias: R: regular; B: bueno; $M B$ : muy bueno; E: excelente, SD: sin dato relevado (corresponde conjuntos analizados por Gil 2006).

La mayor frecuencia de artefactos fragmentados, corresponde al sitio LP-2 (Tabla 7.12). El índice de fragmentación (Número mínimo de artefacto/ Número de piezas artefactuales) muestra que los artefactos fracturados han incrementado el tamaño de la muestra en LP, en un 23\% (Tabla 7.13). La fragmentación de la roca silícea presenta valores similares en sitios enterrados y superficiales, cercanos al $25 \%$. Los índices más altos corresponden a la riolita (50\%) y a la obsidiana (32\%) del sitio LP-2. Si evaluamos la incidencia de fragmentación separando las muestras de LP en registro superficial y estratigráfico, encontramos que hay menor incidencia de la fragmentación en los sitios superficiales, por lo cual se puede considerar que hay una baja incidencia de los procesos post - depositacionales en la fragmentación. 


\begin{tabular}{|c|c|c|c|c|c|c|c|c|c|}
\hline & Sitio & MP & Entero & $\%$ & Fracturado & $\%$ & ND & $\%$ & Tota \\
\hline \multirow{5}{*}{ 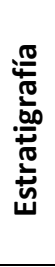 } & LC & SIL & 21 & $60 \%$ & 10 & $29 \%$ & 4 & $11 \%$ & 35 \\
\hline & \multirow{4}{*}{ LP-2 } & BAS & 2 & $100 \%$ & - & - & - & - & 2 \\
\hline & & OBS & 56 & $45 \%$ & 57 & $46 \%$ & 12 & $9 \%$ & 125 \\
\hline & & RIO & - & - & 2 & - & - & - & 2 \\
\hline & & SIL & 940 & $58 \%$ & 597 & $37 \%$ & 81 & $5 \%$ & 1618 \\
\hline \multirow{3}{*}{ 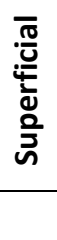 } & LLE & SIL & 50 & $91 \%$ & 4 & $9 \%$ & - & - & 54 \\
\hline & LPT2 & SIL & 21 & $58 \%$ & 15 & $42 \%$ & - & - & 36 \\
\hline & TOTAL & & 1090 & $58 \%$ & 685 & $37 \%$ & 97 & $5 \%$ & 1872 \\
\hline
\end{tabular}

Tabla 7.12. Estado de fragmentación de los conjuntos en LP.

\begin{tabular}{|c|c|c|c|c|c|c|c|c|c|c|c|c|c|}
\hline & $\begin{array}{c}\text { Siti } \\
0\end{array}$ & $\begin{array}{c}M \\
P\end{array}$ & Ent & $\begin{array}{l}\text { Fr. } \\
\text { Prox }\end{array}$ & $\begin{array}{l}\text { Fr. } \\
\text { Med }\end{array}$ & $\begin{array}{l}\text { Fr. } \\
\text { Dist }\end{array}$ & $\begin{array}{l}\text { Fr. } \\
\text { Mar }\end{array}$ & $\begin{array}{c}\text { Long } \\
\text { Der }\end{array}$ & $\begin{array}{l}\text { Long } \\
\text { Izq }\end{array}$ & $\begin{array}{l}\text { Fr. } \\
\text { ND }\end{array}$ & $\begin{array}{c}\text { NA } \\
S\end{array}$ & $\begin{array}{c}\mathrm{MN} \\
\mathrm{A}\end{array}$ & $\begin{array}{c}\text { MNA/N } \\
\text { AS }\end{array}$ \\
\hline \multirow{5}{*}{ 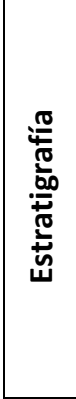 } & LC & SIL & 21 & 4 & - & 6 & - & - & - & - & 35 & 27 & $77 \%$ \\
\hline & \multirow{4}{*}{$\begin{array}{c}\text { LP- } \\
2\end{array}$} & $\begin{array}{c}\text { BA } \\
\mathrm{S}\end{array}$ & 2 & - & - & - & - & - & - & - & 2 & 2 & $100 \%$ \\
\hline & & $\begin{array}{c}\text { OB } \\
\mathrm{S}\end{array}$ & 56 & 25 & 4 & 22 & 1 & 1 & 3 & 1 & 125 & 84 & $67 \%$ \\
\hline & & $\begin{array}{l}\mathrm{RI} \\
\mathrm{O}\end{array}$ & - & 1 & - & - & - & - & - & 1 & 2 & 1 & $50 \%$ \\
\hline & & SIL & 940 & 298 & 71 & 192 & 3 & 12 & 17 & 4 & $\begin{array}{c}161 \\
8 \\
\end{array}$ & $\begin{array}{c}125 \\
5\end{array}$ & $78 \%$ \\
\hline \multirow{3}{*}{ 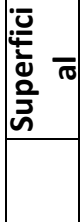 } & LLE & SIL & 50 & 2 & - & 2 & - & - & - & - & 54 & 52 & $96 \%$ \\
\hline & $\begin{array}{c}\mathrm{LPT} \\
2\end{array}$ & SIL & 21 & 7 & - & 5 & - & - & - & 3 & 36 & 28 & $78 \%$ \\
\hline & \multicolumn{2}{|c|}{ Total } & $\begin{array}{c}109 \\
0\end{array}$ & 337 & 75 & 227 & 4 & 13 & 20 & 9 & $\begin{array}{c}187 \\
2 \\
\end{array}$ & $\begin{array}{c}144 \\
9 \\
\end{array}$ & $77 \%$ \\
\hline
\end{tabular}

Tabla 7.13. Estado de fragmentación de los artefactos por materia prima en los conjuntos de LP. Referencia: MP: materia prima; Ent: entero; Fr. Prox: fragmento proximal; Fr. Med: fragmento medial; Fr. Dist: fragmento distal; Fr. Mar: fragmento marginal; Long Der: Fragmento longitudinal derecho; Long Izq: fragmento longitudinal izquierdo; Fr. ND: fragmento no diferenciado; ND: No Diferenciado; NAS: número de especímenes artefactuales; MNA: número mínimo de artefactos.

En cuanto al tamaño de los artefactos enteros por materias primas de LP (Tabla 7.14), se observan diferencias en los sitios enterrados y superficiales. En los primeros los tamaños más representados son los pequeños (muy pequeño, pequeño y mediano pequeño). En los sitios estratigráficos y sobre todo en la sitio cantera LLE, se observa una tendencia inversa ya las frecuencias más altas corresponden a los tamaños grandes 
(grande, muy grande y grandísimo) y no se han registrado tamaños medios ni pequeños. Si evaluamos la reserva de corteza por materias primas (Tabla 7.15), se observa que en los sitios estratigráficos las frecuencias más altas son para artefactos sin corteza. Sólo los artefactos sobre rocas silíceas (17\%) y, en menor medida, sobre obsidiana (2\%), presentan reserva de corteza. En los sitios superficiales, si bien están representadas todas las categorías de reserva de corteza, son altas las frecuencias de artefactos sin corteza (55\%); seguida por las categorías intermedias (25\%; intervalos entre $25 \%$ y $50 \%$ de corteza en la cara dorsal) y por descartes primarios y secundarios (20\%; intervalos entre $75 \%$ y $100 \%$ de reserva de corteza).

Como ya ha sido planteado por otros investigadores (Sullivan y Rozen 1985; Shott 2003; Charlin 2007), la disposición o modo de presentación de las materias primas, influye en la cantidad de corteza que conservan los artefactos. Por lo tanto las inferencias a partir de esta variable deben realizarse con precaución cuando se desconocen la procedencia y modo de aparición de las materias primas. En el sector norte de Payunia, los filones masivos de roca silícea facilitan la extracción de bloques sin grandes reservas de corteza como las esperadas en el caso de filones de menor tamaño y/o presentes como concreciones nodulares (Salgán 2010).

\begin{tabular}{|c|c|c|c|c|c|c|c|c|c|c|}
\hline & Sitio & MP & MPE & $\mathbf{P}$ & MEP & MEG & $\mathbf{G}$ & MG & GD & Tota \\
\hline \multirow{4}{*}{ 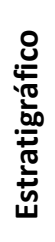 } & LC & SIL & $16 \%$ & $37 \%$ & $21 \%$ & - & $16 \%$ & - & $21 \%$ & 21 \\
\hline & \multirow{3}{*}{ LP-2 } & BAS & $50 \%$ & $50 \%$ & & - & - & - & & 2 \\
\hline & & OBS & $42 \%$ & $12 \%$ & $7 \%$ & $2 \%$ & $1 \%$ & - & $1 \%$ & 56 \\
\hline & & SIL & $29 \%$ & $23 \%$ & $8 \%$ & $4 \%$ & $3 \%$ & $1 \%$ & $7 \%$ & 940 \\
\hline \multirow{3}{*}{$\begin{array}{l}\overline{\frac{\pi}{U}} \\
\frac{0}{\frac{0}{2}} \\
\frac{0}{\frac{0}{n}} \\
\text { n }\end{array}$} & LLE & SIL & - & - & - & - & $2 \%$ & $9 \%$ & $89 \%$ & 52 \\
\hline & LPT2 & SIL & - & - & - & $8 \%$ & $4 \%$ & $8 \%$ & $64 \%$ & 21 \\
\hline & \multicolumn{2}{|c|}{ Total } & $37 \%$ & $28 \%$ & $10 \%$ & $5 \%$ & $4 \%$ & $2 \%$ & $14 \%$ & 1092 \\
\hline
\end{tabular}

Tabla 7.14 Tamaño de los artefactos enteros en los grupos de materias primas en LP. Referencia: MP: materia prima; MPE: Muy pequeño (0-20); P: Pequeño (21-40); MEP: Mediano pequeño (41-60); MEG: Mediano Grande (61-80); G: Grande (81-120); MG: Muy Grande (121-160); GD: Grandísimo (>161). 


\begin{tabular}{|c|c|c|c|c|c|c|c|c|}
\hline & Sitio & MP & $0 \%$ & $25 \%$ & $50 \%$ & $75 \%$ & $100 \%$ & Tota \\
\hline \multirow{4}{*}{ 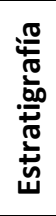 } & LC & SIL & $86 \%$ & - & - & $14 \%$ & - & 21 \\
\hline & \multirow{3}{*}{ LP-2 } & BAS & $100 \%$ & - & - & - & - & 2 \\
\hline & & OBS & $98 \%$ & - & - & $2 \%$ & - & 56 \\
\hline & & SIL & $85 \%$ & $5 \%$ & $2 \%$ & $5 \%$ & $3 \%$ & 940 \\
\hline \multirow{3}{*}{ 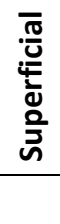 } & LLE & SIL & $58 \%$ & $4 \%$ & $15 \%$ & $15 \%$ & $8 \%$ & 52 \\
\hline & LPT2 & SIL & $48 \%$ & $33 \%$ & $5 \%$ & - & $14 \%$ & 21 \\
\hline & \multicolumn{2}{|c|}{ Total } & $85 \%$ & $5 \%$ & $2 \%$ & $5 \%$ & $3 \%$ & 1092 \\
\hline
\end{tabular}

Tabla 7.15. Reserva de corteza en artefactos enteros en LP.

\subsection{2b ESTRUCTURA TECNOLÓGICA EN LA PELIGROSA}

En clases artefactuales se observa un predominio de desechos de talla, con frecuencias que superan el 90\% (Tabla 7.16). Los artefactos formatizados siguen en importancia con el 1,2\% (Figura 7.15) y las frecuencias más bajas están representadas por los artefactos sin formatización con rastros complementarios, seguido por los núcleos y un percutor, los cuales no superan el 0,5\% de la muestra. En cuanto a las materias primas presentes en la localidad, el sitio LP-2 es el que presenta mayor variedad de rocas, sin embargo su distribución es heterogénea dado que la rocas silíceas son las más representadas. En los conjuntos restantes las rocas silíceas son las únicas materias primas registradas. En la tabla 7.17, se muestran los valores de diversidad de clases artefactuales según materia prima. La prueba Shannon-Wiener (en adelante, Shannon-H) apunta a determinar cuál es la variabilidad de clases artefactuales en una determinada materia prima, mientras que los índices de dominancia y Simpson dan cuenta de la uniformidad o asimetría de la distribución de cantidades entre clases (Capítulo 4). Se destacan valores de diversidad de clases artefactuales nulos en basaltos y bajos en rocas silíceas (Shannon $\mathrm{H}=$ 0,083). En estas últimas la distribución no es homogénea y pocas clases se encuentran representadas por muchos individuos. Si bien las rocas silíceas presentan cinco, de las seis clases artefactuales consideradas, los desechos de talla son la clase artefactual con mayor frecuencia (Tabla 7.16) En el caso de la obsidiana los valores de diversidad son 
intermedios (Shannon $\mathrm{H}=0,18$ ), lo que muestra una riqueza relativamente alta de clases artefactuales distribuidas de modo homogéneo. Sin embargo los valores de dominancia son cercanos a 1 , por lo una clase artefactual se encuentra más representada, en éste caso los desechos de talla. Los valores más altos de las pruebas se encuentran en rocas riolíticas (Shannon $\mathrm{H}=0,69$ ), dado que solo se recuperaron dos muestras que corresponden una a desechos de talla y la otra a un percutor.

\begin{tabular}{|c|c|c|c|c|c|c|c|c|c|c|}
\hline \multicolumn{2}{|c|}{ Sitio } & MP & $\begin{array}{c}\text { AF } \\
\text { Bifacial }\end{array}$ & $\begin{array}{c}\text { AF } \\
\text { Unifacial }\end{array}$ & ASF RC & DT & Núcleo & Percutor & ND & Total \\
\hline \multirow{5}{*}{ 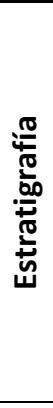 } & LC & SIL & - & - & - & $\begin{array}{c}31 \\
(88,6 \%)\end{array}$ & - & - & $\begin{array}{c}4 \\
(11,4 \%)\end{array}$ & 35 \\
\hline & \multirow{4}{*}{ LP-2 } & $\begin{array}{c}\mathrm{BA} \\
\mathrm{S}\end{array}$ & - & & - & 2 (100\%) & - & - & - & 2 \\
\hline & & $\begin{array}{l}\text { OB } \\
\mathrm{S}\end{array}$ & $4(3,2 \%)$ & $1(0,8 \%)$ & - & $\begin{array}{c}120 \\
(96 \%)\end{array}$ & - & - & - & 125 \\
\hline & & RIO & - & - & - & 1 (50\%) & - & 1 (50\%) & - & 2 \\
\hline & & SIL & $4(0,2 \%)$ & $6(0,3 \%)$ & $\begin{array}{c}3 \\
(0,2 \%) \\
\end{array}$ & $\begin{array}{l}1512 \\
(93 \%) \\
\end{array}$ & $1(0,06 \%)$ & - & $\begin{array}{c}93 \\
(5,7 \%) \\
\end{array}$ & 1619 \\
\hline \multirow{2}{*}{ 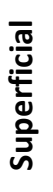 } & LLE & SIL & - & - & - & $\begin{array}{c}53 \\
(98,1 \%)\end{array}$ & $\begin{array}{c}1 \\
(1,9 \%)\end{array}$ & - & - & 54 \\
\hline & LPT2 & SIL & $2(5,6 \%)$ & $4(11,1 \%)$ & - & $\begin{array}{c}30 \\
(83,3 \%)\end{array}$ & - & - & - & 36 \\
\hline \multicolumn{3}{|c|}{ Total } & $11(0,6 \%)$ & $11(0,6 \%)$ & $\begin{array}{c}3 \\
(0,2 \%)\end{array}$ & $\begin{array}{c}1749 \\
(93,3 \%)\end{array}$ & $2(0,1 \%)$ & $1(0,1 \%)$ & $\begin{array}{c}97 \\
(5,2 \%) \\
\end{array}$ & 1873 \\
\hline
\end{tabular}

Tabla 7.16. Clases artefactuales por sitio en LP. Entre paréntesis se detalla la proporción de la clase artefactual por materia prima y sitio de muestreo. Referencia: MP: materia prima; AF Bifacial: artefacto de formatización bifacial; AF Unifacial: artefacto de formatización unifacial; As/F con RC: artefacto sin formatización con rastros complementarios; DT: desecho de talla; ND: no diferenciado.

\begin{tabular}{|c|c|c|c|c|}
\hline & SIL & BAS & OBS & RIO \\
\hline N clase artefacto & 5 & 1 & 3 & 2 \\
\hline $\mathbf{N}$ & 1647 & 2 & 125 & 2 \\
\hline Dominancia & 0,974 & 1 & 0,9227 & 0,5 \\
\hline Shannon H & 0,08566 & - & 0,188 & 0,69 \\
\hline Simpson & 0,02596 & - & 0,07731 & 0,5 \\
\hline
\end{tabular}

Tabla 7.17. Diversidad de clases artefactuales según materas primas en LP. 


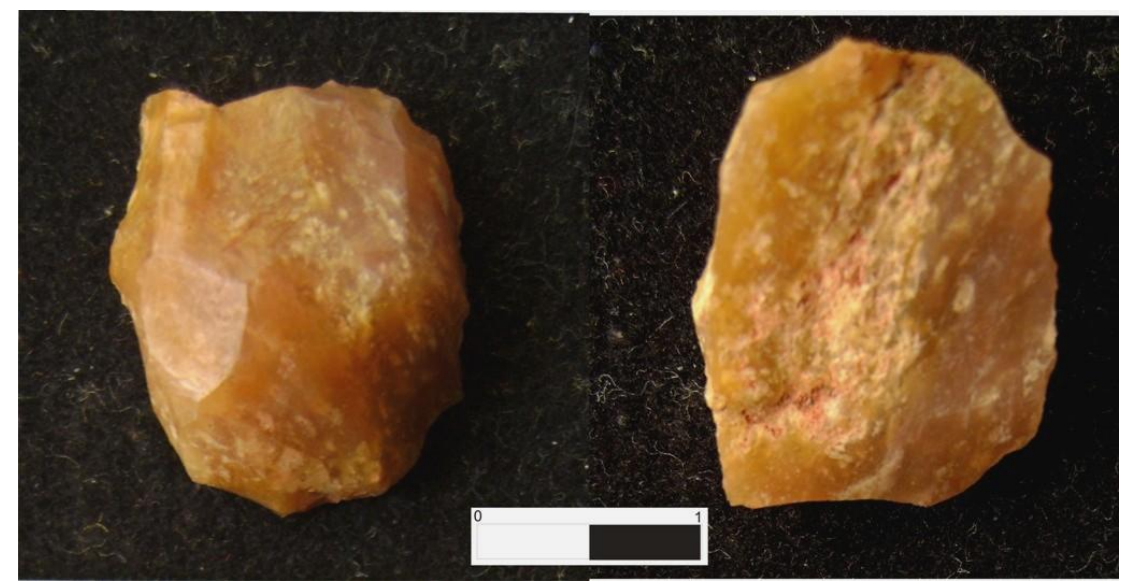

Figura 7.15. Artefactos de formatización unifacial de LP-2.

\subsection{2b.1 DESECHOS DE TALLA}

Desechos de talla es la clase artefactual más representada en LP (93\% de las muestras analizadas). Como se mencionó anteriormente, en desechos de talla se presenta la mayor diversidad de rocas, sin embargo su distribución no es simétrica. La materia prima más representada es la roca silícea (93\%), seguida en abundancia por la obsidiana (7\%) y con una frecuencia menor del $0,2 \%$ se encuentran los basaltos y las riolitas. En cuanto al estado de fragmentación, el 39\% $(n=665)$ de los desechos se encuentra fragmentado y el 61\% ( $n=1071)$ entero (Tabla 7.18). Los desechos enteros sin reserva de corteza representan el $83,6 \%(n=896)$ del total de muestra analizada, seguido en frecuencia por los desechos con el $75 \%$ de su cara dorsal cubierta por corteza $(5,4 \%)$ y aquellos con el $25 \%$ de corteza (5,2\%). Los desechos con reserva de corteza en su cara dorsal corresponden casi exclusivamente a rocas silíceas, con la excepción de una lasca secundaria de obsidiana correspondiente al sitio estratigráfico LP-2. En silícea la frecuencia de desechos sin corteza es mayor en sitios estratigráficos, mientras que en los sitios superficiales se encuentran representada la mayor diversidad de categorías de desechos con reserva de corteza. En las restantes materias primas los desechos sin reserva de corteza superan el $95 \%$ del total de las muestras. 
Entre las subclases o tipos de desechos, las lascas internas -integradas por las lascas angulares (LAN) y de arista (LAR)-, superan el $80 \%$ del total de los conjuntos (Tabla 7.19). Las lascas externas por su parte, integradas por lascas primarias (LPR) y secundarias (LSEC), representan el $8 \%$ del total. Si se analizan los conjuntos por tipo de muestreo (estratigráfico y superficial) se observa que los conjuntos de superficie poseen mayor frecuencia de lascas externas y de reactivación de núcleos (LN), con una proporción cercana al 38\%. Esto es concordante con el hecho de que LLE se encuentra en una cantera primaria, donde se espera estén representados los primeros estadios de reducción. Sin embargo el porcentaje de lascas internas sigue siendo preponderante (60\%). En todos los muestreos se destaca la presencia de lascas correspondiente a los últimos estadios de producción de instrumentos, tales como son las lascas de reactivación de filo (LR), las lascas planas (PL) y las lascas de adelgazamiento bifacial (LAB), los cuales son frecuentes en LP-2 (Figura 7.16). En éste último, los desechos de talla de formatización de filo presentan frecuencias altas en los niveles correspondientes a la Unidad B.

\begin{tabular}{|c|c|c|c|c|c|c|c|}
\hline \multicolumn{2}{|c|}{ Sitio } & MP & $0 \%$ & $25 \%$ & $50 \%$ & $75 \%$ & $100 \%$ \\
\hline \multirow{4}{*}{ 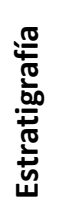 } & LC & SIL & 18 (86\%) & - & - & $3(14 \%)$ & - \\
\hline & \multirow{3}{*}{ LP-2 } & BAS & 2 (100\%) & - & - & & - \\
\hline & & OBS & $53(98 \%)$ & - & - & $1(2 \%)$ & - \\
\hline & & SIL & 784 (85\%) & $48(5 \%)$ & $19(2 \%)$ & $47(5 \%)$ & $28(3 \%)$ \\
\hline \multirow{4}{*}{ 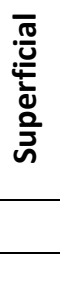 } & LLE & SIL & $29(59 \%)$ & $2(4 \%)$ & $8(16 \%)$ & $6(14 \%)$ & $4(8 \%)$ \\
\hline & LPT2 & SIL & $9(47 \%)$ & $6(32 \%)$ & $1(5 \%)$ & - & $3(16 \%)$ \\
\hline & \multicolumn{2}{|c|}{ Total } & 896 & 56 & 28 & 58 & 35 \\
\hline & \multicolumn{2}{|c|}{$\%$} & $83,6 \%$ & $5,2 \%$ & $2,6 \%$ & $5,4 \%$ & $3,2 \%$ \\
\hline
\end{tabular}

Tabla 7.18. Reserva de corteza en la cara dorsal en desechos enteros en LP. 


\begin{tabular}{|c|c|c|c|c|c|c|c|c|c|c|c|c|c|}
\hline \multicolumn{2}{|c|}{$\stackrel{\circ}{*}$} & $\stackrel{o}{\Sigma}$ & $\frac{\mathscr{a}}{a}$ & 岃 & $z$ & $\frac{\mathscr{L}}{\zeta}$ & $\stackrel{m}{s}$ & $\vec{a}$ & 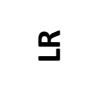 & 3 & $\stackrel{a}{9}$ & 只 & 苛 \\
\hline \multirow{6}{*}{ 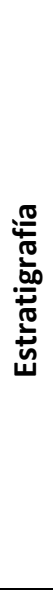 } & $\cup$ & $\vec{\omega}$ & - & 3 & 22 & - & - & 1 & - & 4 & - & 1 & 31 \\
\hline & \multirow{4}{*}{$\stackrel{N}{\beth}$} & 行 & - & - & 1 & 1 & - & & - & - & - & - & 2 \\
\hline & & ఋి & 2 & 1 & 62 & 15 & 4 & 2 & 20 & - & - & 14 & 120 \\
\hline & & $\frac{O}{\alpha}$ & - & - & 1 & - & - & - & - & - & - & - & 1 \\
\hline & & $\overrightarrow{\bar{n}}$ & 48 & 78 & 698 & 280 & 91 & 92 & 132 & 17 & 2 & 74 & 1512 \\
\hline & \multicolumn{2}{|c|}{$\begin{array}{c}\text { Total } \\
\text { Estr }\end{array}$} & $\begin{array}{c}50 \\
(3 \%)\end{array}$ & $\begin{array}{c}81 \\
(5 \%)\end{array}$ & $\begin{array}{c}784 \\
(47 \%)\end{array}$ & $\begin{array}{c}296 \\
(18 \%)\end{array}$ & $\begin{array}{c}95 \\
(6 \%)\end{array}$ & $\begin{array}{c}95 \\
(6 \%)\end{array}$ & $\begin{array}{c}152 \\
(9 \%)\end{array}$ & $\begin{array}{c}21 \\
(1 \%)\end{array}$ & $\begin{array}{c}2 \\
(0 \\
\%)\end{array}$ & $\begin{array}{c}89 \\
(5 \%)\end{array}$ & $\begin{array}{c}1666 \\
(100 \%)\end{array}$ \\
\hline \multirow{3}{*}{ 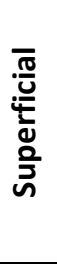 } & 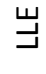 & $\overline{\bar{n}}$ & 4 & 10 & 18 & 10 & - & 3 & - & 8 & - & 1 & 53 \\
\hline & $\stackrel{r}{a}$ & $\overline{\bar{n}}$ & 2 & 3 & 8 & 9 & 1 & 3 & - & 4 & - & - & 30 \\
\hline & \multicolumn{2}{|c|}{$\begin{array}{l}\text { Total } \\
\text { Sup }\end{array}$} & $\begin{array}{c}6 \\
(7 \%) \\
\end{array}$ & $\begin{array}{c}13 \\
(16 \%)\end{array}$ & $\begin{array}{c}26 \\
(32 \%) \\
\end{array}$ & $\begin{array}{c}19 \\
(22 \%)\end{array}$ & $\begin{array}{c}1 \\
(1 \%) \\
\end{array}$ & $\begin{array}{c}6 \\
(7 \%) \\
\end{array}$ & - & $\begin{array}{c}12 \\
(14 \%)\end{array}$ & - & $\begin{array}{c}1 \\
(1 \%) \\
\end{array}$ & $\begin{array}{c}83 \\
(100 \%) \\
\end{array}$ \\
\hline \multicolumn{3}{|c|}{ Total } & 56 & 95 & 810 & 315 & 96 & 101 & 152 & 33 & 2 & 90 & 1749 \\
\hline \multicolumn{3}{|c|}{ Total \% } & $3 \%$ & $5 \%$ & $46 \%$ & $18 \%$ & $5 \%$ & $6 \%$ & $9 \%$ & $2 \%$ & $\begin{array}{c}0,1 \\
\%\end{array}$ & $5 \%$ & $100 \%$ \\
\hline
\end{tabular}

Tabla 7.19. Tipos de desechos de talla discriminados por tipo de extracción, sitio y materia prima procedentes de LP. Referencia: LPR: Iasca primaria; LSEC: lasca secundaria; LAN: lasca angular; LAR: lasca de arista; $L A B$ : lasca de adelgazamiento bifacial; PL: lasca plana; $L R$ : lasca de reactivación; LN: lasca de reactivación de núcleo (incluye lascas de flanco de núcleo, cresta de núcleo y lascas de núcleo); LBIP: Iasca bipolar; ND: lasca no diferenciada.

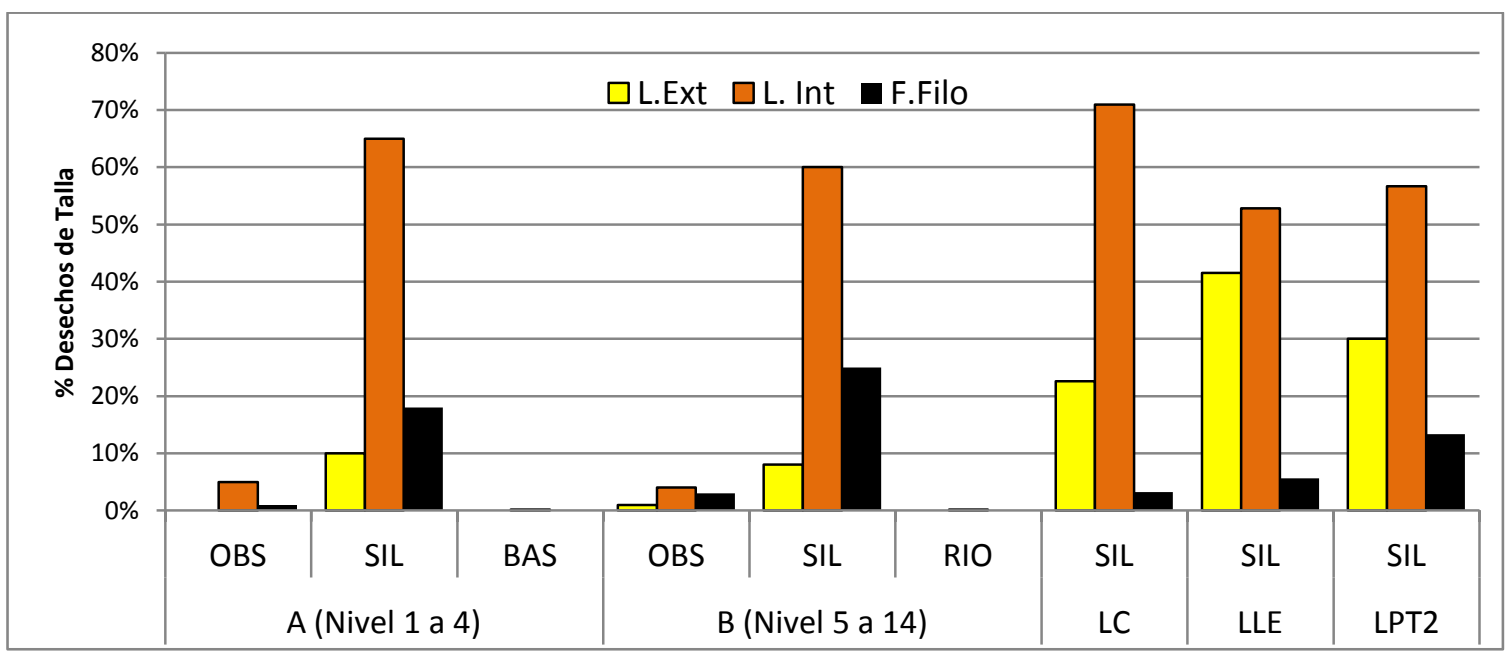

Figura 7.16. Frecuencia de etapas de manufactura en LP. Referencias: L.EXT: Lascas externas; L.INT: lascas internas; F.FILO: lascas de formatización de filo. 
Al considerar el grado de reducción de los desechos de talla, puede obtenerse una calibración de estas tendencias. Para ello se considera el índice de corteza (Ericson 1984), el cual se basa en la proporción de lascas primarias y secundarias sobre el total de desechos de talla enteros de una determinada materia prima (Tabla 7.20), tendencia que puede ser evaluada en conjunto con la densidad de extracciones previas en la cara dorsal de lascas. Los valores de índice más elevados se encuentran en los sitios superficiales, mientras que en los estratigráficos el sitio LC presenta los valores más altos. Los valores elevados en los sitios superficiales, podrían indicar que en éstos espacios se habrían llevado a cabo mayores tareas de descortezamiento, especialmente en LLE. En los sitios estratigráficos los menores valores de índice corresponden a la obsidiana registrada en LP2 , lo que podría indicar que las rocas han ingresado al sitio como formas base o en estado avanzado de formatización. Planteo que es coherente con las frecuencias marcadas de lascas de adelgazamiento bifacial y reactivación de obsidiana presentes en el sitio, así como con la ausencia de lascas de reactivación de núcleos y núcleos (Tabla 7.15). Si observamos las frecuencias de desechos de reactivación en el sitio estratigráfico LP-2 según las unidades cronoestratigráficas A y B (ver supra), notamos que en la Unidad B las frecuencias de lascas de reactivación son mayores respecto a la Unidad A (Figura 7.17). Esto es significativo si recordamos que $\mathrm{A}$ tiene mayor número de piezas que $\mathrm{B}$. Por ello si analizamos las frecuencias de lascas de reactivación de filo por unidad estratigráfica, se observa los porcentajes más altos corresponden a las rocas silíceas tanto en la Unidad A (SIL=6\%, $n=59 / 1046 ; O B S=1 \%, n=10 / 1046)$ como en la Unidad $B$ (SIL=12\%, $n=73 / 589$; $\mathrm{OBS}=2 \%, \mathrm{n}=13 / 589$ ), mientras que en obsidiana hay mayor reacondicionamiento de filos en la Unidad B. Respecto a desechos de adelgazamiento bifacial, se observa una tendencia similar entre las unidades $A$ y $B$, dado que son frecuentes en la unidad más antigua (Figura 7.18). 


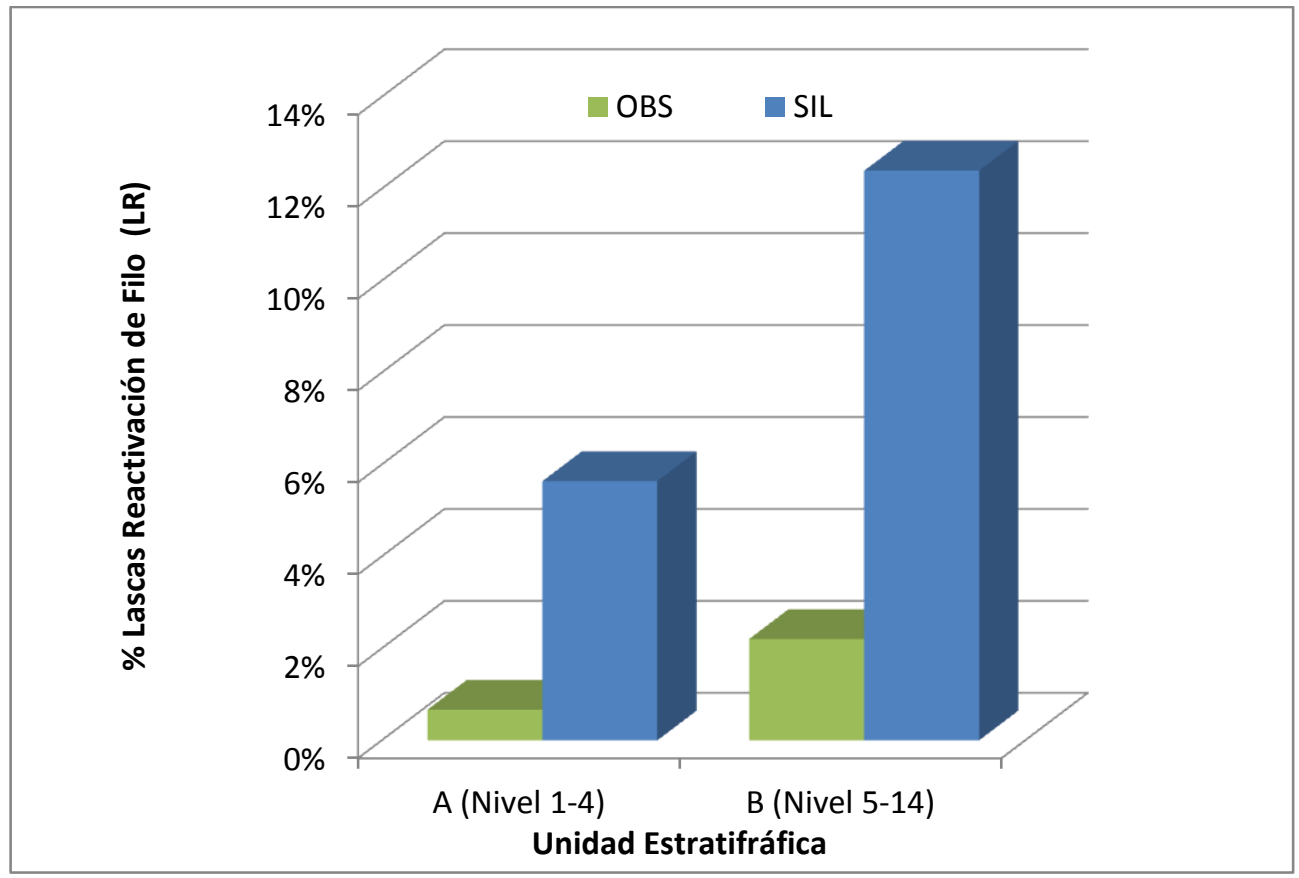

Figura 7.17 Frecuencia de lascas de reactivación en las Unidades A y B, respecto al total de desechos de cada unidad.

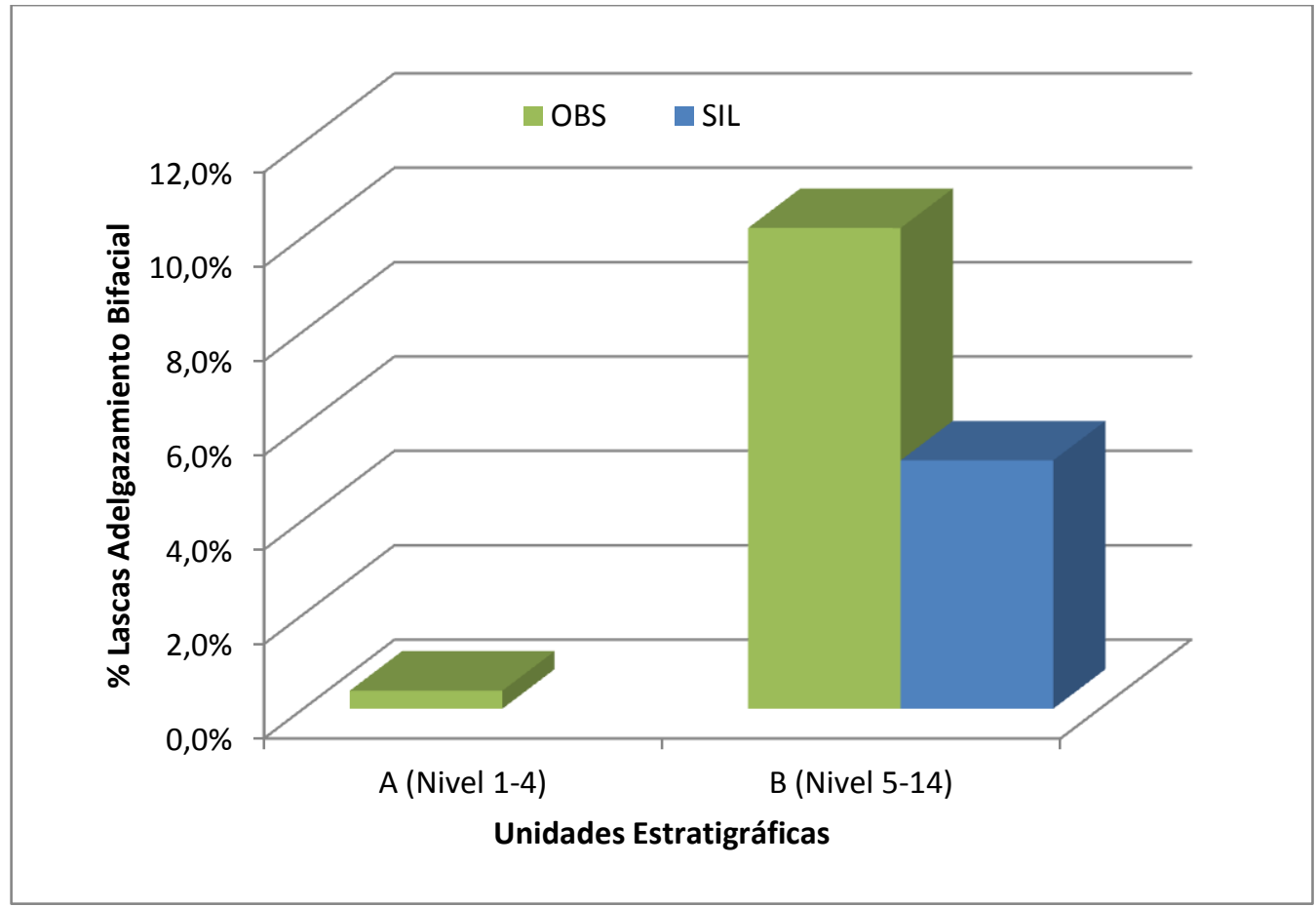

Figura 7.18. Frecuencias de lascas de adelgazamiento bifacial en las Unidades A y B, respecto al total de desechos de cada unidad. 
En la tabla 7.21 se presenta la estadística descriptiva de la densidad de extracciones previas en la cara dorsal de desechos por materia prima y muestreo. En los sitios estratigráficos $\left(x=3,85 \mathrm{e} / \mathrm{mm}^{2}\right)$ éste índice presenta valores mayores que en los superficiales $\left(x=0,47 \mathrm{e} / \mathrm{mm}^{2}\right)$. En los primeros la obsidiana $\left(x=6,43 \mathrm{e} / \mathrm{mm}^{2}\right)$ del sitio LP-2 es la materia prima que presentan mayor reducción, seguido por las rocas silíceas $(x=3,7$ $\left.\mathrm{e} / \mathrm{mm}^{2}\right)$. Asimismo las rocas silíceas en LC presentan un índice alto de extracciones $(x=2,2$ e/ $\mathrm{mm}^{2}$ ). Al comparar la densidad de extracciones en la cara dorsal de roca silíceas en éstos dos últimos sitios, a través del test $t$ para varianzas distintas, este arrojó diferencias significativas $(\mathrm{t}=-4,39 ; p=0,0001)$. Los desechos de talla procedentes de LP-2 presentan una mayor reducción que aquellos recuperados en LC. En los sitios superficiales el sitio LLE $\left(0,41 \mathrm{e} / \mathrm{mm}^{2}\right)$ presenta el menor grado de reducción. No se incluyen en la tabla las materias primas basalto (BAS) y riolita (RIO), debido a su escasa representación. Si analizamos la densidad de extracciones de estas rocas en LP2 por unidad estratigráfica de excavación, notamos que las materias primas presentan un valor de índice mayor en la unidad $B$, tanto en las rocas silíceas (Unidad A: $x=4,05$ e/mm2; Unidad B: $x=4,25$ e/mm2) como en obsidiana (Unidad A: $x=6,63 \mathrm{e} / \mathrm{mm} 2$; Unidad B: $x=6,81 \mathrm{e} / \mathrm{mm} 2$ )

\begin{tabular}{|c|c|c|c|c|c|c|}
\hline & Sitio & MP & N & LPR & LSEC & Índice Corteza \\
\hline \multirow{4}{*}{ Estratigrafía } & LC & SIL & 21 & - & 3 & 0,14 \\
\cline { 2 - 7 } & \multirow{2}{*}{ LP-2 } & OBS & 54 & 1 & 1 & 0,04 \\
\cline { 2 - 6 } & & SIL & 926 & 29 & 55 & 0,09 \\
\hline \multirow{2}{*}{ Superficial } & LLE & SIL & 50 & 4 & 9 & 0,27 \\
\cline { 2 - 6 } & LPT2 & SIL & 19 & 2 & 2 & 0,13 \\
\hline
\end{tabular}

Tabla 7.20. Frecuencia de lascas primarias y secundarias enteras por materia prima lítica en LP. Nota: MP: materia prima; N: abundancia de desechos de talla enteros; LPR: lasca primaria; LSEC: Iasca secundaria.

\begin{tabular}{|c|c|c|c|c|c|c|c|c|c|}
\hline & Sitio & MP & $\mathbf{N}$ & Media & Mediana & Desvío Estándar & Mínimo & Máximo & Rango \\
\hline \multirow{4}{*}{ Estratigrafía } & LC & SIL & 30 & 2,24 & 1,96 & 1,91 & 0,231 & 7,43 & 7,199 \\
\cline { 2 - 10 } & \multirow{2}{*}{ LP-2 } & OBS & 85 & 6,43 & 5,95 & 4,47 & 0 & 23,8 & 23,8 \\
\cline { 2 - 10 } & & SIL & 1345 & 3,7 & 2,58 & 3,61 & 0 & 37,03 & 37,03 \\
\hline \multirow{2}{*}{ Superficial } & LLE & SIL & 53 & 0,41 & 0,37 & 0,29 & 0 & 1,33 & 1,33 \\
\cline { 2 - 9 } & LPT2 & SIL & 30 & 0,59 & 0,39 & 0,54 & 0 & 2,1 & 2,1 \\
\hline
\end{tabular}

Tabla 7.21. Estadística descriptiva de la densidad de extracciones previas en la cara dorsal de los desechos de talla en LP. 
Al considerar los tres indicadores de reducción (reserva de corteza, índice de corteza y grado de reducción), se encontró concordancia entre los resultados obtenidos. Dado que los sitios estratigráficos presentan mayor frecuencia de desechos de talla sin reserva de corteza, bajo índice de corteza y altos valores de reducción o intensidad de lascados en la cara dorsal. Si comparamos los desechos de talla recuperados en ambos sitios estratigráficos, se destaca que en LP-2 los valores obtenidos presentan un bajo índice de corteza y altos valores de reducción, lo que indica una mayor intensidad de reducción de materias primas en el sitio. A esto se suma el hecho de que LP-2 presenta estadios de reducción que van desde los iniciales, como indican los valores mínimos iguales a cero, hasta etapas avanzadas de manufactura (valores máximos de reducción) (Tabla 7.20). Situación que se observa tanto en obsidiana como en silíceas de LP-2 y en las rocas silíceas recuperadas en LC. En los sitios superficiales por su parte, la reserva de corteza es variable, con alto índice de corteza y baja intensidad de reducción en la cara dorsal. Asimismo se encuentran representados casi todos los estadios de manufactura con excepción de lascas de reactivación.

Estudios geoquímicos sobre obsidiana (Capítulo 4 y 8 ), determinaron la procedencia del $9 \%(n=9)$ del total de desechos de talla recuperados en ésta materia prima $(n=125)$. El $45 \%(n=5)$ de la muestra analizada ha sido vinculada a la fuente cordillerana El Maule, ubicada a una distancia lineal aproximada de $180 \mathrm{~km}$; seguida por la fuente no cordillerana El Peceño con el $27 \%(n=3)$, distante $130 \mathrm{~km}$ lineales, y por último la fuente Desconocida-A, con igual frecuencia $(27 \%, n=1)$. Parte de la muestra analizada $(n=3)$ fue procesada por mediante INAA, razón por la cual no fue posible caracterizar la totalidad de los desechos. Las piezas analizadas corresponden a lascas internas de tipo angular, vinculadas a la fuente Desconocida-A. 


\subsection{2b.2 NÚCLEOS}

Los dos núcleos recuperados en LP están enteros y fueron elaborados sobre roca silícea (Figura 7.19). Representan el 0,1\% del total de artefactos de la localidad, fueron recuperados uno en LP-2 y el otro en LLE. Ambos son de morfología amorfa, de forma base nodular y con reserva de corteza ( $50 \%$ y $25 \%$, respectivamente). El tamaño en ambos casos es grandísimo (módulo: 7, rango $>161 \mathrm{~mm}$ ) y muy espeso (módulo AM/EM: <2,4). El núcleo recuperado en LP-2, no está agotado. Tiene una densidad de lascados de $x=2,04$ e/ $\mathrm{mm}^{3}$; y fue elaborado sobre materia prima de calidad muy buena, su peso es de 13,3 gramos. Por su parte el núcleo recuperado en LLE, no está agotado; tiene una densidad de extracciones de $\mathrm{x}=0,5 \mathrm{e} / \mathrm{mm}^{3}$; la materia prima del soporte es de buena calidad y un peso 39,1 gramos. El núcleo de LP-2 presenta un total de cinco negativos de extracción con boca de lascado y el recuperado en LLE sólo presenta dos. El tamaño mínimo de dichas extracciones en LP-2 es muy grande (módulo: 6, rango entre 121-160) a grandísimo (modulo tamaño= 7, rango >161); en LLE ambas extracciones son de tamaño grandísimo. En la relación entre el largo y ancho de las lascas enteras y de los negativos de lascado de los núcleos de LP (Tabla 7.22), podemos observar que en los primeros la razón entre los valores medios de ambos es 0,5 , indicando extracciones que tienden a ser más largas que anchas. Si bien se registra un bajo número de núcleos, el largo de los negativos de los lascados mínimos y máximos permite estimar la media y la mediana, las cuales presentan valores mayores en el largo que en el ancho, sugiriendo la extracción de lascas de módulo largo y angosto. Esta tendencia es coherente con los valores de desechos de talla. Por otro lado si comparamos las medidas de largo y ancho máximo de los negativos de lascado en núcleos, con los obtenidos en instrumentos enteros, notamos que los negativos de los núcleos son más angostos que lo esperado (Tabla 7.22). La calidad para la talla de los núcleos es muy buena en LP-2 y buena en LLE, marcando una selección de las rocas transportadas. 


\begin{tabular}{|c|c|c|c|c|c|c|}
\hline & \multicolumn{2}{|c|}{ Desechos de Talla } & \multicolumn{2}{c|}{ Instrumentos } & \multicolumn{2}{c|}{ Núcleos } \\
\hline & Largo $\mathrm{mm}$ & Ancho $\mathrm{mm}$ & Largo $\mathrm{mm}$ & Ancho $\mathrm{mm}$ & Largo $\mathrm{mm}$ & Ancho $\mathrm{mm}$ \\
\hline $\mathbf{N}$ & 1071 & 1071 & 13 & 13 & 4 & 4 \\
\hline Media & 9,98707 & 9,50677 & 21,56 & 21,71 & 37,62 & 17,55 \\
\hline Desvío Estándar & 7,455 & 6,613 & 8,052 & 5,798 & 24,474 & 2,852 \\
\hline Mediana & 7,6 & 7,4 & 19,3 & 23,3 & 33,2 & 17,85 \\
\hline Mínimo & 1,6 & 1,4 & 13,9 & 10,3 & 12,9 & 14,1 \\
\hline Máximo & 112,4 & 53,7 & 40,9 & 30,5 & 71,2 & 20,4 \\
\hline
\end{tabular}

Tabla 7.22. Estadística descriptiva de las variables longitud y ancho de las lascas e instrumentos enteros y negativos de lascado medidos en los núcleos registrados en LP.

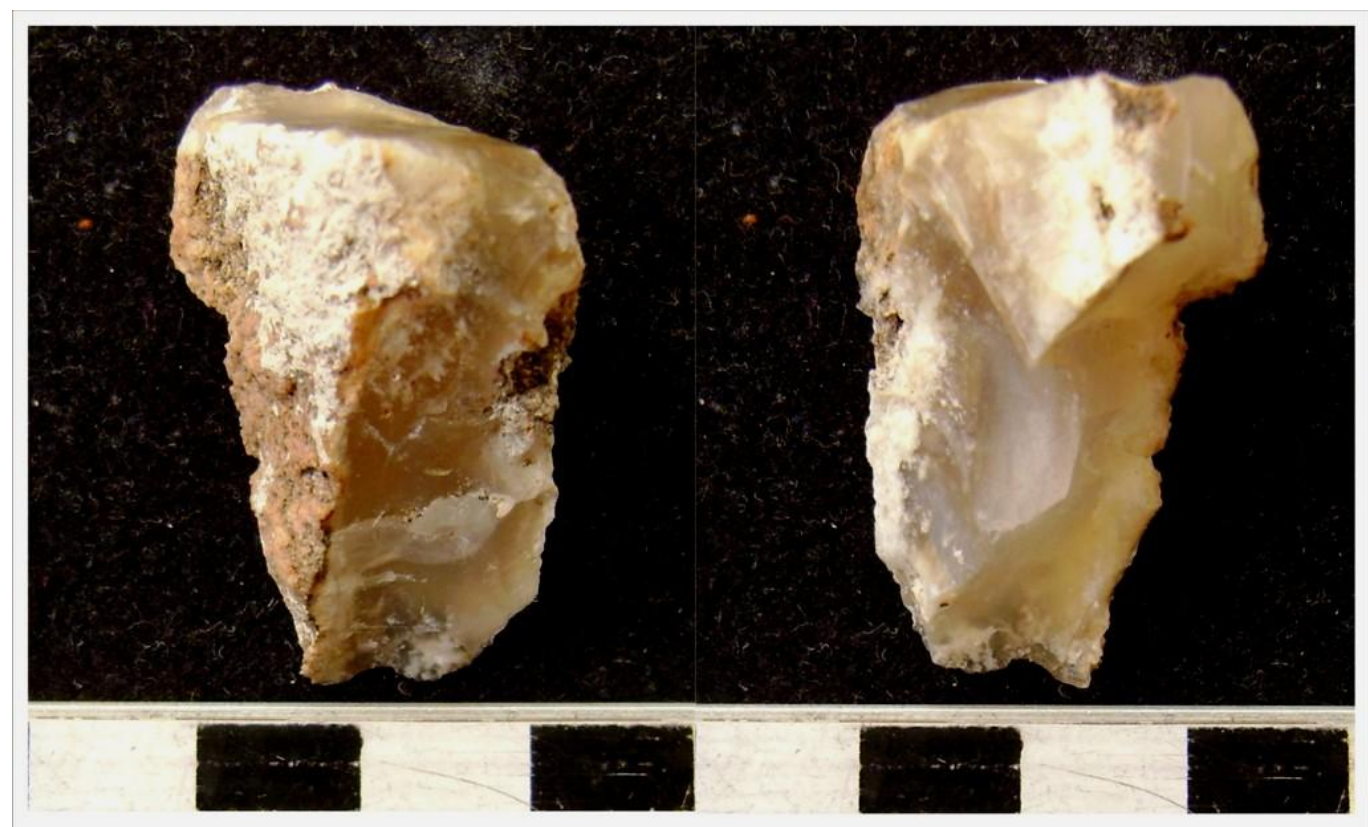

Figura 7.19. Núcleo recuperado en LP.

\subsection{2b.3 INSTRUMENTOS}

Los instrumentos alcanzan el $1 \%(n=24)$ del total de los artefactos de LP. El $75 \%$ $(n=18)$ corresponde a LP-2 y el restante $25 \%(n=6)$ a LPT2 (recordando que ésta transecta está al menos parcialmente en coincidencia espacial con el sitios LP-2, Figura 7.3). Las materias primas seleccionadas para la confección de instrumentos son silíceas $(79 \%, n=19)$ y obsidiana (21\%, $n=5)$. La tabla 7.23 detalla las frecuencias de instrumentos según tipo de 
formatización y/o presencia de rastros complementarios, materia prima y extracción. Se observa que los artefactos de formatización bifacial $(40 \%, n=10)$ son los más representados, seguidos por los artefactos unifaciales y con rastros complementarios (ambos con $28 \%, n=7$ ); los primeros y los últimos se registraron en contextos enterrados y superficiales, mientras que los unifaciales sólo fueron documentados en el sitio estratigráfico LP-2. Es significativo que la obsidiana se utilizó más en bifaciales que las silíceas e inverso en los unifaciales. Si exploramos la diversidad de materias primas seleccionadas (Tabla 7.24), se observa que el índice de diversidad más alto corresponde a los artefactos bifaciales, con una dominancia media entre obsidiana y rocas silíceas. En artefactos unifaciales la diversidad es menor y predomina el uso de rocas silíceas. En los artefactos con rastros complementarios las únicas rocas representadas son las silíceas.

\begin{tabular}{|c|c|c|c|c|c|c|}
\hline & Sitio & MP & AF Bifacial & AF Unifacial & ASF RC & Total \\
\hline \multirow{2}{*}{ Estratigrafía } & \multirow{2}{*}{ LP-2 } & OBS & $4(80 \%)$ & $1(20 \%)$ & - & $5(100 \%)$ \\
\cline { 3 - 7 } & SIL & $4(31 \%)$ & $6(46 \%)$ & $3(23 \%)$ & $13(100 \%)$ \\
\hline Superficial & LPT2 & SIL & $2(33 \%)$ & - & $4(67 \%)$ & $6(100 \%)$ \\
\hline & \multicolumn{2}{|c|}{ Total } & $10(40 \%)$ & $7(28 \%)$ & $7(28 \%)$ & $24(100 \%)$ \\
\hline
\end{tabular}

Tabla 7.23. Frecuencia de artefactos formatizados y con rastros complementarios en LP. Entre paréntesis se detalla la proporción de tipo de artefactos por materia prima.

\begin{tabular}{|l|l|l|l|}
\hline & AF Bifacial & AF Unifacial & ASF_RC \\
\hline N materias primas & 2 & 2 & 1 \\
\hline $\mathbf{N}$ & 10 & 7 & 7 \\
\hline Dominancia & 0,52 & 0,7551 & 1 \\
\hline Shannon-H & 0,673 & 0,4101 & - \\
\hline Simpson & 0,48 & 0,2449 & - \\
\hline
\end{tabular}

Tabla 7.24. Diversidad de materias primas según clases artefactuales en LP.

La manufactura de los instrumentos se realizó en la mayoría de las piezas sobre lascas $(91 \%, n=22)$, otras formas base alcanzan valores inferiores al $5 \%$ (nodulares y no diferenciadas). Predomina la calidad para la talla buena (58\%), seguida por la excelente (21\%) y la muy buena (17\%). Los artefactos bifaciales están confeccionados en rocas 
silíceas $(60 \%, n=6)$ y obsidiana $(40 \%, n=4)$, de calidad para la talla buena y excelente, respectivamente (Tabla 7.25). Los artefactos unifaciales corresponden en un $90 \%(n=6)$ a roca silícea de buena calidad para la talla y en un $10 \%(n=1)$ a obsidiana de calidad excelente. Los artefactos con rastros complementarios sólo se documentaron en roca silícea de calidad para la talla muy buena $(75 \%, n=3)$ y buena $(25 \%, n=1)$. En cuanto a los grupos tipológicos representados entre los artefactos bifaciales $(n=10)$, siete corresponden a puntas de proyectil, seis fracturadas confeccionadas en obsidiana $(n=3)$ y en roca silíceas $(n=3)$, y una entera trabajada en roca silícea (Tabla 7.26). De los tres artefactos bifaciales restantes, dos corresponden a bifaces o preformas bifaciales $(n=2)$ trabajadas en sílice y fracturadas, y uno a un artefacto mediano pequeño de retoque en bisel oblicuo y sección asimétrica (RBO) elaborado en obsidiana y descartado entero. Los artefactos unifaciales $(n=7)$ corresponden en su totalidad al grupo tipológico de los raspadores, seis de roca silícea (cinco enteros y uno fracturado), y el restante de obsidiana y entero (Figura 7.20). Los artefactos sin formatización con rastros complementarios $(n=7)$, corresponden a filos naturales activos con retoque y posible rastros de utilización elaborados en roca silícea, cuatro enteros y tres fracturados. En obsidiana, las puntas de proyectil (60\%) son más frecuentes (Figura 7.21), seguidas por los raspadores y RBO. En roca silícea aparecen los filos naturales con rastros complementarios (37\%), los raspadores (32\%), las puntas de proyectil (21\%) y las preformas bifaciales (11\%). Si analizamos el uso de las rocas silíceas, notamos que en LPT2, son mayoritarios los artefactos con rastros complementarios (67\%) de muy buena calidad para la talla, que podría reflejar una selección de calidad de materias primas. Le siguen las puntas de proyectil (17\%) y bifaces (17\%). En LP-2 el grupo tipológico más representado en rocas silíceas es el de los raspadores (46\%) de buena calidad para la talla, seguidos por las puntas de proyectil (23\%) de muy buena calidad, los filos naturales con rastros complementarios (23\%) de calidad buena, y las preformas bifaciales (8\%). El uso de obsidiana solo se registró en LP-2. 


\begin{tabular}{|c|c|c|c|c|c|c|c|}
\hline & & Calidad para la talla & B & MB & $\mathbf{E}$ & SD & Total \\
\hline \multirow{3}{*}{ Estratigrafía } & \multirow{3}{*}{ LP-2 } & AF Bifacial & 4 & - & 4 & - & 8 \\
\hline & & AF Unifacial & 6 & - & 1 & - & 7 \\
\hline & & ASF RC & 3 & - & - & - & 3 \\
\hline \multirow{4}{*}{ Superficial } & \multirow{2}{*}{ LPT2 } & AF Bifacial & - & 1 & - & 1 & 2 \\
\hline & & ASF RC & 1 & 3 & - & - & 4 \\
\hline & & Total & 14 & 4 & 5 & 1 & 24 \\
\hline & & $\%$ & $58 \%$ & $17 \%$ & $21 \%$ & $4 \%$ & $100 \%$ \\
\hline
\end{tabular}

Tabla 7.25. Calidad para la talla en instrumentos de LP. Referencia: $R$ : regular; $B$ : bueno; $M B$ : muy bueno; E: excelente; SD: sin dato relevado.

\begin{tabular}{|c|c|c|c|c|c|c|c|c|}
\hline & \multirow{2}{*}{ Sitio } & \multirow{2}{*}{ MP } & \multicolumn{2}{|c|}{ AF Bifacial } & \multicolumn{2}{|c|}{ AF Unifacial } & \multicolumn{2}{|c|}{ ASF RC } \\
\hline & & & Entero & Fracturado & Entero & Fracturado & Entero & Fracturado \\
\hline \multirow{2}{*}{ Estratigrafía } & \multirow{2}{*}{ LP-2 } & OBS & 1 & 3 & 1 & - & - & - \\
\hline & & SIL & 2 & 2 & 5 & 1 & 2 & 1 \\
\hline \multirow[t]{3}{*}{ Superficial } & LPT2 & SIL & - & 2 & - & - & 2 & 2 \\
\hline & \multicolumn{2}{|c|}{ Total } & $3(30 \%)$ & $7(70 \%)$ & $6(85 \%)$ & $1(15 \%)$ & $4(57 \%)$ & $3(43 \%)$ \\
\hline & \multicolumn{2}{|c|}{$\mathbf{N}$} & \multicolumn{2}{|r|}{10} & \multicolumn{2}{|r|}{7} & \multicolumn{2}{|r|}{7} \\
\hline
\end{tabular}

Tabla 7.26. Frecuencia de fragmentación en instrumentos de LP.

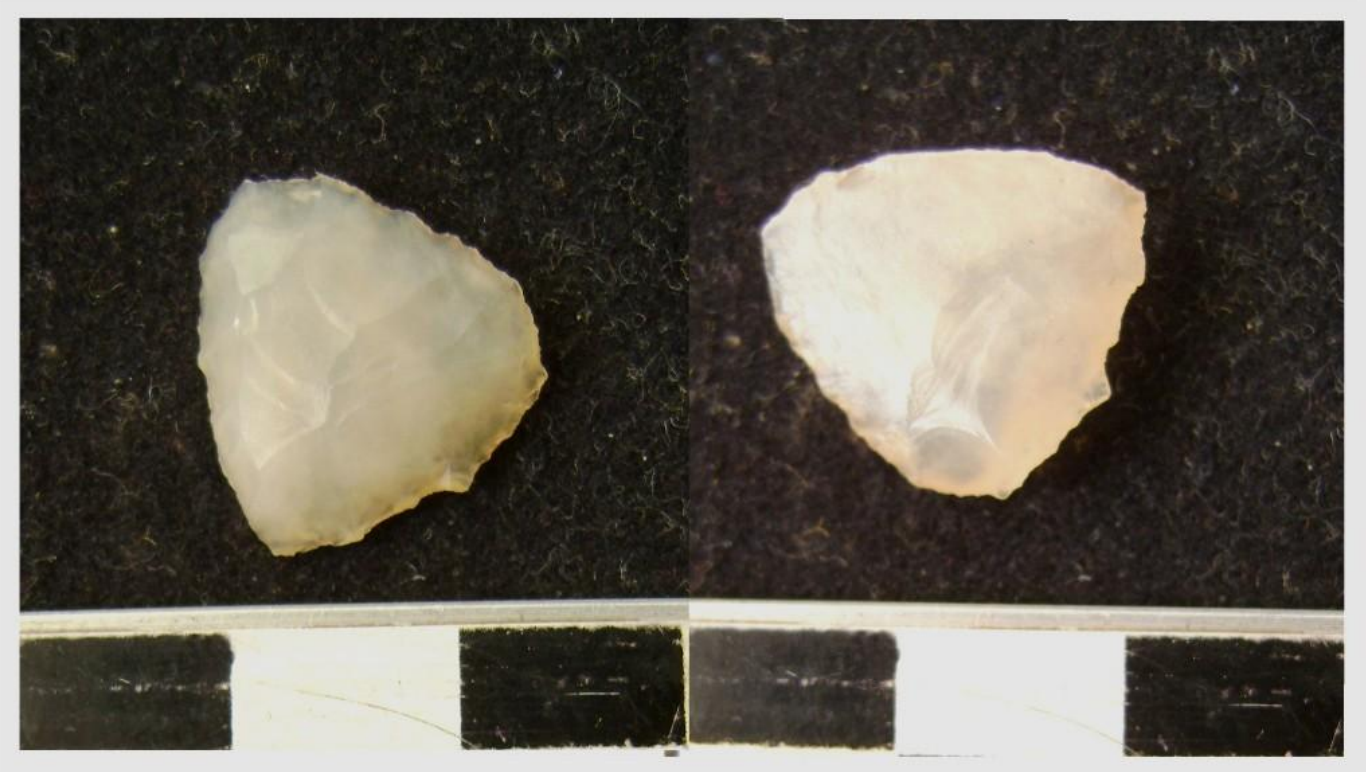

Figura 7.20. Raspador recuperado en LP-2. 


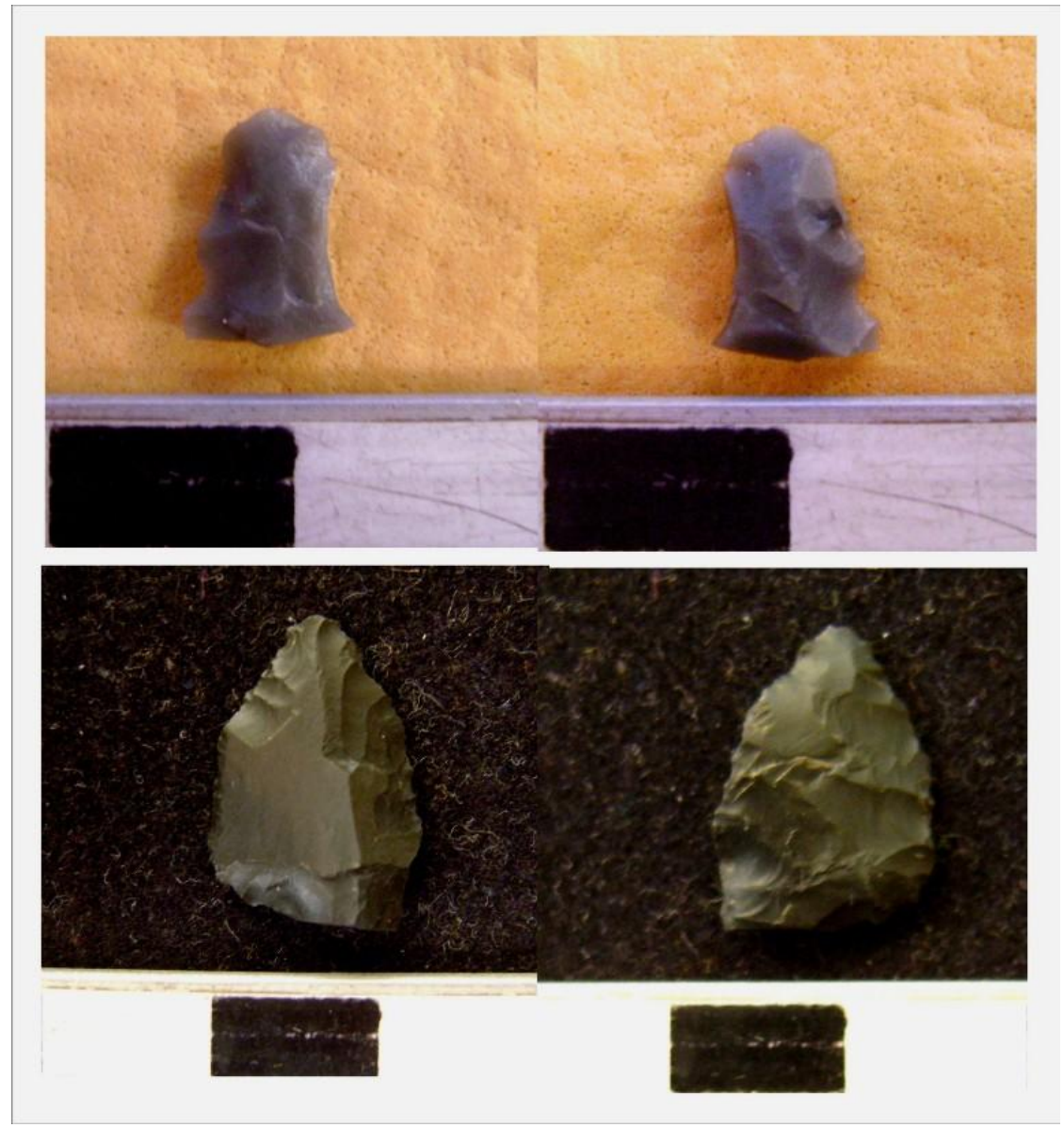

Figura 7.21. Puntas de proyectil trabajadas en obsidiana en LP. Fragmento de ápice (arriba) y pieza entera (abajo).

La relación entre desechos de talla enteros e instrumentos, aporta un valor estimado del descarte y la producción y/o reparación de instrumentos (Tabla 7.27). Los valores más altos se registran en rocas silíceas de la transecta LP-2, seguidas por la obsidiana y las rocas silíceas de la transecta LPT2. Si comparamos las muestras por sitio, se destacan los valores altos de índice para LPT2, quizás como indicador de uso diferencial del espacio en la localidad o la existencia de sectores de taller. Esto es concordante la presencia de los primeros estadios de manufactura y los tamaños mayores de desechos en superficie, mientras que en LP-2 se resalta la presencia de las últimas etapas de formatización y de lascas de reactivación de filos en obsidiana, materia prima que no ha sido identificada en los sitios restantes. Se podría argumentar que el descarte de 
artefactos confeccionados en rocas silíceas y obsidiana, responderían a diferentes trayectorias artefactuales.

\begin{tabular}{|c|c|c|c|c|c|}
\hline & Sitio & BAS & OBS & RIO & SIL \\
\hline \multirow{2}{*}{ Estratigrafía } & LC & - & - & - & - \\
\cline { 2 - 6 } & LP-2 & - & 10,8 & - & 71,23 \\
\hline \multirow{2}{*}{ Superficial } & LLE & - & - & - & - \\
\cline { 2 - 6 } & LPT2 & - & - & - & 3,2 \\
\hline
\end{tabular}

Tabla 7.27. Relación entre total desechos de talla enteros e instrumentos según materia prima en LP.

El tipo preponderante en los artefactos bifaciales es el correspondiente a puntas de proyectil (70\%, $n=7$ ) (Figura 6.22, trabajadas en el 60\% $(n=4)$ de los casos sobre roca silícea y en un $40 \%(n=3)$ en obsidiana. El $85 \%(n=6)$ de las puntas ha sido descartada en estado fragmentado y sólo una, confeccionada en roca silícea, está entera (15\%). Entre las piezas fragmentadas hay fragmentos apicales o distales $(33 \%, n=2)$, mediales y mediobasales $(67 \%, n=4)$. La punta silícea entera procede del sitio LP-2, es de tamaño grande (modulo tamaño=7), espesa (B: AM/EM: 2,5 a 4,9) y de buena calidad para la talla; es de forma lanceolada, con filo normal, pedúnculo no diferenciado de base recta y adelgazamiento de la base por retoques. Las piezas de obsidiana proceden del sitio LP-2, presentan la base escotada $(n=2)$ y filo regular. Las confeccionadas en silíceas, una presenta la base recta $(n=1)$ de filo festoneado y procede del sitio LP-2, y la otra del sitio superficial LPT2 y no pudo ser diferenciada por fractura $(n=1)$. Las puntas de proyectil en rocas silíceas son de buena calidad para la talla y las confeccionadas en obsidiana de calidad excelente. Para estimar las dimensiones de las puntas fragmentadas, se calculan los valores medios de largo, ancho y espesor por materia prima en fragmentos distales, sumando la variable peso como un indicador de diferencia de tamaño. En la tabla 7.28, se observa que la media y la mediana de las tres medidas de tamaño no presentan grandes diferencias de valor, por lo cual no se infiere que no hay grandes variaciones tamaño entre las muestras. Por otro lado si analizamos el coeficiente de variación, que permite comparar las desviaciones típicas de variables distintas, se observa que los pesos en 
gramos de las bases con una media de 1,55 gr presenta un valor de coeficiente alto $(104,4 \%)$, al igual que el espesor con un valor medio de $4,52 \mathrm{~mm}$ y un coeficiente de variación del $68 \%$.

\begin{tabular}{|c|c|c|c|c|}
\hline $\begin{array}{c}\text { Puntas de } \\
\text { proyectil }\end{array}$ & Largo mm & Ancho $\mathbf{m m}$ & Espesor mm & Peso gr \\
\hline $\mathbf{N}$ & 4 & 4 & 4 & 4 \\
\hline Media & 17 & 14,75 & 4,525 & 1,55 \\
\hline Desvío Estándar & 7,79016 & 6,60631 & 3,11595 & 1,61761 \\
\hline Mediana & 18,3 & 14,05 & 4,3 & 1,55 \\
\hline $\begin{array}{c}\text { Coeficiente de } \\
\text { Variación }\end{array}$ & $45,8 \%$ & $44,8 \%$ & $68,9 \%$ & $104,4 \%$ \\
\hline Mínimo & 7,1 & 8,7 & 1,8 & 0,1 \\
\hline Máximo & 24,3 & 22,2 & 7,7 & 3 \\
\hline Rango & 17,2 & 13,5 & 5,9 & 2,9 \\
\hline
\end{tabular}

Tabla 7.28. Estadística descriptiva de las características métricas de los fragmentos de mediobasales de puntas de proyectil en LP.

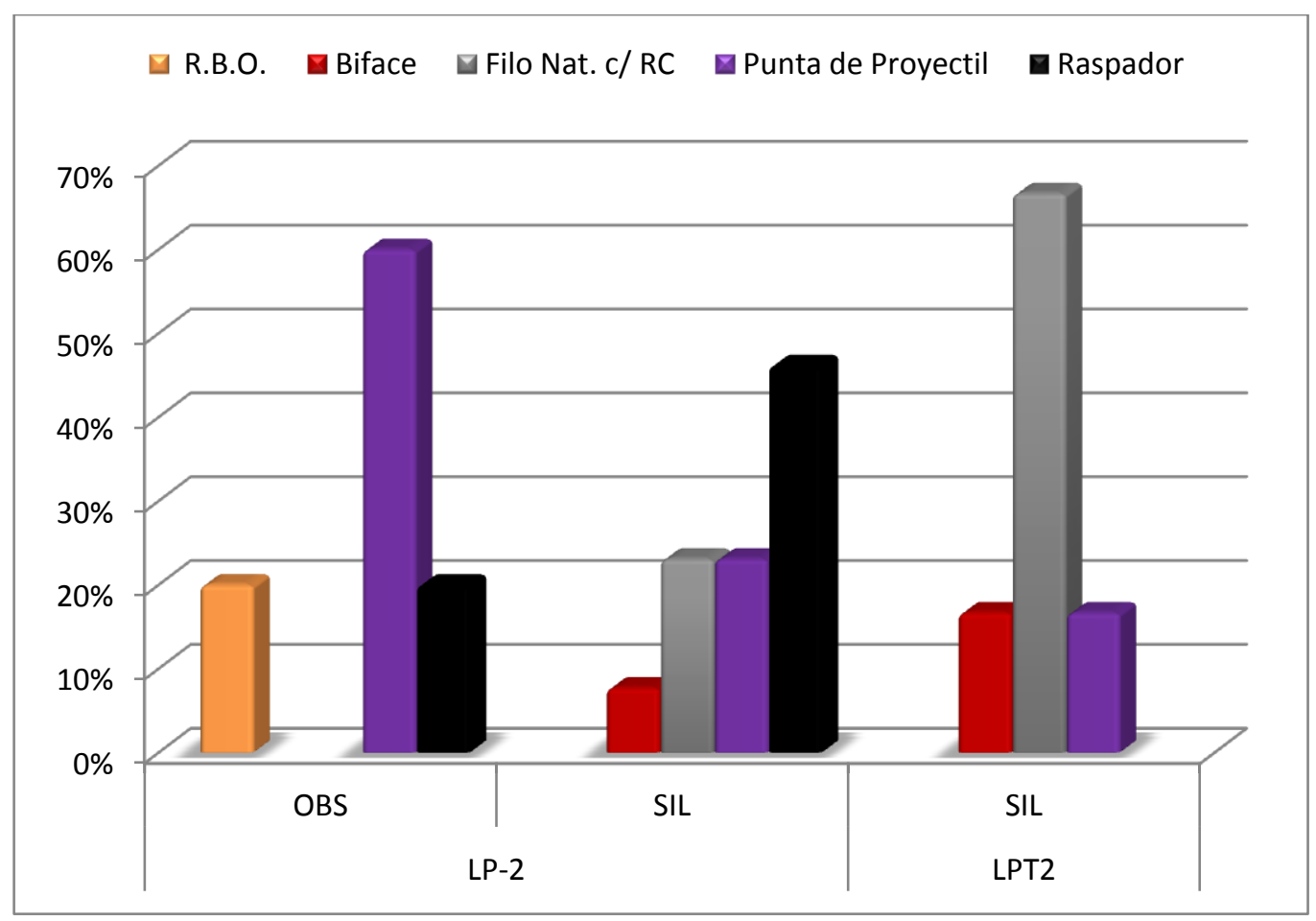

Figura 7.22. Frecuencia de grupos tipológicos según materia prima en LP. 
Las preformas bifaciales representan el $20 \%(n=2)$ de los artefactos bifaciales. Las dos piezas recuperadas están talladas en roca silícea, presentan tamaño grande (módulo tamaño=7), muy espeso (modulo $A M / E M=C,<2,7$ ) y buena calidad para la talla. La preforma procedente del sitio LP-2, ha sido descartada entera y presenta filo normal combinado con filo natural, parcialmente extendido (cubre entre el 50 y $70 \%$ de la pieza) y sección transversal biconvexa. La procedente de LPT2, se encuentra fragmentada, presenta filo normal discontinuo parcialmente extendido y sección transversal triangular redondeada. El artefacto mediano pequeño o muy pequeño de retoque en bisel oblicuo y sección asimétrica (RBO), representa el $10 \%(n=1)$ de los artefacto bifaciales. Este se encuentra entero, presenta un tamaño grande (modulo tamaño=7) y un espesor medio (modulo $A / E=B, 2,5-4,9$ ). Su filo es normal discontinuo combinado con filo natural, de extensión marginal (cubre menos del 50 \% de la pieza) y sección transversal rectangular.

Los artefactos bifaciales documentados en LP-2 provienen de la unidad A, asociada con fechados de ca. 400 años AP. Estudios geoquímicos permitieron determinar la procedencia de parte de las piezas de obsidiana recuperadas en la región Centro Occidental Argentino (Giesso et al. 2011; Salgán et al. 2011). Para la selección de las muestras se consideró la variación macroscópica en esta materia prima (Giesso et al. 2011). En LP se analizaron por medio de la técnica de fluorescencia de rayos-X (ver capítulo 5) dos fragmentos medio-basales de punta de proyectil con escotadura, descriptos anteriormente, cuya procedencia corresponde a la fuente primaria cordillerana El Maule (Capítulo 8).

Los artefactos unifaciales se encuentran trabajados sobre roca silícea $(85 \%, n=6)$ y obsidiana $(15 \%, n=1)$, registrados sólo en el sitio LP-2. Todos son raspadores de tamaño mediano grande (modulo tamaño=4) $(28 \%, n=2)$ y grandísimo (modulo tamaño=7) $(72 \%$, $n=6)$, de los cuales sólo el $15 \%(n=1)$ se encuentra fragmentado. Si consideramos las variaciones de tamaño en raspadores enteros (Tabla 7.28), notamos que la medida que mayor variabilidad presenta es el ancho con un valor medio de $18,27 \mathrm{~mm}$ y un coeficiente de variación del 37,9\%. Sin embargo, la variación más marcada se da en el peso de los raspadores, con un valor medio de 3 gr y un coeficiente de variación del 69,5\%. En cuanto 
a las diferencias entre las unidades cronoestratigráficas de LP-2, la unidad A (niveles 1-4) presenta la mayor riqueza de materias primas y frecuencia de artefactos unifaciales (71\%, $\mathrm{n}=5$ ). En la tabla 7.29, siguiendo la propuesta de Kuhn (1990) para artefactos unifaciales de filo formatizado, se calculó el índice geométrico de reducción (ver Capítulo IV) para raspadores silíceos enteros de la unidad $\mathrm{A}$. El índice para el raspador de obsidiana es de 0,95, mientras que el calculado para el de roca silícea de la unidad $B$ es de 0,72. Teniendo en cuenta los valores medios de la tabla 7.30, los raspadores silíceos de la unidad A son los que presentan el menor grado de reducción $(0,52)$; esto implica que fueron descartados no agotados. En el caso la obsidiana, el índice es alto, dado que fue sometido a reiteradas tareas de reactivación, no obstante este valor debe tomarse como tentativo dado que se trata de un solo artefacto. En la unidad B la única pieza recuperada presenta un índice medio, comparable con los de mayor reducción de la unidad A. Si tenemos en cuenta la variable temporal en LP-2, notamos una disminución en los índices de reducción hacia la unidad $A$, la cual no se expresaría de igual modo en las dos materias primas representadas, dado que la obsidiana presenta valores de reducción mayores.

\begin{tabular}{|c|c|c|c|c|}
\hline Raspadores & Largo $\mathbf{m m}$ & Ancho $\mathbf{~ m m}$ & Espesor $\mathbf{m m}$ & Peso gr \\
\hline $\mathbf{N}$ & 7 & 7 & 7 & 7 \\
\hline Media & 17,95 & 18,27 & 6,25 & 3,01 \\
\hline $\begin{array}{c}\text { Desvío } \\
\text { Estándar }\end{array}$ & 3,64 & 6,92 & 1,78 & 2,09 \\
\hline Mediana & 16,3 & 20,5 & 6,4 & 2,7 \\
\hline $\begin{array}{c}\text { Coeficiente } \\
\text { de Variación }\end{array}$ & $20,3 \%$ & $37,9 \%$ & $28,5 \%$ & $69,5 \%$ \\
\hline Mínimo & 13,9 & 7,5 & 3,4 & 0,7 \\
\hline Máximo & 23,4 & 26 & 8,4 & 6,7 \\
\hline Rango & 9,5 & 18,5 & 5 & 6 \\
\hline
\end{tabular}

Tabla 7.29. Estadística descriptiva de las características métricas de los raspadores en LP. 


\begin{tabular}{|c|c|}
\hline Raspador & Unidad A \\
\hline $\mathbf{N}$ & 4 \\
\hline Media & 0,52 \\
\hline Mediana & 0,49 \\
\hline Desvío Estándar & 0,17 \\
\hline Mínimo & 0,342 \\
\hline Máximo & 0,75 \\
\hline Rango & 0,40 \\
\hline
\end{tabular}

Tabla 7.30 Estadística descriptiva del índice geométrico de reducción en roca silícea de la unidad A, sitio LP-2.

Los artefactos sin formatización con rastros complementarios (ASF-RC), se registraron principalmente en la transecta LPT2 $(57 \%, n=4)$. Las forma base de las piezas son lascas no diferenciadas $(57 \%, n=4)$, lascas secundarias $(28 \%, n=2)$ y lasca de arista $(15 \%, n=1)$. El modulo tamaño registrado en todas las piezas es el grandísimo, con espesores variables. Las piezas enteras $(57 \%, n=4)$ presentan un módulos de espesor poco espeso $(25 \%, n=1)$, espeso $(50 \%, n=2)$ y muy espeso $(25 \%, n=1)$. En las piezas fragmentadas $(43 \%, n=3)$ los espesores son poco espesos $(75 \%, n=2)$ y muy espesos $(25 \%$, $\mathrm{n}=1$ ). En todos los casos se trata de lascas con filo simple, dispuestos de modo discontinuo $(n=4)$, sumario $(n=2)$ y continuo $(n=1)$. La extensión de los lascados y/o rastros complementarios es marginal $(n=4)$ a parcialmente extendido $(n=3)$. Los ASF-RC presentan la mayor frecuencia de artefactos confeccionados en roca silícea de muy buena calidad para la talla $(43 \%, n=3)$; las de buena calidad alcanzan el $57 \%(n=4)$.

\subsubsection{CONSIDERACIONES GENERALES DE LA LOCALIDAD LA PELIGROSA}

En LP, la roca silícea y la obsidiana son las materias primas más representadas. El sitio con mayor diversidad de rocas es LP-2, en el cual se registran -además de las rocas mencionadas- artefactos en basalto y riolita. En los muestreos restantes sólo se documentó artefactos trabajados en rocas silíceas. Esto es coherente con la disponibilidad local de materia prima, dado que se han detectado al menos dos fuentes de rocas silíceas 
(PB y LLE). En esta roca predomina la calidad para la talla muy buena a buena con bajos valores de fragmentación (Tabla 7.12). En obsidiana predomina la calidad excelente y es la roca con mayor proporción de piezas fragmentadas (Tabla 7.14). Los tamaños pequeños (65\%) son los preponderantes, seguidos por los grandes (20\%) y medianos (15\%). En los sitios superficiales, y en especial en LLE, dominan los tamaños grandes, mientras que en los sitios estratigráficos los pequeños son más frecuentes. De modo similar, los artefactos con alta reserva de corteza son dominantes en los sitios superficiales, mientras que en los estratigráficos los artefactos sin corteza son más frecuentes.

En LP-2 se encuentran representadas todas las categorías, con preponderancia de los desechos de talla, entre los cuales están representadas las cuatro materias primas. En los desechos de rocas silíceas se encuentran representadas todas las etapas de manufactura, mientras que en obsidiana y basalto sólo lascas internas, correspondientes a etapas avanzas de manufactura. En cuanto a la intensidad de reducción, la obsidiana es la que posee los índices más elevados. Desde una perspectiva temporal se registran diferencias en las frecuencias y tipos de materias primas entre las unidades A (ca. 400 años AP) y B (ca. 640 años AP). En la Unidad B, las materias primas por orden de importancia son las rocas silíceas, la obsidiana y las riolitas. Entre los tipos de artefacto predominan los desechos de talla, seguidos por los AF Unifacial y núcleos sólo en roca silícea. Por su parte en la Unidad A, la riqueza de materias primas continúa siendo tres, se incorporan registros de basalto pero está ausente la riolita. En relación a las clases artefactuales, si bien los desechos de talla siguen siendo preponderantes, se registra mayor diversidad de clases, en particular instrumentos formatizados y con rastros complementarios. En instrumentos se destacan las puntas de proyectil fragmentadas en rocas silíceas y obsidiana, así como los raspadores en roca silícea. En ésta última unidad la obsidiana presenta mayor frecuencia en relación a la Unidad B. También la Unidad B se diferencia de la A en cuanto a una mayor frecuencia de lascas de reactivación de filo.

En el sitio estratigráfico LC y como se mencionó antes, la única materia prima registrada es la roca silícea en la que predominan los desechos de talla y los núcleos. En desechos las lascas internas (lascas angulares) son las más abundantes, seguidas por 
lascas externas (lascas secundarias y nodulares). El sitio superficial LLE, ubicado en la cantera La Leona, registra en rocas silíceas dos clases artefactuales, núcleos y desechos de talla. Estos últimos son los de mayor frecuencia y presentan en este sitio la mayor diversidad luego de la observada en LP-2. Se encuentran representadas todas las etapas de formatización, con excepción del adelgazamiento bifacial y la reactivación de filos. En núcleos, se registra una pieza amorfa no agotada, de calidad buena para la talla y con reserva de corteza. Por su parte, en la transecta LPT2, ubicada al este de la localidad arqueológica, registra un valor alto de riqueza de clases artefactuales $(n=3)$. La clase de mayor frecuencia es desechos de talla, seguida por los ASF RC y los AF Bifacial. Se encuentran representadas casi todas las etapas de manufactura, siendo las lascas internas las preponderantes y sin registros de reactivación de filos. Se destaca una alta frecuencia de ASF RC entre las rocas silíceas de muy buena calidad para la talla, lo que podría implicar una selección de materias primas. 


\subsection{LOCALIDAD ALTIPLANICIE DEL PAYÉN (ALPA)}

La localidad arqueológica Altiplanicie del Payén (en adelante ALPA) se encuentra en el sector centro sur de La Payunia, a aproximadamente 2000 msnm (Figura 7.23). Su nombre hace referencia a la amplia plataforma basáltica formada a partir de los eventos volcánicos miocénicos (Llambías et al. 2010). En el paisaje se destacan los volcanes Payún Matrú y Payún Liso (Figura 7.24), además de los numerosos conos volcánicos monogenéticos (Capítulo 3). Estos factores y las condiciones ambientales no favorecen la formación de suelos y limitan el desarrollo de cubierta vegetal. La Altiplanicie del Payén está conformada por el plateau basáltico y su contacto con el bloque de San Rafael (González Díaz 1972). En la localidad se encuentra el puesto de la familia Hernández denominado Agua de La Totora (36 $47^{\prime} 39.7^{\prime \prime}$ LS y $69^{\circ} 13^{\prime} 21.9^{\prime \prime}$ LO) y la aguada natural homónima, una de las fuentes de agua más importantes del sector.

Los muestreos superficiales se llevaron a cabo en el año 2004 y parte de estos estudios fueron presentados por Gil y Neme (2006). Para los fines de esta investigación se analizaron las prospecciones realizadas en el sector este de la Altiplanicie y los muestreos puntuales en áreas cercanas (Figura 7.25). Para los trabajos de campo se utilizó la metodología de prospección antes detallada (Capítulo 5) y se efectuaron recolecciones asistemáticas en algunos lugares de interés. En el primero de los casos, los materiales fueron recolectados en su totalidad, según unidades de $60 \mathrm{~m}$ de largo por $4 \mathrm{~m}$ de ancho. Se relevaron un total de 9 transectas que abarcan un área de $263.280 \mathrm{~m}^{2}$. Las transectas varían en extensión entre 12 y 0,45 km (Tabla 7.31). También se muestrearon artefactos de obsidiana en cuatro sectores de la localidad cuyo análisis se presenta en el capítulo 8. 


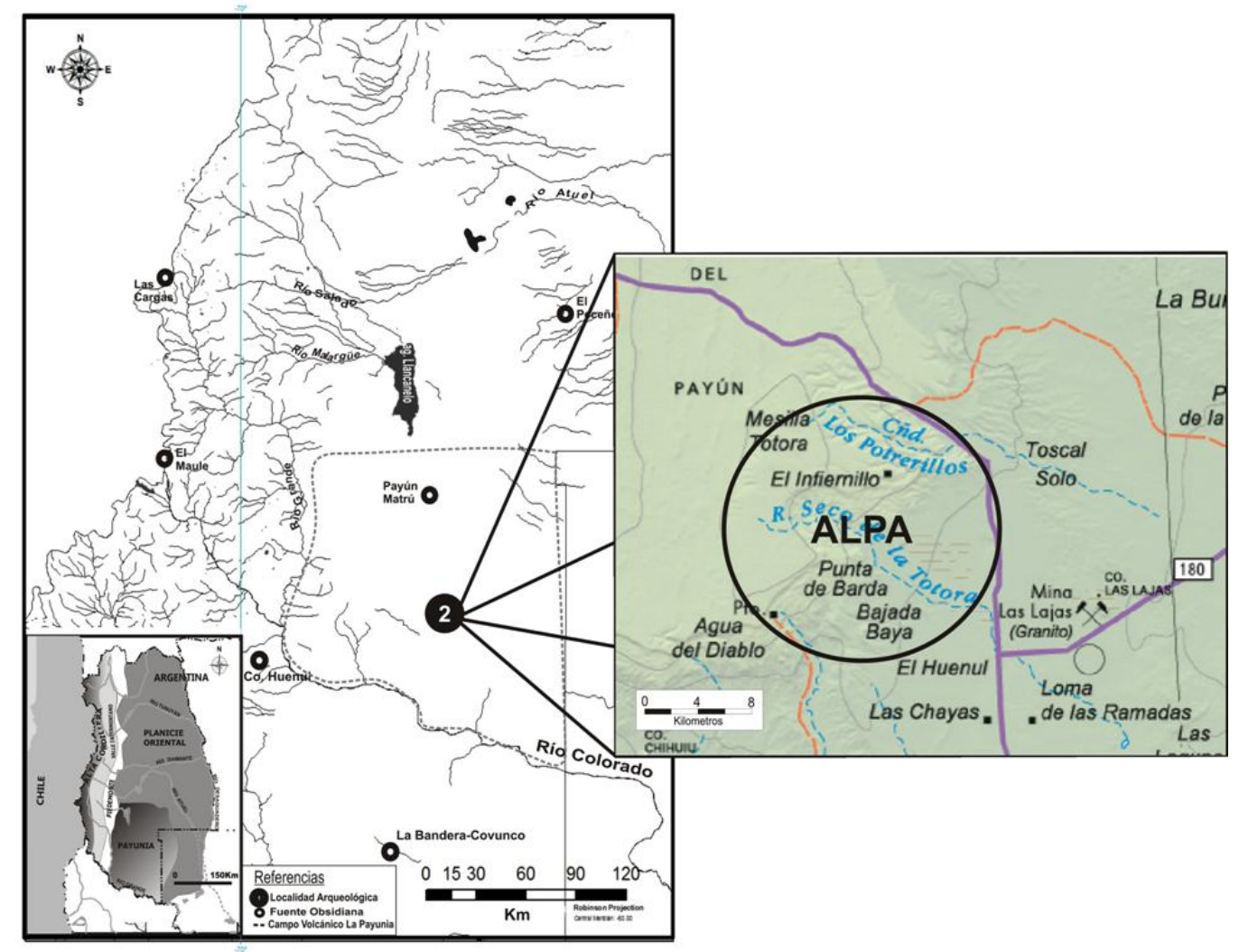

Figura 7.23. Ubicación de localidad arqueológica Altiplanicie del Payén (ALPA).

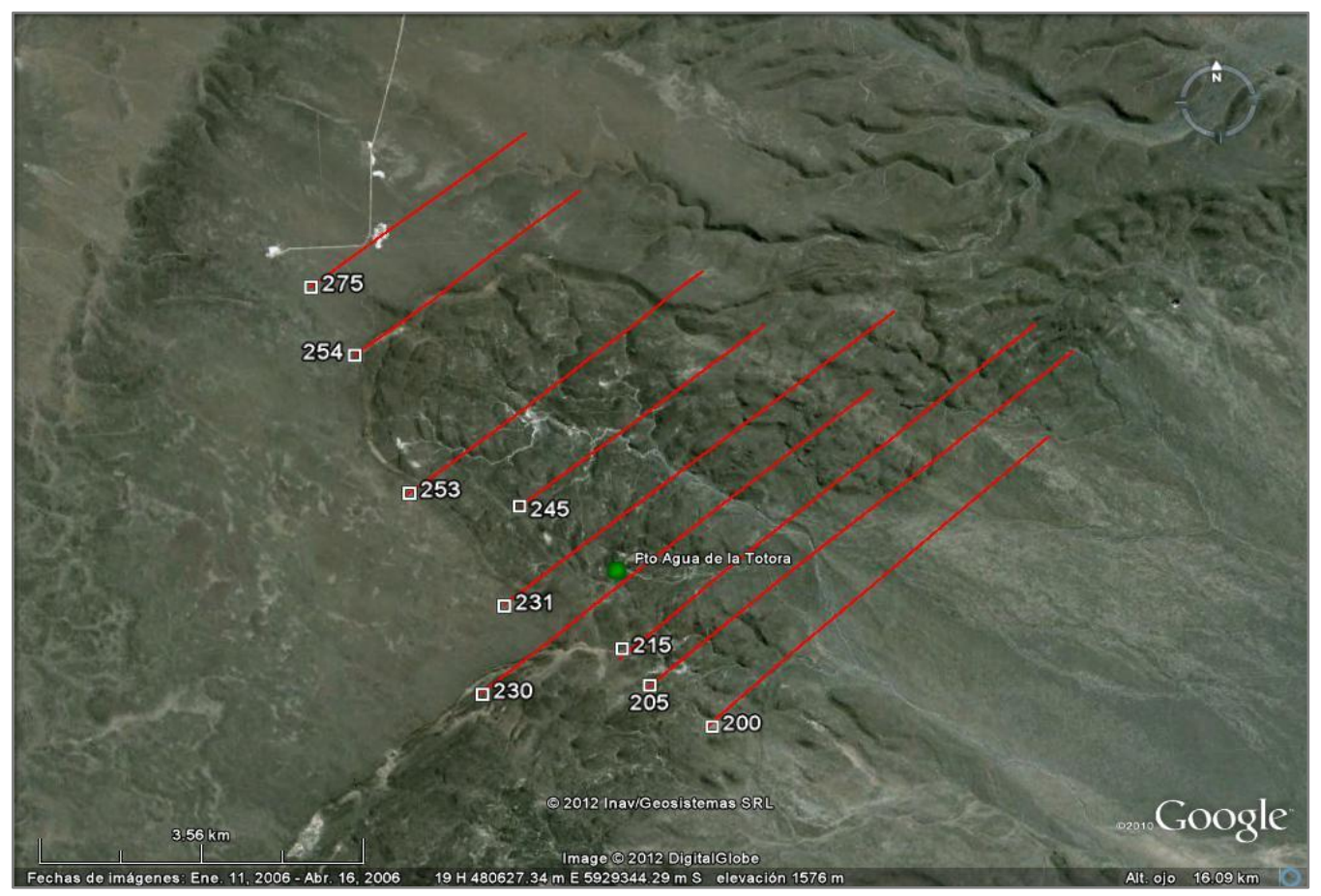

Figura 7.24. Ubicación de las transectas y áreas analizadas en ALPA. 


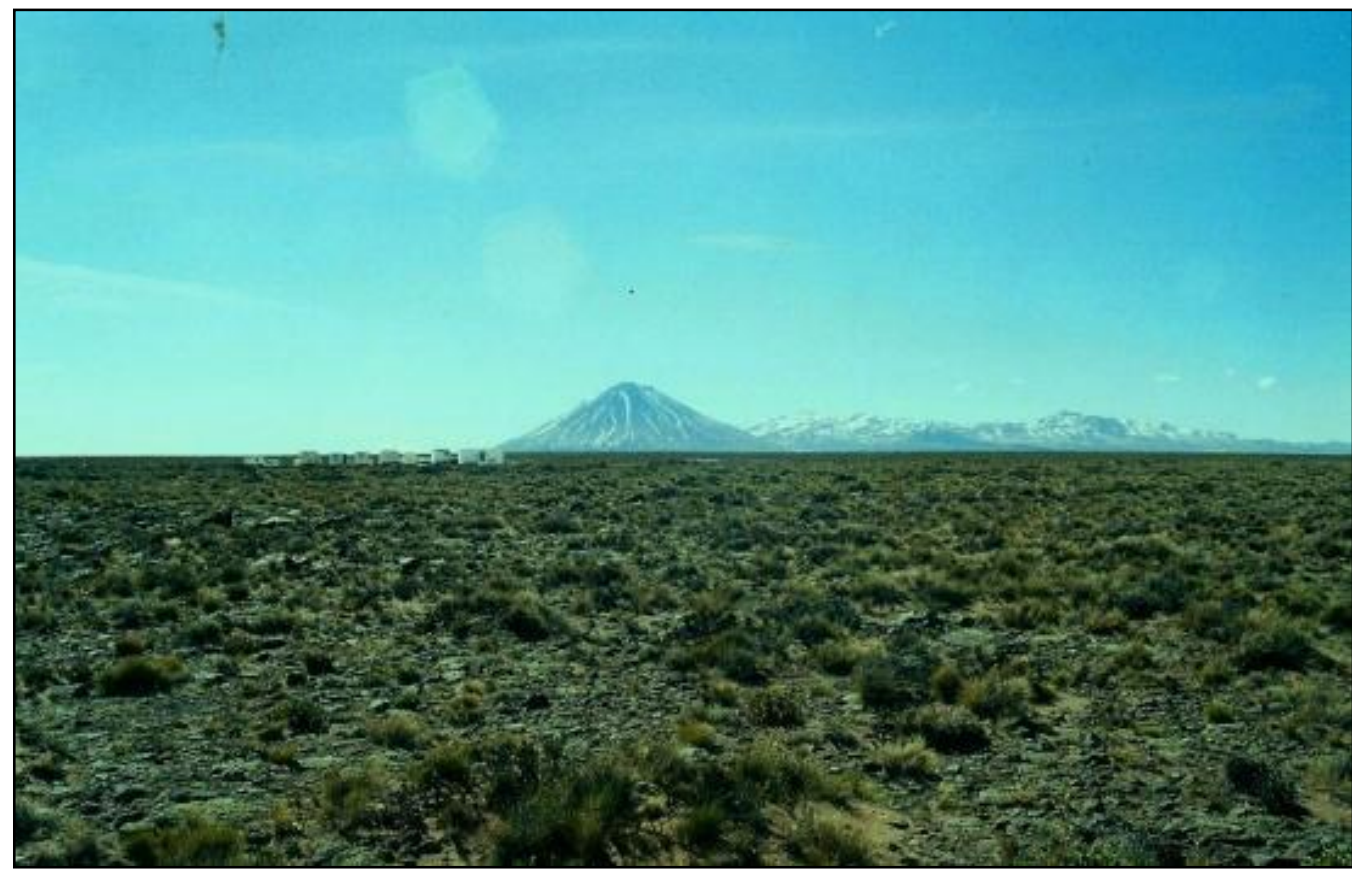

Figura 7.25. Vista de la Altiplanicie del Payén. En la imagen se destacan los volcanes Payún Liso (izquierda) y Payún Matrú (derecha).

\begin{tabular}{|c|c|c|c|c|c|c|c|c|}
\hline Transecta & $\begin{array}{c}\mathbf{N} \\
\text { muestreos }\end{array}$ & $\begin{array}{c}\text { Superficie } \\
\text { muestreo } \\
\mathbf{m}^{\mathbf{2}}\end{array}$ & $\begin{array}{c}\text { Superficie } \\
\mathbf{c / h a l l a z g o} \\
\mathbf{m}^{\mathbf{2}}\end{array}$ & $\begin{array}{c}\mathbf{N} \\
\text { artefactos }\end{array}$ & $\begin{array}{c}\text { Densidad } \\
\text { Max. }\end{array}$ & $\begin{array}{c}\text { Densidad } \\
\text { Min. }\end{array}$ & $\begin{array}{c}\mathbf{N} \\
\text { Muestreos } \\
\text { s/ hallazgo }\end{array}$ & $\begin{array}{c}\text { Riqueza } \\
\text { artefactual }\end{array}$ \\
\hline ALPA 200 & 103 & 24720 & 480 & 3 & 0,00012 & 0,006 & 101 & 2 \\
\hline ALPA 205 & 163 & 39120 & 2640 & 20 & 0,00051 & 0,008 & 82 & 2 \\
\hline ALPA 215 & 167 & 40080 & 8160 & 44 & 0,00110 & 0,005 & 130 & 3 \\
\hline ALPA 230 & 103 & 24720 & 8400 & 132 & 0,00534 & 0,016 & 68 & 3 \\
\hline ALPA 231 & 170 & 40800 & 240 & 3 & 0,00007 & 0,013 & 169 & 2 \\
\hline ALPA 245 & 93 & 22320 & 3120 & 16 & 0,00072 & 0,005 & 80 & 2 \\
\hline ALPA 253 & 148 & 35520 & 8160 & 64 & 0,00180 & 0,008 & 114 & 3 \\
\hline ALPA 254 & 75 & 18000 & 240 & 1 & 0,00006 & 0,004 & 74 & 2 \\
\hline ALPA 275 & 75 & 18000 & 240 & 3 & 0,00017 & 0,013 & 72 & 1 \\
\hline Total & 1097 & 263.280 & 31.680 & 286 & 0,00109 & 0,009 & 890 & 3 \\
\hline
\end{tabular}

Tabla 7.31. Información superficial relevada en ALPA.

Se analizaron 303 artefactos líticos, de los cuales 286 fueron recuperados en líneas de transecta, y se recolectaron 17 artefactos de obsidiana fuera de muestreo sistemático para análisis geoquímico (Capítulo 8). Se destaca una alta frecuencia de núcleos (47\%, 
$\mathrm{n}=141)$, seguidos por desechos de talla $(31 \%, n=93)$ e instrumentos $(3,3 \%, n=10)$ (Tabla 7.32). La materia primas más representada es la silícea $(89 \%, n=271)$, seguida por el basalto $(3 \%, n=9)$, la obsidiana $(1 \%, n=3)$ y las rocas no diferenciadas $(1 \%, n=3)$ (Tabla 7.33 ; Figura 7.26). En cada unidad se relevó la información ambiental (cobertura vegetal, agua, etc.) y la correspondiente a pendiente, visibilidad, geoformas y sedimentos. La visibilidad general del área es de muy buena (44,9\%) a buena (41,7\%) (Figura 7.27 ) y la pendiente es nula (47\%) en la mayoría de los casos, seguida por pendientes suaves (38\%) y pronunciadas (19\%).

\begin{tabular}{|c|c|c|c|c|c|c|c|}
\hline \multirow{2}{*}{ Transecta } & \multicolumn{6}{|c|}{ Artefactos } & \multirow{2}{*}{ Total } \\
\hline & DT & ND & Núcleo & AF Bifacial & AF Unifacial & ASF- RC & \\
\hline 200 & 1 & 1 & 1 & - & - & - & 3 \\
\hline 205 & 11 & 2 & 6 & 1 & - & - & 20 \\
\hline 215 & 17 & 17 & 9 & - & 1 & - & 44 \\
\hline 230 & 30 & 33 & 68 & - & - & 1 & 132 \\
\hline 231 & 2 & - & 1 & - & - & - & 3 \\
\hline 245 & 3 & - & 13 & - & - & - & 16 \\
\hline 253 & 16 & 6 & 41 & 1 & - & - & 64 \\
\hline 254 & & - & - & 1 & - & - & 1 \\
\hline 275 & 1 & - & 2 & - & - & - & 3 \\
\hline Total & 81 & 59 & 141 & 3 & 1 & 1 & 286 \\
\hline$\%$ & $28,3 \%$ & $20,6 \%$ & $49,3 \%$ & $1 \%$ & $0,3 \%$ & $0,3 \%$ & $100 \%$ \\
\hline
\end{tabular}

Tabla 7.32. Clases artefactuales en ALPA.

\begin{tabular}{|c|c|c|c|c|c|}
\hline Transecta & BAS & ND & OBS & SIL & Total \\
\hline 200 & - & - & - & $3(100 \%)$ & $3(100 \%)$ \\
\hline 205 & $1(5 \%)$ & - & $1(5 \%)$ & $18(90 \%)$ & $20(100 \%)$ \\
\hline 215 & - & - & $1(2 \%)$ & $43(98 \%)$ & $44(100 \%)$ \\
\hline 230 & $6(5 \%)$ & $1(1 \%)$ & $1(1 \%)$ & $124(94 \%)$ & $132(100 \%)$ \\
\hline 231 & $1(33 \%)$ & - & - & $2(67 \%)$ & $3(100 \%)$ \\
\hline 245 & - & - & - & $16(100 \%)$ & $16(100 \%)$ \\
\hline 253 & - & $2(3 \%)$ & - & $62(97 \%)$ & $64(100 \%)$ \\
\hline 254 & - & - & - & $1(100 \%)$ & $1(100 \%)$ \\
\hline 275 & $1(33 \%)$ & - & - & $2(67 \%)$ & $3(100 \%)$ \\
\hline Total & $9(3 \%)$ & $3(1 \%)$ & $3(1 \%)$ & $271(95 \%)$ & $286(100 \%)$ \\
\hline
\end{tabular}

Tabla 7.33. Distribución y frecuencia de materias primas en ALPA. 


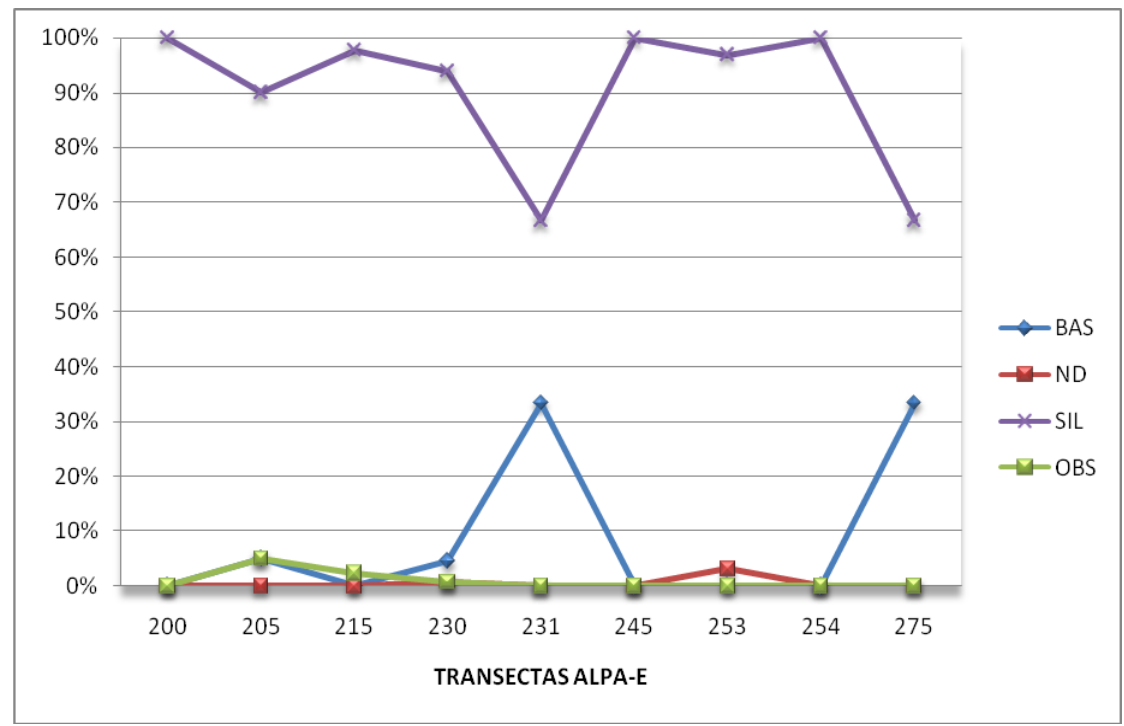

Figura 7.26. Frecuencia de materias primas por transecta en ALPA.

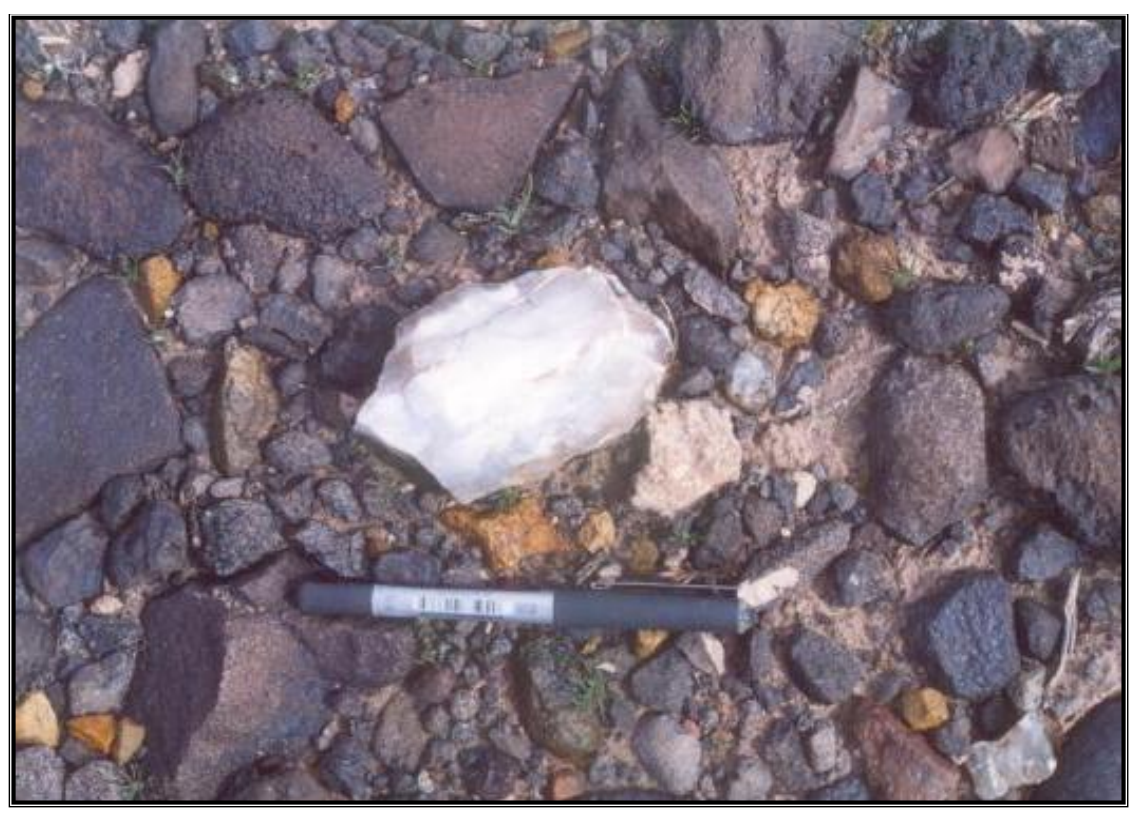

Figura 7.27 Artefacto de roca silícea recuperado en muestreos superficiales en ALPA-E. 


\subsubsection{ANÁLISIS TECNOLÓGICO DE LA LOCALIDAD ALTIPLANICIE DEL PAYÉN (ALPA)}

En ALPA se realizaron fundamentalmente relevamientos superficiales sistemáticos y recolecciones asistemáticas en distintos sectores. En este apartado analizamos las muestras recuperadas en forma sistemática $(n=286)$.

\subsection{2a MATERIAS PRIMAS LÍTICAS}

En ALPA la materia prima más frecuente es la roca silícea (95\%), seguida por el basalto $(3 \%)$, la obsidiana (1\%) y las rocas no diferenciadas (1\%). La mayor diversidad de rocas se encuentra en la línea de transecta 230 , que coincide con uno de los sectores del paisaje de mayor concentración de artefactos. En cuanto a calidad para la talla predomina la calidad muy buena (60\%), seguida por la buena (30\%) y la excelente (10\%). El $22 \%$ de calidad excelente corresponde a obsidiana $(95 \%)$ y roca silícea $(5 \%)$. Sólo el $12 \%$ de los artefactos se encuentra fracturado (Tabla 7.34). En la tabla 7.35 se observa el índice de fragmentación por tipo de materia prima, el indice mayor corresponde a basalto (33\%), seguido por las rocas silíceas (14\%). 


\begin{tabular}{|c|c|c|c|c|c|c|c|c|}
\hline Transecta & MP & Entero & $\%$ & Fracturado & $\%$ & ND & $\%$ & Total \\
\hline 200 & SIL & 1 & $33 \%$ & - & - & 2 & $67 \%$ & 3 \\
\hline \multirow{3}{*}{205} & BAS & 1 & $100 \%$ & - & - & - & - & 1 \\
\hline & OBS & 1 & $100 \%$ & - & - & - & - & 1 \\
\hline & SIL & 14 & $78 \%$ & 1 & $6 \%$ & 3 & $17 \%$ & 18 \\
\hline \multirow{2}{*}{215} & OBS & 1 & $100 \%$ & - & - & - & - & 1 \\
\hline & SIL & 30 & $70 \%$ & 9 & $21 \%$ & 4 & $9 \%$ & 43 \\
\hline \multirow{4}{*}{230} & BAS & 2 & $33 \%$ & 2 & $33 \%$ & 2 & $33 \%$ & 6 \\
\hline & ND & 1 & $100 \%$ & - & - & - & - & 1 \\
\hline & OBS & - & - & 1 & $100 \%$ & - & - & 1 \\
\hline & SIL & 110 & $89 \%$ & 8 & $6 \%$ & 6 & $5 \%$ & 124 \\
\hline \multirow{2}{*}{231} & BAS & - & - & 1 & $100 \%$ & - & - & 1 \\
\hline & SIL & - & - & - & - & 2 & $100 \%$ & 2 \\
\hline 245 & SIL & 15 & $94 \%$ & 1 & $6 \%$ & - & - & 16 \\
\hline \multirow{2}{*}{253} & ND & 1 & $50 \%$ & 1 & $50 \%$ & - & - & 2 \\
\hline & SIL & 51 & $82 \%$ & 8 & $13 \%$ & 3 & $5 \%$ & 62 \\
\hline 254 & SIL & - & - & 1 & $100 \%$ & - & - & 1 \\
\hline \multirow{2}{*}{275} & BAS & 1 & $100 \%$ & - & - & - & - & 1 \\
\hline & SIL & 2 & $100 \%$ & - & - & - & - & 2 \\
\hline \multicolumn{2}{|c|}{ Total } & 231 & $81 \%$ & 33 & $12 \%$ & 22 & $8 \%$ & 286 \\
\hline
\end{tabular}

Tabla 7.34. Estado de fragmentación de los artefactos en ALPA.

\begin{tabular}{|c|c|c|c|c|c|c|c|}
\hline MP & Ent & Fr. Prox & Fr. Dist & Fr. ND & NAS & MNA & MNA/NAS \\
\hline BAS & 4 & 2 & 1 & - & 9 & 6 & $67 \%$ \\
\hline ND & 2 & - & 1 & - & 3 & 3 & $100 \%$ \\
\hline OBS & 2 & 1 & - & - & 3 & 3 & $100 \%$ \\
\hline SIL & 223 & 10 & 11 & 7 & 271 & 234 & $86 \%$ \\
\hline Total & 231 & 13 & 13 & 7 & 286 & 246 & $85 \%$ \\
\hline
\end{tabular}

Tabla 7.35. Estado de fragmentación de los artefactos por materia prima en ALPA. Referencia: MP: materia prima; Ent: entero; Fr. Prox: fragmento proximal; Fr. Dist: fragmento distal; Fr. ND: fragmento no diferenciado; ND: No Diferenciado; NAS: número de especímenes artefactuales; MNA: número mínimo de artefactos.

La mayor parte de los artefactos enteros son de tamaño grande (grande, muy grande y grandísimo) con frecuencias que superan el 95\%, les siguen los tamaños medianos $(3,4 \%)$ y los pequeños $(0,9 \%)$ (Tabla 7.36$)$. Se destaca la ausencia de tamaños 
muy pequeños y una alta proporción de artefactos enteros de obsidiana sin corteza, así como una alta frecuencia de reserva de corteza en artefactos de roca silícea (Tabla 7.37).

\begin{tabular}{|c|c|c|c|c|c|c|c|}
\hline MP & P & MEP & MEG & G & MG & GD & Total \\
\hline BAS & $25 \%$ & - & - & - & - & $75 \%$ & 4 \\
\hline OBS & - & $33 \%$ & - & - & - & $67 \%$ & 3 \\
\hline SIL & $0,4 \%$ & $1,3 \%$ & $1,8 \%$ & $1,8 \%$ & $3,1 \%$ & $91,5 \%$ & 223 \\
\hline ND & - & - & - & - & - & $100 \%$ & 2 \\
\hline Total & $0,9 \%$ & $1,7 \%$ & $1,7 \%$ & $1,7 \%$ & $3 \%$ & $91,3 \%$ & 231 \\
\hline
\end{tabular}

Tabla 7.36. Tamaño de los artefactos enteros en las materias primas representadas en ALPA. Referencia: MP: materia prima; MPE: Muy pequeño (0-20); P: Pequeño (21-40); MEP: Mediano pequeño (4160); MEG: Mediano Grande (61-80); G: Grande (81-120); MG: Muy Grande (121-160); GD: Grandísimo (>161).

\begin{tabular}{|c|c|c|c|c|c|c|c|}
\hline MP & $\mathbf{0 \%}$ & $\mathbf{2 5 \%}$ & $\mathbf{5 0 \%}$ & $\mathbf{7 5 \%}$ & $\mathbf{1 0 0 \%}$ & ND & Total \\
\hline BAS & $50 \%$ & - & $50 \%$ & - & - & - & 4 \\
\hline OBS & $100 \%$ & - & - & - & - & - & 2 \\
\hline SIL & $10 \%$ & $0 \%$ & $71 \%$ & $2 \%$ & $10 \%$ & $6 \%$ & 223 \\
\hline ND & $50 \%$ & - & - & - & - & $50 \%$ & 2 \\
\hline Total & $15 \%$ & $0 \%$ & $69 \%$ & $3 \%$ & $10 \%$ & $6 \%$ & 231 \\
\hline
\end{tabular}

Tabla 7.37. Reserva de corteza en artefactos enteros en ALPA.

\subsection{2b ESTRUCTURA TECNOLÓGICA EN ALPA}

En ALPA predominan los núcleos (49\%), seguidos por los desechos de talla (28\%) y los instrumentos (2\%). Los instrumentos más frecuentes son los de formatización bifacial (1\%), seguidos por los de formatización unifacial $(0,3 \%)$ y los artefactos con rastros complementarios (0,3\%) (Tabla 7.38). Si analizamos el conjunto por transecta, se observa que en todos los casos se registraron artefactos elaborados en roca silícea, mientras que la obsidiana y el basalto se encuentra en menor frecuencia y no están presentes de modo uniforme. La materia prima con mayor número de clases artefactuales es la roca silícea, seguida por la obsidiana, el basalto y las rocas no diferenciadas (Tabla 7.39). El valor de diversidad, que combina las variables de tamaño de la muestra y distribución, es mayor en rocas silíceas. En esta roca se destaca un valor de dominancia medio y son frecuentes los 
desechos de talla y los núcleos. En obsidiana el valor de diversidad sigue en importancia con dominancia media, registrando mayor frecuencia de desechos e instrumentos. En basalto la clase artefactual dominante es la de desechos de talla y en muy baja proporción núcleos. Entre las rocas no diferenciadas el valor de diversidad supera el 0.5 y están representados núcleos y desechos de talla en proporciones similares.

\begin{tabular}{|c|c|c|c|c|c|c|c|c|}
\hline Transecta & MP & AF Bifacial & AF Unifacial & ASF RC & DT & Núcleo & ND & Total \\
\hline 200 & SIL & - & - & - & $1(33,3 \%)$ & $1(33,3 \%)$ & $1(33,3 \%)$ & 3 \\
\hline \multirow{3}{*}{205} & BAS & - & - & - & $1(100 \%)$ & - & - & 1 \\
\hline & OBS & $1(100 \%)$ & - & - & - & - & - & 1 \\
\hline & SIL & - & - & - & $10(55,6 \%)$ & $6(33,3 \%)$ & $2(11,1 \%)$ & 18 \\
\hline \multirow{2}{*}{215} & OBS & - & - & - & $1(100 \%)$ & - & - & 1 \\
\hline & SIL & - & $1(2,3 \%)$ & - & $16(37,2 \%)$ & $9(20,9 \%)$ & $17(39,5 \%)$ & 43 \\
\hline \multirow{4}{*}{230} & BAS & - & - & - & $6(100 \%)$ & - & - & 6 \\
\hline & ND & - & - & - & - & $1(100 \%)$ & - & 1 \\
\hline & OBS & - & - & - & $1(100 \%)$ & - & - & 1 \\
\hline & SIL & - & - & $1(0,8 \%)$ & $23(18,5 \%)$ & 67 (54\%) & $33(26,6 \%)$ & 124 \\
\hline \multirow{2}{*}{231} & BAS & - & - & - & $1(100 \%)$ & - & - & 1 \\
\hline & SIL & - & - & - & $1(50 \%)$ & $1(50 \%)$ & - & 2 \\
\hline 245 & SIL & - & - & - & $3(18,8 \%)$ & $13(81,3 \%)$ & & 16 \\
\hline \multirow{2}{*}{253} & ND & - & - & - & $1(50 \%)$ & $1(50 \%)$ & - & 2 \\
\hline & SIL & $1(1,6 \%)$ & - & - & $15(24,2 \%)$ & $40(64,5 \%)$ & $6(9,7 \%)$ & 62 \\
\hline 254 & SIL & $1(100 \%)$ & - & - & - & - & - & 1 \\
\hline \multirow{2}{*}{275} & BAS & - & - & - & - & $1(100 \%)$ & - & 1 \\
\hline & SIL & - & - & - & $1(50 \%)$ & $1(50 \%)$ & - & 2 \\
\hline \multicolumn{2}{|c|}{ Total Transecta } & $3(1 \%)$ & $1(0,3 \%)$ & $1(0,3 \%)$ & $81(28,3 \%)$ & $141(49,3 \%)$ & $59(20,6 \%)$ & $286(100 \%)$ \\
\hline
\end{tabular}

Tabla 7.38. Clases artefactuales en ALPA. Entre paréntesis se detalla la proporción de la clase artefactual por materia prima y sitio de muestreo. Referencia: MP: materia prima; AF Bifacial: artefacto de formatización bifacial; AF Unifacial: artefacto de formatización unifacial; As/F con RC: artefacto sin formatización con rastros complementarios; DT: desecho de talla; ND: no diferenciado. 


\begin{tabular}{|c|c|c|c|c|}
\hline & BAS & OBS & SIL & ND \\
\hline N clase artefacto & 2 & 2 & 5 & 2 \\
\hline $\mathbf{N}$ & 9 & 3 & 212 & 0,555 \\
\hline Dominancia & 0,8 & 0,55 & 0,532 & 0,636 \\
\hline Shannon H & 0,348 & 0,636 & 0,739 & 0,444 \\
\hline Simpson & 0,197 & 0,44 & 0,467 & \\
\hline
\end{tabular}

Tabla 7.39. Diversidad de clases artefactuales según materias primas en ALPA. Referencia: BAS: basalto; OBS: obsidiana; SIL: rocas silíceas; ND: rocas no diferenciadas.

\subsection{2b.1 DESECHOS DE TALLA}

En ALPA los desechos de talla representan el $28 \%$ de la muestra y exhiben la mayor diversidad de rocas. Las silíceas (86\%) son las más representadas, seguidas por el basalto (10\%) y la obsidiana (4\%). El 56\% de los artefactos está entero y el 31\% fracturado. El 13\% restante corresponde a desechos de talla no diferenciados. Entre los desechos enteros, los elaborados en roca silícea son los que presentan mayor reserva de corteza, seguidos en frecuencia por el basalto (Tabla 7.40). En la tabla 7.41, se observa que las lascas externas son las más frecuentes (62\%), seguidas por los desechos internos correspondientes a estadios de formatización secundaria (19\%). Los desechos de formatización de filo son escasos y sólo se presentan en rocas silíceas (6\%). En basalto, el 75\% corresponde a lascas internas (LAN) y el $25 \%$ a desechos externos (LSEC). En la figura 7.28 se presentan los estadios de formatización discriminados por desechos externos, correspondientes a las primeras etapas de formatización, e internos, vinculados con las etapas de formatización secundaria y acabado de filos. Las rocas silíceas se encuentran presentes en todas las transectas, sin embargo se observan diferencias en las etapas representadas en los distintos sectores del espacio. De modo tal que en las transectas 200, 231 y 275 se registran desechos correspondientes a las primeras etapas, mientras que en las 215, 245 y 253 son mayoritarios los asociados con las etapas de formatización secundaria. Sólo en las líneas 205 y 230 están presentes todas las etapas de formatización. Asimismo, en basalto las etapas de formatización se encuentran en sectores del espacio diferentes. En obsidiana sólo se registran desechos internos y están ausentes las primeras etapas de formatización. 


\begin{tabular}{|c|c|c|c|c|c|c|}
\hline MP & $\mathbf{0 \%}$ & $\mathbf{2 5 \%}$ & $\mathbf{5 0 \%}$ & $\mathbf{7 5 \%}$ & $\mathbf{1 0 0 \%}$ & Total \\
\hline BAS & $2(75 \%)$ & - & $1(25 \%)$ & & - & 3 \\
\hline OBS & $2(100 \%)$ & - & - & - & - & 2 \\
\hline SIL & $18(45 \%)$ & - & $17(42,5 \%)$ & $5(12,5 \%)$ & - & 40 \\
\hline Total & 22 & - & 18 & 5 & - & 45 \\
\hline$\%$ & $49 \%$ & - & $40 \%$ & $11 \%$ & - & - \\
\hline
\end{tabular}

Tabla 7.40. Reserva de corteza en la cara dorsal de desechos de talla enteros en ALPA.

\begin{tabular}{|c|c|c|c|c|c|c|c|c|}
\hline Transecta & MP & LPR & LSEC & LAN & PL & LN & ND & Total \\
\hline 200 & SIL & - & - & 1 & - & - & - & 1 \\
\hline \multirow{2}{*}{205} & BAS & - & - & 1 & - & - & - & 1 \\
\cline { 2 - 9 } & SIL & - & - & - & 1 & 1 & 2 & 4 \\
\hline \multirow{2}{*}{215} & OBS & - & - & 1 & - & - & - & 1 \\
\cline { 2 - 9 } & SIL & - & 16 & - & 3 & 1 & 1 & 21 \\
\hline \multirow{2}{*}{230} & BAS & - & 6 & - & - & - & - & 6 \\
\cline { 2 - 10 } & OBS & - & - & 1 & - & - & - & 1 \\
\hline 231 & SIL & - & 9 & 8 & 1 & 2 & 3 & 23 \\
\hline 245 & SIL & - & - & 1 & - & - & - & 1 \\
\hline \multirow{2}{*}{253} & SIL & - & 9 & - & 2 & 1 & - & 12 \\
\hline & SIL & 1 & - & - & - & 1 & - & 1 \\
\hline 275 & SIL & - & - & 1 & - & - & - & 1 \\
\hline \multicolumn{2}{|c|}{ Total } & 1 & 41 & 14 & 7 & 6 & 6 & 75 \\
\hline
\end{tabular}

Tabla 7.41. Desechos de talla recuperados en ALPA. Nota: LPR: lasca primaria; LSEC: Iasca secundaria; LAN: lasca angular; LAR: lasca de arista; LAB: lasca de adelgazamiento bifacial; PL: Iasca plana; $L R$ : lasca de reactivación; LN: lasca nucleiforme (incluye lascas de flanco de núcleo, cresta de núcleo y lascas de reactivación de núcleo); ND: lasca no diferenciada. 


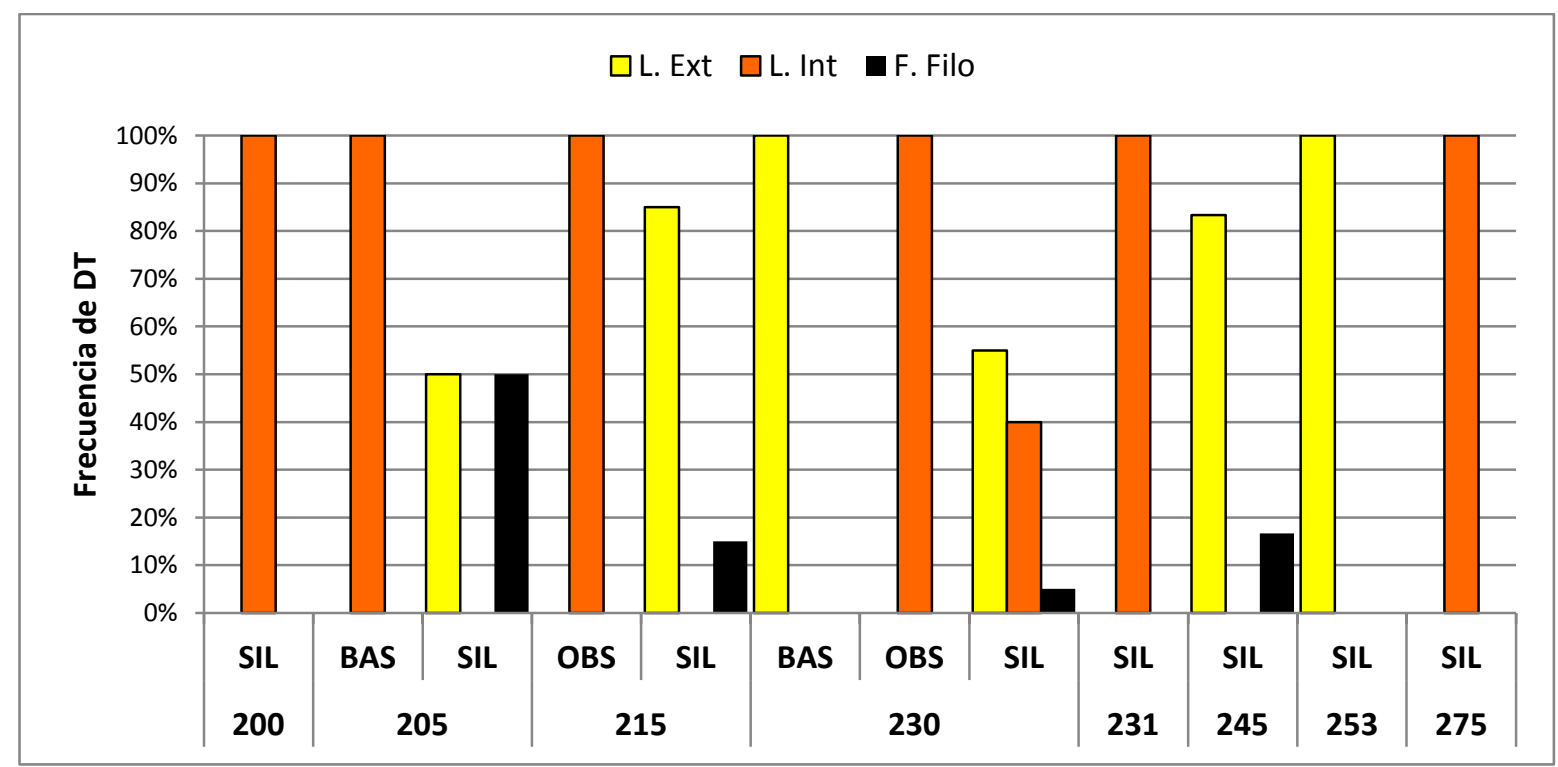

Figura 7.28. Distribución de desechos de talla externos (EXT) e internos (INT) por materia prima en ALPA. Frecuencia respecto a cada materia prima por Transecta.

El índice de corteza más elevado se encuentra en rocas silíceas, seguido por el basalto (Tabla 7.41). En rocas silíceas se registran en proporciones similares las lascas internas y externas, representando todos los estadios de formatización. En cuanto a la densidad de extracciones previas en la cara dorsal por materia prima (Tabla 7.42), se destaca el valor para el basalto $\left(x=1,661 \mathrm{e} / \mathrm{mm}^{2}\right)$. Esta materia prima ha sido registrada en las transectas $205(n=1), 230(n=6)$ y $231(n=1)$ y, en la mayoría de los casos, se trata de desechos de talla internos (75\%). En menor proporción, de lascas externas (25\%). En los valores máximo y mínimos se encuentra expresada esta relación, dado que si bien se registra la densidad mayor de lascados previos, los valores máximos son bajos y el rango de variación es pequeño. Los valores de reducción más bajos corresponden a rocas silíceas, sin embargo esta materia prima posee un rango amplio que incluye todas las etapas de reducción. La obsidiana no presenta desechos correspondiente a las primeras etapas de formatización y su valor medio de densidad de lascados en su cara dorsal es de $\mathrm{x}=2,41 \mathrm{e} / \mathrm{mm}^{2}$, con un valor máximo de $4,46 \mathrm{e} / \mathrm{mm}^{2}$ y un valor mínimo de $0,358 \mathrm{e} / \mathrm{mm}^{2}$, constituyendo la materia prima con mayor reducción. Cabe recordar que se han recuperado sólo dos desechos de obsidiana enteros, por lo cual puede considerarse una 
tendencia tentativa. Al evaluar los tres indicadores de reducción (reserva de corteza, índice de corteza e intensidad de reducción) notamos que en basalto se encuentran mayormente representadas las etapas finales de formatización, dada la baja frecuencia de artefactos con reserva de corteza, índice de formatización inicial o corteza bajo y alto valor de intensidad de reducción. En obsidiana la corteza es nula, con valores de intensidad de reducción altos y baja frecuencia en el conjunto. Por su parte en rocas silíceas, los tres indicadores señalan variación en los estadios de reducción, en los cuales se incluye desde los primeros estadios de reducción hasta la formatización de instrumentos. No se registran desechos de reactivación de filos y las etapas iniciales de formatización están presentes pero distribuidas de forma heterogénea en el paisaje (Tabla 7.43).

\begin{tabular}{|c|c|c|c|c|}
\hline MP & N & PR & SEC & Índice Corteza \\
\hline BAS & 3 & - & 2 & 0,333 \\
\hline OBS & 2 & - & - & - \\
\hline SIL & 40 & 1 & 20 & 0,525 \\
\hline
\end{tabular}

Tabla 7.41. Frecuencia de lascas primarias y secundarias enteras respecto a materia prima en ALPA. Referencia: MP: materia prima; N: número total de de desechos de talla enteros; LPR: lasca primaria; LSEC: lasca secundaria.

\begin{tabular}{|c|c|c|c|c|c|c|c|}
\hline MP & $\mathbf{N}$ & Media & Mediana & $\begin{array}{c}\text { Desvío } \\
\text { Estándar }\end{array}$ & Mínimo & Máximo & Rango \\
\hline BAS & 8 & 1,661 & 1,01 & 1,28 & 0,56 & 3,97 & 3,41 \\
\hline SIL & 70 & 0,617 & 0,403 & 0,93 & 0 & 7,65 & 7,65 \\
\hline
\end{tabular}

Tabla 7.42. Estadística descriptiva de la densidad de extracciones previas en la cara dorsal de los desechos de talla en ALPA. 


\begin{tabular}{|c|c|c|c|c|c|}
\hline Transecta & MP & $\mathbf{N}$ & LPR & LSEC & $\begin{array}{l}\text { Índice } \\
\text { Corteza }\end{array}$ \\
\hline \multirow{2}{*}{205} & BAS & 1 & - & - & - \\
\hline & SIL & 6 & - & 3 & 0,5 \\
\hline \multirow{2}{*}{215} & OBS & 1 & - & - & - \\
\hline & SIL & 9 & - & 3 & 0,333 \\
\hline \multirow{2}{*}{230} & BAS & 2 & - & 1 & 0,5 \\
\hline & SIL & 15 & - & 2 & 0,133 \\
\hline 245 & SIL & 2 & - & 1 & 0,5 \\
\hline 253 & SIL & 7 & 1 & 4 & 0,714 \\
\hline 275 & SIL & 1 & - & - & - \\
\hline \multicolumn{2}{|c|}{ Total } & 44 & 1 & 14 & - \\
\hline
\end{tabular}

Tabla 7.43. Frecuencia de las cas primarias y secundarias enteras por transecta y sector de muestreo en ALPA. Referencia: MP: materia prima; N: número total de desechos de talla enteros; LPR: Iasca primaria; LSEC: Iasca secundaria.

\subsection{2b.2 NÚCLEOS}

Los núcleos recuperados en ALPA suman un total de 141 piezas y constituyen la clase artefactual más representada. Las materias primas predominantes son las rocas silíceas (98\%), seguidas por el basalto (1\%) y las rocas no diferenciadas (1\%). Las rocas silíceas se encuentran distribuidas en todas las transectas de modo homogéneo, sin embargo los basaltos y las rocas no diferenciadas aparecen en sectores acotados de ALPA (Figura 7.30). La morfología general de los núcleos es de lascados aislados, los cuales varían entre uno y tres lascados (97\%) y sólo el 3\% restante presenta un máximo de 4 lascados. El estado de las piezas es en el 97,5\% entero. El tamaño más frecuente es el grandísimo (módulo 7, rango >161 mm) en el 95\% de los núcleos, seguido por el 2,8\% de tamaños muy grandes (módulo 6, rango entre 121-160), el 1,4\% grandes (módulo 5, rango entre $80-120$ ) y el 0,7\% de núcleos mediano grandes. La mayor variación de tamaños de núcleos se encuentra entre los confeccionados en roca silícea. En cuanto al espesor, en la mayoría de los casos es muy espeso (94\%), seguido por los espesos (6\%). La densidad de 
negativos de lascados en rocas silíceas es $\mathrm{x}=3,332 \mathrm{e} / \mathrm{mm}^{3}$, en rocas no diferenciadas de $2,7 \mathrm{e} / \mathrm{mm}^{3}$ y en el basalto de $0,17 \mathrm{e} / \mathrm{mm}^{3}$. Los valores correspondientes a basalto y no diferenciadas se considera tentativo dada la escasa representatividad en la muestra. En la tabla 7.44, se presenta la relación de las medidas de largo y ancho en desechos de talla, instrumentos y núcleos enteros. En esta localidad no se tuvieron en cuenta los negativos de lascados, dado el alto número de núcleos registrados; solo se consideraron las medidas de largo y ancho máximos de la pieza. Las piezas de las distintas clases de artefactos son más largos que anchos, con un tamaño mayor de los núcleos (Tabla 7.44). Esto puede ser observado en la relación entre dichas variables respecto a las clases artefactuales (Figura 7.31 a-d). En la figura 7.31d se comparan los valores medios, validando la relación lineal entre las clases. Tendencia que puede responder a la extracción de lascas para la formatización de instrumentos y el descarte de núcleos con potencial para la talla (Figura 7.32).

\begin{tabular}{|c|c|c|c|c|c|c|}
\hline & \multicolumn{2}{|c|}{ Desechos de talla } & \multicolumn{2}{c|}{ Instrumentos } & \multicolumn{2}{c|}{ Núcleos } \\
\hline & Largo $\mathbf{~ m m}$ & Ancho $\mathbf{~ m m}$ & Largo $\mathbf{m m}$ & Ancho $\mathbf{~ m m}$ & Largo mm & Ancho mm \\
\hline $\mathbf{N}$ & 51 & 51 & 4 & 4 & 134 & 134 \\
\hline Media & 22,8565 & 21,0843 & 30,4 & 21,725 & 40,606 & 29,8051 \\
\hline $\begin{array}{c}\text { Desvío } \\
\text { Estándar }\end{array}$ & 10,136 & 9,68231 & 7,79476 & 3,44559 & 15,4356 & 12,6173 \\
\hline Mediana & 21,65 & 19,1 & 31,4 & 22,4 & 39,15 & 27,3 \\
\hline Mínimo & 7,2 & 6,6 & 21,5 & 17,3 & 12,5 & 10,1 \\
\hline Máximo & 68 & 39,6 & 37,3 & 24,8 & 85,9 & 97,1 \\
\hline
\end{tabular}

Tabla 7.44 Estadística descriptiva de las variables largo y ancho en desechos de talla, instrumentos y núcleos en ALPA. 


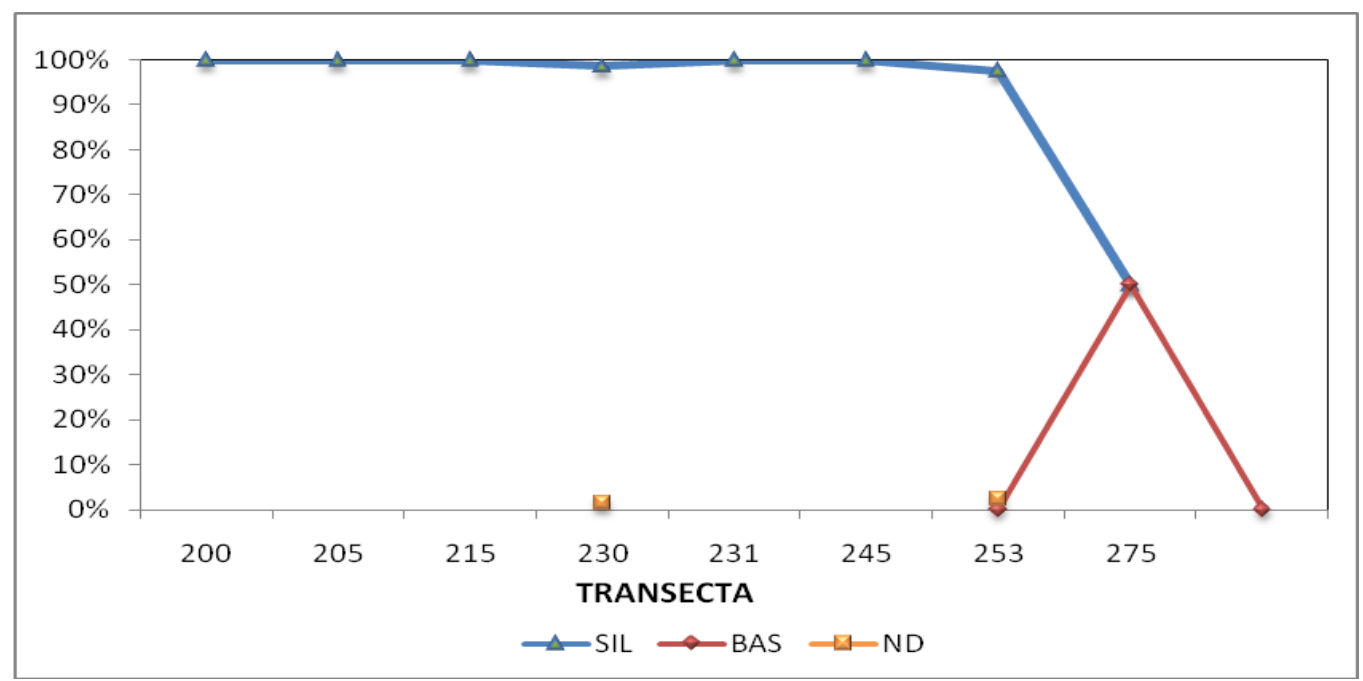

Figura 7.30. Distribución de núcleos en las transectas en ALPA. Nota: SIL: rocas silíceas; BAS: basalto; ND: rocas no diferenciadas.
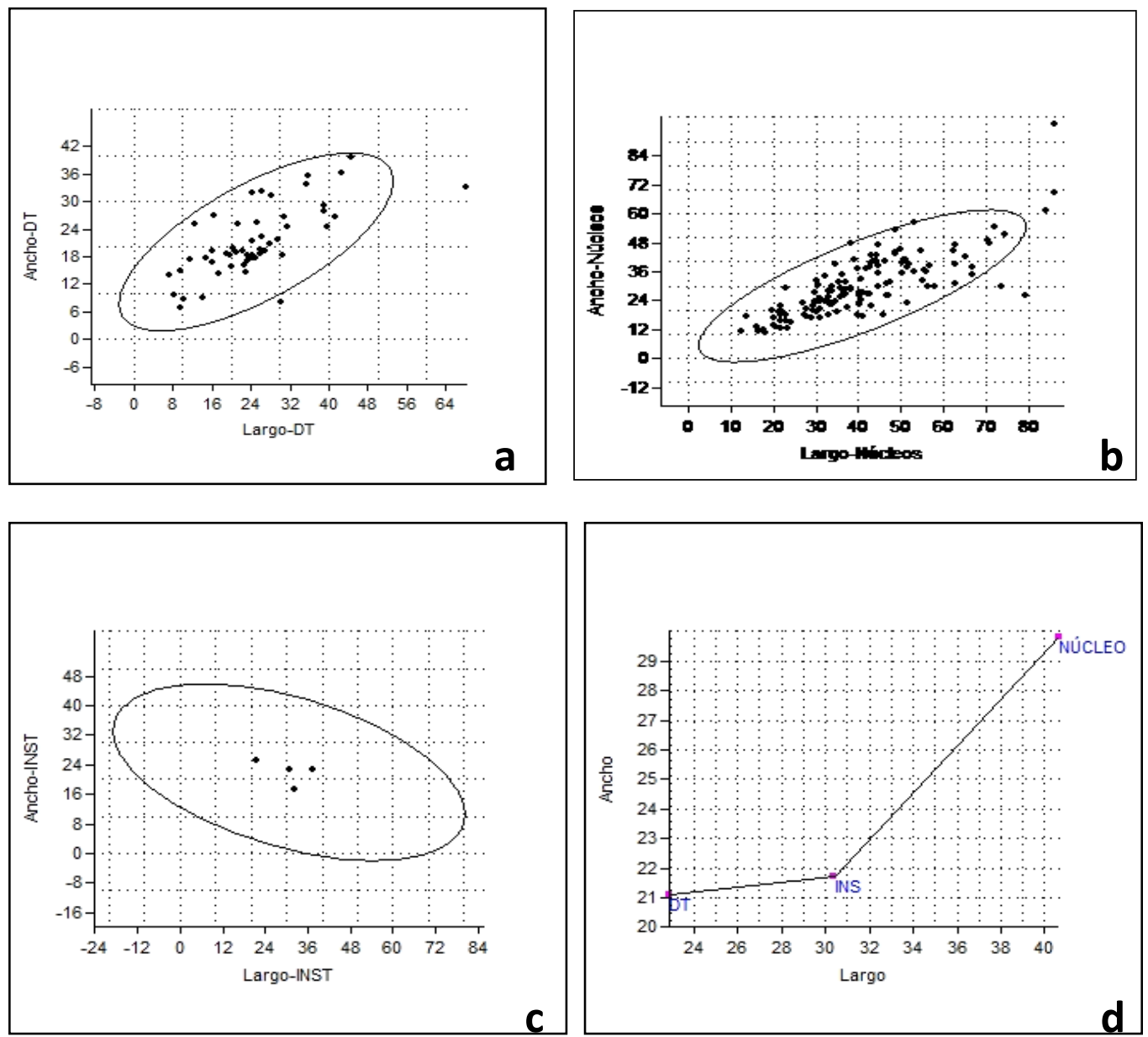

Figura 7.31. Relación entre variables de tamaño (largo y ancho en mm) en artefactos de ALPA. Referencias: $a$ : desechos de talla; $b$ : negativos de lascados en núcleos; $c$ : instrumento; d: relación de variables de tamaño entre clases artefactuales. 


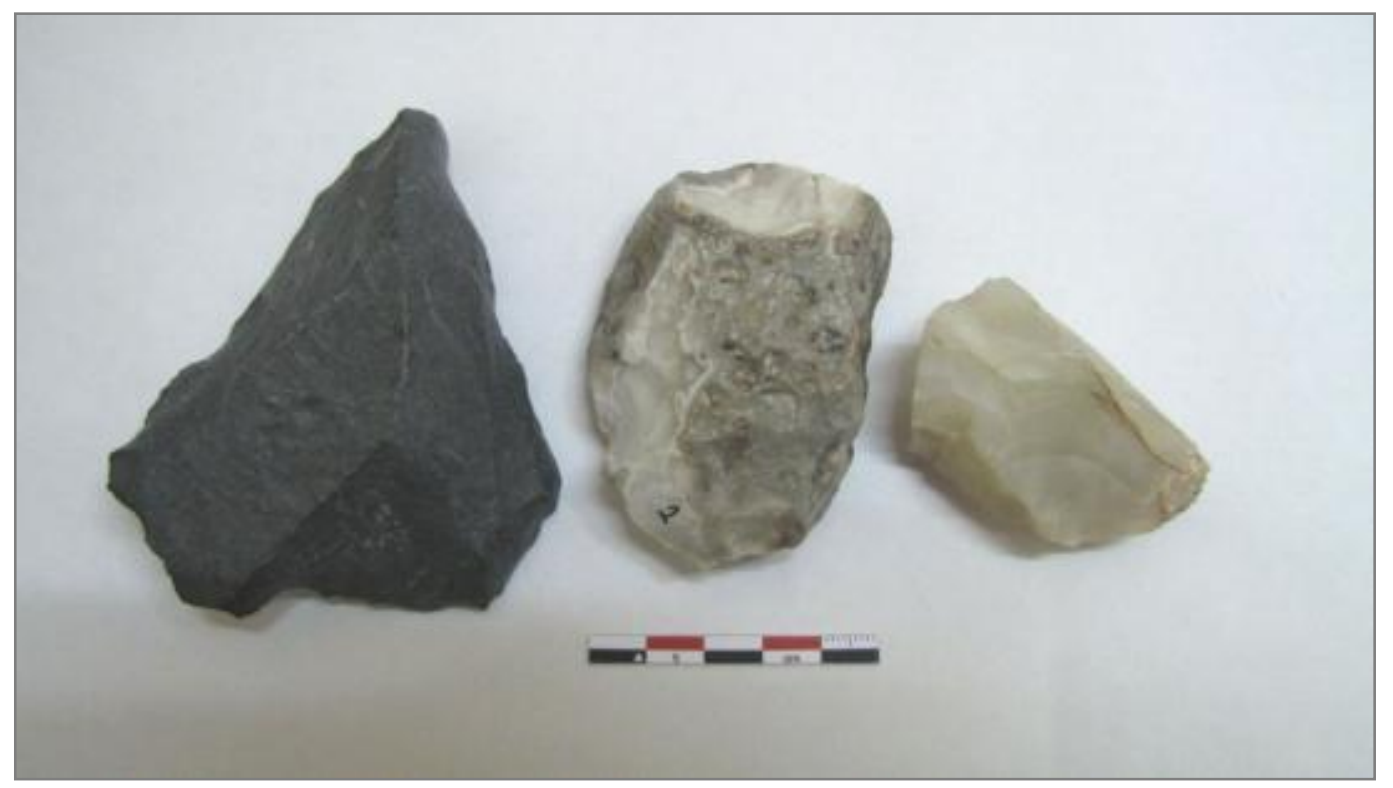

Figura 7.32. Núcleo de basalto (izquierda) y rocas silíceas (centro y derecha) recuperados en ALPA.

\subsection{2b.3 INSTRUMENTOS}

Los instrumentos recuperados en ALPA representan el 1,6\% $(n=5)$ del total de los artefactos (Tabla 7.38). Las rocas más utilizadas son las rocas silíceas (80\%) y la obsidiana (20\%). En las primeras los instrumentos frecuentes son los formatizados de modo bifacial (60\%), seguido por los unifaciales (20\%) y los artefactos con rastros complementarios (20\%) (Tabla 7.45). El índice de productividad es 20,25 y el de bifacialidad de 0,3. El $80 \%$ de los artefactos está fracturado y sólo los instrumentos bifaciales están enteros (20\%) (Tabla 7.46). El valor de diversidad de materias primas es alto para artefactos de formatización bifacial (Figura 7.33). En artefactos unifaciales y con rastros complementarios los valores de diversidad son nulos, dado que la única materia prima representada es la roca silícea (Tabla 7.47). 


\begin{tabular}{|c|c|c|c|c|c|}
\hline Transecta & MP & AF Bifacial & AF Unifacial & ASF RC & Total \\
\hline 205 & OBS & 1 & - & - & 1 \\
\hline 215 & SIL & - & 1 & - & 1 \\
\hline 230 & SIL & - & - & 1 & 1 \\
\hline 253 & SIL & 1 & - & - & 1 \\
\hline 254 & SIL & 1 & - & 1 & 1 \\
\hline \multicolumn{2}{|c|}{ Total } & $3(60 \%)$ & $1(20 \%)$ & $100 \%)$ \\
\hline
\end{tabular}

Tabla 7.45. Frecuencia de los artefactos formatizados y con rastros complementarios en ALPA.

Entre paréntesis se detalla la proporción de tipo de artefactos por materia prima.

\begin{tabular}{|c|c|c|c|c|c|}
\hline \multirow{2}{*}{ Transecta } & \multirow{2}{*}{ MP } & \multicolumn{2}{|c|}{ AF Bifacial } & AF Unifacial & ASF RC \\
\cline { 2 - 6 } & Entero & Fracturado & Fracturado & Fracturado \\
\hline 205 & OBS & 1 & - & - & - \\
\hline 215 & SIL & - & - & 1 & - \\
\hline 230 & SIL & - & - & - & 1 \\
\hline 253 & SIL & 1 & - & - & - \\
\hline 254 & SIL & - & 1 & - & $1(100 \%)$ \\
\hline
\end{tabular}

Tabla 7.46. Estado de fragmentación en instrumentos en ALPA.

\begin{tabular}{|c|c|c|c|}
\hline & AF Bifacial & AF Unifacial & ASF RC \\
\hline $\begin{array}{c}\text { N materias } \\
\text { primas }\end{array}$ & 2 & 1 & 1 \\
\hline $\mathbf{N}$ & 3 & 1 & 1 \\
\hline Dominancia & 0,55 & 1 & 1 \\
\hline Shannon-H & 0,636 & - & - \\
\hline Simpson & 0,44 & - & - \\
\hline
\end{tabular}

Tabla 7.47. Diversidad de materias primas según clases artefactuales en ALPA. 


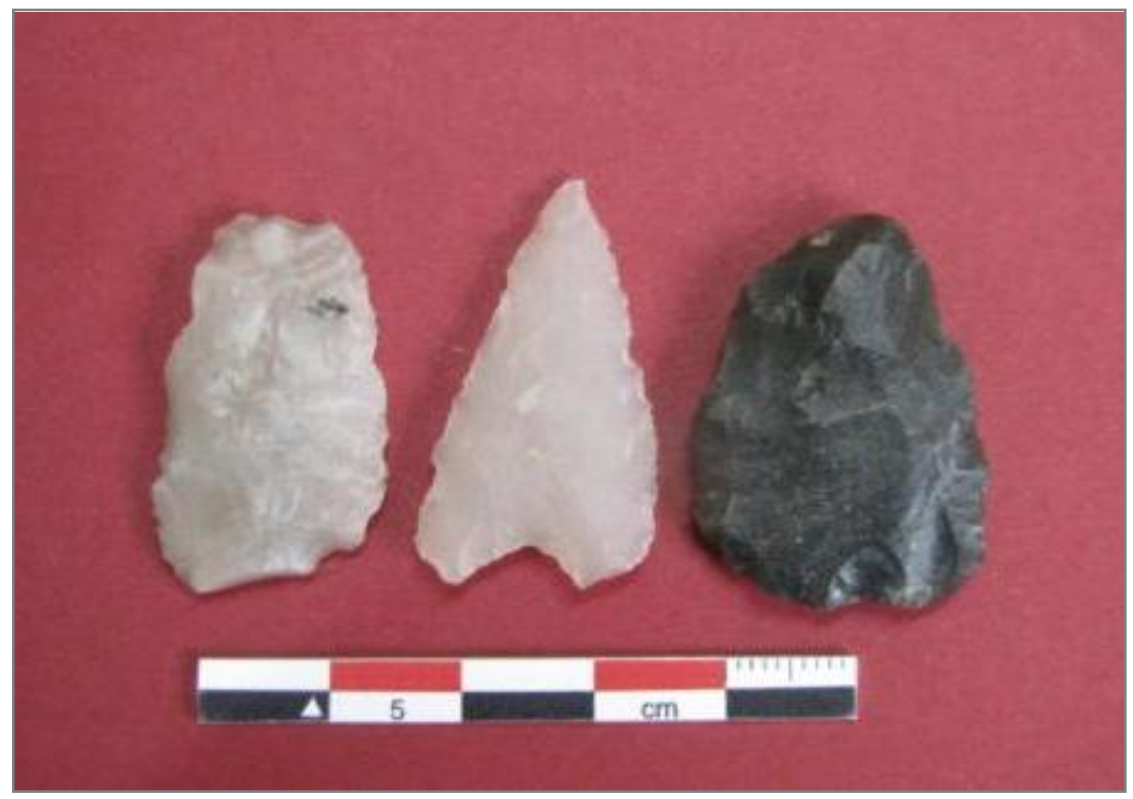

Figura 7.33. Artefactos bifaciales de ALPA.

La manufactura de los instrumentos se realizó sobre lascas. La calidad para la talla en las piezas es muy buena en el caso de rocas silíceas $(80 \%)$ y excelente $(20 \%)$ en obsidiana. Predominan los artefactos bifaciales confeccionados en roca silícea (66\%), seguidos por la obsidiana (34\%), cuyo tipo morfológico corresponde a puntas de proyectil (Figura 7.33). Son de tamaño grande y módulo espeso o medio. La punta de proyectil trabajada en obsidiana, es de tamaño grande y de módulo espeso, con la superficie externa cubierta por la pátina del desierto. Entre los unifaciales el tipo representado es el de los raspadores, y fue confeccionado en roca silícea, de tamaño grande y muy espeso (Figura 7.34). En la misma materia prima, también se recuperó un artefacto con rastros complementarios sobre roca silícea descartado fracturado (Figura 7.35). 


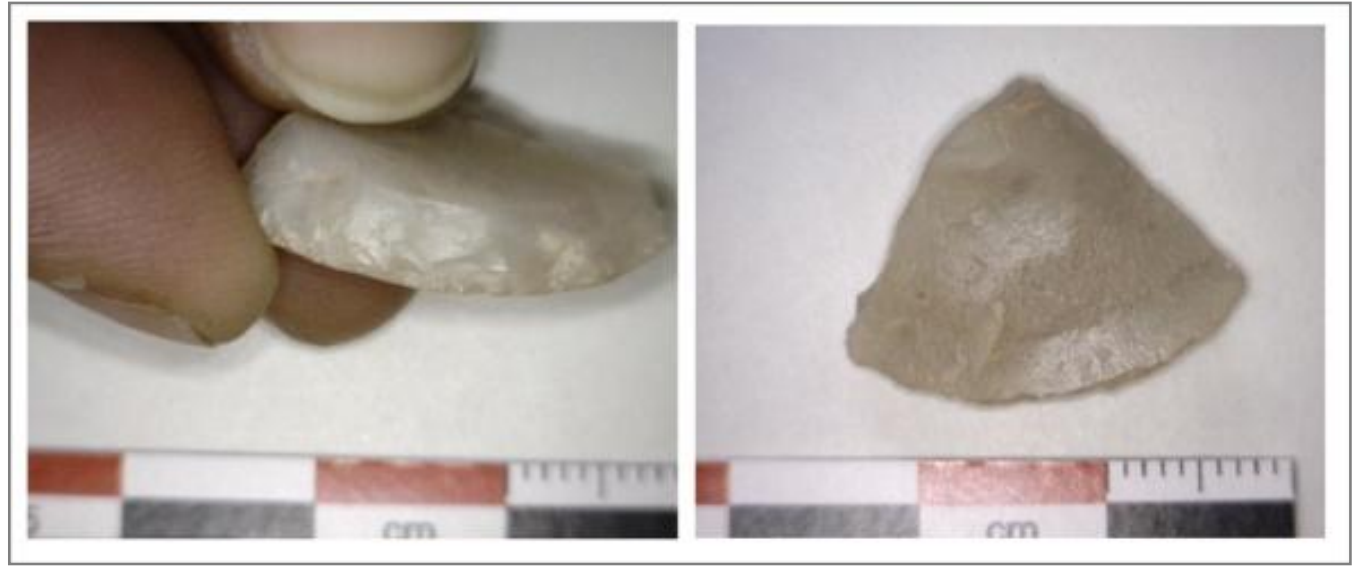

Figura 7.34. Artefacto de formatización unifacial recuperado en transecta 215 en ALPA.

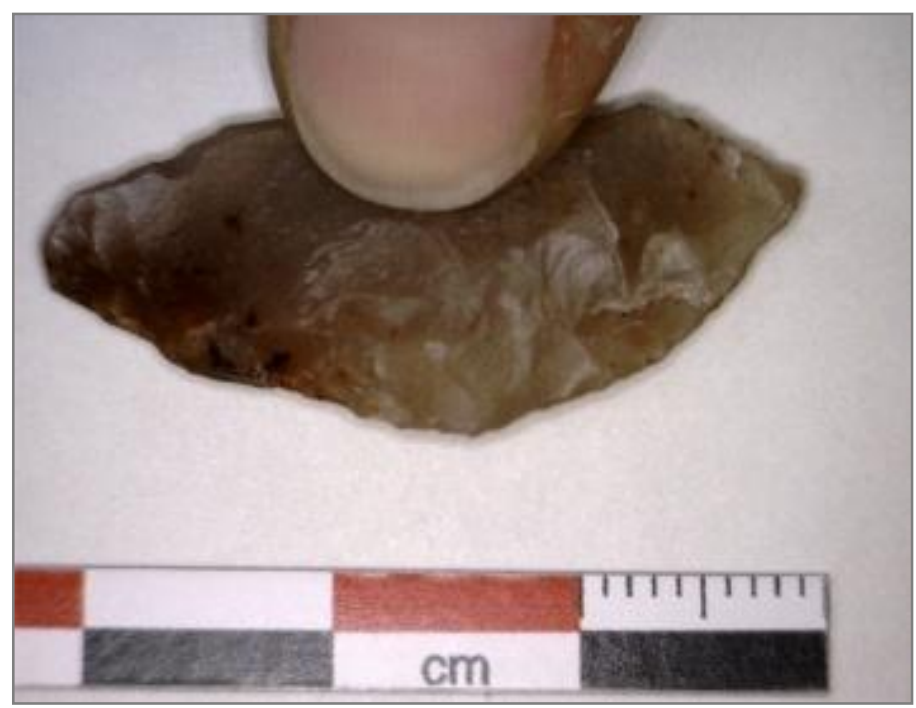

Figura 7.35. Artefacto sin formatización con rastros complementarios recuperado en transecta 230 en ALPA.

\subsubsection{CONSIDERACIONES GENERALES DE LA LOCALIDAD ALPA}

En la localidad predominan los artefactos en rocas silíceas, seguidos por el basalto y en menor medida la obsidiana. En los muestreos lineales realizados, la distribución de las materias primas no es homogénea y hay sectores del espacio en los cuales se concentra mayor diversidad de recursos líticos, como es el caso de las transectas 205 y 230. La 
calidad para la talla en rocas silíceas y basalto es muy buena (90\%), mientras que la excelente sólo está presente en obsidiana (10\%). La clase artefactual más representada es la de los núcleos, seguida por la de los desechos de talla y los instrumentos. En las dos primeras la materia prima más frecuente es la roca silícea, seguida por el basalto y la obsidiana. En instrumentos, la forma base general es la de lasca y la obsidiana le sigue en frecuencia a las rocas silíceas. En cuanto a los índices de corteza e intensidad de reducción en desechos de talla, se observa que si bien la obsidiana presenta los índices más altos de reducción y valores nulos de corteza, en basalto los valores de reducción son mayores a los de las rocas silíceas y los valores de corteza son bajos. Las primeras secuencias de formatización se registran de modo heterogéneo en el espacio, al igual que las etapas finales de formatización de obsidiana. La única roca que presenta evidencias de todas las etapas de reducción es la silícea. La relación entre el tamaño de los instrumentos y núcleos, indicarían que los núcleos eran descartados antes de ser agotados, quizás como resultado de su disponibilidad local -al menos en el caso de las rocas silíceas-. Se destaca la ausencia de desechos de reactivación de filo y de instrumentos en su mayoría fracturados. Se puede plantear que en ALPA los nódulos silíceos de disponibilidad local eran utilizados para la extracción de lascas de utilidad, primando la selección de calidad y tamaños, aptos para la talla. 


\subsection{LOCALIDAD AGUA DE PÉREZ (APE)}

La localidad Agua de Pérez (en adelante APE) se encuentra ubicada en el sector suroeste del CVLP (Figura 7.36). En la misma se asientan los puestos pertenecientes a las familias Moyano y Heredia, ambos ubicados en la margen oeste de la aguada natural denominada Agua de la Zorra o de Nani. Estos cauces transitorios se originan en la Altiplanicie del Payén y están asociados a una leve inclinación de la plataforma basáltica en sentido suroeste (Groeber 1933), que encauza el agua de estación por el lecho seco. Agua de la Zorra, Agua de Nani y Agua del Diablo conforman el Cañadón Amarillo, parte del sistema de subcuenca del río Colorado (Capítulo 3). Los aumentos bruscos del caudal de la aguada en las épocas de lluvia, excavan en el terreno barrancas superiores a los 10 metros, que facilitan la detección de materiales arqueológicos enterrados. En la figura 7.37, se observa el cauce transitorio y las vegas formadas por la vertiente natural ubicada en el puesto homónimo.

Entre los años 2004 y 2009, estudios de impacto arqueológico llevados a cabo en el sector permitieron la detección de sitios arqueológicos en un área que hasta entonces había sido poco explorada. La localidad APE se encuentra aproximadamente a $1000 \mathrm{~m}$ al suroeste de la meseta basáltica Altiplanicie del Payén, en el borde de meseta de degradación que se dispone a modo de escalones de deslizamientos o remoción en masa (Narciso et al 2001b). En la localidad se realizaron diferentes estudios superficiales y estratigráficos, de los cuales se incluyen aquí los realizados en el sitio estratigráfico Agua de Pérez 1 (en adelante APE-1), el muestreo superficial del sitio cantera-taller Agua de Pérez Cantera (en adelante APE-C) y recolecciones superficiales de artefactos de obsidiana en el sitio Payún Sur (Figura 7.38). 


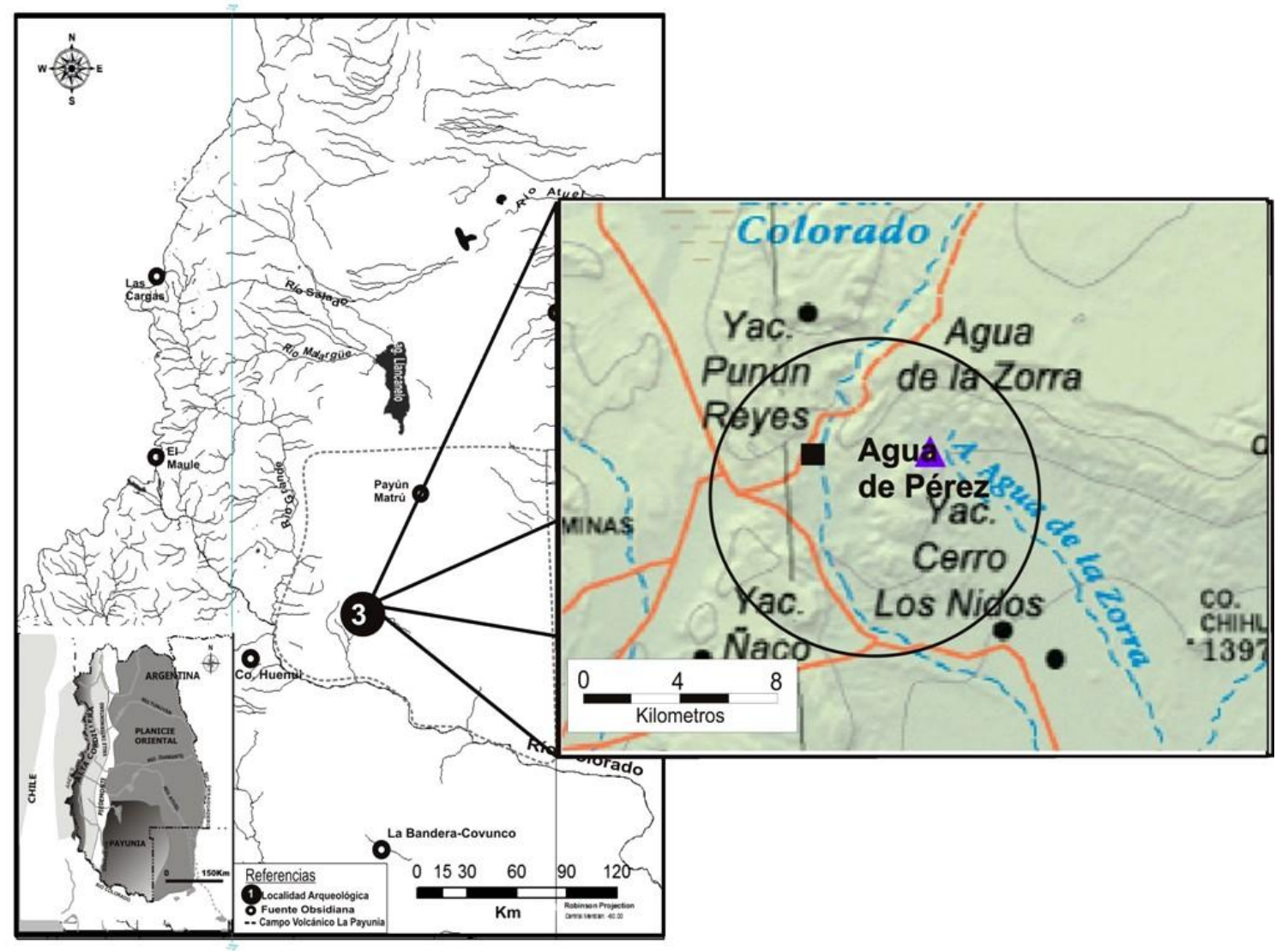

Figura 7.36 Ubicación de la Localidad Agua de Pérez (APE). 


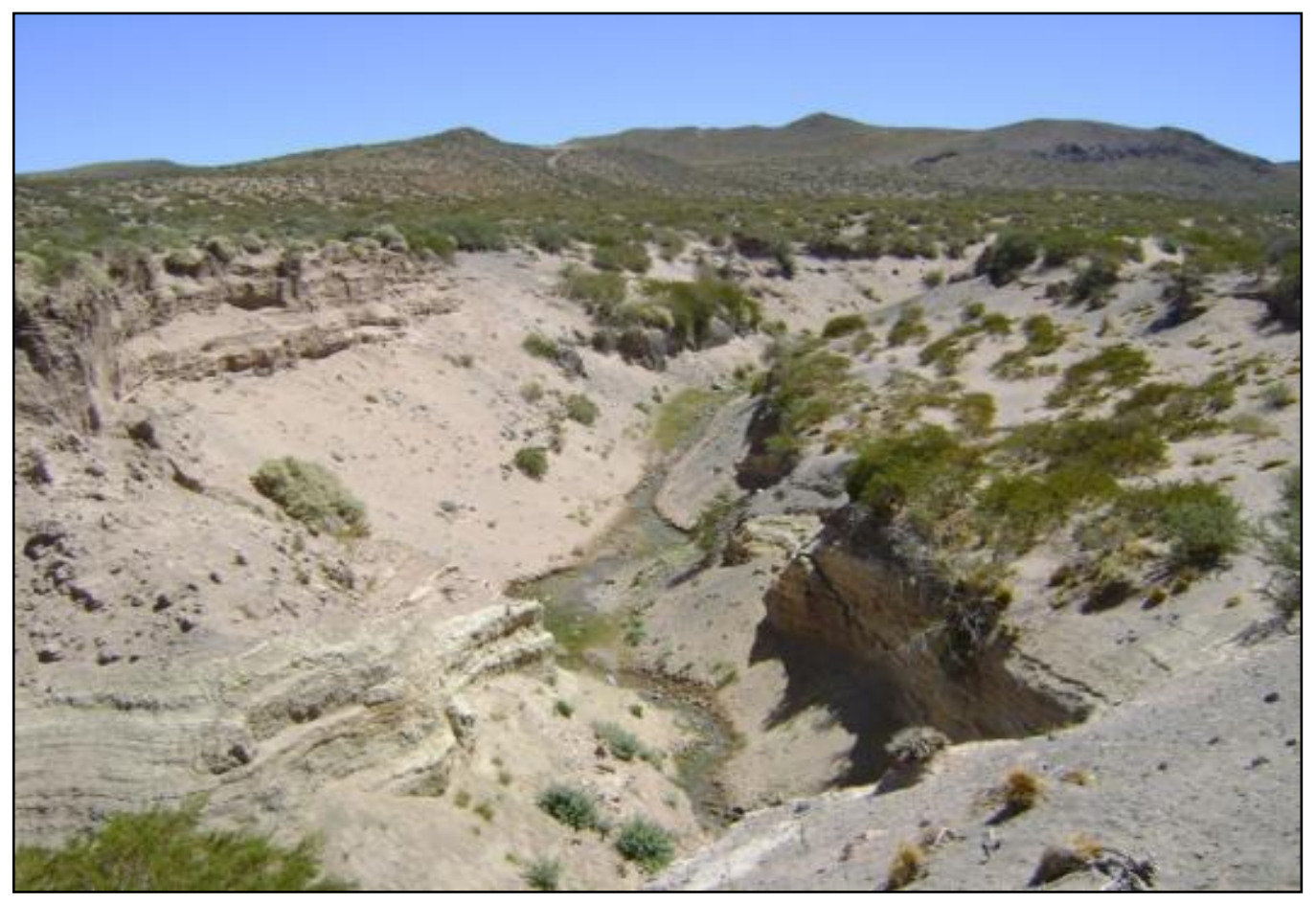

Figura 7.37. Localidad arqueológica Agua de Pérez, vista del cauce temporal Agua de la Zorra.

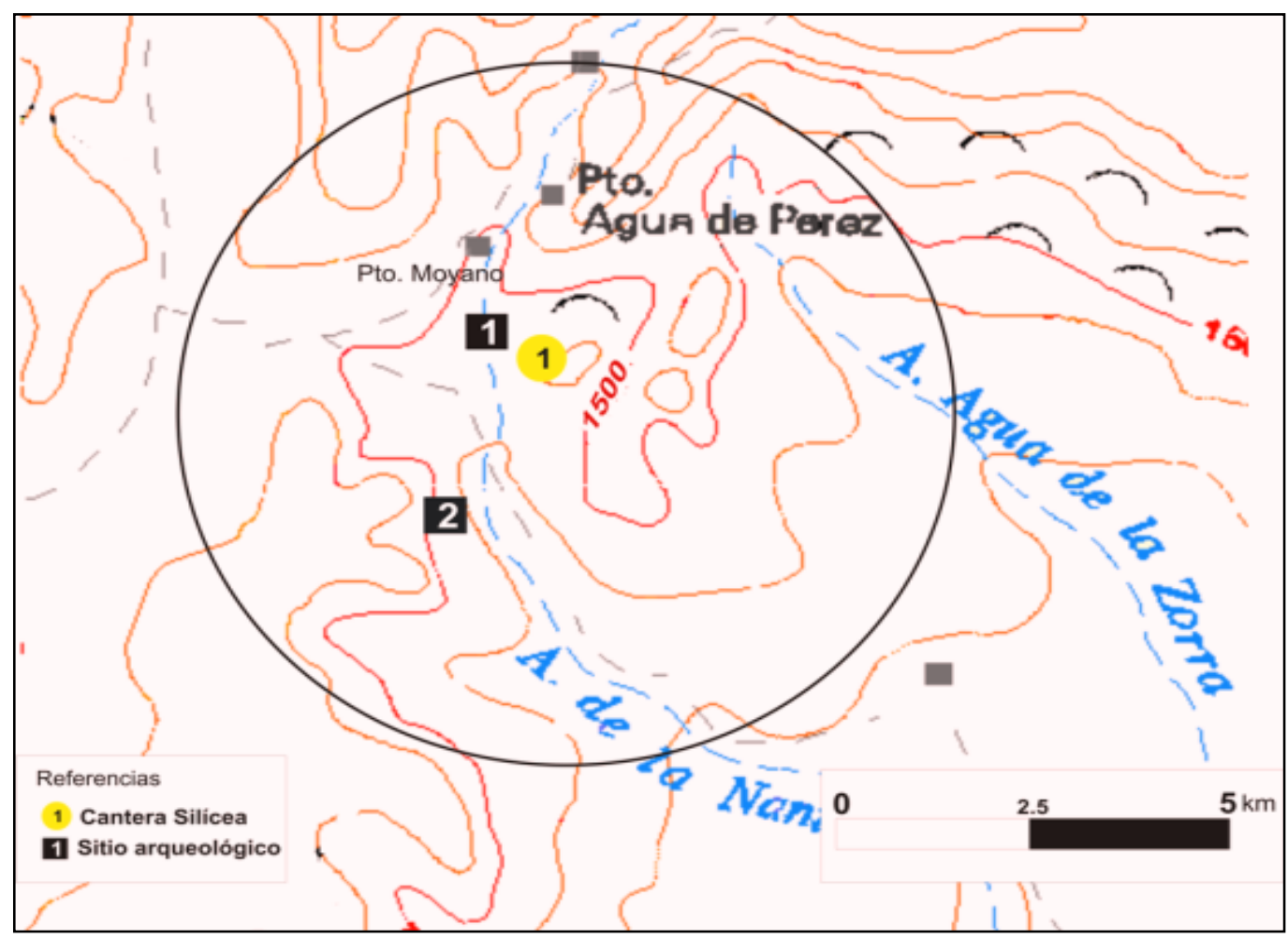

Figura 7.38. Ubicación de los sitios analizados en la Localidad arqeuológica Agua de Pérez. Referencia: en círculo amarillo se indica la fuente de roca silícea Agua de Pérez-Cantera (APE-C). En cuadros negros: 1: Agua de Pérez - (APE-1)1; 2: Payún Sur (PS). 


\subsection{1a AGUA DE PÉREZ 1(APE-1)}

El sitio estratigráfico Aguada de Pérez (en adelante APE-1), se encuentra entre las coordenadas $36^{\circ} 50^{\prime} 42.3^{\prime \prime}$ L. S. y 69²9’17.6”' L.O (1.400 msnm). En el año 2009, se excavó un sector expuesto de la barranca actual, donde se evidenciaban perfiles con potencial arqueológico. La unidad de muestreo estratigráfico se denominó A1 y se excavaron dos sectores orientados en la barranca en sentido norte-sur, los cuales fueron denominados respectivamente sector norte $(\mathrm{N})$ y sector sur $(\mathrm{S})$. La excavación de $A 1$, se profundizó por niveles naturales de potencia variable hasta los $1,45 \mathrm{~m}$ de profundidad (Figura 7.39). El sedimento es fundamentalmente arenoso con lentes de arcilla y varía en compactación. El primer estrato se niveló hasta una profundidad de $80 \mathrm{~cm}$. El nivel 2 es homogéneo y presenta en sectores raíces carbonatadas, con una potencia aproximada de $20 \mathrm{~cm}$ en ambos sectores. El nivel 3 presenta cuatro variaciones o unidades sedimentarias, denominadas: 3 (Turba y Posturba), 3bis, 3bis2 y 3bis3. El nivel 3 Turba se presenta en el sector S y posee una potencia de $13 \mathrm{~cm}(100-110,5 \mathrm{~cm})$; el nivel 3 Posturba se documentó en el sector $\mathrm{N}$, entre los 107,5 y $120 \mathrm{~cm}$ de profundidad. Por su parte los niveles 3bis, 3 bis 2 y 3 bis 3 poseen en conjunto una potencia de entre 5 y $8 \mathrm{~cm}$ y corresponden a los niveles con mayor densidad de hallazgos. Hacia el nivel 4 se reduce marcadamente la cantidad de hallazgos en planta (Figura 7.40). En la tabla 7.48 se presentan los fechados obtenidos para este sitio, que sugieren que la dinámica de los suelos produjo la migración vertical de los materiales; a partir de ellos se plantea que el sitio fue ocupado al menos entre 650 y 1050 años ${ }^{14} \mathrm{C}$ AP. 


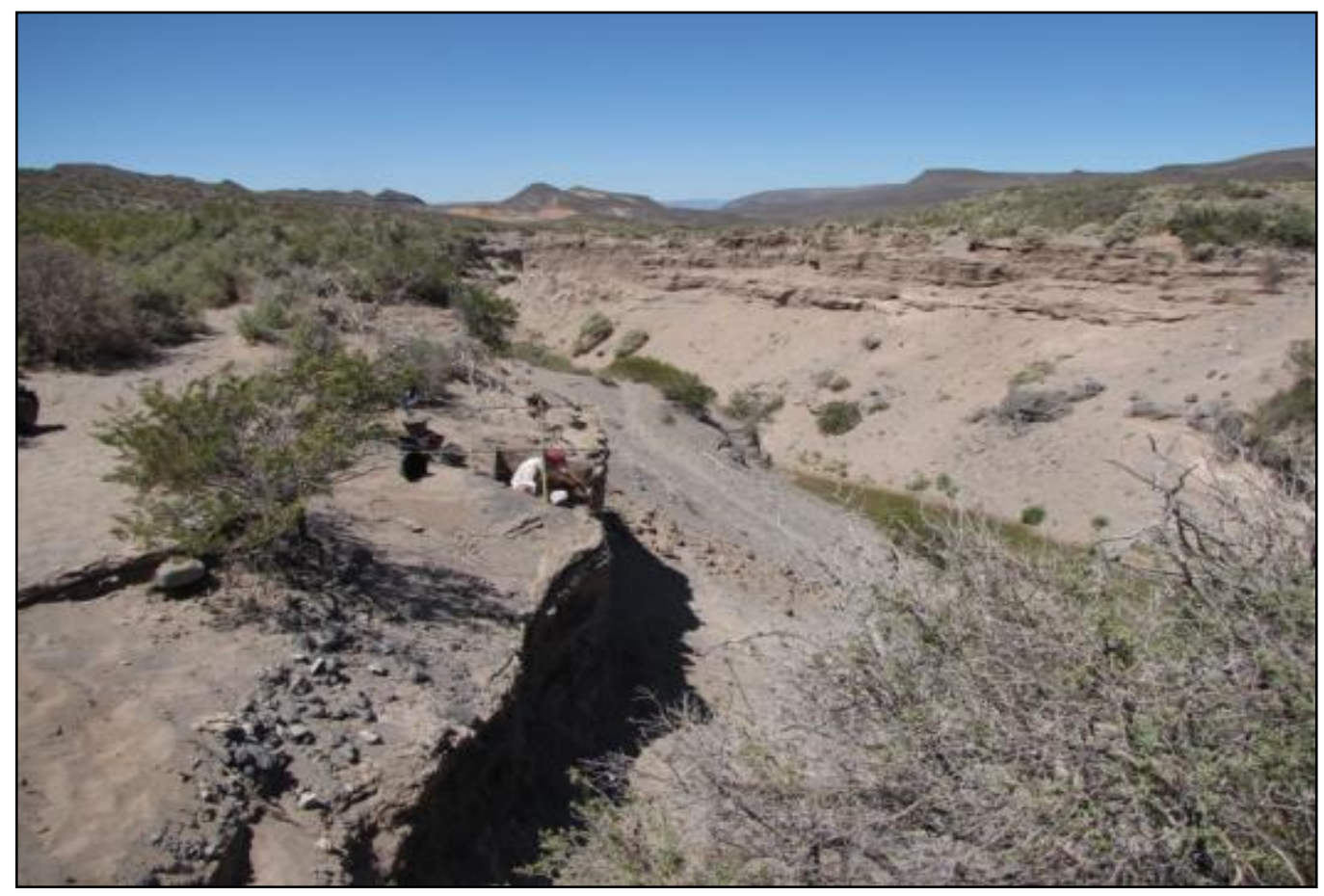

Figura 7.39. Sitio estratigráfico APE-1.

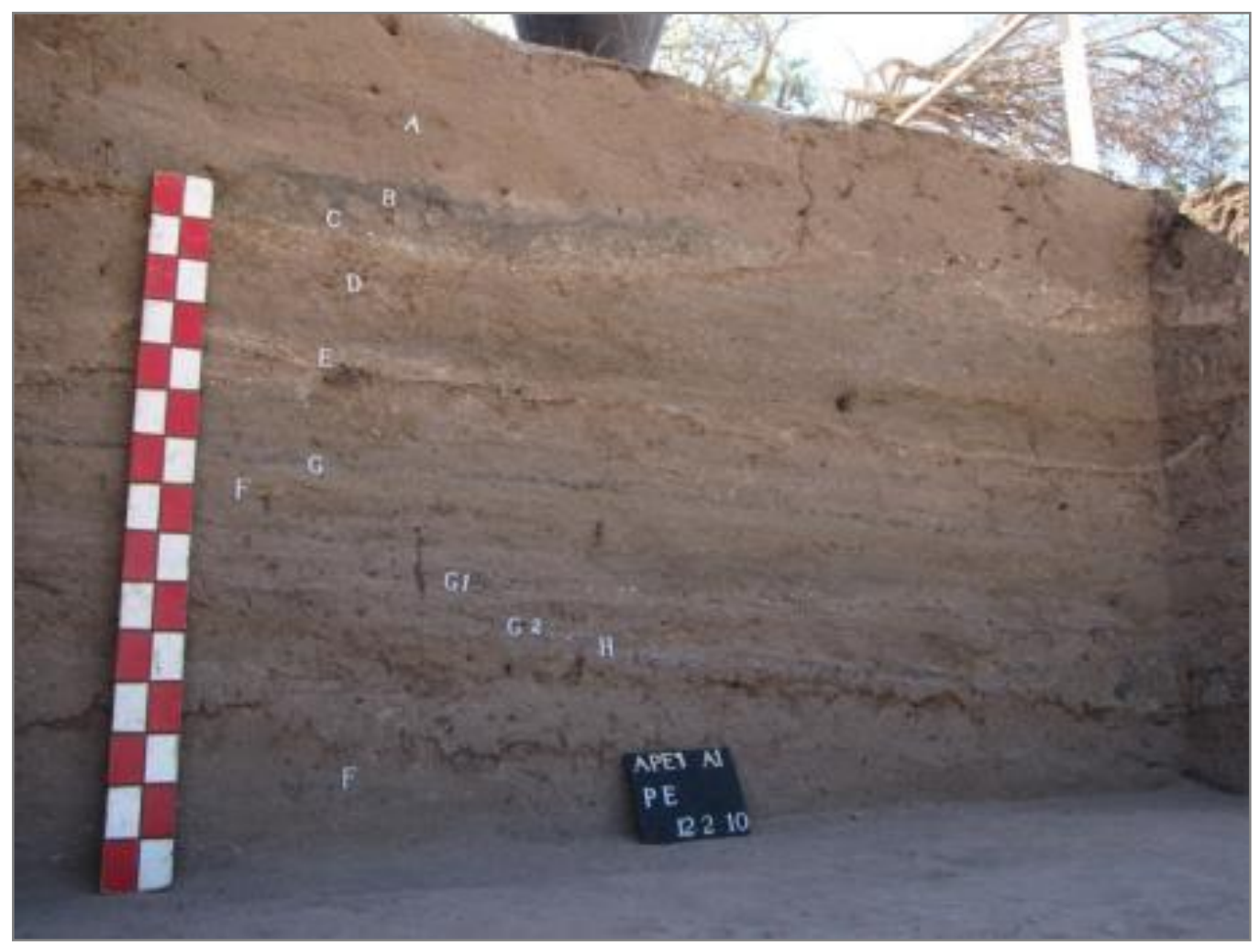

Figura 7.40. Estratigrafía del sitio APE-1. 


\begin{tabular}{|c|c|c|c|}
\hline APE-1 & Código & Material & Fecha \\
\hline Nivel 2 & AA-85709 & Turba? & $1.504 \pm 37$ \\
\hline Nivel 3 & AA-85706 & Falange guanaco & $685 \pm 31$ \\
\hline Nivel 3bis & AA-85707 & Falange guanaco & $685 \pm 31$ \\
\hline Nivel 4 (S) & AA-85708 & Carbón & $1.010 \pm 32$ \\
\hline
\end{tabular}

Tabla 7.48. Fechados radiocarbónicos del sitio APE-1.

En APE-1 se recuperó un total de 435 piezas líticas, las cuales fueron analizadas en su totalidad. Se calculó una densidad de depositación artefactual anual de 0,217 $\mathrm{m}^{2}$. Las clases artefactuales registradas en el sitio presentan un valor de riqueza de cinco. Las rocas silíceas son las más abundantes (Tablas 7.49 y 7.50). En los niveles inferiores (3-bis, 3-bis2 y 4) se observan frecuencias altas en el uso de obsidiana, que al aumentar desciende la frecuencia de silíceas (Figura 7.41). El conjunto está integrado por un 58,4\% $(n=254)$ de artefactos enteros y 41,6\% $(n=181)$ fragmentados. Entre los artefactos de obsidiana predominan los enteros $(57 \%, n=24)$ por sobre los fracturados; en rocas silíceas también son más abundantes los enteros $(59 \%, n=230)$ que los fragmentados $(51 \%$, $n=163)$.

\begin{tabular}{|c|c|c|c|c|c|c|}
\hline APE-1 & DT & Núcleo & AF Bifacial & AF Unifacial & ASF RC & Total \\
\hline 0 & 41 & 6 & - & 5 & 3 & 55 \\
\hline 1 & 10 & - & - & - & - & 10 \\
\hline 2 & 1 & - & - & - & - & 1 \\
\hline 3-Turba & - & 1 & - & - & - & 1 \\
\hline 3-Posturba & 38 & - & - & - & - & 38 \\
\hline 3-bis & 109 & - & 4 & - & - & 113 \\
\hline 3-bis2 & 179 & - & 1 & - & - & 180 \\
\hline 3-bis3 & 33 & - & - & - & - & 33 \\
\hline 4 & 4 & - & - & - & - & 4 \\
\hline Total & 415 & 7 & 5 & 5 & 3 & 435 \\
\hline$\%$ & $95,4 \%$ & $1,6 \%$ & $1,1 \%$ & $1,1 \%$ & $0,7 \%$ & $100 \%$ \\
\hline
\end{tabular}

Tabla 7.49. Clases artefactuales presentes en APE. 


\begin{tabular}{|c|c|c|c|}
\hline APE-1 & OBS & SIL & Total \\
\hline 0 & $2(4 \%)$ & $53(96 \%)$ & $55(100 \%)$ \\
\hline 1 & $1(10 \%)$ & $9(90 \%)$ & $10(100 \%)$ \\
\hline 2 & - & $1(100 \%)$ & $1(100 \%)$ \\
\hline 3 -Turba & - & $1(100 \%)$ & $1(100 \%)$ \\
\hline 3-Posturba & $5(13 \%)$ & $33(87 \%)$ & $38(100 \%)$ \\
\hline 3-bis & $5(4 \%)$ & $108(96 \%)$ & $113(100 \%)$ \\
\hline 3-bis2 & $21(12 \%)$ & $159(88 \%)$ & $180(100 \%)$ \\
\hline 3-bis3 & $6(18 \%)$ & $27(82 \%)$ & $33(100 \%)$ \\
\hline 4 & $2(50 \%)$ & $2(50 \%)$ & $4(100 \%)$ \\
\hline Total & 42 & 393 & 435 \\
\hline
\end{tabular}

Tabla 7.50. Distribución y frecuencia de materias primas por nivel de excavación.

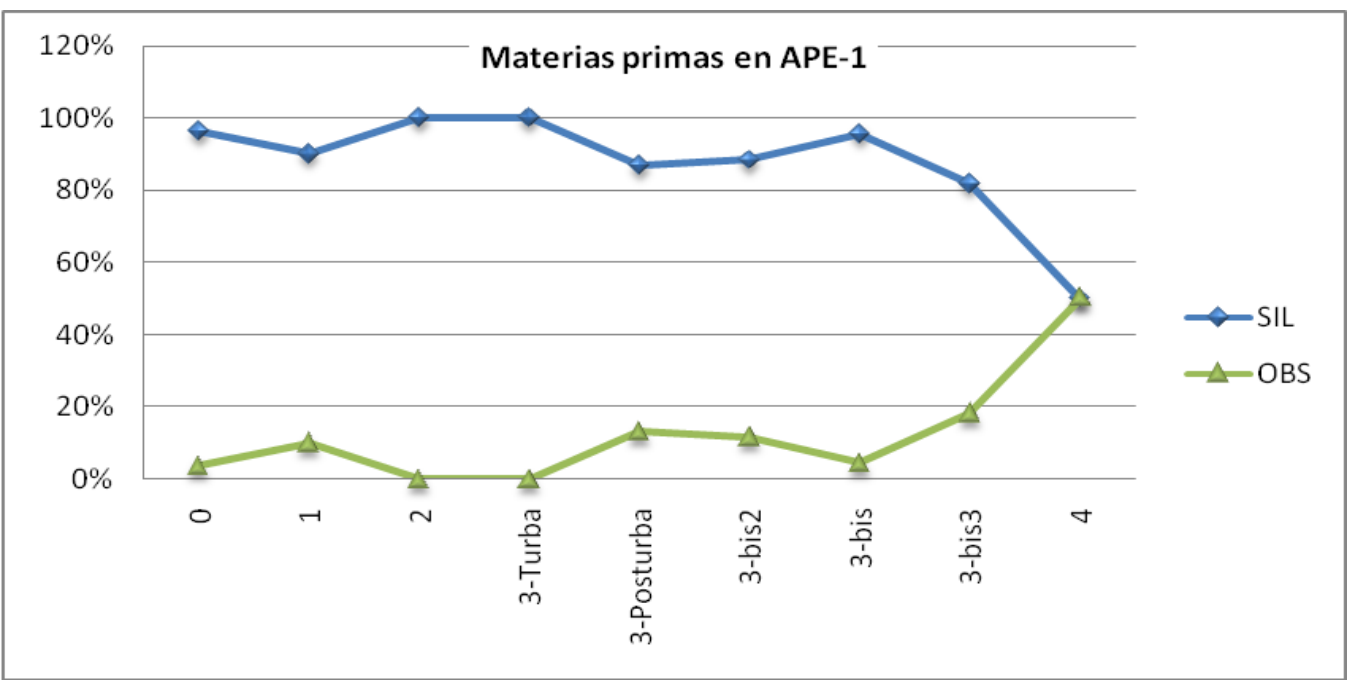

Figura 7.41Frecuencia de artefactos trabajados en rocas silíceas y obsidiana por nivel estratigráfico en APE-1.

\subsection{1b AGUA DE PÉREZ - CANTERA (APE-C)}

El sitio cantera taller APE-C se encuentra a $36^{\circ} 50^{\prime} 46.5^{\prime \prime}$ L S y $69^{\circ} 29^{\prime} 0.8 .8^{\prime \prime}$ L O, a $500 \mathrm{~m}$ de APE-1. Es un afloramiento de roca silícea, dispuesto a modo de filones longitudinales y nódulos dispersos de tamaño variable, con tonalidades que van desde el blanco lechoso - negro (opaco) al traslúcido (incoloro). El sitio cubre un área aproximada 
de $5000 \mathrm{~m}^{2}$ y aflora en distintos sectores de una meseta basáltica cuya altitud varía entre 1.465 msnm y 1.510 msnm (Figura 7.42). La materia prima puede ser caracterizada como roca sedimentaria química con alto contenido de sílice, con posibles vetas de textura tipo calcedonia (Eduardo Llambías 2009, comunicación personal). En una primera descripción la génesis de la materia prima del sitio se asoció a procesos hidrotermales de vulcanismo reciente (Salgán y Pérez Winter 2008-09), sin embargo, estudios petrográficos posteriores sostienen un origen vinculado a procesos de silicificación y reemplazo de rocas sedimentarias, con sectores rellenos parcialmente por procesos diagenéticos hidrotermales posteriores de recristianización (Bertotto y Garrido 2010; Anexo 1).

En el sitio se identificaron siete áreas de mayor concentración de artefactos o conjuntos superficiales, de tamaño variable. Se definieron siete concentraciones (Figura 7.42), cuyos tamaños varían entre los 480 y $1002 \mathrm{~m}^{2}$ (Tabla 7.51). Se relevaron 14 unidades de muestreo de $1 \mathrm{~m}^{2}$. En cada una se recolectó el total del material superficial y se relevaron las variables de visibilidad, pendiente, sector de la meseta y características del sustrato (Figura 7.43). En cada muestreo se calculó la densidad relativa de artefactos (Tabla 7.51; Figura 7.44). Como puede observarse, los valores menores de densidad por $\mathrm{m}^{2}$ se registran en los sectores de meseta correspondientes a los faldeos o laderas medias, mientras que los valores mayores corresponden a los sectores altos o cima. En las unidades de muestreo 1 a 5 se tomaron muestras directas del filón expuesto en superficie, para poder realizar un estudio petrográfico de la cantera. En el sector cima de la meseta se localizó el $57 \%(n=8)$ de las concentraciones, con valores de pendiente del $30^{\circ}$ (suave) y visibilidad muy buena y óptima en el $95 \%$ de las unidades. En las unidades ubicadas en los faldeos, el valor de pendientes es regular (57\%) a suave (40\%) y la visibilidad muy buena y buena (70 \%) (Tabla 7.52$)$. 


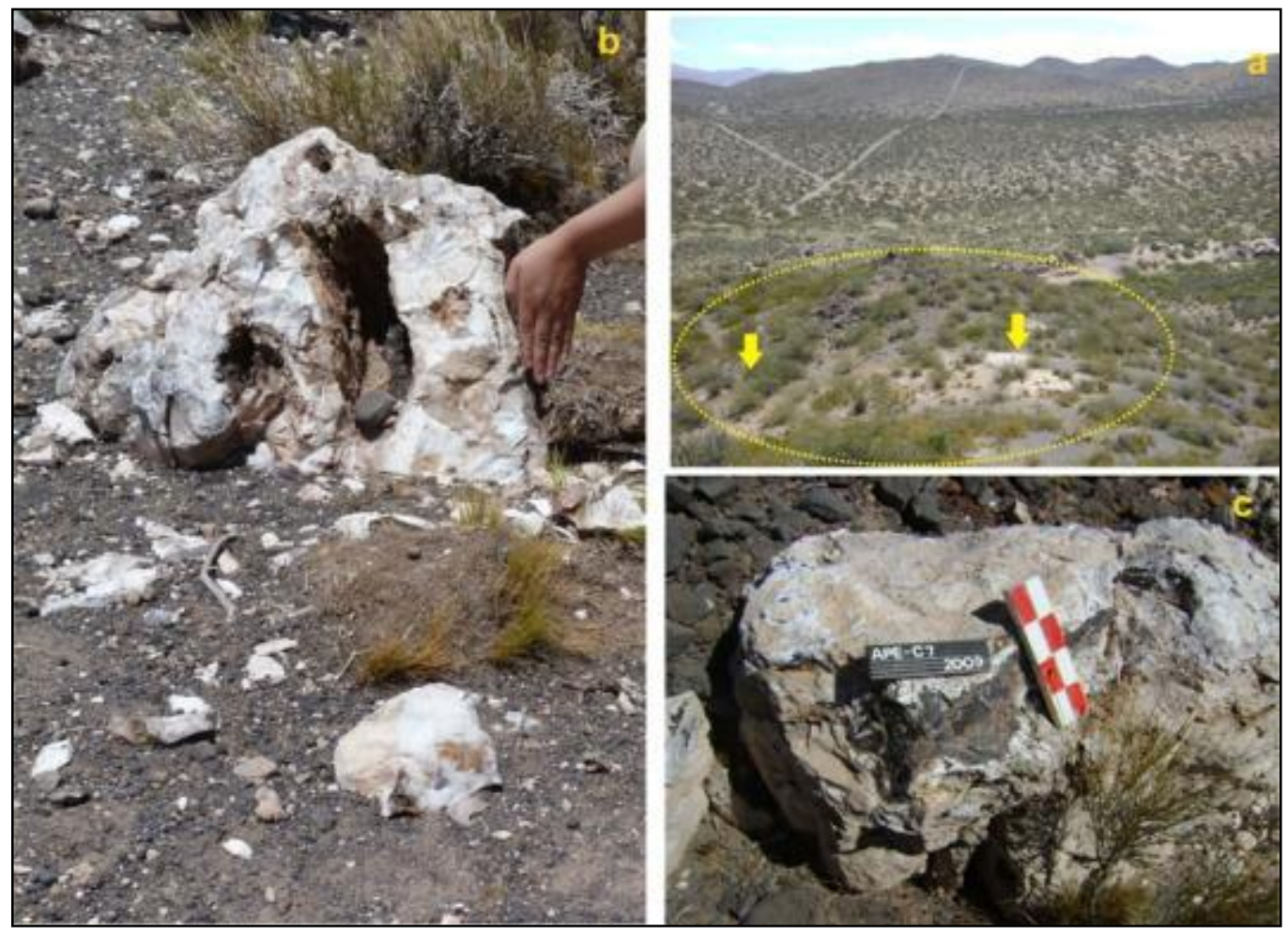

Figura 7.42. Fuente de roca silícea APE-C. En la figura a, se señala con línea punteada la meseta donde se encuentra la cantera APE-C y con flechas se señala la cima y el sector medio o faldeo. En las figuras b y c, se muestran detalles de los filones de roca expuestos y la variabilidad macroscópica observada en la fuente (color, textura y brillo).

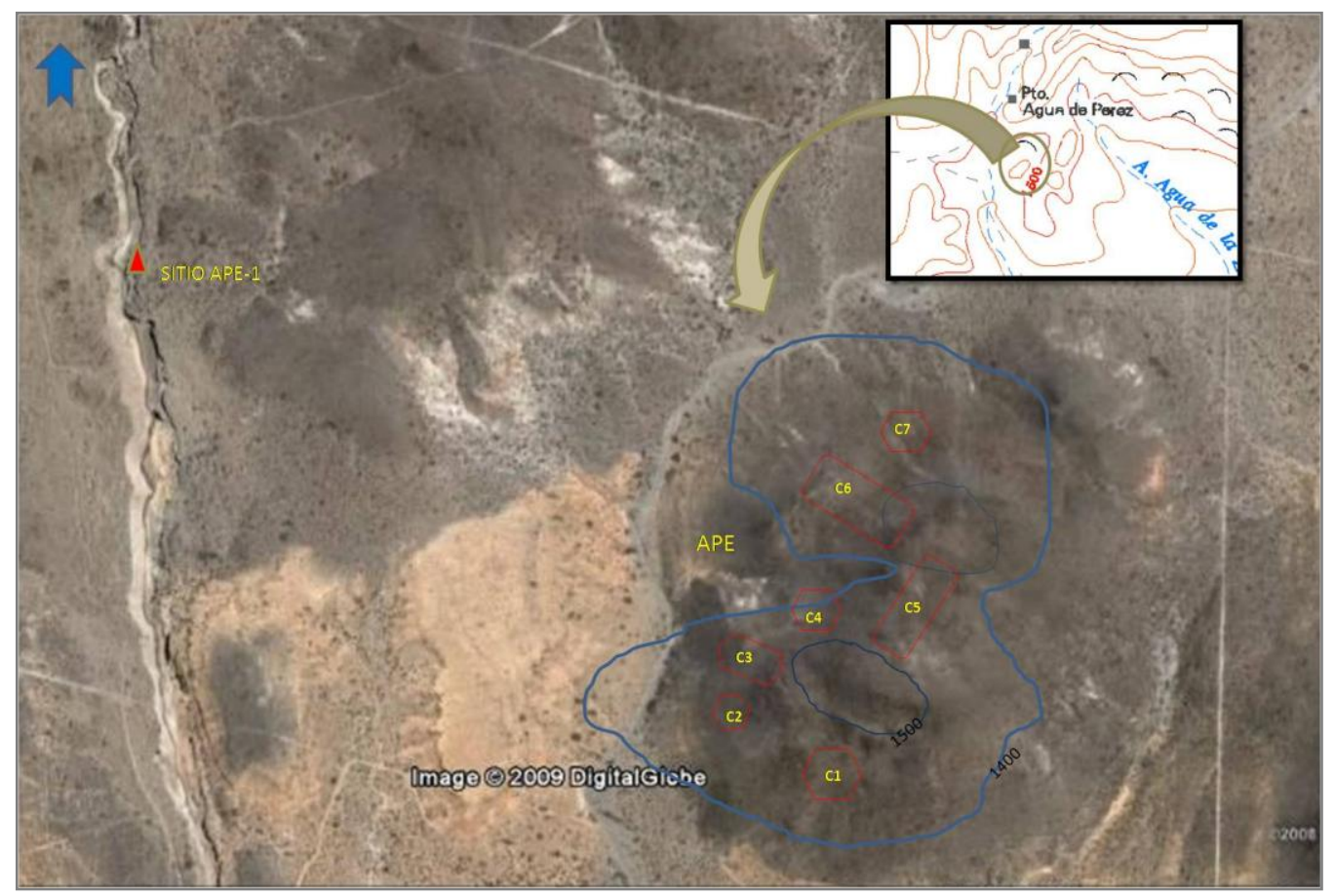

Figura 7.43. Ubicación de áreas de muestreo en APE-C. 


\begin{tabular}{|c|c|c|c|c|c|c|c|c|c|}
\hline Conjunto & \multicolumn{2}{|c|}{ Ubicación GPS } & $\begin{array}{c}\mathrm{msn} \\
\mathrm{m}\end{array}$ & Área $\mathrm{m}^{2}$ & $\begin{array}{l}\text { Sector } \\
\text { Meseta }\end{array}$ & $\mathbf{N}^{\circ}$ Muestreos & $\mathbf{N}$ & Densidad & Riqueza \\
\hline APE-C1 & $36^{\circ} 50^{\prime} 46.5^{\prime}$ & $69^{\circ} 29^{\prime} 08.8^{\prime \prime}$ & 1491 & 693 & Cima & 2 & 334 & 0,482 & 4 \\
\hline APE-C2 & $36^{\circ} 50^{\prime} 45.6^{\prime}$ & $69^{\circ} 29^{\prime} 07.0^{\prime \prime}$ & 1489 & 333 & Faldeo & 1 & 202 & 0,607 & 2 \\
\hline APE-C3 & $36^{\circ} 50^{\prime} 46.5^{\prime}$ & $69^{\circ} 29^{\prime} 06.4^{\prime \prime}$ & 1495 & 737 & Cima & 2 & 151 & 0,205 & 2 \\
\hline APE-C4 & $36^{\circ} 50^{\prime} 46.6^{\prime}$ & $69^{\circ} 29^{\prime} 05.7^{\prime \prime}$ & 1501 & 745 & Cima & 2 & 812 & 1,090 & 4 \\
\hline APE-C5 & $36^{\circ} 50^{\prime} 47.4^{\prime}$ & $69^{\circ} 29^{\prime} 02.8^{\prime \prime}$ & 1508 & 853 & Cima & 2 & 289 & 0,339 & 3 \\
\hline APE-C6 & $36^{\circ} 50^{\prime} 46.1^{\prime}$ & $69^{\circ} 29^{\prime} 02.5^{\prime \prime}$ & 1493 & 1002 & Faldeo & 3 & 26 & 0,026 & 2 \\
\hline APE-C7 & $36^{\circ} 50^{\prime} 44.7^{\prime}$ & $69^{\circ} 29^{\prime} 00.4^{\prime \prime}$ & 1494 & 484 & Faldeo & 2 & 35 & 0,072 & 2 \\
\hline
\end{tabular}

Tabla 7.51 Conjunto y unidades de muestreo superficial en el sitio APE-C.

\begin{tabular}{|c|c|c|c|}
\hline Muestreo & Sector de meseta & Pendiente & Visibilidad \\
\hline APE-C1M1 & Cima & $30^{\circ}$ & $75 \%$ \\
\hline APE-C1M2 & Cima & $0^{\circ}$ & $100 \%$ \\
\hline APE-C2M1 & Faldeo & $15^{\circ}$ & $75 \%$ \\
\hline APE-C3M1 & Faldeo & $60^{\circ}$ & $75 \%$ \\
\hline APE-C3M2 & Cima & $80^{\circ}$ & $100 \%$ \\
\hline APE-C4M1 & Cima & $50^{\circ}$ & $100 \%$ \\
\hline APE-C4M2 & Cima & $50^{\circ}$ & $100 \%$ \\
\hline APE-C5M1 & Cima & $0^{\circ}$ & $100 \%$ \\
\hline APE-C5M2 & Cima & $10^{\circ}$ & $75 \%$ \\
\hline APE-C6M1 & Faldeo & $80^{\circ}$ & $75 \%$ \\
\hline APE-C6M2 & Faldeo & $60^{\circ}$ & $75 \%$ \\
\hline APE-C6M3 & Cima & $20^{\circ}$ & $100 \%$ \\
\hline APE-C7M1 & Faldeo & $60^{\circ}$ & $25 \%$ \\
\hline APE-C7M2 & Faldeo & $70^{\circ}$ & $100 \%$ \\
\hline
\end{tabular}

Tabla 7.52. Visibilidad y rangos de pendiente de las unidades de muestreo en APE-C.

En APE-C se registraron 1849 artefactos líticos. La materia prima más abundante es la roca silícea $(99,7 \%)$; el resto son artefactos no diferenciados $(0,3 \%)$ sobre el basalto de la roca de caja que contiene los filones silíceos. Las clases artefactuales identificadas en la muestra analizada en APE-C son cuatro: artefactos de formatización bifacial, artefactos con rastros complementarios, desechos de talla y núcleos. El conjunto está integrado por una alta frecuencia de desechos de talla $(55,7 \%, n=1029)$, seguidos por los artefactos no diferenciados $(40,3 \%, n=745)$, núcleos $(3,5 \%, n=64)$ e instrumentos $(0,6 \%, n=11)$ (Tabla 
7.53). La clase artefactual no diferenciados está integrada en la mayoría de los casos por misceláneas o fragmentos que no presentan atributos para ser identificados como desecho de talla, pero que pudieron generarse al momento de la formatización de artefactos (Nami 1992). Esta categoría se considera de utilidad para caracterizar el volumen de los conjuntos recuperados en áreas de cantera y las materias primas presentes, pero no serán considerados en el análisis tecnológico posterior.

\begin{tabular}{|c|c|c|c|c|c|c|}
\hline \multirow{2}{*}{ Conjunto } & \multicolumn{5}{|c|}{ Artefactos } & \multirow{2}{*}{ Total } \\
\cline { 2 - 6 } & DT & ND & Núcleo & AF Bifacial & ASF RC & \\
\hline APE-C1 & 190 & 119 & 20 & 1 & 4 & 334 \\
\hline APE-C2 & 144 & 51 & 7 & - & - & 202 \\
\hline APE-C3 & 63 & 80 & 8 & - & - & 151 \\
\hline APE-C4 & 515 & 281 & 11 & 2 & 3 & 812 \\
\hline APE-C5 & 101 & 175 & 12 & 1 & - & 288 \\
\hline APE-C6 & 4 & 21 & 1 & - & - & 26 \\
\hline APE-C7 & 12 & 18 & 5 & - & - & 35 \\
\hline Total & 1029 & 598 & 64 & 4 & 7 & 1849 \\
\hline \% & $55,7 \%$ & $40,3 \%$ & $3,5 \%$ & $0,2 \%$ & $0,4 \%$ & $100 \%$ \\
\hline
\end{tabular}

Tabla 7.53. Frecuencia de clases artefactuales registradas por unidad de muestreo.

En la muestra analizada, es alta la frecuencias de artefactos enteros $(78 \%, n=1009)$ por sobre los fragmentados (22\%, $n=281)$. Entre los artefactos enteros, el $77,3 \%(n=780)$ corresponde a desechos de talla, seguidos por los no diferenciados con el 16,2\% ( $n=163$ ), los núcleos con el $6 \%(n=61)$ y los instrumentos con el 0,5\% ( $n=5)$ (Figura 7.45). De los artefactos fragmentados, la mayoría corresponde a desechos de talla con el 85,4\% $(n=240)$, el $11,4 \%(n=32)$ a no diferenciados, los instrumentos con el $2,2 \%(n=11)$ y los núcleos con el 1,1\% ( $n=3)$. 


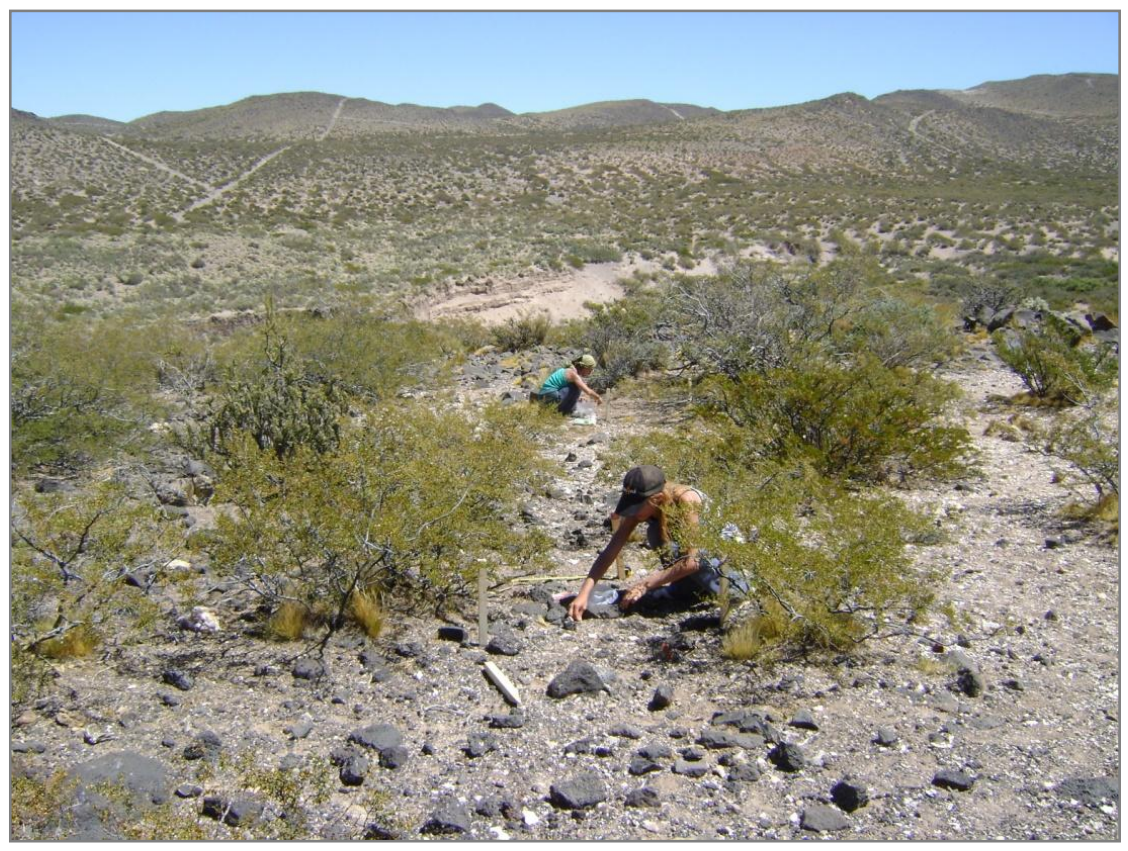

Figura 7.44. Unidades de muestreo en APE-C.

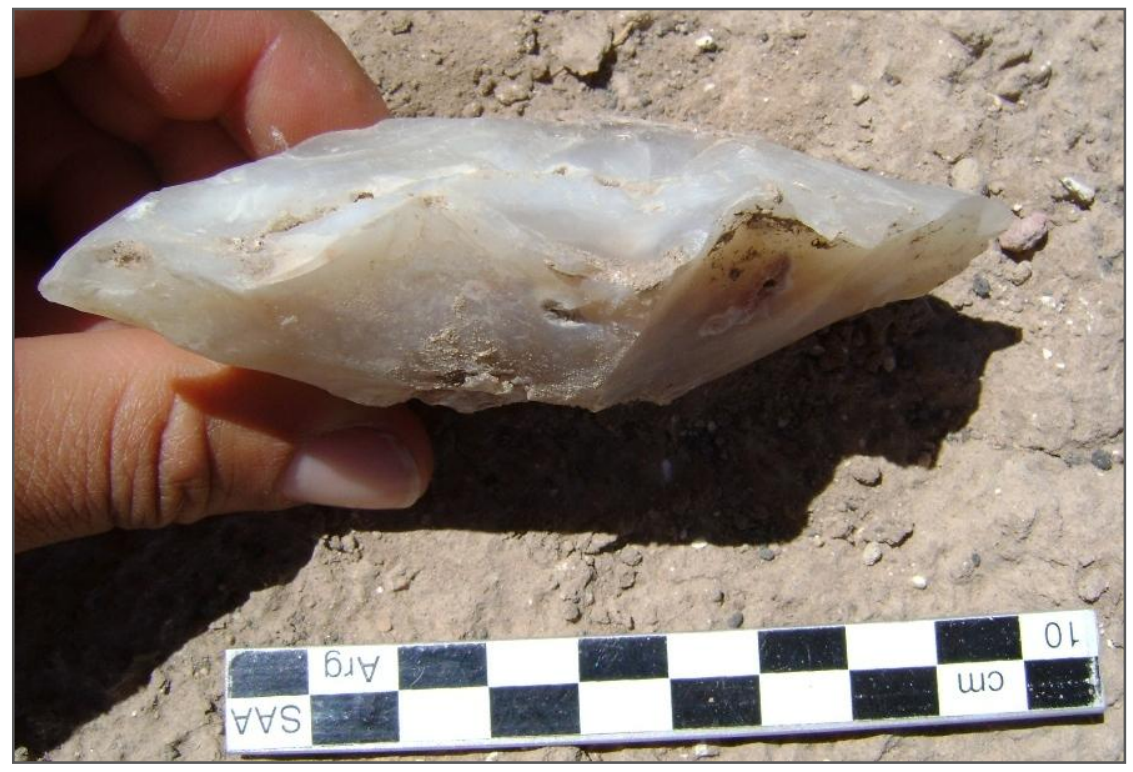

Figura 7.45. Bifaz recuperado en APE-C. 


\subsubsection{ANÁLISIS TECNOLÓGICO DE LA LOCALIDAD AGUA DE PÉREZ}

En base al muestreo llevado a cabo, se analizó el registro estratigráfico del sitio APE-1 y la cantera de roca silícea APE-C. El total de la muestra analizada es de $n=1734$ artefactos líticos.

\subsection{2a MATERIAS PRIMAS LÍTICAS EN LA LOCALIDAD APE}

La materia prima más frecuente en la localidad es la roca silícea $(97,3 \%, n=1688)$, le siguen la obsidiana $(2,4 \%, n=45)$ y el basalto $(0,2 \%, n=4)$. En los sitios APE-1 y APE-C, solo hay dos tipos de materias primas, siendo la roca silícea común a ambos sitios. En la localidad predomina la calidad para la talla buena (37\%) y regular (36\%) seguida por la calidad mala (18\%), muy buena (8\%) y excelente (2\%) (Tabla 7.54$)$. Los artefactos sobre basalto corresponden a nódulos naturales sin claros indicadores de uso y cómo se mencionó anteriormente, corresponden a la roca de caja que contiene los filones silíceos.

\begin{tabular}{|c|c|c|c|c|c|c|c|}
\hline Sitio/área & MP & M & R & B & MB & E & Total general \\
\hline \multirow{2}{*}{ APE-1 } & OBS & - & - & $2(5 \%)$ & $7(17 \%)$ & $33(79 \%)$ & $42(100 \%)$ \\
\cline { 2 - 8 } & SIL & - & $128(33 \%)$ & $233(59 \%)$ & $28(7 \%)$ & $4(1 \%)$ & $393(100 \%)$ \\
\hline \multirow{2}{*}{ APE-C } & BAS & $4(100 \%)$ & - & - & - & - & $4(100 \%)$ \\
\cline { 2 - 8 } & SIL & $300(23 \%)$ & $496(38 \%)$ & $400(31 \%)$ & $99(8 \%)$ & - & $1295(100 \%)$ \\
\hline \multicolumn{2}{|r|}{ Total general } & $304(18 \%)$ & $624(36 \%)$ & $635(37 \%)$ & $134(8 \%)$ & $37(2 \%)$ & $1734(100 \%)$ \\
\hline
\end{tabular}

Tabla 7.54. Calidad para la talla en materias primas representadas en APE. Nota: MP: materia prima; M: mala; R: regular; B: bueno; MB: muy bueno; E: excelente.

La mayor frecuencia de artefactos fragmentados corresponde al sitio APE-1. EI índice de fragmentación (MNA/NAS) muestra que los artefactos fragmentados han incrementado muy poco el tamaño de muestra (12\%) (Tabla 7.55). Si bien los índices para 
APE son bajos, el estado de fragmentación es mayor en el sitio estratigráfico $(<20 \%)$ en relación con los valores obtenidos en los conjuntos de superficie (<10\%) (Tabla 7.56).

\begin{tabular}{|c|c|c|c|c|c|c|c|c|}
\hline Sitio/área & MP & Entero & $\mathbf{\%}$ & Fracturado & $\mathbf{\%}$ & ND & \% & Total \\
\hline & OBS & 24 & $57 \%$ & 18 & $43 \%$ & - & - & 42 \\
\cline { 2 - 9 } APE-1 & SIL & 230 & $59 \%$ & 163 & $41 \%$ & 9 & - & 393 \\
\hline & BAS & 4 & $100 \%$ & - & - & - & - & 4 \\
\cline { 2 - 10 } APE-C & SIL & 1005 & $78 \%$ & 281 & $22 \%$ & - & - & 1295 \\
\hline \multicolumn{2}{|c|}{ Total } & 1265 & $72,80 \%$ & 463 & $26,70 \%$ & 9 & $0,50 \%$ & 1737 \\
\hline
\end{tabular}

Tabla 7.55. Estado de fragmentación de los conjuntos en APE.

\begin{tabular}{|c|c|c|c|c|c|c|c|c|c|c|c|c|}
\hline Sitio & MP & Ent & $\begin{array}{c}\text { Fr. } \\
\text { Prox }\end{array}$ & $\begin{array}{l}\text { Fr. } \\
\text { Med }\end{array}$ & $\begin{array}{l}\text { Fr. } \\
\text { Dist }\end{array}$ & $\begin{array}{l}\text { Fr. } \\
\text { Mar }\end{array}$ & $\begin{array}{c}\text { Long } \\
\text { Der }\end{array}$ & $\begin{array}{c}\text { Long } \\
\text { Izq }\end{array}$ & $\begin{array}{l}\text { Fr. } \\
\text { ND }\end{array}$ & NAS & $\begin{array}{c}\mathrm{MN} \\
\mathrm{A}\end{array}$ & $\begin{array}{c}\text { MNA/NA } \\
\text { S }\end{array}$ \\
\hline \multirow{2}{*}{$\begin{array}{c}\text { APE- } \\
1 \\
\end{array}$} & $\begin{array}{c}\text { OB } \\
\mathrm{S}\end{array}$ & 24 & 7 & 2 & 4 & - & - & 2 & 3 & 42 & 33 & $79 \%$ \\
\hline & SIL & 230 & 77 & 25 & 47 & 4 & 5 & 2 & 3 & 402 & 312 & $78 \%$ \\
\hline \multirow[b]{2}{*}{$\begin{array}{l}\text { APE- } \\
\text { C }\end{array}$} & BAS & 4 & - & - & - & - & - & - & - & 4 & 4 & $100 \%$ \\
\hline & SIL & $\begin{array}{c}100 \\
5 \\
\end{array}$ & 160 & 12 & 59 & - & 5 & 7 & 38 & $\begin{array}{c}128 \\
6 \\
\end{array}$ & 1172 & $91 \%$ \\
\hline \multicolumn{2}{|c|}{ Total } & $\begin{array}{c}126 \\
5 \\
\end{array}$ & 245 & 39 & 110 & 4 & 10 & 11 & 44 & $\begin{array}{c}173 \\
7\end{array}$ & 1524 & $88 \%$ \\
\hline
\end{tabular}

Tabla 7.56. Estado de fragmentación de los artefactos por materia prima en los conjuntos de APE. Referencias: MP: materia prima; Ent: entero; Fr. Prox: fragmento proximal; Fr. Med: fragmento medial; Fr. Dist: fragmento distal; Fr. Mar: fragmento marginal; Long Der: Fragmento longitudinal derecho; Long Izq: fragmento longitudinal izquierdo; Fr. ND: fragmento no diferenciado; ND: No Diferenciado; NAS: número de especímenes artefactuales; MNA: número mínimo de artefactos.

En APE-1 el tamaño más frecuente de los artefactos enteros es el muy pequeño, tanto en obsidiana como en roca silícea, seguido en el primero de los casos por los tamaños pequeños y en el segundo por el grandísimo. En rocas silíceas se destaca la gran variabilidad de tamaños representada (Tabla 7.57). En la cantera APE-C el tamaño más representado es el grandísimo, seguido por el mediano pequeño y el pequeño en roca silícea; aquí también están representados todos los rangos de tamaño. En cuanto a la reserva de corteza, en APE se observa que tanto en el sitio estratigráfico como en la 
cantera son mayoritarios los artefactos sin corteza, al contrario que lo observado APE-C (Tabla 7.58).

\begin{tabular}{|c|c|c|c|c|c|c|c|c|c|}
\hline Sitio/área & MP & MP & P & MEP & MEG & G & MG & GD & Total \\
\hline & OBS & $62,50 \%$ & $25,00 \%$ & - & $4,17 \%$ & - & $4,17 \%$ & $4,17 \%$ & 24 \\
\cline { 2 - 10 } APE-1 & SIL & $52,17 \%$ & $18,26 \%$ & $4,78 \%$ & $1,74 \%$ & $2,17 \%$ & $1,30 \%$ & $19,57 \%$ & 230 \\
\hline & BAS & - & - & - & - & $25,00 \%$ & - & $75,00 \%$ & 4 \\
\cline { 2 - 10 } APE-C & SIL & $2,39 \%$ & $12,24 \%$ & $15,42 \%$ & $9,25 \%$ & $7,96 \%$ & $6,87 \%$ & $45,87 \%$ & 1005 \\
\hline \multicolumn{2}{|c|}{ Total } & $12,57 \%$ & $13,52 \%$ & $13,12 \%$ & $7,75 \%$ & $6,80 \%$ & $5,77 \%$ & $40,47 \%$ & 1263 \\
\hline
\end{tabular}

Tabla 7.57. Tamaño de los artefactos enteros en las materias primas representadas en APE. Referencia: MP: materia prima; MPE: Muy pequeño (0-20); P: Pequeño (21-40); MEP: Mediano pequeño (4160); MEG: Mediano Grande (61-80); G: Grande (81-120); MG: Muy Grande (121-160); GD: Grandísimo (>161).

\begin{tabular}{|c|c|c|c|c|c|c|c|}
\hline Sitio & MP & $\mathbf{0}$ & $\mathbf{0 , 2 5}$ & $\mathbf{0 , 5}$ & $\mathbf{0 , 7 5}$ & $\mathbf{1}$ & Total \\
\hline \multirow{3}{*}{ APE-1 } & OBS & $63 \%$ & $21 \%$ & $13 \%$ & - & $4 \%$ & 24 \\
\cline { 2 - 9 } & SIL & $79 \%$ & $13 \%$ & $4 \%$ & $3 \%$ & $1 \%$ & 230 \\
\hline \multirow{3}{*}{ APE-C } & BAS & - & - & - & - & $100 \%$ & 4 \\
\hline \multicolumn{2}{|c|}{ SIL } & $31 \%$ & $23 \%$ & $12 \%$ & $17 \%$ & $18 \%$ & 1005 \\
\hline \multicolumn{2}{|c|}{ Total } & $41 \%$ & $21 \%$ & $10 \%$ & $14 \%$ & $15 \%$ & 1263 \\
\hline
\end{tabular}

Tabla 7.58. Reserva de corteza en artefactos enteros en APE.

\subsection{2b ESTRUCTURA TECNOLÓGICA EN AGUA DE PÉREZ (APE)}

La clase artefactual más representada en APE es la de desechos de talla $(83,2 \%)$, seguida por los artefactos no diferenciados (11,2\%), los núcleos $(4,1 \%)$, los artefactos sin formatización con rastros complementarios $(0,6 \%)$, y los artefactos bifaciales $(0,5 \%)$ y unifaciales (0,3\%) (Tabla 7.59). Cabe aclarar los artefactos no diferenciados, sólo se proceso el $25 \%$ del total, dado su volumen y los objetivos planteados en esta tesis. Si analizamos los conjuntos por tipo de extracción notamos que en APE-1 la frecuencia de obsidiana $(9,7 \%, n=42)$ es mayor que en los conjuntos superficiales $(0,2 \%, n=3)$, en los cuales el basalto posee una frecuencia mayor $(0,3 \%, n=4)$. Sin embargo el basalto no se 
registra en APE 1. En la tabla 7.60 se detalla la estadística descriptiva de la diversidad de clases artefactuales según materia prima. En obsidiana los valores de diversidad son bajos (Shannon $\mathrm{H}=0,349)$, con valores de dominancia altos, por lo cual la representación de clases no es homogénea y una clase se destaca en frecuencia. En este último caso, la clase desechos de talla es la más representada (91\%). Entre las rocas silíceas se observa el valor de riqueza artefactual más alto, dado que están representadas cinco de las seis clases consideradas. Sin embargo, los valores de diversidad no superan el 0.5; en este caso se destacan las frecuencias de desechos de talla y núcleos en la cantera APE-C.

\begin{tabular}{|c|c|c|c|c|c|c|c|c|}
\hline \multicolumn{2}{|c|}{ Sitio/área } & $\begin{array}{c}\text { AF } \\
\text { Bifacial }\end{array}$ & $\begin{array}{c}\text { AF } \\
\text { Unifacial }\end{array}$ & ASF RC & DT & Núcleo & ND & Total \\
\hline \multirow{2}{*}{$\begin{array}{c}\text { APE- } \\
1\end{array}$} & OBS & $\begin{array}{c}3 \\
(7,1 \%) \\
\end{array}$ & - & - & $\begin{array}{c}39 \\
(92,9 \%) \\
\end{array}$ & - & - & 42 (100\%) \\
\hline & SIL & $\begin{array}{c}2 \\
(0,5 \%)\end{array}$ & $\begin{array}{c}5 \\
(1,3 \%)\end{array}$ & $\begin{array}{c}3 \\
(0,8 \%)\end{array}$ & $376(95,7 \%)$ & $\begin{array}{c}7 \\
(1,8 \%)\end{array}$ & - & $393(100 \%)$ \\
\hline \multicolumn{2}{|c|}{$\begin{array}{c}\text { Total } \\
\text { Estratigrafía }\end{array}$} & $\begin{array}{c}5 \\
(1,1 \%)\end{array}$ & $\begin{array}{c}5 \\
(1,1 \%)\end{array}$ & $\begin{array}{c}3 \\
(0,7 \%)\end{array}$ & $415(95,4 \%)$ & $\begin{array}{c}7 \\
(1,6 \%)\end{array}$ & - & 435 (100\%) \\
\hline \multirow{2}{*}{$\begin{array}{l}\text { APE- } \\
\text { C }\end{array}$} & BAS & - & - & - & - & - & $\begin{array}{c}4 \\
(100 \%)\end{array}$ & $4(100 \%)$ \\
\hline & SIL & $4(0,3 \%)$ & - & $\begin{array}{c}7 \\
(0,5 \%)\end{array}$ & $\begin{array}{c}1029 \\
(79,5 \%)\end{array}$ & $\begin{array}{c}64 \\
(4,9 \%)\end{array}$ & $\begin{array}{c}191 \\
(3,7 \%)\end{array}$ & $\begin{array}{c}1295 \\
(100 \%)\end{array}$ \\
\hline \multicolumn{2}{|c|}{ Total Superficial } & $4(0,3 \%)$ & - & $\begin{array}{c}7 \\
(0,6 \%)\end{array}$ & $\begin{array}{c}1029 \\
(79,2 \%)\end{array}$ & $\begin{array}{c}64 \\
(16,2 \%)\end{array}$ & $\begin{array}{c}195 \\
(15 \%)\end{array}$ & $\begin{array}{c}1302 \\
(100 \%)\end{array}$ \\
\hline \multicolumn{2}{|c|}{ Total APE } & $\begin{array}{c}9 \\
(0,5 \%)\end{array}$ & $\begin{array}{c}5 \\
(0,3 \%)\end{array}$ & $\begin{array}{c}10 \\
(0,6 \%)\end{array}$ & $\begin{array}{c}1444 \\
(83,3 \%)\end{array}$ & $\begin{array}{c}71 \\
(4,1 \%)\end{array}$ & $\begin{array}{c}195 \\
(11,2 \%)\end{array}$ & $\begin{array}{c}1734 \\
(100 \%)\end{array}$ \\
\hline
\end{tabular}

Tabla 7.59 Clases artefactuales por sitio en APE. Entre paréntesis se detalla la proporción de la clase artefactual por materia prima y sitio de muestreo. Referencia: MP: materia prima; ; OBS: obsidiana; SIL: rocas silíceas; BAS: basalto. AF Bifacial: artefacto de formatización bifacial; AF Unifacial: artefacto de formatización unifacial; ASF RC: artefacto sin formatización con rastros complementarios; DT: desecho de talla; ND: no diferenciado.

\begin{tabular}{|c|c|c|}
\hline & SIL & OBS \\
\hline N clase artefacto & 5 & 3 \\
\hline $\mathbf{N}$ & 1640 & 45 \\
\hline Dominancia & 0,751 & 0,835 \\
\hline Shannon H & 0,467 & 0,349 \\
\hline Simpson & 0,249 & 0,165 \\
\hline
\end{tabular}

Tabla 7.60. Diversidad de clases artefactuales según materias primas en APE. 


\subsection{2b.1 DESECHOS DE TALLA}

Los desechos de talla son la clase más frecuente en APE $(83,2 \%)$. La materia prima más representada es la roca silíceas con el 97\% ( $n=1405)$, seguida por la obsidiana con el $3 \%(n=39)$. El $29 \%(n=416)$ de los desechos se encuentra fragmentado y el $71 \%(n=1021)$ entero. De los desechos enteros el $48 \%(n=487)$ no presenta reserva de corteza en su cara dorsal (Tabla 7.60). Las mayores frecuencias de artefactos sin corteza se registran en rocas silíceas en el sitio estratigráfico APE-1, contrario a lo registrado en APE-C donde están las frecuencias más altas de corteza (Figura 7.46). En las subclases o tipos de desechos, las lascas internas son las más frecuentes y alcanzan el 50\% del total (Tabla 7.61). Las lascas externas por su parte, representan el $29 \%$ del total, registrando su valor más alto en la cantera APE-C. En este sitio se registra alta frecuencia de lascas nodulares (LN=13\%) y lascas de reducción bipolar (LBIP=7\%). Se destaca en el sitio APE-1 la frecuencia de lascas internas (69\%) y desechos correspondientes a las últimas etapas de manufactura o reactivación de filos (17\%), tales como lascas de adelgazamiento bifacial (LAB), las lascas planas (PL) y lascas de reactivación de filo (LR). Los desechos de reactivación de filo, están presentes tanto en APE-1 $(64 \%, N=25)$ como en APE-C $(36 \%, n=14)$ pero en frecuencias muy diferentes. En el primero, la frecuencia de lascas de formatización de filos en silíceas y obsidiana presentan frecuencias similares (Figura 7.47).

\begin{tabular}{|c|c|c|c|c|c|c|c|}
\hline Sitio & MP & 0 & 0,25 & 0,5 & 0,75 & 1 & Total \\
\hline \multirow[b]{2}{*}{ APE-1 } & OBS & $15(63 \%)$ & $5(21 \%)$ & $3(13 \%)$ & - & $1(4 \%)$ & $24(100 \%)$ \\
\hline & SIL & $175(81 \%)$ & $26(12 \%)$ & $8(4 \%)$ & $6(3 \%)$ & $1(0,5 \%)$ & $216(100 \%)$ \\
\hline \multicolumn{2}{|c|}{ Subtotal Estratigrafía } & $190(79 \%)$ & $31(13 \%)$ & $11(5 \%)$ & $6(3 \%)$ & $2(1 \%)$ & $240(100 \%)$ \\
\hline \multirow[b]{2}{*}{ APE-C } & BAS & - & - & - & - & - & - \\
\hline & SIL & $297(37 \%)$ & $203(26 \%)$ & $99(13 \%)$ & $114(15 \%)$ & $67(9 \%)$ & $780(100 \%)$ \\
\hline \multicolumn{2}{|c|}{ Subtotal Superficial } & $297(37 \%)$ & $203(26 \%)$ & $99(13 \%)$ & $114(15 \%)$ & $67(9 \%)$ & $781(100 \%)$ \\
\hline \multicolumn{2}{|c|}{ Total } & $487(48 \%)$ & $234(23 \%)$ & $110(11 \%)$ & $120(12 \%)$ & $69(7 \%)$ & $1020(100 \%)$ \\
\hline
\end{tabular}

Tabla 7.60. Reserva de corteza en desechos de talla enteros en APE. 


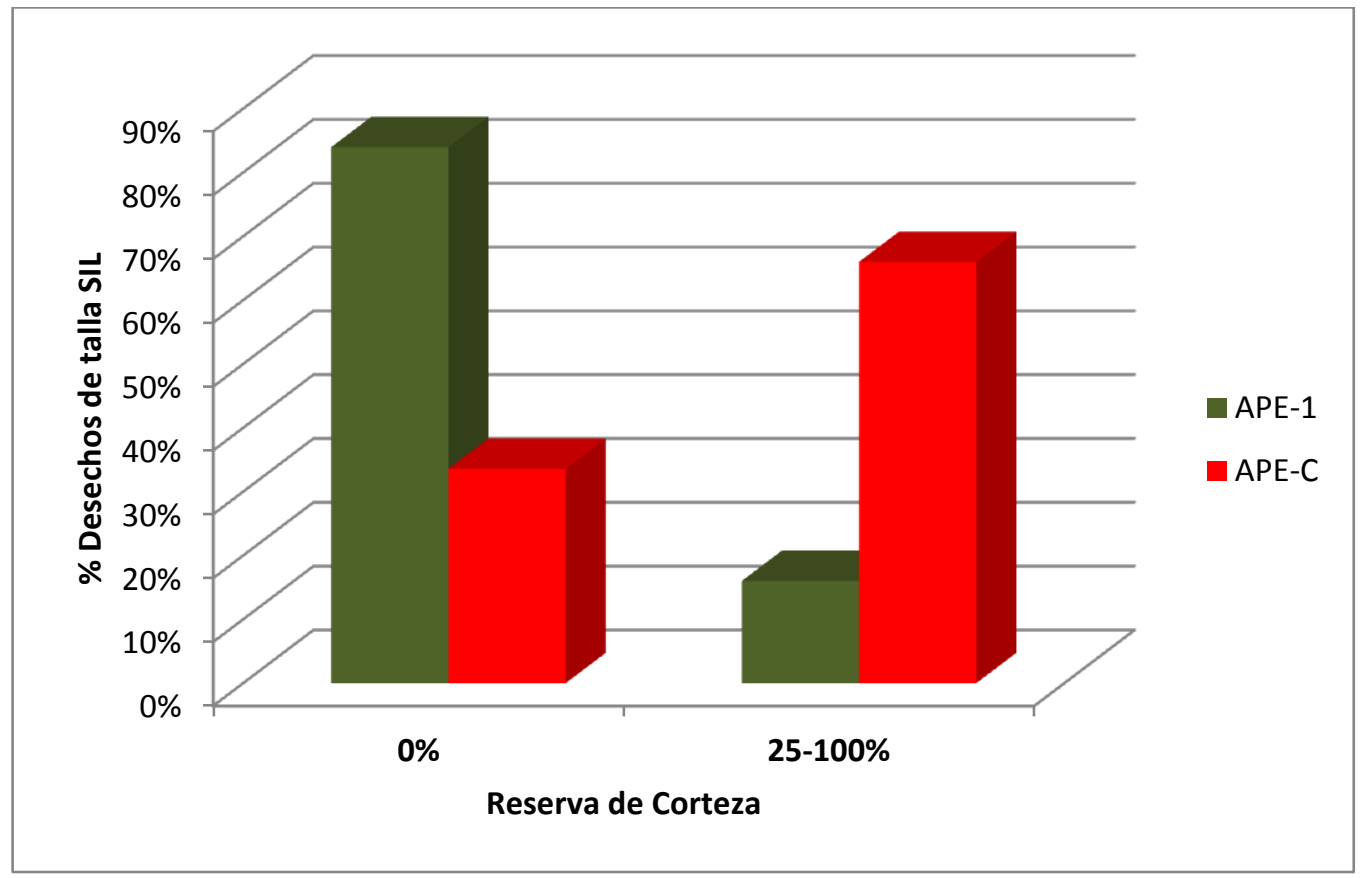

Figura 7.46. Reserva de corteza en rocas silíceas de APE-1 y APE-C.

\begin{tabular}{|c|c|c|c|c|c|c|c|c|c|c|c|c|}
\hline Sitio & MP & LPR & LSEC & LAN & LAR & LAB & PL & LR & LN & LBIP & ND & Total \\
\hline \multirow{2}{*}{$\begin{array}{c}\text { APE- } \\
1\end{array}$} & OBS & 1 & - & 17 & 10 & - & 2 & 5 & 2 & - & 2 & 39 \\
\hline & SIL & 4 & 7 & 146 & 114 & 18 & 28 & 20 & 7 & - & 32 & 376 \\
\hline \multicolumn{2}{|c|}{$\begin{array}{c}\text { Subtotal } \\
\text { Estratigrafía }\end{array}$} & $\begin{array}{c}5 \\
(1 \%) \\
\end{array}$ & $\begin{array}{c}7 \\
(2 \%) \\
\end{array}$ & $\begin{array}{c}163 \\
(39 \%) \\
\end{array}$ & $\begin{array}{c}124 \\
(30 \%) \\
\end{array}$ & $\begin{array}{c}18 \\
(4 \%) \\
\end{array}$ & $\begin{array}{c}30 \\
(7 \%) \\
\end{array}$ & $\begin{array}{c}25 \\
(6 \%) \\
\end{array}$ & $\begin{array}{c}9 \\
(2 \%) \\
\end{array}$ & - & $\begin{array}{c}34 \\
(8 \%) \\
\end{array}$ & $\begin{array}{c}415 \\
(100 \%) \\
\end{array}$ \\
\hline \multirow{2}{*}{$\begin{array}{c}\text { APE- } \\
\text { C }\end{array}$} & BAS & - & - & - & - & - & - & - & - & - & - & - \\
\hline & SIL & 94 & 121 & 280 & 188 & 24 & 35 & 14 & 138 & 71 & 64 & 1029 \\
\hline \multicolumn{2}{|c|}{$\begin{array}{c}\text { Subtotal } \\
\text { Superficial }\end{array}$} & $\begin{array}{c}94 \\
(9 \%) \\
\end{array}$ & $\begin{array}{c}121 \\
(12 \%) \\
\end{array}$ & $\begin{array}{c}280 \\
(27 \%) \\
\end{array}$ & $\begin{array}{c}188 \\
(18 \%) \\
\end{array}$ & $\begin{array}{c}24 \\
(2 \%) \\
\end{array}$ & $\begin{array}{c}35 \\
(3 \%) \\
\end{array}$ & $\begin{array}{c}14 \\
(1 \%) \\
\end{array}$ & $\begin{array}{c}138 \\
(13 \%) \\
\end{array}$ & $\begin{array}{c}71 \\
(7 \%) \\
\end{array}$ & $\begin{array}{c}64 \\
(6 \%) \\
\end{array}$ & $\begin{array}{c}1029 \\
(100 \%)\end{array}$ \\
\hline \multicolumn{2}{|c|}{ Total } & $\begin{array}{c}99 \\
(7 \%)\end{array}$ & $\begin{array}{l}129 \\
(9 \%)\end{array}$ & $\begin{array}{c}444 \\
(31 \%)\end{array}$ & $\begin{array}{c}312 \\
(22 \%)\end{array}$ & $\begin{array}{c}42 \\
(3 \%)\end{array}$ & $\begin{array}{c}65 \\
(4 \%)\end{array}$ & $\begin{array}{c}39 \\
(3 \%)\end{array}$ & $\begin{array}{c}147 \\
(10 \%)\end{array}$ & $\begin{array}{c}71 \\
(5 \%)\end{array}$ & $\begin{array}{c}98 \\
(7 \%)\end{array}$ & $\begin{array}{c}1444 \\
(100 \%)\end{array}$ \\
\hline
\end{tabular}

Tabla 7.61. Tipos de desechos de talla por tipo de extracción en APE. Referencia: LPR: lasca primaria; LSEC: Iasca secundaria; LAN: lasca angular; LAR: lasca de arista; LAB: lasca de adelgazamiento bifacial; PL: lasca plana; LR: lasca de reactivación; LN: lasca nucleiforme (incluye lascas de flanco de núcleo, cresta de núcleo y lascas de reactivación de núcleo); LBIP: lasca bipolar; ND: lasca no diferenciada. 


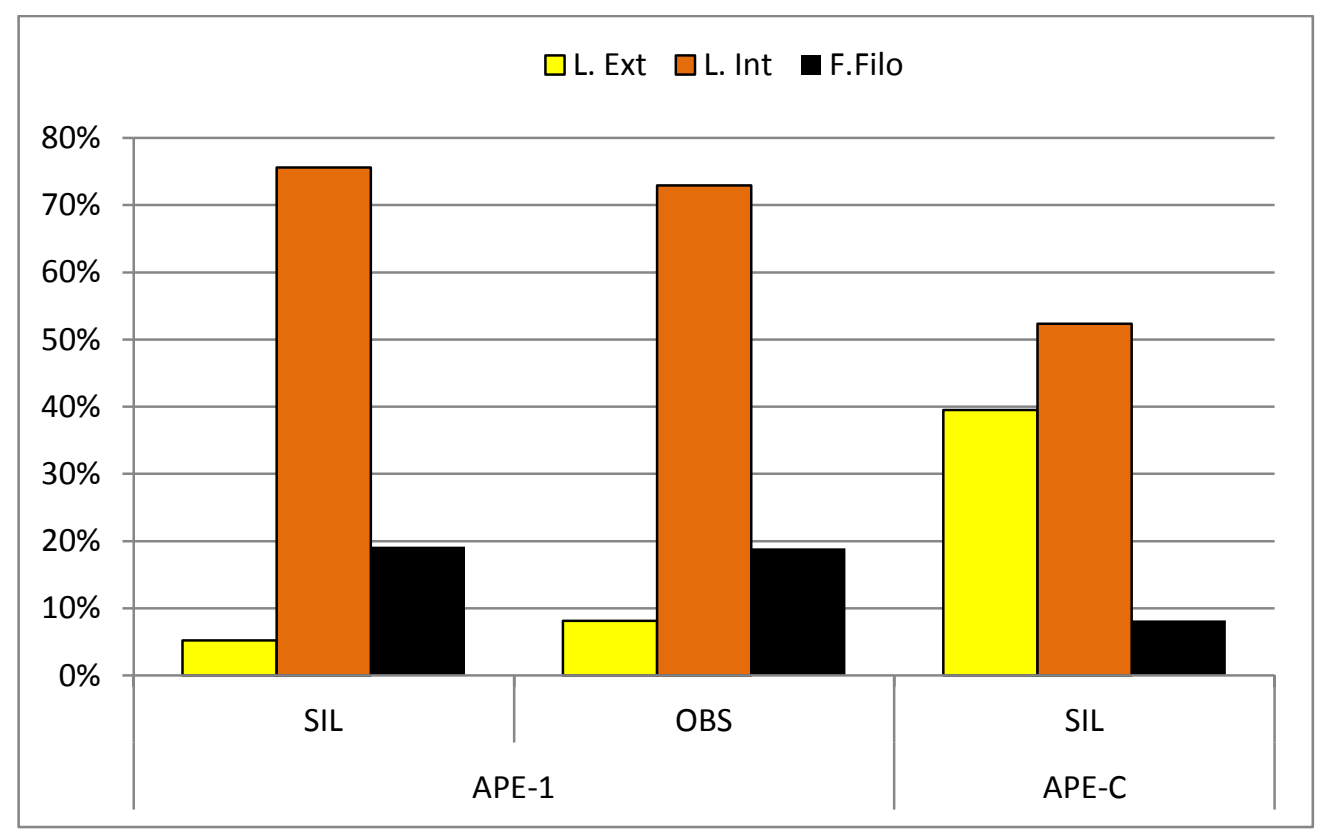

Figura 7.47. Frecuencia de etapas de reducción en APE. Referencias: L. Ext: lascas externas; L. Int: lascas internas; F. Filo: lascas de formatización de filo; SIL: rocas silíceas; OBS: obsidiana.

Si consideramos el grado de reducción de los desechos de talla, a través de los estimativos de corteza (Ericson 1984) y la intensidad de reducción de las materias primas, a partir de la densidad de extracciones en la cara dorsal (Tabla 7.62 y 7.63 ) notamos que el índice de corteza mayor se registra en la cantera APE-C, donde son abundantes los descartes correspondientes a las primeras etapas de formatización. Asimismo, la estadística descriptiva de la densidad de extracciones previas en la cara dorsal de los desechos en APE-C registra los valores de media bajos $\left(x=1,14 \mathrm{e} / \mathrm{mm}^{2}\right)$, así como las primeras etapas de reducción. Esto último evidenciado por los valores de reducción (Tabla 7.61). En APE-1, por su parte, se registran índices de corteza bajos sobre todo en rocas silíceas, lo que sugiere etapas finales de manufactura. Al calcular la intensidad de reducción de cada materia prima, la obsidiana es la que presenta el mayor índice de reducción (Tabla 7.63). Al comparar la densidad de extracciones en rocas silíceas y obsidiana a través del test $t$, se observan diferencias significativas $(t=1,98 ; p=0,04)$. De modo que los tres indicadores de reducción (reserva de corteza en la cara dorsal, índice de corteza y densidad de lascados), sugieren los últimos estadios de reducción en APE-1, siendo la obsidiana la materia prima más intensamente utilizada. Por su parte, en la 
fuente APE-C son frecuentes los desechos correspondientes a las primeras etapas de reducción, tales como desechos con corteza (63\%), índices de corteza altos e índice de reducción bajo.

\begin{tabular}{|c|c|c|c|c|c|}
\hline Sitio & MP & N & LPR & LSEC & Índice Corteza \\
\hline \multirow{2}{*}{ APE-1 } & OBS & 24 & 1 & - & 0,041 \\
\cline { 2 - 6 } & SIL & 216 & 3 & 5 & 0,037 \\
\hline \multirow{2}{*}{ Subtotal Estratigrafía } & 240 & 4 & 5 & 0,037 \\
\hline \multirow{2}{*}{ APE-C } & BAS & - & - & - & - \\
\cline { 2 - 6 } & SIL & 780 & 68 & 85 & 0,196 \\
\hline \multicolumn{2}{|c|}{ Subtotal Superficial } & 780 & 68 & 85 & 0,195 \\
\hline
\end{tabular}

Tabla 7.62. Frecuencia de lascas primarias y secundarias enteras por materia prima en APE. Nota: MP: materia prima; $N$ : número total de desechos de talla enteros; LPR: lasca primaria; LSEC: lasca secundaria.

\begin{tabular}{|c|c|c|c|c|c|c|c|c|c|}
\hline & Sitio & MP & N & Media & Mediana & $\begin{array}{c}\text { Desvío } \\
\text { Estándar }\end{array}$ & Mínimo & Máximo & Rango \\
\hline \multirow{2}{*}{ Estratigrafía } & \multirow{2}{*}{ APE-1 } & OBS & 33 & 7,9 & 6,7 & 7,18 & 0,4 & 34,48 & 34,08 \\
\cline { 3 - 9 } & & SIL & 351 & 6,05 & 5,34 & 5,16 & 0,01 & 33,44 & 33,43 \\
\hline Superficial & APE-C & SIL & 894 & 1,14 & 0,65 & 0,65 & 0,001 & 10,82 & 10,82 \\
\hline
\end{tabular}

Tabla 7.63. Estadística descriptiva de la densidad de extracciones previas en la cara dorsal de los desechos de talla en APE.

En APE se llevaron a cabo estudios geoquímicos sobre obsidiana y petrográficos sobre rocas silíceas (Anexo 1). Se seleccionaron cinco muestras de los filones expuestos en los sectores de muestreo, lo que permitió determinar la coexistencia en la cantera de rocas silíceas de origen hidrotermal (muestras APE/1 y APE/2) y diagenético (muestras $\mathrm{APE} / 3, \mathrm{APE} / 4$ y $\mathrm{APE} / 5)$. De los estudios geoquímicos sobre artefactos de obsidiana mencionados en este capítulo, dos corresponden a desechos de talla; uno con una señal química asimilable a la de Cerro Huenul y el otro a la de Laguna El Maule (Capítulo 8). 


\subsection{2b.2 NÚCLEOS}

Los núcleos recuperados en APE suman un total de 64 y representan el $4,1 \%$ de muestra del sitio. La única materia prima representada es la roca silícea. Se ha registrado asimismo basalto, pero como nódulos sin modificar. En el sitio APE-1 se registró el 9,8\% $(n=7)$ de los núcleos, mientras que el 90,2\% ( $n=64)$ restante proviene de la cantera APE-C. En la tabla 7.64 se detallan los tipos identificados. La forma base es nodular en el $84 \%$ de los casos y lasca no diferenciada en el $16 \%$ restante. La mayor variedad de tipos se observa en la cantera APE-C, donde predomina el tipo de lascados aislados (55\%). Si bien APE-1 presenta menor variedad de tipos de núcleos, los más frecuentes son los bifaciales (Figura 7.48 y 7.49). Esta morfología de núcleo se considera versátil y es generalmente seleccionada para el transporte de materia prima, por su potencial para la extracción de lascas de filo y/o forma base de artefactos bifaciales, tales como puntas de proyectil y cuchillos, entre otros (Kelly 1988). El tamaño de los núcleos enteros es grandísimo (módulo 7, rango >161 mm) en todos los casos; en su mayoría son muy espesos $(87,3 \%$ ) y, en menor proporción, espesos (12,7\%). El 63,4\% (n=45) de los núcleos no están agotados y presentan una densidad de extracciones general de $\mathrm{x}=3,26 \mathrm{e} / \mathrm{mm}^{3}$. Entre los núcleos agotados $(36,6 \%, n=26)$, el $96 \%$ corresponden a la cantera APE-C y sólo el $4 \%$ al sitio APE1. En cuanto al estado de fragmentación, el $7 \%(n=5)$ se encuentra fragmentado y proceden en su mayoría de la cantera APE-C $(60 \%, n=3)$. Con respecto a la densidad de extracciones en los sitios, encontramos que el índice mayor se registra en APE-C $(x=3,30$ e/ $\mathrm{mm}^{3}$ ) con un peso promedio de $56,55 \mathrm{gr}$, mientras que en APE-1 se registra un valor de índice $\left(x=2,9 \mathrm{e} / \mathrm{mm}^{3}\right)$ y peso promedio menor, 50,44 gr. Sin embargo si comparamos el grado de reducción de los núcleos por medio del test $t$, la diferencia no resulta significativa $(t=0,28 ; p=0,77) y$, por lo tanto, la materia prima habría sido reducida en grado similar en ambos sitios. La calidad de la materia prima para la talla presenta valores similares, dado que predominan los núcleos de calidad regular (57\%) a buena (43\%) en ambos sitios. 


\begin{tabular}{|c|c|c|c|c|c|c|c|c|c|c|}
\hline \multicolumn{2}{|c|}{ Sitio } & MP & Amorfo & Bifacial & Bipolar & Discoidal & Lascados & Piramidal & Poliédrico & Total \\
\hline 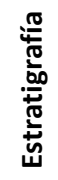 & $\begin{array}{c}\text { APE } \\
-1\end{array}$ & SIL & - & $5(71 \%)$ & - & - & 1 (14\%) & 1 (14\%) & - & $7(100 \%)$ \\
\hline $\begin{array}{l}\overline{\frac{\pi}{U}} \\
\frac{0}{\frac{1}{0}} \\
\frac{0}{3}\end{array}$ & $\begin{array}{l}\text { APE } \\
-C\end{array}$ & SIL & $3(5 \%)$ & - & $\begin{array}{c}10 \\
(16 \%)\end{array}$ & $1(2 \%)$ & 35 (55\%) & $11(17 \%)$ & $4(6 \%)$ & $\begin{array}{c}64 \\
(100 \%)\end{array}$ \\
\hline \multicolumn{3}{|c|}{ Total } & $3(4 \%)$ & $5(7 \%)$ & $\begin{array}{c}10 \\
(14 \%)\end{array}$ & $1(1 \%)$ & 36 (51\%) & $12(17 \%)$ & $4(6 \%)$ & $\begin{array}{c}71 \\
(100 \%)\end{array}$ \\
\hline
\end{tabular}

Tabla 7.64. Tipos morfológicos de núcleos identificados en APE.

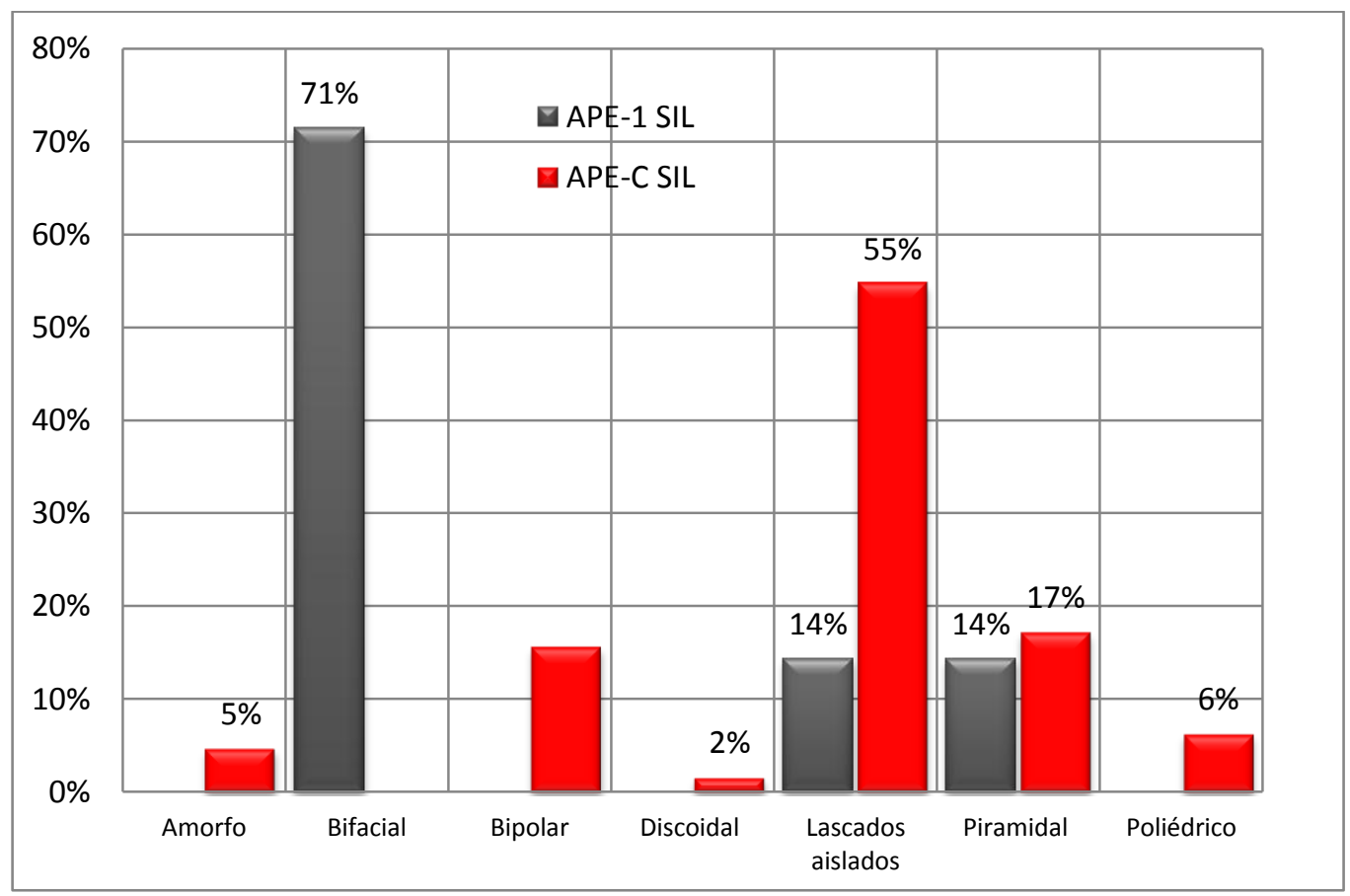

Figura 7.48. Frecuencia de tipos de núcleos identificados en rocas silíceas en los sitios APE-1 y APE-

C. 


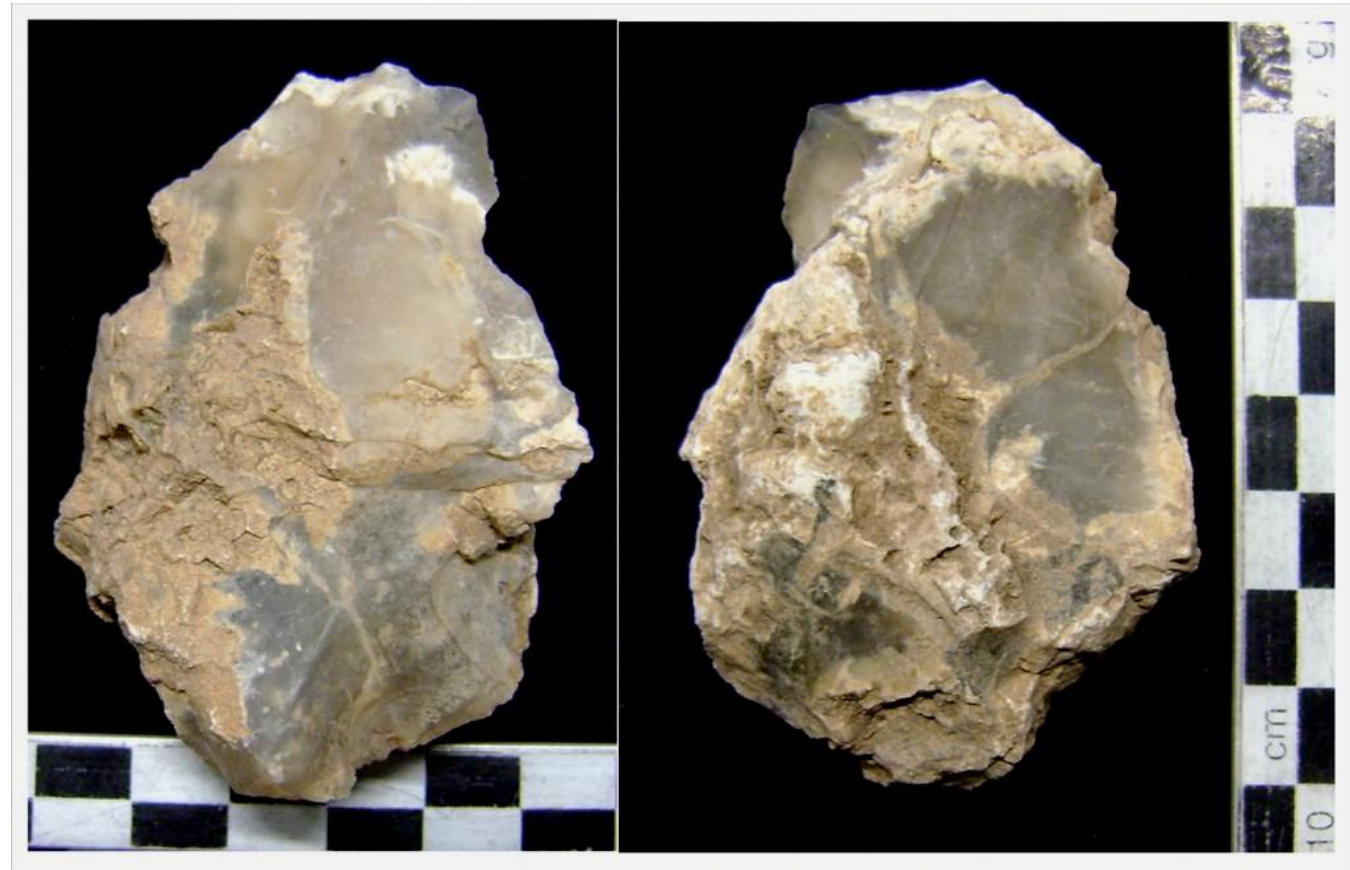

Figura 7.49. Núcleo bifacial de roca silícea recuperado en APE-C.

En la relación entre las medidas de largo y ancho de los negativos de lascados previos medidos en los núcleos y las mismas variables en desechos de talla e instrumentos enteros (Tabla 7.64), se observa que el valor medio de ambas variables en los instrumentos es mayor al observado en núcleos y en desechos de talla. Si analizamos los valores máximos y mínimos notamos que los negativos de núcleos son más largos que anchos, a la inversa que en desechos de talla. En el sitio cantera APE-C, por su parte el valor medio de los negativos de lascados en núcleos es más largo que ancho (Largo $x=$ 24,374; Ancho $x=20,584$ ) pero no alcanza al valor medio observado en instrumentos. Los negativos de lascado en núcleos de APE-1 son más anchos que largos (Largo $\mathrm{x}=19,828$; Ancho $x=20,85$ ). En las figuras $7.50 a$, b y c se observa esta relación preponderante entre las variables de tamaño, cuya elipse encierra el $95 \%$ de los casos. Se destaca la relación lineal positiva entre los negativos de lascado de núcleos (Figura 7.50a) y desechos de talla (Figura 7.50b). En instrumentos no se observa relación (Figura 7.50c). Al vincular las medidas de tamaño de las clases artefactuales (Figura 7.50d), se destaca el tamaño mayor de los instrumentos en relación a los negativos de lascado de los núcleos descartados. Se 
realizó una prueba $t$ para dos muestras, con el objeto de determinar la magnitud de esta diferencia. Se obtuvo como resultado una diferencia significativa $(t=4,5 ; p=0,045)$, que rechaza la hipótesis nula que valida el carácter aleatorio de las diferencias observadas. En este marco se evalúa la posibilidad del uso de formas base nodular para la formatización de instrumentos. Para ello analizamos el tamaño medio de los núcleos enteros en la cantera APE-C (Largo x= 39,8; Ancho x= 43,5; Peso x=26) y en el sitio APE-1 (Largo x=39,5; Ancho $x=42,2$; Peso $x=39,2$ ), sumando la variable peso para discriminar diferencias de tamaño. A partir de esto se observa que los valores son mayores en APE-1 y que en ambos casos los tamaños sobrepasan el de los instrumentos, admitiendo su formatización a partir de esta forma base. Por lo tanto puede plantearse el uso de formas base nucleiforme o nodular para la formatización de instrumentos y el descarte de núcleos que no admitían la obtención de lascas de gran tamaño o admitían su uso como forma base.

\begin{tabular}{|c|c|c|c|c|c|c|}
\hline & \multicolumn{2}{|c|}{ Desechos de Talla } & \multicolumn{2}{c|}{ Instrumentos } & \multicolumn{2}{c|}{ Negativo Núcleos } \\
\hline & Largo mm & Ancho $\mathbf{m m}$ & Largo $\mathbf{m m}$ & Ancho $\mathbf{m m}$ & Largo mm & Ancho $\mathrm{mm}$ \\
\hline $\mathbf{N}$ & 1020 & 1020 & 14 & 14 & 132 & 132 \\
\hline Media & 15,0427 & 13,9291 & 29,6357 & 29,6929 & 23,8926 & 20,6129 \\
\hline Desvío Estándar & 9,76051 & 9,28354 & 9,5009 & 4,07779 & 14,38 & 12,1832 \\
\hline Mediana & 12,2 & 11,3 & 30,45 & 29 & 20,35 & 17,55 \\
\hline Mínimo & 2 & 2,4 & 15,2 & 23 & 6,6 & 6,1 \\
\hline Máximo & 62 & 64,4 & 43,8 & 36,8 & 107,4 & 91,7 \\
\hline
\end{tabular}

Tabla 7.64. Estadística descriptiva de las variables largo y ancho en desechos de talla e instrumentos enteros y su relación con los negativos de lascado en núcleos en APE. 

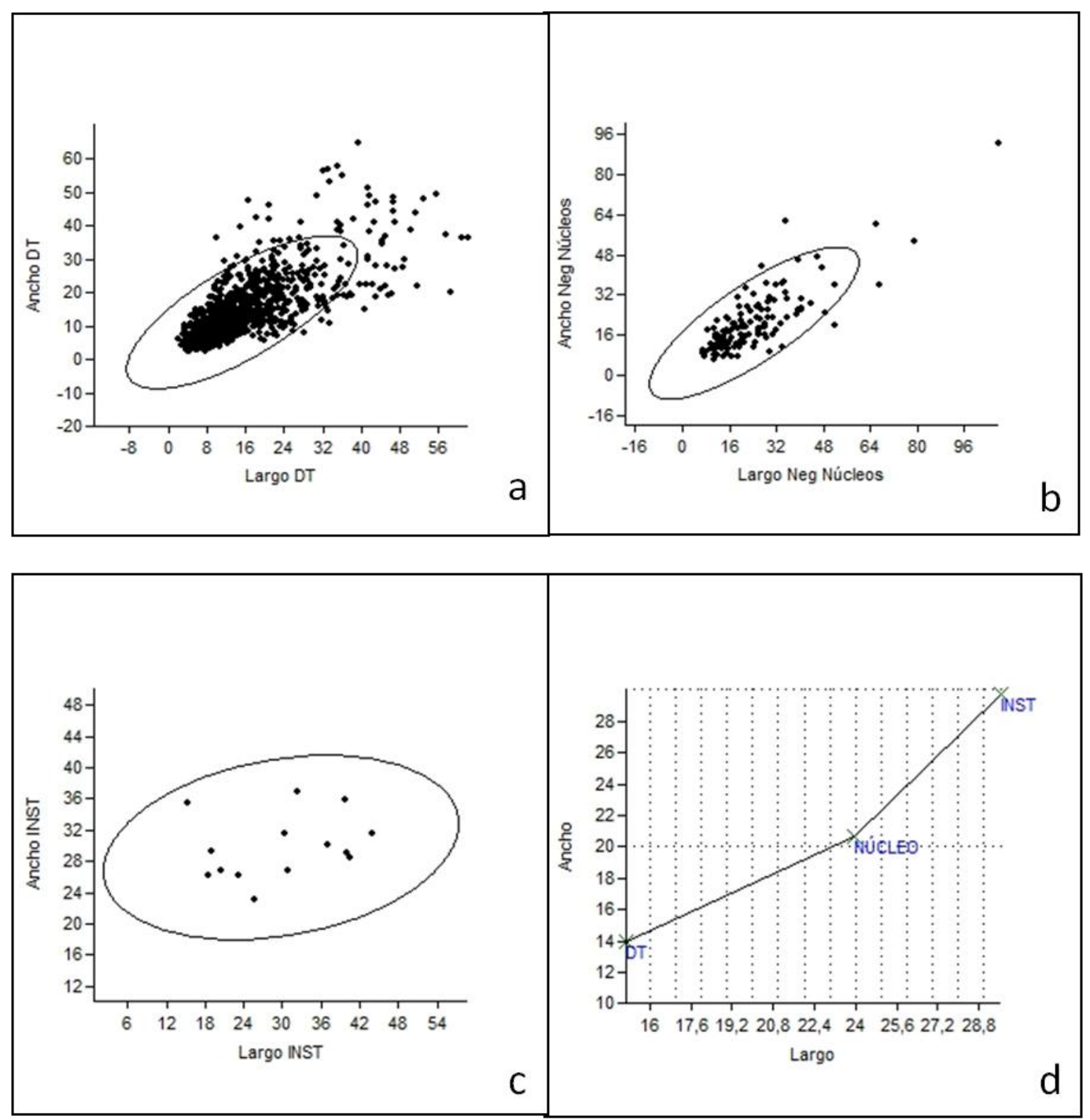

Figura 7.50. Tamaños de negativos de lascado en núcleos respecto a clases artefactuales en APE. Referencias: $\boldsymbol{a}$ : relación entre largo y ancho en desechos de talla; $\boldsymbol{b}$ : relación entre largo y ancho en negativos de lascados de núcleos; c: relación entre largo y ancho en instrumentos; $\boldsymbol{d}$ : relación entre valores medios relativos de largo y ancho en clases artefactuales y negativos de lascado en núcleos.

\subsection{2b.3 INSTRUMENTOS}

Los instrumentos recuperados en APE representan el $14 \%(n=24)$ del total de artefactos de la localidad (Tabla 7.59). El 54\% corresponde al sitio estratigráfico APE-1, seguido por el $46 \%$ de la cantera APE-C. La materia prima seleccionadas para la formatización de instrumentos es la roca silícea en el $87 \%(n=21)$ de los casos y en menor 
medida la obsidiana, con el $13 \%(n=3)$. La tabla 7.65 muestra las frecuencias de instrumentos según el tipo de formatización y/o presencia de rastros complementarios, materia prima y muestreo. Los artefactos sin formatización con rastros complementarios enteros son los más representados, seguidos por los artefactos bifaciales, en su mayoría fracturados (Tabla 7.66), y por artefactos de formatización unifacial enteros. Si exploramos la diversidad de materias primas en los instrumentos (Tabla 7.67), se observa que el índice de diversidad más alto se encuentra en los artefactos bifaciales (Shannon-H: 0,63), con dominancia nula. Sigue en diversidad los artefactos con rastros complementarios (Shannon-H: 0,3) y valor de dominancia alto, dado que el $90 \%$ de los mismos están confeccionados en roca silícea y el $10 \%$ restante a obsidiana. En artefactos unifaciales el valor de diversidad es nulo y predomina el uso de roca silícea.

\begin{tabular}{|c|c|c|c|c|c|}
\hline Muestreo & MP & AF Bifacial & AF Unifacial & ASF RC & Total \\
\hline & OBS & $3(100 \%)$ & - & - & 3 \\
\hline APE-1 & SIL & $2(20 \%)$ & $5(50 \%)$ & $3(30 \%)$ & 10 \\
\hline APE-C & SIL & $4(36 \%)$ & - & $7(64 \%)$ & 11 \\
\hline \multicolumn{2}{|c|}{ Total } & $9(38 \%)$ & $5(21 \%)$ & $10(42 \%)$ & 24 \\
\hline
\end{tabular}

Tabla 7.65. Frecuencia de artefactos formatizados y con rastros complementarios en APE. Entre paréntesis se detalla la proporción de tipo de artefactos por materia prima.

\begin{tabular}{|c|c|c|c|c|c|c|}
\hline \multirow{2}{*}{ Muestreo } & \multirow{2}{*}{ MP } & \multicolumn{2}{c|}{ AF Bifacial } & AF Unifacial & \multicolumn{2}{c|}{ ASF RC } \\
\cline { 3 - 8 } & & Entero & Fracturado & Entero & Entero & Fracturado \\
\hline \multirow{2}{*}{ APE-1 } & OBS & - & 3 & - & - & - \\
\hline APE-C & SIL & 1 & 1 & 5 & 3 & 3 \\
\hline \multicolumn{2}{r|}{ Total } & $2(23 \%)$ & $7(77 \%)$ & $5(100 \%)$ & $7(73 \%)$ & $3(27 \%)$ \\
\hline
\end{tabular}

Tabla 7.66 Estado de fragmentación en instrumentos en APE. 


\begin{tabular}{|c|c|c|c|}
\hline & AF Bifacial & AF Unifacial & ASF RC \\
\hline N materias primas & 2 & 1 & 2 \\
\hline $\mathbf{N}$ & 9 & 5 & 11 \\
\hline Dominancia & 0,55 & 1 & 0,83 \\
\hline Shannon-H & 0,63 & - & 0,3 \\
\hline Simpson & 0,44 & - & 0,16 \\
\hline
\end{tabular}

Tabla 7.67. Diversidad de materias primas según clases artefactuales en APE.

La manufactura de los instrumentos se realizó en la mayoría de los casos sobre lascas (84\%) y, en menor medida, sobre nódulos (16\%). Predominan las materias primas de buena calidad en roca silícea y excelente en obsidiana. En la figura 7.51 se observa una mayor variedad de tipos manufacturados en roca silícea, mientras que en obsidiana el grupo tipológico más representado es el de puntas de proyectil. Entre los artefactos confeccionados en sílice el $47 \%(n=10)$ proviene de APE-1 y están enteros en un $90 \%$. En este sitio los grupos tipológicos más representado son los filos naturales con rastros complementarios $(43 \%, n=3)$, las lascas de retoque unifacial $(43 \%, n=3)$ y, en menor frecuencia, los raspadores $(14 \%, n=1)$. La única pieza silícea fragmentada corresponde a un artefacto bifacial no diferenciado. En obsidiana el $100 \%(n=3)$ fue descartado fracturado y pertenece al grupo tipológico de las puntas de proyectil. En la cantera APE-C, todos los artefactos están manufacturados sobre roca silícea (Tabla 7.66) y el 60\% se encuentra fracturado. Los grupos tipológicos representados en la cantera corresponden en un $64 \%(n=7)$ a artefactos con rastros complementarios y por los bifaces en el $36 \%$. En la tabla 7.68, se muestra la relación entre los desechos de talla enteros y el número total de instrumentos, por tipo de muestreo y materia prima. Los valores más bajos se registran en obsidiana y rocas silíceas del sitio APE-1. De modo que los eventos de formatización se encuentran mayormente representados en el sitio estratigráfico. El área Payún Sur presenta un índice alto $(0,5)$, aunque debe considerarse con cautela porque solo se analizaron los artefactos de obsidiana. 


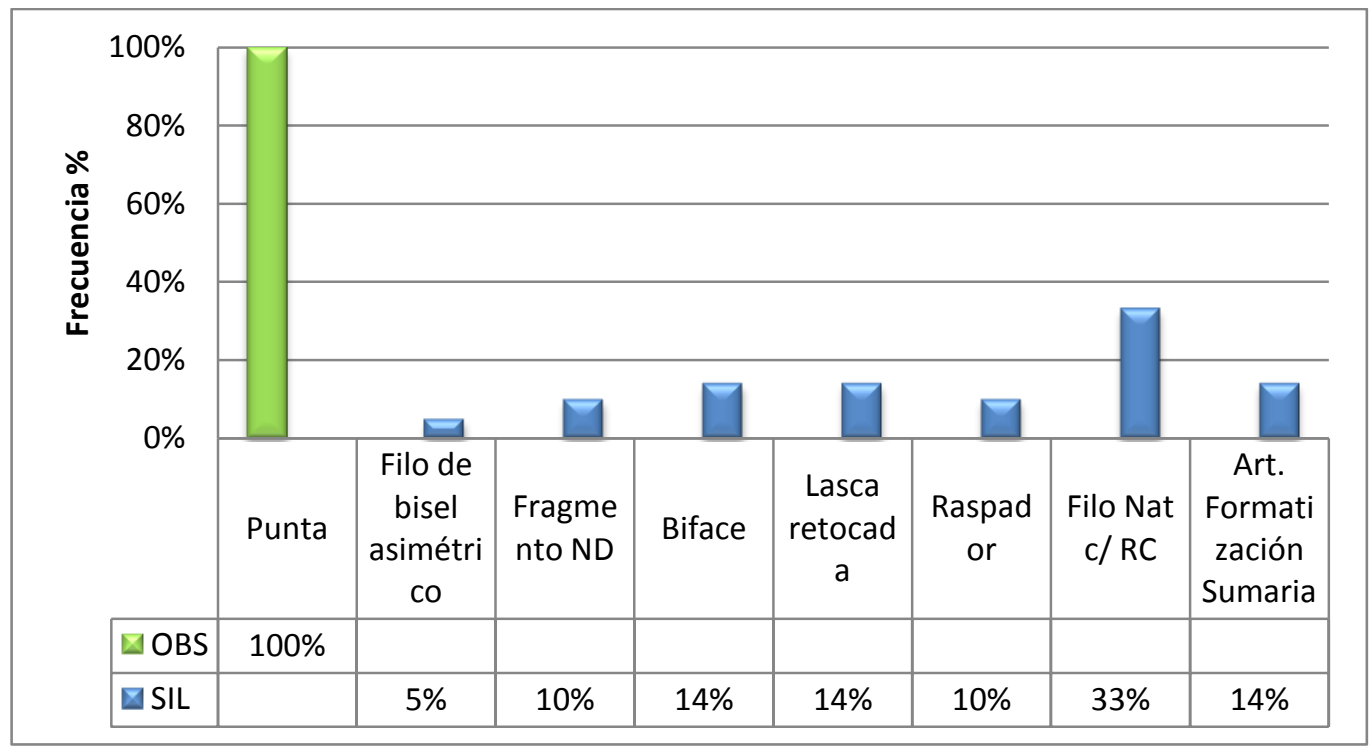

Figura 7.51. Grupos tipológicos representados en instrumentos en APE.

\begin{tabular}{|c|c|c|}
\hline Muestreo & OBS & SIL \\
\hline APE-1 & 8 & 21,6 \\
\hline APE-C & - & 70,9 \\
\hline
\end{tabular}

Tabla 7.68. Relación entre desechos de talla enteros y instrumentos (DT/INST) según materia prima en APE.

Las puntas de proyectil registradas en la localidad $(n=3)$ proceden todas del sitio APE-1, están fracturadas y fueron manufacturadas sobre obsidiana. Proceden del nivel de excavación 3, en el cual el $88 \%$ de los artefactos es de obsidiana. Se registra un fragmento apical y dos basales (Figura 7.51). Los fragmentos basales no presentan diferencias de tamaño y peso $(0,2 \mathrm{gr})$, poseen sección transversal biconvexa, base escotada adelgazada por acanaladura, tamaño mediano pequeño y poco espeso. Los artefactos de formatización unifacial están trabajados en roca silícea y corresponden en un $60 \%(n=2)$ a lascas de filo retocado frontal y lateral corto, y en un $40 \%$ a raspadores. Todas las piezas fueron descartadas enteras, son de tamaño grandísimo y modulo espeso. Uno de los raspadores presenta filos convergentes y pesa 3,3 gr., y el otro tiene filo fronto-lateral y pesa $4,4 \mathrm{gr}$. 
La clase artefactual ASF RC es la más representada en la localidad. Están trabajados todos sobre roca silícea; las formas base son lascas no diferenciadas espesas $(73 \%, n=7)$, lascas angulares delgadas $(18 \%, n=2)$ y una pieza sobre lasca bipolar muy espesa (9\%, $\mathrm{n}=1)$. El tamaño en todos los artefactos es grande. Poseen filo lateral restringido $(n=8)$ y perimetral restringido $(n=2)$. La mayoría de las piezas presenta filo simple marginal $(73 \%)$ y en menor proporción presentan filos múltiples parcialmente extendidos (27\%).

\subsubsection{CONSIDERACIONES GENERALES DE LA LOCALIDAD APE}

La roca silícea y la obsidiana son las materias primas utilizadas para la manufactura de artefactos en la localidad. El sitio APE-1 es el que presenta mayor diversidad de rocas. En los artefactos confeccionados en roca silícea las calidades para la talla preponderantes son la buena (36\%) y la regular (37\%), tendencia que se mantiene en los instrumentos a pesar de registrar desechos de talla de calidad muy buena $(9 \%)$ y excelente $(0,2 \%)$. En obsidiana la calidad para la talla es excelente (73\%), muy buena $(22 \%)$ y buena (5\%). Los mayores índices de fragmentación se registran en roca silícea y, en menor medida, obsidiana en APE-1; los más bajos provienen de la cantera APE-C.

En rocas silíceas se registra la mayor riqueza y variabilidad artefactual, siendo más marcado en APE-1. Asimismo, en este último se encuentran representadas todas las etapas de reducción en roca silícea aunque prevalecen las etapas finales, alta frecuencia de desechos de reactivación y formatización de filos, así como valores altos de intensidad de uso en desechos. En la cantera APE-C prevalecen las primeras etapas de formatización, sin embargo han sido descartados instrumentos de formatización bifacial, en su mayoría fracturados, y altas frecuencias de artefactos con rastros complementarios tanto enteros como fracturados. Se destaca la alta variabilidad de tipos morfológicos en núcleos aunque la frecuencia más elevada corresponde a los de lascados aislados. En APE-1 los núcleos

corresponden en su mayoría al tipo bifacial, con tamaño de negativos de lascados menores al de los instrumentos. Esto podría indicar que la formatización de los mismos se 
realizaba preferentemente a partir de formas bifaciales. Lo antes expuesto daría cuenta de la baja frecuencia de núcleos en los sitios y el alto porcentaje de núcleos bifaciales en APE-1.

Entre los instrumentos se destaca la presencia de puntas de proyectil, confeccionadas exclusivamente en obsidiana. En rocas silíceas hay una alta variedad de tipos morfológicos, entre los que se destacan los filos con rastros complementarios, los bifaces y raspadores. La presencia de fragmentos basales de puntas de proyectil y un fragmento apical, puede responder a que en APE-1 se hayan llevado a cabo tareas de remplazo de puntas en astiles y la formatización de los cabezales. Esto último apoyado por la presencia casi exclusiva de desechos de talla y valores altos en la relación instrumentos y productos de talla. Por su parte en rocas silíceas se observa escasa inversión de trabajo en la manufactura de instrumentos, el uso frecuente de filos activos y su descarte con escasa reactivación. 


\subsection{LOCALIDAD CARMONINA (CAR)}

La Localidad Arqueológica Carmonina (en adelante CAR) se encuentra en el sector sur de La Payunia, en la margen izquierda del Cañadón Amarillo (Figura 7.52). La localidad no contaba con estudios sistemáticos previos y fue detectada en el marco de prospecciones superficiales entre los años 2005 y 2010, donde se detectaron los sitios incluidos en esta tesis: Carmonina-1 y Pista. Recientes investigaciones desarrolladas por el equipo del Museo de Historia Natural de San Rafael (MHNSR), permitieron localizar otras concentraciones o sitios arqueológicos y actualmente la localidad está compuesta por al menos siete sitios ubicados sobre ambas márgenes del cañadón (Neme et al. 2012b).

Desde el punto de vista geológico, CAR se encuentra en la Cuenca Neuquina, subcuenca Río Colorado (Narciso et al. 2001b). El suelo es principalmente arenoso-rocoso, constituido por rocas sedimentarias (areniscas, conglomerados y arcillitas) erosionadas y cubiertas en parte por clastos y bloques provenientes de la erosión de la Altiplanicie del Payén (Capítulo 3). Los trabajos de investigación han sido desarrollados en dos ambientes diferentes: pedimentos o superficies de erosión activa (Pista) y márgenes del arroyo seco que conforma el Cañadón Amarillo (Carmonina 1). Este cauce se encuentra limitado por paredones sub-verticales formados por areniscas rojas del Grupo Neuquén y depósitos coluviales-aluviales en el techo (Figura 7.53 y 7.54). En Pista se realizaron muestreos superficiales abarcando parte del área de disponibilidad de roca silícea. 


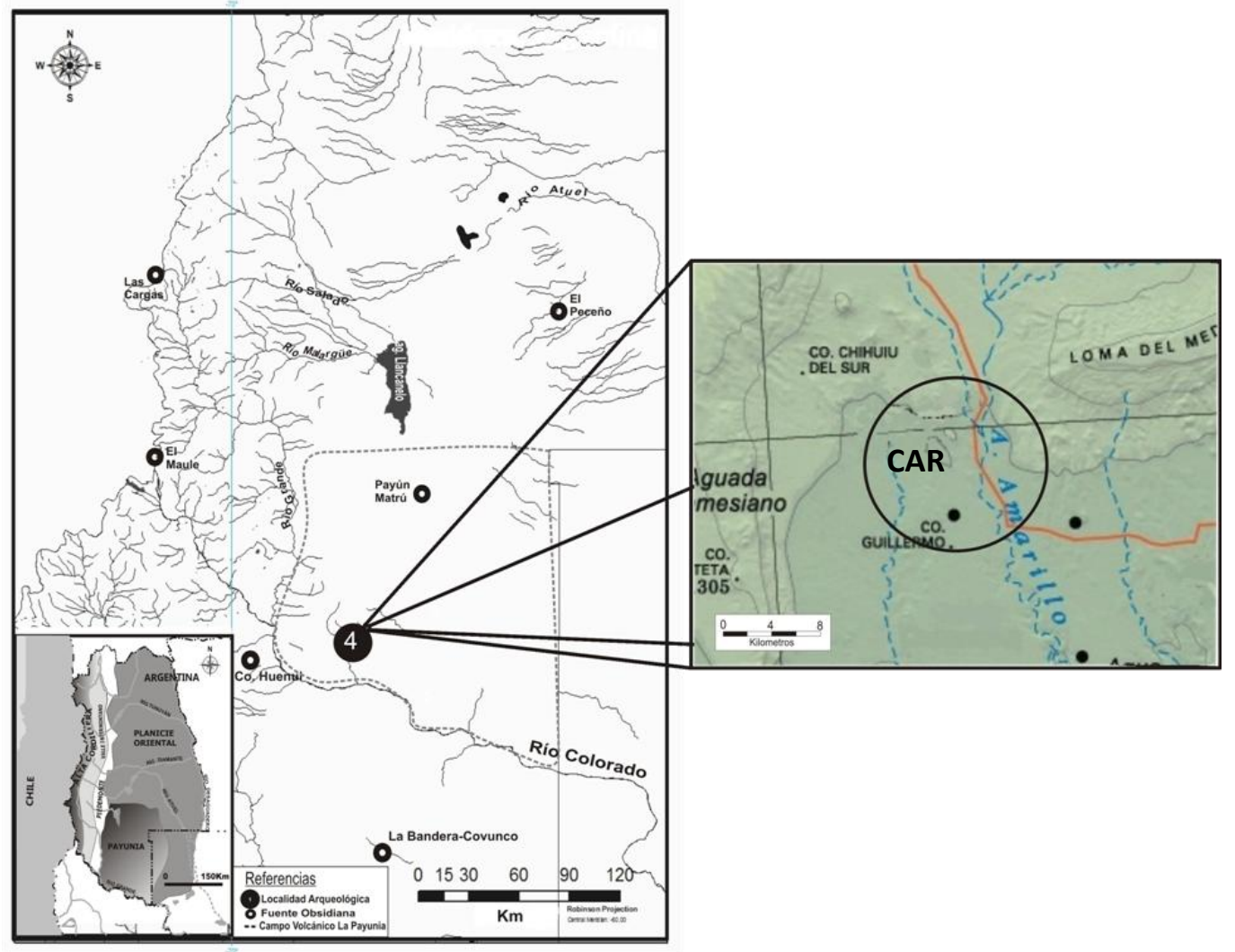

Figura 7.52. Ubicación de la Localidad Arqueológica Carmonina.

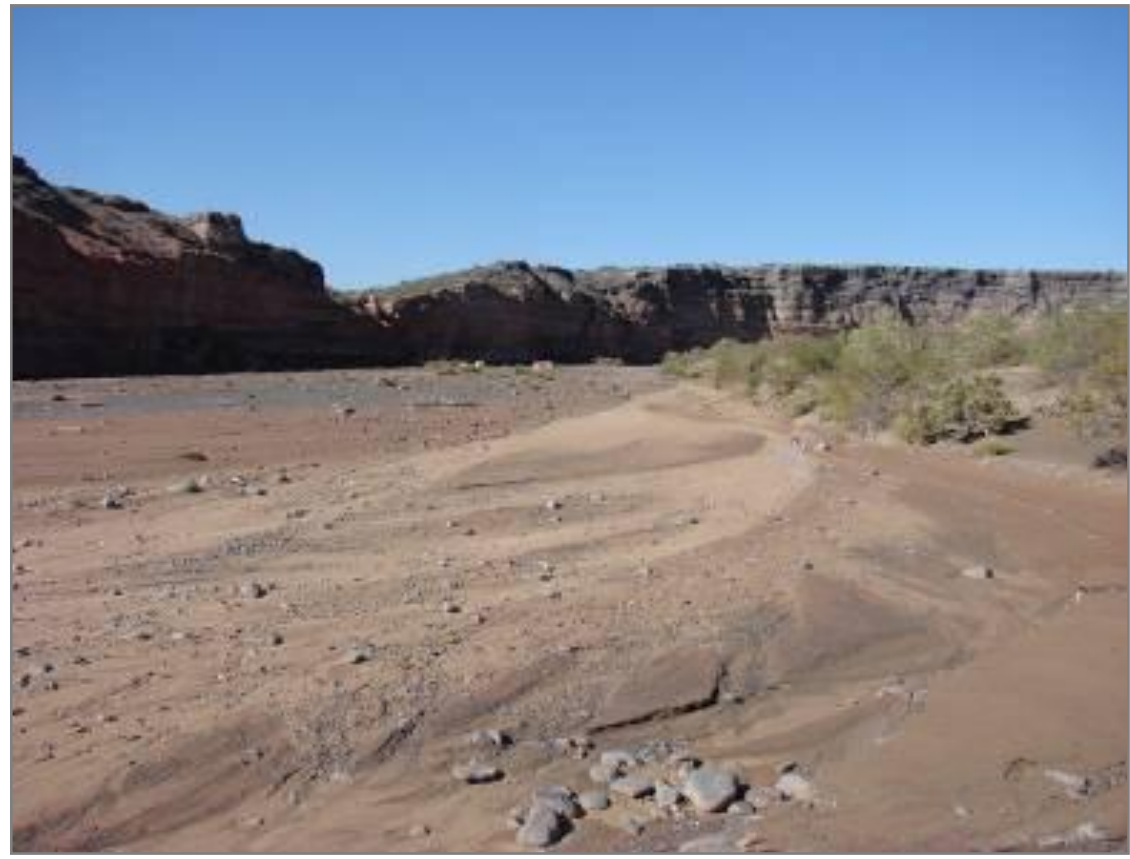

Figura 7.53. Cauce intermitente de Cañadón Amarillo. 


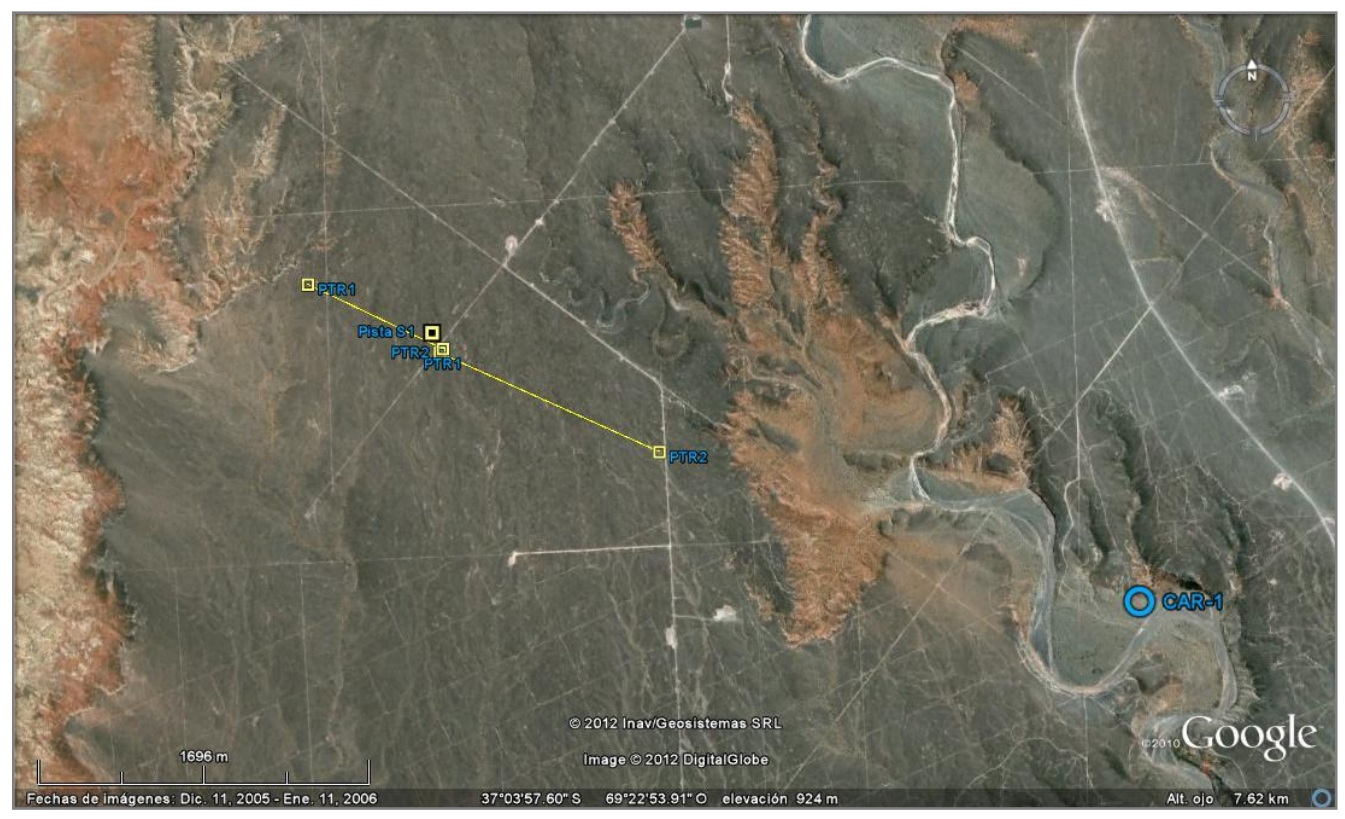

Figura 7.54. Sitios arqueológicos analizados en CAR. Nota: En tonos de gris se representan las diferencias de elevación del terreno. El circulo azul indica el sitio excavado CAR -1: Carmonina 1.: PTR1: Pista Transecta 1; y PTR2: Pista Transecta 2.Imagen tomada de Google Earth.

\subsection{1a CARMONINA 1 (CAR-1)}

Carmonina-1 (en adelante CAR-1) es un sitio estratigráfico a cielo abierto ubicado entre las coordenadas $37^{\circ} 4^{\prime} 32.91^{\prime \prime}$ L S y 69² 21' 19.09" L O, se encuentra en un área de médano, próximo a la vertiente natural homónima y en el margen izquierda del Cañadón Amarillo (Figura 7.54). El sitio CAR-1, fue identificado en el año 2005. En el sitio se realizó un sondeo de $50 \mathrm{~cm} \times 50 \mathrm{~cm}$ (S1), para evaluar la presencia de materiales en estratigrafía; se excavó por niveles artificiales de $10 \mathrm{~cm}$ hasta una profundidad de $70 \mathrm{~cm}$ (Figura 7.55), sin llegar a la roca base. Mediante el sondeo se recuperaron artefactos líticos, huesos y carbón. Sobre carbón del nivel 6 se obtuvo un fechado de $1398 \pm 39$ años AP (AA-66576).

En el S1 se recuperó un total de 304 artefactos líticos (Tabla 7.69). La tasa temporal de depositación de artefactos por año es de 0,869 artefactos por $\mathrm{m}^{2}$. Los artefactos son en su mayoría desechos de talla enteros $65,8 \%(n=200)$, seguidos por los fracturados $(33,8 \%$, 
$\mathrm{n}=103)$ e indeterminados $(0,4 \%, \mathrm{n}=1)$. La materia prima más representada es la roca silícea $(93,8 \%, n=285)$, seguida por la obsidiana $(5,3 \%, n=16)$, los basaltos $(0,7 \%, n=2)$ y las riolitas $(0,3 \%, n=1)$. En rocas silíceas la clase artefactual más frecuente es la de los desechos de talla $(98,5 \%, n=281)$, seguida por la de los artefactos de manufactura bifacial $(0,7 \%, n=2)$, artefactos unifaciales $(0,3 \%, n=1)$ y con rastros complementarios $(0,3 \%, n=1)$ (Figura 7.56). En obsidiana sólo se encuentra representados los desechos de talla (n=16). Del conjunto analizado se seleccionó una muestra para estudios de elementos traza, que señaló procedencia de Laguna El Maule. Sobre basaltos se recuperaron dos desechos de talla $y$, en el caso de las riolitas, un percutor fragmentado. Se observa un marcado aumento en la diversidad de rocas a partir del nivel 3 de excavación, mientras que en los niveles 4 a 7 sólo se encuentra representada la roca silícea (Tabla 7.70).

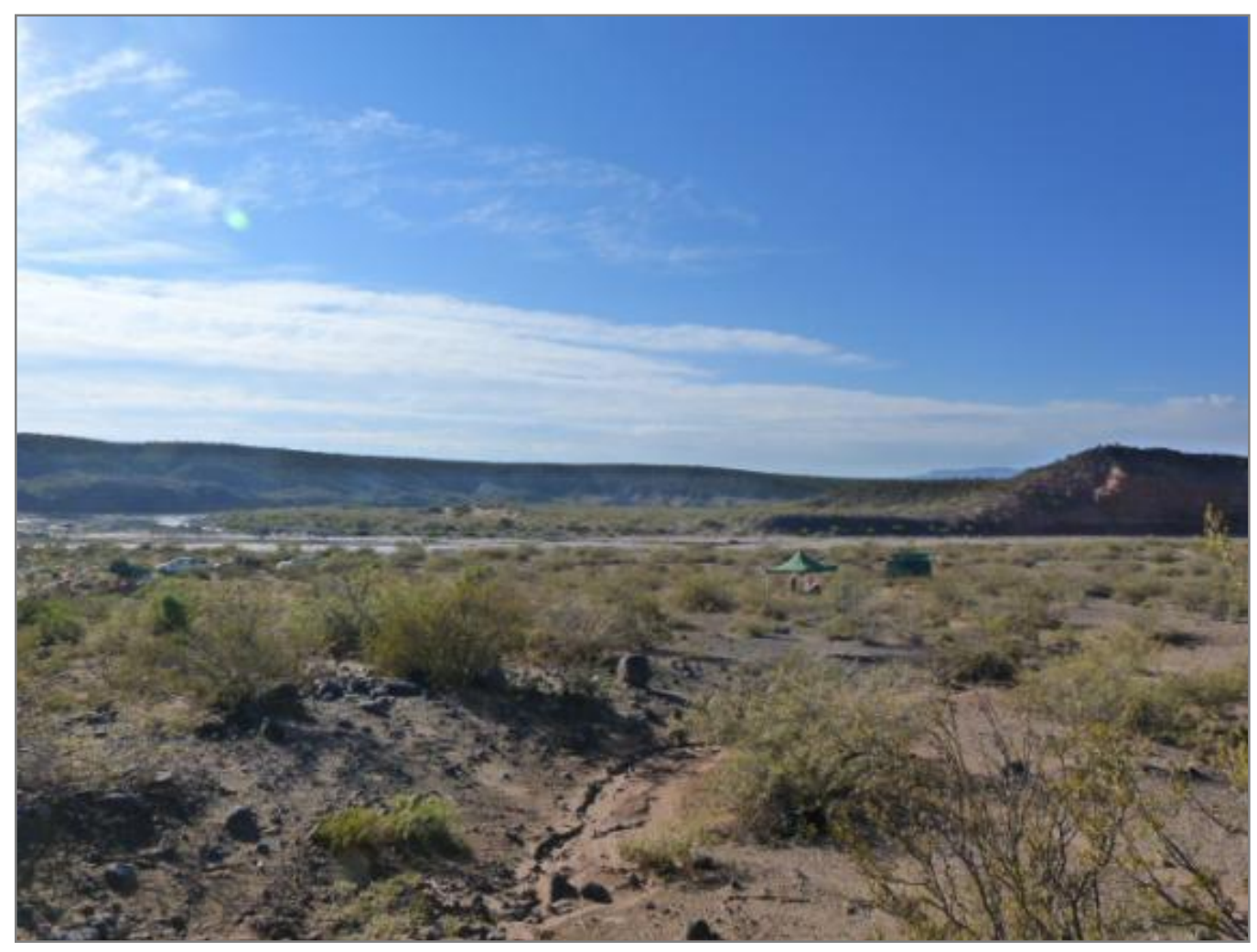

Figura 7.55 Sitio Carmonina 1. 


\begin{tabular}{|c|c|c|c|c|c|c|}
\hline \multirow{2}{*}{ Nivel } & \multicolumn{5}{|c|}{ Artefactos } & \multirow{2}{*}{ Total } \\
\hline & DT & Ecofacto & AF Bifacial & AF. Unifacial & ASF-RC & \\
\hline 0 & 13 & - & - & - & 1 & 14 \\
\hline 1 & 120 & 1 & 1 & 1 & - & 123 \\
\hline 2 & 32 & - & - & - & - & 32 \\
\hline 3 & 34 & - & - & - & - & 34 \\
\hline 4 & 15 & - & - & - & - & 15 \\
\hline 5 & 27 & - & 1 & - & - & 28 \\
\hline 6 & 28 & - & - & - & - & 28 \\
\hline 7 & 30 & - & - & - & - & 30 \\
\hline Total & 299 & 1 & 2 & 1 & 1 & 304 \\
\hline$\%$ & $98,4 \%$ & $0,3 \%$ & $0,7 \%$ & $0,3 \%$ & $0,3 \%$ & $100 \%$ \\
\hline
\end{tabular}

Tabla 7.69. Frecuencias de clases artefactuales recuperadas por nivel de excavación en el sitio CAR-

1.

\begin{tabular}{|c|c|c|c|c|c|}
\hline Nivel & BAS & OBS & RIO & SIL & Total \\
\hline 0 & - & $1(7,1 \%)$ & - & $13(92,9 \%)$ & $14(100 \%)$ \\
\hline 1 & $1(0,8 \%)$ & $8(6,5 \%)$ & $1(0,8 \%)$ & $113(91,9 \%)$ & $123(100 \%)$ \\
\hline 2 & $1(3,1 \%)$ & $5(15,6 \%)$ & - & $26(81,3 \%)$ & $32(100 \%)$ \\
\hline 3 & - & $2(5,9 \%)$ & - & $32(94,1 \%)$ & $34(100 \%)$ \\
\hline 4 & - & - & - & $15(100 \%)$ & $15(100 \%)$ \\
\hline 5 & - & - & - & $28(100 \%)$ & $28(100 \%)$ \\
\hline 6 & - & - & - & $28(100 \%)$ & $28(100 \%)$ \\
\hline 7 & $2(0,7 \%)$ & $16(5,3 \%)$ & $1(0,3 \%)$ & $285(93,8 \%)$ & $30(100 \%)$ \\
\hline Total & $-704(100 \%)$ \\
\hline
\end{tabular}

Tabla 7.70. Distribución y frecuencia de materias primas por nivel de excavación en CAR-1. 


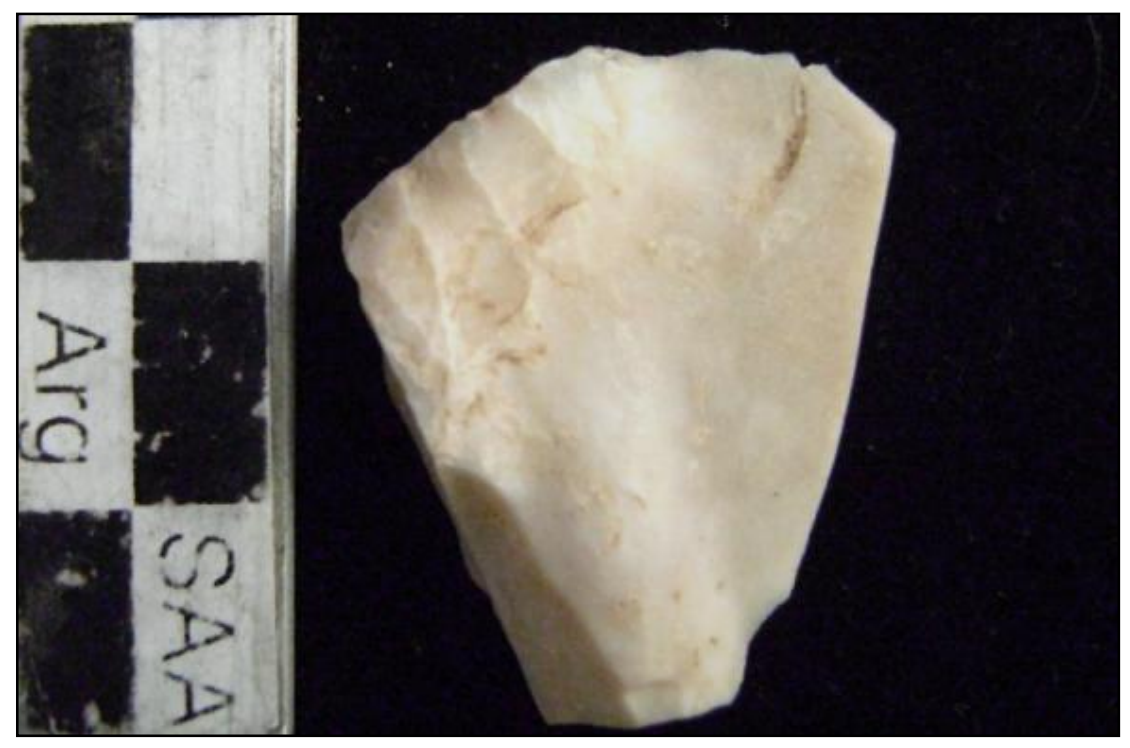

Figura 7.56. Artefactos sin formatización con rastros complementarios en roca silícea recuperado en CAR-1.

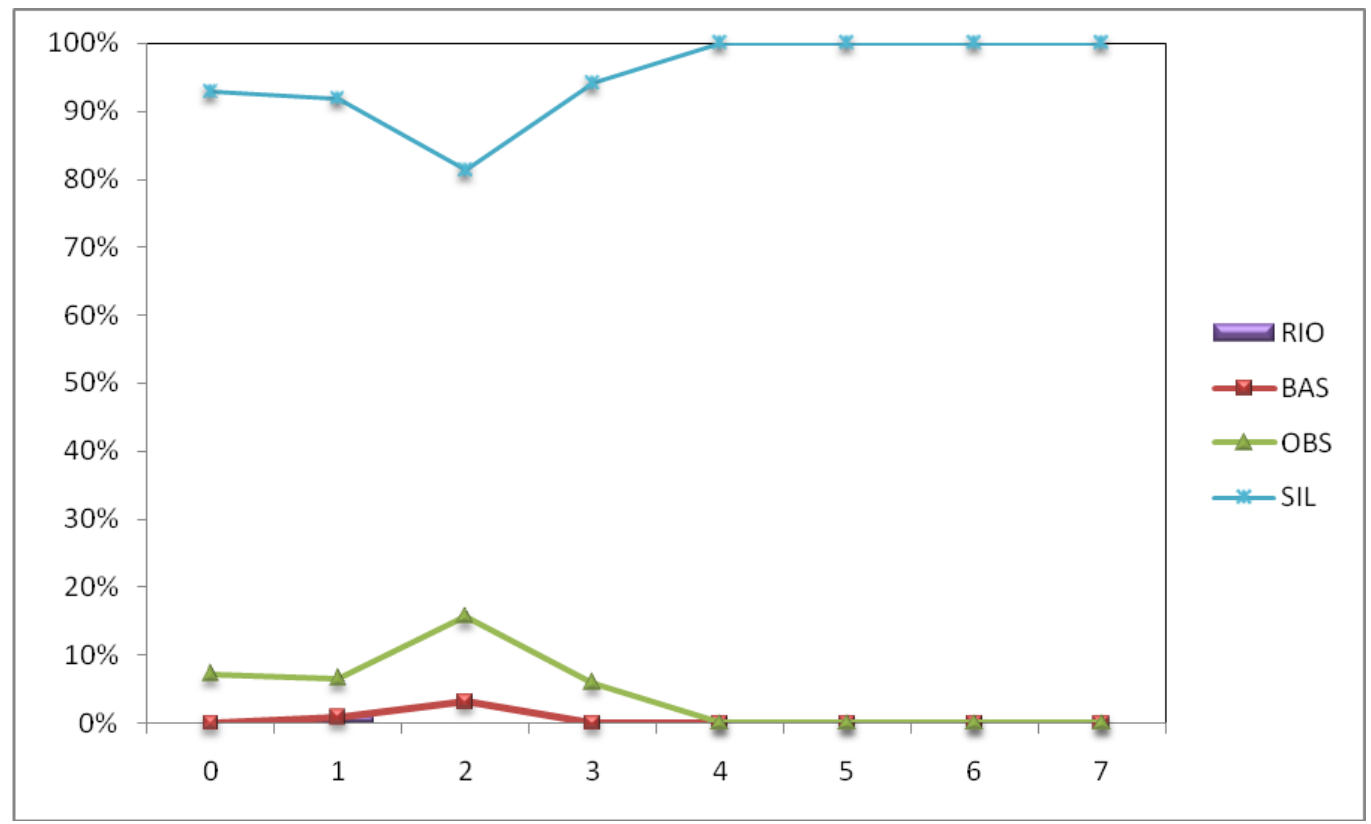

Figura 7.57. Frecuencia de materias primas por nivel de excavación en CAR-1.

\subsection{1b PISTA}


Pista es un sitio superficial ubicado en el pedimento de la sub-cuenca del Río Colorado. Se encuentra en un área relativamente llana y uniforme (Altitud: $1.700 \mathrm{msnm}$ ), de suelo rocoso-arenoso cubierto por clastos de basalto provenientes de la erosión de la Altiplanicie del Payún y con escasa cubierta vegetal (Figura 7.58). Entre los clastos aparecen nódulos de tamaño mediano a grande de rocas silíceas de origen diagenético, muchos con signos de canteo (Figura 7.59). En el sitio se realizaron dos transectas continuas de $1000 \mathrm{~m}$ de longitud y $8 \mathrm{~m}$ de ancho. El área prospectada abarca unos 16.000 $\mathrm{m}^{2}$ entre las coordenadas $37^{\circ} 03^{\prime} 33^{\prime \prime}$ L. S/69²4'7" L. O y $37^{\circ} 04^{\prime} 4^{\prime \prime}$ L. S/69²2'57' L. O (Figura 7.60). Se recolectaron todos los materiales $(n=392)$, registrando una densidad máxima de 0,023 artefactos por $\mathrm{m}^{2}$, con una riqueza artefactual de cinco. La transecta 1 (TR1) presenta una densidad máxima de 0,021 artefactos por $\mathrm{m}^{2}$, mientras que la 2 (TR2) posee un valor de densidad de 0,026 artefactos por $\mathrm{m}^{2}$. La única materia prima representada es la roca silícea.

Se destaca una alta frecuencia de instrumentos $(15,6 \%, n=58)$, entre los que predominan los artefactos con rastros complementarios $(7,7 \%, n=30)$, seguidos por los artefactos unifaciales $(5,6 \%, n=22)$ y bifaciales $(2 \%, n=8)$ (Tabla 7.71). Asimismo, se observaron evidencias de locus de eventos de talla donde están representadas las distintas etapas de manufactura. El tamaño de las lascas faltantes puede ser estimado como parámetro de tamaño de artefactos a ser transportado o seleccionado para uso y/o formatización (Figura 7.61).

Con el objeto de evaluar el potencial de enterramiento en las planicies de pedimento se realizó un sondeo de $50 \mathrm{~cm}$ x $50 \mathrm{~cm}\left(32^{\circ} 23^{\prime} 50^{\prime \prime}\right.$ LS y 6903'50') cerca de las líneas de transecta (PS1). Se excavaron dos niveles de $10 \mathrm{~cm}$ y no se observó material enterrado (Figura 7.62). La visibilidad en el sitio es muy buena (100\%) y la pendiente nula $(47 \%)$ a suave $(53 \%)$. 


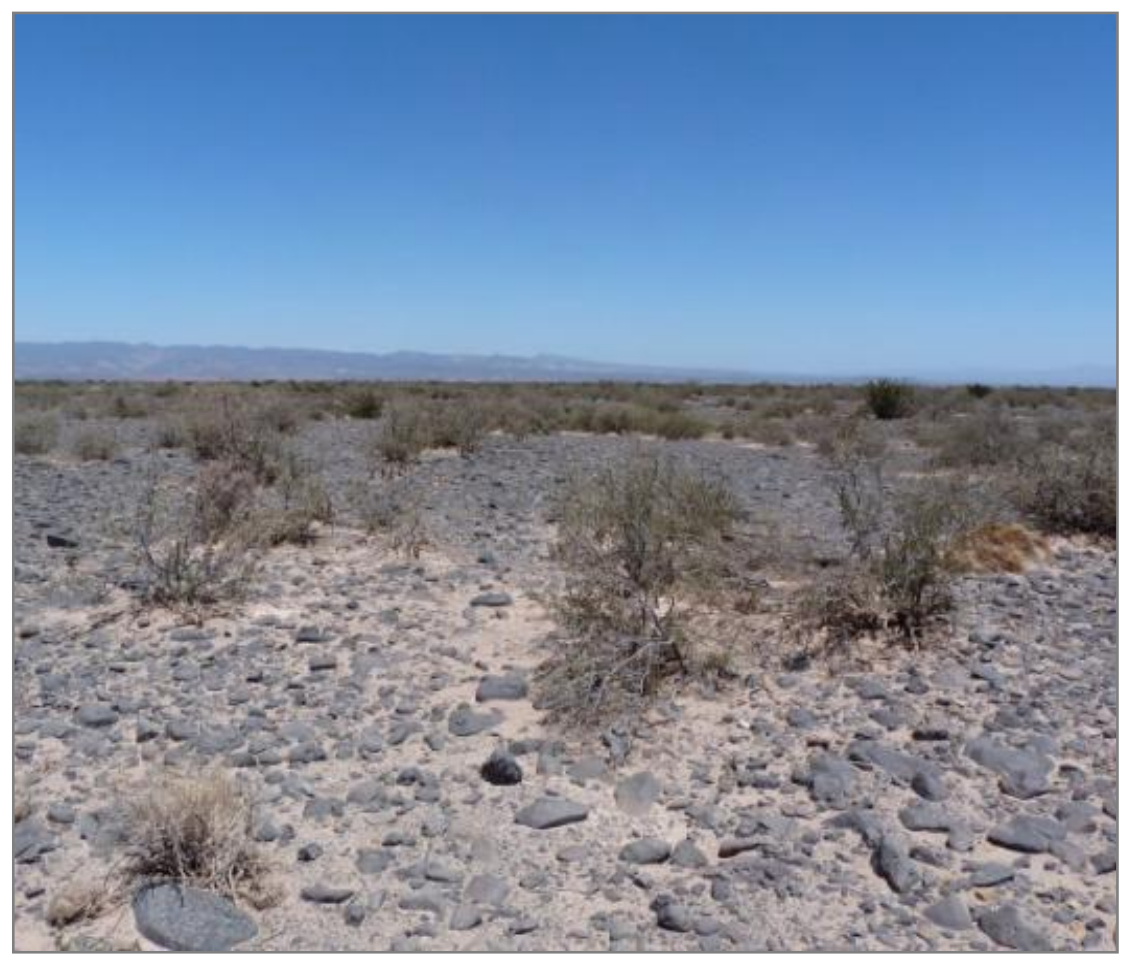

Figura 7.58. Vista del sitio Pista.

\begin{tabular}{|c|c|c|c|c|c|c|c|}
\hline \multirow{2}{*}{ Pista } & \multicolumn{6}{|c|}{ Artefactos } & \multirow{2}{*}{ Total } \\
\hline & DT & ND & Núcleo & AF Bifacial & AF Unifacial & ASF-RC. & \\
\hline FTRAN (Ev-talla) & 6 & - & 1 & - & - & - & 7 \\
\hline TR1-UN1 & 20 & 10 & 28 & - & - & 3 & 61 \\
\hline TR1-UN2 & 16 & 13 & 19 & 1 & 1 & 3 & 53 \\
\hline TR1-UN3 & - & - & - & - & - & - & - \\
\hline TR1-UN4 & 30 & 1 & 7 & 1 & - & 2 & 41 \\
\hline TR1-UN5 & 6 & - & 6 & - & 2 & 1 & 15 \\
\hline TR2-UN2 & 22 & - & & 2 & 4 & 10 & 38 \\
\hline TR2-UN3 & 40 & - & 1 & 2 & 9 & 6 & 58 \\
\hline TR2-UN4 & 20 & - & 24 & - & 5 & 4 & 53 \\
\hline TR2-UN5 & 23 & 3 & 21 & 2 & 1 & - & 50 \\
\hline TR2-UN6 & 1 & - & 12 & - & - & - & 13 \\
\hline TR2-UN7 & 1 & - & - & - & - & - & 1 \\
\hline TR2-UN8 & 1 & - & - & - & - & - & 1 \\
\hline TR2-UN9 & 1 & - & - & - & - & - & 1 \\
\hline Total & 187 & 27 & 118 & 7 & 22 & 29 & 392 \\
\hline$\%$ & $47,7 \%$ & $6,9 \%$ & $30,1 \%$ & $2 \%$ & $5,6 \%$ & $7,7 \%$ & $100 \%$ \\
\hline
\end{tabular}

Tabla 7.71. Clases artefactuales presentes en Pista. 


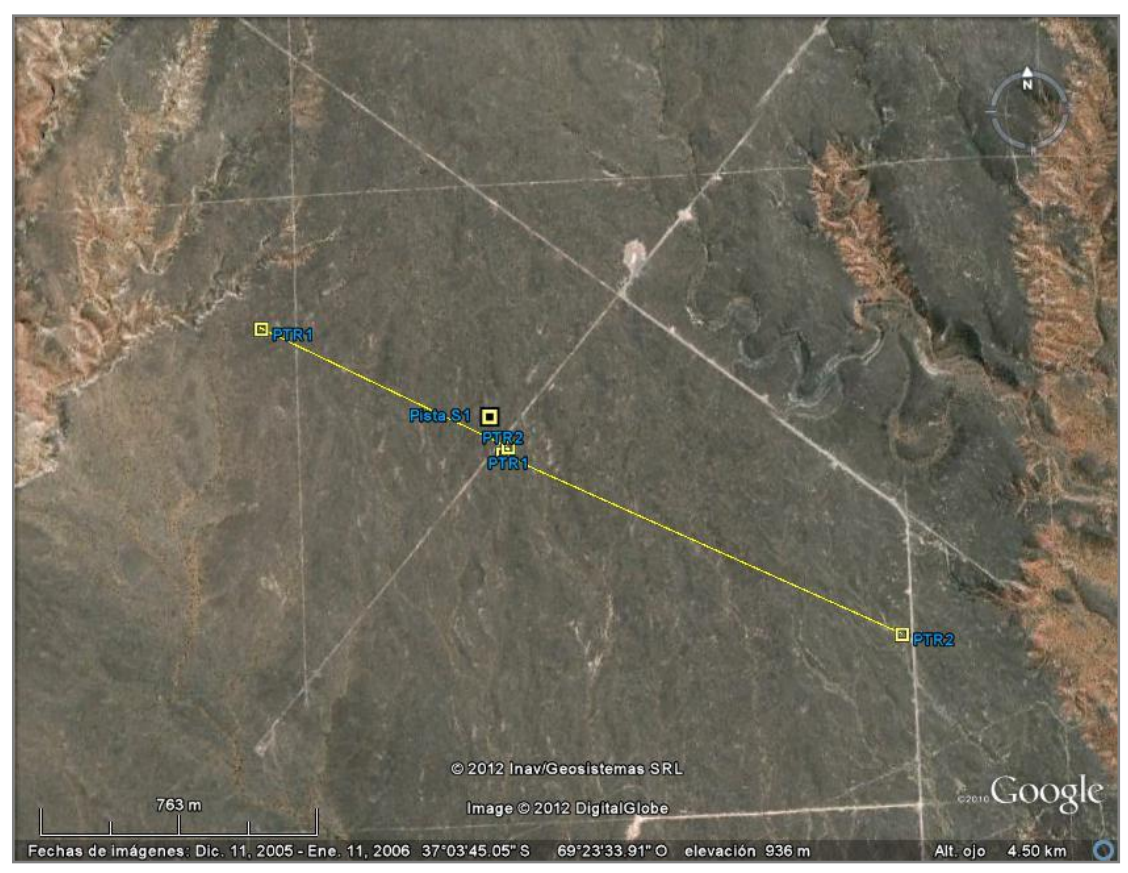

Figura 7.59. Transectas realizadas en la Pista. Imagen tomada de Google Earth.

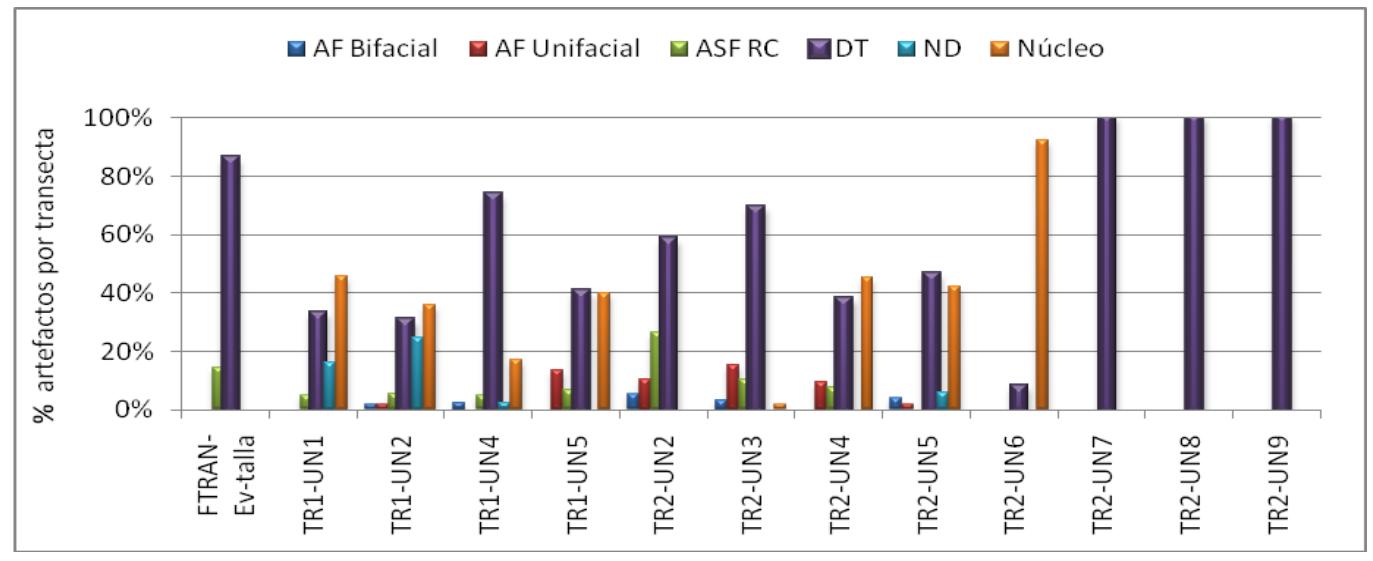

Figura 7.60. Clases artefactuales en Pista. 


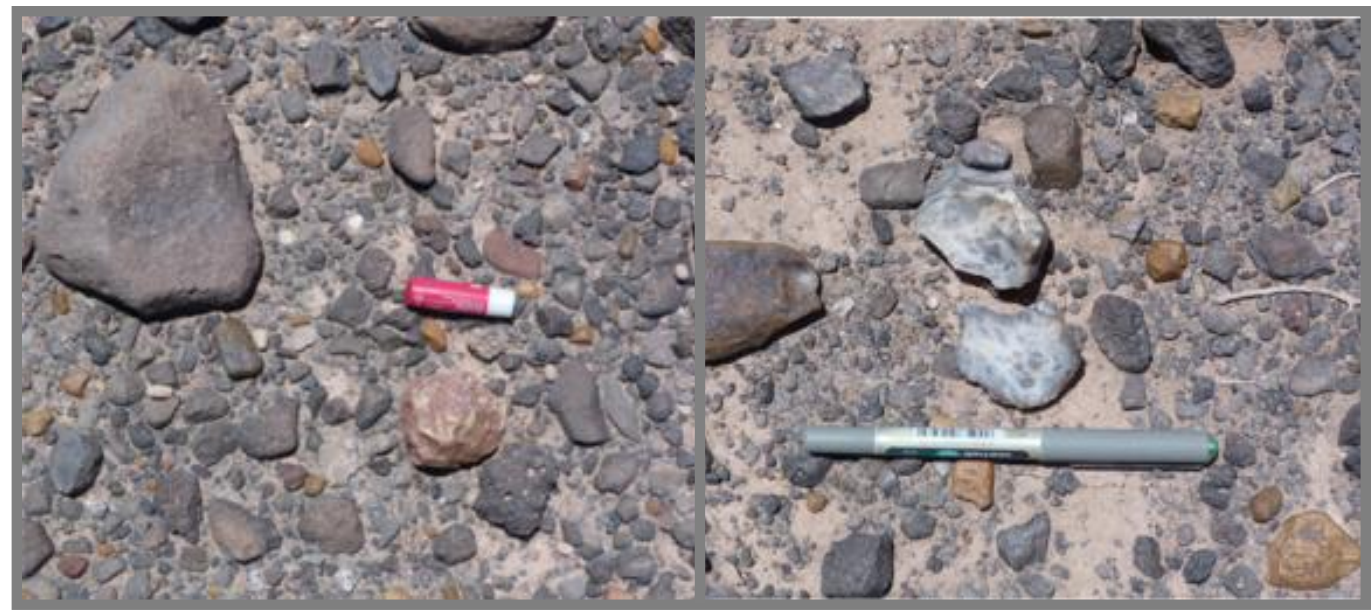

Figura 7.61. Nódulos silíceos en Pista. A la derecha se observa un nódulo natural y a la izquierda un núcleo con lasca de ensamble.

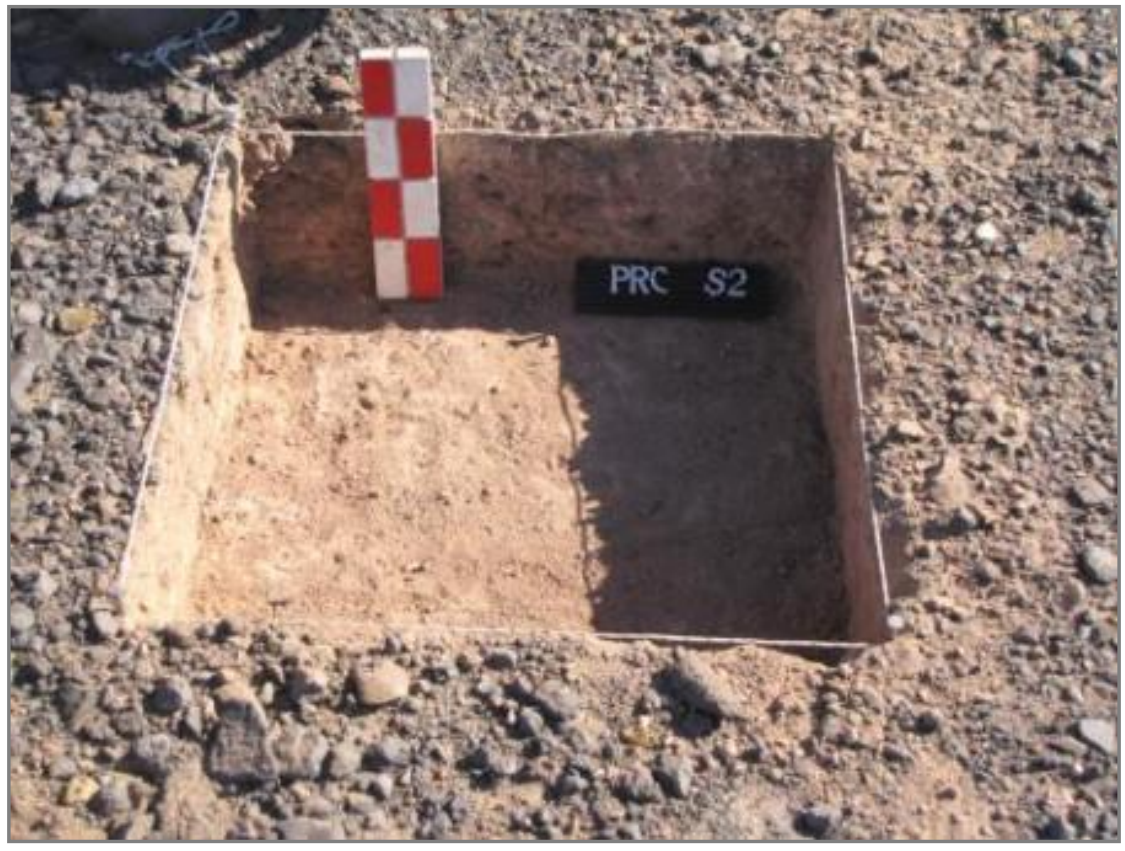

Figura 7.62. Vista de sondeo realizado en sitio Pista.

\subsubsection{ANÁLISIS TECNOLÓGICO DE LA LOCALIDAD CARMONINA}


En este apartado se presentan las tendencias generales para la localidad, considerando en conjunto los resultados obtenidos mediante el estudio de CAR-1 y Pista. El total de la muestra analizada es de $n=696$ artefactos líticos.

\subsection{2a MATERIA PRIMAS LÍTICAS}

La materia prima más abundante en la localidad es la roca silícea $(97,3 \%, n=677)$, seguida por la obsidiana $(2,3 \%, n=16)$, el basalto $(0,3 \%, n=2)$ y la riolita $(0,1 \%, n=1)$. La mayor diversidad de rocas se encuentra en CAR-1, donde se registran las cuatro materias primas mencionadas. En Pista sólo se han detectado artefactos confeccionados en roca silícea. La distribución de rocas en CAR-1, no se encuentra representada en la misma proporción en los diferentes niveles de excavación (Figura 7.57). La calidad para la talla muy buena $(61,2 \%)$ es predominante, seguida por la calidad buena $(21,1 \%)$, regular $(13,2 \%)$ y excelente $(2,3 \%)$ (Tabla 7.71$)$. La muy buena es predominante en rocas silíceas tanto en CAR-1 como en Pista, siendo más frecuente en el primero. El 21,1\% de rocas de calidad buena está compuesto por un $77,5 \%$ de rocas silíceas de Pista, mientras que el $22,4 \%$ corresponde a CAR-1. La calidad regular $(13,2 \%)$ es frecuente en Pista y poco frecuente en CAR-1. Esto sugiere una posible selección de las rocas silíceas para su posterior traslado a los sitios de actividades múltiples. En calidad excelente sólo se registra la materia prima obsidiana en CAR-1.

\begin{tabular}{|c|c|c|c|c|c|c|}
\hline SITIO & MP & $\mathbf{R}$ & B & MB & $\mathbf{E}$ & TOTAL \\
\hline \multirow{4}{*}{ CAR-1 } & BAS & - & - & 2 (100\%) & - & 2 \\
\hline & OBS & - & - & - & $16(100 \%)$ & 16 \\
\hline & $\mathrm{RIO}$ & $1(100 \%)$ & - & - & - & 1 \\
\hline & SIL & $5(1,8 \%)$ & $33(11,6 \%)$ & $247(86,7 \%)$ & - & 285 \\
\hline \multicolumn{2}{|c|}{ Total CAR-1 } & $6(2 \%)$ & $33(10,9 \%)$ & $249(81,9 \%)$ & $16(5,3 \%)$ & 304 \\
\hline PISTA & SIL & $86(21,9 \%)$ & $114(29,1 \%)$ & $177(45,2 \%)$ & - & 392 \\
\hline \multicolumn{2}{|c|}{ TOTAL } & $92(13,2 \%)$ & 147 (21,1\%) & $426(61,2 \%)$ & $16(2,3 \%)$ & 696 \\
\hline
\end{tabular}

Tabla 7.71. Calidad para la talla en materias primas en CAR. 
El $80 \%$ de los artefactos se encuentra entero y un $20 \%$ fragmentado. En CAR-1 se encuentran las frecuencias más altas de fragmentación tanto en obsidiana como en rocas silíceas, mientras que en Pista el porcentaje de artefactos fragmentados no alcanza el $10 \%$ del total recuperado en el sitio (Tabla 7.72). El cálculo del índice de fragmentación, señala una baja incidencia de la fragmentación (11\%) en los conjuntos de CAR (Tabla 7.73). En CAR-1 los artefactos de obsidiana y rocas silíceas son las que muestran mayor frecuencia de fractura ( $9 \%$ cada tipo de roca) y en Pista la abundancia de artefactos fracturados es menor (6\%). Lo sugiere una baja incidencia de factores post-depositacionales en la localidad. El tamaño de los artefactos enteros presenta variaciones entre los sitios (Tabla 7.74). En CAR-1 están representadas todas las categorías de tamaño, aunque predominan los pequeños y mediano pequeños. En obsidiana sólo se encuentran representados los tamaños pequeños en sus tres categorías, siendo el más frecuente el rango muy pequeño. En Pista sólo se encuentran representados en roca silícea los tamaños muy grande y grandísimo (Tabla 7.74).

\begin{tabular}{|c|c|c|c|c|c|c|c|c|}
\hline SITIO & MP & ENTERO & $\%$ & FRACTURADO & $\%$ & ND & $\%$ & TOTAL \\
\hline \multirow{4}{*}{ CAR-1 } & BAS & - & - & 2 & - & - & - & 2 \\
\hline & OBS & 8 & $50 \%$ & 7 & $44 \%$ & 1 & $6 \%$ & 16 \\
\hline & $\mathrm{RIO}$ & 1 & $100 \%$ & - & - & - & - & 1 \\
\hline & SIL & 191 & $67 \%$ & 94 & $33 \%$ & - & - & 285 \\
\hline \multicolumn{2}{|c|}{ Total CAR-1 } & 200 & $66 \%$ & 103 & $34 \%$ & 1 & $0 \%$ & 304 \\
\hline PISTA & SIL & 354 & $90,3 \%$ & 37 & $9,4 \%$ & 1 & $0,3 \%$ & 392 \\
\hline \multicolumn{2}{|c|}{ TOTAL } & 554 & $80 \%$ & 140 & $20 \%$ & 2 & $0 \%$ & 696 \\
\hline
\end{tabular}

Tabla 7.72. Estado de fragmentación de los conjuntos en CAR. 


\begin{tabular}{|c|c|c|c|c|c|c|c|c|c|c|c|c|c|}
\hline & MP & Ent & Fr. Prox & Fr. Med & Fr. Dist & Fr. Mar & Long Der & Long Izq & Fr. ND & ND & NAS & MNA & MNA/ NAS \\
\hline \multirow{4}{*}{ 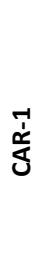 } & BAS & & 2 & - & - & - & - & - & - & - & 2 & 2 & $100 \%$ \\
\hline & OBS & 8 & 5 & 2 & - & - & - & - & - & 1 & 16 & 13 & $81 \%$ \\
\hline & RIO & 1 & - & - & - & - & - & - & - & - & 1 & 1 & $100 \%$ \\
\hline & SIL & 191 & 34 & 18 & 30 & 2 & 2 & 5 & 3 & - & 285 & 230 & $81 \%$ \\
\hline$\frac{5}{\frac{n}{0}}$ & SIL & 354 & 7 & 1 & 10 & 1 & 4 & 2 & 12 & & 392 & 368 & $94 \%$ \\
\hline \multicolumn{2}{|c|}{ TOTAL } & 554 & 48 & 21 & 40 & 3 & 6 & 7 & 15 & 1 & 696 & 612 & $88 \%$ \\
\hline
\end{tabular}

Tabla 7.73. Estado de fragmentación de los artefactos por materia prima en conjuntos de CAR. MP: materia prima; Ent: entero; Fr. Prox: fragmento proximal; Fr. Med: fragmento medial; Fr. Dist: fragmento distal; Fr. Mar: fragmento marginal; Long Der: Fragmento longitudinal derecho; Long Izq: fragmento longitudinal izquierdo; Fr. ND: fragmento no diferenciado; ND: No Diferenciado; NAS: número de especímenes artefactuales; MNA: número mínimo de artefactos.

\begin{tabular}{|c|c|c|c|c|c|c|c|c|c|}
\hline SITIO & MP & MPE & $\mathrm{PE}$ & MEP & MEG & G & MG & GD & TOTAL \\
\hline \multirow{3}{*}{ CAR-1 } & OBS & $63 \%$ & $13 \%$ & $25 \%$ & - & - & - & - & 8 \\
\hline & RIO & - & - & - & - & - & - & $100 \%$ & 1 \\
\hline & SIL & $17 \%$ & $27 \%$ & $12 \%$ & $13 \%$ & $6 \%$ & $2 \%$ & $24 \%$ & 191 \\
\hline \multicolumn{2}{|c|}{ Total CAR-1 } & $19 \%$ & $26 \%$ & $13 \%$ & $12 \%$ & $6 \%$ & $2 \%$ & $23 \%$ & 200 \\
\hline PISTA & SIL & - & - & - & - & - & $0,3 \%$ & $99,7 \%$ & 354 \\
\hline \multicolumn{2}{|c|}{ TOTAL } & $7 \%$ & $9 \%$ & $5 \%$ & $4 \%$ & $2 \%$ & $1 \%$ & $72 \%$ & 554 \\
\hline
\end{tabular}

Tabla 7.74. Tamaño de los artefactos enteros en las materias primas representadas en APE. Nota: MP: materia prima; MPE: Muy pequeño (0-20mm); PE: Pequeño (21-40mm); MEP: Mediano pequeño (4160mm); MEG: Mediano Grande (61-80mm); G: Grande (81-100); MG: Muy Grande (101-120mm); GD: Grandísimo (121-140mm).

\subsection{2b ESTRUCTURA TECNOLÓGICA EN CARMONINA}

En ambos sitios la clase artefactual más representada es la de desechos de talla (70\%), seguida por los núcleos $(17 \%)$, los instrumentos $(9,2 \%)$ y un percutor $(0,1 \%)(T a b l a$ 7.75). En CAR-1, no se registraron núcleos y el total de los instrumentos está confeccionado en roca silícea. El total de los núcleos recuperados en la localidad 
corresponden a Pista, en conjunto con una alta frecuencia de instrumentos. Entre estos últimos, los más frecuentes son los artefactos sin formatización con rastros complementarios. En la tabla 7.76 se detalla la estadística descriptiva de la diversidad de clases artefactuales según materia prima. La mayor variabilidad de clases se observa en rocas silíceas (Shannon- $\mathrm{H}=0,866$ ), mientras que en las restantes materias primas los valores son nulos. Una situación similar se observa en los índices de dominancia y Simpson, dado que en obsidiana y basalto sólo se encuentran representados los desechos de talla y, en riolita, solo un percutor. Este último corresponde a un rodado de tamaño grandísimo, similar a los transportados por el cauce del río transitorio de Cañadón Amarillo (Figura 7.63).

\begin{tabular}{|c|c|c|c|c|c|c|c|c|c|}
\hline Sitio & MP & AF Bifacial & AF Unifacial & ASF RC & DT & ND & Núcleo & Ecofacto & Total \\
\hline \multirow{4}{*}{ CAR-1 } & BAS & - & - & - & $2(100 \%)$ & - & - & - & 2 \\
\cline { 2 - 9 } & OBS & - & - & - & $16(100 \%)$ & - & - & - & 16 \\
\cline { 2 - 10 } & RIO & - & - & - & - & - & - & $1(100 \%)$ & 1 \\
\cline { 2 - 10 } & SIL & $2(0,7 \%)$ & $1(0,4 \%)$ & $1(0,4 \%)$ & $281(98,6 \%)$ & - & - & - & 285 \\
\hline \multicolumn{2}{|c|}{ Total CAR-1 } & $2(0,7 \%)$ & $1(0,3 \%)$ & $1(0,3 \%)$ & $299(98,4 \%)$ & - & - & $1(0,3 \%)$ & 304 \\
\hline \multicolumn{2}{|c|}{ PISTA } & SIL & $8(2 \%)$ & $22(5,6 \%)$ & $30(7,7 \%)$ & $187(47,7 \%)$ & $27(6,9 \%)$ & $118(30,1 \%)$ & - \\
\hline \multicolumn{2}{|c|}{ TOTAL } & $10(1,4 \%)$ & $23(3,3 \%)$ & $31(4,5 \%)$ & $486(70 \%)$ & $27(3,9 \%)$ & $118(17 \%)$ & $1(0,1 \%)$ & 696 \\
\hline
\end{tabular}

Tabla 7.75. Clases artefactuales por sitio en CAR. Entre paréntesis se detalla la frecuencia de cada clase por materia prima y muestreo. Referencia: MP: materia prima; BAS: basalto; OBS: obsidiana; RIO: riolita; SIL: rocas silíceas. AF Bifacial: artefacto de formatización bifacial; AF Unifacial: artefacto de formatización unifacial; ASF RC: artefacto sin formatización con rastros complementarios; DT: desecho de talla; ND: no diferenciado.

\begin{tabular}{|c|c|c|c|c|}
\hline & SIL & BAS & OBS & RIO \\
\hline N clases artefactos & 5 & 1 & 1 & 1 \\
\hline $\mathbf{N}$ & 648 & 2 & 16 & 1 \\
\hline Dominancia & 0,558 & 1 & 1 & 1 \\
\hline Shannon H & 0,866 & - & - & - \\
\hline Simpson & 0,441 & - & - & - \\
\hline
\end{tabular}

Tabla 7.76 Diversidad de clases artefactuales según materia prima en CAR. 


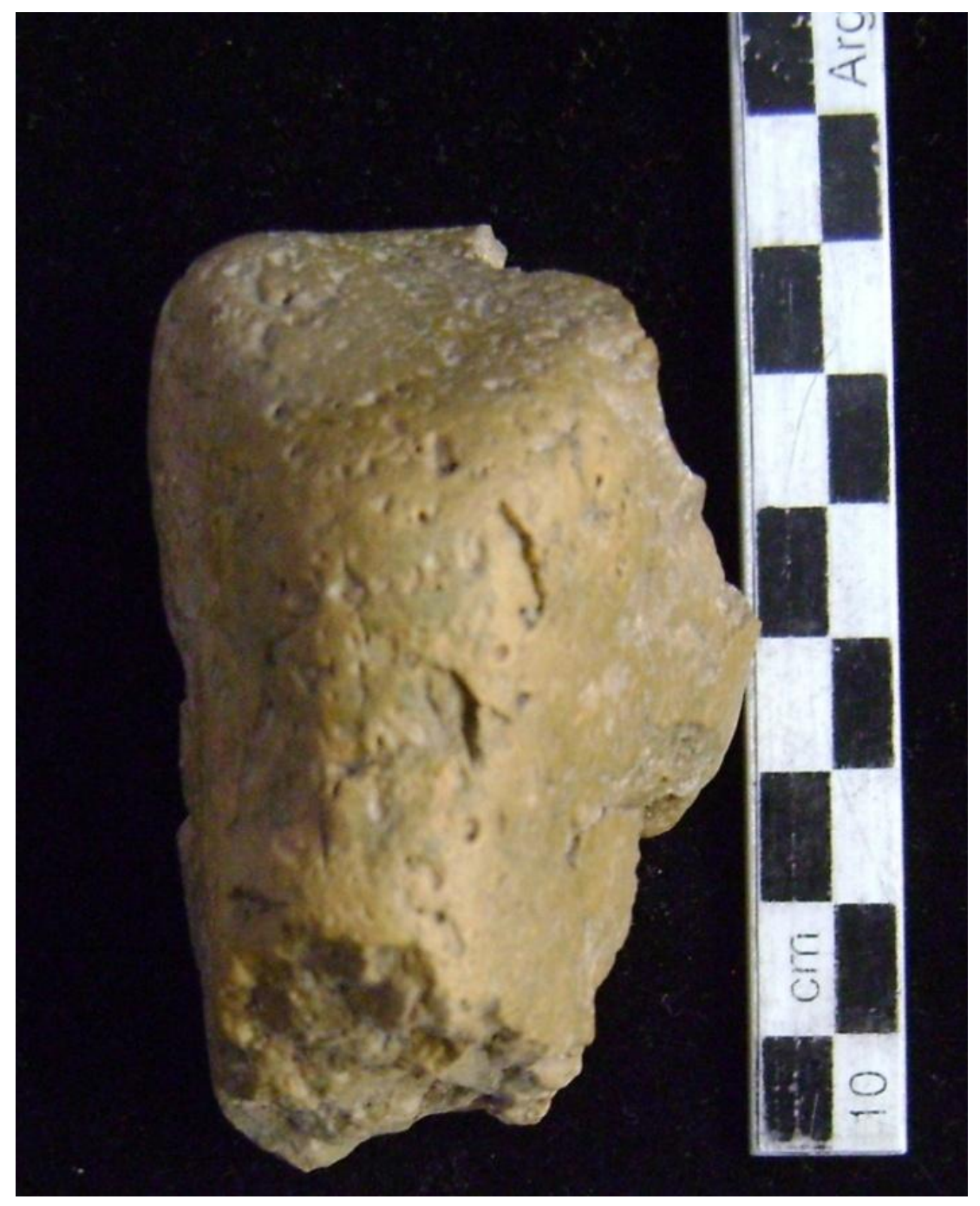

Figura 7.63. Percutor recuperado en el sitio CAR-1.

\subsection{2b.1 DESECHOS DE TALLA}

Los desechos de talla son la clase artefactual más frecuente en CAR (70\%) y la que presenta mayor diversidad de rocas, con dominancia las rocas silíceas en ambos sitios (Tabla 7.75). El 26\% ( $n=125)$ de la muestra se encuentra fragmentada y el $74 \%(n=360)$ restante entero. Del total de desechos fragmentados, el $80 \%$ corresponde al sitio CAR-1 y el $20 \%$ a Pista. El $51 \%$ de los desechos de talla enteros presenta reserva de corteza en la cara dorsal y, del total de artefactos con corteza, el $67 \%$ proviene de Pista y el $33 \%$ 
restante de CAR-1 (Tabla 7.76). Tendencia que también puede observarse en los tipos de desechos (Tabla 7.77), dado que en CAR-1 las lascas internas (angulares y de arista) representan el $40 \%$ del total, seguido en frecuencia por desechos de formatización de filo (lascas planas, lascas de adelgazamiento bifacial y lascas de reactivación de filo, 33\%) y por los desechos externos (lascas primarias, secundarias y nodulares, 23\%). En obsidiana los tipos más frecuentes son las lascas internas (38\%) y de formatización de filo (50\%), mientras que las lascas externas representan sólo el 6\% de los artefactos de obsidiana. En basalto, los dos desechos recuperados son una lasca angular y una de reactivación de filo. Por su parte en Pista, las lascas externas y de reactivación de núcleo representan el 77\% del total de la muestra recuperada, siendo significativa la representación de las primeras etapas de manufactura (Figura 7.64).

\begin{tabular}{|c|c|c|c|c|c|c|}
\hline \multirow{2}{*}{ SITIO } & \multirow{2}{*}{ MP } & \multicolumn{5}{|c|}{ PROPORCION DE CORTEZA } \\
\hline & & $0 \%$ & $25 \%$ & $50 \%$ & $75 \%$ & $100 \%$ \\
\hline \multirow{2}{*}{ CAR-1 } & OBS & $6(75 \%)$ & $1(12,5 \%)$ & - & - & $1(12,5 \%)$ \\
\hline & SIL & $133(70 \%)$ & $8(4 \%)$ & $12(6 \%)$ & $20(11 \%)$ & $17(9 \%)$ \\
\hline \multicolumn{2}{|c|}{ TOTAL CAR-1 } & 139 (70\%) & $9(5 \%)$ & $12(6 \%)$ & $20(10 \%)$ & $18(9 \%)$ \\
\hline PISTA & SIL & $37(23 \%)$ & $23(14 \%)$ & $28(17 \%)$ & 47 (29\%) & 27 (17\%) \\
\hline \multicolumn{2}{|c|}{ TOTAL } & $176(49 \%)$ & $32(8,9 \%)$ & $40(11,1 \%)$ & $67(18,6 \%)$ & $45(12,5 \%)$ \\
\hline
\end{tabular}

Tabla 7.76. Reserva de corteza en la cara dorsal de desechos de talla enteros en CAR. 


\begin{tabular}{|c|c|c|c|c|c|c|c|c|c|c|c|c|}
\hline 음 & $\hat{\Sigma}$ & $\frac{\kappa}{a}$ & 岃 & $\frac{z}{s}$ & 孚 & $\stackrel{\infty}{\leq}$ & $\vec{a}$ & $\stackrel{\hookrightarrow}{ }$ & 3 & $\stackrel{\circ}{9}$ & 只 & $\begin{array}{l}\overline{0} \\
\text { 。ㅁ }\end{array}$ \\
\hline \multirow{3}{*}{ 宅 } & $\frac{n}{\Phi}$ & - & - & - & $\begin{array}{c}1 \\
(50 \%)\end{array}$ & - & - & $\begin{array}{c}1 \\
(50 \%)\end{array}$ & - & - & - & $\begin{array}{c}2 \\
(100 \%)\end{array}$ \\
\hline & ठิ & $1(6 \%)$ & - & $\begin{array}{c}4 \\
(25 \%) \\
\end{array}$ & $\begin{array}{c}2 \\
(13 \%) \\
\end{array}$ & $1(6 \%)$ & - & $\begin{array}{c}7 \\
(44 \%) \\
\end{array}$ & - & - & $\begin{array}{c}1 \\
(6 \%) \\
\end{array}$ & $\begin{array}{c}16 \\
(100 \%) \\
\end{array}$ \\
\hline & $\vec{n}$ & $\begin{array}{c}26 \\
(9 \%)\end{array}$ & $\begin{array}{c}30 \\
(11 \%)\end{array}$ & $\begin{array}{c}64 \\
(23 \%)\end{array}$ & $\begin{array}{c}48 \\
(17 \%)\end{array}$ & $\begin{array}{c}27 \\
(10 \%)\end{array}$ & $\begin{array}{c}28 \\
(10 \%)\end{array}$ & $\begin{array}{c}29 \\
(11 \%)\end{array}$ & $\begin{array}{c}11 \\
(4 \%)\end{array}$ & - & $\begin{array}{c}12 \\
(4 \%)\end{array}$ & $\begin{array}{c}275 \\
(100 \%)\end{array}$ \\
\hline \multicolumn{2}{|c|}{$\begin{array}{l}\text { Total } \\
\text { CAR-1 }\end{array}$} & $\begin{array}{c}26 \\
(9 \%)\end{array}$ & $\begin{array}{c}30 \\
(10 \%)\end{array}$ & $\begin{array}{c}66 \\
(23 \%)\end{array}$ & $\begin{array}{c}51 \\
(17 \%)\end{array}$ & $\begin{array}{c}28 \\
(10 \%)\end{array}$ & $\begin{array}{c}28 \\
(10 \%)\end{array}$ & $\begin{array}{c}37 \\
(13 \%)\end{array}$ & $\begin{array}{c}11 \\
(4 \%)\end{array}$ & - & $\begin{array}{c}15 \\
(5 \%)\end{array}$ & $\begin{array}{c}292 \\
(100 \%)\end{array}$ \\
\hline$\frac{a}{\frac{n}{a}}$ & ज & $\begin{array}{c}33 \\
(18 \%)\end{array}$ & $\begin{array}{c}51 \\
(27 \%)\end{array}$ & $\begin{array}{c}31 \\
(17 \%)\end{array}$ & $\begin{array}{c}11 \\
(6 \%)\end{array}$ & - & $1(1 \%)$ & - & $\begin{array}{c}55 \\
(29 \%)\end{array}$ & $\begin{array}{c}4 \\
(2 \%)\end{array}$ & $\begin{array}{c}1 \\
(1 \%)\end{array}$ & $\begin{array}{c}187 \\
(100 \%)\end{array}$ \\
\hline \multicolumn{2}{|c|}{ Total } & $\begin{array}{c}60 \\
(13 \%)\end{array}$ & $\begin{array}{c}81 \\
(17 \%)\end{array}$ & $\begin{array}{c}97 \\
(20 \%)\end{array}$ & $\begin{array}{c}62 \\
(13 \%)\end{array}$ & $\begin{array}{c}28 \\
(6 \%)\end{array}$ & $\begin{array}{c}29 \\
(6 \%)\end{array}$ & $\begin{array}{c}37 \\
(8 \%)\end{array}$ & $\begin{array}{c}66 \\
(14 \%)\end{array}$ & $\begin{array}{c}4 \\
(1 \%)\end{array}$ & $\begin{array}{c}16 \\
(3 \%)\end{array}$ & $\begin{array}{c}480 \\
(100 \%)\end{array}$ \\
\hline
\end{tabular}

Tabla 7.77. Tipos de desechos de talla por tipo de extracción en CAR. Referencia: LPR: lasca primaria; LSEC: lasca secundaria; LAN: lasca angular; LAR: lasca de arista; LAB: lasca de adelgazamiento bifacial; PL: lasca plana; LR: lasca de reactivación; LN: lasca nodular (incluye lascas de flanco de núcleo, cresta de núcleo y lascas de reactivación de núcleo); LBIP: lasca bipolar; ND: lasca no diferenciada.

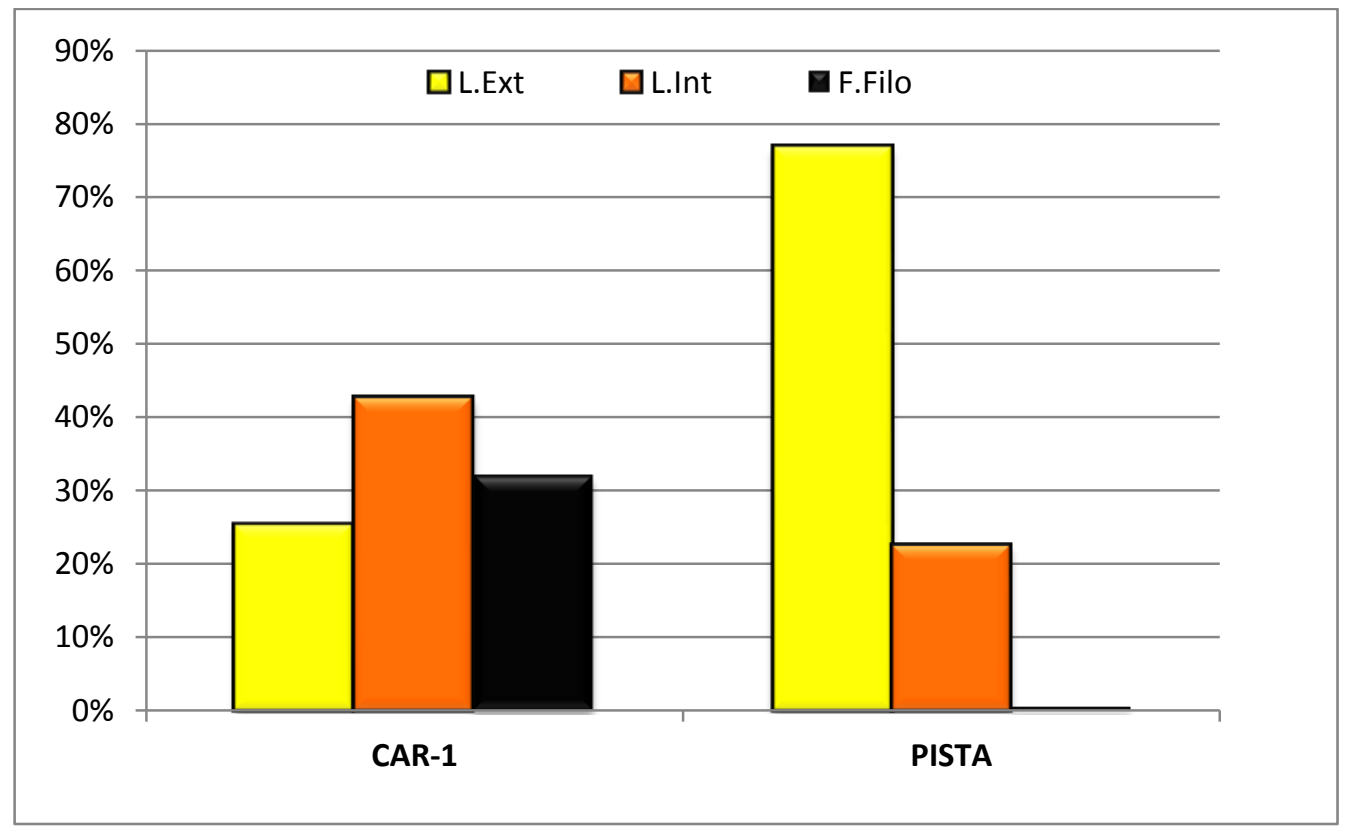

Figura 7.64. Frecuencia de manufactura en rocas silíceas. Referencia: L.EXT: Lascas externas; L.INT: lascas internas; F.FILO: lascas de formatización de filo.

El índice de corteza más elevado corresponde a rocas silíceas del sitio Pista y CAR1, seguidos por la obsidiana en éste último sitio (Tabla 7.78). En relación a la intensidad de 
extracciones previas en la cara dorsal de los desechos de talla (sin incluir las lascas de reactivación de filo), se observa que la obsidiana presenta los valores más altos, seguido por las rocas silíceas de CAR-1 y Pista (Tabla 7.79). Como se observa en la tabla 7.79, los valores de mediana -en todos los casos- se diferencian de la media e indica la existencia de valores extremos, como se observa en los mínimos y máximos en cada materia prima. Al analizar los tres indicadores de reducción, el sitio CAR-1 presenta valores bajos de corteza y los índices de intensidad de reducción altos, con mayor intensidad de reducción en obsidiana. En Pista, los desechos frecuentes son los que corresponden a las primeras etapas de manufactura; los índices de corteza son altos y la densidad de reducción bajos. En este último sitio se han documentado eventos de talla mayormente completos (Figura 7.65) y, pese la alta frecuencia de instrumentos descartados en el sitio, no se registran desechos de formatización de filo.

\begin{tabular}{|c|c|c|c|c|c|}
\hline Sitio & MP & N & LPR & LSEC & Índice Corteza \\
\hline \multirow{2}{*}{ CAR-1 } & OBS & 16 & 1 & - & 0,063 \\
\cline { 2 - 6 } & SIL & 275 & 26 & 30 & 0,204 \\
\hline PISTA & SIL & 187 & 33 & 51 & 0,449 \\
\hline
\end{tabular}

Tabla 7.78. Frecuencia de lascas primarias y secundarias enteras respecto a materias primas en CAR. Referencia: MP: materia prima; N: número total de de desechos de talla enteros; LPR: lasca primaria; LSEC: lasca secundaria. 


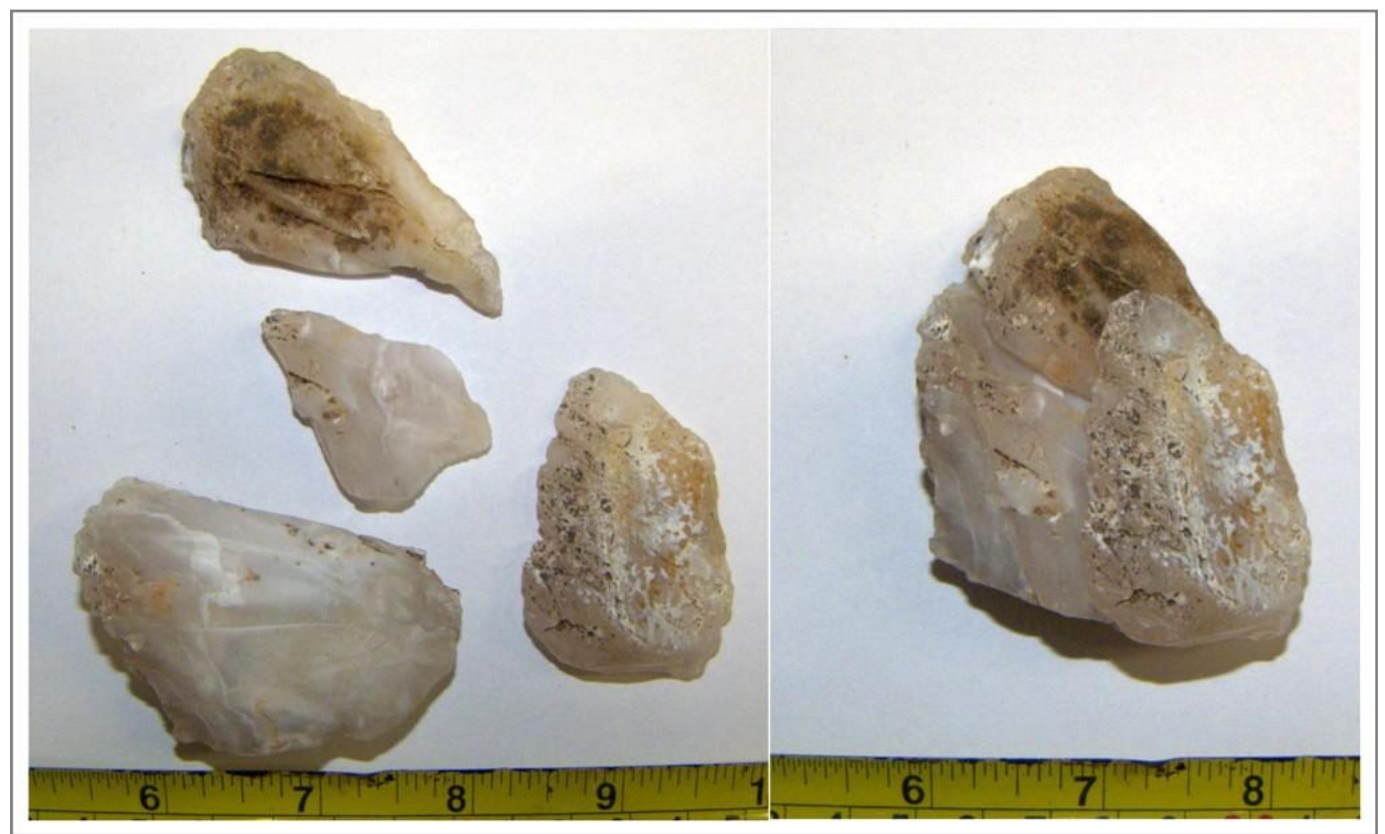

Figura 7.65 Artefactos que ensamblan (izquierda) correspondiente a un mismo evento de talla (derecha), hallados asociados en Pista.

\begin{tabular}{|c|c|c|c|c|c|c|c|c|}
\hline Sitio & MP & $\mathbf{N}$ & Media & Mediana & Desvío Estándar & Mínimo & Máximo & Rango \\
\hline \multirow{2}{*}{ CAR-1 } & OBS & 9 & 5,36 & 4,82 & 4,54 & 0 & 12,8 & 12,8 \\
\cline { 2 - 9 } & SIL & 252 & 1,67 & 1,31 & 1,31 & 0 & 9,97 & 9,97 \\
\hline \multirow{2}{*}{ PISTA } & SIL & 187 & 0,21 & 0,15 & 0,15 & 0 & 1,25 & 1,25 \\
\hline
\end{tabular}

Tabla 7.79. Densidad de extracciones previas en la cara dorsal de los desechos de talla en CAR.

\subsection{2b.2 NÚCLEOS}

Los núcleos alcanzan el $17 \%(n=118)$ de la muestra y han sido registrados únicamente en Pista, donde representan el 30,1\% del total. El 95\% de los artefactos están enteros y el $5 \%$ fracturados. La calidad para la talla más frecuente entre los núcleos es la muy buena (41\%) y la buena (41\%), seguidas por la regular (19\%). La morfología de los núcleos predominante es la de lascados aislados (60\%), seguida por la de amorfos (11\%), bifaciales (8\%), bipolares (7\%), piramidales (7\%), discoidales (3\%), poliédricos (2\%) y prismáticos (1\%) (Figura 7.76). En todos los casos el tamaño de los núcleos es grandísimo 
(módulo: 7, rango >161 mm), con espesores que varían entre espeso (módulo AM/EM: $2,5-4,9$ ) en el $13 \%$ de los casos y muy espeso (módulo AM/EM: < 2,4), en el $87 \%$ restante. Presentan en promedio dos negativos de lascado y la mayoría no se encuentra agotado (70\%). La intensidad de extracciones o negativos de lascados en núcleos de la cantera es de $1,587 \mathrm{e} / \mathrm{mm}^{3}$ y el peso medio de los núcleos enteros es de 81,03 gr. Si analizamos la densidad de lascados respecto a la calidad para la talla, notamos que -como era de esperar- los núcleos con calidad para la talla muy buena presenta mayor densidad de lascados $\left(x=2,043 \mathrm{e} / \mathrm{mm}^{3}\right)$ que los correspondientes a calidad buena $\left(x=1,506 \mathrm{e} / \mathrm{mm}^{3}\right)$ y regular $\left(x=1,451 \mathrm{e} / \mathrm{mm}^{3}\right)$. El tamaño mínimo de los negativos es grandísimo (84\%), seguido por los muy grandes (10\%), grandes (3\%) y mediano grande (2\%). La distribución en el espacio de los núcleos no es homogénea, sino que presenta áreas de mayor concentración (Figura 7.66). Al comparar las variables de tamaño entre clases, se observan diferencias en el valor de tamaño medio de negativos de lascado en núcleos, en comparación con instrumentos y núcleos (Tabla 7.80) En la se comparan el largo y ancho de los núcleos, los desechos de talla e instrumentos a fin de observar la relación entre el de tamaño de los soportes o formas base utilizados tanto para la formatización de instrumentos como para el transporte de materia prima. Se observa que el tamaño medio de los negativos de extracción en núcleos es más menor que el de los instrumentos. Sin embargo los tamaños máximos de negativos en núcleos incluyen medidas que pudieron ser apropiadas para la manufactura de instrumentos (Figura 7.68). Si tomamos el valor medio de los núcleos enteros (Largo $\mathrm{mm} \mathrm{x}=45,759$, Ancho $\mathrm{mm} \mathrm{x}=52,293$ ), notamos que éstos se ajustan mejor a las medidas observadas en los instrumentos. Por lo cual no se puede descartar la talla a partir de formas base nodular y su transporte para la formatización de instrumentos en la localidad.

\begin{tabular}{|c|c|c|c|c|c|c|}
\hline & \multicolumn{2}{|c|}{ Desechos de Talla } & \multicolumn{2}{c|}{ Instrumentos } & \multicolumn{2}{c|}{ Núcleos } \\
\hline & Largo $\mathbf{~ m m}$ & Ancho $\mathbf{~ m m}$ & Largo $\mathbf{~ m m}$ & Ancho $\mathbf{m m}$ & Largo $\mathbf{m m}$ & Ancho $\mathbf{m m}$ \\
\hline $\mathbf{N}$ & 485 & 485 & 64 & 64 & 212 & 212 \\
\hline Media & 20,1697 & 20,3843 & 35,8391 & 31,6281 & 30,594 & 28,856 \\
\hline Desvío Estándar & 14,1963 & 14,042 & 12,6701 & 8,83824 & 11,1498 & 11,2682 \\
\hline
\end{tabular}




\begin{tabular}{|c|c|c|c|c|c|c|}
\hline Mediana & 15,3 & 15,5 & 34,05 & 30,75 & 30,85 & 27,35 \\
\hline Mínimo & 3 & 2,7 & 8,9 & 10,2 & 9,5 & 8,5 \\
\hline Máximo & 63,5 & 83,8 & 68,8 & 55 & 71,2 & 72,3 \\
\hline
\end{tabular}

Tabla 7.80. Estadística descriptiva de tamaño en clases artefactuales de CAR.

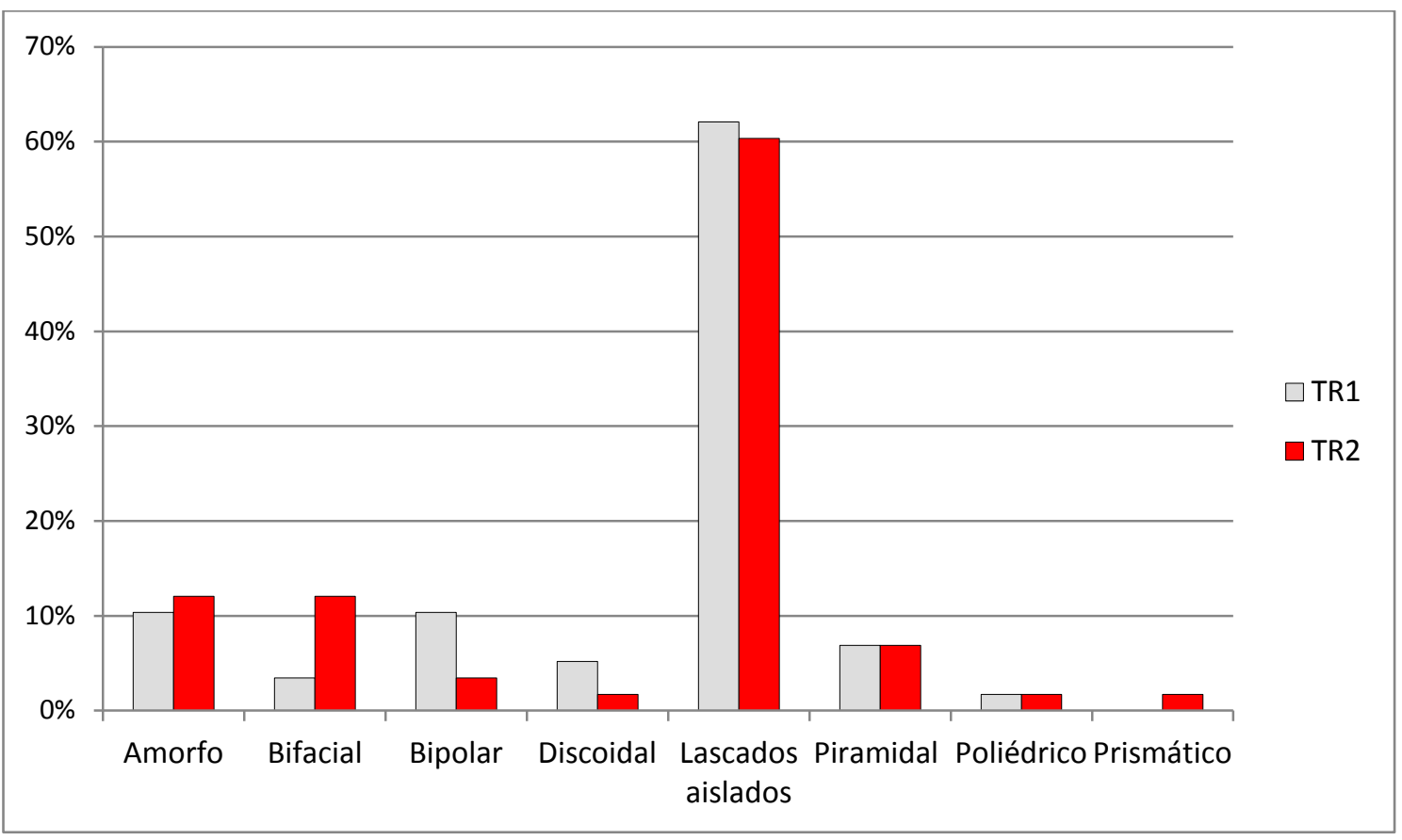

Figura 7.66. Frecuencia de núcleos respecto a transectas 1 y 2 en Pista. 


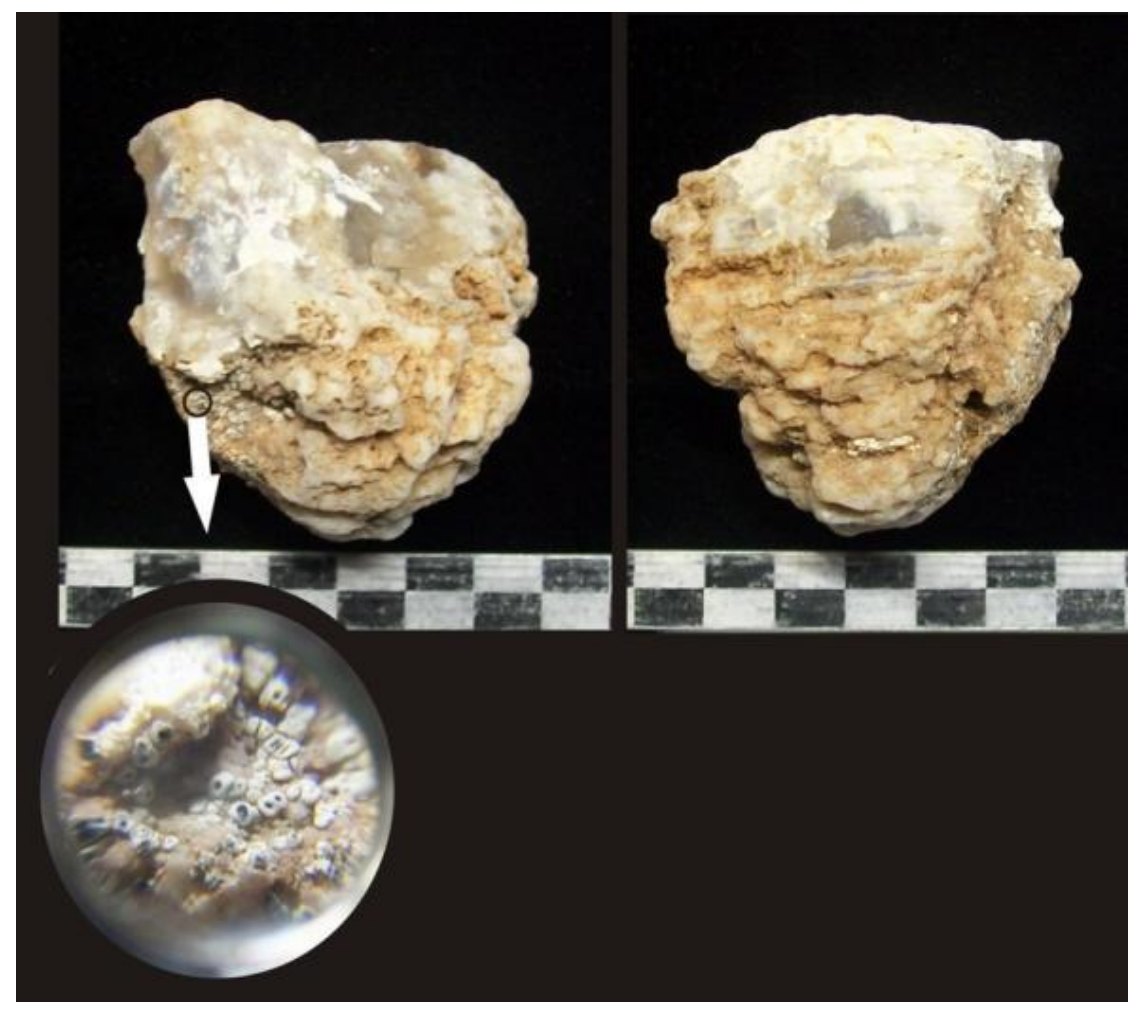

Figura 7.67. Vista dorsal y ventral de nódulo silíceo con lascados aislados registrado en Pista. En el circulo inferior se detalla la presencia de líquenes en la corteza (tomada con lupa de aumento 20x). 


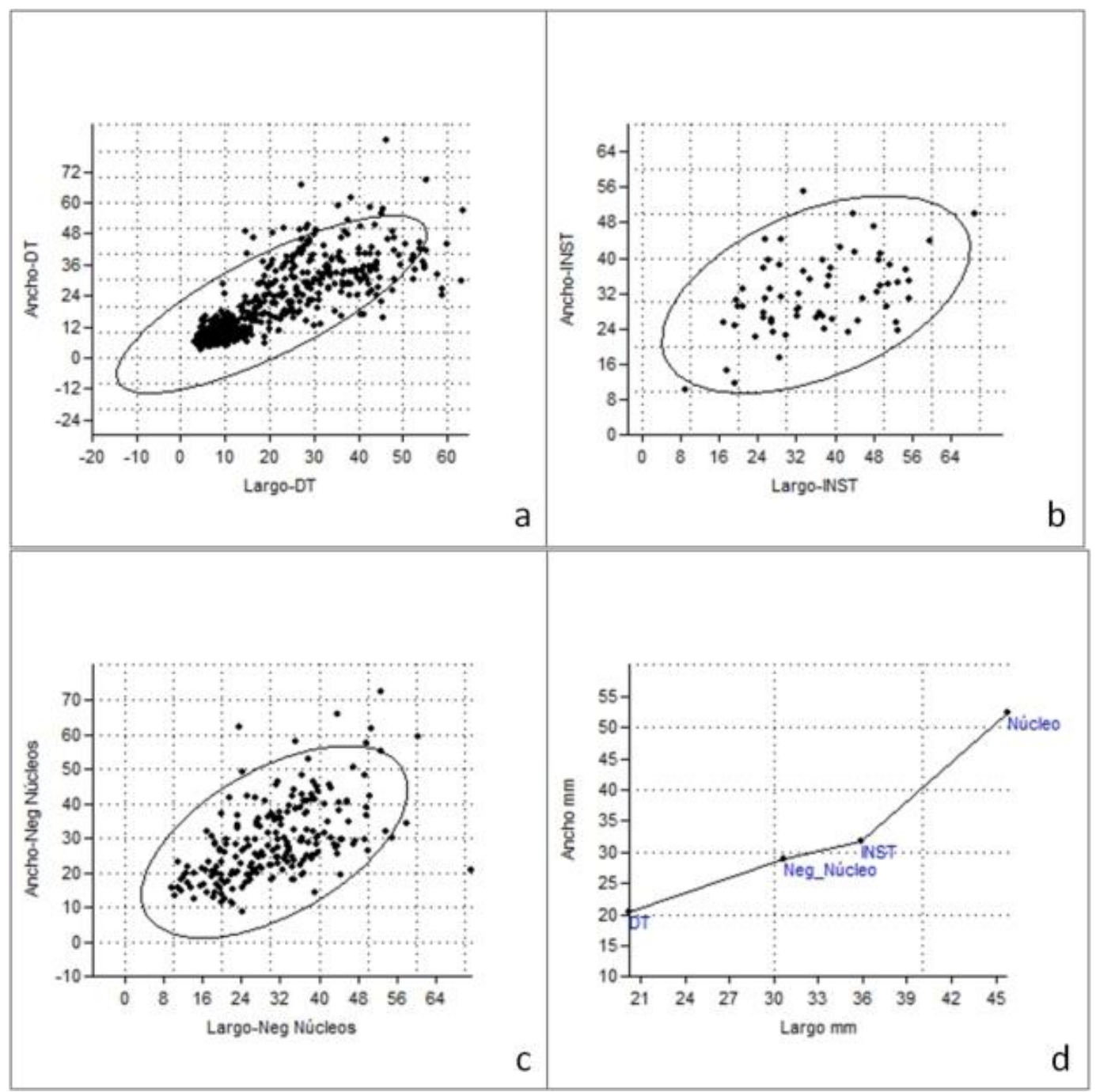

Figura 7.68. Tamaños de negativos de lascado en núcleos respecto a clases artefactuales en CAR. Referencias: a: relación entre largo y ancho en desechos de talla; b: relación entre largo y ancho en instrumentos; c: relación entre largo y ancho en negativos de lascados de núcleos; d: relación entre valores medios relativos de largo y ancho en clases artefactuales y negativos de lascado en núcleos.

\subsection{2b.3 INSTRUMENTOS}

Los instrumentos alcanzan el 9,2\% $(n=64)$ de los artefactos recuperados en CAR (Tabla 7.75). El 93,7\% se registró en Pista y 6,2 \% restante en CAR-1. La única materia prima representada es la roca silícea. En el sitio Pista los artefactos con rastros complementarios $(50 \%)$ son los más abundantes, seguidos por los de formatización 
unifacial (37\%) y los bifaciales (13\%). En CAR-1 los artefactos bifaciales (50\%) son los más representados, seguidos por frecuencias iguales de unifaciales (25\%) y con rastros complementarios (25\%) (Tabla 7.81). La distribución espacial de los mimos no es homogénea en el espacio y presenta sectores de mayor densidad (Figura 7.69).

\begin{tabular}{|c|c|c|c|c|}
\hline Sitio & AF Bifacial & AF Unifacial & ASF RC & Total \\
\hline CAR-1 & $2(50 \%)$ & $1(25 \%)$ & $1(25 \%)$ & 4 \\
\hline PISTA & $8(13 \%)$ & $22(37 \%)$ & $30(50 \%)$ & 60 \\
\hline Total & $10(16 \%)$ & $23(36 \%)$ & $31(48 \%)$ & 64 \\
\hline
\end{tabular}

Tabla 7.81. Frecuencia de instrumentos en CAR. Entre paréntesis se detalla la frecuencia de cada tipo respecto a al sitio.

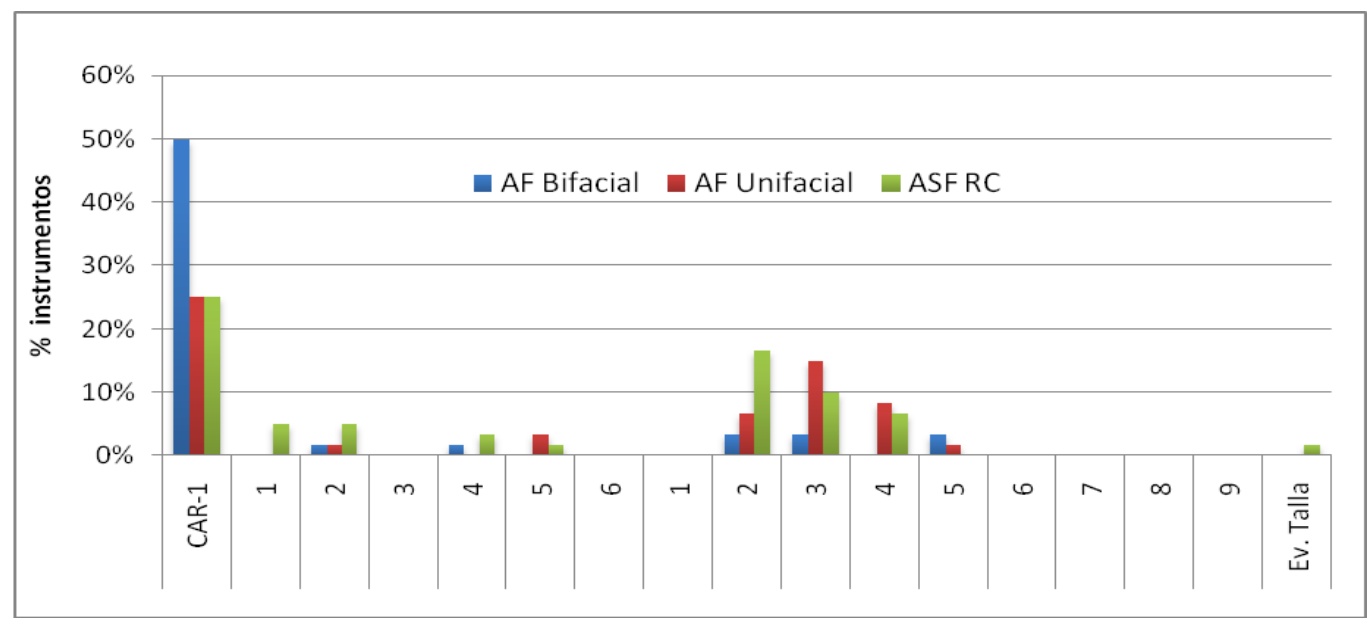

Figura 7.69. Distribución de instrumentos según modo de formatizados en CAR.

La forma base seleccionada para la manufactura de instrumentos es la lasca (75\%) y la nodular (25\%). En CAR-1 todas las formas base son lascas silíceas de buena calidad para la talla (Tabla 7.82). En Pista la calidad para la talla predominante es la muy buena (67\%), seguida por la buena (28\%) y la regular (5\%). Entre los instrumentos de calidad muy buena, los artefactos sin formatización con rastros complementarios representan el 52\% (Figura 7.70), seguido por los artefactos de formatización unifacial $(32,5 \%)$ y los bifaciales (15\%). El 75\% de los artefactos de CAR-1 están fracturados y sólo un artefacto con rastros complementarios está entero (25\%) (Tabla 7.83). Entre los artefactos de formatización 
bifacial en CAR-1, los tipos representados son los bifaces (60\%), las puntas de proyectil (20\%) y los artefactos medianos pequeños de retalla bilateral oblicuo y sección asimétrica (RBO) (20\%) (Figura 7.71). Entre los unifaciales se destacan los artefactos de filo unifacial (45\%), los raspadores (22\%) y los RBO (31\%). Los artefactos con rastros complementarios poseen forma base de lasca (lasca angular, 40\%; lasca secundaria, 60\%) y presentan filo lateral (40\%) y fronto-lateral (60\%) (Figura 7.71). En Pista sólo el 15\% está fracturado y el $85 \%$ restante entero. De los artefactos enteros, el $53 \%$ son artefactos con rastros complementarios, el $36 \%$ unifaciales y el $11 \%$ bifaciales.

\begin{tabular}{|c|c|c|c|c|}
\hline Sitio & INST & R & B & MB \\
\hline \multirow{3}{*}{ CAR-1 } & AF Bifacial & - & 2 & - \\
\cline { 2 - 5 } & AF Unifacial & - & 1 & - \\
\cline { 2 - 5 } & ASF RC & - & 1 & 6 \\
\hline \multirow{3}{*}{ PISTA } & AF Bifacial & - & 3 & 13 \\
\cline { 2 - 5 } & AF Unifacial & 1 & 7 & 21 \\
\cline { 2 - 5 } & ASF RC & 2 & $17(28 \%)$ & $40(67 \%)$ \\
\hline
\end{tabular}

Tabla .782. Calidad para la talla de instrumentos en CAR. Referencia: INST: instrumentos; R: regular; B: bueno; MB: muy buena.

\begin{tabular}{|c|c|c|c|c|c|c|}
\hline \multirow{2}{*}{ Sitio } & \multicolumn{2}{|c|}{ AF Bifacial } & \multicolumn{2}{c|}{ AF Unifacial } & \multicolumn{2}{c|}{ ASF RC } \\
\cline { 2 - 7 } & Entero & Fracturado & Entero & Fracturado & Entero & Fracturado \\
\hline CAR-1 & - & 2 & - & 1 & 1 & - \\
\hline PISTA & 7 & 2 & 19 & 2 & 28 & 2 \\
\hline Total & $6(60 \%)$ & $4(40 \%)$ & $19(87 \%)$ & $3(13 \%)$ & $29(94 \%)$ & $2(6 \%)$ \\
\hline N & \multicolumn{2}{|c|}{11} & \multicolumn{2}{|c|}{22} & \\
\hline
\end{tabular}

Tabla 7.83. Estado de fragmentación en instrumentos de CAR. 

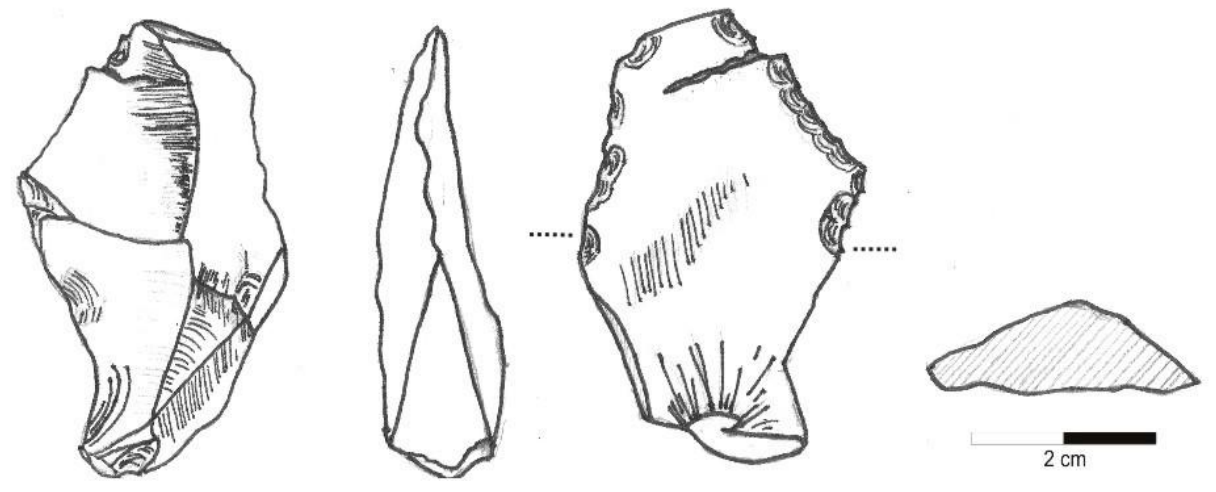

Figura 7.70. Artefacto sin formatización con rastros complementarios de Pista.

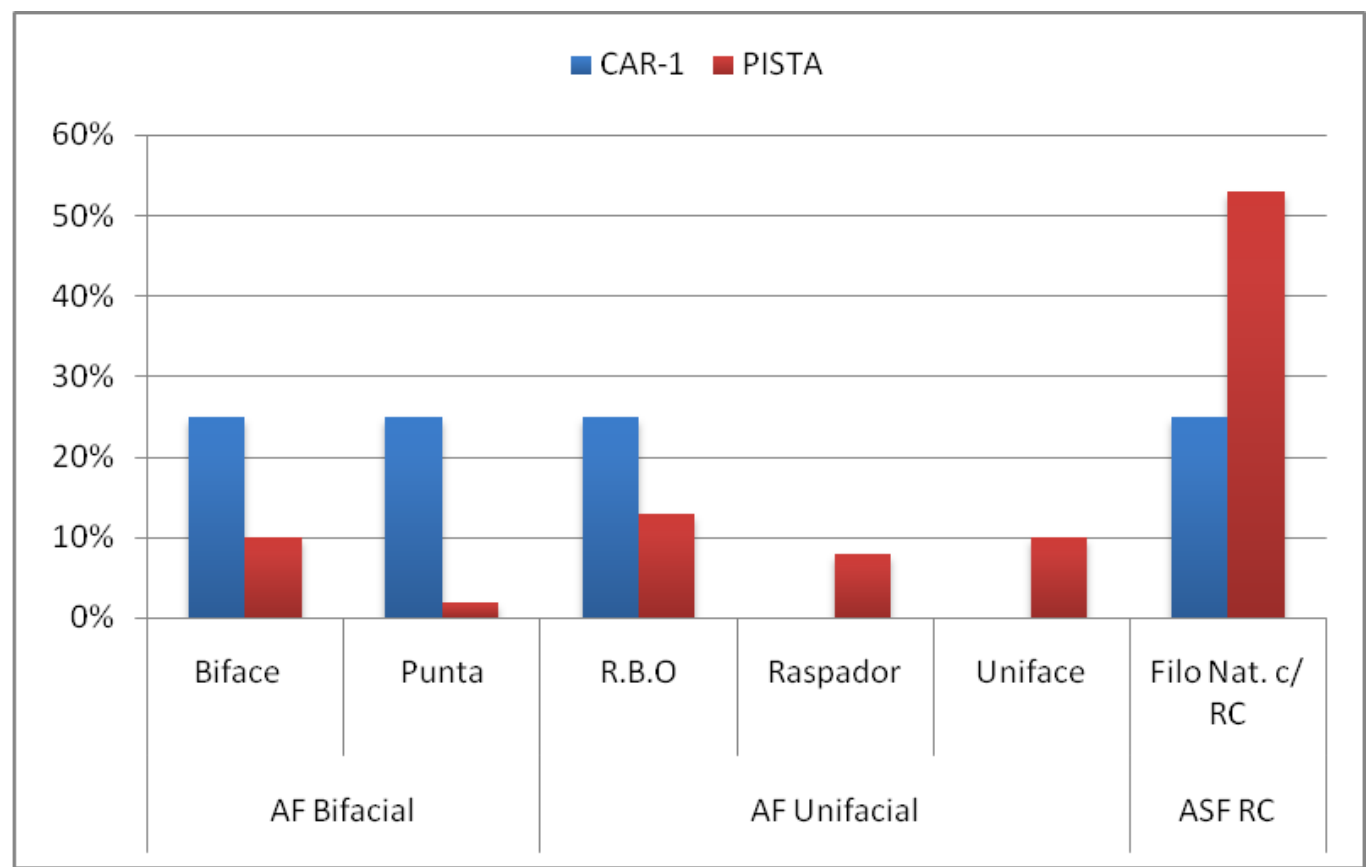

Figura 7.71. Grupos tipológicos en CAR.

El valor de producción en CAR-1 es alto (DT/INST=190/1=190), lo que indica alta tasa de producción y baja frecuencia de descarte de instrumentos. Por otra parte Pista presenta un valor de producción bajo (DT/INST=162/55=2,94) y una alta frecuencia de 
descarte de instrumentos enteros. El índice de bifacialidad (relación entre artefactos bifaciales y el total de instrumentos) en la localidad es de 0,17 , con valores mayores en CAR-1 $(0,5)$ respecto a Pista $(0,15)$.

En Pista se destaca la alta frecuencia de instrumentos enteros. Entre los artefactos con rastros complementario el $65 \%(n=19)$ presenta un único filo con rastros, mientras que el $35 \%$ restante presenta dos filos con rastros. La ausencia de indicadores de reactivación de los artefactos, sumado a la alta frecuencia en el descarte de piezas enteras puede ser resultado de la alta disponibilidad de materias primas silíceas en la localidad. Por otro lado, en CAR-1 el único instrumento entero corresponde a un artefacto con rastros complementarios.

En Pista, los unifaciales se encuentran representados los filos laterales cortos regulares e irregulares (47\%), seguidos por los raspadores (26\%) y RBO (26\%). Presentan tamaño grandísimo, más largos $(x=30,7 \mathrm{~mm})$ que anchos $(x=28,5 \mathrm{~mm})$, espesos $(40 \%)$ a muy espeso (60\%) y de forma base lasca. En los raspadores la relación del valor medio entre el largo máximo $(29,8 \mathrm{~mm})$ y el ancho $(33,5 \mathrm{~mm})$ se invierte, siendo más anchos que largos. Se calculó en índice geométrico de reducción propuesto por Kuhn (1990), tomando todos los artefactos de formatización unifacial enteros con el objeto de evaluar la intensidad de reducción al momento de descarte. Los valores de reducción son bajos para los artefactos de filo unifacial $(x=0,35)$, respecto a los raspadores $(x=0,51)$, lo que indica una mayor intensidad de reducción en éstos últimos (Tabla 7.84). Sin embargo los valores máximos y mínimos no presentan diferencias marcadas. Se realizó una prueba $t$ para determinar la significancia de la diferencia observada entre los índices de reducción geométrica, que arrojó una diferencia no significativa $(t=1,17 ; p=0,25)$. Esto implica que no habría diferencias en la intensidad de reducción de los raspadores y los artefactos de filo unifacial. Los bifaciales enteros, corresponden a bifaces con filo fronto-lateral y una posible preforma. Esta última fue hallada con otros desechos producidos durante el mismo evento de talla. El tamaño en todos los casos es grandísimo, con un largo máximo medio de 39,9 $\mathrm{mm}$ y ancho máximo medio de $14,6 \mathrm{~mm}$. 
En instrumentos fracturados (14\%), los bifaciales pertenecen al grupo tipológico de las puntas de proyectil (50\%) y bifaces con filo irregular (50\%). Las puntas de proyectil están representadas por un fragmento basal de punta apedunculada (Pista) y un fragmento de ápice (CAR-1) (Figura 7.72).

\begin{tabular}{|c|c|c|}
\hline Índice Geométrico & Unifaces - RBO & Raspador \\
\hline $\mathbf{N}$ & 14 & 5 \\
\hline Media & 0,356 & 0,516 \\
\hline Mediana & 0,303 & 0,424 \\
\hline Desvío Estándar & 0,23 & 0,344 \\
\hline Mínimo & 0,097 & 0,094 \\
\hline Máximo & 0,965 & 0,968 \\
\hline Rango & 0,8682 & 0,8740 \\
\hline
\end{tabular}

Tabla 7.84. Estadística descriptiva del índice de reducción en artefactos de formatización unifacial enteros en Pista.

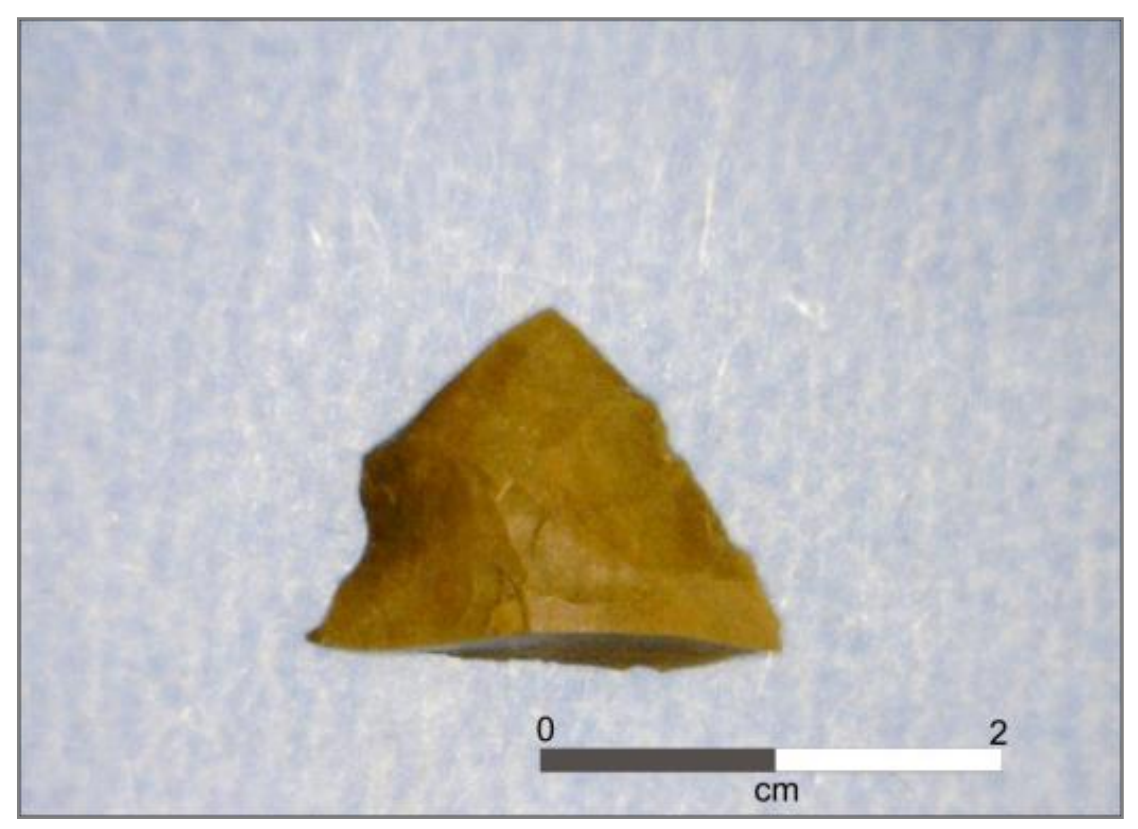

Figura 7.72. Fragmento apical de puntas de proyectil registrado en CAR-1. 


\subsubsection{CONSIDERACIONES GENERALES DE LA LOCALIDAD CARMONINA}

En CAR la materia prima más representada es la roca silícea, seguida por la obsidiana, el basalto y la riolita. La distribución espacial de estas rocas es heterogénea; por ejemplo, en Pista sólo se registraron artefactos sobre silíceas. La calidad para la talla en rocas silíceas y basalto es muy buena, reservando la calidad excelente para los artefactos de obsidiana. Se destaca la mayor frecuencia de instrumentos de calidad para la talla muy bueno descartados en Pista, mientras que en CAR-1 los instrumentos son de calidad buena. El estado de fragmentación de los conjuntos es mayor en CAR-1 que en Pista, situación que ya se había registrado en la localidad APE, donde la frecuencia de artefactos fragmentados es menor en los conjuntos superficiales. La clase artefactual más representada es desechos de talla (70\%), seguidos por los núcleos (17\%) e instrumentos (9,2\%). En desechos de talla se presenta la mayor diversidad de materias primas. En núcleos e instrumentos sólo se registran rocas silíceas. En desechos de talla, Pista presenta valores altos de corteza (77\%), siendo los tamaños frecuentes grande y grandísimo. Por el contrario en CAR-1, los artefactos con reserva de corteza son escasos (30\%) y los tamaños más frecuentes son muy pequeño y mediano pequeño. Los índices de corteza presentan los valores más altos en Pista donde se encuentran representadas con mayor frecuencia las primeras etapas de formatización, así como los valores de intensidad de reducción más bajos. En CAR-1 por el contrario, se registran índices de corteza bajos y altos valores de reducción, siendo más elevados en obsidiana. La roca silícea es la que presenta todas las etapas de manufactura. En CAR-1 no se registra el descarte de núcleos, sin embargo, hay registro de lascas nodulares, vinculadas a tareas de reactivación de núcleos. En Pista la densidad de negativos de lascados en núcleos es baja y prevalecen los núcleos de lascados aislados. La relación entre el tamaño de instrumentos, de los negativos de lascados de núcleos y los núcleos enteros hace suponer que la manufactura de los mismos se hacía a partir de formas base nodulares. La alta frecuencia de instrumentos en Pista y la ausencia de núcleos en CAR-1, hace suponer que gran parte de 
las tareas de manufactura de instrumentos era llevado a cabo en el área de Pista (o sectores próximos similares), donde se reemplazaban instrumentos con potencial de reactivación. En CAR-1 por su parte, se habrían llevado a cabo principalmente tareas de manufactura y reactivación de filos. 


\subsection{RÍO COLORADO (RC)}

La Localidad Río Colorado (en adelante RC), se ubica en las inmediaciones del valle del río homónimo y la planicie elevada denominada Pampa del Carrizalito, al oeste de Cañadón Amarillo (Figura 7.73). En el área cruza el lecho seco de un río transitorio que corre en sentido norte sur, conocido como Aguada Colorada o Aguada Arenosa, donde desaguan los cauces menores provenientes de Sierra de Reyes (p.ej. Aguada de Reyes y Aguada del Ñaco) y de la Altiplanicie del Payén (Figura 7.74). El sector oeste y central se encuentra cubiertos por depósitos aluviales y coluviales, con importantes asomos de arcillas rojizas de la Formación Neuquén (areniscas y limoarcilitas) y calizas y pelitas de la Formación Agrio. La poca compactación del suelo facilita su remoción y la erosión fluvial y limita el desarrollo de la vegetación. El extremo este abarca parte de la Pampa del Carrizalito, un pavimento cubierto donde predomina la erosión eólica (Capítulo 3). La localidad no cuenta con antecedentes arqueológicos previos. 


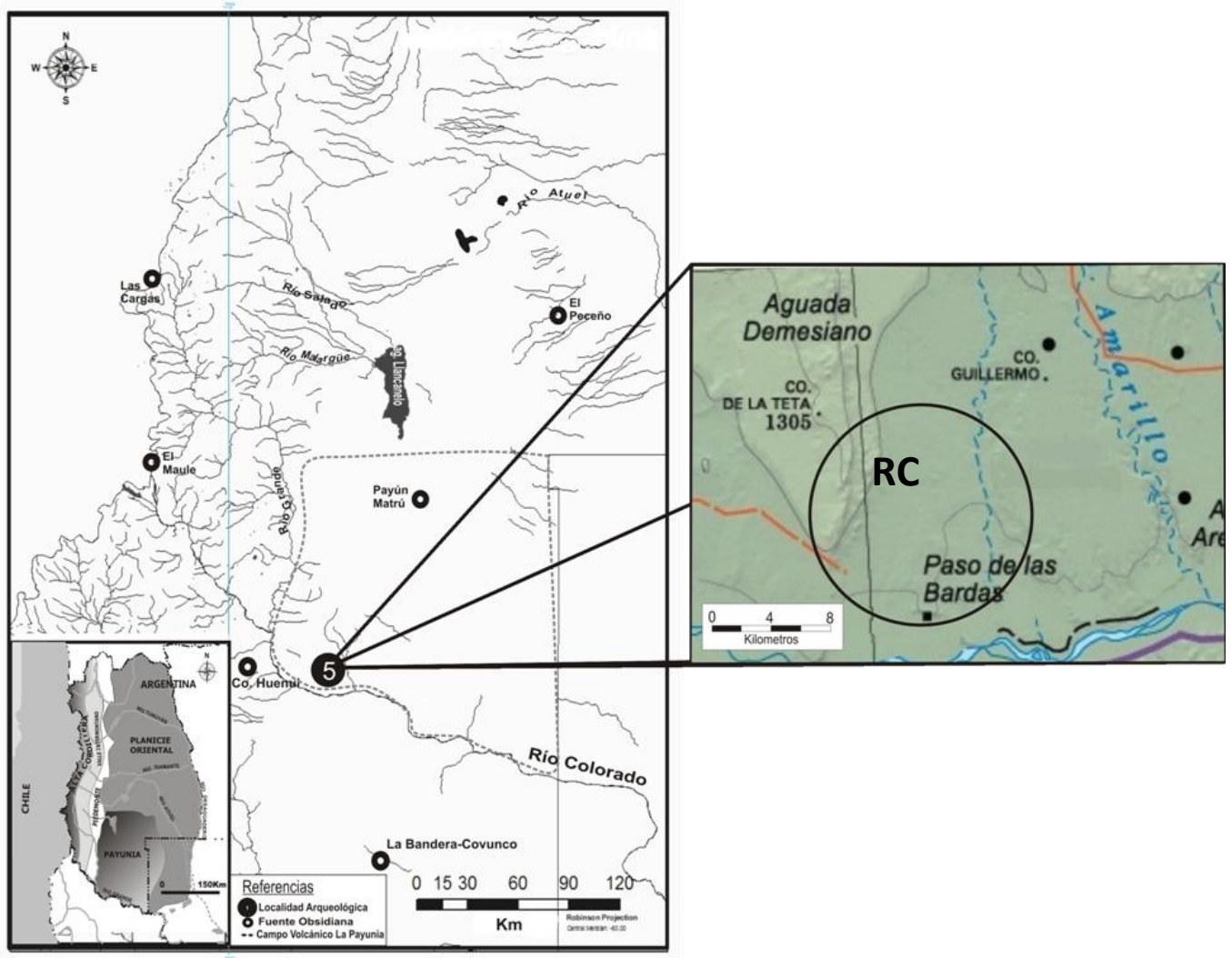

Figura 7.73. Ubicación de la localidad Río Colorado. 


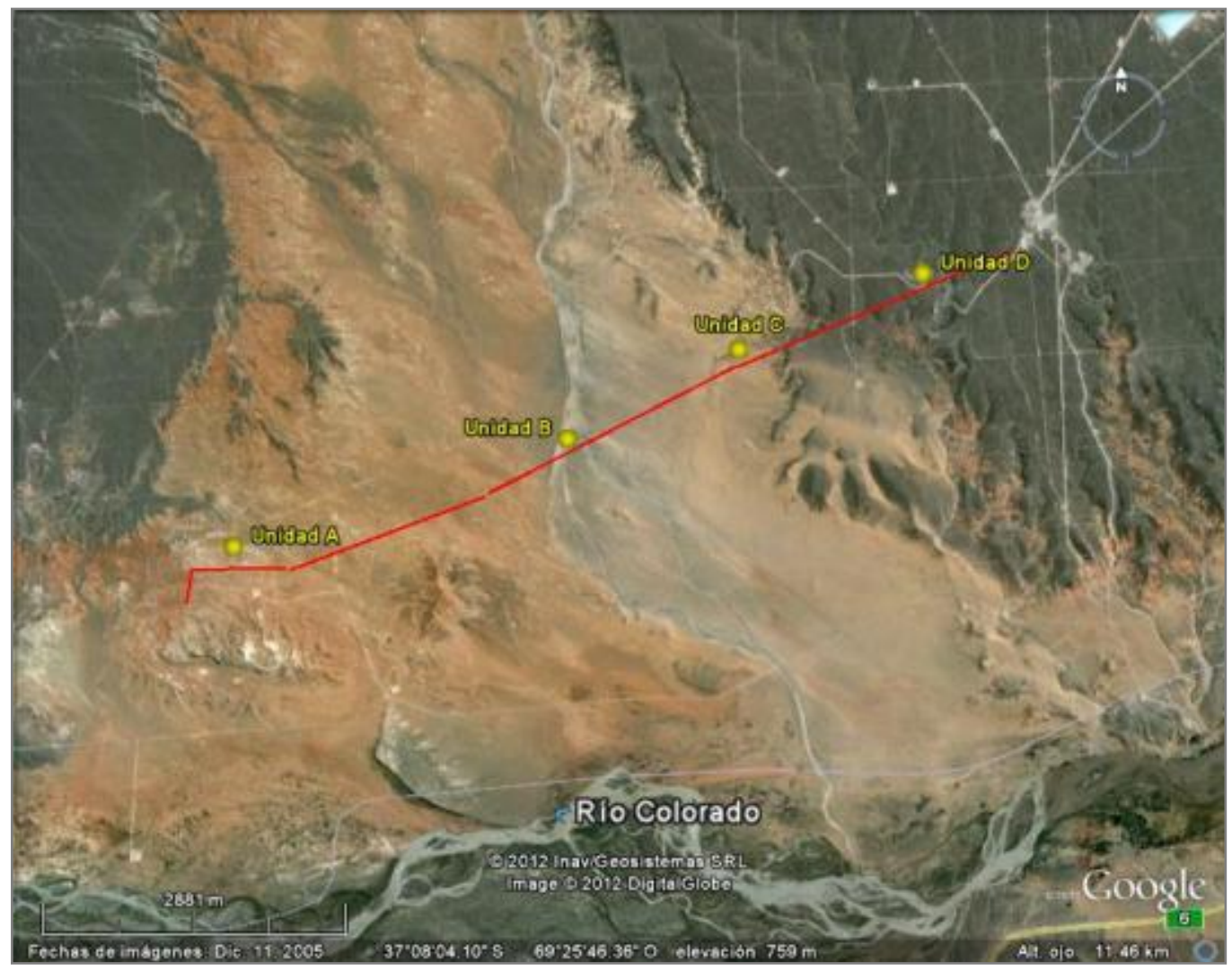

Figura 7.74. Ubicación de transectas en RC.

\subsubsection{MUESTREO RÍO COLORADO (RC)}

En RC se realizó un muestreo superficial en sentido suroeste noreste, que abarca un área aproximada de $8 \mathrm{~km}$ de largo por $12 \mathrm{~m}$ de ancho. Se realizaron tres transectas, con unidades de recolección continuas de aproximadamente $100 \mathrm{~m}$ de longitud. En la localidad se diferenciaron cuatro geoformas o unidades de paisaje, denominadas A, B, C y D (Tabla 7.84). La Unidad A incluye las unidades 1 a 19 de la Transecta 1. La Unidad B incluye las unidades 20 a 26 de Transecta 1 y 28-31 de la Transecta 3. La Unidad C incluye las Unidades 1 a 11 de la Transecta 2 y unidades 37 a 41 de la Transecta 3. La Unidad D abarca las unidades 32 a 36 de la Transecta 3. Las unidades A y B se encuentra en el valle pedemontano, la $C$ en la zona de remoción en masa de la plataforma basáltica y la $D$ en el pedimento cubierto. El muestreo superficial se realizó de modo continuo con unidades de 
$100 \mathrm{~m}$ de longitud y un ancho variable, entre $6 \mathrm{~m}$ y $4 \mathrm{~m}$, relevando una superficie total de $24.600 \mathrm{~m}^{2}$. En cada unidad se recolecto todo el material superficial y se relevó la información de pendiente, visibilidad, geoformas y sedimento (Figura 7.75).

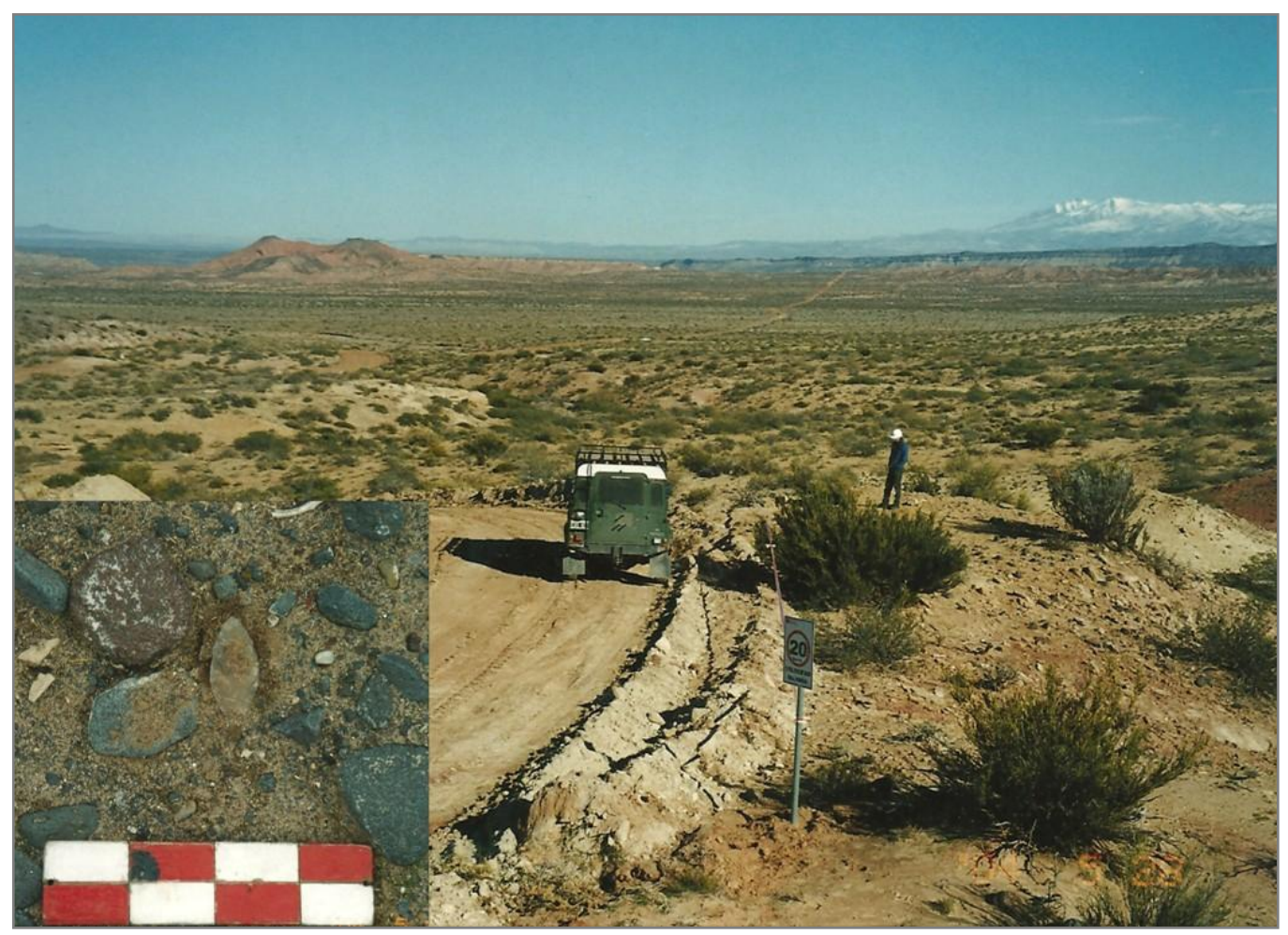

Figura 7.75. Vista de localidad RC y detalle de material superficial.

\begin{tabular}{|c|c|c|c|c|c|c|c|c|c|}
\hline Muestreo & \multicolumn{2}{|c|}{ Ubicación GPS } & msnm & $\mathbf{m 2}$ & N Muestreo & N & Densidad & N s/ Hallazgos & Riqueza \\
\hline A & $37^{\circ} 08^{\prime} 31^{\prime \prime}$ & $69^{\circ} 28^{\prime} 33^{\prime \prime}$ & 790 & 11400 & 19 & 222 & 0,0194 & 3 & 4 \\
\hline B & $37^{\circ} 08^{\prime} 4^{\prime \prime}$ & $69^{\circ} 27^{\prime} 18^{\prime \prime}$ & 764 & 4400 & 11 & 27 & 0,0061 & - & 3 \\
\hline C & $37^{\circ} 07^{\prime} 34^{\prime \prime}$ & $69^{\circ} 25^{\prime} 17^{\prime \prime}$ & 800 & 6000 & 15 & 208 & 0,0346 & 9 & 3 \\
\hline D & $37^{\circ} 07^{\prime} 74^{\prime \prime}$ & $69^{\circ} 24^{\prime} 5^{\prime \prime}$ & 850 & 3200 & 8 & 17 & 0,0053 & 4 & 2 \\
\hline
\end{tabular}

Tabla 7.84. Muestreo superficial en Río Colorado.

Se analizaron 474 artefactos líticos (con una riqueza artefactual de 5), todos procedentes de los muestreos superficiales. En la tabla 7.85 se detallan las frecuencias de las clases artefactuales en las distintas unidades del paisaje. Las materias primas 
registradas son las rocas silíceas y el basalto (Tabla 7.86). Los artefactos se encuentran mayormente enteros (87\%) y en menor medida fragmentados (13\%), presentando fractura solo los confeccionados en rocas silíceas. La distribución de las clases artefactuales es heterogénea en el paisaje (Figura 7.76). En las unidades $A$ y $C$, se observan las mayores concentraciones. En la unidad A la visibilidad es muy buena, con terreno de pendiente regular a suave. En la unidad B la visibilidad es muy buena (70\%) a regular $(30 \%)$ y la pendiente es en general suave (45\%), con sectores que varían entre nula (18\%), regular (18\%) y pronunciada (18\%). Esta última unidad se encuentra en la actual planicie de inundación de un cauce seco, que en épocas de lluvia actúa como principal agente de remoción de sedimento y entierro de material superficial. La unidad C presenta una visibilidad buena (100\%) y pendiente suave (66\%) a regular (33\%). En ella predominan los procesos de remoción o flujo de material de conglomerados y areniscas de la Formación Tristeza (Narciso et al. 2001b). Esta plataforma, presenta altitudes superiores a los 1500 msnm. La unidad D presenta visibilidad buena (80\%) a mala (20\%) y pendiente abrupta (80\%) a regular (20\%). Se ubica sobre el pedimento cubierto que separa el Cañadón Amarillo del cauce seco Aguada Colorada. Las unidades A y D se encuentran próximas a instalaciones mineras actuales, por lo cual se espera un mayor impacto antrópico moderno.

\begin{tabular}{|c|c|c|c|c|c|c|c|}
\hline Unidad & AF Bifacial & AF Unifacial & ASF RC & DT & Núcleo & ND & Total \\
\hline A & 9 & 4 & 2 & 94 & 91 & 22 & 222 \\
\hline B & 2 & - & - & 16 & 8 & 1 & 27 \\
\hline C & - & - & 2 & 112 & 74 & 17 & 208 \\
\hline D & - & - & - & 8 & 8 & 1 & 17 \\
\hline Total & $11(2 \%)$ & $4(1 \%)$ & $4(1 \%)$ & $230(49 \%)$ & $181(38 \%)$ & $41(9 \%)$ & $474(100 \%)$ \\
\hline
\end{tabular}

Tabla 7.85. Clases artefactuales en RC. 


\begin{tabular}{|c|c|c|c|}
\hline Muestreo & BAS & SIL & Total \\
\hline A & $3(1 \%)$ & $219(99 \%)$ & 222 \\
\hline B & - & $27(100 \%)$ & 27 \\
\hline C & $2(1 \%)$ & $206(99 \%)$ & 208 \\
\hline D & - & $17(100 \%)$ & 17 \\
\hline Total & $5(1 \%)$ & $469(99 \%)$ & $474(100 \%)$ \\
\hline
\end{tabular}

Tabla 7.86. Distribución y frecuencia de materias primas en RC.

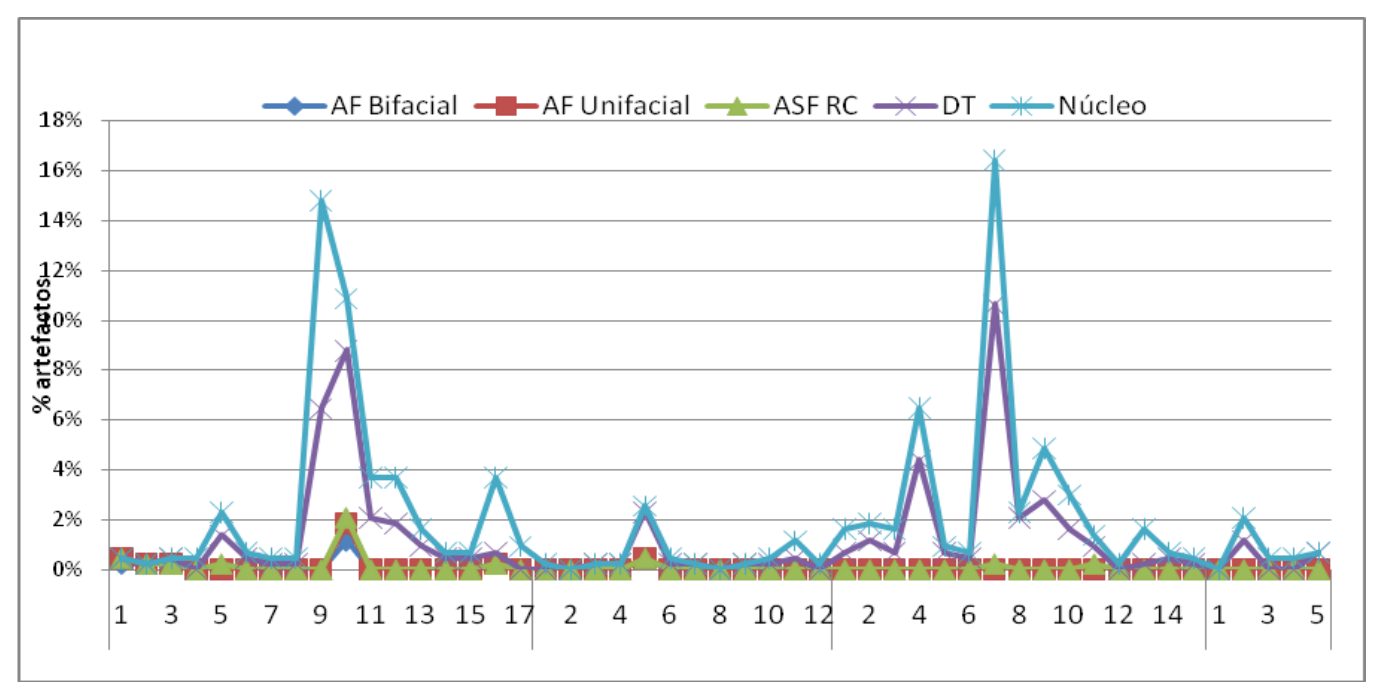

Figura 7.76. Distribución de clases artefactuales en RC, respecto al total recuperado en la localidad.

\subsubsection{ANÁLISIS TECNOLÓGICO DE LA LOCALIDAD RÍO COLORADO}

Teniendo en cuenta que las condiciones de visibilidad, y posiblemente la historia depositacional y post-depositacional, es diferente en las distintas geoformas, la información en este apartado se organiza según las unidades de paisaje definidas con anterioridad. 


\subsection{2a MATERIAS PRIMAS LÍTICAS}

En la localidad se registran las rocas silíceas (99\%) y en menor proporción el basalto (1\%) (Tabla 7.86). Las rocas silíceas se registran en todas las unidades de paisaje, mientras que el basalto se registra solo en las unidades $A$ y $C$. La calidad para la talla se determinó para el $20 \%(n=90)$ de los artefactos, predominando la muy buena $(56 \%)$, sobre la buena (34\%) y la regular (10\%). Los conjuntos se encuentran en su mayoría entero y en menor medida fragmentado (Tabla 7.87).

En todas las unidades las rocas silíceas presentan un índice de fragmentación cercano al $12 \%$. Los basaltos por su parte no presentan fractura (Tabla 7.88). En cuanto al tamaño, el 99\% de los artefactos es de tamaño grandísimo (modulo 7, >161) y el 1\% muy grande (modulo 6, 121-160). Se observa una alta frecuencia de artefactos con reserva de corteza (73\%), respecto a artefactos sin corteza (27\%) (Tabla 7.89). En basalto, todos los artefactos presentan reserva de corteza. En rocas silíceas, los artefactos presentan corteza entre los rangos de $25 \%$ a $50 \%$, seguidos por los artefactos sin corteza. En todas las unidades los artefactos sin corteza representan menos del $40 \%$ del total. La unidad B es la que posee mayor proporción de artefactos corteza (81\%).

\begin{tabular}{|c|c|c|c|c|c|c|c|}
\hline UNIDAD & MP & Entero & \% & Fracturado & \% & ND & \% \\
\hline \multirow{2}{*}{ A } & BAS & 3 & $100 \%$ & - & - & - & - \\
\cline { 2 - 9 } & SIL & 188 & $86 \%$ & 22 & $10 \%$ & 9 & $4 \%$ \\
\hline \multirow{2}{*}{ B } & SIL & 20 & $74 \%$ & 6 & $22 \%$ & 1 & $4 \%$ \\
\hline \multirow{2}{*}{ C } & BAS & 2 & $100 \%$ & - & - & - & - \\
\cline { 2 - 9 } & SIL & 166 & $81 \%$ & 26 & $13 \%$ & 14 & $13 \%$ \\
\hline D SIL & 10 & $35 \%$ & 6 & $35 \%$ & 1 & $35 \%$ \\
\hline
\end{tabular}

Tabla 7.87. Materias primas y calidad para la talla en RC. 


\begin{tabular}{|c|c|c|c|c|c|c|c|c|}
\hline UNIDAD & MP & Ent & Fr. Prox & Fr. Mar & Fr. Dist & NAS & MNA & MNA/NAS \\
\hline \multirow{2}{*}{ A } & BAS & 1 & - & - & - & 1 & 1 & $100 \%$ \\
\hline & SIL & 72 & 12 & 1 & 9 & 94 & 84 & $89 \%$ \\
\hline B & SIL & 11 & 3 & - & 2 & 16 & 14 & $88 \%$ \\
\hline \multirow{2}{*}{ C } & BAS & 1 & - & - & - & 1 & - & $0 \%$ \\
\hline & SIL & 75 & 12 & - & 14 & 101 & 89 & $88 \%$ \\
\hline D & SIL & 2 & 1 & - & 5 & 8 & 7 & $88 \%$ \\
\hline \multicolumn{2}{|c|}{ Total } & 162 & 26 & 1 & 30 & 221 & 195 & $88 \%$ \\
\hline
\end{tabular}

Tabla 7.88. Estado de fragmentación de los artefactos respecto a materia prima y muestreo en RC. Referencias: MP: materia prima; Ent: entero; Fr. Prox: fragmento proximal; Fr. Dist: fragmento distal; Fr. ND: fragmento no diferenciado; NAS: número de especímenes artefactuales; MNA: número mínimo de artefactos.

\begin{tabular}{|c|c|c|c|c|c|c|}
\hline UNIDAD & MP & $\mathbf{0 \%}$ & $\mathbf{2 5 \%}$ & $\mathbf{5 0 \%}$ & $\mathbf{7 5 \%}$ & $\mathbf{1 0 0 \%}$ \\
\hline \multirow{2}{*}{ A } & BAS & - & - & $50 \%$ & - & $50 \%$ \\
\cline { 2 - 7 } & SIL & $20 \%$ & $28 \%$ & $36 \%$ & $7 \%$ & $8 \%$ \\
\hline \multirow{2}{*}{ B } & SIL & $40 \%$ & $35 \%$ & $15 \%$ & $10 \%$ & $0 \%$ \\
\hline & BAS & - & - & - & $100 \%$ & - \\
\hline & SIL & $37 \%$ & $35 \%$ & $24 \%$ & - & $4 \%$ \\
\hline D SIL & $43 \%$ & $43 \%$ & - & - & $14 \%$ \\
\hline
\end{tabular}

Tabla 7.89. Reserva de corteza en la cara dorsal de artefactos enteros en RC.

\subsection{2b ESTRUCTURA TECNOLÓGICA EN RÍO COLORADO}

La clase artefactual predominante es desechos de talla (54\%), seguida por los núcleos (42\%) y los instrumentos (5\%). Entre los instrumentos se destacan los artefactos de formatización bifacial (3\%) (Tabla 7.90). La distribución y frecuencia de las clases artefactuales presenta variaciones en el espacio. Las unidades $A$ y $B$ son las únicas que presentan artefactos de formatización unifacial y bifacial. Las unidades A y C son las que concentran mayor número de piezas, principalmente desechos de talla y núcleos. Respecto a la distribución de materias primas en el espacio, en todas las unidades se registran rocas silíceas. Las unidades $\mathrm{A}$ y $\mathrm{C}$ son las únicas que presentan artefactos en basalto. La tabla 7.91 detalla los valores de diversidad de clases artefactuales según materias primas. Los valores de riqueza y variabilidad artefactual son mayores en rocas 
silíceas que en basalto. En ambos casos los desechos de talla y núcleos son las clases más frecuentes.

\begin{tabular}{|c|c|c|c|c|c|c|c|}
\hline UNIDAD & MP & AF Bifacial & AF Unifacial & ASF RC & DT & Núcleo & Total general \\
\hline \multirow{2}{*}{ A } & BAS & - & - & - & $1(50 \%)$ & $1(50 \%)$ & 2 \\
\hline & SIL & $9(5 \%)$ & $4(2 \%)$ & $2(1 \%)$ & $93(47 \%)$ & $90(45 \%)$ & 198 \\
\hline B & SIL & $2(8 \%)$ & - & - & 16 (62\%) & $8(31 \%)$ & 26 \\
\hline \multirow{2}{*}{ C } & BAS & - & - & - & $1(50 \%)$ & $1(50 \%)$ & 2 \\
\hline & SIL & - & - & $2(1 \%)$ & $114(60 \%)$ & 73 (39\%) & 189 \\
\hline D & SIL & - & - & - & $8(50 \%)$ & $8(50 \%)$ & 16 \\
\hline \multicolumn{2}{|c|}{ Total } & $11(3 \%)$ & $4(1 \%)$ & $4(1 \%)$ & 233 (54\%) & 181 (42\%) & 433 \\
\hline
\end{tabular}

Tabla 7.90. Clases artefactuales por sitio en RC. Entre paréntesis se detalla la proporción de la clase artefactual por materia prima y sitio de muestreo. Referencia: MP: materia prima; AF Bifacial: artefacto de formatización bifacial; AF Unifacial: artefacto de formatización unifacial; As/F con RC: artefacto sin formatización con rastros complementarios; DT: desecho de talla; ND: no diferenciado.

\begin{tabular}{|c|c|c|}
\hline & SIL & BAS \\
\hline N clases artefacto & 5 & 2 \\
\hline $\mathbf{N}$ & 433 & 4 \\
\hline Dominancia & 0,4651 & 0,5 \\
\hline Shannon H & 0,8779 & 0,6931 \\
\hline Simpson & 0,5349 & 0,5 \\
\hline
\end{tabular}

Tabla 7.91. Diversidad de clases artefactuales según materas primas en RC.

\subsection{2b.1 DESECHOS DE TALLA}

Los desechos de talla son los artefactos más representados en RC (54\%). La materia primas más frecuente en esta clase artefactual es la roca silícea $(99 \%, n=231)$, seguida por el basalto $(1 \%, n=2)$. El $75 \%(n=176)$ de los artefactos se encuentra entero y el $25 \%(n=57)$ fragmentado. Entre los enteros, el $67 \%$ presenta remanente de corteza en la cara dorsal (Tabla 7.92). En las geoformas A y C se observan valores más altos de reserva de corteza, en coincidencia con las unidades en las cuales se registro mayor número de desechos. En la unidad B y D la frecuencia de desechos sin corteza es mayor al 50\%. En rocas silíceas se 
encuentran representados todos los rangos de reserva de corteza, mientras que en basalto solo los rangos $75 \%$ y $100 \%$.

En la localidad los desechos externos (lascas primarias, secundarias y de desechos de reactivación de núcleo) alcanzan el 64\% del total analizado (Tabla 7.93). Mientras las lascas internas (lascas de arista y angulares) representan el 34\%, primando las primeras etapas de manufactura de artefactos. El índice de corteza (Tabla 7.94), refleja diferencias entre las unidades analizadas. Las unidades $A$ y $D$, presentan en rocas silíceas un alto índice de corteza (A: 0,688 ; D: 0,625$)$, mientras que en $C(0,5)$ y $B(0,437)$ son menores. En basalto el índice es el máximo esperado, dado que los únicos desechos registrados corresponden a lascas externas. En cuanto a la intensidad de reducción, es mayor en la unidad $B\left(x=0,259 \mathrm{e} / \mathrm{mm}^{2}\right)$, mientras que en las unidades $A$ y $C$ el valor es menor (Tabla 7.95). Sin embargo la mediana y la desviación estándar en el caso de la unidad A se alejan de la media, lo que implica una mayor variación interna; esto también puede observase en el valor de rango. Por otro lado, las unidades $B$ y $A$ son las únicas donde se registraron desechos de reactivación de filo. La unidad D, presenta los valores menores de intensidad de reducción, en coincidencia con los altos índices de corteza.

\begin{tabular}{|c|c|c|c|c|c|c|c|c|}
\hline UNIDAD & MP & $0 \%$ & $25 \%$ & $50 \%$ & $75 \%$ & $100 \%$ & ND & Total \\
\hline \multirow{2}{*}{ A } & BAS & - & - & - & - & 1 (100\%) & - & 1 \\
\hline & SIL & $19(26 \%)$ & $17(23 \%)$ & $16(22 \%)$ & $8(11 \%)$ & 11 (15\%) & $2(3 \%)$ & 73 \\
\hline B & SIL & $6(55 \%)$ & $3(27 \%)$ & $1(9 \%)$ & $1(9 \%)$ & - & - & 11 \\
\hline \multirow{2}{*}{ C } & BAS & - & - & - & $1(100 \%)$ & - & - & 1 \\
\hline & SIL & 32 (36\%) & $28(32 \%)$ & 19 (22\%) & - & $2(2 \%)$ & 7 (8\%) & 88 \\
\hline D & SIL & $1(50 \%)$ & - & - & - & $1(50 \%)$ & - & 2 \\
\hline \multicolumn{2}{|c|}{ Total } & $58(33 \%)$ & $48(27 \%)$ & $36(20 \%)$ & $10(6 \%)$ & $15(9 \%)$ & $9(5 \%)$ & 176 \\
\hline
\end{tabular}

Tabla 7.92. Reserva de corteza en desechos enteros en RC. 


\begin{tabular}{|c|c|c|c|c|c|c|c|c|c|}
\hline UNIDAD & MP & LPR & LSEC & LAN & LAR & LR & LN & ND & Total \\
\hline \multirow{2}{*}{ A } & BAS & $1(100 \%)$ & - & - & - & - & - & - & 1 \\
\hline & SIL & 18 (19\%) & 46 (49\%) & $16(17 \%)$ & $2(2 \%)$ & 1 (1\%) & 11 (12\%) & - & 93 \\
\hline B & SIL & $3(19 \%)$ & $4(25 \%)$ & $6(38 \%)$ & - & 3 (19\%) & - & - & 16 \\
\hline \multirow{2}{*}{ C } & BAS & - & 1 (100\%) & - & - & - & - & - & 1 \\
\hline & SIL & $11(10 \%)$ & 46 (40\%) & $52(46 \%)$ & - & - & $4(4 \%)$ & $1(1 \%)$ & 114 \\
\hline D & SIL & $1(13 \%)$ & 4 (50\%) & $3(38 \%)$ & - & - & - & - & 8 \\
\hline \multicolumn{2}{|c|}{ Total } & 34 (15\%) & $101(43 \%)$ & 77 (33\%) & $2(1 \%)$ & $4(2 \%)$ & $15(6 \%)$ & $1(0,4 \%)$ & $233(100 \%)$ \\
\hline
\end{tabular}

Tabla 7.93. Tipos de desechos de talla respecto unidad de paisaje de muestreo y materia prima en RC. Referencia: LPR: lasca primaria; LSEC: Iasca secundaria; LAN: lasca angular; LAR: lasca de arista; LAB: lasca de adelgazamiento bifacial; PL: lasca plana; LR: lasca de reactivación; LN: lasca nodular (incluye lascas de flanco de núcleo, cresta de núcleo y lascas de reactivación de núcleo); LBIP: lasca bipolar; ND: lasca no diferenciada.

\begin{tabular}{|c|c|c|c|c|c|}
\hline UNIDAD & MP & N & LPR & LSEC & Índice Corteza \\
\hline \multirow{2}{*}{ A } & BAS & 1 & 1 & - & 1 \\
\cline { 2 - 6 } & SIL & 93 & 18 & 46 & 0,688 \\
\hline \multirow{2}{*}{ B } & SIL & 16 & 3 & 4 & 0,437 \\
\hline \multirow{2}{*}{ C } & BAS & 1 & - & 1 & 1 \\
\hline D & SIL & 114 & 11 & 46 & 0,5 \\
\hline
\end{tabular}

Tabla 7.94. Frecuencias de lascas primarias y secundarias enteras por materias primas líticas en RC. Referencias: MP: materia prima; N: abundancia de desechos de talla enteros; LPR: lasca primaria; LSEC: Iasca secundarias.

\begin{tabular}{|c|c|c|c|c|c|c|c|}
\hline Muestreo & $\mathbf{N}$ & Media & Mediana & Desvío Estándar & Mínimo & Máximo & Rango \\
\hline UNA & 93 & 0,18 & 0,096 & 0,238 & 0 & 1,649 & 1,649 \\
\hline UNB & 13 & 0,259 & 0,303 & 0,189 & 0 & 0,638 & 0,638 \\
\hline UNC & 114 & 0,18 & 0,142 & 0,166 & 0 & 0,812 & 0,812 \\
\hline UND & 8 & 0,154 & 0,095 & 0,167 & 0 & 0,525 & 0,525 \\
\hline
\end{tabular}

Tabla 7.95. Estadística descriptiva de la densidad de extracciones previas en la cara dorsal de los desechos de talla en RC.

Los indicadores de las etapas y de la intensidad de reducción de los desechos no son homogéneos en el espacio. En la unidad A se registran frecuencias altas de desechos con corteza, índices de corteza altos e intensidad de reducción media con alta variación interna. En la unidad B, los dos primeros indicadores son bajos, siendo frecuentes los 
descartes sin corteza y con valores de intensidad de reducción altos. En la unidad C y D, por su parte, los tres indicadores presentan valores medios a bajos. En la figura 7.77, se observa la frecuencia de las etapas de reducción en las geoformas. Se destacan las primeras etapas de manufactura en las unidades $A$ y $D$, y la manufactura de filos en la unidad B, la cual se suma a los registros de mayor intensidad de reducción.

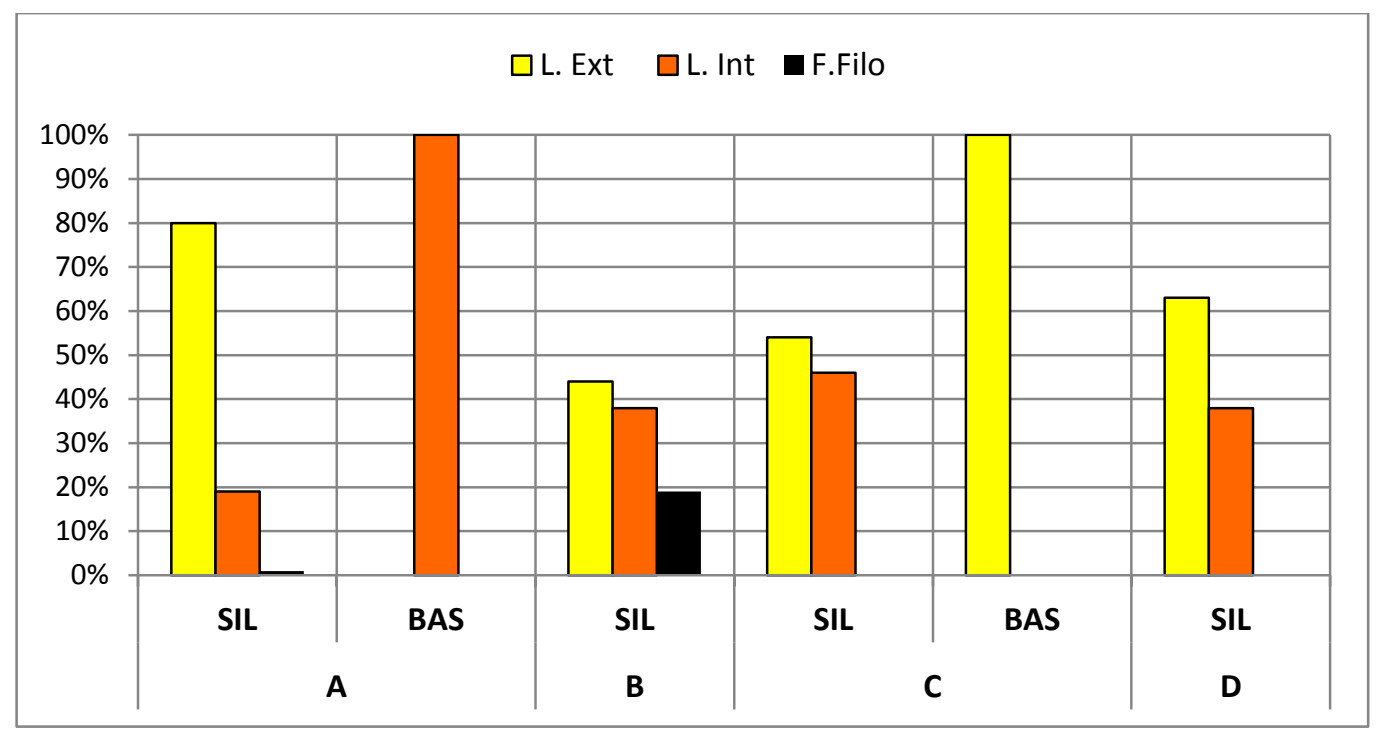

Figura 7.77. Frecuencia de lascas externas (L. Ext), lascas internas (L. Int) y de lascas de formatización de filos (F. Filo) por transecta y materia prima en RC. Referencia: SIL: rocas silíceas; BAS: basalto.

\subsubsection{B.2 NÚCLEOS}

Los núcleos representan el $42 \%(n=181)$ de la muestra de RC. Las materias primas registradas son las rocas silíceas (99\%) y el basalto (1\%). Las primeras se encuentran distribuidas en todas las unidades de modo homogéneo mientras que los basaltos sólo aparecen en las unidades A y C (Figura 7.78). La morfología de los núcleos más frecuente es de lascados aislados (75\%), los cuales varían entre uno y tres lascados (60\%) y más de cuatro extracciones con boca de lascado (40\%). Siguen en frecuencia los amorfos (10\%), prismáticos (10\%) y bifaciales (1\%). El 99\% se encuentran enteros, de tamaño grandísimo 
(módulo 7, rango >161 mm) y con espesor variable entre muy espeso (90\%) y espeso (10\%). La calidad para la talla es muy buena en el $45 \%$ de las piezas, seguida por la regular (30\%) y la buena (25\%). La densidad de negativos de lascados en rocas silíceas es de 1,638 e/ $\mathrm{mm}^{3}$ (peso promedio de 52,62 gr), mientras que en basaltos es de 0,629 e/ $\mathrm{mm}^{3}$ (peso promedio $250 \mathrm{gr}$ ); este último valor debe considerarse con cautela porque son solo dos los núcleos de basalto (Figura 7.79). El tamaño de los negativos de lascado es en la mayoría de los casos grandísimo (90\%, modulo 7$)$, seguido por el muy grande (10\%, modulo 6$)$.

La relación entre las medidas máximas de largo y ancho en las clases artefactuales, muestran que los instrumentos registrados en la localidad son más largos que anchos, tendencia que también se observa en desechos y negativos de lascados medidos en los núcleos (Tabla 7.96). Estas dos últimas clases, presentan tamaños medios similares. En negativos de lascado los valores medios de largo y anchos máximo son menores a los observados en instrumentos, diferencia que supera en poco los valores mínimos y máximos medidos en el total de los negativos. Los tamaños medios de los núcleos enteros (Largo x=49,94; Ancho x=38,766) superan el de los instrumentos. Se realizó una prueba de $t$ para evaluar la significancia de las diferencias que arrojó el siguiente resultado: $t=1,9$; $p=0,20$; por lo que se acepta la hipótesis nula que afirma la ausencia de relación y lo aleatorio de las diferencias observadas. No se puede sostener que las diferencias observadas entre negativos de lascados e instrumentos se deban a que los mismo han sido tallados a partir de formas base distintas a lascas. Mostrando una relación lineal entre las clases (Figura 7.80), que puede responder a la extracción de lascas para la formatización de instrumentos y el descarte de núcleos con potencial para la talla. 


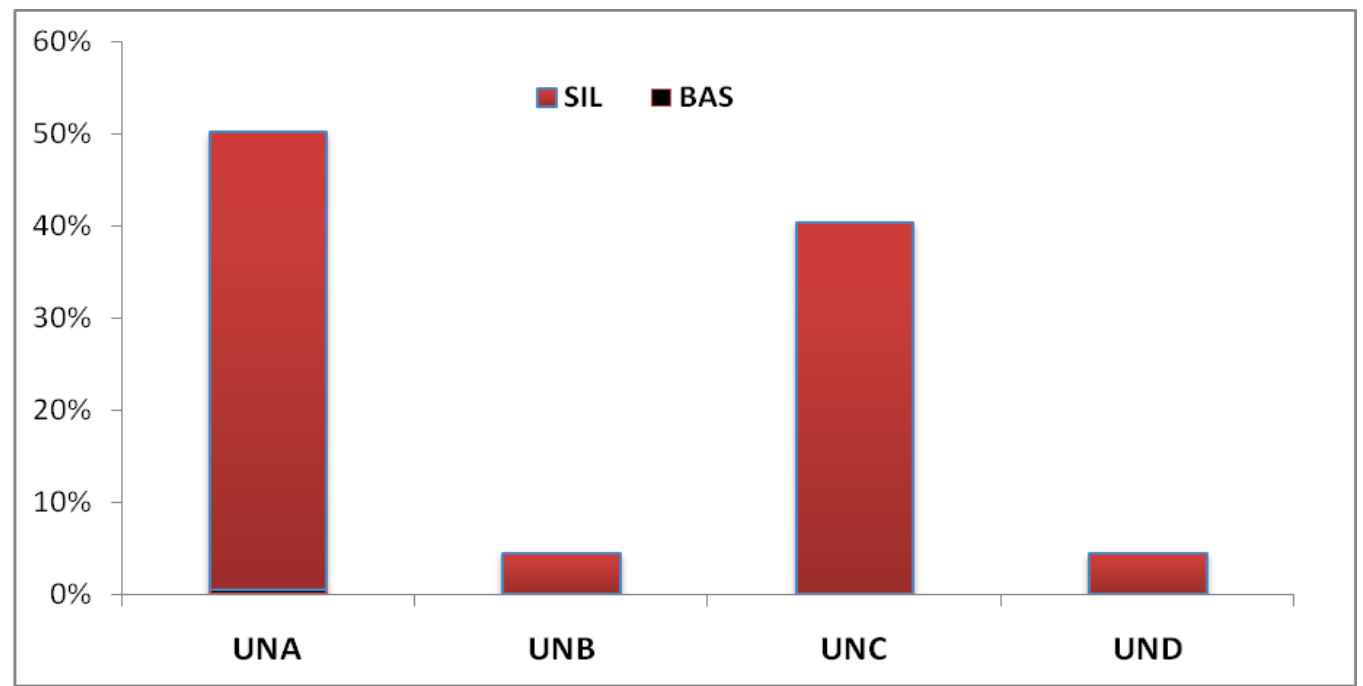

Figura 7.78. Frecuencia de núcleos respecto a geoformas en RC. Referencia: SIL: rocas silíceas; BAS: basalto.

\begin{tabular}{|c|c|c|c|c|c|c|}
\hline & \multicolumn{2}{|c|}{ Desechos de talla } & \multicolumn{2}{c|}{ Instrumentos } & \multicolumn{2}{c|}{ Núcleos } \\
\hline & Largo $\mathrm{mm}$ & Ancho $\mathrm{mm}$ & Largo $\mathrm{mm}$ & Ancho $\mathrm{mm}$ & Largo mm & Ancho $\mathrm{mm}$ \\
\hline $\mathbf{N}$ & 233 & 233 & 19 & 19 & 37 & 37 \\
\hline Media & 32,683 & 30,647 & 41,742 & 33,494 & 31,186 & 30,916 \\
\hline Desvío Estándar & 10,844 & 9,573 & 17,796 & 11,327 & 14,639 & 12,498 \\
\hline Mediana & 32 & 29,9 & 36,1 & 31,7 & 28,5 & 29,6 \\
\hline Mínimo & 11,5 & 12 & 20,1 & 19,5 & 13,4 & 16,7 \\
\hline Máximo & 67 & 77,3 & 78,8 & 62 & 77 & 76,3 \\
\hline
\end{tabular}

Tabla 7.96 Estadística descriptiva de las variables largo y ancho en desechos de talla e instrumentos enteros y su relación con los negativos de lascado en núcleos en RC. 


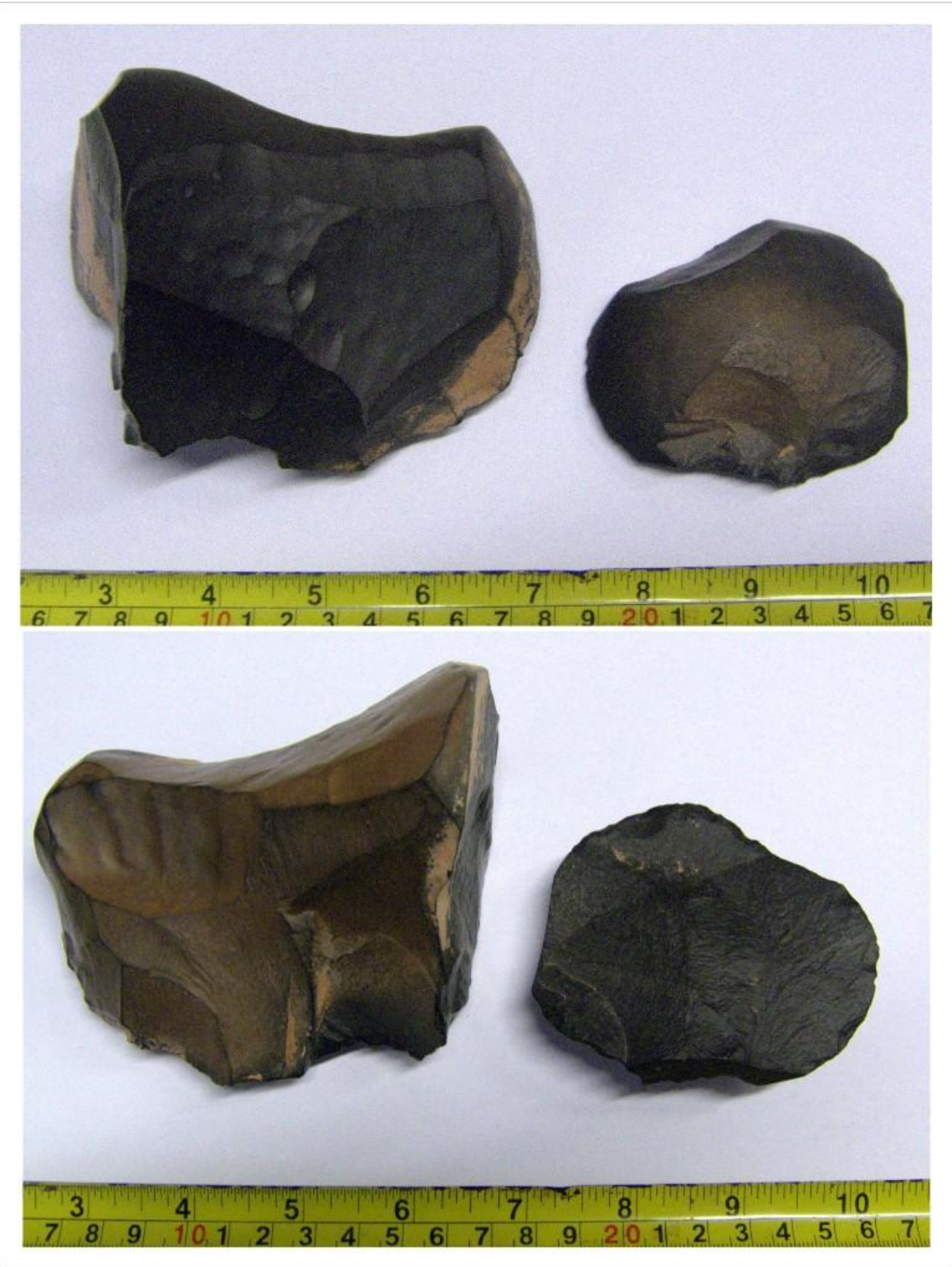

Figura 7.79 Núcleo y lasca secundaria de basalto recuperados en RC. 

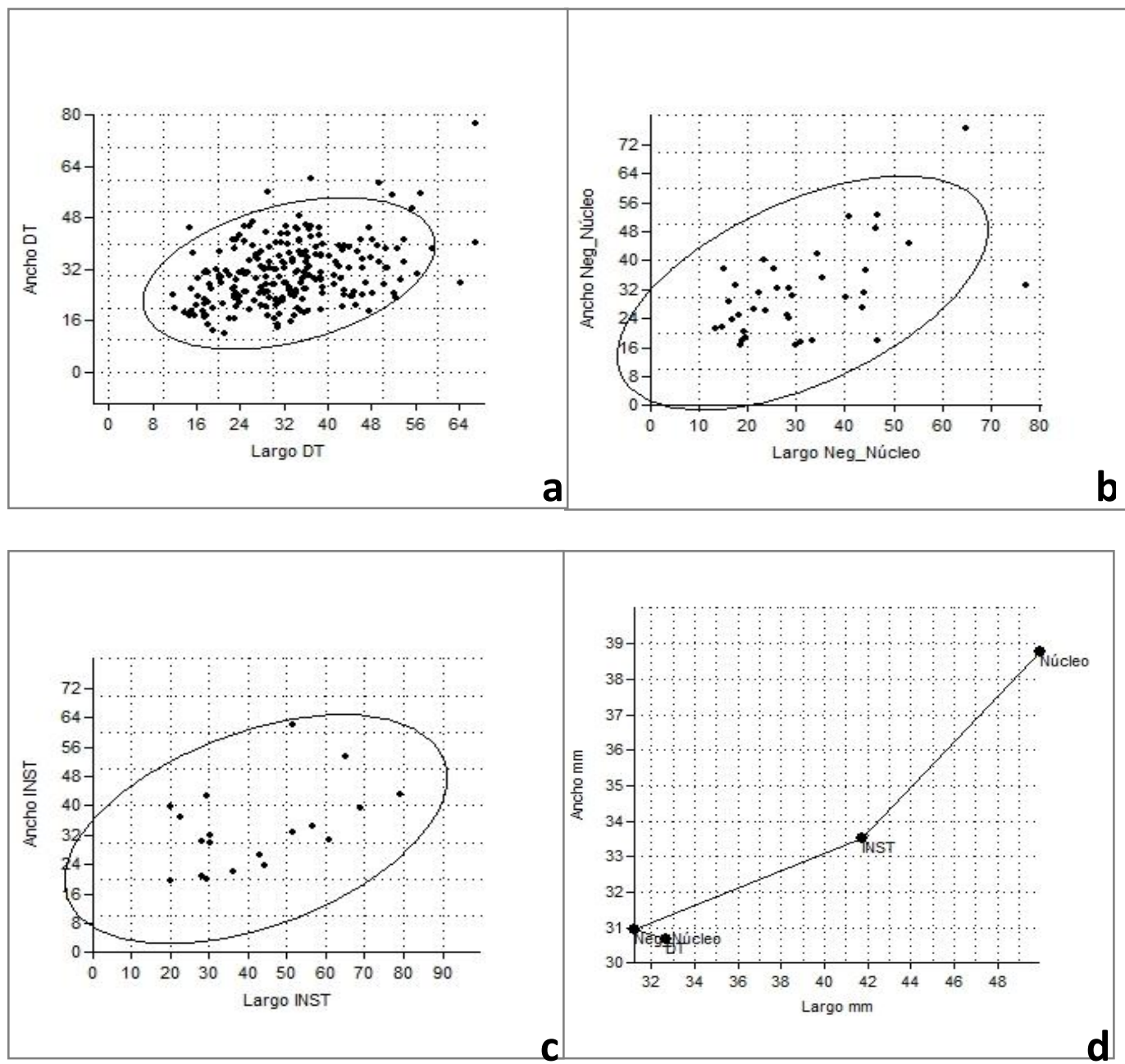

Figura 7.80 Tamaño de negativos de lascado respecto a clases artefactuales en RC. Referencias: $\boldsymbol{a}$ : relación entre largo y ancho en desechos de talla; b: relación entre largo y ancho en negativos de lascado de núcleos; c: relación entre largo y ancho en instrumentos; $d$ : relación entre valores medios relativos de largo y ancho en clases artefactuales y negativos de lascado en núcleos.

\subsection{2b.3 INSTRUMENTOS}

Los instrumentos representan el 5\% ( $n=19)$ del total de piezas de RC (Tabla 7.90). La materia prima representada es la roca silícea. Entre los instrumentos, los artefactos formatizados de modo bifacial (58\%) son los más abundantes, seguidos por los unifaciales (21\%) y los artefactos con rastros complementarios (21\%). Su distribución en las 
geoformas no es homogénea: el 78\% $(n=15)$ proviene de la unidad A, seguido por las unidades $B$ y $C$ donde en ambas se registra un $11 \%(n=2)$.

La manufactura de los artefactos se realizó en todos los casos sobre lasca. Predomina la calidad para la talla muy buena (68\%), seguida por la buena (13\%) y la regular $(13 \%)$. Los artefactos bifaciales $(n=9)$ recuperados en la unidad A poseen calidad para la talla muy buena (77\%) y buena (22\%). Están representados por los tipos: bifaces (56\%), raederas (2\%) y puntas de proyectil (22\%); un bifaz se encuentra fracturado (Figura 7.81). En la misma unidad se recolectaron artefactos de manufactura unifacial $(n=4)$ enteros de calidad muy buena para la talla, entre los cuales se registraron dos RBO (50\%), una raedera (25\%) y un unifaz de filo lateral corto (25\%). También se registraron artefactos sin manufactura con rastros complementarios, uno fracturado de calidad para la talla regular y otro entero de buena calidad. En la unidad B se registraron dos artefactos bifaciales de filo irregular y calidad para la talla muy buena. En la unidad C, se reconocieron dos artefactos con rastros complementarios enteros y de calidad regular para la talla (Tabla 7.97).

\begin{tabular}{|c|c|c|c|}
\hline UNIDAD & Instrumento & Entero & Fracturado \\
\hline \multirow{3}{*}{ A } & AF Bifacial & $8(89 \%)$ & $1(11 \%)$ \\
\cline { 2 - 4 } & AF Unifacial & $4(100 \%)$ & - \\
\cline { 2 - 4 } & ASF RC & $1(50 \%)$ & $1(50 \%)$ \\
\hline B & AF Bifacial & $1(50 \%)$ & $1(50 \% 9$ \\
\hline C & ASF RC & $2(100 \%)$ & - \\
\hline \multicolumn{2}{|c|}{ Total } & $16(84 \%)$ & $3(16 \%)$ \\
\hline
\end{tabular}

Tabla 7.97. Estado de fragmentación de instrumentos en RC. 


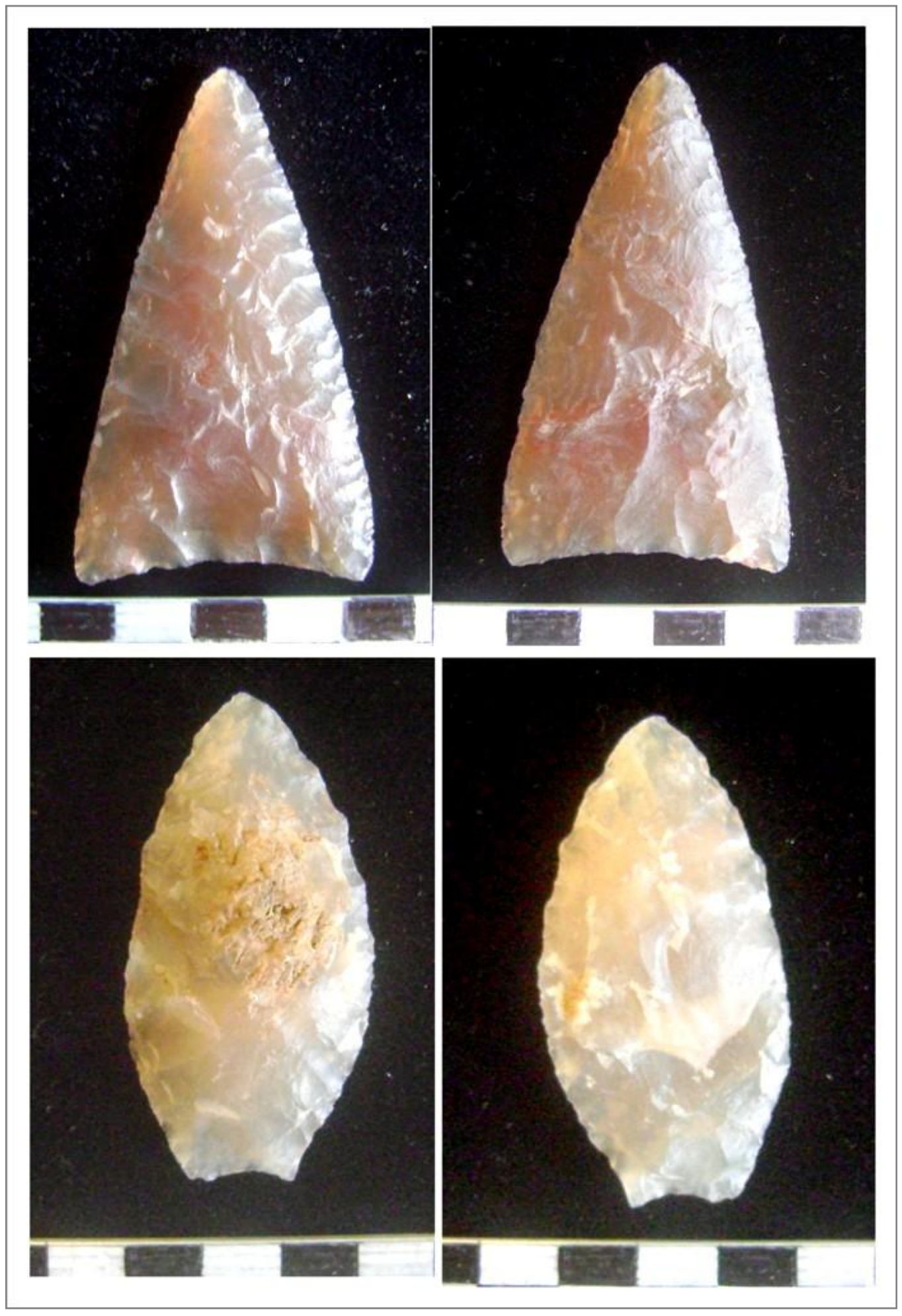

Figura 7.81. Puntas de proyectil recuperadas en RC. 
La relación entre desechos de talla enteros e instrumentos, en el caso de RC, pudo calcularse sólo para rocas silíceas. La unidad C es la que presenta la mayor frecuencia de desechos de talla por instrumentos (DT/INST: 57), seguido por la unidad $A(8,45)$, la unidad B (8) y valores nulos para la unidad C. Si consideramos los valores de este indicador para las rocas silíceas de todas las unidades, el valor de frecuencia obtenido es 12,26 desechos por cada instrumento. Los artefactos de formatización bifacial son los más representados, con un índice de bifacialidad de 0,473 , sin embargo no se registran desechos de talla de adelgazamientos bifacial. Los bifaces de filo irregular de sección transversal, biconvexa (40\%), triangular (40\%) y planoconvexa (20\%), de tamaño grandísimo son los más frecuentes. El espesor es medio o espeso (80\%) a muy espeso (20\%) y una de las piezas presenta remanentes de corteza. Entre las puntas de proyectil $(n=2)$, el tamaño más frecuente es el grandísimo. Una de las puntas es triangular sin pedúnculo, chata o poco espesa y la otra es lanceolada y espesa (Figura 7.81). Esta última presenta reserva de corteza. El índice de rejuvenecimiento (Largo/espesor) en el primer caso es igual a 10,1 y, en el segundo, de 5; esto sugiere una mayor reducción en la primera. Las raederas de filo lateral largo (50\%) y perimetral (50\%) son de tamaño grandísimo y lascado parcialmente extendidos.

Los artefactos unifaciales presentan un modulo de tamaño grandísimo y un espesor medio (modulo B). El índice geométrico de reducción, presenta valores altos en RBO (valor medio 0,376), seguido por el cuchillo $(0,219)$ y artefacto unifacial de filo irregular $(0,191)$. Los artefactos sin formatización con rastros complementarios presentan su mayor frecuencia en la unidad $C$, donde no se registraron artefactos formatizados. En todos los casos se trata de lascas con rastros marginales en uno de sus filos (Figura 7.82). 

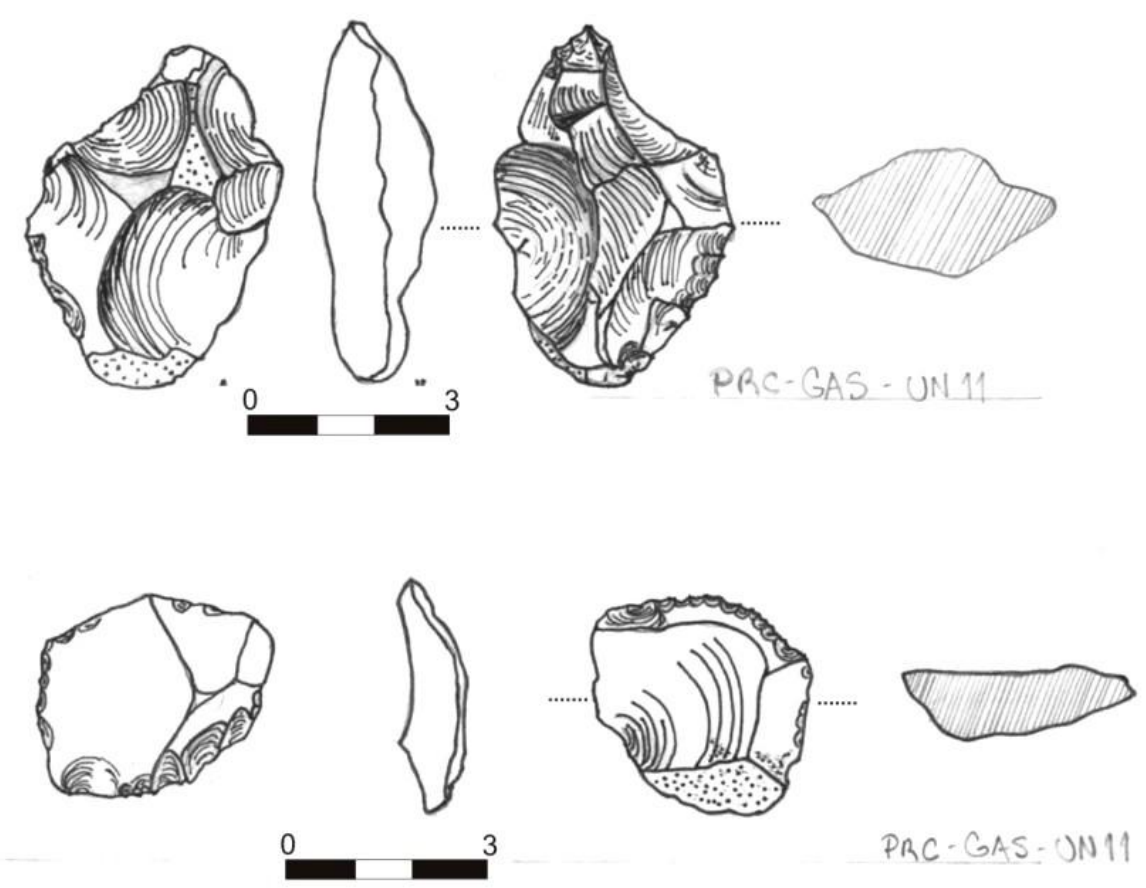

PRC-GAS - ON 11

Figura 7.82 Artefactos con rastros complementarios de RC.

\subsubsection{CONSIDERACIONES GENERALES DE LA LOCALIDAD RÍO COLORADO}

En RC la roca más frecuente es la silícea y en menor medida el basalto. La distribución de los artefactos no es homogénea entre las unidades geomorfológicas definidas, sin embargo el registro es continuo a los largo del espacio. Se destaca una alta frecuencia de artefactos con corteza (73\%) y de los tamaños grandísimo (99\%) y muy grandes (1\%) en todas las clases artefactuales. Las clases más frecuentes corresponden a los desechos de talla y núcleos, los cuales poseen para las unidades $\mathrm{A}$ y $\mathrm{C}$ baja intensidad de reducción en rocas silíceas. El basalto presenta índices bajos de reducción y descartes correspondientes a las primeras etapas de manufactura, lo cual puede responder a un uso ocasional o circunstancial de esta materia prima. En las unidades B y D, que corresponden 
al cauce seco de Aguada Colorada y al pedimento cubierto - respectivamente-, el registro de artefactos y la variedad de clases disminuye. Sin embargo la unidad B presenta los valores más altos de intensidad de reducción en rocas silíceas, a lo cual se suma la presencia de desechos de talla generados como resultados de la reactivación de filos. En la unidad D, en cambio, se registran índices de corteza altos acompañados de bajos índices de reducción. Esta unidad, ubicada en el extremo este, abarca la zona de Pampa del Carrizalito; por tratarse de una zona elevada, se observan en los artefactos evidencias de erosión eólica como los ventifactos (barniz del desierto, clastos con picaduras y corroídos por golpeteo). 


\section{CAPÍTULO 8}

\section{EL USO DE LAS OBSIDIANAS EN LA PAYUNIA}

\section{INTRODUCCIÓN}

La distribución espacial de las materias primas líticas, es una variable utilizada con frecuencia para estudiar los rangos de acción y los procesos de interacción entre las poblaciones humanas (Renfrew 1977; Meltzer 1989; Beck et al. 2002; Jones et al. 2003; 2012). Entre ellas la obsidiana ocupa un lugar especial, principalmente porque las características de su estructura geoquímica permiten utilizarla como un indicador sensible de procedencia (Glascock et al. 1998; Shackley 2005). En el centro occidente los primeros abordajes estuvieron orientados principalmente a la búsqueda e identificación de las fuentes dentro de la región y a la caracterización de procedencia de muestras arqueológicas (Seelenfreud et al. 1996; Durán et al. 2004; De Francesco et al. 2006; Durán et al. 2008; Giesso et al. 2011). La colaboración entre diferentes laboratorios y equipos de investigación ayudaron en este desarrollo inicial, que fue facilitado por el avance en las técnicas de análisis a través de equipos portátiles (Cortegoso et al. 2012). En los últimos años se abordaron aspectos temporales en el uso de las fuentes identificadas, y su incorporación dentro de los circuitos de producción y circulación a lo largo del tiempo (Durán et al. 2004; Neme y Gil 2008; Barberena et al. 2011; Giesso et al. 2011). Estos trabajos, apuntaron a resolver problemas de escala macro espacial, sin considerar el papel que jugaron los aspectos tecnológicos en los patrones encontrados. En el marco de esta tesis se propuso explorar el aprovisionamiento y uso de la mencionada materia prima en una escala espacial menor - La Payunia-, enfatizando los aspectos tecnológicos (Salgán et al. 2012). En este capítulo se presentan los resultados del abordaje de este problema, para el cual se tuvieron en cuenta los análisis de fluorescencia de rayos $X$ (XRF) y activación neutrónica (INAA), sobre artefactos prevenientes de sitios arqueológicos de La Payunia y 
la información geoquímica de las canteras de obsidianas generada en los proyectos antes mencionados (Barberena et al. 2011; Giesso et al 2011; Cortegoso et al. 2012).

\subsection{LA OBSIDIANA EN EL SUR DE MENDOZA}

La variabilidad en el uso de la obsidiana en el sur de Mendoza, ha sido un tema fuertemente abordado en los últimos cinco años (Durán et al. 2004; De Francesco et al. 2006; Giesso et al. 2011; Barberena et al. 2011). Estudios previos caracterizaron geoquímicamente seis canteras de obsidianas localizadas entre el sur de Mendoza y norte de Neuquén. En el sur de Mendoza se detectadas cuatro, tres en la cordillera andina (Laguna El Diamante, Las Cargas y Laguna El Maule) y una extra-cordillerana (El Peceño) (Figura 8.1). Por su parte, en para el norte de Neuquén se registran dos, todas en ubicadas en el área no cordillerana: Cerro Huenul y La Bandera - Portada Covunco (Durán et al. 2004; Bellelli et al. 2006, López et al. 2009; Barberena et al. 2011; Giesso et al. 2011). Los trabajos realizados hasta el momento mostraron diferencias entre las distintas canteras, en cuanto a la disponibilidad, calidad y accesibilidad de la materia prima (Giesso et al. 2011). En el estudio de artefactos de La Payunia, se detectó el uso de cuatro de las seis fuentes reconocidas (Las Cargas, El Maule, El Peceño y Cerro Huenul), cuyas distancias varían entre 30 y $200 \mathrm{~km}$. 


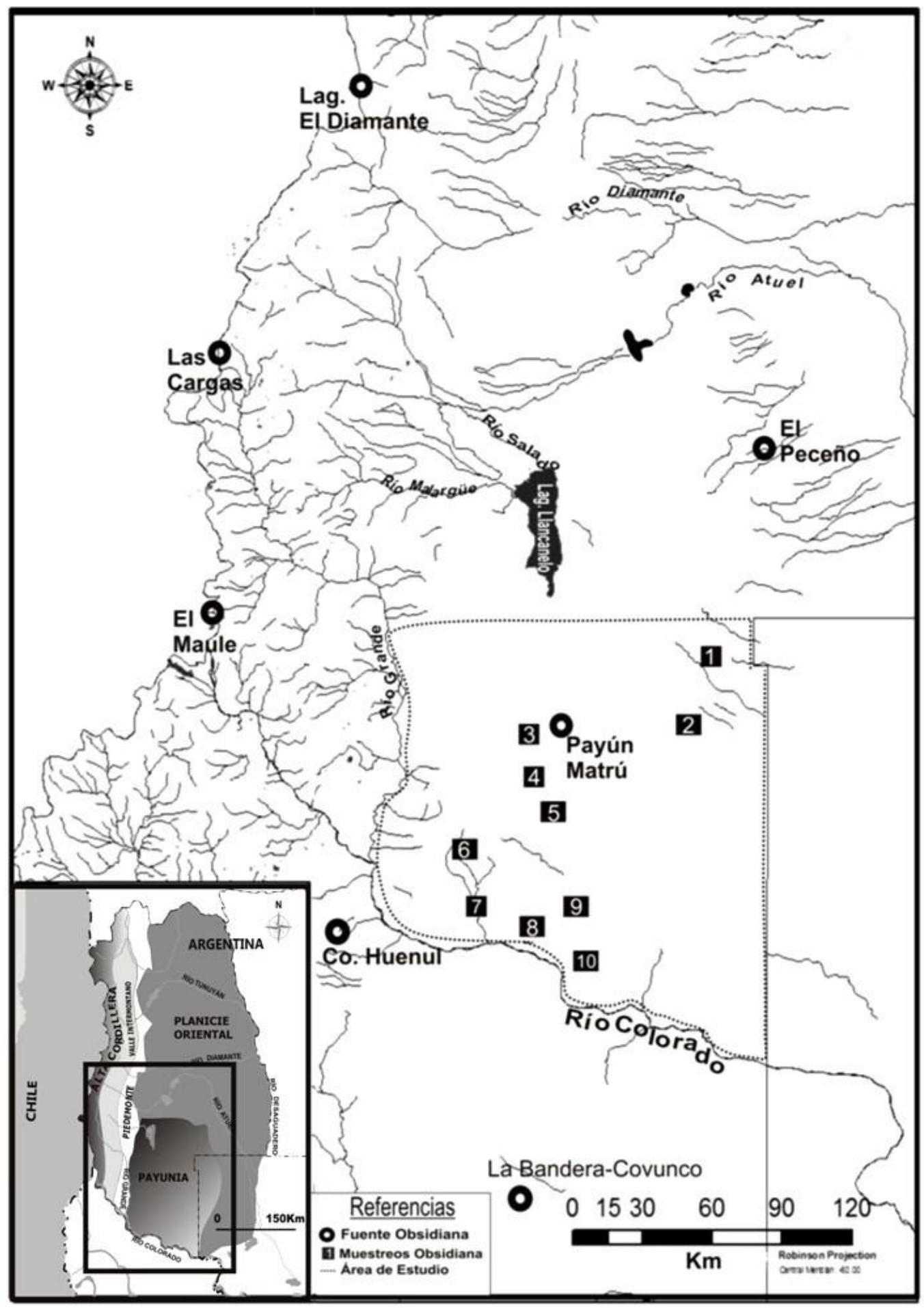

Figura 8.1. Ubicación de las fuentes de obsidiana. Referencias: Sector Norte: 1: La Corredera; 2: La Peligrosa. Sector Central: 3: Puesto Mira; 4: Loma Alta; 5: ALPA-Este. Sector Sur: 6: Agua de Pérez; 7: Carmonina 1; 8: Rincón Blanco; 9: PRC Tren; 10: PRC. 


\subsubsection{LAS FUENTES DE OBSIDIANA}

La caracterización de fuentes ha sido realizada a partir del análisis de materiales provenientes de las canteras y de los sitios arqueológicos. De esta forma se documentó un total de seis fuentes, cinco de ellas conocidas (Laguna del Diamante-Paramillos, Laguna El Maule, El Peceño, Las Cargas y Cerro Huenul) y una desconocida (Desconocida A) (Giesso et al. 2011; Cortegoso et al. 2012) (Figura 8.1). Los promedios y desviación estándar de los elementos químicos obtenidos de las fuentes, permiten distinguir tres sub-fuentes de Laguna El Maule, dos de El Peceño y dos de Laguna del Diamante (Cortegoso et al. 2012) (Figuras 8.2 y 8.3). Algunas muestras de artefactos fueron catalogadas como "Desconocida", dado que su señal química no correspondía a ninguna de las fuentes o sub fuentes conocidas, ni pudieron ser agrupadas dentro de alguno de los espectros químicos que indicaran su proveniencia de alguna fuente aún no conocida, como en el caso de la Desconocida A (Cortegoso et al. 2012).

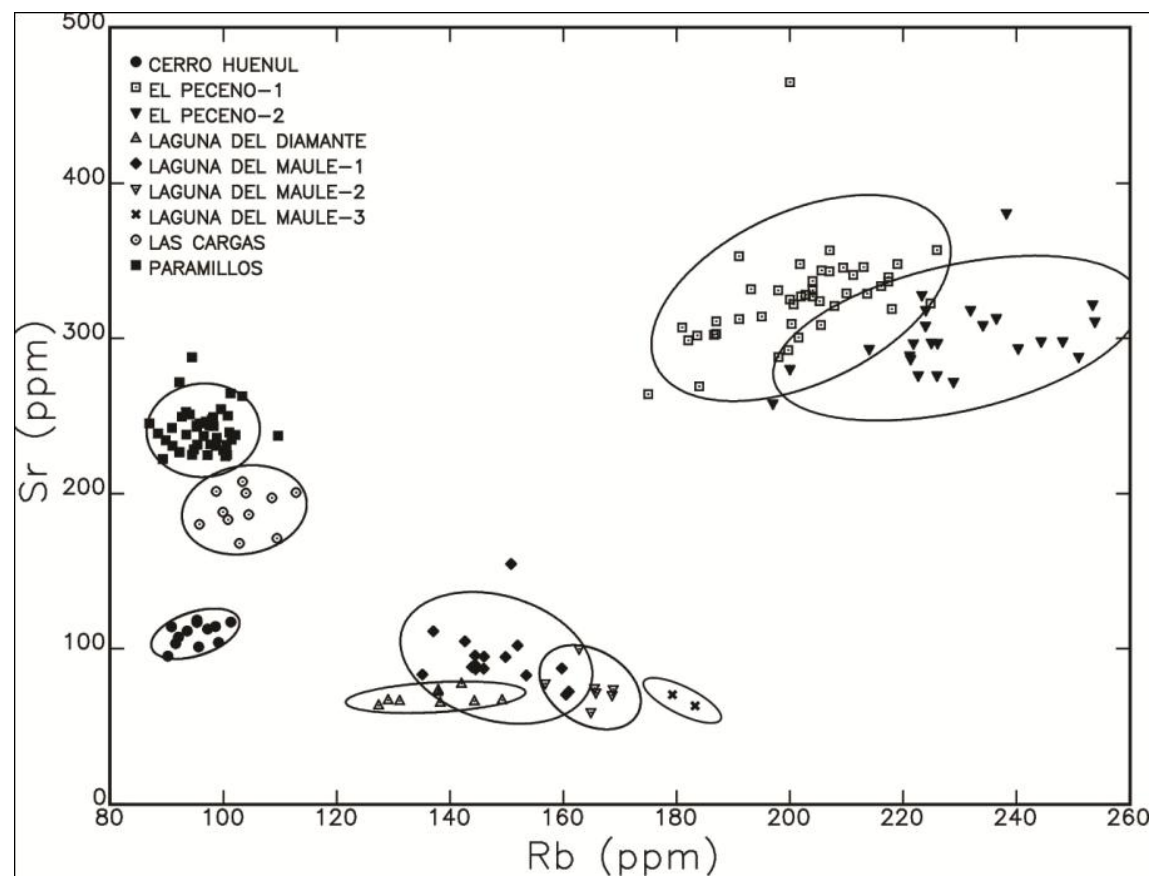

Figura 8.2. Caracterización química de las muestras de fuentes del sur de Mendoza y norte de Neuquén a partir de la distribución de estroncio ( $\mathrm{Sr}$ ) y rubidio (Rb) (Cortegoso et al. 2012). 


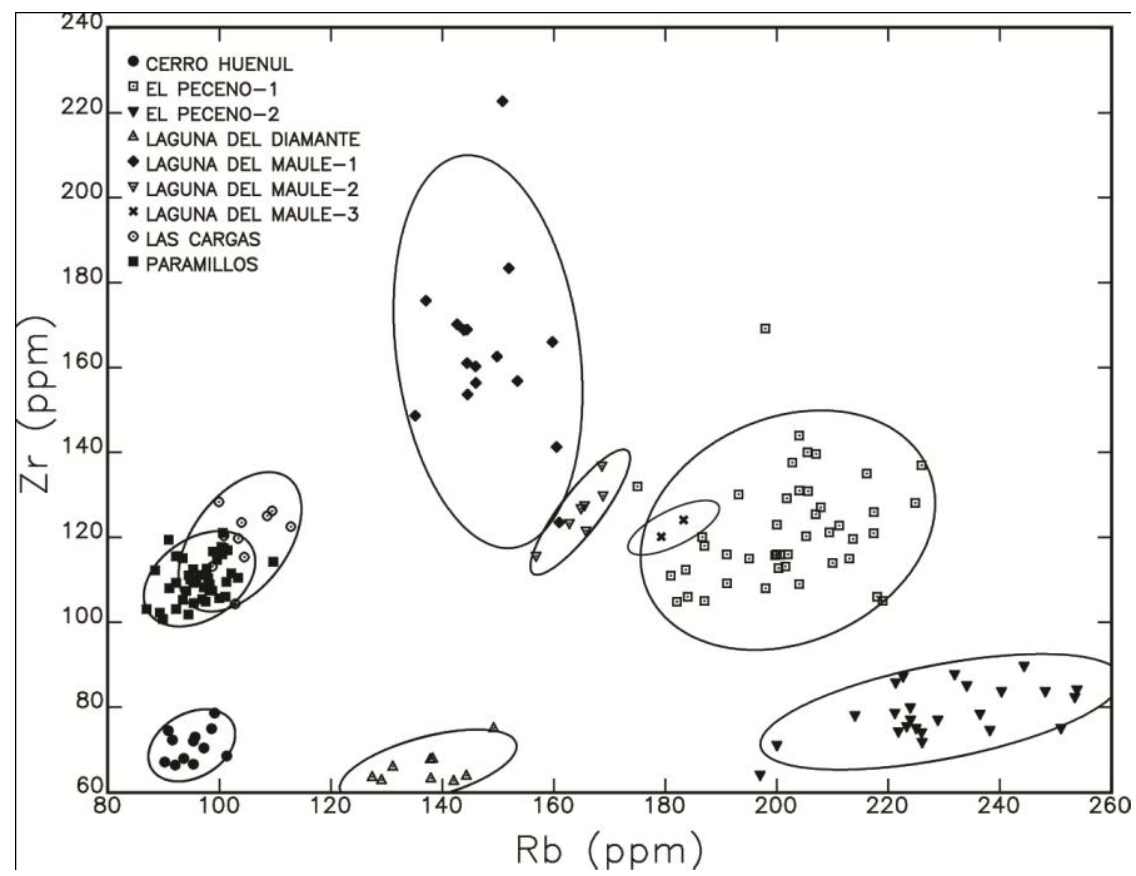

Figura 8.3. Caracterización química de las muestras de fuentes del sur de Mendoza y norte de Neuquén a partir la distribución de circonio $(\mathrm{Zr})$ y rubidio $(\mathrm{Rb})$ (Cortegoso et al. 2012).

Las fuentes cordilleranas (Laguna El Diamante, Las Cargas, y El Maule) se encuentran a más de 2500 msnm, por lo que no es posible su acceso en época invernal, dada las bajas temperaturas y la acumulación nívea. La materia prima disponible en estas fuentes, es abundante y de buena calidad para la talla (Giesso et al. 2011). Laguna El Diamante es la fuente más septentrional, La fuente El Maule (Figura 8.4) es la más austral de las cordilleranas y se presenta en forma de varias coladas volcánicas que cubren un área discontinua de ca. $600 \mathrm{~km}^{2}$ (Seelenfreund et al. 1996; Giesso et al. 2011). Entre estas dos fuentes se encuentra Las Cargas, también con una amplia dispersión areal y muy buena calidad de materia prima (Figura 8.5).

Las obsidianas de las fuentes extra cordilleranas (EI Peceño y Cerro Huenul), están disponibles todo el año y son de fácil acceso, y buena calidad. En ellas las materias primas se presenta de forma distinta; en El Peceño como afloramientos de vitrófilos (Figura 8.6), mientras que en Cerro Huenul en forma de nódulos superficiales, enterrados o semienterrados del tamaño de un puño y de excelente calidad para la talla (Durán et al. 2004; Barberena et al. 2011; Giesso et al. 2011) (Figura 8.7). 


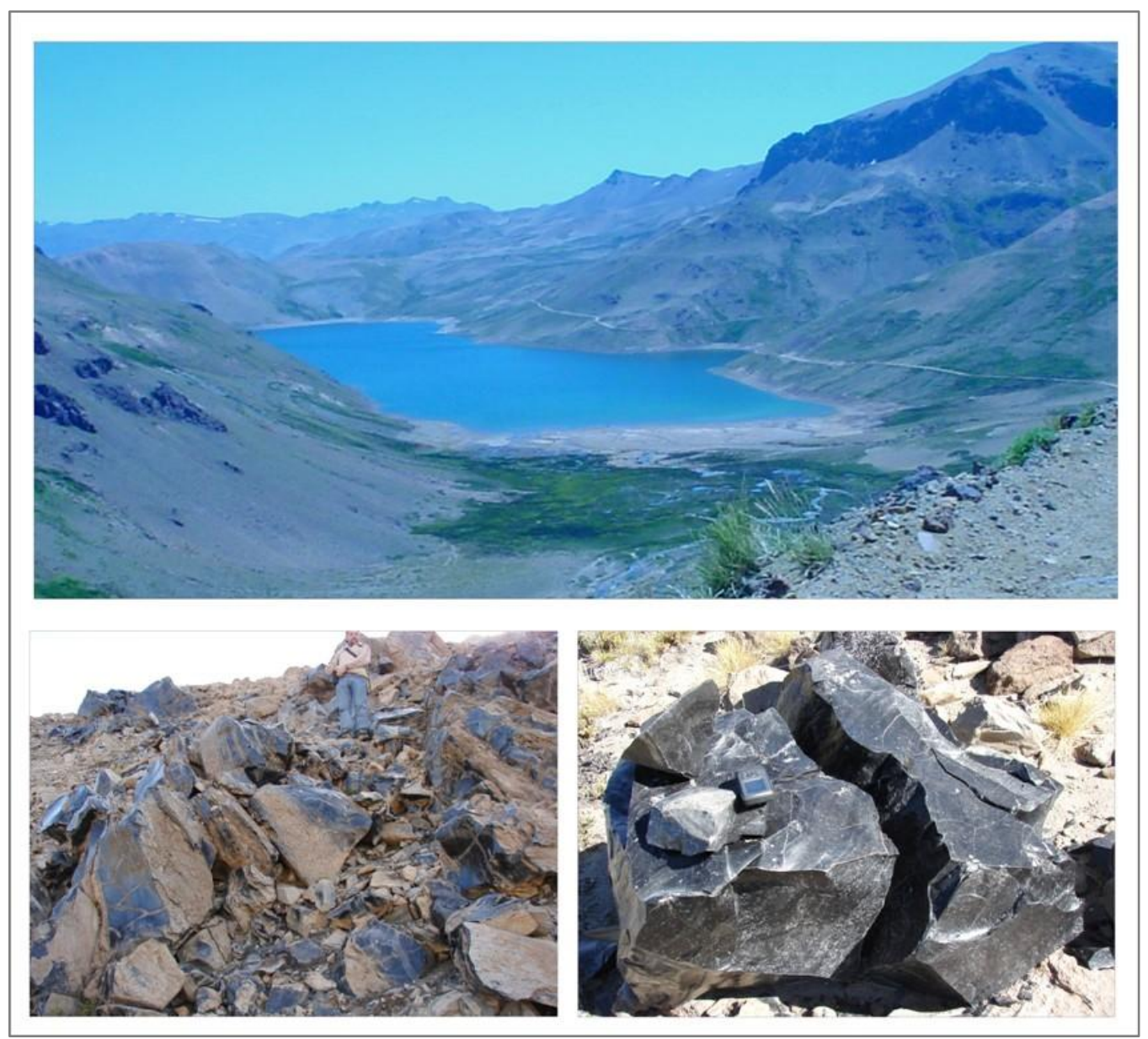

Figura 8.4. Vista de fuente Laguna El Maule (arriba) y modo en que se presenta la materia prima (abajo). 


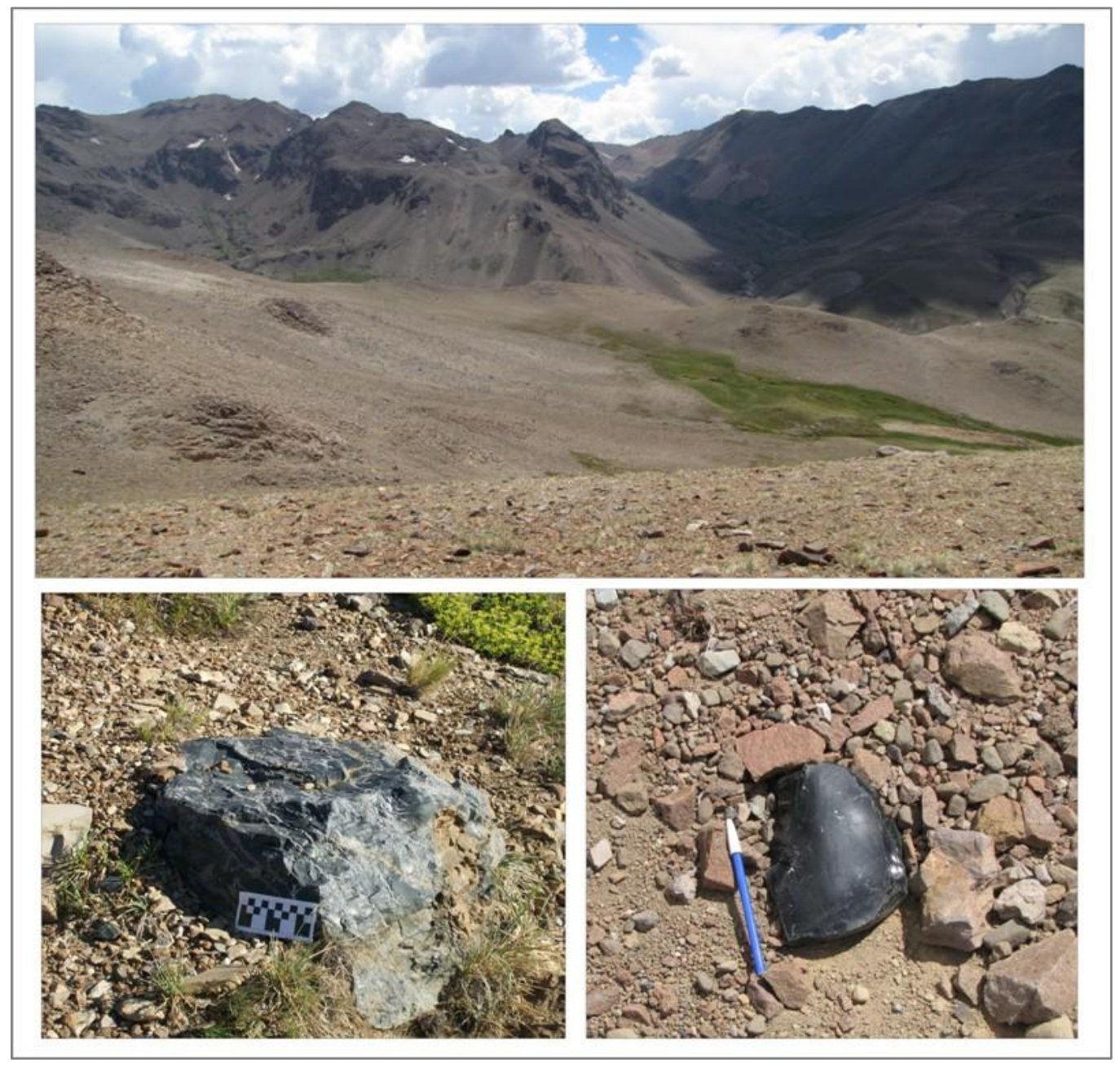

Figura 8.5. Vista de fuente Las Cargas (arriba) y modo en que se presenta la materia prima (abajo). 


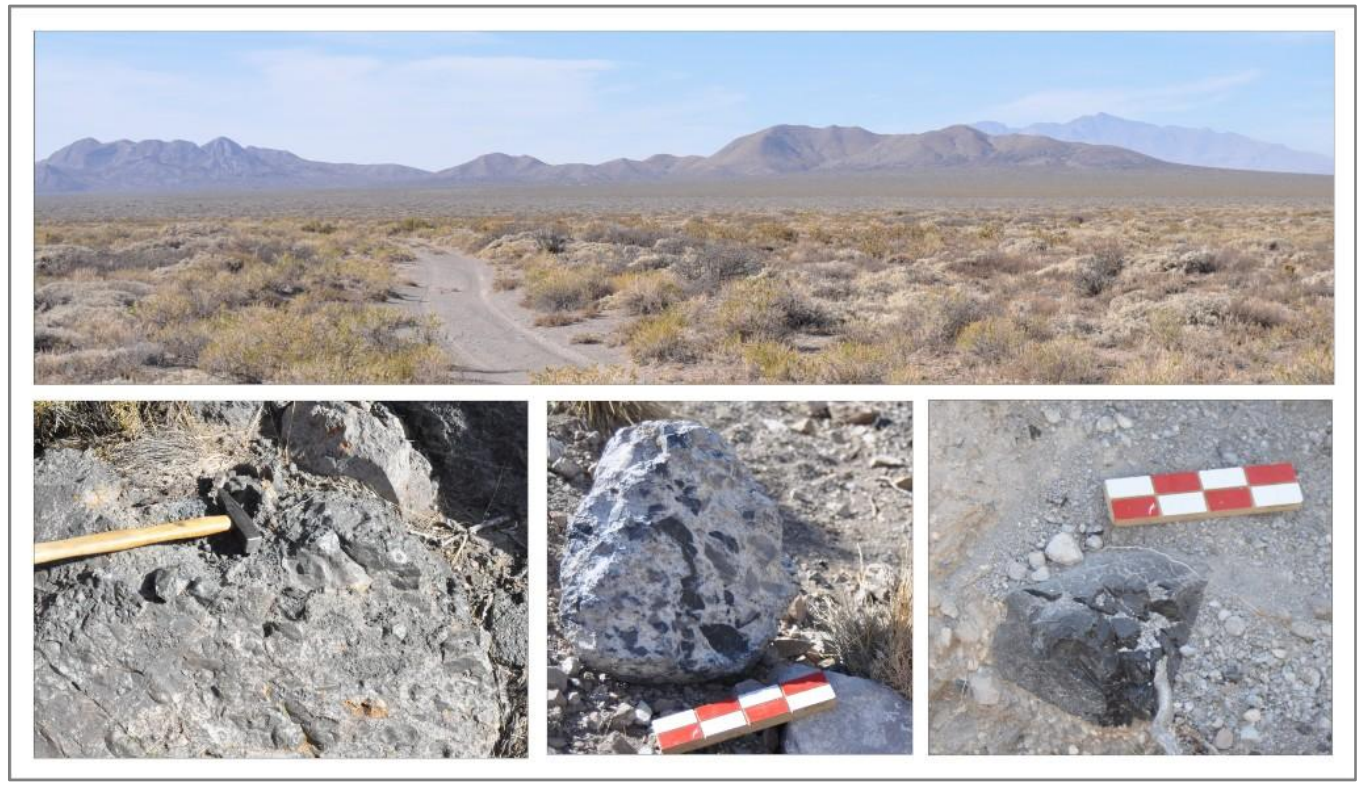

Figura 8.6. Vista de fuente extra cordillerana El Peceño (arriba) y modo en que se presenta la materia prima (abajo).

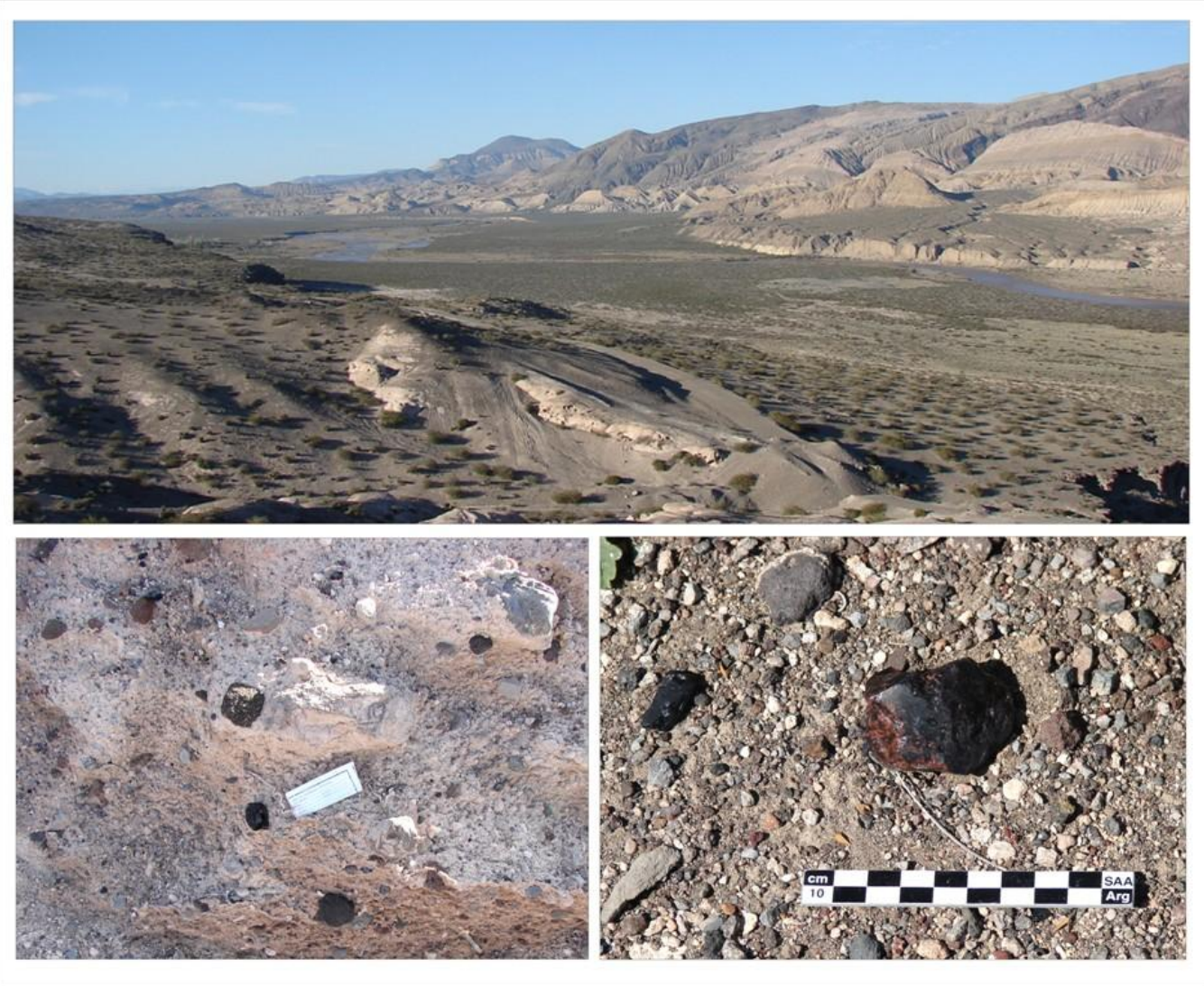


Figura 8.7. Vista de fuente extra cordillerana Cerro Huenul (arriba) y modo en que se presenta la materia prima (abajo).

\subsection{OBSIDIANAS EN LA PAYUNIA}

La ubicación geográfica de las fuentes de recursos líticos y el trazado de distancias mínimas (Stern y Franco 2000), permiten estimar el transporte de objetos y/o la distancia de desplazamiento de los individuos. Sin embargo su abordaje no es simple, ni sigue un patrón lineal (Franco 2004). En este sentido, las rocas de disponibilidad local son comúnmente consideradas como de acceso directo e indicadoras de rangos de acción (Binford 1979). En cambio, las fuentes no locales o exóticas, son interpretadas o entendidas como resultados de interacción entre poblaciones $y$, por consiguiente, del intercambio de recursos (Meltzer 1989). Sobre la base de las expectativas planteadas por los modelos descriptos en el capítulo 3 (Renfrew 1977; Binford 1979; Gould y Saggers 1985; Meltzer 1989; Bamforth 1991; Ingbar 1994; Franco 2004, 2007; Kuhn 2004; Charlin 2009), se generaron expectativas que permiten explorar los modos de aprovisionamiento de obsidiana (Tablas 8.1 y 8.2.)

\begin{tabular}{|c|c|c|}
\hline EXPECTATIVAS ARQUEOLÓGICAS & ACCESO DIRECTO & ACCESO INDIRECTO \\
\hline $\begin{array}{l}\text { Frecuencia de materia prima en } \\
\text { el conjunto }\end{array}$ & Alta & Baja \\
\hline $\begin{array}{c}\text { Representación de estadios de } \\
\text { manufactura }\end{array}$ & Todas las etapas & Predominio de etapas finales \\
\hline Clases artefactuales & Amplio & Restringido \\
\hline Tamaño de los artefactos & Variable & Muy pequeños -pequeños \\
\hline Porcentaje de Corteza & Alto & Bajo \\
\hline $\begin{array}{l}\text { Diversidad estilística en diseño } \\
\text { de instrumentos }\end{array}$ & Alta & Baja \\
\hline
\end{tabular}
aprovisionamiento. 


\begin{tabular}{|c|c|c|}
\hline CLASES ARTEFACTUALES & ACCESO DIRECTO & ACCESO INDIRECTO \\
\hline NÚCLEOS & Agotados, formas estandarizadas. & Ausentes o muy explotados. \\
\hline DESECHOS DE TALLA & $\begin{array}{c}\text { Alta variabilidad y frecuencia, } \\
\text { presentes todas las etapas } \\
\text { aunque prevalecen las finales. }\end{array}$ & $\begin{array}{c}\text { Baja variabilidad, prevalecen } \\
\text { etapas finales y de reactivación de } \\
\text { artefactos. }\end{array}$ \\
\hline INSTRUMENTOS & Alta variabilidad de tipos \\
artefactuales. & $\begin{array}{c}\text { Alta frecuencia en relación a otras } \\
\text { clases artefactuales. Baja } \\
\text { variabilidad en tipos. Artefactos } \\
\text { con corteza. }\end{array}$ \\
\hline
\end{tabular}

Tabla 8.2. Expectativas arqueológicas en artefactos líticos.

En sitios con acceso directo a los recursos líticos, se espera encontrar: a) una alta frecuencia de artefactos procedentes una misma fuente en el conjunto; b) un elevado índice de corteza; c) todas las etapas de la secuencia de manufactura de los artefactos a nivel regional; d) la presencia de núcleos y e) que la utilización de la materia prima no se encuentre restringido a un tipo particular de artefacto (Franco 2007; Charlin 2009).

En casos de acceso indirecto al recurso, se contemplan dos posibilidades alternativas (Franco 2007; Charlin 2009): el intercambio de artefactos ya formatizados o de materia prima en bruto (nódulos o núcleos). En ambos casos se espera que: a) la materia prima tenga una escasa representatividad en el conjunto arqueológico; b) que su utilización se encuentre restringida a determinadas clases de instrumentos y; c) que los instrumentos sean conservados (sensu Binford 1979). Para distinguir entre las dos alternativas, Charlin (2009) sostiene que, en el primer caso, se espera que estén representadas sólo las etapas finales de reducción de instrumentos, lo que implica la presencia de lascas de reactivación y/o reutilización de aquellos. En el caso de intercambio de nódulos, se espera que se encuentren representadas las distintas etapas en la secuencia de manufactura (aunque predominen las etapas finales por conservación de la materia prima), presencia de núcleos agotados, lascas y artefactos con corteza (Franco 2007; Charlin 2009).

A partir de estas expectativas se compara la utilización de las distintas fuentes en los sectores norte, central y sur, en cuanto a: 1) frecuencia de las diferentes fuentes de obsidiana reconocidas para la región; 2) clases artefactuales representadas; 3) presencia 
de corteza; 4) modo de descarte de instrumentos; 5) etapas de manufactura y 6) densidad de negativos de lascados (o extracciones previas) en la cara dorsal de los desechos de talla (Ingbar et al. 1989).

\subsubsection{ANÁLISIS TECNOLÓGICO}

Con el fin de evaluar formas de obtención de las materias primas y se procesaron 98 artefactos arqueológicos procedentes de La Payunia. Las muestras fueron procesadas en el MURR siguiendo la metodología para INAA y XRF antes descripta (Capítulo 5; Anexo 2). La información geoquímica de los artefactos procesados corresponde a la publicada en Giesso et al. (2011a) y la obtenida para este trabajo de tesis (Anexo 2). El muestreo de los artefactos se llevó a cabo en el marco de un proyecto mayor, cuyo objetivo fue caracterizar la variabilidad macroscópica en las obsidianas del Centro Occidente Argentino (Giesso et al. 2011) (Tabla 8.3). Las muestras seleccionadas en La Payunia, corresponden a nueve sitios arqueológicos, en su mayoría a cielo abierto; tres en estratigrafía (10\% de las muestras), y seis superficiales ( $90 \%$ de las muestras) (Figura 8.1). De los sitios estratigráficos dos se encuentran en el sector norte, en la localidad LP (La Peligrosa 2 y Cueva Delerma) y uno en el sector sur, en la localidad CAR (Carmonina 1). Las prospecciones superficiales se realizaron en los sectores central (Puesto Mira, Loma Alta y Altiplanicie Este) y sur (APE, RC y Rincón Blanco). Los análisis tecno-morfológicos de las piezas se profundizaron a posteriori del análisis geoquímico, razón por la cual cuatro de las muestras analizadas por medio de métodos destructivos (INAA), sólo pudieron ser diferenciadas a nivel de clase tecnológica (4\%). En el análisis tecnológico de los artefactos de obsidiana se priorizó el tratamiento de las muestras por sector de muestreo (norte, central y sur). 


\begin{tabular}{|c|c|c|c|c|c|c|c|c|c|c|c|c|c|c|c|c|c|c|c|c|c|c|c|c|c|c|c|c|c|c|c|c|c|c|c|c|c|c|c|}
\hline \multirow{3}{*}{ Fuentes } & \multicolumn{8}{|c|}{ Norte } & \multicolumn{11}{|c|}{ Central } & \multicolumn{20}{|c|}{ Sur } \\
\hline & \multicolumn{4}{|c|}{ La Peligrosa } & \multicolumn{4}{|c|}{ Cueva Delerma } & \multicolumn{4}{|c|}{ ALPA Este } & \multicolumn{3}{|c|}{ LOMA ALTA } & \multicolumn{4}{|c|}{ Puesto Mira } & \multicolumn{4}{|c|}{ PRC } & \multicolumn{4}{|c|}{ PRC Tren } & \multicolumn{4}{|c|}{ Rincón Blanco } & \multicolumn{4}{|c|}{ APE } & \multicolumn{4}{|c|}{ Caemonina-1 } \\
\hline & $D$ & DT & $\mathrm{N}$ & 1 & $\mathrm{D}$ & DT & $\mathrm{N}$ & 1 & D & DT & $\mathrm{N}$ & 1 & D & DT & \begin{tabular}{l|l}
$N$ & 1
\end{tabular} & $\mathrm{D}$ & DT & $\mathrm{N}$ & 1 & D & \begin{tabular}{|l|l} 
DT & \\
\end{tabular} & $\mathrm{N}$ & 1 & D & DT & $\mathrm{N}$ & 1 & D & DT & $\mathrm{N}$ & 1 & D & DT & $\mathrm{N}$ & 1 & D & DT & $N$ & 1 \\
\hline El Peceño & 130 & 3 & - & - & 100 & - & - & - & 155 & - & - & - & 160 & - &. & 145 & - & - &. & 210 & - &. & -2 & 200 & - & - & - & 200 & - & $\cdot$ & - & 180 & - & - & - & 207 & - & . & - \\
\hline El Maule & 180 & - & - & 4 & 170 & 1 & - & - & 115 & 4 & - & 2 & 120 & 14 & -2 & 112 & - & - & - & 180 & 4 & - & $1 \mid 1$ & 160 & 3 & - & 1 & 165 & 13 & \begin{tabular}{l|l}
1 & 1
\end{tabular} & 12 & 125 & 1 & - & - & 151 & 1 & - & - \\
\hline Las Cargas & 220 & - & - & - & 205 & - & - & - & 180 & - & - & 1 & 180 & 6 & -3 & 175 & - & - & - & 250 & - & - & & 230 & - & - & - & 235 & - & - & - & 200 & - & - & - & 230 & - & - & - \\
\hline Cerro Huenul & 125 & - & - & - & 140 & - & - & - & 55 & 7 & - & 1 & 55 & - & $-\cdot-$ & 62 & 1 & - & 1 & 80 & - & 1 & - & 60 & 1 & - & - & 65 & - & $\cdot$ & 1 & 30 & 1 & - & 1 & 50 & - & - & - \\
\hline Desconocida-A & i? & - & 1 & - & ¿? & - & - & - & ¿? & - & - & - & ¿? & - &.- & ¿? & - & - & - & ¿? & - & - & 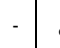 & ¿? & - & - & $\cdot$ & ¿? & - & $\cdot$ & - & ¿? & - & - & & ¿? & - & - & - \\
\hline Desconocida & i? & - & - & - & ¿? & - & - & - & $i ?$ & 1 & - & 1 & ¿? & 1 &. & ¿? & - & 1 & - & $i ?$ & - & - & & $i ?$ & - & - & - & ¿? & 1 & - & & $i ?$ & - & 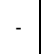 & - & $i ?$ & - & - & \\
\hline Total Sitio & \multicolumn{4}{|c|}{8} & \multicolumn{4}{|c|}{1} & \multicolumn{4}{|c|}{17} & \multicolumn{3}{|c|}{26} & \multicolumn{4}{|c|}{3} & \multicolumn{7}{|c|}{5} & & \multicolumn{4}{|c|}{28} & \multicolumn{4}{|c|}{3} & \multicolumn{4}{|c|}{1} \\
\hline Total Sector & \multicolumn{8}{|c|}{ 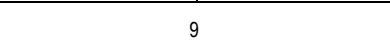 } & & & & & & 46 & & & & & & & & & & & & & & & 43 & & & & & & & & & & \\
\hline
\end{tabular}

Tabla 8.3. Frecuencia de obsidiana por categoría tecnológica y fuente en relación a los sitios y distancia a las fuentes. Referencias: D: Distancia aproximada en Km; DT: Desechos de talla; N: Núcleos; I: Instrumentos. 
Se observan diferencias en la frecuencia de las fuentes representadas y entre los sectores definidos para La Payunia (Figura 8.8). En el norte y sur se registraron obsidiana de El Maule. A ésta se suma, artefactos provenientes de El Peceño (en el sector norte) y de Cerro Huenul (en el sector sur). En el sector central se registraron tres de las cuatro variedades de obsidiana reconocidas para la región, de las cuales Las Cargas es exclusiva de este sector. La fuente que registra mayor distribución espacial es El Maule, seguida por Cerro Huenul. Esta última presenta amplia distribución espacial, pero baja frecuencia, y es la única fuente que por su distancia puede ser considerada de disponibilidad local en el sector sur. Los artefactos provenientes de la fuente cordillerana El Maule (65 \%), distante de la región entre 80-200 km, posee frecuencias altas en los tres sectores (figura 8.9). Le sigue en importancia la fuente no cordillerana Cerro Huenul (16\%), documentada en los sectores central y sur, con distancias entre los 30 y 120 km lineales. Las Cargas (10\%) sólo fue documentada en el sector central, con distancias de entre 161 y 200 km. Finalmente, El Peceño (3\%), está presente solo en el sector norte, con distancias de entre 121 y $160 \mathrm{~km}$ (Figura 8.10). Además de las obsidianas con procedencias definidas, se registraron fuentes desconocidas: Desconocida-A y Desconocida. La primera (Giesso et al. 2011a; Cortegoso et al. 2012) procede del sector norte (localidad LP) y la segunda, de tres sitios del sector central $(80 \%, n=4)$ y en uno del sector sur $(20 \%, n=1)$. De este modo, los valores más altos de diversidad de fuentes de obsidiana se registran en el sector central (Tabla 8.4), con baja dominancia de una fuente particular y alta diversidad de procedencia. Asimismo, en el sector norte se presentan alta diversidad de fuentes, pero mayor valor de dominancia, dado que El Maule es la fuente más frecuente. Por último, en el sector sur, se presentan los valores de diversidad más bajos, acompañados de alta dominancia de la fuente El Maule y los valores bajos de variedad de fuentes de obsidiana. 


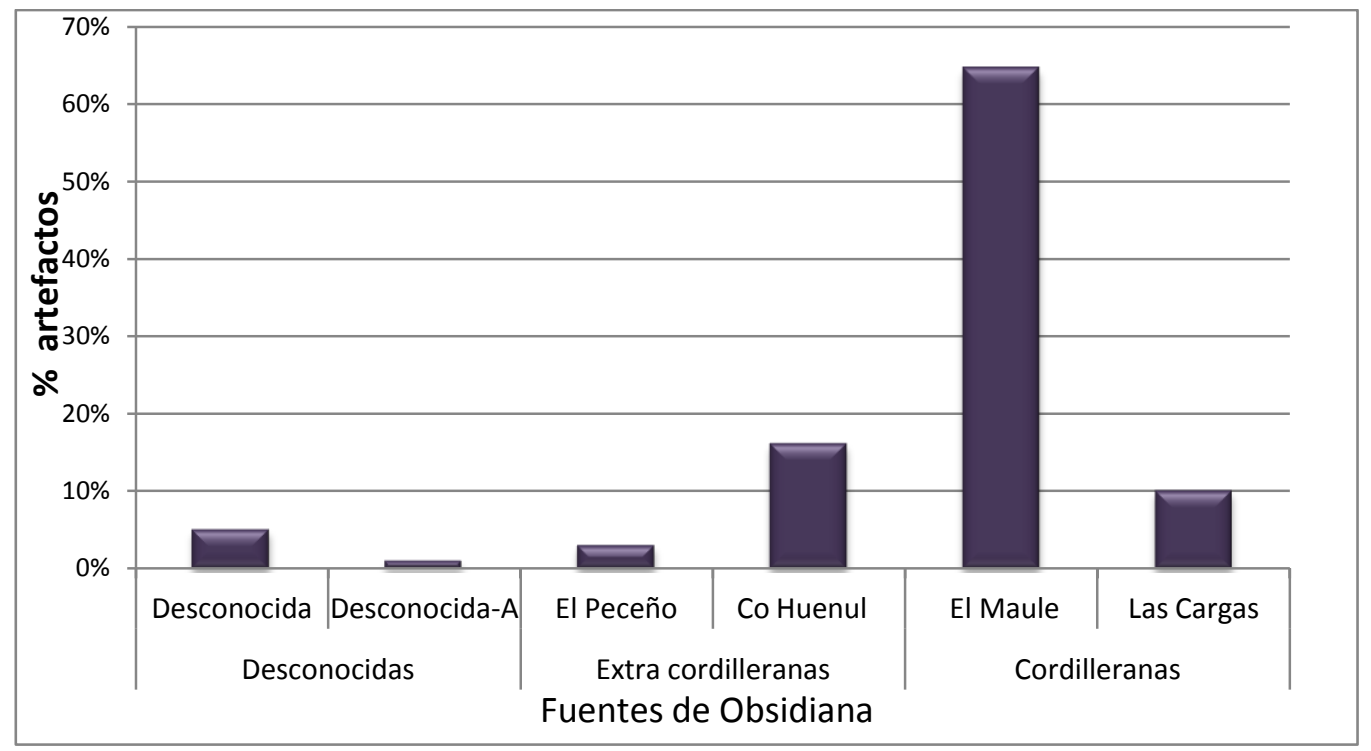

Figura 8.8. Frecuencia de artefactos respecto a fuente en La Payunia.

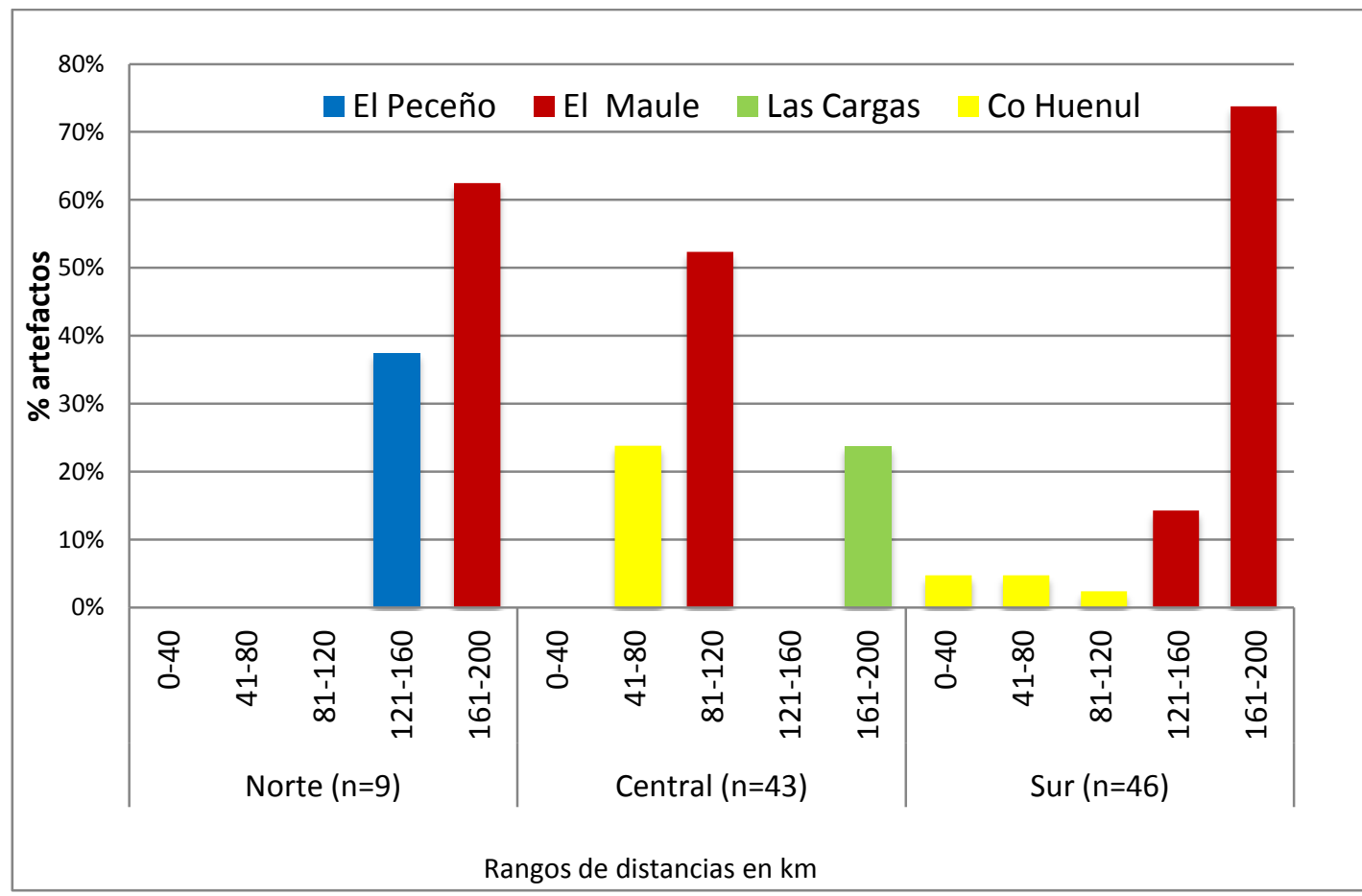

Figura 8.9. Frecuencia de cada fuente en relación a la distancia de los sitios analizados en cada sector. 


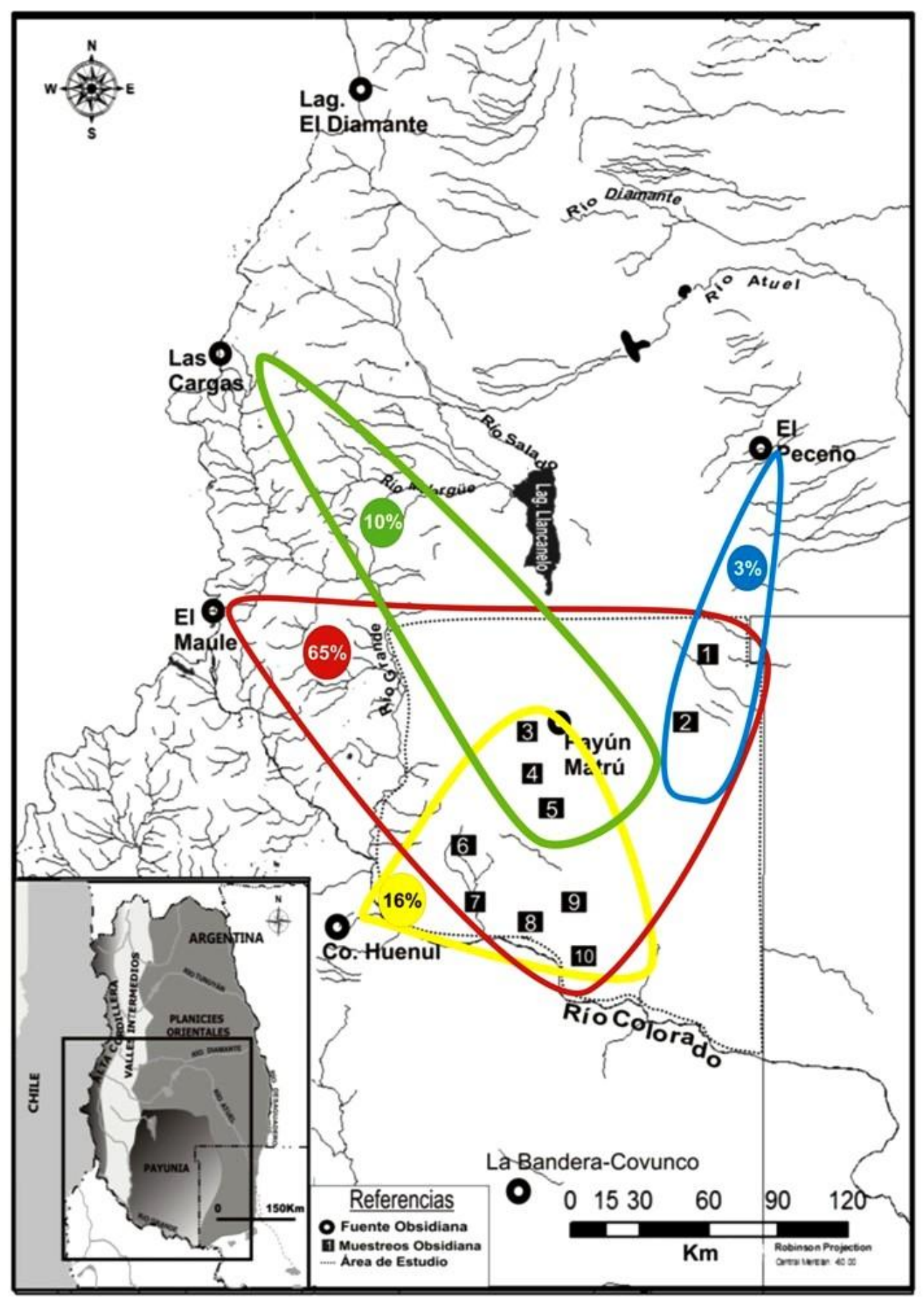

Figura 8.10. Distribución de obsidianas en La Payunia. Referencias: 1. Cueva Delerma; 2 La Peligrosa; 3. Puesta Mira; 4. Loma Alta; 5. ALPA Este; 6. Agua de Pérez; 7.Carmonina; 8. PRC; 9. Rincón Blanco; 10. PRC Tren. 


\begin{tabular}{|c|c|c|c|}
\hline & NORTE & CENTRAL & SUR \\
\hline N fuentes OBS & 3 & 4 & 3 \\
\hline $\mathbf{N}$ & 9 & 46 & 43 \\
\hline Dominancia & 0,4321 & 0,3308 & 0,7545 \\
\hline Shannon-H & 0,9369 & 1,229 & 0,467 \\
\hline Simpson & 0,5679 & 0,6692 & 0,2455 \\
\hline
\end{tabular}

Tabla 8.4. Diversidad de fuentes de obsidiana respecto a los sectores de La Payunia.

Las tablas 8.5 y 8.6 , muestran las clases artefactuales según la fuente de procedencia de la materia prima y el sector. En el norte predominan las obsidianas de El Maule tanto en desechos de talla como en instrumentos. Las otras fuentes ingresan como desechos de talla. En el sector central los artefactos más frecuentes también son de obsidiana El Maule y aparecen como desechos de talla e instrumentos. También se registran estas dos clases artefactuales en obsidiana de Cerro Huenul y de Las Cargas, mientras que entre las Desconocidas se registran las tres clases artefactuales (instrumentos, desechos de talla y núcleos). En el sur, por su parte, El Maule es la fuente de mayor frecuencia y se presenta en las tres clases de artefactos, es decir como desechos de talla, instrumentos y núcleos. Esta tendencia también se observa pero en menor frecuencia en artefactos confeccionados sobre obsidiana Cerro Huenul, mientras que en Desconocidas sólo se registran desechos de talla.

En cuanto a la proporción de corteza (Tabla 8.7), en el sector norte no se registraron artefactos con este atributo. Las frecuencias más altas de corteza corresponden a la obsidiana Cerro Huenul, de sector central y sur, mientras que los artefactos sobre obsidiana de otras fuentes no presentan corteza. Los relevamientos superficiales realizados en la cantera Cerro Huenul (Durán et al. 2004; Barberena et al. 2011) muestran que la materia prima se presenta como clastos medianos y pequeños de depósito secundario, con morfología esférica a sub-redondeada, de excelente calidad, abundantes y fácilmente transportables. A partir de los estudios de la variación morfométrica y la calidad para la talla, se propuso que el tamaño sería una de las variables consideradas para la selección de los nódulos, limitando el testeo de los mismos en la fuente (Barberena et al. 2011). Si bien esta caracterización es preliminar, se podría esperar que los nódulos sean transportados enteros y que un porcentaje significativo de los artefactos obtenidos presenten remanentes de corteza, 
lo que es coherente con lo observado en los sectores central y sur. En el caso de Las Cargas, si bien la fuente presenta una gran extensión espacial (Giesso et al. 2011a), los relevamientos superficiales realizados en el marco de este trabajo de tesis, dan cuenta de la presencia escasa a nula de corteza en su forma primaria. En su lugar presenta una cubierta en forma de pátina de espesor variable, difícil de identificar como corteza en los conjuntos arqueológicos. Esto sugiere que la variabilidad registrada es la esperable, para el modo en que se presenta la obsidiana en la fuente primaria.

\begin{tabular}{|c|c|c|c|c|c|c|c|}
\hline & $\begin{array}{c}\text { Clase } \\
\text { Artefacto }\end{array}$ & $\begin{array}{c}\text { Co } \\
\text { Huenul }\end{array}$ & $\begin{array}{c}\text { El } \\
\text { Peceño }\end{array}$ & $\begin{array}{c}\text { El } \\
\text { Maule }\end{array}$ & $\begin{array}{c}\text { Las } \\
\text { Cargas }\end{array}$ & $\begin{array}{c}\text { Desconocid } \\
\text { a }\end{array}$ & $\begin{array}{c}\text { Desconocida- } \\
\text { A }\end{array}$ \\
\hline \multirow{3}{*}{$\begin{array}{l}\stackrel{0}{t} \\
\text { 운 }\end{array}$} & AF Bifacial & - & - & $2(22 \%)$ & - & - & - \\
\hline & DT & - & $3(33 \%)$ & $3(33 \%)$ & - & - & 1 (11\%) \\
\hline & Total & - & $3(33 \%)$ & $5(56 \%)$ & - & - & $1(11 \%)$ \\
\hline \multirow{5}{*}{ 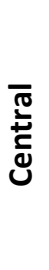 } & AF Bifacial & $1(2 \%)$ & - & $3(7 \%)$ & $3(7 \%)$ & - & - \\
\hline & AF Unifacial & $1(2 \%)$ & - & $1(2 \%)$ & $1(2 \%)$ & $1(2 \%)$ & - \\
\hline & DT & $8(17 \%)$ & - & $18(39 \%)$ & $6(13 \%)$ & $2(4 \%)$ & - \\
\hline & Núcleo & - & - & - & - & $1(2 \%)$ & - \\
\hline & Total & $10(22 \%)$ & - & $22(48 \%)$ & $10(22 \%)$ & $4(9 \%)$ & - \\
\hline \multirow{6}{*}{ 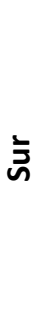 } & AF Bifacial & $1(2 \%)$ & - & $6(14 \%)$ & - & - & - \\
\hline & AF Unifacial & - & - & $6(14 \%)$ & - & - & - \\
\hline & ASF RC & $1(2 \%)$ & - & $2(5 \%)$ & - & - & - \\
\hline & DT & $2(5 \%)$ & - & $22(51 \%)$ & - & $1(2 \%)$ & - \\
\hline & Núcleo & $1(2 \%)$ & - & $1(2 \%)$ & - & - & - \\
\hline & Total & $5(12 \%)$ & - & $37(86 \%)$ & - & $1(2 \%)$ & - \\
\hline
\end{tabular}

Tabla 8.5. Representación de cada categoría artefactual por fuente y discriminado sector. 


\begin{tabular}{|c|c|c|c|c|c|c|c|}
\hline & & Co Huenul & El Peceño & El Maule & Las Cargas & Desconocida & Desconocida-A \\
\hline \multirow{3}{*}{$\begin{array}{l}\stackrel{0}{ \pm} \\
\text { 은 }\end{array}$} & AF Bifacial & - & - & $2(40 \%)$ & - & - & - \\
\hline & DT & - & $3(100 \%)$ & $3(60 \%)$ & - & - & $1(100 \%)$ \\
\hline & Total & - & 3 & 5 & - & - & 1 \\
\hline \multirow{5}{*}{ 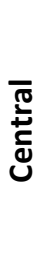 } & AF Bifacial & $1(10 \%)$ & - & $3(14 \%)$ & $3(30 \%)$ & - & - \\
\hline & AF Unifacial & $1(10 \%)$ & - & $1(5 \%)$ & $1(10 \%)$ & $1(25 \%)$ & - \\
\hline & DT & $8(80 \%)$ & - & $18(82 \%)$ & $6(60 \%)$ & $2(50 \%)$ & - \\
\hline & Núcleo & - & - & & - & $1(25 \%)$ & - \\
\hline & Total & 10 & - & 22 & 10 & 4 & - \\
\hline \multirow{6}{*}{ 亏ั } & AF Bifacial & $1(20 \%$ & - & $6(16 \%)$ & - & - & - \\
\hline & AF Unifacial & - & - & $6(16 \%)$ & - & - & - \\
\hline & ASF RC & $1(20 \%)$ & - & $2(5 \%)$ & - & - & - \\
\hline & DT & $2(40 \%)$ & - & $22(59 \%)$ & - & $1(100 \%)$ & - \\
\hline & Núcleo & $1(20 \%)$ & - & $1(3 \%)$ & - & - & - \\
\hline & Total & 5 & - & 37 & - & 1 & - \\
\hline
\end{tabular}

Tabla 8.6. Representación de cada fuente por categoría artefactual y discriminando sector.

\begin{tabular}{|c|c|c|c|c|c|c|}
\hline SECTOR & $\%$ Corteza & Co Huenul & El Maule & Las Cargas & Desconocida & Desconocida-A \\
\hline \multirow{2}{*}{$\begin{array}{l}\stackrel{0}{t} \\
\text { Z }\end{array}$} & $0 \%$ & - & - & - & - & $100 \%$ \\
\hline & Total Norte & - & - & - & - & 1 \\
\hline \multirow{5}{*}{ 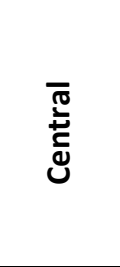 } & $0 \%$ & - & $85 \%$ & $50 \%$ & $100 \%$ & - \\
\hline & $25 \%$ & - & $15 \%$ & $50 \%$ & - & - \\
\hline & $75 \%$ & $50 \%$ & - & - & - & - \\
\hline & $100 \%$ & $50 \%$ & - & - & - & - \\
\hline & Total Central & 2 & 13 & 2 & 1 & - \\
\hline \multirow{6}{*}{ 气ั } & $0 \%$ & - & $42 \%$ & - & $100 \%$ & - \\
\hline & $25 \%$ & - & $33 \%$ & - & - & - \\
\hline & $50 \%$ & $50 \%$ & & - & - & - \\
\hline & $75 \%$ & - & $25 \%$ & - & - & - \\
\hline & $100 \%$ & $50 \%$ & & - & - & - \\
\hline & Total Sur & 2 & 12 & - & 1 & - \\
\hline
\end{tabular}

Tabla 8.7. Proporción de corteza en artefactos enteros, discriminados por sector.

En el sector norte y central los instrumentos se encuentran en su mayoría fracturados, mientras que en el sur se registra una mayor frecuencia de descarte de instrumentos enteros por sobre las fracturados (Tabla 8.8). En el sector norte los dos instrumentos registrados son de obsidiana El Maule y corresponden al grupo tipológico de las puntas de proyectil. Ambas tienen el ápice fracturado y una presenta posibles lascados de reactivación (Figura 8.11). 
En el sector central los instrumentos más frecuentes son los bifaciales (64\%, $n=7)$, seguidos por los unifaciales $(36 \%, n=4)$, todos confeccionados sobre lasca. En este sector la obsidiana El Maule (57\%), está representada por los tipos bifaces ( $n=2)$ y las puntas de proyectil $(n=2)$. La procedente de Las Cargas aparece en forma de puntas de proyectil descartadas fracturadas $(29 \%, n=2)$, y la de Cerro Huenul como un artefacto no diferenciado (14\%). Los artefactos de formatización unifacial $(36 \%, n=4)$, son en su totalidad lascas con retoque unifacial y presentan una señal química diferente. En el sector sur, el $81 \%$ de los instrumentos está entero $(n=13)$ y el $19 \%$ restante fracturado $(n=3)$; todos fueron confeccionados sobre lasca. Los artefactos de formatización bifacial son los más frecuentes (44\%), seguidos por los unifaciales (38\%) y los artefactos con rastros complementarios (19\%). En este sector se han identificado las fuentes El Maule (87\%) y Cerro Huenul (12\%). Sobre obsidiana de la primera se recuperaron, entre los bifaciales, cuatro artefactos de retoque bilateral oblicuo (RBO) enteros y dos puntas de proyectil fracturadas. En unifaciales se destacan los filos laterales cortos sobre lascas $(n=3)$ y un posible perforador $(n=1)$, con reserva de corteza en toda su cara dorsal (Figura 8.12); y dos artefactos con rastros complementarios enteros (Figura 8.13). En obsidiana de Cerro Huenul se recuperaron una punta de proyectil y un artefacto con rastros complementarios, ambos enteros.

En cuanto a la relación ancho/espesor de los artefactos enteros (Tabla 8.9), en los sectores central y sur hay una tendencia a módulos espesos y muy espesos de obsidiana El Maule y Cerro Huenul. Mientras que en el sector norte la fuente Desconocida A, presenta módulos muy espesos. La alta proporción de módulos muy espesos, estaría indicando el descarte de artefactos con potencial reactivación y/o mantenimiento. En lo referido al tamaño relativo de los artefactos enteros (Tabla 8.10), se observa que en los sectores central y sur, predominan los grandes (grandísimo, muy grande y grande) en obsidiana El Maule, Cerro Huenul y Desconocida. Le siguen los tamaños medianos (mediano grande y mediano pequeño) tanto en el sector central (Las Cargas y Desconocida), como en el sector sur (Cerro Huenul). En el sector norte, se registraron artefactos grandes de obsidiana Desconocida-A. 


\begin{tabular}{|c|c|c|c|c|c|c|c|}
\hline \multirow{3}{*}{ Sector } & \multirow{2}{*}{ INST } & \multicolumn{2}{|c|}{ Cerro Huenul } & \multicolumn{2}{c|}{ El Maule } & Las Cargas & Desconocida \\
\cline { 3 - 8 } & & Entero & Fracturado & Entero & Fracturado & Fracturado & Entero \\
\hline \multirow{3}{*}{ Norte } & AF Bifacial & - & - & - & 1 & - & - \\
\cline { 2 - 8 } & Total Norte & - & - & - & $100 \%(1)$ & - & - \\
\hline \multirow{4}{*}{ Central } & AF Bifacial & - & 1 & 2 & 1 & 3 & - \\
\cline { 2 - 9 } & AF Unifacial & - & 1 & 1 & - & 1 & 1 \\
\cline { 2 - 9 } & Total Central & - & $100 \%(2)$ & $75 \%(3)$ & $25 \%(1)$ & $100 \%(4)$ & $100 \%(1)$ \\
\hline \multirow{4}{*}{ Sur } & AF Bifacial & 1 & - & 4 & 2 & - & - \\
\cline { 2 - 9 } & AF Unifacial & - & - & 5 & 1 & - & - \\
\cline { 2 - 9 } & ASF RC & 1 & - & 2 & - & - & - \\
\cline { 2 - 8 } & Total Sur & $100 \%(2)$ & - & $79 \%(11)$ & $21 \%(3)$ & - & - \\
\hline
\end{tabular}

Tabla 8.8 Tendencia en el estado de fragmentación de los instrumentos; frecuencias relativas a cada fuente.

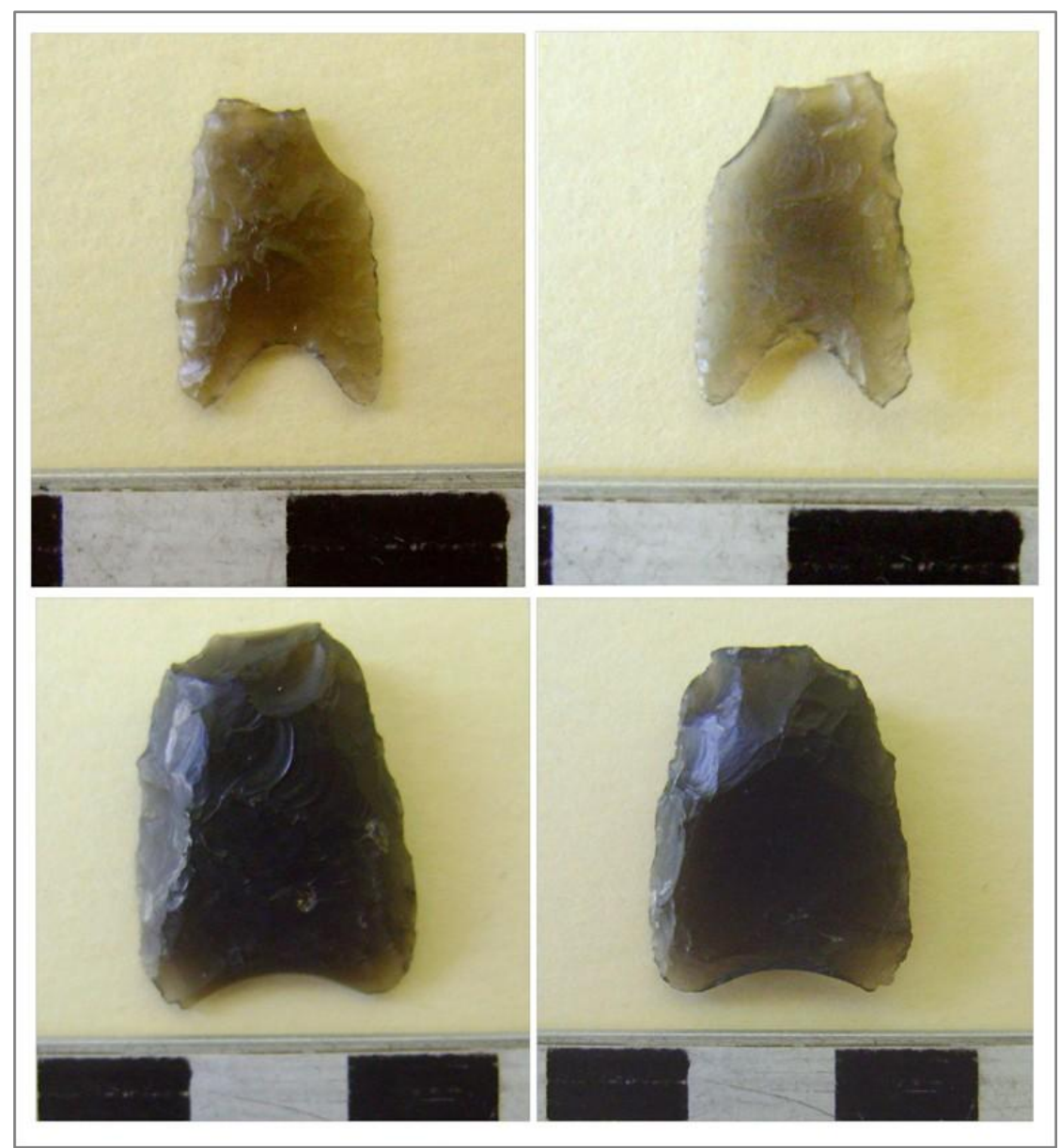

Figura 8.11. Puntas de proyectil sobre obsidiana El Maule (Sector norte-LP) (vista ventral y dorsal). Arriba, punta de proyectil con ápice fracturado; abajo, punta de proyectil con ápice fracturado y posibles lascados de reactivación. 


\begin{tabular}{|c|c|c|c|c|c|c|}
\hline \multirow{3}{*}{ Sector } & Módulo A/E & Co Huenul & El Maule & Las Cargas & Desconocida & Desconocida-A \\
\hline \multirow{4}{*}{ Norte } & Muy Espeso & - & - & - & - & $100 \%$ \\
\cline { 2 - 7 } & Total Norte & - & - & - & - & $100 \%(1)$ \\
\hline \multirow{5}{*}{ Central } & Poco espeso & - & $25 \%$ & - & - & - \\
\cline { 2 - 7 } & Espeso & $100 \%$ & $44 \%$ & $100 \%$ & $75 \%$ & - \\
\cline { 2 - 7 } & Muy Espeso & - & $31 \%$ & - & $25 \%$ & - \\
\cline { 2 - 7 } & Total Central & $100 \%(2)$ & $100 \%(16)$ & $100 \%(2)$ & $100 \%(3)$ & - \\
\hline \multirow{5}{*}{ Sur } & Poco espeso & - & $4 \%$ & - & - & - \\
\cline { 2 - 7 } & Espeso & $75 \%$ & $54 \%$ & - & $100 \%$ & - \\
\cline { 2 - 7 } & Muy Espeso & $25 \%$ & $42 \%$ & - & - & - \\
\cline { 2 - 7 } & Total Sur & $100 \%(5)$ & $100 \%(24)$ & - & $100 \%(1)$ & - \\
\hline
\end{tabular}

Tabla 8.9. Módulo ancho/espesor en artefactos enteros de cada sector, frecuencia relativa de cada fuente.

\begin{tabular}{|c|c|c|c|c|c|c|}
\hline Sector & Tamaño & Co Huenul & El Maule & Las Cargas & Desconocida & Desconocida-A \\
\hline \multirow{2}{*}{$\begin{array}{l}\stackrel{ \pm}{t} \\
\text { Z }\end{array}$} & GR & - & - & - & - & $100 \%$ \\
\hline & Total Norte & - & - & - & - & $100 \%(1)$ \\
\hline \multirow{5}{*}{ 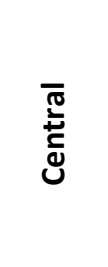 } & MEP & - & - & $50 \%$ & $25 \%$ & - \\
\hline & MEG & - & $13 \%$ & $50 \%$ & - & - \\
\hline & GR & - & $19 \%$ & - & - & - \\
\hline & GD & $100 \%$ & $69 \%$ & - & $75 \%$ & - \\
\hline & Total Central & $100 \%(2)$ & $100 \%(16)$ & $100 \%(2)$ & $100 \%(3)$ & \\
\hline \multirow{5}{*}{ 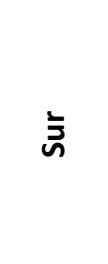 } & MEG & $20 \%$ & $4 \%$ & - & - & - \\
\hline & GR & - & $4 \%$ & - & - & - \\
\hline & MG & $20 \%$ & $17 \%$ & - & - & - \\
\hline & GD & $60 \%$ & $75 \%$ & - & $100 \%$ & - \\
\hline & Total Sur & $100 \%(5)$ & $100 \%(24)$ & - & $100 \%(1)$ & \\
\hline
\end{tabular}

Tabla 8.10. Tamaño de artefactos en cada sector; frecuencia relativa a cada fuente. Referencias: MEP: mediano pequeño; MEG: mediano grande; G: grande; MG: muy grande; GD: grandísimo. 


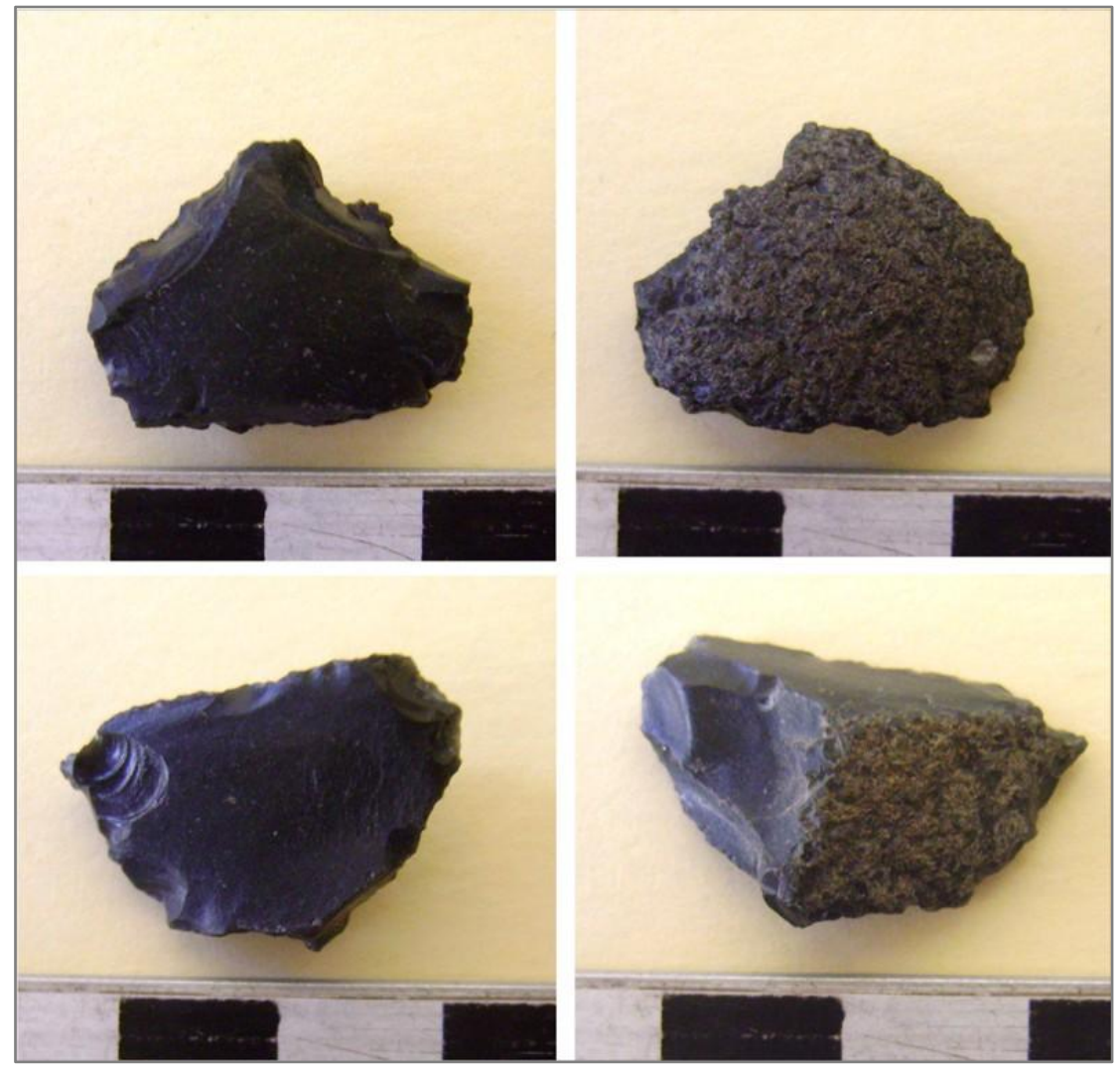

Figura 8.12. Artefacto de formatización unifacial con reserva de corteza en obsidiana El Maule, sector sur. Vista de cara ventral y dorsal, muestra MRBPO6 (arriba) y MRBP09 (abajo).

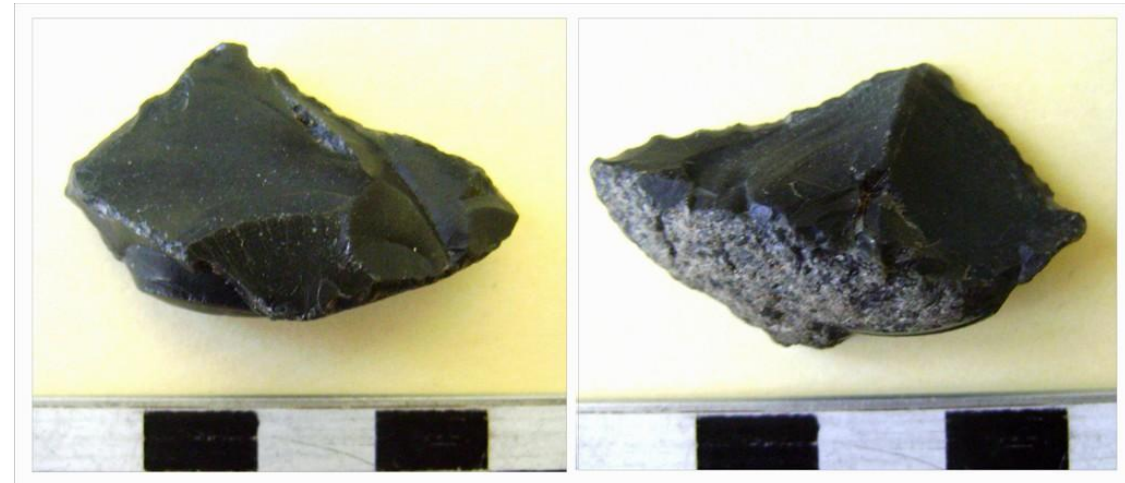

Figura 8.13. Artefacto sin formatización con rastros complementarios en obsidiana Cerro Huenul, sector sur. Vista de cara ventral y dorsal, muestra MPRC05.

En desechos de talla la fuente El Maule en el sector norte, está constituida únicamente como lascas internas (LAR y LAN) vinculadas a etapas intermedias de manufactura (Tabla 8.11; Figura 8.14). En los sectores central y sur, en cambio, están presentes todas las etapas del proceso de manufactura sobre la misma materia prima. En obsidiana Cerro Huenul (sector sur y central) son más frecuentes los desechos 
asociados a las primeras etapas de manufactura; sólo en el sector central se encuentran representados todos los estadios. Entre las obsidianas de Las Cargas (sector central) predominan las lascas internas (LAR y LAN) y de mantenimiento de filos (LR), mientras que en las Desconocidas solo aparecen lascas internas. Al considerar el grado de reducción de los tipos de obsidiana por medio del cálculo de estimativos de corteza y la intensidad de reducción de las materias primas (Tablas 8.12 y 8.13), se observa que el índice de corteza mayor se registra en obsidiana Cerro Huenul, en ambos sectores. Sin embargo, la intensidad de reducción de desechos del sector central es mayor. La obsidiana El Maule presenta valores de corteza e intensidad de reducción altos en el sector sur, y más bajos en el sector central. Asimismo, si observamos los valores mínimos de densidad de reducción en el sector central (Tabla 8.13), se destaca un valor mayor que en el sector sur. Esto podría indicar que la obsidiana El Maule habría ingresando en el sector central con menos reserva de corteza, a diferencia del sector sur donde son frecuentes las lascas primarias. Las obsidianas Desconocidas y Las Cargas en el sector central, son las que presentan los índices de reducción más altos de la región.

En ambos sectores se observa variabilidad en la relación entre densidad de extracciones y rangos de distancia (Figura 8.15). En el sector central la mayor variabilidad se presenta en obsidiana Cerro Huenul (rango de distancia entre 41 y 80 km) y Las Cargas (rango de distancia entre 161 y 200 km). Esto es con la presencia de todas las etapas de manufactura en Cerro Huenul. En La Cargas se registran únicamente lascas internas con distinta intensidad de lascado además de algunas de reactivación de filo (no incluidas en el cálculo de este índice de intensidad de reducción). En El Maule (rango entre 81 y $120 \mathrm{~km}$ ), se observa menor variabilidad en la intensidad de extracciones, pero con valores extremos (como lascas primarias y desechos alta intensidad de lascado). Sin embargo, las diferencias de varianza en la intensidad de lascado de las distintas obsidianas en el sector central no son significativas (ANOVA, $p=0,722 ; d f .=3$ ). Por lo tanto la distancia no es un factor que esté influyendo en la intensidad de lascados de los artefactos en el sector.

En el sector sur, la obsidiana El Maule (rango de distancia entre 161-200 km) presenta una variabilidad semejante a la observada en el sector central. Posee un valor 
medio de densidad de extracción mayor, pero no resulta significativo $(t=0,35 ; p=0,72)$. La obsidiana Cerro Huenul, sólo se presenta como lascas externas, con escasa variabilidad. Al comparar la intensidad de extracciones en artefactos de obsidiana entre sectores, las diferencias observada no resultan significativas (ANOVA, $p=0,89$; $d f .=5)$. La distancia de procedencia de la materia prima, por lo tanto no afecta de manera significativa la intensidad de uso.

En cuanto a los núcleos recuperados $(n=3)$, uno corresponde al sector central (34\%) y dos al sector sur (66\%). El primero fue confeccionado sobre obsidiana de fuente desconocida, se encuentra fragmentado, está cubierto por una gruesa pátina y su tamaño estimado es muy grande. Presenta una densidad de extracciones media $\left(x=0,493 \mathrm{e} / \mathrm{mm}^{3}\right)$ y su forma base no pudo ser determinada. Las obsidianas de los núcleos recuperados en el sector sur, provienen de las fuentes El Maule y Cerro Huenul. Uno es piramidal y el otro amorfo y ambos se encuentran agotados. La densidad de extracciones o numero de negativos de lascado es alta en el núcleo $\mathrm{El}$ Maule $\left(x=1,66 \mathrm{e} / \mathrm{mm}^{3}\right)$ y menor en el caso de Cerro Huenul $\left(x=1,588 \mathrm{e} / \mathrm{mm}^{3}\right)$. Sólo la pieza procedente de Cerro Huenul presenta remanentes de corteza (25\%). 


\begin{tabular}{|c|c|c|c|c|c|c|}
\hline SECTOR & DT & Co Huenul & El Maule & Las Cargas & Desconocida & Desconocida-A \\
\hline \multirow{2}{*}{$\begin{array}{l}\stackrel{ \pm}{ \pm} \\
\text { 은 }\end{array}$} & LAN & - & $100 \%$ & - & - & $100 \%$ \\
\hline & Total Norte & - & 1 & - & - & 1 \\
\hline \multirow{9}{*}{ 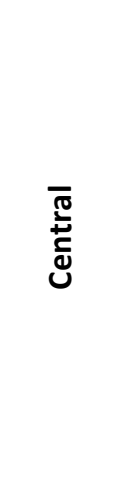 } & LPR & $29 \%$ & - & - & - & - \\
\hline & LSEC & - & $6 \%$ & - & - & - \\
\hline & LAN & $14 \%$ & $44 \%$ & $40 \%$ & $50 \%$ & - \\
\hline & LAR & $14 \%$ & $22 \%$ & $40 \%$ & $50 \%$ & - \\
\hline & LAB & $14 \%$ & - & - & - & - \\
\hline & PL & - & $11 \%$ & - & - & - \\
\hline & LR & - & $17 \%$ & $20 \%$ & - & - \\
\hline & LN & $29 \%$ & - & - & - & - \\
\hline & Total Central & 7 & 18 & 5 & 2 & \\
\hline \multirow{8}{*}{ うう } & LPR & & $5 \%$ & - & - & - \\
\hline & LSEC & $50 \%$ & $20 \%$ & - & - & - \\
\hline & LAN & - & $30 \%$ & - & $100 \%$ & - \\
\hline & LAR & - & $25 \%$ & - & - & - \\
\hline & LR & - & $5 \%$ & - & - & - \\
\hline & LN & $50 \%$ & $10 \%$ & - & - & - \\
\hline & LBIP & & $5 \%$ & - & - & - \\
\hline & Total Sur & 2 & 20 & - & 1 & - \\
\hline
\end{tabular}

Tabla 8.11. Desechos de talla de cada área; frecuencia relativa de cada fuente. Referencias: LPR: lasca primaria; LSEC: lasca secundaria; LAN: lasca angular; LAR: lasca de arista; LAB: lasca de adelgazamiento bifacial; LR: lasca de reactivación de instrumentos; LN: lascas nodular o de reactivación de núcleo; LBIP: lasca bipolar.

\begin{tabular}{|c|c|c|c|c|c|}
\hline SECTOR & FUENTE & $\mathbf{N}$ & LPR & LSEC & ÍNDICE CORTEZA \\
\hline \multirow{4}{*}{ 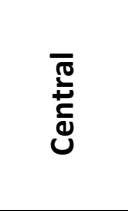 } & Co Huenul & 2 & 1 & - & 0,5 \\
\hline & El Maule & 13 & - & 1 & 0,0769 \\
\hline & Las Cargas & 2 & - & - & - \\
\hline & Desconocida & 1 & - & - & - \\
\hline \multirow{3}{*}{ 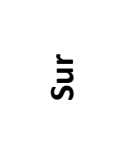 } & Co Huenul & 2 & - & 1 & 0,5 \\
\hline & El Maule & 12 & 1 & 3 & 0,333 \\
\hline & Desconocida & 1 & - & - & - \\
\hline
\end{tabular}

Tabla 8.12. Índice de corteza de las distintas fuentes en cada sector. 


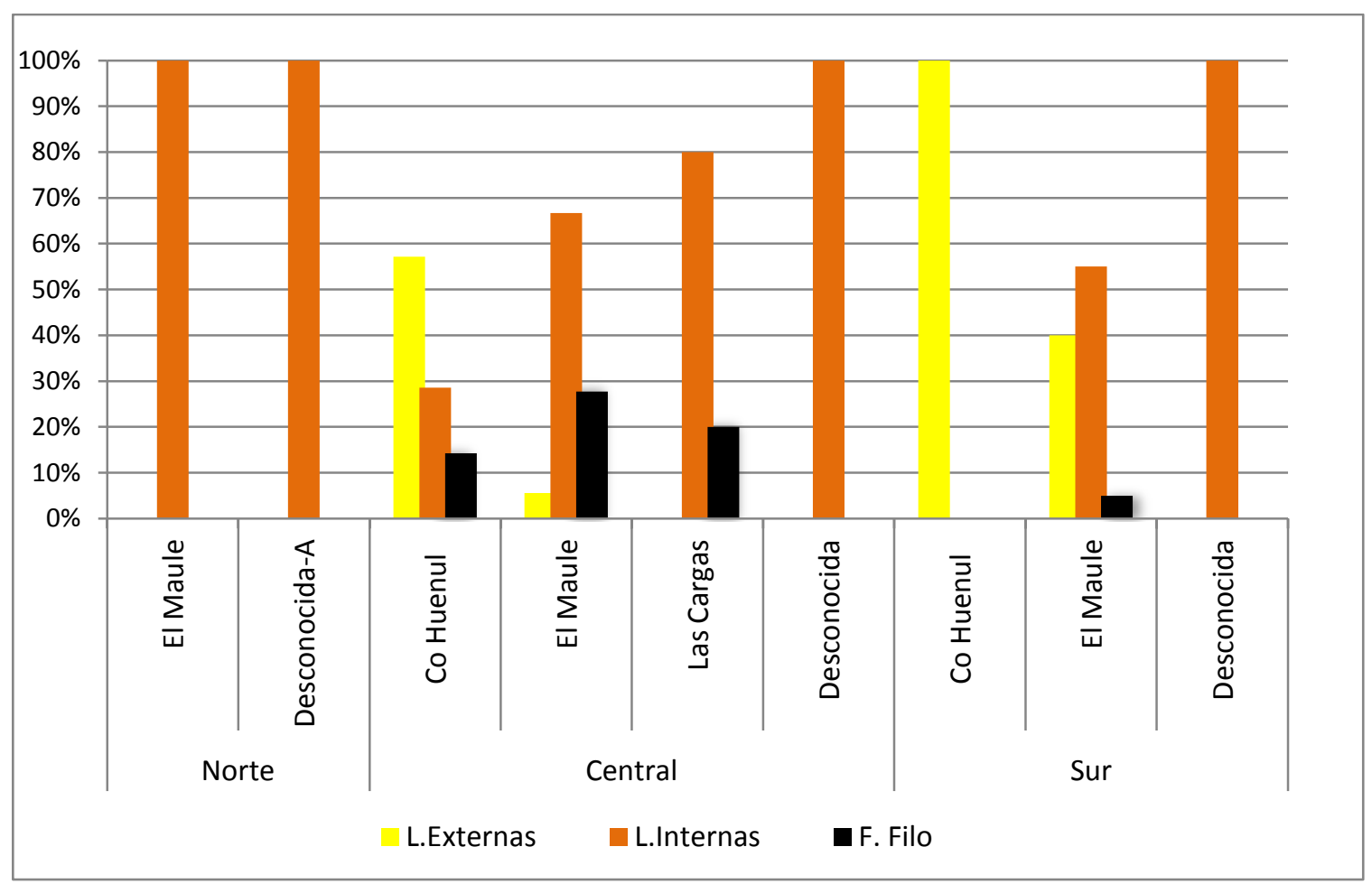

Figura 8.14. Distribución de desechos de talla externos (L. Externas), internos (L. Internas) y de reactivación de filos (F. Filo), discriminados según fuente de procedencia y sector.

\begin{tabular}{|c|c|c|c|c|c|c|c|c|}
\hline Sector & Fuente & $\mathbf{N}$ & Media & Mediana & Desvío Estándar & Mínimo & Máximo & Rango \\
\hline \multirow{4}{*}{ 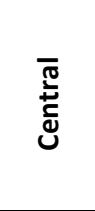 } & Co Huenul & 8 & 0,511 & 0,351 & 0,621 & 0 & 1,712 & 1,712 \\
\hline & El Maule & 15 & 0,639 & 0,528 & 0,51 & 0,181 & 2,08 & 1,899 \\
\hline & Las Cargas & 5 & 0,819 & 0,932 & 0,432 & 0,32 & 1,28 & 0,96 \\
\hline & Desconocida & 2 & 0,847 & - & - & 0,544 & 1,151 & 0,607 \\
\hline \multirow{2}{*}{ 气े } & Co Huenul & 2 & 0,375 & - & - & 0,104 & 0,646 & 0,541 \\
\hline & El Maule & 19 & 0,677 & 0,462 & 0,683 & 0 & 2,48 & 2,48 \\
\hline
\end{tabular}

Tabla 8.13. Estadística descriptiva de la densidad de extracciones previas en la cara dorsal de los desechos de talla de las distintas fuentes en cada sector. 


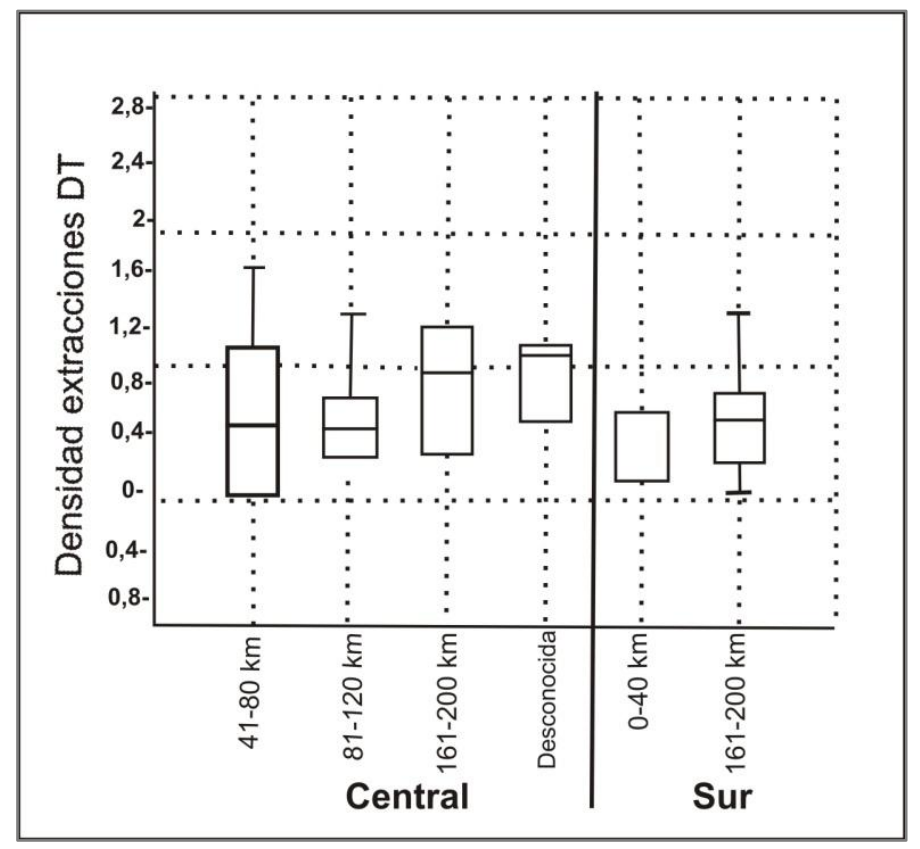

Figura 8.15. Frecuencia de densidad de extracciones en sector central y sur, según distancia estimada en $\mathrm{km}$ a la fuente.

\subsubsection{TENDENCIAS ESPACIALES EN EL APROVISIONAMIENTO DE OBSIDIANA EN LA PAYUNIA}

Los resultados de los análisis geoquímicos y tecnológicos muestran diferencias significativas en cuanto a diversidad de fuentes de obsidiana representadas, etapas de manufactura presentes e intensidad de reducción, entre el sector norte por un lado y, central y sur por otro. En los tres, la fuente cordillerana El Maule es la más representada, distante de la región entre 120 y $200 \mathrm{~km}$ de los sitios de hallazgo. Las fuentes menos representadas poseen rangos de distancia que superan los $40 \mathrm{~km}$, con excepción de la fuente Cerro Huenul en sitios del sector sur. En todos los casos están representadas en baja proporción las fuentes distantes más cercanas, con rangos de entre 40 y 180 km (e.g.. El Peceño en el sector norte con distancias entre 100 y 130 km, Las Cargas en sector central, distante aproximadamente 180 km y Cerro Huenul en los sectores sur y central con distancias entre 30 y $60 \mathrm{~km}$ ). Un caso particular es el de la fuente El Maule, que en todos los casos supera el rango de los $120 \mathrm{~km}$ y su frecuencia disminuye en sentido sur-norte. 
En cuanto a la diversidad de obsidianas representadas en cada sector, el central posee los valores de diversidad más altos, seguido por los sectores norte y sur. En el sector central las fuentes Cerro Huenul y El Maule presentan alta variabilidad de clases artefactuales y en ellas están representadas todas las etapas de manufactura de artefactos. En la primera, son abundantes las lascas externas y en menor proporción las lascas internas y de formatización de filo. Todos los instrumentos, están fracturados e incluyen bifaciales y unifaciales. En obsidiana El Maule, en cambio, son frecuentes las lascas internas y las últimas etapas de manufactura. La reserva de corteza es baja y los instrumentos, trabajados en su mayoría de modo bifacial (75\%), están en su mayoría enteros. En obsidiana Las Cargas, sólo se encuentran representados los estadios finales de manufactura e instrumentos fracturados. Además, en este sector es donde se registra la frecuencia más alta de obsidianas con señal química no asignada o Desconocida. Esta posee alta variación de clases artefactuales (instrumentos, desechos de talla y núcleos). No presenta reserva de corteza y el descarte de los instrumentos es entero. El núcleo recuperado corresponde a un fragmento no diferenciado, con negativos de lascado de tamaño grande y muy grande. En las cuatro variedades de obsidiana, los tamaño varían entre mediano (Las Cargas y Desconocidas) y grande (Cerro Huenul y El Maule) y de módulo predominante son espesos.

En el sector norte se registran tres variedades de obsidiana (El Peceño, El Maule y Desconocida-A). La obsidiana El Maule, es la que presenta mayor variación de clases artefactuales (instrumentos y desechos de talla), mientras que El Peceño sólo se registra como desechos de talla. No hay reserva de corteza y el espesor relativo es espeso y muy espeso, con tamaños grandes. Los desechos de talla corresponden a lascas internas en todos los casos y los instrumentos se encuentran fracturados. Es de destacar que este sector es el único donde se registra la señal química Desconocida-A, presente como lasca interna.

En el sector sur, se registran dos fuentes de obsidiana conocidas (Cerro Huenul y El Maule) y una procedencia aún Desconocida. La obsidiana El Maule es la única que exhibe todas las etapas de manufactura, acompañada de alta variación de clases artefactuales. Cerro Huenul por su parte, si bien presenta todas las clases artefactuales, en desechos de talla prevalecen los correspondientes a lascas externas, 
es decir, a las primeras etapas de manufactura. La reserva de corteza en artefactos El Maule se presenta en todas las clases artefactuales, con excepción de los núcleos; descartados agotados y con alta intensidad de lascados. Los instrumentos están trabajados de modo bifacial y unifacial, además de presentar artefactos con rastros complementarios. Los instrumentos se encuentran mayormente enteros (79\%), pero los formatizados por medio de retoque bifacial, se encuentran fracturados. En el caso de Cerro Huenul, si bien registran todas las clases artefactuales, estas presentan muy baja frecuencia a pesar de su proximidad espacial (Tabla 8.7). El descarte de los instrumentos es entero y fueron manufacturados de forma bifacial, y se registran artefactos con rastros complementarios. Las Desconocidas poseen baja proporción y sólo se registran como lascas internas. En las tres variedades de obsidiana, el modulo relativo de tamaño frecuente es espeso y muy espeso y tamaños grandes (módulos muy grande y grandísimo).

En base a las expectativas planteadas referentes a los artefactos líticos y los modos de aprovisionamiento, la obsidiana El Maule estaría ingresando a la región en forma de núcleos (núcleos de morfología amorfa y piramidal y descarte en estado agotado) y hay evidencias para sostener la manufactura del instrumental in situ, al menos en los sectores sur y central. Al respecto, se evidencia en desechos de talla una alta variabilidad de tipos, en particular en el sector sur y en menor medida en sector central. En ambos se encuentran representadas todas las etapas de manufactura. El $50 \%$ de los artefactos presenta reserva de corteza, el espesor relativo es espeso-muy espeso y el tamaño grande. En cuanto a instrumentos la mayor variabilidad de tipos se registra en sector sur, seguido por central y, sólo presente como puntas de proyectil en el norte. Dado el tamaño del instrumental y la forma base utilizada, la búsqueda de soportes adecuados para la manufactura de puntas de proyectil parece ser el eje direccional del procesamiento de esta materia prima. Se puede apreciar a nivel regional que la mayoría de las lascas producidas se utiliza fundamentalmente para la manufactura de artefactos bifaciales y en menor medida unifaciales. Quizás éstas últimas en aquellos subproductos poco adecuados para la talla bifacial y, en el marco de una maximización en el aprovechamiento del recurso. De éste modo, lascas externas e internas han sido modificadas para producir algunos instrumentos 
unifaciales con procedimientos de retoque marginal y/o ultra marginal, así como el aprovechamiento de filos naturales. El registro de lascas nodulares y productos bipolares, dan sustento a la idea de actividades orientadas a la preservación o economía de esta materia prima. En el sector central, la obsidiana El Maule exhibe un menor porcentaje de corteza y ausencia de núcleos, lo que indicaría un ingreso de formas base o núcleos en parte descortezados, ya que no hay evidencias de instrumentos confeccionados sobre lascas externas y las mismas, poseen escasa representación. En el sector norte, por su parte, la presencia de lascas internas y de reactivación de filo, sostiene la idea de el ingreso de instrumentos formatizados y/o formas base en avanzado estado de manufactura. Asimismo, la alta frecuencia de lascas de reactivación y los posibles intentos de reactivación en las puntas descartadas, podrían apoyar la idea de un ingreso poco frecuente o más restringido de ésta materia prima al sector.

Por su parte, la obsidiana Cerro Huenul estaría ingresando a la región en forma de nódulos, facilitado quizás por el modo de yacencia en la fuente y su excelente calidad (Barberena et al. 2011). Se registró un núcleo agotado en el sector sur y una alta frecuencia de lascas externas en los sectores sur y central. El aprovisionamiento y/o acceso a ésta fuente sería poco frecuente o esporádica, dada su cercanía a los sitios y su baja frecuencia a nivel regional. En los sitios próximos se encuentran representadas solo las primeras etapas de manufactura, variabilidad que aumenta en el sector central, donde se presentan todas las etapas de manufactura. El instrumental es en su mayoría trabajado en forma bifacial (puntas de proyectil) y aprovechado sus filos en sector sur. En el sector central la variabilidad de manufactura de instrumentos aumenta. A su uso poco económico en el sector sur, se suma el descarte de instrumentos enteros en este últimos y fracturados en el central, manifestándose en este último una mayor maximización de la materia prima.

En cuanto a La Cargas, solo se presenta en el sector central, donde estaría ingresando como formas base o instrumentos terminados, dado el registro de lascas internas, de lascas de formatización de filos y módulos de tamaño mediano y mediano pequeños. La reserva de corteza es nula y el instrumental exhibe escasa variabilidad de tipos, optando por su descarte en estado fracturado. El Peceño y Desconocida-A, se 
registran sólo en el sector norte, como lascas internas y en muy baja frecuencia. No poseen reserva de corteza y sus tamaños son medianos a grandes. Se considera que éstas materia primas, estarían ingresando como artefactos terminados, sujetos a mantenimiento y quizás altamente conservados. Por último las Desconocidas, se presentan con mayor frecuencia en los sectores central y sur, sin embargo su variabilidad en clases artefactuales es alta, sobre todo en el sector central.

Sobre esta base podemos decir que la obsidiana se comporta de acuerdo a las expectativas de distancia relativas entre las diferentes fuentes y los sitios arqueológicos. En este sentido las fuentes más próximas están mejor representadas que las ubicadas a mayor distancia y el grado de trabajo de los artefactos recuperados sigue una línea de reducción acorde con el aumento de la distancia entre los sitios arqueológicos y las fuentes. Es decir que a medida que aumenta la distancia a la fuente, estas se encuentran representadas con menor frecuencia, se registran las etapas iniciales del proceso de manufactura y disminuyen los módulos de tamaño de los artefactos.

No obstante, hay algunas tendencias que escapan a este patrón y que pueden ser explicadas en términos biogeográficos. En primer lugar es inesperada la mayor presencia de obsidiana de El Maule (62\%) en el sector norte, en relación a la proveniente de la fuente de El Peceño (38\%), dado que esta última se encuentra más próxima, de disponibilidad anual y fácil acceso. En un trabajo previo se planteó que la región muestra evidencias de ejes de circulación oeste-este por sobre los norte-sur (Giesso et al. 2011; Cortegoso et al. 2012). Las razones que expliquen esta tendencia aún no han sido discutidas, pero podrían estar relacionadas con la dirección predominante de los ríos, los cuales siguen el mismo eje latitudinal. Esto podría dificultar o restringir en cierta manera la circulación norte-sur. De todas formas hay que tener en cuenta que la muestra analizada para el sector norte es de sólo 9 piezas, por lo que las conclusiones que de allí emanen deberán ser tomadas con cuidado hasta tanto no se amplié el tamaño de la misma. La evidencia de ejes de circulación preferenciales ha sido destacado por otros investigadores, tal es el caso de los mostrado del Jones y colaboradores (2003, 2012; Eerkens et al. 2007; Beck et al. 2012) para la circulación de la obsidiana en la Grana Cuenca. 
Otro punto interesante en términos de la distribución contra-intuitiva de obsidiana en la región, es la representación que tiene la fuente Cerro Huenul dentro de los sectores analizados. Considerando que es la fuente más próxima a los sectores central y sur, la misma se halla pobremente representada, sin superar en ningún caso a los valores de frecuencia que muestra la obsidiana El Maule (localizada a una distancia hasta tres veces mayor que Cerro Huenul). Las características tecnológicas son coherentes con la proximidad de esta fuente a la región, pero su abundancia no lo es, dado que El Maule supera los porcentajes de esta fuente. Esto sugiere un acceso esporádico a la fuente, cuyo uso sigue las expectativas tecnológicas de la distancia a la cual se encuentra. Barberena et al. (2011) plantean la posibilidad de que el río Colorado funcione como una barreras temporal (sensu Veth 1993) durante periodos específicos de año. La cual en el tiempo, contribuyen a una baja representación macro regional de la cantera.

Por último, el tercer punto que no condice las expectativas de distancia entre sitios y fuentes, ocurre entre las áreas central y sur en relación a la fuente de El Maule. Hay una menor proporción de obsidiana procedente de El Maule en el sector central en relación al sur, y a su vez los artefactos recuperados en el sector central muestran etapas de manufactura más avanzadas. Esto es contrario a lo esperado dado que el área centro se encuentra más próximo a la fuente de El Maule que el área sur. Todos los indicadores mencionados parecen mostrar que la obsidiana estaría ingresando al sector central desde los ríos Barrancas y Colorado, circulando previamente por el sector sur (recorrido aproximado de 270 km) (Figura 8.16. A). Esta errática circulación de la obsidiana puede ser explicada por la presencia de la sierra de Reyes y de Cara cura al oeste de los sectores central y sur, que sólo posee un paso al norte a través del área de Los Volcanes y Pampas negras (camino más corto -ca. $200 \mathrm{~km}$-, pero sin disponibilidad de aguadas) (Figura 8.16. B); o siguiendo el curso de los ríos Grande y Colorado (evitando las sierras de Reyes y Cara Cura; $c a .350$ km) que se desvía hacia el sur, antes de ingresar a las áreas bajo estudio. 


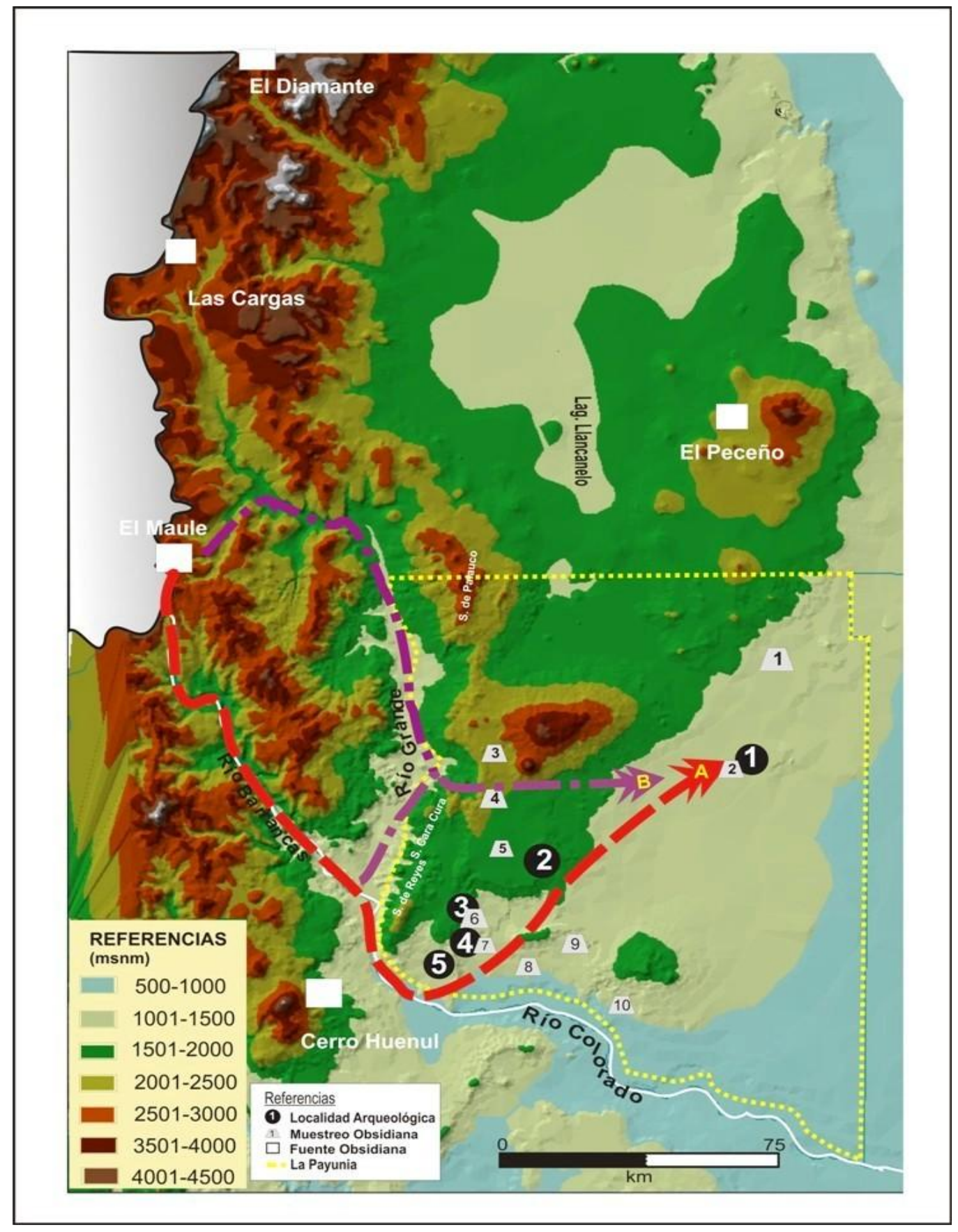

Figura 8.16. Posibles vías de circulación de obsidiana El Maule. Referencia: (A) vías de menor resistencia ríos Barrancas y Colorado; (B) vía cercana acceso río Grande y Los Volcanes. Referencias: Localidades arqueológicas: 1. La Peligrosa; 2. Altiplanicie del Payén; 3. Agua de Pérez; 4. Carmonina; 5. Río Colorado. Muestreos de obsidiana: 1 La Corredera; 2. La Peligrosa 2; 3. Puesto Mira; 4. Loma Alta; 5. Alpa este; 6. Agua de Pérez; 7. Carmonina 1; 8. PRC; 9. Rincón Blanco; 10. PRC Tren. 


\section{CAPÍTULO 9}

\section{TENDENCIAS EN EL APROVISIONMIENTO Y USO DE MATERIAS PRIMAS LÍTICAS EN LA PAYUNIA}

\section{INTRODUCCIÓN}

Sobre la base de los resultados detallados en los capítulo previos y siguiendo la metodología descripta en el capítulo 5, se analizan las trayectorias de producción de los recursos líticos en La Payunia. Estas trayectorias incluyen el abastecimiento, la selección y obtención de formas base, la formatización, el uso, mantenimiento y descarte de los artefactos. La integración de la información fue abordada contemplando las unidades espaciales definidas, de modo que en cada sector se incluyen: en el sector norte la localidad La Peligrosa (LP); el sector central la localidad Altiplanicie del Payén (ALPA) y el sector sur se integran las localidades de Agua de Pérez (APE), Carmonina (CAR) y Río Colorado (RC) (Tabla 9.1).

\begin{tabular}{|c|c|c|c|c|c|c|c|c|c|}
\hline & \multicolumn{3}{|c|}{ Sector Norte } & \multicolumn{3}{|c|}{ Sector Central } & \multicolumn{3}{|c|}{ Sector Sur } \\
\hline & $\mathbf{N}$ & Sup. & Estrat. & $\mathbf{N}$ & Sup. & Estrat. & $\mathbf{N}$ & Sup. & Estrat. \\
\hline Conjuntos & 4 & $\begin{array}{l}\text { LLE; } \\
\text { LPT2 }\end{array}$ & LC; LP-2 & 9 & $\begin{array}{c}200 ; 205 ; \\
215 ; 230 ; \\
231 ; 245 ; \\
253 ; 254 \\
275\end{array}$ & - & 9 & $\begin{array}{l}\text { APE-C; Pista; } \\
\text { RC (A, B, C, D) }\end{array}$ & APE-1; CAR-1 \\
\hline $\begin{array}{l}\text { Recursos } \\
\text { Locales }\end{array}$ & $\begin{array}{l}17 \\
50\end{array}$ & $100 \%$ SIL & $\begin{array}{c}99,8 \% \text { SIL; } \\
0,1 \% \text { BAS; } \\
0,1 \% \text { RIO }\end{array}$ & 283 & $\begin{array}{c}97 \% \text { SIL; } 3 \% \\
\text { BAS }\end{array}$ & - & 681 & $\begin{array}{c}99,6 \% \text { SIL; 0,3\% } \\
\text { BAS; 0,1\% RIO }\end{array}$ & $\begin{array}{c}99,8 \% \text { SIL; } 0,2 \% \\
\text { BAS }\end{array}$ \\
\hline $\begin{array}{c}\text { Recursos No } \\
\text { Locales }\end{array}$ & $\begin{array}{c}12 \\
5\end{array}$ & - & $100 \%$ OBS & 3 & $100 \%$ OBS & - & 67 & $100 \%$ OBS & $100 \%$ OBS \\
\hline
\end{tabular}

Tabla 9.1. Conjuntos analizados en La Payunia. 


\subsection{TENDENCIAS ESPACIALES EN EL APROVISIONAMIENTO Y USO DE RECURSOS LÍTICOS}

\subsubsection{SECTOR NORTE}

En la localidad La Peligrosa (LP), la materia prima más representada es la roca silícea $(93,1 \%)$, seguida por la obsidiana $(6,7 \%)$ y en menor media el basalto $(0,1 \%)$ y la riolita (0,1\%). La cercanía a las fuentes primarias Piedras Bayas (PB) y La Leona (LLE) (ambas locales) y los estudios petrográficos (Capítulo 6 y Anexo 1), llevan a plantear que la trayectoria de las silíceas comienza en estas canteras, ubicadas en el rango de distancia inmediato (menor a 5 km) (Civalero y Franco 2001). En LLE, las etapas de abastecimiento y selección de materias primas están representadas por un núcleo amorfo y lascas de descortezamiento (lascas externas). En términos generales, los análisis sugieren que en las fuentes las actividades productivas más frecuentes serían la de descortezamiento y preparación de formas base (lascas de tamaños grandes y muy grandes) (Tabla 7.14).

Las rocas silíceas ingresaron a los sitios La peligrosa 2 (LP-2) y La Corredera (LC), donde se registran actividades múltiples, como lascas con escasa reserva de corteza y, en menor medida núcleos. En dichos locus, se registró una baja frecuencia de corteza en los rangos $75 \%$ y $100 \%(8,6 \%$, Tabla 7.15$)$ y una alta frecuencia de desechos sin corteza $(83,6 \%)$. Los núcleos son poco frecuente $(0,1 \%)$, y habrían estado orientados a la obtención de lascas grandes y muy grandes, y sujetos a reactivaciones -dado el registro de lascas de reactivación de núcleos en todos los muestreos- (Tablas 7.19). Asimismo, las medidas de tamaño medio de largo y ancho de los negativos de lascado de los núcleos (tamaño grande y más largos que anchos), son menores que el rango observado en el instrumental (tamaño muy grande, más anchos que largos) pero se ajustan a lo observado en los desechos de talla (Tabla 7.22). Por ello, algunos descartes de núcleos agotados pudieron llegar a convertirse en formas base de instrumentos de manufactura simple, con retoque marginal unifacial (p.ej. muescas y artefactos mediano pequeños/muy pequeños de retoque de bisel oblicuo) o filos aprovechados de los cuales se conservan rastros complementarios (Hayden 1980; Flegenheimer et al. 
1996). El índice de corteza en los sitios estratigráficos es bajo, siendo mayor en LC $(0,14)$, que en LP-2 $(0,04)$. En las áreas muestreadas se registran las tres etapas de manufactura en rocas silíceas y obsidiana; sin embargo, las etapas finales o de formatización y manteamientos de filos (lascas de formatización de filos) son más frecuentes en LP-2. En este último sitio, la unidad B (fechada en $640 \pm 50$ años AP) presenta mayor frecuencia de lascas de reactivación de filos en silíceas y obsidiana (Figura 7.17) y lascas de adelgazamiento bifacial (Figura 7.18) que en la unidad más reciente (A). Se destaca asimismo, en la unidad $B$, mayor frecuencia de lascas de adelgazamiento bifacial en obsidiana, que en la unidad A. El tamaño de los desechos de talla de LP-2 es en el 75\% muy pequeño y pequeño, en LC el 53\% es muy pequeño y pequeño, el $21 \%$ mediano y el $37 \%$ grande. Distinto a LLE, ubicado próximo a la fuente La Leona, donde el $98 \%$ son muy grandes a grandísimos. La calidad para la talla en desechos en los sitios estratigráficos es muy buena (40\%) a buena (19\%), con registros de calidad excelente en LP-2; lo que implica una selección de la materia prima.

La roca más frecuentemente utilizada en LP para la manufactura del instrumental es la silícea (79\%; Tabla 7.16). La manufactura se realizó tanto por medio de retoques bifaciales (32\%) como unifaciales (32\%), y predominan los filos con rastros complementarios (37\%). Los artefactos bifaciales más frecuentes son la puntas de proyectil, seguido por las preformas bifaciales y los artefactos de retoques en bisel oblicuo. Los artefactos unifaciales son fundamentalmente raspadores, recuperados en la unidad $\mathrm{A}$ (86\%), atribuida a los últimos ca. 400 años AP. En todos los casos la forma base de los artefactos corresponde a lascas y en su mayoría están enteros (58\%) (Tabla 7.26). Los artefactos fracturados (42\%) son en su mayoría bifaciales -puntas de proyectil- (50\%); los siguen los artefactos con rastros complementarios (37\%) y un unifaz (12\%).

En obsidiana y sobre la base de estudios geoquímicos (Capítulo 8), la trayectoria de producción se inició en las fuentes El Maule (a $175 \mathrm{~km}$ lineales) y El Peceño (a 110 km lineales) (Capítulo 6). En LP, hay evidencia del ingreso de obsidiana en forma de lascas o formas base en avanzada reducción, dado que sólo se recuperó un $2 \%$ de lascas primarias (todas en LP-2) (Tabla 7.19). No se registraron núcleos, ni desechos de reactivación de núcleos. La clase artefactual más representada es 
desechos de talla (Tabla 7.20), entre los que son frecuentes las lascas internas y las correspondientes a la manufactura y reactivación de filos, eventos que pueden ser atribuidos a tareas de mantenimiento de herramientas (Tablas 7.19 y 8.6). Los instrumentos representan el $4 \%$ del total de artefactos de obsidiana, están en su mayoría fracturados, y dos de las piezas bifaciales presentan signos de reactivación. La manufactura bifacial, específicamente puntas de proyectil, es la preponderante (Figura 7.19; Tabla 8.9). Se recuperó una sola pieza unifacial, que fue determinada por el ángulo de su filo como raspador. Dada la baja frecuencia de unifaciales, es posible postular que los desechos poco adecuados para la formatización de proyectiles, hayan sido aprovechados para la manufactura de artefactos simples, a fin de se maximizar la explotación de la materia prima (Tabla 7.30) (Escola 2004; Franco 2004).

En el caso de las rocas minoritarias de disponibilidad local (basalto y riolita) (Capitulo 6), en basalto se recuperaron solo dos lascas internas sin corteza de calidad regular y buena. El basalto disponible en la región, si bien no presenta buenas aptitudes para la talla, es factible de producir filos útiles. Su uso puede plantearse como situacional o circunstancial, debido a su baja frecuencia, a la ausencia de otras clases artefactuales representadas (registrada solo en el sitio LP-2). La riolita se utilizó como percutor, conformando una categoría artefactual poco frecuente. Esto puede deberse a su baja visibilidad arqueológica, dada su amplia disponibilidad como materia prima en el sector.

La obsidiana es la más intensamente reducida en el conjunto (Tablas 7.21). Asimismo, el índice de producción (DT/INST) en obsidiana es significativamente menor que en silíceas, dado que en esta última están presentes todas las etapas de reducción (Tabla 9.2). En cuanto a la manufactura de instrumental según materia prima, el índice de bifacialidad (AF Bifacial/ $n$ total INST) por materia prima es notoriamente mayor en obsidiana que en silíceas (Tabla 9.2). En cuanto a la reducción de los instrumentos unifaciales, es otra vez la obsidiana la que presenta el índice mayor respecto a las rocas silíceas (Capítulo 7.1).

Al considerar la variabilidad temporal, en el sitio LP-2, el registro de los últimos 400 años presenta una frecuencia artefactual mayor (tasa de depositación temporal 
5,5 artefactos por $\mathrm{m}^{2} / \mathrm{año}$ ) al de ocupaciones previas (ca. 640 años AP; 2,1 artefactos por $\mathrm{m}^{2} / \mathrm{año}$ ). En ambos bloques cronoestratigráficos la tendencia en el uso de las materias primas es similar a la planteada para el sector, es decir, un uso frecuente de rocas silíceas por sobre la obsidiana y otras. Sin embargo, en la unidad A es mayor la frecuencia de piezas de obsidiana, respecto de B. En la unidad A están representadas las etapas de formatización y mantenimiento de filos y una mayor diversidad artefactual (Shannon-H=0,1495). En la unidad B, la diversidad artefactual es menor (Shannon- $\mathrm{H}=0,1125$ ) y se encuentran todas las etapas de reducción en desechos de talla, sugiriendo el ingreso de ésta materia prima en forma de nódulos o formas base con reserva de corteza. También en esta última unidad hay una mayor frecuencia de lascas de reactivación de filos, así un índice de reducción mayor en silíceas y obsidiana. El índice geométrico de reducción en artefactos unifaciales también muestra las diferencias entre $A(0,52)$ y $B(0,72)$.

Previamente se planteó que la obsidiana habría sido la materia prima más seleccionada para la manufactura de artefactos bifaciales, en especial puntas de proyectil. Sólo en forma ocasional, y como un intento de optimizar el uso de este recurso, se habrían formatizado instrumentos unifaciales. La roca silícea fue destinada a la manufactura de instrumental diverso -inclusive puntas de proyectil- y al aprovechamiento de sus filos (Figura 9.1). Las puntas de proyectil poseen tamaños y morfologías similares en ambas materia primas.

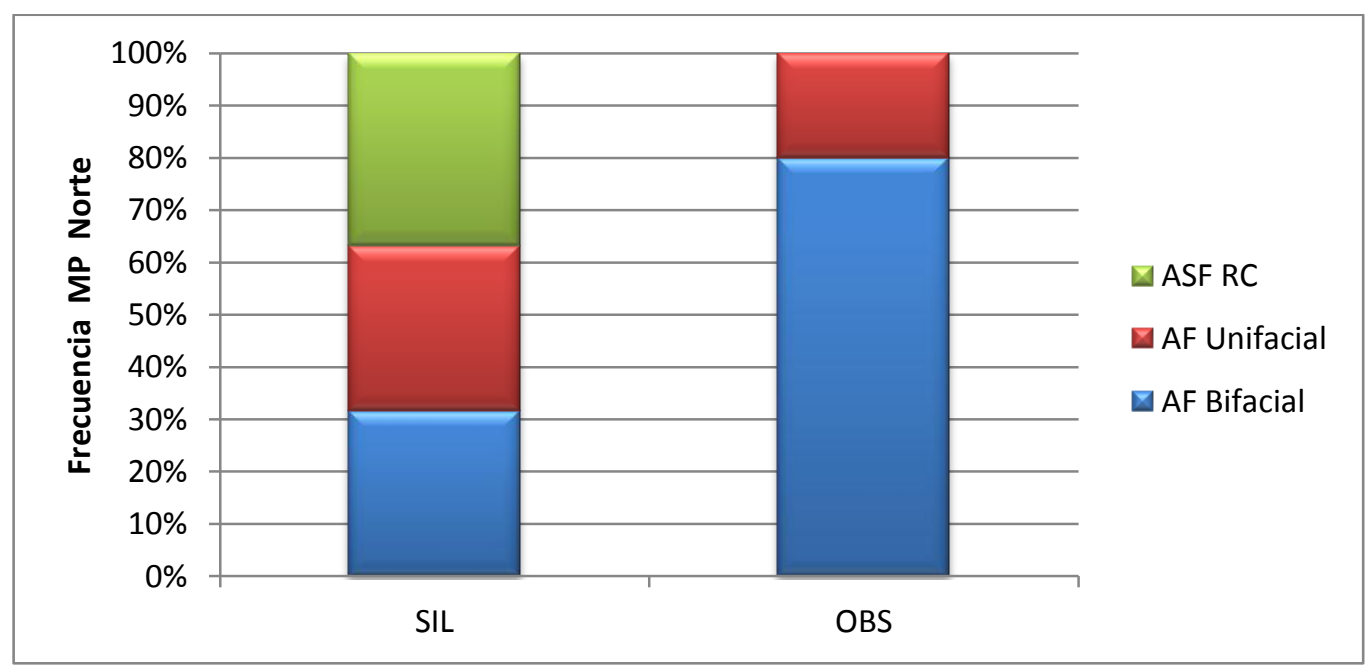

Figura 9.1. Frecuencia de instrumentos según materia prima en sector norte. 


\subsubsection{SECTOR CENTRAL}

En el sector central la materia prima predominante es la roca silícea, seguida por el basalto y la obsidiana (estas dos con valores significativamente menores a la primera, Tabla 7.33). Las silíceas se encuentran disponibles en el sector como concreciones nodulares dispersas (Capítulo 6) por lo que es esperable que su trayectoria de producción haya tenido lugar en el espacio local. Las actividades productivas relativas a la obtención del recurso, sugieren la realización de tareas de testeo y selección de lascas viables para su procesamiento. El registro de núcleos supera el $50 \%$ del total de artefactos de roca silícea (en su mayoría de calidad para la talla muy buena) (Capítulo 7.2.5) y sin morfología definida (Tabla 7.36). El tamaño de los núcleos supera en largo y ancho al tamaño de los instrumentos, por lo cual se

plantea el uso de lascas como soportes (Tabla 7.44). Los núcleos no están agotados y la frecuencia de desechos de reactivación de núcleos es bajo (0,2\%); esto implica que no era frecuente la preparación de plataformas de percusión. Se registran todas las etapas de manufactura de artefactos, siendo el descortezamiento la más frecuente, seguido por el mantenimiento y la formatización de filos (Figura 7.28). El tamaño más frecuente en desechos de talla es el grande (muy grande y grandísimo), seguidos por los medianos y pequeños (Tabla 7.36). Las lascas habrían sido destinadas a la manufactura de instrumentos de retoque bifacial extendido o parcialmente extendido $y$, en menor frecuencia, instrumentos unifaciales y lascas con filo (Tabla 7.38). Todos los artefactos bifaciales son puntas de proyectil, ambas de tamaño grande y espesor medio. El único artefacto unifacial recuperado es un raspador fracturado. La baja frecuencia de instrumentos y la alta proporción de artefactos fracturados (Tabla 7.34), sumado a las características de disponibilidad local de ésta roca (dispersa y de baja densidad; Tabla 7.31), sugiere que estos artefactos habrían tenido larga vida útil.

El basalto se encuentra disponible en todos los sectores de la localidad, por lo cual su aprovisionamiento podría ser considerado local (Capítulo 6). La adquisición de soportes se daría a partir de núcleos y lascas de tamaño grande con reserva de corteza. El registro de un núcleo sub-piramidal y lascas de descortezamiento de buena calidad 
en baja frecuencia, implica un traslado previo y uso selectivo de éste recurso (Tabla 7.37).

La obsidiana es la materia prima de menor frecuencia en el conjunto. Los análisis geoquímicos llevados cabo en distintos sectores del sector, muestran amplia diversidad de fuentes de procedencia (Salgán et al. 2012) (Capítulo 8). El ingreso a la localidad se habría dado como formas base sin corteza o como instrumentos formatizados (Capítulo 7). Se registró una punta de proyectil de tamaño grande y de módulo espeso, cubierta por pátina del desierto. Esta materia prima fue explotada de forma diferente a las rocas silíceas, pero al igual que otras localidades de La Payunia, su reducción refleja comportamientos de optimización, vinculado a la conservación del instrumental de calidad excelente y muy buena -en espacial de artefactos bifaciales-.

En ALPA, la obsidiana es la que presenta un mayor índice de reducción, seguida por el basalto y las rocas silíceas. Si bien la muestra de las dos primeras es pequeña, permite observar una tendencia referente a su uso. Las rocas silíceas presentan los mayores índices de producción de esta localidad (Tabla 9.2), siendo bajos para obsidiana y nulos para basalto. La frecuencia de artefactos bifaciales es alta en obsidiana y silíceas y nula en basalto (Tabla 9.2). Se observa una tendencia similar al sector norte, en cuanto a que la obsidiana ha sido destinada preferentemente a la manufactura de artefactos bifaciales, mientras las silíceas a la manufactura de mayor diversidad de instrumentos (Figura 9.2).

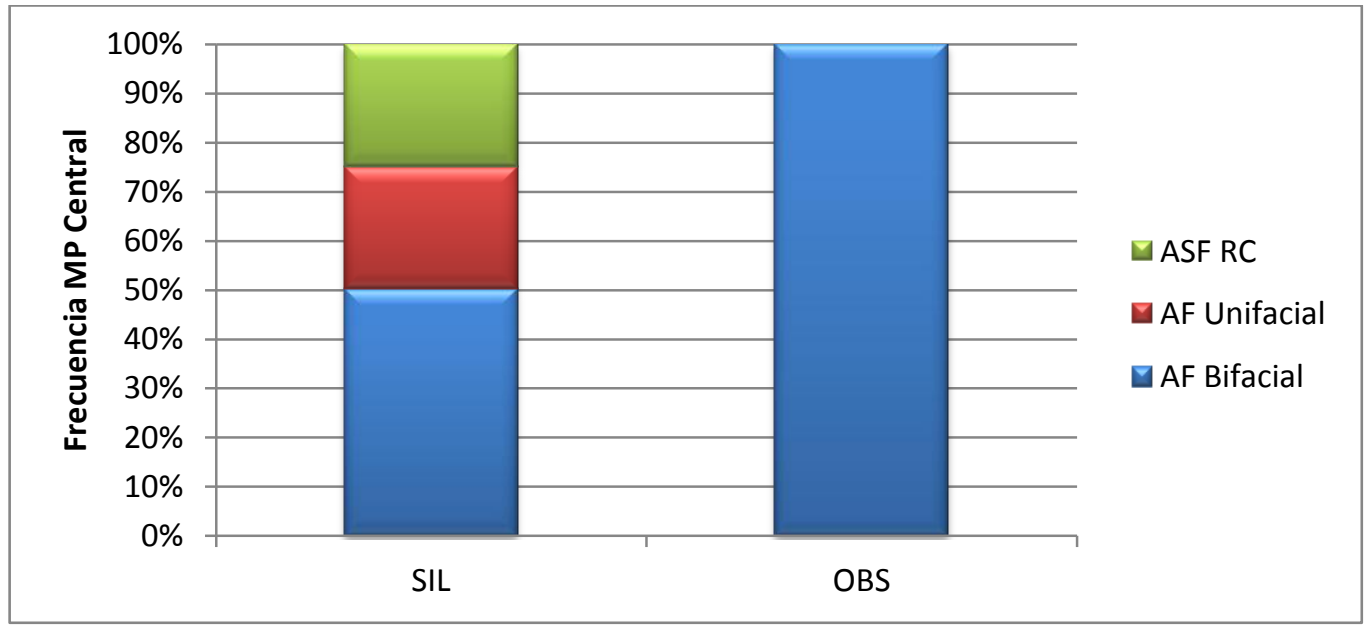

Figura 9.2. Frecuencia de instrumentos según materia prima en sector central. 


\subsubsection{SECTOR SUR}

En el sector sur se cuenta con información de tres localidades: APE, CAR y RC. La roca silícea también es la materia prima preponderante, seguida con valores menores por la obsidiana, el basalto y la riolita (Tabla 9.2). En el primer caso la disponibilidad local constatada a partir de los trabajos llevados a cabo en esta tesis (APE-C, Pista), sugiere que su trayectoria productiva se inicia en las fuentes inmediatamente disponibles (localidades APE y CAR) o locales (RC). Los estudios realizados en la cantera APE-C sugieren actividades de descortezamiento y extracción de formas base. La variedad de tipos de núcleos responde quizás a la necesidad de transporte de materia prima a otras localizaciones. Sin embargo son frecuentes los núcleos de lascados aislados, seguidos por el piramidal, el bipolar, el poliédrico y el amorfo (Figura 7.48). Pista, por su parte, cuenta con disponibilidad dispersa de nódulos silíceos, similar a lo descripto para ALPA (Capítulo 6). Se destacan las actividades de testeo y selección de nódulos y lascas. Los nódulos con lascados aislados (60\%) y no agotados, son los más representados, sin embargo - y al igual que en APE-C- hay variedad de tipos morfológicos (Figura 7.66). Diferentes autores proponen (Kelly 1988; Odell 2003), que la preparación de núcleos, suele estar asociada con la búsqueda de estandarización de los productos perseguidos, así como para optimizar el transporte de materia prima (Beck et al. 2002).

Si comparamos la intensidad de lascados de los núcleos de ambas áreas de disponibilidad silícea (APE-C y Pista), APE-C exhibe un índice de reducción mayor $\left(x=3,30 \mathrm{e} / \mathrm{mm}^{3}\right.$, peso promedio $\left.50,44 \mathrm{gr}\right)$, que en Pista $\left(x=1,587 \mathrm{e} / \mathrm{mm}^{3}\right.$, peso promedio $81,04 \mathrm{gr})$. Las diferencias de tamaño pueden responder al modo en que se presenta la materia prima, dado que en la primera se trata de filones longitudinales en los cuales es posible controlar el tamaño de las extracciones y en Pista el tamaño de los nódulos puede funcionar como condicionante del tamaño de las extracciones (Capítulo 6). El largo y ancho de los negativos de lascado en APE-C y Pista, es menor al observado en instrumentos, lo que sugiere el uso frecuente de núcleos y nódulos como forma base o a la búsqueda de lascas de mayor tamaño que la obtenida en los núcleos descartados. 
La localidad RC no está vinculada en forma directa a una fuente de roca silícea, pero dada la distancia a las fuentes conocidas, esta materia prima es considerada de disponibilidad local (a $8,5 \mathrm{~km}$ de Pista). Los núcleos alcanzan el $42 \%$ del total de artefactos. Predominan los de lascados aislados, seguido por los amorfos, prismáticos y bifaciales y en su mayoría no están agotados (Capítulo 7.5). Su intensidad de reducción $\left(1,537 \mathrm{e} / \mathrm{mm}^{3}\right.$, peso promedio $\left.250 \mathrm{gr}\right)$ es similar a Pista $\left(1,638 \mathrm{e} / \mathrm{mm}^{3}\right.$, peso promedio $52,62 \mathrm{gr})$, pero menor a APE-C (3,30 e/ $\mathrm{mm}^{3}$, peso promedio $\left.50,44 \mathrm{gr}\right)$. Si comparamos la intensidad de uso de los núcleos recuperados en los tres locus, las diferencias observadas son estadísticamente significativas ( $F=15,39 ; \mathrm{GL}=2 ; \mathrm{p}=0,00006)$ y, como planteamos antes, podrían explicarse por el modo de presentación del recurso en la fuente. Sin embargo, al comparar de a pares los distintos niveles (Prueba de Tukey), no se observan diferencias significativas en la intensidad de reducción de núcleos entre Pista $(Q=0,2187)$ y $R C(Q=0,9869)$.

En cuanto al ingreso de rocas silíceas a los sitios de actividades múltiples (APE-1 y $C A R-1)$, en APE-1, hay registro de núcleos de morfología bifacial, piramidal y en menor proporción de lascados aislados (Tabla 7.48). El registro de una menor variedad de tipos morfológicos que en APE-C (ubicado a menos de $500 \mathrm{~m}$ ), acompañado de una alta frecuencia de núcleos bifaciales, permite sostener el traslado frecuente de materia prima con formas base nodular (Kelly 1988; Beck et al. 2002). Los núcleos y la cantera no presentan diferencias significativas en intensidad de reducción (Capítulo 7). En desechos de talla hay bajo índice de corteza y por consiguiente escasa proporción de lascas externas (Tabla 9.2). Predominan las lascas internas (76\%) por sobre las de mantenimiento y reactivación de filos (19\%). En CAR-1, por su parte, se destaca la ausencia de núcleos y un índice de corteza bajo, respecto al observado en Pista (Tabla 9.2). También, predominan las lascas internas y la frecuencia de desechos de mantenimiento y formatización de filos es elevada. A pesar de ello, no se encontraron diferencias significativas entre la frecuencia de lascas internas y de formatización de filo entre los sitios APE-1 y CAR-1 $\left(X^{2}=13,809 ; G L=1 ; p=0,22\right)$, y no podemos afirmar que existan diferencias en la manufactura y mantenimiento de instrumentos en ambos sitios. En RC, el índice de corteza es mayor al observado en las localidades APE y CAR (Tabla 9.2), a pesar de no poseer las características de los sitios antes mencionados. En 
esta localidad, las lascas externas son las más frecuentes en relación a las internas y de formatización de filo (Tabla 7.93), lo que indicaría una mayor frecuencia de actividades de descortezamiento y formatización primaria. Realizamos una prueba de $\mathrm{X}^{2}$, para analizar la significancia de las diferencias observadas en la frecuencia de lascas externas (LPR y LSEC) de RC y Pista (CAR), resultando significativa $\left(X^{2}=5,096 ; G L=1\right.$; $\mathrm{P}=0,023)$. Si bien, se podría plantear que en $\mathrm{RC}$ las actividades de descortezamiento son mayores, la intensidad de dicha relación es baja (Cramer's $V=0,15$ ), y explica solo el 15\% de la variación en la frecuencia de lascas internas.

Los instrumentos manufacturados en roca silícea en el sector sur, representan el $97 \%$ del total de los conjuntos del sector. La forma base seleccionada es de lasca y la clase más frecuente es la correspondiente a artefactos sin formatización con rastros complementarios, seguida por los instrumentos de retoque unifacial y los bifaciales. Los primeros corresponden a lascas de tamaño grande y módulo espeso, con rastros en sus filos laterales, frontales y fronto-laterales. En manufactura unifacial los tipos más frecuentes son los de retoque unifacial simple (79\%; p.ej., unifaces no diferenciados; artefactos mediano pequeños, retoque en bisel oblicuo), seguido por raspadores (23\%) y cuchillos (3\%). Entre los artefactos de formatización bifacial, el tipo más frecuente es el de bifaces (79\%, p.ej., filos de bisel asimétrico; artefacto mediano pequeño, retoque en bisel oblicuo), seguido por las puntas de proyectil (14\%) y las raederas (7\%). Las puntas de proyectil fueron recuperadas en su gran mayoría en muestreos superficiales (75\%: Pista y RC) y sólo una fue recuperada en estratigrafía (25\%: CAR-1). El estado del instrumental es mayormente entero (82\%) y no se observaron signos de reactivación.

Artefactos confeccionados en obsidiana se han registrado en APE (APE-1) y CAR (CAR-1), y no en RC. Los análisis geoquímicos llevados a cabo sugieren que la trayectoria de esta materia prima tendría su comienzo en las fuente El Maule y Cerro Huenul (Capítulo 8; Salgán et al. 2012). Esta última, se encuentra en el rango de los recursos locales para APE, pero no para las otras localidades del sector donde la distancia es mayor (a $30 \mathrm{~km}$ lineales de APE y a $60 \mathrm{~km}$ lineales de CAR) (Tabla 8.3). El Maule, por su parte, se encuentra a una distancia promedio de $150 \mathrm{~km}$ lineales (a 125 $\mathrm{km}$ lineales de APE y a $170 \mathrm{~km}$ lineales de CAR), y es considerada un recurso no local en 
todos los locus analizados. La obsidiana de Cerro Huenul se presenta como clastos medianos y pequeños de depósitos secundarios, con morfología esférica a subredondeados, de excelente calidad, abundantes y fácilmente transportables enteros (Barberena et al. 2011). Estas características reducirían la necesidad del testeo, lo que podría explica en parte la alta frecuencia de artefactos con reserva de corteza presente en la región (Salgán et al. 2012).

En el sector sur, la obsidiana habría ingresado en dos modalidades, como núcleos con reserva de corteza y, principalmente como formas base con cierto grado de manufactura. Si bien no se recuperaron núcleos y las proporciones de corteza son bajas, la presencia en artefactos de tamaño pequeño y mediano-pequeño con reserva de corteza, sumada al registro de un artefacto con rastros complementarios sobre una lasca secundaria (Figura 8.13), podrían reflejar el primer modo de transporte. La materia prima habría ingresado principalmente como lascas.

Por último, se mantiene la tendencia del uso del basalto en bajas proporciones, al igual que en los sectores antes descriptos. Se habrían seleccionado grandes nódulos y lascas grandes con corteza (RC) y lascas descortezadas (CAR), de buena calidad para la talla. No se han registrado instrumentos en esta roca.

La obsidiana es el la materia prima más intensamente reducida en el sector (Tabla 9.2), le sigue la roca silícea, que en sitios como APE-1, presenta un valor de índice cercano al calculado para obsidiana, posiblemente por su proximidad con la fuente APE-C. El índice de producción en rocas silíceas, es alto en las tres localidades que integran el sector. Pero si agrupamos los conjuntos superficiales, notamos que los valores más altos se presentan en $\mathrm{APE}-\mathrm{C}$, seguido con valores significativamente menores por los sitios estratigráficos CAR-1, APE-1, Pista y RC (Tabla 9.2). En APE-C prevalecen las tareas de descortezamiento y formatización de formas base; en los sitios donde se registran actividades múltiples son comunes las tareas de formatización final y mantenimiento de instrumentos, así como el descarte de instrumentos. En Pista y RC, la baja frecuencia de desechos en relación a los instrumentos, puede ser explicada por el aprovechamiento de lascas de filo y una tendencia a la baja inversión en la manufactura. El índice de bifacialidad en rocas silíceas, presenta valores mayores 
en el sitio estratigráfico CAR-1, seguido por RC, APE-C, APE-1 y Pista (Tabla 9.2). En la reducción de instrumentos unifaciales, el índice geométrico muestra valores altos en los sitios CAR-1 $(0,95)$ y APE-1 $(0,55)$ mientras que en Pista $(0,35)$ y $R C(0,34)$ se observan índices menores y en APE-C no se registran artefactos unifaciales.

La obsidiana, sigue a las silíceas en cuanto a índice de producción (Tabla 9.2), y su registro como instrumento se restringe al sitio estratigráfico APE-1, dado que en CAR-1 sólo se recuperaron desechos de talla de esta materia prima. Se puede plantear que en el sector sur esta materia prima ha sido conservada y seleccionada para la manufactura de artefactos bifaciales (Figura 9.3). Los basaltos sólo se presentan como desechos de talla y núcleos no agotados, mientras que la riolita se presenta como percutor.

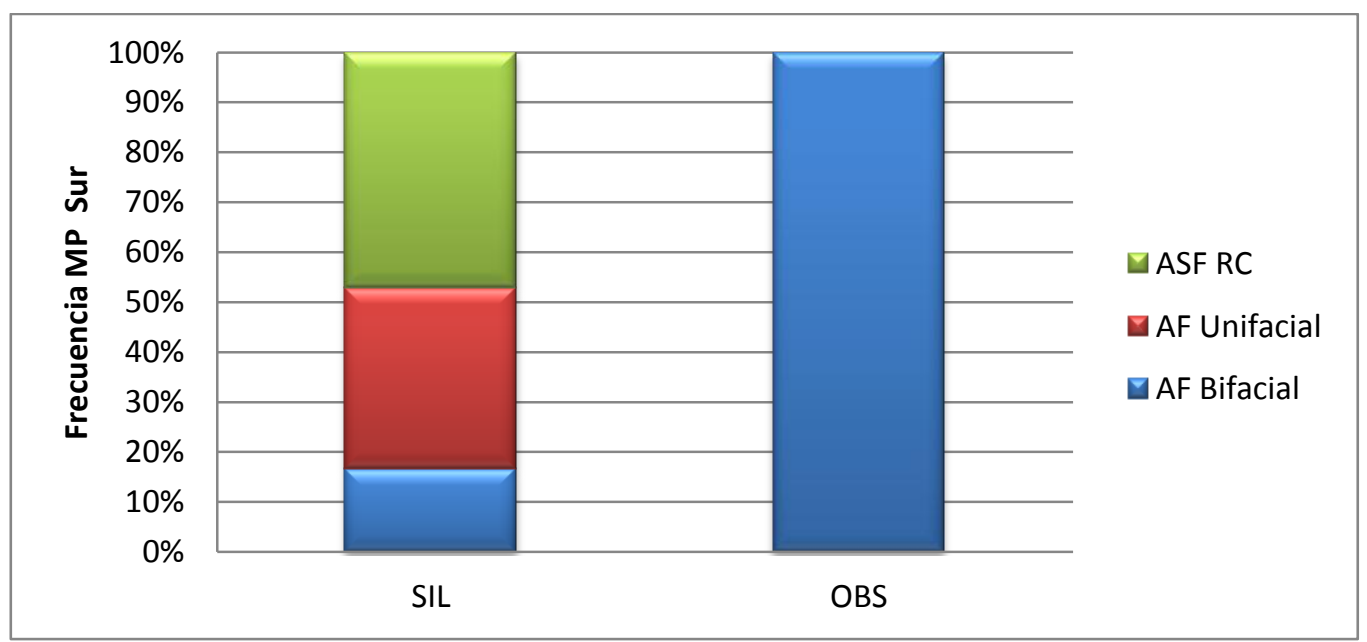

Figura 9.3. Frecuencia de instrumentos según materia prima en sector sur.

\subsubsection{CONSIDERACIONES GENERALES DE LAS TENDENCIAS ESPACIALES EN LA PAYUNIA}

La información obtenida a través del análisis tecnológico y las trayectorias productivas indican modos de circulación diferentes de las materias primas en La Payunia. En todos los sectores se destaca el uso frecuente de los recursos locales inmediatos y la incorporación de recursos no locales en una frecuencia significativamente menor. Estos últimos fueron destinados a la manufactura de 
instrumentos por medio de retoques bifaciales, entre los que se destacan las puntas de proyectil. Asimismo, cabe mencionar la incorporación en frecuencias bajas de otras materias primas locales como el basalto y la riolita. La primera, quizás responda a un uso ocasional, dado que se presenta como desechos o núcleos amorfos no agotados y en forma aislada. La segunda, está representada por percutores medianos y grandes, y como desecho de talla, quizás desprendidos al momento de talla.

Como se mencionó en el capítulo 6, la roca silícea (de calidad variable), es abundante en toda La Payunia. Supera el $90 \%$ del total de artefactos en los sitios y puede ser considerada de acceso local inmediato (Capítulo 6). Los análisis tecnológicos, sin embargo, muestran diferencias en la morfología y tamaño de los núcleos, sobre todo en los sectores norte y sur. En el sector sur (Pista y RC), observamos morfologías con mayor estandarización, que podría estar vinculada a su transporte. Por el contrario, en el sector norte, son preponderantes los núcleos no estandarizados (lascados aislados). La densidad artefactual de las canteras primarias PB y APE-C, presentan valores mayores a los observados en LLE, ALPA, Pista y RC (Figura 9.4). Estas diferencias pueden responder al modo en que se presenta la materia prima, concentrada en el PB y APE-C y dispersa en ALPA, Pista y RC (Capítulo 6). PB es de mayor extensión areal que APE-C, pero si comparamos la densidad de artefactos no presentan diferencias significativas $(t=0,739, p=0,49)$.

Ninguna de las otras materias primas representadas alcanza el $5 \%$ del total. La obsidiana ha sido utilizada preferentemente para la confección de instrumentos bifaciales, y está representada por lascas internas y de formatización de filos. Las fuentes de obsidiana mayormente representadas son El Maule (presente en todos los sectores) Y Cerro Huenul (en el sector central y sur). La fuente Las Cargas, sólo en sector central; y El Peceño, en el sector norte. En basalto, se registran núcleos de lascados aislados y lascas externas (sector central y sur) y en riolita percutores, siempre en ambientes donde esta se encuentra disponible (sector norte y sur) (Capítulo 6). De modo que en los sectores estudiados observamos que la roca silícea es la materia prima más frecuentemente utilizada, para la confección de variedad de instrumentos, aunque prevalecen los artefactos simples (artefactos de formatización unifacial y artefactos con rastros complementarios). Sigue en frecuencia la obsidiana, 
registrada exclusivamente en sitios estratigráficos en los sectores norte y sur, y en forma superficial sólo en el sector central. El uso de esta materia prima, habría estado vinculado a la formatización de artefactos bifaciales, sometidos a reactivación en el sector norte. El basalto, por su parte, se presenta en los sectores central y sur, con mayor frecuencia en el primero. Fue recuperado tanto en depósitos estratigráficos como en superficie y está representado por un núcleo y lascas de descortezamiento. Por último la riolita, se registra en los sectores norte y sur, mientras que en el sector central no ha sido registrada. 


\begin{tabular}{|c|c|c|c|c|c|c|c|c|}
\hline \multicolumn{2}{|c|}{$\begin{array}{l}\text { CONJUNTOS } \\
\text { LA PAYUNIA }\end{array}$} & 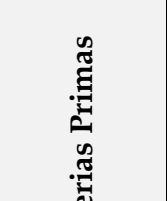 & 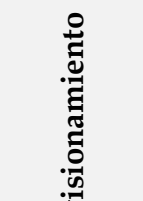 & 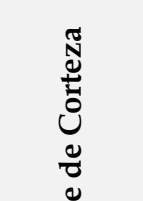 & 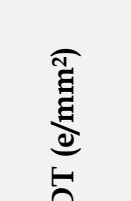 & 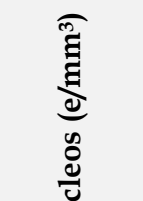 & 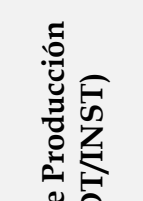 & 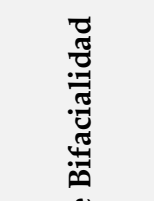 \\
\hline \multirow{8}{*}{ 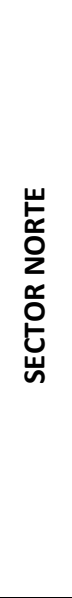 } & \multirow{4}{*}{ 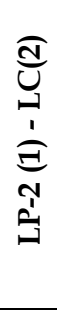 } & $\begin{array}{l}\text { Rocas } \\
\text { silíceas }\end{array}$ & Local & $\begin{array}{l}0,09(1) \\
0,14(2)\end{array}$ & $\begin{array}{l}3,7(1) \\
2,24(2)\end{array}$ & 2,04 (1) & $71,23(1)$ & $0,30(1)$ \\
\hline & & Obsidiana & No Local & $0,04(1)$ & $6,43(1)$ & - & $10,8(1)$ & $0,8(1)$ \\
\hline & & Basalto & Local & - & - & - & - & - \\
\hline & & Riolita & Local & - & - & - & - & - \\
\hline & \multirow{4}{*}{ 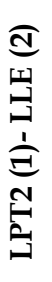 } & $\begin{array}{l}\text { Rocas } \\
\text { silíceas }\end{array}$ & Local & 0,15 (1) & $\begin{array}{l}0,59(1) ; \\
0,41(2)\end{array}$ & $0,5(2)$ & $3,2(1)$ & 0,33 (1) \\
\hline & & Obsidiana & No Local & - & - & - & - & - \\
\hline & & Basalto & Local & - & - & - & - & - \\
\hline & & Riolita & Local & - & - & - & - & - \\
\hline \multirow{4}{*}{ 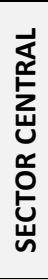 } & \multirow{4}{*}{ 岁 } & $\begin{array}{c}\text { Rocas } \\
\text { silíceas }\end{array}$ & Local & 0,525 & 0,617 & 2,7 & 20,25 & 0,3 \\
\hline & & Obsidiana & No Local & 0 & 2,41 & - & - & 1 \\
\hline & & Basalto & Local & 0,33 & 1,66 & 0,17 & - & - \\
\hline & & Riolita & Local & - & - & - & - & - \\
\hline \multirow{12}{*}{ 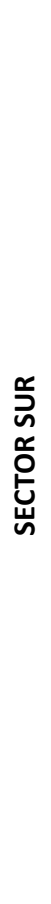 } & \multirow{4}{*}{ 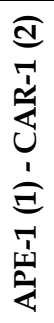 } & $\begin{array}{l}\text { Rocas } \\
\text { silíceas }\end{array}$ & Local & $\begin{array}{c}0,037(1) ; \\
0,204(2)\end{array}$ & $\begin{array}{l}6,05(1) \\
1,67(2)\end{array}$ & $2,9(1)$ & $\begin{array}{c}21,6(1) \\
73(2)\end{array}$ & $\begin{array}{c}0,2(1) ; 0,5 \\
\text { (2) }\end{array}$ \\
\hline & & Obsidiana & No Local & $\begin{array}{l}0,041(1) ; \\
0,063(2)\end{array}$ & $\begin{array}{l}7,9(1) \\
5,36(2)\end{array}$ & - & $8(1)$ & $1(1)$ \\
\hline & & Basalto & Local & - & - & - & - & - \\
\hline & & Riolita & Local & - & - & - & - & - \\
\hline & \multirow{4}{*}{ 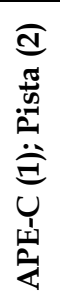 } & $\begin{array}{l}\text { Rocas } \\
\text { silíceas }\end{array}$ & Local & $0,449(2)$ & $3,7(2)$ & $\begin{array}{l}3,30(1) ; \\
1,587(2)\end{array}$ & $\begin{array}{c}93,72(1) ; \\
2,94(2)\end{array}$ & $\begin{array}{l}0,36(1) \\
0,15(2)\end{array}$ \\
\hline & & Obsidiana & No Local & - & - & - & - & - \\
\hline & & Basalto & Local & - & - & - & - & - \\
\hline & & Riolita & Local & - & - & - & - & - \\
\hline & \multirow{4}{*}{$\underset{\simeq}{\mathscr{U}}$} & $\begin{array}{c}\text { Rocas } \\
\text { silíceas } \\
\end{array}$ & Local & 0,625 & 0,19 & 1,537 & 12,26 & 0,473 \\
\hline & & Obsidiana & No Local & - & - & - & - & - \\
\hline & & Basalto & Local & 1 & 0 & 0,62 & - & - \\
\hline & & Riolita & Local & - & - & - & - & - \\
\hline
\end{tabular}

Tabla 9.2. Índices relativos a intensidad y modo de uso de materias primas en La Payunia. Referencias: IR DT: índice de reducción en desechos de talla; IR Núcleos: índice de reducción en núcleos. 


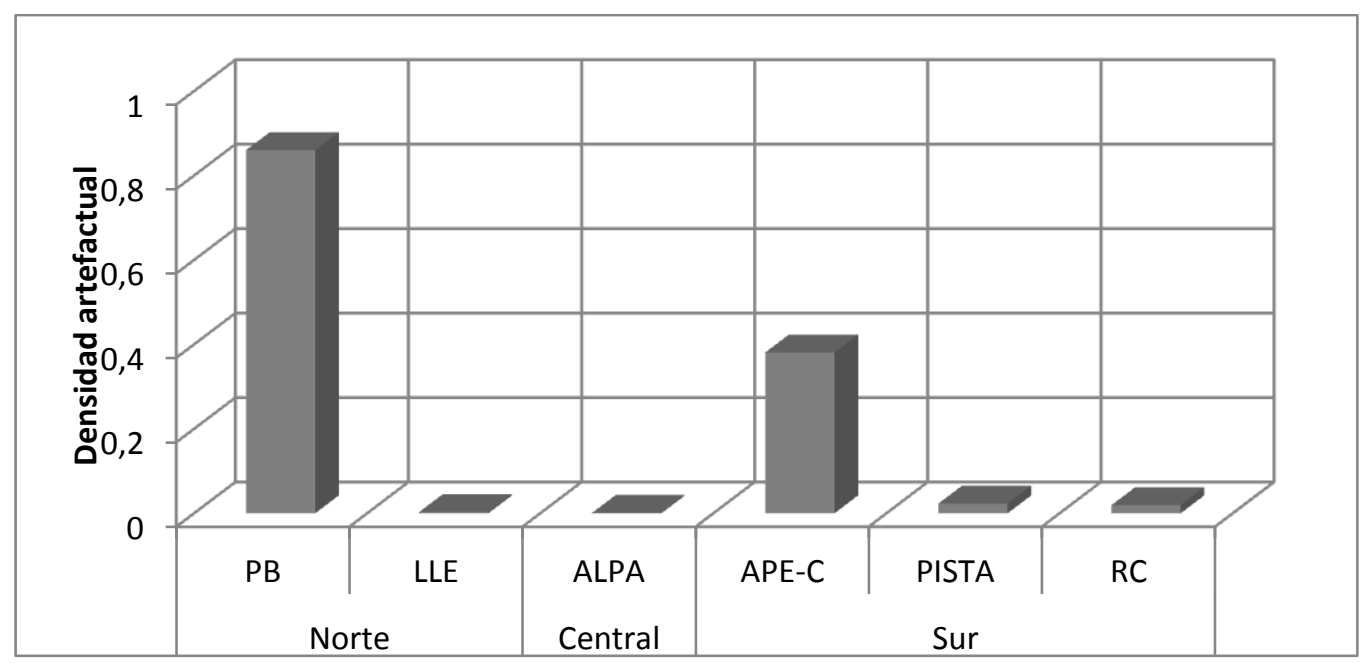

Figura 9.4. Densidad de artefactos en canteras y áreas de disponibilidad de nódulos silíceos.

\subsection{TENDENCIAS TEMPORALES EN EL USO DE LOS RECURSOS LÍTICOS}

Los fechados obtenidos en los sitios excavados permiten observar tendencias para los últimos ca. 2.000 años (Tabla 9.3). Gil (2006) ha propuesto una fase de exploración y/o colonización 2.000 años AP, mientras que hacia 1.000-1.200 años AP, se definiría una ocupación efectiva de la región (Gil 2006; Capítulo 4 y 7). Dicho modelo se basó en la jerarquía de los ambientes según su estructura ambiental (Gil 2000, 2006; Neme y Gil 2008). Solo con fines analíticos y con el objeto de ordenar la diversidad arqueológica, se propuso agrupar los sitios con edades disponibles en dos grupos temporales: los más tempranos, entre los ca. 2.000-1.000 años AP (sitios CAR-1 y LC), en adelante Bloque Temprano (en adelante BTEM); y los más tardíos a partir de los 1.000 años AP (sitios LP-2 y APE-1), denominados Bloque Tardío (en adelante BTAR) (Tabla 9.3).

Para una primera aproximación a los conjuntos por bloque temporal, se comparó la tasa de descarte de artefactos (artefactos por año $/ \mathrm{m}^{2}$ ) (Figura 9.5). En el BTEM ésta es baja, siendo mayor en el sector sur (CAR-1), relación que se invierte en el BTAR, con un notable aumento en el descarte de artefactos en el sector norte (LP-2), y una disminución en sector sur (APE-1). En frecuencia de materias primas, si bien en 
ambos bloques las rocas silíceas superan el $90 \%$, en el BTAR hay un aumento en la frecuencia de obsidiana, de $4,6 \%$ a $7,4 \%$ del total (Figura 9.6). Por su parte las rocas minoritarias (basalto y riolita) disminuyen en el BTAR. Dentro del BTAR se resalta que en los últimos 400 años AP, el sitio LP-2 muestra una maximización de los recursos, evidenciado en: a) mayores frecuencias de desechos de reactivación de los filos, b) una mayor intensidad de uso de obsidiana y de silíceas, y c) mayor frecuencia de instrumental vinculado a estadías más largas de ocupación en el lugar (p.ej. raspadores confeccionados en materia prima local).

\begin{tabular}{|c|c|c|c|c|c|}
\hline Bloque temporal & Sitio & $\begin{array}{c}\text { Fechados } \\
\text { Años }{ }^{14} \text { C AP }\end{array}$ & Código & Material & $\begin{array}{c}\text { Tasa } \\
\text { descarte } \\
\text { (producto } \\
\text { x m²/año) }\end{array}$ \\
\hline \multirow{2}{*}{$\begin{array}{c}\text { BTEM } \\
(2000-1000 \text { años AP) }\end{array}$} & LC & $1930 \pm 50$ & LP-1012 & Carbón & 0,005 \\
\hline & CAR-1 & $1398 \pm 39$ & AA-66576 & Carbón & 0,869 \\
\hline \multirow{5}{*}{$\begin{array}{c}\text { BTAR } \\
(1.000-250 \text { años AP) }\end{array}$} & \multirow{2}{*}{ LP-2 } & $400 \pm 70$ & LP-1474 & Carbón & \multirow{2}{*}{2,7296} \\
\hline & & $640 \pm 70$ & LP-1513 & Carbón & \\
\hline & \multirow{3}{*}{ APE-1 } & $685 \pm 31$ & AA-85706 & Óseo & \multirow{3}{*}{0,2175} \\
\hline & & $685 \pm 31$ & AA-85707 & Óseo & \\
\hline & & $1.010 \pm 32$ & AA-85708 & Carbón & \\
\hline
\end{tabular}

Tabla 9.3. Fechados radiocarbónicos en sitios estratigráficos.

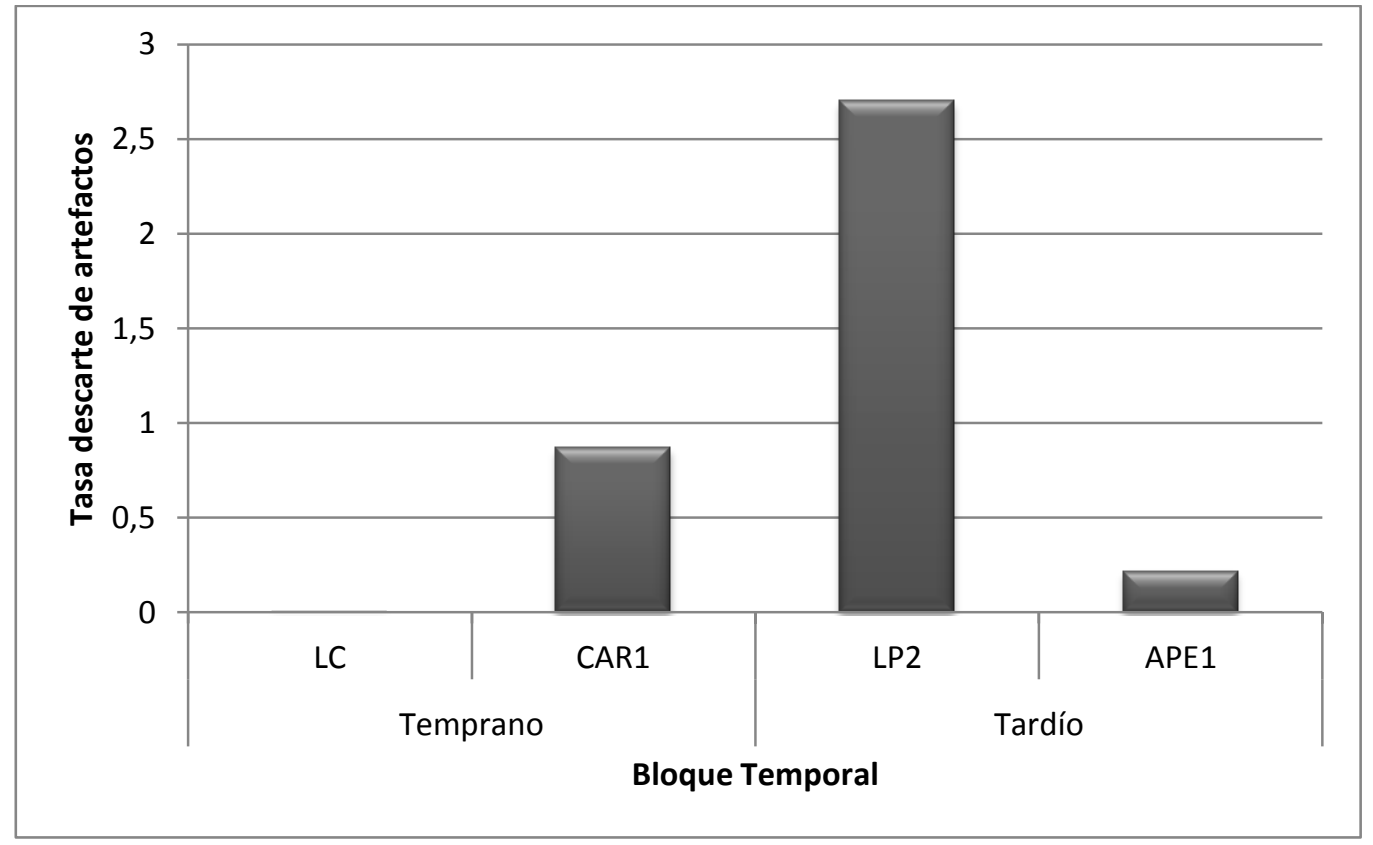

Figura 9.5. Tasa de descarte de artefactos por bloque temporal. 


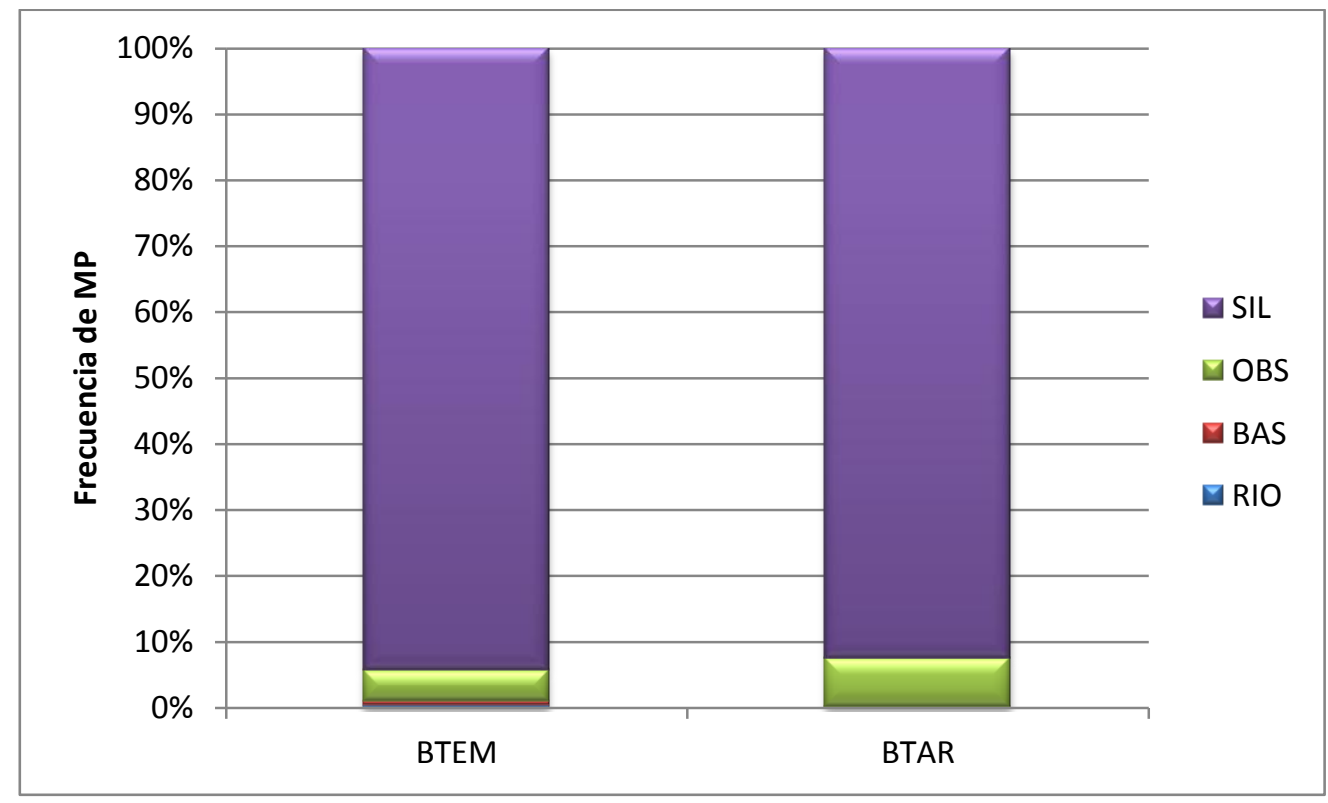

Figura 9.6. Frecuencia de materias primas respecto a bloques temporales. Referencia: SIL: roca silícea; OBS: obsidiana; BAS: basalto; RIO: riolita.

El número de clases artefactuales también se incrementa en BTAR, en la mayoría de las rocas, con excepción del basalto (Tabla 9.4). En rocas silíceas y obsidiana es donde se observa un mayor incremento, con índices de diversidad también mayores en el último bloque. Los valores de dominancia son altos y similares en los dos bloques (Tabla 9.4), esto quizás se debe a que en silíceas hay preponderancia de desechos, al igual que en el basalto. En riolita hay un valor de dominancia menor, dado que para BTAR aumenta el número de clases (además de un percutor, se encuentra un desecho de talla). En rocas no locales, específicamente obsidiana, se registra un mayor número de clases para el BTAR (3), acompañado de un aumento en el valor de diversidad $(0,215)$. En adelante se analiza el comportamiento de las rocas más frecuentes en el registro arqueológico de ambos bloques, con el objeto de evaluar continuidades y cambios en el uso de los recursos locales (rocas silíceas) y no locales (obsidiana).

Anteriormente, señalamos diferencias en la trayectoria productiva de las rocas más frecuentes, dado que en rocas silíceas están presentes todas las etapas de reducción, a diferencias de la obsidiana, que muestra mayor frecuencia de las últimas 
etapas de manufactura. En BTEM, se registra obsidiana sólo el sitio CAR-1 y en BTAR en los dos sitios analizados (LP-2 y APE-1). El modulo tamaño en BTEM muestra diferencias respecto a BTAR, en este último los tamaños pequeños son más frecuentes en ambas materias primas y se observa menor proporción de los módulos grandísimo y grande (grande y muy grande) (Figura 9.7). Si comparamos las etapas de manufactura en desechos de talla, observamos que en obsidiana, en el bloque temprano (BTEM) están representadas todas las etapas de manufactura, siendo más frecuentes las etapas de formatización de filos, mientras que en el bloque temporal tardío (BTAR) son más frecuentes las lascas internas y las correspondientes a formatización y reactivación de filos (Figura 9.8). En rocas silíceas se observa una tendencia similar, dado que en BTEM se encuentran representadas todas las etapas de formatización y en BTAR predominan las internas y de formatización de filo (Figura 9.9). Patrón que sumado a la disminución de tamaño de los soportes, puede responder a una maximización de ambas materias primas en el BTAR.

\begin{tabular}{|c|c|c|c|c|c|c|c|c|}
\hline & \multicolumn{4}{|c|}{ BTEM } & \multicolumn{4}{c|}{ BTAR } \\
\cline { 2 - 9 } & BAS & RIO & SIL & OBS & BAS & RIO & SIL & OBS \\
\hline N clase artefacto & 1 & 1 & 4 & 1 & 1 & 2 & 5 & 3 \\
\hline $\mathbf{N}$ & 2 & 1 & 306 & 16 & 2 & 2 & 1919 & 162 \\
\hline Dominancia & 1 & 1 & 0,974 & 1 & 1 & 0,5 & 0,968 & 0,905 \\
\hline Shannon-H & 0 & 0 & 0,083 & 0 & 0 & 0,693 & 0,104 & 0,215 \\
\hline
\end{tabular}

Tabla 9.4. Diversidad de clases artefactuales según materias primas según bloque temporal. Referencias: BAS: basalto; RIO: riolita; SIL: silíceas; OBS: obsidiana. 


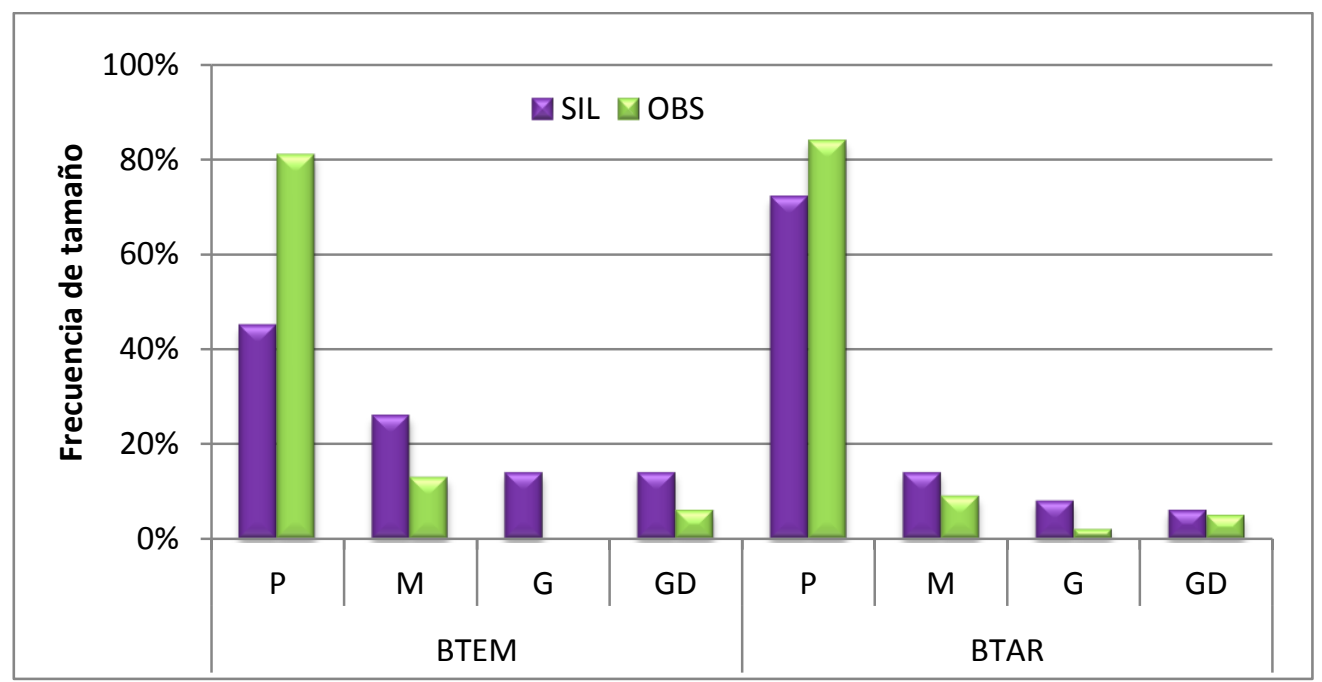

Figura 9.7. Frecuencia de modulo tamaño en artefactos de de roca silícea y obsidiana según bloque temporal.

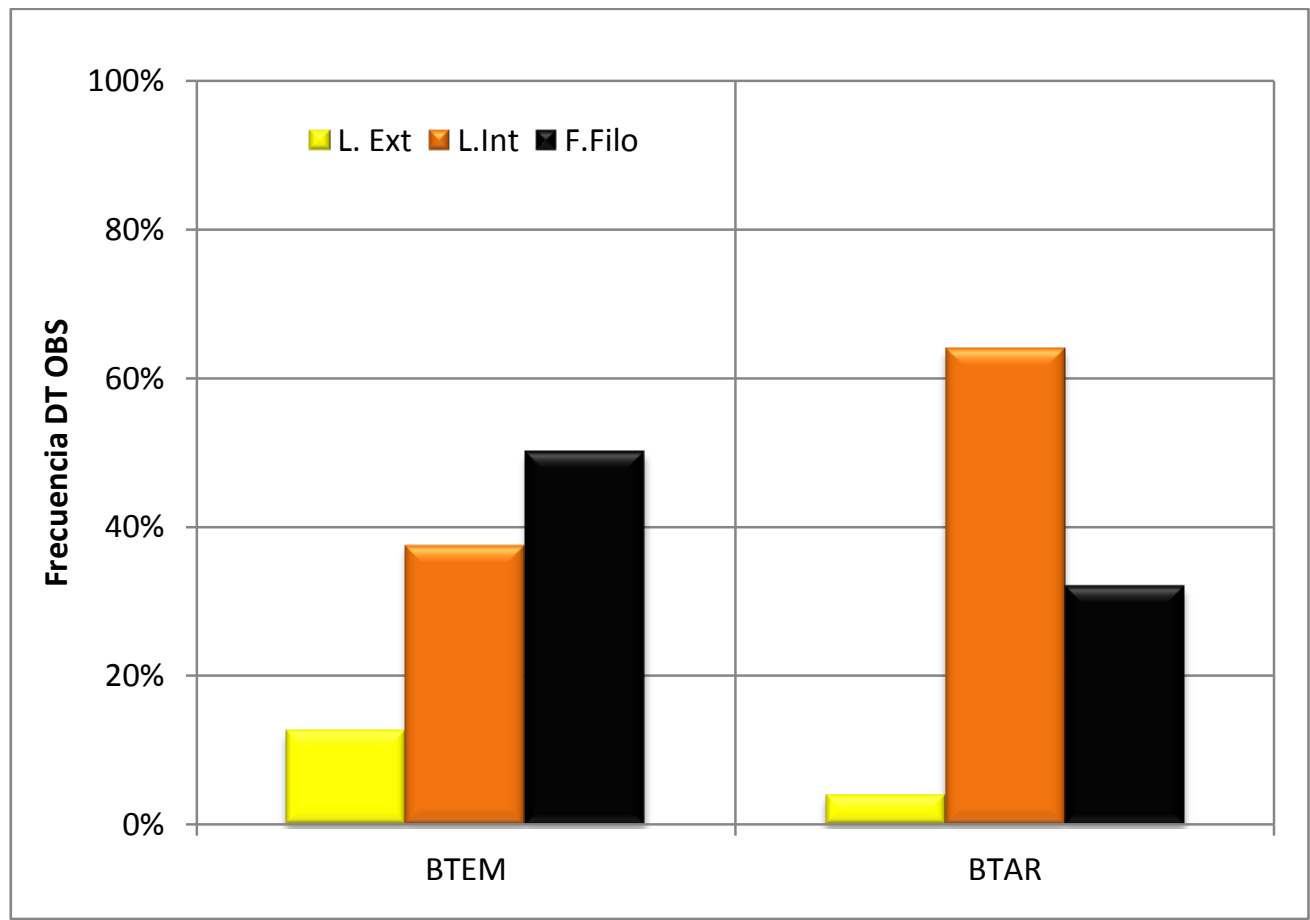

Figura 9.8. Frecuencia de desechos de talla de obsidiana según etapas de manufactura y bloque temporal. Referencia: DT: desechos de talla; OBS: obsidiana; L. Ext.: lascas externas; L. Int.: lascas internas; F. Filo: lascas de formatización de filo. 


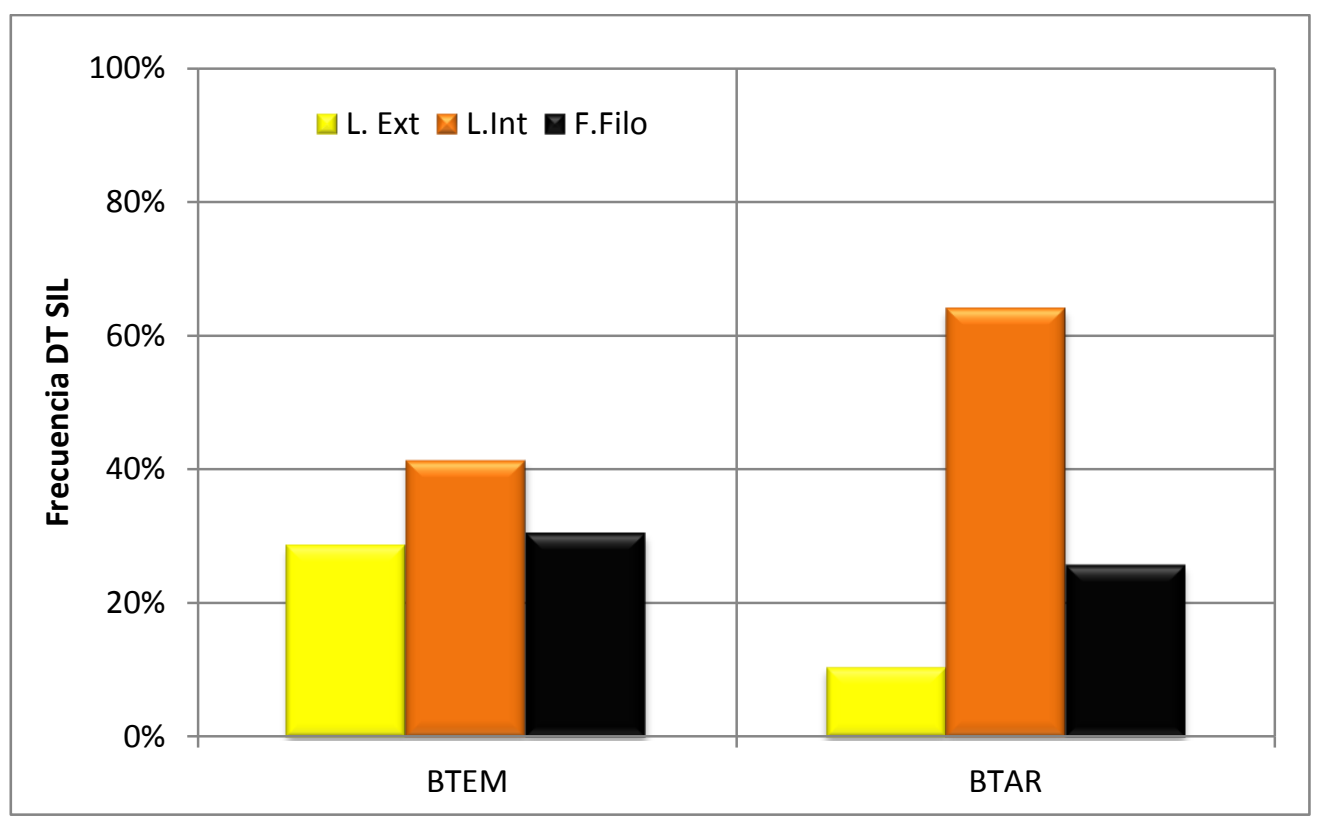

Figura 9.9. Frecuencia de desechos de talla de roca silícea según etapas de manufactura y bloque temporal. Referencia: DT: desechos de talla; SIL: roca silícea; L. Ext.: lascas externas; L. Int.: lascas internas; F.Filo: lascas de formatización de filo.

El índice de corteza en rocas silíceas es alto para el BTEM, (LC=0,14; CAR-1= 2,04), mientras que en BTAR es significativamente menor (APE-1=0,037; LP-2=0,09). Esto es concordante con lo observado en las etapas de manufactura, es decir, que hay una tendencia a una menor reserva de corteza en el BTAR (Tabla 9.2). En obsidiana, se observa una tendencia similar dado que el índice es más alto en el BTEM (CAR-1= $0,063)$, que en el BTAR (LP-2=0,04; APE-1=0,04). Asimismo, la intensidad de uso de las materias primas locales en el BTEM ha sido menor que en BTAR (Tabla 9.2), al igual que la obsidiana que en CAR-1 presenta valores menores que los observados en los sitios del BTAR (Tabla 9.2). Los indicadores analizados indicarían una tendencia a un mayor aprovechamiento tanto de los recursos líticos locales como de los no locales en el bloque temporal tardío.

El índice de producción también muestra diferencias entre los bloques y se destaca la mayor producción y descarte de instrumentos en BTAR en las dos materias primas. En BTEM hay un índice alto en materia prima local, en sitios asociados a actividades múltiples y valores nulos en materia prima no local (Figura 9.10). Por otro lado en instrumentos, el índice de bifacialidad en BTAR, es cercano a 1 para las materias primas no locales y en rocas locales no sobrepasa el valor de 0,3 (Tabla 9.2). Para BTEM, no se registran instrumentos en obsidiana y en materias primas locales el 
índice es medio $(0,5)$. Si bien en BTEM (CAR-1) no se registran instrumentos bifaciales, el $6 \%$ de los desechos de talla de obsidiana corresponden a lascas de adelgazamiento bifacial, al igual que el $10 \%$ de los desechos de silíceas (Tabla 7.77), por lo cual la técnica de reducción es utilizada en ambas materias primas para la manufactura de artefactos bifaciales. Los instrumentos en BTEM están confeccionados en su totalidad en roca silícea y son frecuentes los artefactos bifaciales (bifaces y puntas de proyectil). En cambio en el BTAR, los instrumentos están confeccionados tanto en silíceas (sobre todo raspadores) como en obsidiana (principalmente puntas de proyectil y fragmentos de bifaces) (Figura 9.11).

Los análisis geoquímicos sobre artefactos de obsidiana en BTEM, sugieren que proceden de la fuente cordillerana El Maule; mientras que en el BTAR aumenta el número de fuentes representadas (EI Maule, Cerro Huenul en el sector sur y El Peceño en sector norte; Capítulo 8). Estudios recientes referentes a la distribución espacial y temporal de la obsidiana en el Centro Oeste Argentino (Cortegoso et al. 2012), sostienen que entre 9.000 y 8.000 años AP, aparecen materiales de Las Cargas y El Maule asociadas a ambientes de cordillera norte y sur, respectivamente. Estas dos fuentes son las únicas explotadas hasta avanzado el Holoceno tardío, cuando se incorporan registros de obsidiana procedente de El Diamante, la Desconocida A; Cerro Huenul y El Peceño (ambas en ca. 2.000 años APA) son temporalmente las últimas fuentes en incorporarse. Esta tendencia se ajusta a lo observado en La Payunia, donde la fuente más representada (El Maule), está asociada a los registros más antiguos de la región (Cueva Delerma, ca. 7.600 años AP) y a los conjuntos del BTEM. Cerro Huenul y El Peceño, aparecen sólo en los conjuntos de BTAR, con baja frecuencia y una distribución restringida en el sector sur y central, en el primer caso y en el sector norte en el segundo. 


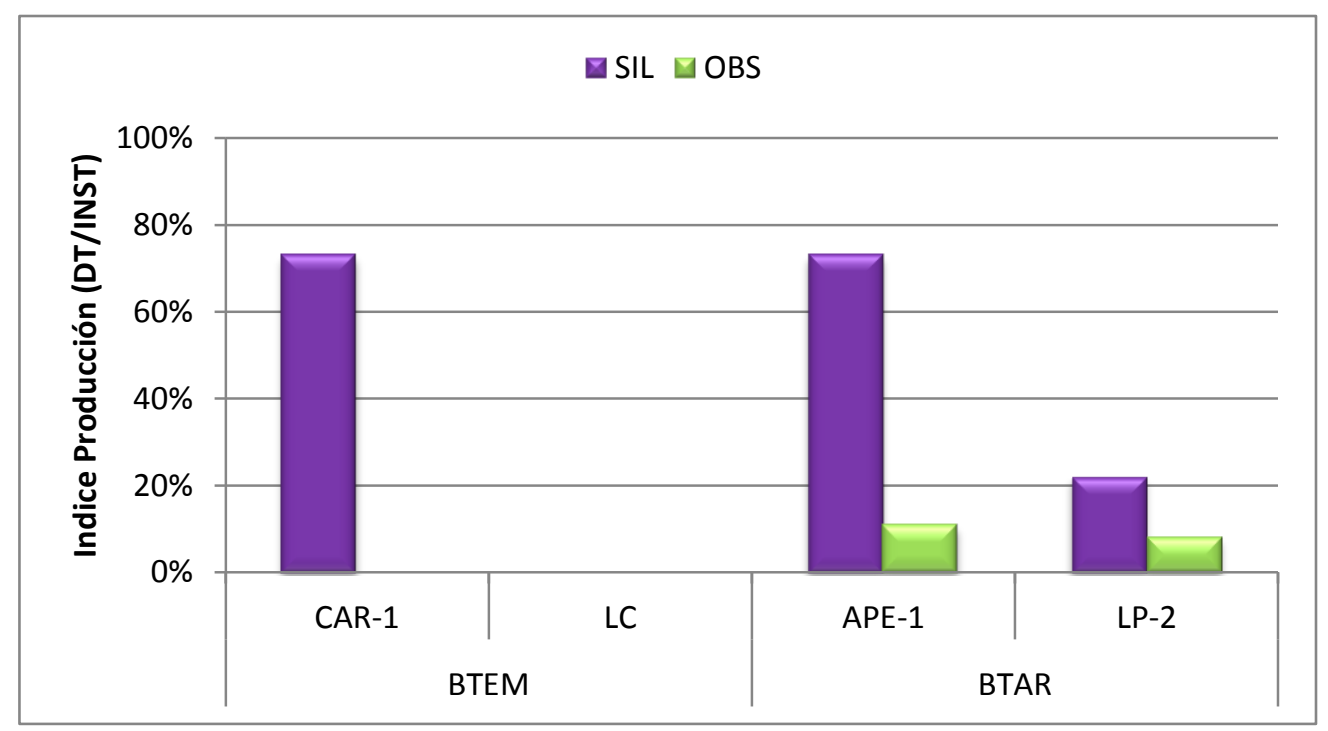

Figura 9.10. Índice de Producción según bloque temporal.

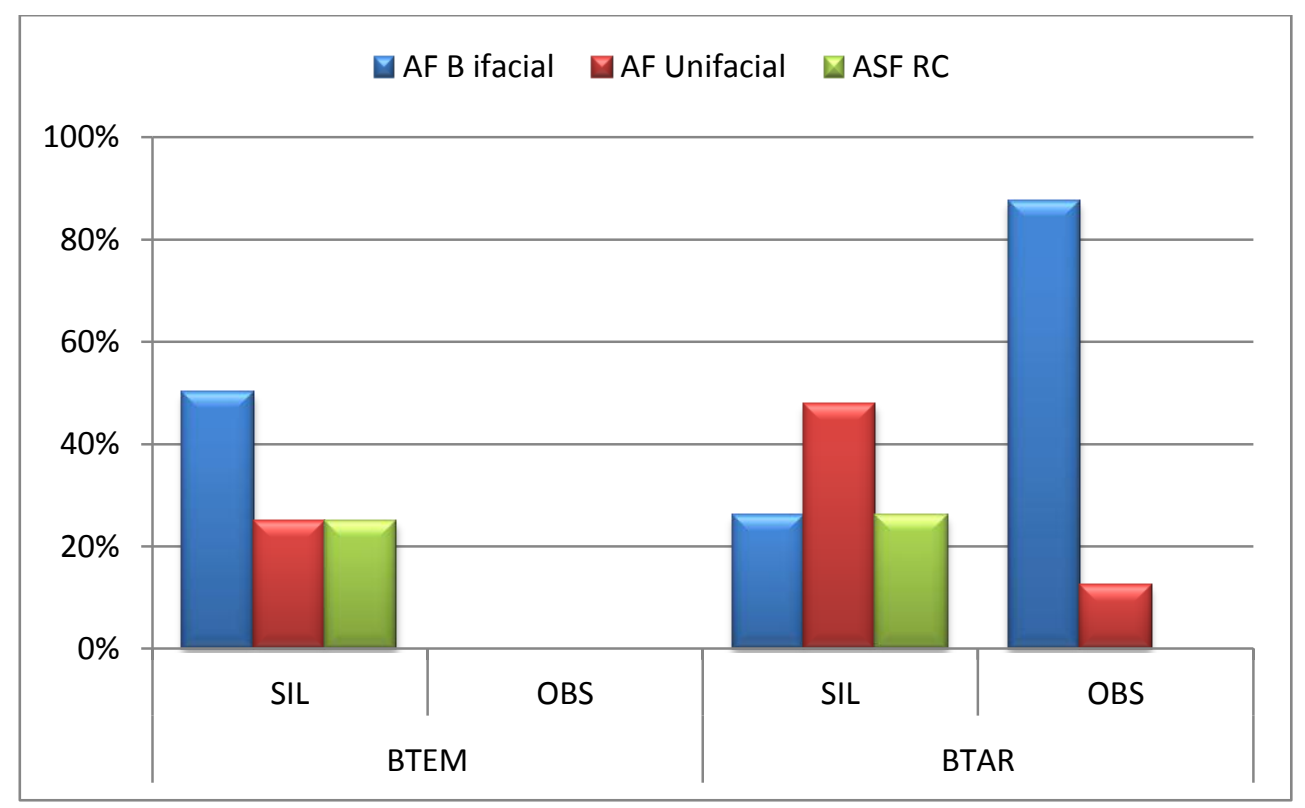

Figura 9.11. Frecuencia de instrumentos por bloque temporal.

\subsubsection{CONSIDERACIONES GENERALES DE TENDENCIAS} TEMPORALES EN LA PAYUNIA 
Sobre la base de las tendencias detalladas arriba se observa en La Payunia, un aumento en la frecuencia de uso de obsidiana en BTAR respecto al BTEM, acompañado de un incremento en la diversidad de clases artefactuales, un aumento en la intensidad de uso de esta materia prima, en el número de sitios en los cuales se registra y en la diversidad de fuentes de obsidiana. Las rocas silíceas, por su parte, ubicadas en el rango de distancia inmediata, muestran una tendencia similar en comparación con BTEM, dado que se observa un amento en la intensidad de uso, una reducción en el tamaño de los artefactos descartados y la formatización de una mayor variedad de instrumental. En BTEM observamos una menor tasa de depositación de artefactos. En este bloque temporal, las rocas silíceas de origen local son las más frecuentes en el registro arqueológico, poseen mayor diversidad artefactual que las no locales y están representadas en los locus todas las etapas de reducción. Su intensidad de uso es baja y presenta un índice de producción mayor que las rocas no locales. La obsidiana, presenta una diversidad artefactual baja (Tabla 9.4) y una mayor intensidad de reducción que las rocas locales y fue documentada solo en el sitio CAR-1. Para este último bloque, el registro de una mayor proporción de instrumentos unifaciales, como raspadores, a la maximización de los recursos locales y no locales, y la tasa de descarte de artefactos más elevada, podrían ser reflejo de estadías más largas en la ocupación de los locus hacia el BTAR.

Los indicadores analizados, muestran diferencias en el uso de las rocas locales y no locales en los bloques temporales considerados. La tendencia a maximizar los recursos líticos de disponibilidad local y los procedentes de distancias ubicadas en el rango de los 120-180 km durante el BTAR, permite sostener la idea de un cambio en el modo de aprovisionamiento y uso de los recursos líticos en la escala regional. Esta tendencia es concordante con lo observado por Gil $(2000,2006)$ para la región en los Contexto $B$ y $C$ (Capítulo 3). Contextos que coinciden con las etapas de exploración y/o colonización (Contexto $B$ ) y ocupación efectiva (Contexto $C$ ) del modelo biogeográfico de poblamiento (Gil 2000, 2006).

Sin embargo, los resultados aquí obtenidos en relación a BTEM, plantean dudas con las expectativas referidas a la interpretación biogeográfica del Contexto $B$ (ubicado entre los 2.000 años AP y los 1.000-1.200 años AP) en el modelo de Gil (2002) utiliza 
los conjuntos arqueológicos de La Corredera (LC, retomados en esta tesis) y los niveles inferiores de sitios de Área El Nevado (Agua de La Mula y Agua de los Caballos) (Capítulo 2). Este contexto ha sido propuesto como una fase de exploración y colonización. El registro arqueológico que sirve de base para la definición de dicha etapa en Gil (2006), se centra en lo que para esta tesis denominamos sector norte. La ampliación de los estudios del Área El Payén, incorporando los sectores aquí denominados centro y sur, nos permite observar diferencias intrarregionales que permiten discutir los modelos postulados para la región.

Entre ellas la diferencia en la tasa de descarte de artefactos de BTEM a BTAR, indica una leve disminución para el sector sur, y un marcado aumento en el norte. Esto puede ser vinculado a modos diferentes de ocupación del espacio, y no necesariamente a diferentes etapas de poblamiento. Los sitios del sector norte se encuentran en locus de amplia disponibilidad de materia prima y agua en forma puntual, mientras que en sector sur los conjuntos diacrónicos analizados se encuentran en ambientes con variable disponibilidad de recursos de dichos recursos líticos y agua (Capítulos 3 y 7). Esta diferencia en la estructura espacial de los recursos puede explicar patrones de ocupación diferentes (dispersos en el sur y puntuales en norte). Algunas expectativas tecnológicas de BTEM concuerda con el Contexto B: baja frecuencia de rocas no locales, alta frecuencia en desechos de reactivación o asociado a etapas finales de manufactura, y un mayor tamaño de los artefactos. Sin embargo, el registro de raspadores, la baja frecuencia de artefactos expeditivos en materia prima local y la presencia de las distintas etapas de manufactura en rocas locales y no locales durante el BTEM, plantean que durante estas fechas se registraría una ocupación efectiva (sensu Borrero 1994-95) y no la exploración propuesta previamente. De ser así, entonces la etapa de ocupación efectiva del ambiente se habría dado con anterioridad a lo propuesto por Gil $(2000,2006)$, mostrando esta misma etapa biogeográfica cambios en la organización tecnológica hacia el BTAR. Estos cambios señalarían una variación en los tiempos de estadía en los locus y en el acceso a los recursos respecto al BTEM. Este patrón está claramente registrado en CAR-1 pero no en LC. Gil $(2000,2006)$ caracterizó a LC como resultado de ocupaciones efímeras, dada la ausencia de registro vinculado con actividades de subsistencia. La cercanía de este 
sitio con las fuente primaria Piedras Bayas (PB), la presencia de actividades vinculadas a las primeras etapas de formatización y la densidad artefactual, similar a la observada en otros sitios de esta localidad (LP), sugieren que puede ajustarse más a un espacio de trabajo vinculado a áreas de actividades múltiples próximas.

Para poder discutir la hipótesis propuesta, será necesario definir mejor la cronología de LP (p.ej. ajustar la cronología inicial de LP-2). Esta diferencia en el patrón temporal registrado en CAR-1, también podría deberse a su cercanía al río Colorado (ca. $10 \mathrm{~km}$ ). Este vínculo con un valle fluvial no fue considerado previamente en el modelo de Gil $(2000,2006)$ y puede entonces señalar una distinta situación biogeográfica en La Payunia, de mayor variabilidad que la asumida hasta ahora. El modelo biogeográfico planteado previamente consideró la disponibilidad de agua y la biomasa primaria como variables claves para la jerarquización de los ambientes (Neme y Gil 2008). Por ello, la incorporación de nuevos sectores en el modelo (como el valle del río Colorado), abre una nueva perspectiva para repensar en otra escala la forma en que las poblaciones humanas exploraron, colonizaron y ocuparon efectivamente esta región. Los estudios recientes en el valle del río Colorado validan esta tendencia del valle respecto al resto de La Payunia (Gil et al. 2012).

En el análisis diacrónico de los conjuntos de BTEM y BTAR, observamos diferencias que pueden ser atribuidas a cambios en la movilidad de los grupos. Por ejemplo: las tasa de descarte, la diversidad artefactual en rocas locales y no locales, los cambios en las frecuencias de las etapas de manufactura en los sitio, el aumento en la intensidad de uso de las rocas en el BTAR, sumado a la diversidad de fuentes de obsidiana y a una mayor frecuencia de artefactos vinculados a estadías más largas en el lugar, estarían señalando a una disminución de la movilidad en el BTAR respecto al BTEM.

Neme (2007) plantea que en los últimos 2.000 años habría tenido lugar en el sur de Mendoza, un proceso gradual de crecimiento demográfico. Esto habría llevado a las poblaciones a explotar más intensivamente los ambientes sobre la base de la incorporación de nuevas estrategias de aprovechamiento de los recursos y cambios en los hábitos de consumo. El autor define este proceso como de intensificación en el uso 
de los recursos (Neme 2007). Entre los principales correlatos o indicadores arqueológicos de este proceso menciona: la reducción de la movilidad, el uso frecuente de estructuras habitacionales, una mayor reocupación de los sitios, la presencia de una estrategia tecnológica expeditiva, el aumento en el número de instrumentos de molienda, la incorporación de innovaciones tecnológicas como la cerámica, y la colonización de nuevos hábitats.

Estudios recientes en el sur de Mendoza, indagan el proceso de intensificación, desde el estudio de distintos indicadores de subsistencia, e investigan específicamente el supuesto de la incorporación de una mayor diversidad de recursos (Giardina 2010; Llano 2011; Fernández 2012). Llano (2011) corrobora estos planteos en lo que respecta al registro arqueobotánico para ambiente del piedemonte, sin embargo las evidencias no son del todo claras en lo que respecta al registro zooarqueológico (Giardina 2010; Fernández 2012; Otaola 2012). Llano (2011) sostiene que los recursos vegetales habrían tenido un rol creciente en el Holoceno tardío y, sobre la base de la diversidad taxonómica, señala que entre los 2.000 y 1.000 años AP se explotó una mayor cantidad de plantas que en momentos previos. Observa diferencias entre las distintas regiones biogeográficas en cuanto a las variaciones temporales en la diversidad taxonómica de éstos recursos. La mayor disponibilidad de plantas de alto retorno en el monte, habría hecho que las poblaciones humanas centraran su atención en éstas. En cambio, en los sitios localizados en la Provincia Patagónica (piedemonte y Payunia), la menor cantidad de plantas de alto retorno condujo a que haya una mayor diversificación y que durante el mencionado proceso de intensificación se incluyeran las plantas de menor retorno (Llano 2011). Giardina (2010), por su parte, al analizar el registro avifaunístico en la escala del sur de Mendoza, señala una mayor diversidad de taxones aprovechados en la segunda mitad del Holoceno tardío (Giardina 2010). Señala que hacia ca. 2.000 años AP, en los sitios de La Payunia, planicie oriental y cordillera, hay un incremento en la diversidad de taxones de aves con signos de consumo, con una posterior disminución hacia los 1.000 años AP. Estos resultados le permiten sostener, que en éstos ambientes es donde podría haber tenido lugar un proceso de intensificación, como el propuesto por Neme (2007). Fernández (2012), desde el análisis del grupo de los roedores, no observa un consumo de esta clase taxonómica como sucede en otros contextos de 
intensificación de la Argentina, tales como: Sierras centrales, Pampa y Patagonia (Fernández 2012). Plantea que el consumo pudo ocurrir en sitios de cordillera (Caueva Arroyo Colorado), de La Payunia (La Peligrosa-1) y de planicies orientales (Rincón del Atuel 1), pero el carácter aislado del registro no alcanza para sostener un uso sistemático de los microvertebrados para los últimos 2.000 años AP (Fernández 2012).

En La Payunia, Gil $(2000,2006)$ propuso que la colonización de la región, habría sido contemporánea al proceso de intensificación macro regional y puede ser interpretada como una respuesta a la necesidad de utilizar nuevos hábitat. Las poblaciones que ocuparon efectivamente La Payunia (ca. 1.000-1.200 años AP), mantenían un sistema de baja movilidad residencial, en el marco de las cuales podrían ser frecuentes los mecanismos de interacción intersocietal (Gil 2000, 2006). Desde el punto de vista tecnológico, la intensificación en la producción se refiere a un incremento en el rendimiento productivo, siendo factible su abordaje desde indicadores tecnológicos y de uso (Babot 2006). En base a los resultados obtenidos, y si aceptamos la idea de una ocupación efectiva más temprana de La Payunia, es posible argumentar que dicho proceso de intensificación se habría dado en la región bajo estudio desde alrededor de ca. 1.000 años AP. Los indicadores tecnológicos analizados en BTAR, señalan una estrategia conservada de las rocas no locales (mayor inversión en modo de manufactura, estandarización de los soportes, y evidencias de reactivación de instrumentos) y estrategias mayormente expeditivas en rocas silíceas locales (mayor frecuencia de artefactos con rastros complementarios y unifaciales, ausencia de reactivación de filos, y descarte de instrumentos enteros). Sin embargo se observa que ambas materias primas registran un índice de reducción notablemente mayor en relación a BTEM. En el bloque temprano, en cambio, la estrategia de uso de los recursos líticos locales muestra mayor inversión en la manufactura y puede suponer estrategias conservadas, del mismo modo en rocas exóticas, tendencia que puede ser atribuida a una maximización del recurso dada su escasez y a una estrategia conservada. Las tendencias observadas en BTAR son las esperables bajo una estrategia de reducción de la movilidad logística, que sumada al registro de mayor diversidad de materias primas exóticas, pueden estar evidenciando procesos de intensificación. 
En este sentido se acuerda en parte con la idea propuesta con Borrero (2002) que sostiene que las poblaciones humanas habrían incorporado La Payunia como resultado de la ampliación de los rangos de acción. Es decir que la región, o parte de ella, habría sido ocupada en forma estacional y/o alternativa a desplazamientos anuales. El registro de obsidiana procedente de El Maule en los conjuntos de BTEM, y al registro de ocupaciones tempranas en el valle medio del río Grande (Durán 2000), podría ser interpretado como indicio de la amplitud de dichos rangos. Si se acepta la direccionalidad de transporte de ésta la obsidiana (capítulo 8), podría plantearse que en el BTEM, La Payunia es ocupada en el marco de desplazamientos de los grupos humanos, con una fuerte direccionalidad sur-norte. Los cambios en la demografía y en la territorialidad habrían llevado a una disminución de la movilidad, a un aumento en los tiempos de permanencia en los sitios y a un incremento en las relaciones de intercambio. Estos planteos alternativos no contradicen lo propuesto por trabajos previos, sino que ofrecen un modo de explicación alternativa del registro arqueológico de la región. 


\section{CAPÍTULO 10}

\section{DISCUSIÓN GENERAL}

\section{INTRODUCCIÓN}

En este capítulo, se discuten las hipótesis que guiaron la presente investigación y se plantea un modelo tentativo referente a los modos de aprovisionamiento y la movilidad de las poblaciones humanas.

\subsection{EL USO DE LOS RECURSOS LÍTICOS EN LA PAYUNIA}

A partir del estudio de la base regional de recursos líticos (capítulo 6) y el análisis de las trayectorias productivas de los conjuntos de La Payunia (Capítulos 7, 8 y 9), se delinearon tendencias temporales y espaciales, en el aprovisionamiento y uso de los recursos líticos en la región. En el capítulo 8, se propuso que las materias primas locales habrían sido las más utilizadas en La Payunia, y representan sistemas de producción lítica terminal (sensu Ericson 1984). Un sistema terminal, como expusimos en el capítulo 4, implica que todo el proceso de producción se encuentra dentro en una misma área. Estas áreas en La Payunia pueden circunscribirse a espacios que en la mayoría de los casos no supera los $5 \mathrm{~km}$ de radio, dada la disponibilidad de rocas silíceas de buena calidad para la talla (Capítulo 8). Los estudios petrográficos realizados en las fuentes de rocas silíceas y en los sitios arqueológicos, permitieron vincular a ambos entre sí, pero no discriminar entre fuentes de procedencia (Capítulo 6, Anexo 1). La única fuente que mostro diferencias texturales internas es APE-C, que muestra un origen mixto, entre veta hidrotermal y reemplazo sedimentario (Anexo 1). Estas diferencias no fueron observadas en las muestras arqueológicas de APE-1 (sitio 
ubicado a menos de 500 metros de la fuente; capítulo 7), pero sus características petrográficas se corresponden con las de la fuente inmediata APE-C.

Los indicadores tecnológicos de secuencias de reducción e intensidad de uso de materias primas, mostraron patrones que sugieren la explotación de las fuentes inmediatas. En los sectores norte y sur, la amplia disponibilidad de las rocas silíceas, habría implicado una inversión mínima de tiempo y energía en el abastecimiento, dado que son frecuentes los núcleos amorfos y con lascados aislados, tanto en las fuentes como en los sitios (Capítulo 8). Favoreciendo estrategias de utilización de recursos en forma expeditiva. En el sector central, la menor disponibilidad de rocas silíceas y las características del ambiente (Capítulo 3 y 7), habrían motivado el transporte de materias primas y el desplazamiento de los grupos con el propósito de abastecerse (sensu Binford 1979), primando quizás estrategias de aprovisionamiento de individuos o equipamiento personal (Kuhn 2004).

Más allá de las tendencias generales no todos los recursos locales fueron utilizados del mismo modo en el área. El basalto está disponible en todos los ambientes, su calidad para la talla es regular y su uso es escaso (entre $1 \%$ a $3 \%$ del total), inclusive en aquellos ambientes donde posee mayor disponibilidad y variedad, como es el caso de la localidad RC (próxima al río Colorado) y ALPA (cercana al campo volcánico Payunia) (Capítulo 3 y 7). El uso de esta roca puede ser definido como un sistema de producción irregular, es decir que no muestra un patrón claro (Ericson 1984). En el sector central (ALPA), su mayor frecuencia fue asociada a su cercanía al área de Los Volcanes (capítulo 6, 7 y 9). Esta fuente es de carácter potencial y no se descarta la posibilidad de que la roca sea trasladada desde otros lugares de la región (tales como la cuenca del río Colorado) o de áreas colindantes, como las formaciones de basalto mencionadas por Durán (2000) para el cauce medio del río Grande (Gruta El Manzano).

La riolita no se encuentra disponible en todos los sectores, dado que no ha sido encontrada en el sector central y aparecen en frecuencias menores al $1 \%$ en los sectores donde se encuentra disponible (sectores norte y sur). En todos los casos, fue utilizada para la confección de percutores, lo que sugiere que formaban parte del 
toolkit (en el sentido de Kuhn 2004), descartados por pérdida de utilidad y reemplazado (p.ej. por fractura). Su nula y baja frecuencia, puede responder al hecho de que sean transportados y altamente conservados (sensu Binford 1979), sobre todo en aquellos espacios donde no se encuentra disponible (p.ej. ALPA).

En obsidiana se registran sistemas de producción secuenciales, dado que las etapas de abastecimiento, manufactura y descarte se encuentran en espacios diferentes (Ericson 1984). Esta materia prima ocupa el segundo lugar en las frecuencias de rocas utilizadas, y su representatividad en los conjuntos no supera el $7 \%$ del total (Capítulo 8 y 9). Los estudios geoquímicos y tecnológicos (Capítulo 8), permitieron realizar inferencias sobre los rangos de desplazamiento de las poblaciones, la extensión de los territorios explotados, la direccionalidad de los movimientos o interacción, así como posibles barreras biogeográficas que condicionan su modo de uso y transporte (Capítulos 8 y 9). En La Payunia se registró el uso de cuatro fuentes de obsidiana conocidas, dos cordilleranas (El Maule y Las Cargas) y dos no cordilleranas (EI Peceño y Cerro Huenul), y al menos dos señales geoquímicas desconocidas (Desconocidas A y Desconocidas). Tres de las canteras (El Maule, Las Cargas y El Peceño) se encuentran en el rango de distancia propuesto para los recursos no locales (Capítulo 8).

En los sectores se observan similitudes y variaciones en el acceso y uso a las fuentes de obsidiana. Los artefactos recuperados en el área, corresponden a las canteras no locales más próximas y sólo en el caso de El Maule y Cerro Huenul las etapas de reducción e intensidad covaría con la distancia entre los sitios arqueológicos y las fuentes (Capítulo 8). Como plantean estudios previos, el transporte de obsidiana provee una direccionalidad general oeste-este (Giesso et al. 2011a). Sin embargo en La Payunia, los estudios tecnológicos y de trayectorias productivas no muestran el mismo patrón. Tal es el caso de El Maule (la fuente de uso más frecuente en la región, aunque no la más próxima) cuyas variaciones en la trayectoria de producción plantean una direccionalidad intrarregional sur-norte. Es de destacar que los artefactos procedentes de esta fuente, representan el $65 \%$ de muestras recuperadas, y que supera en frecuencia incluso a la fuente Cerro Huenul, considerada por su distancia en el rango de las rocas locales en el sector sur. La presencia de las sierras de Cara Cura y de Reyes, 
en el límite oeste de la región, podrían haber actuado como barrera de movilidad, debido a la ausencia de cursos de agua permanentes y su difícil tránsito, aún para los pobladores actuales. Por esta razón, es probable que los artefactos procedentes de El Maule, hayan ingresando a la región por el sur, desde los ríos Barrancas, Grande y Colorado, y de allí transportados a los sectores central y norte. En el sector norte disminuye su frecuencia y sólo se encuentra representada como instrumentos bifaciales, con signos de reactivación. El Maule, pese a que se encuentra a más de 180 $\mathrm{km}$ de distancia, ha sido propuesta de acceso directo, dada su abundancia, trayectoria de producción, diversidad de clases artefactuales, variedad de tamaños y reserva de corteza.

Cerro Huenul, si bien se comporta como una fuente local, desde el punto de vista tecnológico, su baja frecuencia en los conjuntos puede ser resultado de un uso y/o difícil acceso (Giesso et al. 2011a). En frecuencia e intensidad de uso, esta obsidiana sigue una direccionalidad intrarregional sur-norte, al igual que El Maule. En el sector central (distante $60 \mathrm{~km}$ ) en contra de lo esperado, esta obsidiana se encuentra mejor representada y registra mayor diversidad de clases artefactuales. Cabe resaltar, que el sector central es el que presenta menor disponibilidad de recursos líticos locales, escasez que puede potenciar el traslado de rocas desde sectores vecinos, entre ellas la obsidiana (El Maule, Cerro Huenul y Las Cargas). Artefactos provenientes de Las Cargas (distante entre 175 y $180 \mathrm{~km}$ ), solo se registran en este sector con frecuencias bajas (Capítulo 8, Figura 8.10). Su trayectoria de producción permite proponer su ingreso por medio de acceso indirecto. Neme et al. 2012, registran una tendencia similar en los artefactos del sitio Gruta el Manzano. Encuentran un predominio de la fuente El Maule (79\%) por sobre Las Cargas (21\%) y un claro aumento en el uso de este recurso hacia finales de la ocupación. La distribución de bienes exóticos puede ser un indicador de la existencia y amplitud de redes (Whallon 2006), sobre todo en ambientes con alta variabilidad de recursos.

En el sur de Mendoza, los artefactos de Las Cargas registran la mayor dispersión espacial y temporal, con registros que van desde el Holoceno temprano (9.000-8.000 años AP) hasta tiempos post-hispánicos (Giesso et al. 2011a; Cortegoso et al. 2012). En La Payunia, que integra las áreas de El Nevado y El Payén (Gil 2000, 2006), estudios 
referentes al uso de obsidiana, mostraron marcadas diferencias entre las áreas. En área El Nevado (AEN) se registraron artefactos de la mayoría de las fuentes (Las Cargas, Cerro Huenul, La Bandera), un uso frecuente de la obsidiana local (El Peceño) y la ausencia de artefactos de El Maule. En el área El Payén (AEP), por su parte, se registra una alta frecuencia de El Maule, una baja frecuencia de las locales (Cerro Huenul) y artefactos manufacturados y desechos aislados de otras fuentes exóticas (Las Cargas y El Peceño) (Salgán et al. 2012). Las razones que explican esta tendencia, aún no fueron discutidas en profundidad. Podrían ser resultado de: 1) su transporte por vías de circulación de fácil acceso, la dirección predominante de los ríos en sentido norte-sur, favorecería la interacción en ese eje longitudinal en AEN, y 2) la existencia de factores de territorialidad que restringen interacción entre ambas áreas. Esta última hipótesis ya fue planteada por Barberena et al. (2011), para el uso de la obsidiana Cerro Huenul, pero ambas requieren de una mayor resolución de información arqueológica para ser validada. Estos planteos, sin embargo, requieren del abordaje de distintas vías de análisis, con fuerte énfasis en los patrones de movilidad, tales como frecuencias en los bienes de intercambio, indicadores de diseño de instrumentos y estudios de isótopos estables, entre otros.

En términos de estrategias de aprovisionamiento implementadas en La Payunia, es posible sostener la coexistencia de al menos cuatro estrategias diferentes. La primera, se vincula a los recursos locales, y en la que prevalece el acceso incluido (Binford 1979). Tal es el caso de las rocas silíceas en los sectores norte y sur. Allí la amplia disponibilidad de rocas de buena a muy buena calidad para la talla, habrían favorecido una inversión mínima de tiempo y energía en el abastecimiento y la manufactura, y el aprovechamiento de filos naturales. Es decir, se registra una estrategia expeditiva (Binford 1979) en la utilización de los artefactos. En segundo lugar, la menor disponibilidad de rocas silíceas en el sector central, habrían favorecido el empleo de estrategias de aprovisionamiento directo (sensu Binford 1979), que implica movimientos en el ambiente con el propósito exclusivo de obtener materias primas. Asimismo se evidencian, estrategias de aprovisionamiento de individuos, tanto en rocas locales como no locales, primando una estrategia de utilización de los artefactos de tipo conservada. 
La tercera estrategia, está vinculada al aprovisionamiento de los recursos no locales, para las cuales se plantea el aprovisionamiento de individuos (sensu Kuhn 2004), de obsidianas El Maule y Cerro Huenul. Esta estrategia implica el transporte de materias primas e instrumentos a la región, y es coherente con la presencia de las distintas etapas de manufactura, y de índices altos de reducción (Capítulo 9, Tabla 9.14), asociado con altos costos de transporte (Kuhn 2004). Por último, la obsidiana de El Peceño y Las Cargas, habrían ingresado a la región como resultado de la interacción de grupos (tal vez intercambio). Esto habría ocurrido en el marco de los desplazamientos anual/estacional, su principal correlato son: su baja frecuencia, su registro como instrumentos fracturados y, en el caso de Las Cargas, su alto índice de reducción.

\subsubsection{VALIDACIÓN DE HIPÓTESIS}

Las tendencias espaciales y temporales del registro arqueológico presentadas en los capítulos previos permiten discutir las hipótesis de trabajo formuladas en esta tesis. Tres de las hipótesis hacen referencia al aprovisionamiento y uso de los recursos líticos locales (Hipótesis 1) y no locales (Hipótesis 2 y 3) y una, a las variaciones temporales en el uso de las rocas y, en particular, a los procesos de intensificación propuestos para fines del Holoceno tardío (Gil 2006; Neme 2007).

En relación al aprovisionamiento y uso de los recursos líticos locales, hemos corroborado, que su amplia disponibilidad de rocas de buena calidad para la talla y de fácil accesibilidad, habrían favorecido estrategias de aprovisionamiento incidentales o incluidas con otras actividades de subsistencia (Capítulo 9). El análisis de la base regional de recursos líticos destacó la disponibilidad de variedad de rocas con aptitudes para la talla (tales como basalto), sin embargo en todos los sitios analizados las rocas silíceas son las más utilizadas (Capítulo 7 y 9), con frecuencias que superan el 90\% del total. Los estudios petrográficos permitieron determinar (Capítulo 6, Anexo 1), que las fuentes de rocas silíceas representadas corresponden a las disponibles en la 
inmediata vecindad. Es decir, las áreas de explotación, procesamiento, utilización y descarte están dispuestas de manera próxima en el espacio.

Desde el punto de vista tecnológico las trayectorias de producción en rocas silíceas permiten postular un escaso tiempo e inversión en la obtención de formas base en las fuentes primarias. En los sitios de actividades múltiples se registran todas las etapas de manufactura, altas frecuencias en reserva de corteza y variedad de tamaños (capítulos 7 y 9). En lo que se refiere a la manufactura de instrumentos, en rocas silíceas se registran las tres clases consideradas, con mayor frecuencia de artefactos simples; predominan los tamaños grandes y no se documentaron evidencias de reactivación de instrumentos. La alta frecuencia de instrumentos enteros y de baja inversión en su manufactura, hace suponer que en general, fueron descartados con poco uso y mantenimiento. En suma, la ausencia de formas base altamente estandarizadas, de indicadores de reactivación y la corta vida útil de los instrumentos, un contexto donde la obtención de recursos es predecible (Nelson 1991).

En referencias a la hipótesis 2 y 3, las expectativas formuladas incluían estrategias diferentes en la obtención y uso de recursos ubicados a una distancia superior a los $40 \mathrm{~km}$. Como se detalló previamente en este capítulo y en los capítulos 6 y 8 , los recursos no locales están representados mayormente por la obsidiana, que evidencian diferentes modos de acceso. La obsidiana El Maule y Cerro Huenul, fueron consideradas de acceso directo, primando estrategias de aprovisionamiento de individuos (Kuhn 2004), principalmente puntas de proyectil. Se sugirió que debido a su mayor estandarización de los soportes, presencia de reactivación e intensidad de uso, estos son el resultado de estrategias conservadas. Por otro lado, las obsidianas procedentes de Las Cargas y El Peceño, habrían ingresado como resultado de intercambio con otros grupos, dado su registro como instrumentos formatizados o sólo como desechos de talla internos (Capítulo 8). En ambientes áridos-semiáridos, como los de La Payunia, los mecanismos sociales de intercambio habrían constituido uno de los principales mecanismos para el manejo del riesgo (Torrence 1989).

Por último, en relación a momentos de ocupación efectiva del espacio (Hipótesis 4), las expectativas formuladas eran un aumento en las frecuencias de 
materias primas exóticas en los niveles superiores de los sitios y una mayor proporción de artefactos formatizados vinculados a estadías más largas en el lugar (p.ej. los raspadores e instrumentos de molienda). Los resultados descriptos en el capítulo 9, apoyan esta idea. Los materiales depositados entre los ca. 2.000-1.000 años AP y los ca. 1.000-250 años AP (Capítulo 9), muestran un incremento en la frecuencia de obsidiana en el último periodo. Este incremento, está acompañado por una mayor diversidad de clases artefactuales, un índice alto de reducción y la incorporación de variedad de obsidianas procedentes de regiones vecinas (p.ej. El Peceño y Cerro Huenul). Asimismo, el registro de: a) una mayor intensidad de uso y mantenimiento de las rocas silíceas inmediatamente disponibles, b) un incremento en la tasa de descarte de artefactos en BTAR y c) registro de mayor frecuencia de artefactos vinculados a estadías más largas en el lugar, sugieren una disminución en la movilidad de las poblaciones hacia finales de BTAR (capítulo 9).

Por lo tanto, es posible sostener que en el bloque temporal tardío (BTAR) se registra un aumento en los tiempos de permanecía en los sitios, tal vez ligado a una disminución de la movilidad residencial. El aumento en la frecuencia y diversidad de obsidiana sugiriere su mayor disponibilidad dentro de la región, posiblemente por un aumento en las redes de intercambio. El registro de artefactos provenientes de El Maule, El Peceño y Cerro Huenul en este último periodo apoyan esta idea.

\subsubsection{UN MODELO PARA EL APROVISIONAMIENTO DE RECURSOS LÍTICOS EN LA PAYUNIA}

En capítulos previos, hicimos referencia a distintos factores que influyen en los modos de aprovisionamiento y transporte de los recursos líticos desde sus fuentes hasta los locus de descarte. Para su abordaje es necesario conocer la base regional de recursos líticos (Ericson 1984) y la calidad de las materias primas disponibles en el espacio regional (Binford 1979; Nelson 1991). Esto también implica evaluar las estrategias de asentamiento y subsistencia del grupo (Binford 1979); la frecuencia de movilidad de las poblaciones (Kuhn 2004); la distancia a las fuentes de procedencia y el grado de interacción entre las poblaciones (Renfrew 1977; Torrence 1984; Meltzer 
1989). De modo que para entender la relación entre las áreas de abastecimiento y las estrategias de obtención de recursos líticos, se requiere de la integración de información referente a la disponibilidad de recursos en el ambiente y de las áreas donde se emplaza cada cantera en particular, con aquella referida al transporte, uso y descarte final de la materia prima en el espacio regional amplio (cf. Binford 1980; Ericson 1984; Elston 1992; Bousman 1993). En este marco, la cantera actúa como una medida proxy para entender las estrategias de obtención de recursos o "gestión integral" de los mismos, fuera de las áreas primarias de abastecimiento (Carr y Boszhardt 2010:132).

A partir de los resultados de esta investigación, y teniendo en cuenta, en particular, el modelos de Custer et al. (1983) (Capítulo 4), es posible delinear dos estrategias de aprovisionamiento directo en el Holoceno tardío en La Payunia. La primera, hace referencia al aprovisionamiento de los recursos disponibles en el espacio local, específicamente a las rocas silíceas. Estos recursos de abundante disponibilidad local responderían a una estrategia de aprovisionamiento serial (sensu Custer et al. 1983), donde los grupos móviles hacen uso de fuentes líticas próximas, situadas en puntos diferentes del espacio a lo largo de su ciclo anual. Estas fuentes son visitadas en el transcurso de las actividades de subsistencia, lo que genera un patrón similar a las estrategias de abastecimiento incluido. En esta estrategia, se espera que los sitios muestren una representación de las fuentes inmediatas en altas proporciones (superior al $90 \%$ ) y que no sean frecuentes las tareas de transporte de materias primas, dado que se prevé la disponibilidad de tiempo y materiales para el desarrollo de tareas específicas. Se asume la reocupación de ciertos lugares, desde los cuales se puede tener un fácil acceso al recurso.

En el caso de La Payunia, los sitios estratigráficos están vinculados generalmente con pequeñas vertiente de agua permanente y fuentes de rocas (LP-2 y APE-1); recursos poco frecuentes en la región. En aquellos casos en que la fuente de roca no se encuentra en el mismo espacio, esta aparece a menos de los $10 \mathrm{~km}$ (en el rango de la rocas locales cercanas) (CAR-1 y Pista). La tasa de descarte es mayor en los sitios asociados a ambos recursos (LP-2 y APE-1), que en los vinculados sólo a vertientes (CAR-1). Por el contrario, los sondeos llevados a cabo en sectores sin 
fuentes de agua y con disponibilidad de rocas, resultaron estériles (Sondeo Jagüel Avelino en ALPA y Sonseo 1, en Pista), mostrando que no fueron seleccionados para su ocupación (Figura 10.1).

En cuanto a las rocas no locales, su aprovisionamiento respondería a una estrategia de tipo cíclica (Custer et al. 1983), que implica el abastecimiento repetido de una fuente por parte de una población, que retorna periódicamente a abastecerse en su ciclo anual o estacional de desplazamiento. En esta estrategia se espera que no sea frecuente el abastecimiento de otras rocas de características similares (en distancia y calidad para la talla) y, que en los sitios la fuente posea altas frecuencias, debido a su transporte y uso sostenido en el tiempo. En el caso de La Payunia, la fuente El Maule, se encuentra presente en los tres sectores, siendo en todos los casos la obsidiana más frecuente. Si se aceptan estos planteos para dar cuenta del aprovisionamiento de obsidiana El Maule durante el Holoceno tardío en La Payunia, los rangos de desplazamientos estivales tendrían una direccionalidad preponderante este-oeste, cuya amplitud sería de ca. 120 y $200 \mathrm{~km}$. En el recorrido se privilegiarían las rutas de fácil tránsito como los valles de los ríos Barrancas, Grande y Colorado, ingresando a la región preferentemente por el sector sur.

Este modelo da cuenta de la escasa presencia de fuentes como El Peceño o Cerro Huenul en la región. En el caso de El Peceño, el fácil acceso y la ausencia de limitantes geográficas y/o temporales entre el sector norte de La Payunia y el área El Nevado, sumado a su disponibilidad anual y a una mayor oferta de recursos hídricos (Gil 2000, 2006), hacen suponer la existencia de grupos con patrones de movilidad excluyentes, y con escasa interacción social. En el caso de Cerro Huenul, quizás su aprovisionamiento resultara una opción de acceso invernal (cuando El Maule no admite su acceso), momento en que el caudal del río es menor y facilitaría su tránsito. El uso de esta fuente podría plantearse como una alternativa de explotación estacional y de uso poco frecuente. 


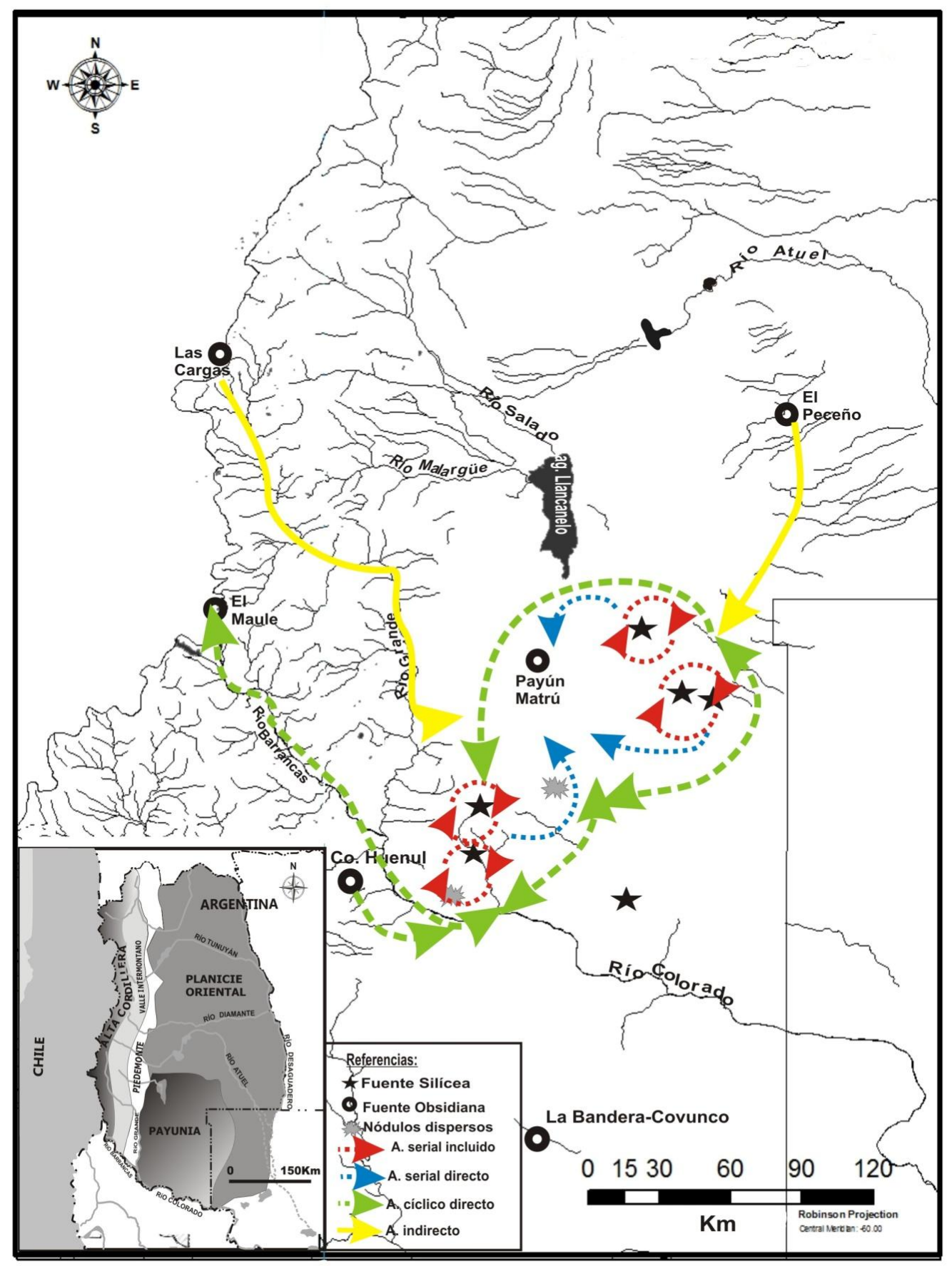

Figura 10.1. Modelo espacial de aprovisionamiento de rocas en La Payunia.

\subsection{LA PAYUNIA EN EL CONTEXTO DEL SUR DE MENDOZA}

En este trabajo de tesis se abordó el estudio de la base regional de recursos líticos y de los sistemas productivos, con el objeto de contribuir a la comprensión de 
los patrones de circulación humana y las formas de utilización del espacio en el Holoceno tardío. Los problemas abordados pueden ser agrupados en dos grandes ejes, con fuertes implicancias extra-regionales: la estructura tecnológica y a la disponibilidad de materias primas en La Payunia y los patrones de movilidad y rangos de acción de las poblaciones en el Holoceno tardío.

En relación al primero, Durán $(2000)$ y Gil $(2000,2006)$ propusieron que en La Payunia, los recursos líticos eran ampliamente disponibles y de distribución homogénea en el espacio. Los resultados detallados en el capítulo 6 nos permiten sostener que si bien La Payunia posee disponibilidad de recursos líticos, estos se restringen a rocas silíceas y que su distribución en el espacio es heterogénea. En el sector norte y sur las silíceas y otras rocas minoritarias (p.ej. basalto, riolita y andesitas), poseen amplia disponibilidad; mientras que en la Altiplanicie del Payén o sector central, la disponibilidad de rocas es menor. Los ambientes norte y sur presentan mayor disponibilidad de agua (en forma de vertientes naturales) y productividad primaria, mientras que en el sector central, la disponibilidad de agua es escasa y no hay formación de suelos (Capítulo 3). Estas variaciones nos permiten jerarquizar el espacio regional en función de la disponibilidad de materias primas líticas, ubicando en primer lugar al sector norte (área de Agua Escondida), en segundo lugar el sector sur (Cañadón Amarillo) y por último el sector central (Altiplanicie del Payén).

En regiones vecinas, tales como la cuenca media del río Grande y el centrooeste de la Pampa Seca, fueron localizadas fuentes primarias de rocas silíceas de amplia disponibilidad y calidad para la talla, tales como: Caverna de las Brujas (Durán y Altamira 2001; Durán 2002; Campos et al. 2006) y Meseta del Fresco (Berón 2004, 2006). En el marco de este trabajo también se identificaron fuentes de roca silícea en el cauce medio del río Malargüe (Salgán 2010) y en el área El Nevado (Delandatti 2005; Rubinstein 2005; Gargiulo et al. 2007). El conocimiento de dichas fuentes, cuestiona la premisa de que la obtención de rocas haya sido uno de los principales fines-objetivos de incursiones logísticas a la región, al menos desde las regiones norte, este y oeste. Respecto al norte de Neuquén, la baja frecuencia de artefactos de obsidiana de Cerro Huenul en La Payunia, puede ser interpretado como resultado de desplazamientos 
poco frecuentes (Barberena et al. 2011; Salgán et al. 2012). A nivel regional, los resultados obtenidos nos permiten sostener que el aprovisionamiento de silíceas habría estado inserto en la realización de otras actividades (sectores norte y sur) y que su estrategia de uso habría sido mayormente expeditiva. En el sector sur, el registro de núcleos preparados, hace suponer una mayor estandarización en los soportes instrumentales y quizás eventos de traslado de formas base (capítulo 7 y 9). Por el contrario, en el sector central, el aprovisionamiento de silíceas habría sido directo, es decir, mediado por desplazamientos orientados al abastecimiento de individuos y su uso mayoritariamente conservado (Capítulo 9).

En segundo lugar y en relación a los patrones de movilidad y rangos de acción de las poblaciones, desde los trabajos pioneros de Gambier (1985) se hace referencia a la inclusión de La Payunia en los circuitos de desplazamiento estacional entre tierras bajas a tierras altas (Lagiglia 1997a; Durán 2000). Entre los bienes materiales mencionados como indicadores de desplazamiento o interacción entre grupos se destacan: la cerámica (Lagiglia 1977a, 1999; Durán 2000; Berón 2004; Neme y Gil 2005), los adornos personales (tembetá, cuentas de collar, piezas de metal) (Neme 2002, 2007; Berón 2004, 2007), los ornamentos de moluscos provenientes del Pacífico (Durán 2000; Neme y Gil 2005), la obsidiana (Seelenfreud et al. 1996; Durán 2000; Durán et al. 2004; Giesso et al. 2008; Giesso et al. 2011a; Barberena et al. 2011; Salgán et al. 2012) y los productos vegetales (caña colihue) y cultivados (maíz) (Gil 2000, 2006), entre otros (Capítulo 2). Distintos autores coinciden en que estos bienes exóticos son recurrentes en el registro arqueológico macro regional en la segunda mitad del Holoceno tardío y, más específicamente, en los último 1.000 años AP (Durán 2000; Gil 2000, 2006; Berón 2004; Neme y Gil 2005; Giesso et al. 2011a y b). Momento para el que se plantea un proceso de regionalización en toda la zona de Cuyo y Chile central (Neme 2002, 2007). En La Payunia, los estudios geoquímicos sobre obsidiana indican un aumento en la diversidad de fuentes para los últimos 1.000 años AP (Capítulo 8 y 9). Acompañado de un aumento en la frecuencia de obsidiana, en la intensidad de reducción de rocas locales y no locales y de la tasa de descarte de artefactos en los sitios, indicando una disminución en la frecuencia de los desplazamientos y un incremento en las relaciones de intercambio. Según Ericson 
(1984), existe una relación inversa entre el afianzamiento de la territorialidad y el aprovisionamiento directo. En el sector norte, la baja frecuencia de artefactos de obsidiana El Peceño puede responder a esta situación.

El modelo de movilidad propuesto por Durán (2000), involucra momentos de fusión y de fisión de las poblaciones cazadores recolectoras como respuesta a las variaciones estacionales en la disponibilidad de los recursos (Capítulo 2), con desplazamientos estivales a ambientes de cordillera, valles y La Payunia. Si bien los datos presentados aquí no permiten discutir el modelo propuesto, la presencia de obsidiana Las Cargas en el sector central y el registro temprano del uso de esta obsidiana en el cauce medio del río Grande (sitio Gruta El Manzano, Durán 2000; Neme et al. 2011), puede ser indicador de la direccionalidad de ingreso de este recurso. Desde el punto de vista biogeográfico, la interrupción en el sector central del anticlinal que forma las sierras de Palauco (al norte), respecto de las sierras de Cara Cura y de Reyes (al sur), pudo haber facilitado los desplazamientos desde el río Grande a la Altiplanicie del Payén (pero no entre la cordillera y la altiplanicie). Es de destacar que el sitio Alero Puesto Carrasco (Durán 2000), ubicado en la margen derecha del río Grande en las sierras de Palauco y fechado entre $2090 \pm 80{ }^{14} \mathrm{C}$ años AP y el siglo XIX, se registran obsidianas procedentes de El Maule (89\%), Las Cargas (6\%) y Cerro Huenul (5\%) (Giesso et al. 2011a) en frecuencias y variedades similares a las observadas en el sector central.

Es necesario tener en cuenta que dos de los tres tipos de acceso a las materias primas dentro de la región implican una movilidad intra regional, sin necesidad de moverse hacia regiones distantes. Esto hace pensar en la posibilidad de que los grupos humanos que habitaron este sector de La Payunia habrían pasado largos periodos de tiempo dentro de la región y no lapsos cortos. Como se mencionó anteriormente, tanto la presencia de equipamiento de molienda como de raspadores, indicarían la presencia de todo el grupo en el lugar y no solo de pequeños grupos logísticos altamente móviles. En este sentido, es interesante destacar los resultados de isótopos de $\delta^{18}$ sobre muestras obtenidas en restos humanos de La Payunia, muestran una fuerte señal de aguas procedentes de esta misma región, incluso más marcada que las señales de isotopos de $\delta^{18}$ de regiones vecinas, como cordillera o piedemonte (Gil et 
al. 2011; Ugan et al. 2012). Esto indicaría que las poblaciones habrían pasado largos periodos de tiempo en La Payunia, explotando diferentes tipos de recursos y no solo extrayendo materias primas líticas para ser utilizadas en áreas vecinas.

En Pampa seca, Giesso et al. (2008) analizan artefactos de obsidiana de diferentes contextos del Holoceno tardío, donde identifican tres procedencias conocidas (El Maule, Cerro Huenul y La Bandera-Covunco) y cuatro desconocidas. Sobre la base de las edades radiocarbónicas disponibles, asocian la obsidiana Cerro Huenul (13\%) sólo a las ocupaciones tempranas, lo que indicaría su incorporación a este registro desde al menos 3.000 años AP (sitio Tapera Moreira). El Maule (25\%) y La Bandera-Covunco (31\%) están documentados en los últimos dos bloques temporales (sitios Tapera Moreira y El Chenque 1), mientras que los artefactos con señales químicas desconocidas se documentaron en los tres periodos. Estos estudios aportan mayor profundidad temporal para el uso de la fuente Cerro Huenul. Giesso et al. (2008) y Berón (2010), sostienen el intercambio de bienes a través de las grandes cuencas hídricas, tales como los ríos Colorado, Barrancas, Grande y Neuquén (sur de Mendoza y norte Neuquén) y Chadileuvú y Curacó (La Pampa). Con posterioridad a los 1.000 años AP, Berón $(2004,2010)$ sostiene que el aumento demográfico habría llevado a las poblaciones a una reducción de la movilidad, al establecimiento de diferencias étnicas y a la territorialidad de los espacios. Donde la permanencia de los circuitos de movilidad macro regional habría facilitado las relaciones interétnica y los sistemas de alianza entre grupos. Trabajos recientes analizan para este último periodo situaciones de conflicto intergrupal (Berón 2010) y resaltan la necesidad de explorar procesos de interacción por competencia, las cuales pudieron acentuar condiciones preexistentes (Barberena 2011).

En el marco de esta investigación, cabe resaltar que en el cauce medio del río Grande (piedemonte) y en el suroeste de la región Pampa Seca, hay presencia de artefactos de obsidiana El Maule, sin embargo las tendencias temporales y los modos de aprovisionamiento parecen responder a estrategias diferentes. En el río Grande, el modo de acceso a la cantera responde a estrategias de aprovisionamiento directo (Durán 2000; Neme et al. 2011), en contextos atribuidos al Holoceno medio (ca. 7.200 años AP). Por su parte, en el oeste pampeano, su ingreso está asociado a eventos de 
intercambio entre grupos y a contextos de la última mitad del Holoceno tardío (1.200 años AP) (Giesso et al. 2008). Desde una perspectiva macro regional, los rangos de desplazamiento para la primera mitad del Holoceno tardío parecen responder a espacios de mayor amplitud que los evidenciados para periodos previos y posteriores. A mediados del Holoceno tardío (2.000 años AP), artefactos de obsidiana El Maule se registran en el cauce del río Grande -oeste de La Payunia (Alero Puesto Carrasco) y en el sector sur de La Payunia (CAR-1). En el cauce del río Grande, esta obsidiana se encuentra asociada a obsidiana Cerro Huenul y Las Cargas. En cambio en el oeste pampeano sólo se registra el uso de obsidiana de Cerro Huenul. Con posterioridad a los ca. 1.000 años AP, la variedad de procedencias de obsidiana se incrementa en toda la macro región, junto con indicadores de mayor permanencia en los sitios y una reducción en la movilidad, pero con las diferencias en el acceso observadas en momentos previos. Esto podría indicar la permanencia de amplios rangos de acción, pero con baja movilidad residencial, mayor número de incursiones logísticas prolongadas e interacción intergrupal (Gil 2000; Berón 2004). En esta escala amplia de análisis, cobra mayor relevancia la baja frecuencia de obsidiana Las Cargas (cuya distribución sur parece restringirse al piedemonte y la Altiplanicie del Payén) y de artefactos de El Peceño (registrado en solo en el sector norte de La Payunia). Tendencia que refuerza la hipótesis de diferencias en la direccionalidad de los desplazamientos e interacción social respecto a área El Nevado (Salgán et al. 2012) y cordillera norte (Cortegoso et al. 2012), cuya permanencia pudo conducir a diferencias territoriales. Será necesario profundizar y discutir estas ideas desde distintos indicadores de movilidad y fundamentalmente, a partir de muestreos sistemáticos de artefactos de obsidiana de procedencia conocida y estratificados temporalmente, que permitan abordar trayectorias tecnológicas de las variedades de obsidiana en diferentes bloques temporales. 


\section{CAPÍTULO 11}

\section{CONCLUSIONES Y PERSPECTIVAS}

El objetivo general de esta tesis fue avanzar en el conocimiento de la organización de la tecnología de los grupos cazadores recolectores que en el Holoceno tardío ocuparon los ambientes áridos y semiáridos del sur de Mendoza. En este marco general, y como objetivos específicos, se propuso conocer los modos de aprovisionamiento y utilización de los recursos líticos en La Payunia, a fin de reconstruir los patrones de obtención, uso y circulación de las diferentes materias primas. Para ello, se profundizó en el estudio de la variabilidad tecnológica de los conjuntos líticos, en el papel que los diferentes sectores del espacio cumplieron como fuentes potenciales de aprovisionamiento, y en los cambios y/o estabilidad temporal en el uso de los recursos líticos.

Las conclusiones alcanzadas, surgen del análisis de las cuatro hipótesis enunciadas en el capítulo 1 . Tres de ellas hacen referencia al aprovisionamiento y uso de los recursos líticos locales y no locales, y una, a las variaciones temporales en el uso de las rocas. La definición de la base regional de recursos líticos permitió definir dos sectores de alta disponibilidad (sectores norte y sur) y uno de escasa disponibilidad (sector central) de rocas silíceas, basalto y riolitas. La cercanía de las fuentes de rocas silíceas a los sitios en los primeros, las sitúa en el rango de las rocas inmediatamente disponibles (PB y LLE en el sector norte y; APE-C y Pista en el sector sur) y local cercanas (Pista respecto a RC). La obsidiana de excelente calidad para la talla, en su mayoría resultó de procedencia extra-regional (El Maule, Cerro Huenul, Las Cargas y El Peceño) y dos de procedencia desconocida (Desconocida-A y Desconocida).

En relación a la organización de la tecnología se reconoció la coexistencia de al menos tres estrategias de aprovisionamiento y dos de utilización de rocas: 1 ) aprovisionamiento incidental o incluido de rocas locales, de uso principalmente 
expeditivo; 2) aprovisionamiento directo de larga distancia de rocas de buena y excelente calidad, de uso conservado, y 3 ) aprovisionamiento indirecto por medio de redes de intercambio y/o resultado de interacción entre grupos, de uso principalmente conservado. La primera estrategia fue propuesta en relación al aprovisionamiento y uso de las rocas silíceas, de amplia disponibilidad regional pero de distribución heterogénea en La Payunia. La escasa disponibilidad de materias primas en el sector central y la ausencia de rocas de calidad excelente en toda la región, habría llevado a la adopción de la segunda estrategia; que involucra el aprovisionamientos directo y transporte de rocas silíceas (sector central) y de obsidiana (EI Maule y Cerro Huenul). EI aprovisionamiento indirecto, se refiere al ingreso de instrumentos de obsidiana de fuentes distantes (Las Cargas) y su registro aislado (El Peceño). Para la realización de estas inferencias se utilizaron indicadores tecnológicos de intensidad de uso de rocas (tales como, índice de reducción de desechos y núcleos; tamaño de los artefactos; el índice geométrico de reducción en artefactos de formatización unifacial), la inversión en la manufactura de instrumentos y la trayectoria de producción de cada materia prima.

En esta tesis las estrategias tecnológicas de aprovisionamiento utilizadas en La Payunia, han sido explicadas mediante los conceptos de aprovisionamiento serial y cíclico (Custer et al. 1983). El primero da cuenta del aprovisionamiento de los recursos locales, principalmente las rocas silíceas, que implican la ocupación de los espacios con disponibilidad de recursos considerados críticos, como es el agua. En la segunda estrategia, se destaca el abastecimiento repetido en una fuente a la cual se retorna periódicamente durante los ciclos de desplazamiento anual y que no implica un costo extra de aprovisionamiento. A estas estrategias de aprovisionamiento debe sumarse el acceso indirecto, por medio de intercambio, frecuente en la última mitad del holoceno tardío final (últimos $c a .1 .000$ años AP). Este modelo permite sostener que las poblaciones que ocuparon la región en el Holoceno tardío, mantenían rangos de desplazamientos con una fuerte direccionalidad extra-regional en sentido este-oeste, en espacios cuya amplitud llegaría a cubrir el rango entre los 120 y $200 \mathrm{~km}$. En este recorrido se privilegiarían las rutas de fácil tránsito como los ríos Barrancas, Grande y Colorado, ingresando a la región preferentemente por el sector sur. 
La información cronológica indica para los últimos ca. 1.000 años AP: un aumento en la tasa de descarte de artefactos, una mayor intensidad de uso de rocas locales y no locales, un aumento en la diversidad de clases de artefactos y un aumento en la variedad de procedencias de artefactos de obsidiana. Estos indicadores se plantearon como reflejo de estadías más largas de ocupación, de aumento en la demografía y en el afianzamiento de redes de intercambio. Los resultados propuestos para este último bloque temporal, concuerdan con lo esperado por Neme (2007) en su modelo de intensificación y discuten los planteos en torno a la ocupación tardía de la región (Gil 2000, 2006). Proponiendo que la misma se habría dado hacia mediados del Holoceno tardío (ca. 2000 años AP). La incorporación de información arqueológica de nuevos sectores (como el valle del río Colorado) abre una nueva perspectiva para repensar en otra escala la forma en que las poblaciones humanas exploraron, colonizaron y ocuparon efectivamente La Payunia.

En capítulos previos se planeó que una de las metas de la perspectiva organizativa de la tecnología es reconstruir los patrones de movilidad y asentamiento, y la manera en que éstos determinan necesidades artefactuales y el acceso a las materias primas (Carr 1994). Los resultados alcanzados en esta tesis permitieron además de esto, explorar en profundidad y desde nuevos enfoques el registro arqueológico de la región. Principalmente, se realizaron análisis de la tecnología lítica desde perspectivas poco desarrolladas con anterioridad, que posibilitaron generar tendencias referidas a la movilidad y los rangos de acción de las poblaciones cazadoras recolectoras. Los temas pendientes más importantes incluyen: a) profundizar el estudio de los artefactos de obsidiana en La Payunia, a partir de un diseño de muestreo sistemático de los conjuntos. Esto permitirá complementar la información de elementos traza disponible a nivel regional, superando los problemas de sub o sobre representación de muestras que pueden haber enmascarado algunas de las tendencias enunciadas; b) mejorar el conocimiento de la base regional de recursos líticos de la región. Los estudios realizados identificaron al menos dos señales geoquímicas desconocidas, las cuales también han sido identificadas en regiones colindantes. Asimismo, la señal química de las fuentes potenciales de obsidiana Payún Matrú y Payún Liso presentó dificultades, impidiendo hasta el momento su caracterización 
geoquímica. Lo que sugiere la necesidad de concentrar esfuerzos en muestrear e identificar geoquímicamente estas fuentes potenciales conocidas; c) por último, planteamos profundizar el análisis cronológico de la región que permita discutir los resultados aquí presentados. Todo esto permitirá contrastar los modelos generales propuestos para la región y generar nuevos modelos explicativos sobre las ocupaciones prehispánicas del sur de Mendoza. 
ANEXOS 


\section{ANEXO 1}

\section{ANÁLISIS PETROGRÁFICO}

\section{INTRODUCCIÓN}

Se detalla la procedencia de las muestras, código, características macroscópicas de la pasta y determinación petrográfica de las muestras de roca tomadas en las fuentes $(n=31)$ y en los sitios arqueológicos $(n=15)$. Las muestras fueron agrupadas por fuente o sitio arqueológicos de procedencia y en los casos en que la similitud en las características petrográficas lo permitió, fueron descritas en conjunto. El análisis y descripción de los cortes delgados fue realizado por el Dr. Walter G. Bertotto ${ }^{2}$ y la colaboración de la Dra. Mirta Garrido ${ }^{3}$. En este apartado sólo se describe a las muestras representativas de cada conjunto.

\section{FUENTES DE ROCA SILÍCEA}

\subsection{PIEDRAS BAYAS (PB)}

Sitio: PB

Localidad: La Peligrosa

Muestras: LP12 a LP21.

Descripción macroscópica: roca silicificada con textura de brecha (fragmentos o clastos más cemento), cementada por cuarzo transparente.

Descripción petrográfica: Clastos de ópalo o reemplazados por ópalo. Cemento de calcedonia (más abundante) y cuarzo. La calcedonia adquiere en sectores textura fibrosa y costriforme. Además se observan cavidades sub-circulares a irregulares rellenas por calcedonia más cuarzo.

\footnotetext{
${ }^{2}$ Instituto de Ciencias de la Tierra y Ambientales de La Pampa, CONICET-Universidad Nacional de La Pampa

${ }^{3}$ Departamento de Geología, Universidad Nacional del Sur
} 

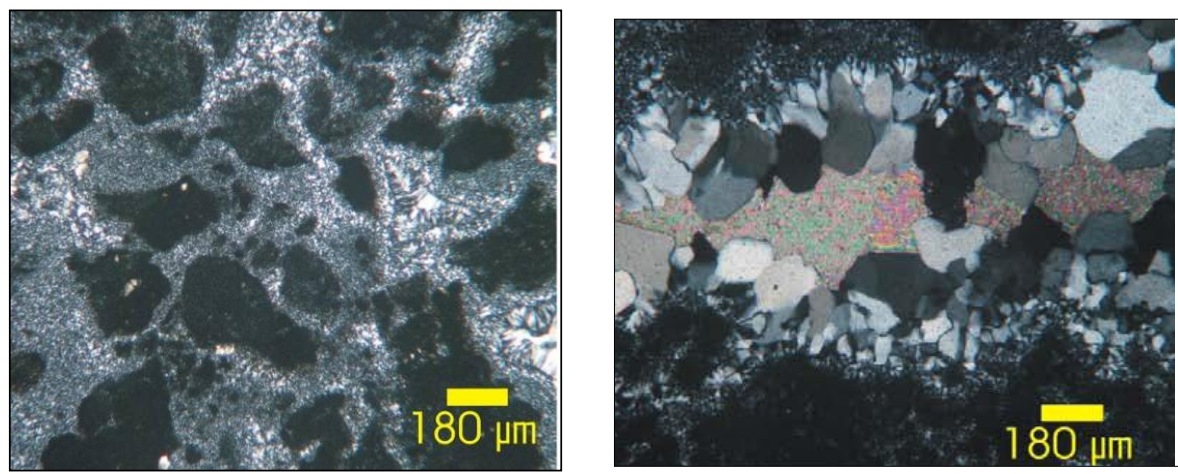

Figura A1.1. Muestra LP12. Microfotografía con luz polarizada 20x. Referencia: Izquierda: Roca silicificada con textura de brecha. Clastos de ópalo y cemento de calcedonia. Derecha:cavidades que terminan en calcita despues de la presipitación de calcedonia y caurzo.
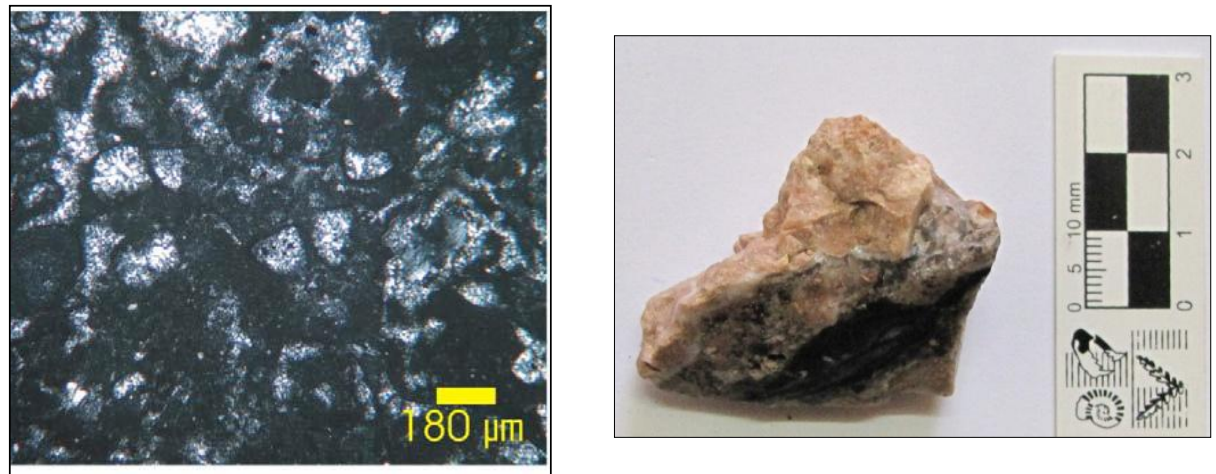

Figura A1.2. Muestra LP14. Silice amorfo con relleno de espacios subcirculares con cuarzo de grano fino. Referencia: izquierda: microfotografía con luz polarizada. Derecha: muestra de mano.

\subsection{LA LEONA (LLE)}

Sitio: LLE

Localidad: La Peligrosa

Muestra: muestras LP6 a LP11 (Figuras A1.3 a A1.5)

Descripción macroscópica: Roca silicificada (posiblemente la roca original era una volcanoclástica con cristaloclastos de cuarzo).

Descripción petrográfica: Vesículas rellenas por calcedonia de grano fino, fibrosa y cuarzo en el centro. Matriz de la roca reemplazada principalmente por ópalo con presencia de minerales opacos y en algunos casos venillas de calcedonia. 

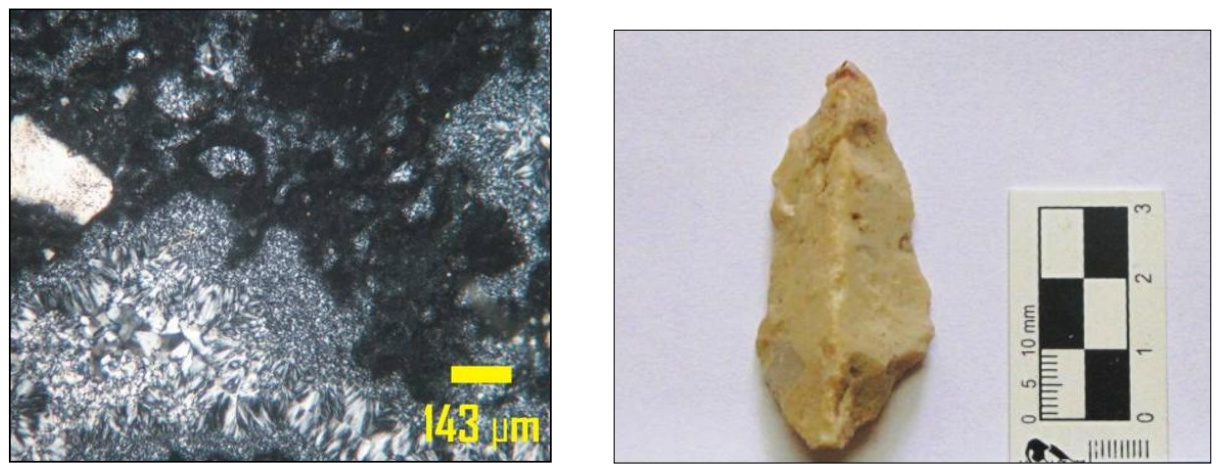

Figura A1.3. Muestra LP7. Roca silicificada. Cristaloclastos de cuarzo vesículas rellenas con calcedonia de grano fino y cuarzo. Referencia: Izquierda:microfotografía con luz polarizada. Derecha: muestra de mano.
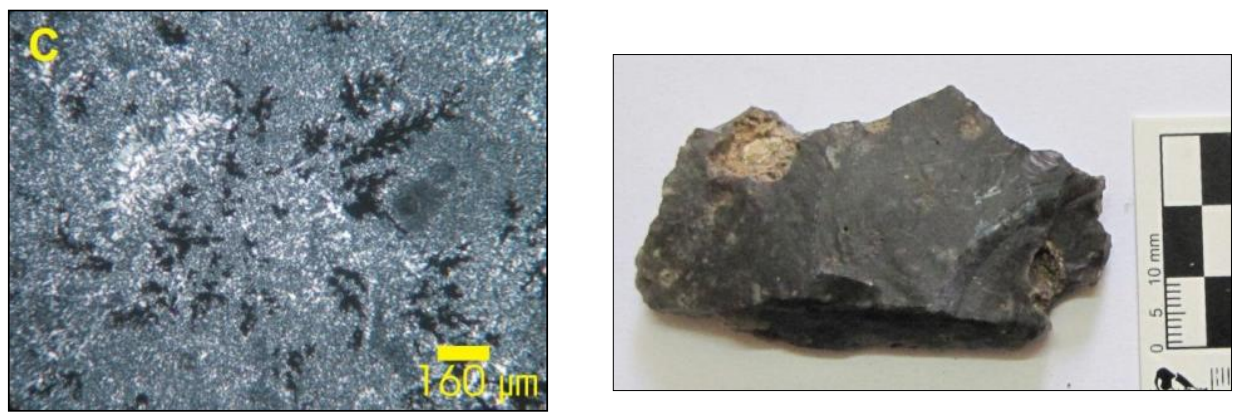

Figura A1.4. Muestra LP8. Roca silicificada. Fenocristales? Reemplazados por calcedonia y matriz reemplazada por ópalo. Referencia: izquierda: microfotografía con luz polarizada; derecha: muestra de mano.
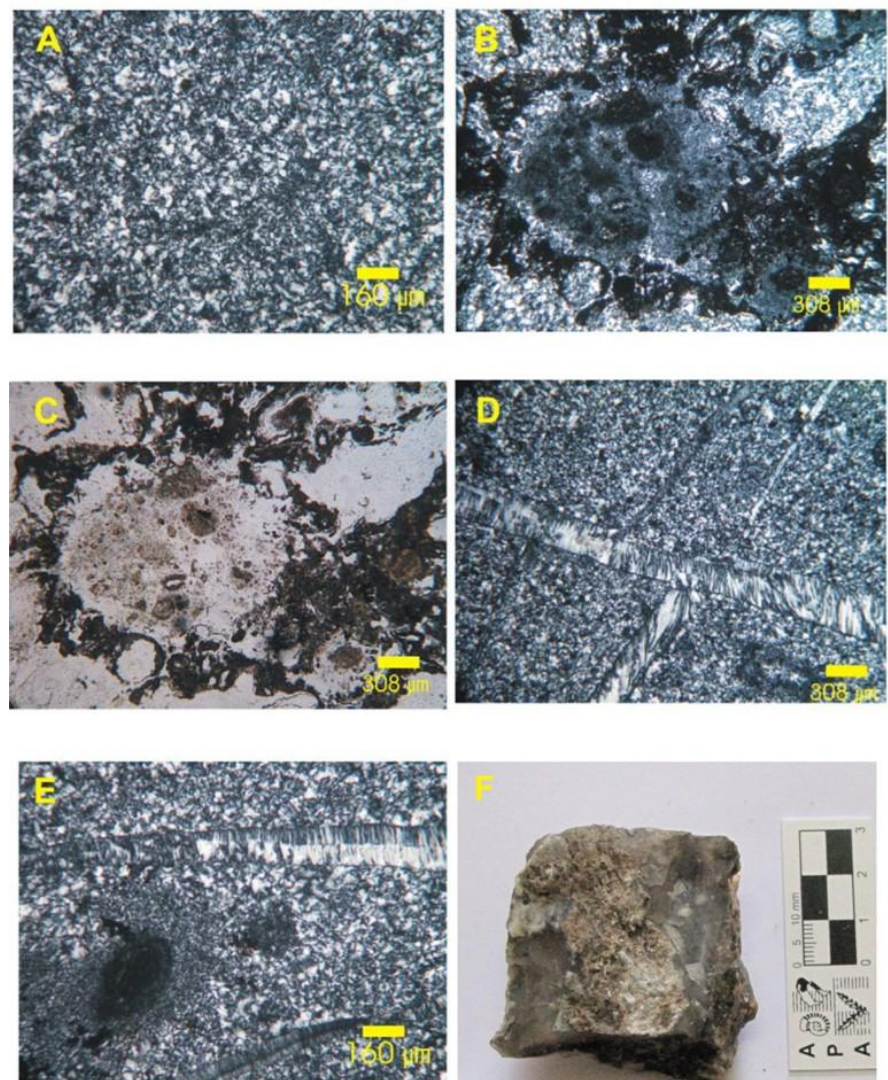
Figura A1.5. Muestra LP10. Roca silicificada. Espacios huecos semicirculares rellenos con calcedonia en los bordes y cuarzo en el centro. Las cavidades están delineadas por óxidos de hierro. Microfotografía B con luz polarizada y C con luz natural. Referencia: izquierda: microfotografía con luz polarizada; derecha: muestra de mano.

\subsection{AGUA DE PÉREZ CANTERA (APE-C)}

Sitio: APE-C

\section{Localidad: Agua de Pérez}

Muestra: muestras APE1 a APE5.

Descripción macroscópica: La roca de caja es de grano muy fino, color blanco grisáceo, dura y no se observa la textura original de la roca. Presenta una silicificación penetrativa.

Descripción petrográfica: Dos grupos de muestras, APE1 y APE2 con textura costriforme de relleno de veta (calcedonia y ópalo) (Figuras A1.6 y A1.8). El segundo grupo (muestras APE 3, APE4 y APE5), se corresponde con una roca silicificada con textura de brecha (clastos o fragmentos + cemento) (Figuras A1.9 y A1.10). Clastos de ópalo o reemplazados por ópalo y cemento de calcedonia de grano fino y fibrosa.
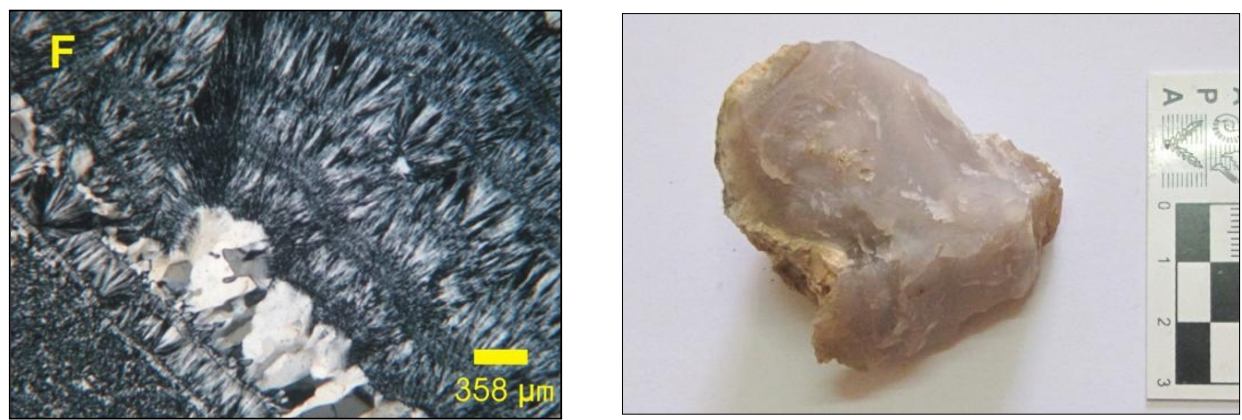

Figura A1.7. Muestra APE1. Segunda generación de venillas de calcedonia. Referencia: izquierda: microfotografía con luz polarizada; derecha: muestra de mano.
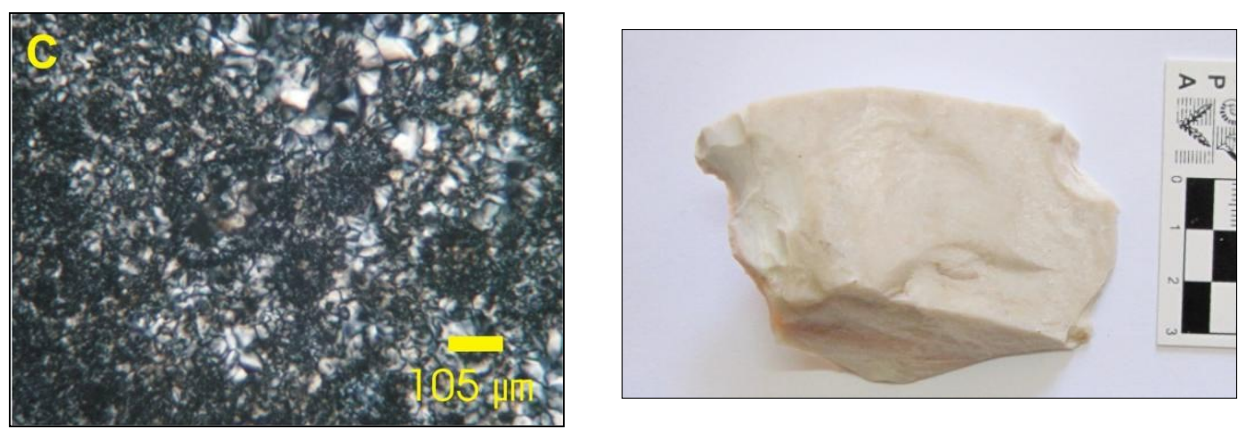
Figura A1.8. Muestra APE2. Calcedonia de grano fino. Referencia: izquierda: microfotografía con luz polarizada; derecha: muestra de mano.
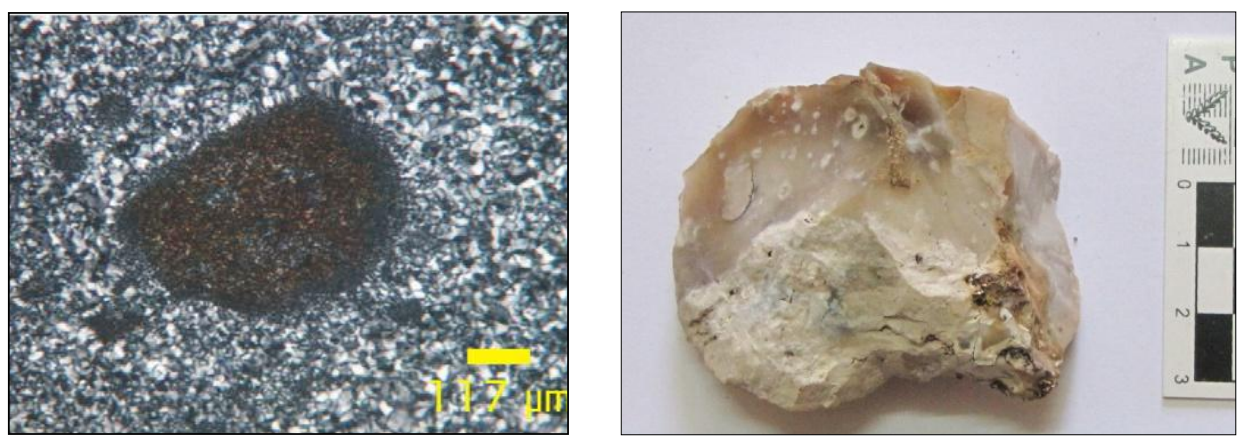

Figura A1.9. Muestra APE4. Textura de brecha, con fragmentos de ópalo, con textura en escarapela con bandas concéntricas de calcedonia que crecen alrededor. Referencia: izquierda: microfotografía con luz polarizada; derecha: muestra de mano.
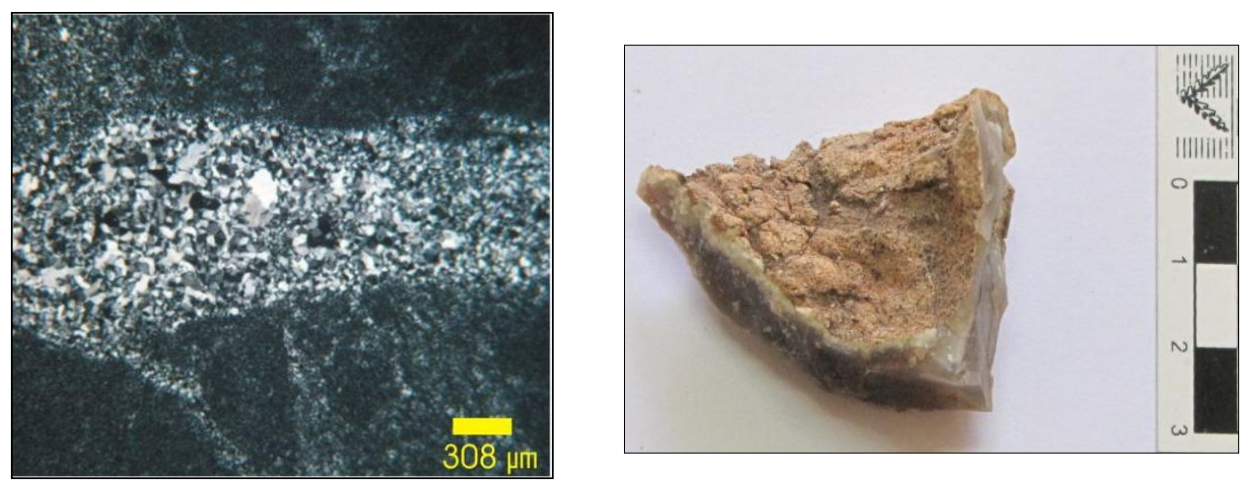

Figura A1.10. Muestra APE5. Textura de brecha, calcedonia de grano fino cementando clastos de ópalo. Referencia: izquierda: microfotografía con luz polarizada; derecha: muestra de mano.

\subsection{DESCRIPCIÓN GENERAL DE LAS MUESTRAS}

Los tres conjuntos de fuentes muestras corresponden a rocas con silicificación penetrativa, una parte de las muestras de APE tienen texturas típicas de una veta por lo que podrían tener ese tipo de yacencia.

\section{ARTEFACTOS ARQUEOLÓGICOS}

\subsection{LOCALIDAD LA PELIGROSA (LP)}


Muestra: LP2A1NE2

Sitio: La Peligrosa 2

Clase artefactual: Desecho de Talla.

Descripción macroscópica: color marrón y pasta homogénea.

Descripción petrográfica: la muestra se destruyo durante la realización del corte.

\section{Muestra: LP2A1NE5.3}

\section{Sitio: La Peligrosa 2}

Clase artefactual: Desecho de Talla.

Descripción macroscópica: Textura de brecha, color negro con clastos blancos y violetas.

Descripción petrográfica: Clastos de ópalo de bordes redondeados (o reemplazados por ópalo), cementados por calcedonia en venillas. Algunos poseen manchas negras y otros de color óxido de hierro. Los clastos de mayor tamaño tienen en su interior estructuras subcirculares en algunos casos delimitadas por óxidos de hierro. Escasos cristales (o cristaloclastos) de cuarzo.

Los clastos de líticos poseen cristales/cistaloclastos de cuarzo en matriz afanítica color pardo (pelítica). El clasto de mayor tamaño tiene $1,4 \mathrm{~mm}$ de diámetro y cristales de hasta $0,05 \mathrm{~mm}$. La roca original era probablemente una volcaniclástica (Figura A1.11).
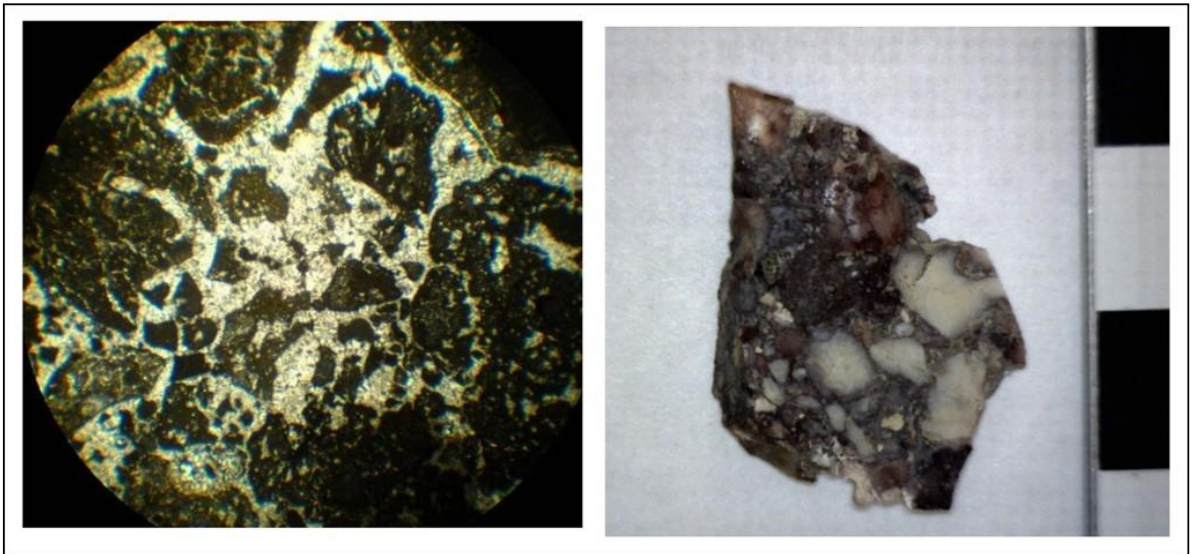

Figura A1.11. Muestra LP2A1NE5.3. Referencia: izquierda: microfotografía con luz polarizada, 10x; derecha: muestra de mano.

\section{Muestra: LP2A1NE5.2}

Sitio: La Peligrosa 2

Clase artefactual: Desecho de Talla. 
Descripción macroscópica: color rosado, de pasta heterogénea.

Descripción petrográfica: Silicificación de una roca sedimentaria (caliza bioclástica). El reemplazo está compuesto por cristales de cuarzo muy pequeños $(<0,01 \mathrm{~mm})$ llenando por completo las fisuras pequeñas o en el borde de las fisuras grandes y en los bordes de huecos irregulares. Sobre estos cristales de cuarzo, hacia el centro de las fisuras, se observa cuarzo calcedónico con textura llameante y en el centro de los espacios vacíos más grandes (> $2 \mathrm{~mm}$ ) se desarrolla un mosaico de cristales de cuarzo subhedrales de hasta 0,35mm con zonación incipiente (Figura A1.12 y A1.13).

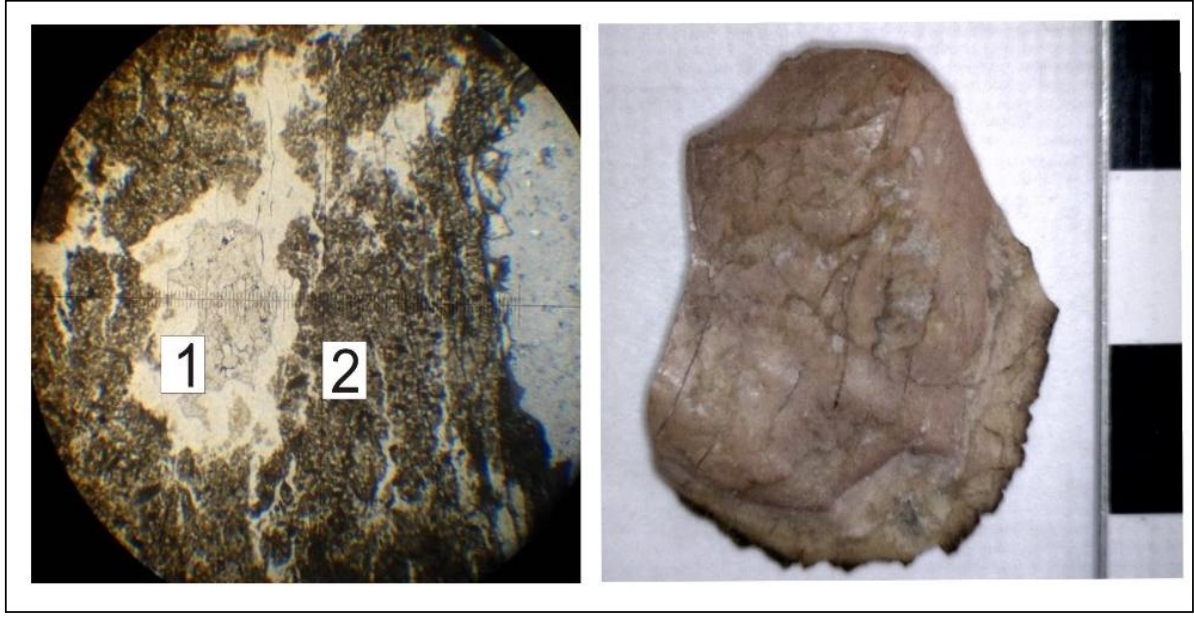

Figura A1.12. LP2A1NE5.2. Referencia: izquierda: microfotografía con luz polarizada, 10x. Derecha: muestra de mano.
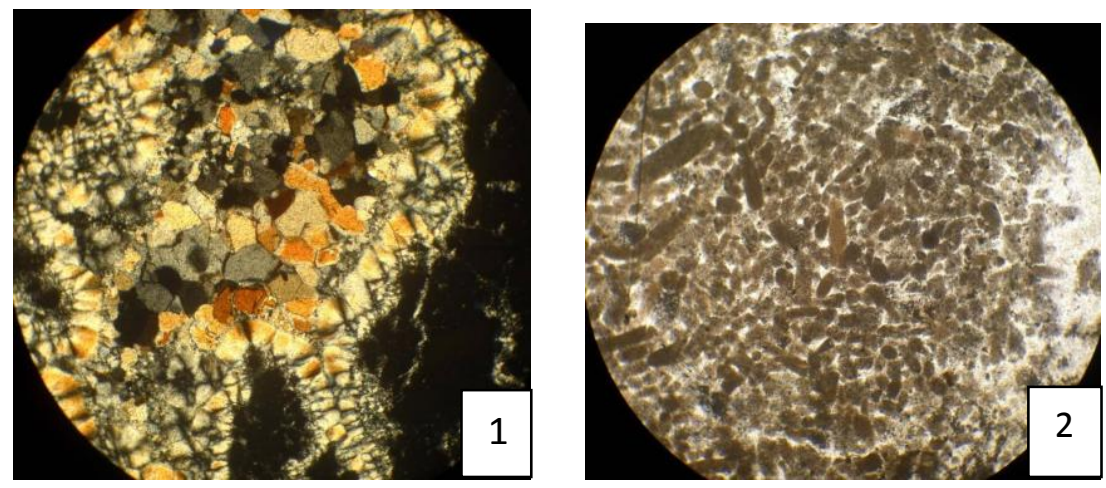

Figura A1.13. LP2A1NE5.2. Detalle de la zona 1 incolora: cristales de cuarzo con zonación incipiente (Luz polarizada, 63x). Detalle de la zona 2 (oscura). Estructuras orgánicas (posibles trozos de equinodermos) (Luz natural, 63x).

Muestra: LP2A1NE3.1

Sitio: La Peligrosa 2

Clase artefactual: Desecho de Talla. 
Descripción macroscópica: color blanco, pasta homogénea.

Descripción petrográfica: Calcedonia de grano fino con tamaño de grano menor o igual a 0,05mm. Presenta semicírculos con margen definido por una línea color óxido de hierro, rellenos con calcedonia plumosa y fibrosa-radiada (esta textura resulta de desvitrificación o de recristalización de un gel). Escasos opacos de hasta $0,03 \mathrm{~mm}$ (Figura A1.14).

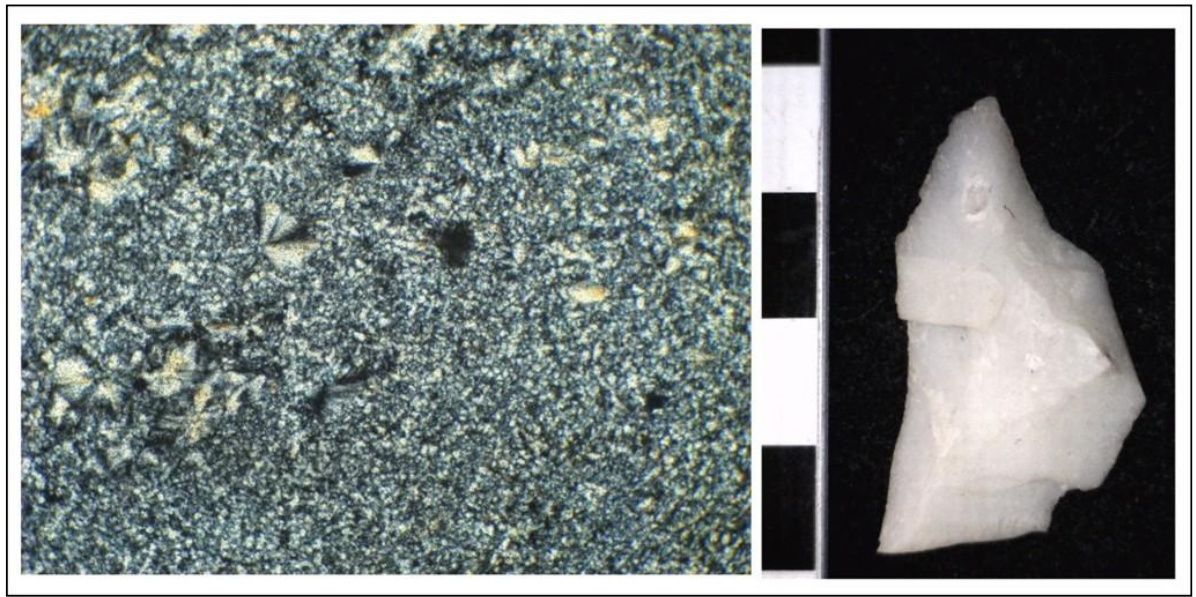

Figura A1.14. LP2A1NE3.1. Referencia: izquierda: microfotografía con luz polarizada, 63x. Derecha: muestra de mano.

Muestra: LP2A1NE3.2

Sitio: La Peligrosa 2

Clase artefactual: Desechos de Talla.

Descripción macroscópica: Textura de brecha, color gris traslucida.

Descripción petrográfica: clastos de calcedonia cementados por calcedonia de grano más fino. En la calcedonia de grano más fino (cemento), se observan sectores de contornos irregulares rellenos con calcedonia fibrosa. Se presenta un orificio de aspecto coloforme de más de $4 \mathrm{~mm}$ relleno con calcedonia fibrosa en los bordes y cuarzo en el sector central. Los cristales de cuarzo tienen hasta $0,4 \mathrm{~mm}$. Opacos aislados y agrupados en glomérulos de hasta 0,16mm (Figura A1.16). 


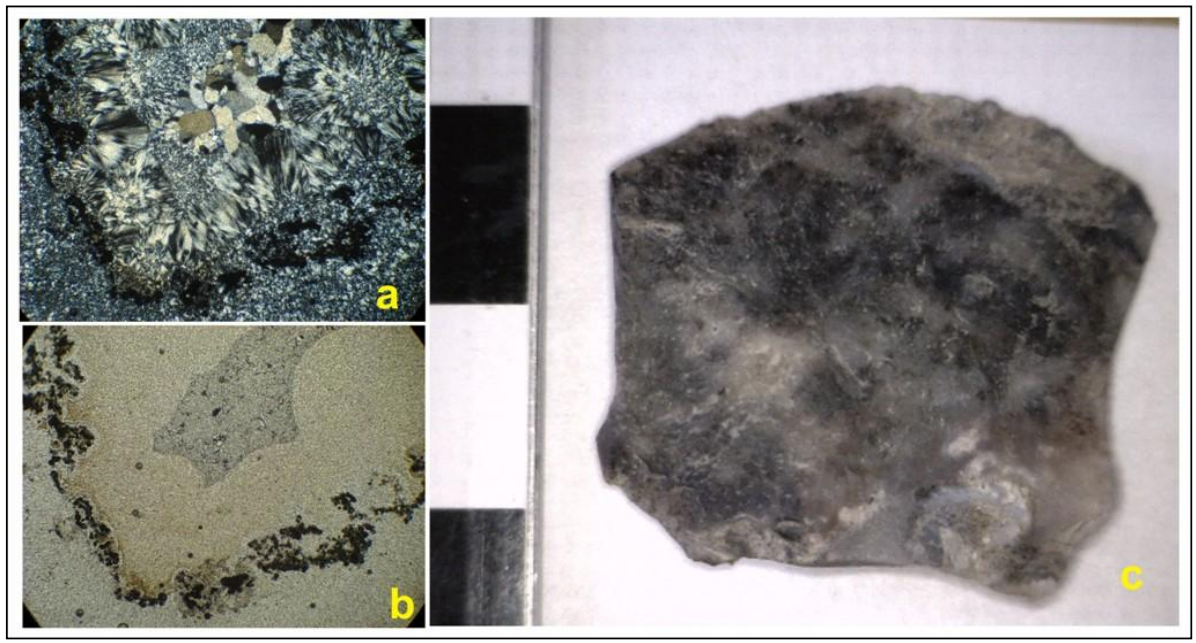

Figura A1.15. LP2A1NE3.2. Relleno coloforme de calcedonia fibrosa y cuarzo en el centro, microfotografía con luz polarizada, 63x (a) y luz natural, 63x (b). Detalle de muestra de mano (c).

\section{Muestra LP2A1NE5.1}

Sitio: La Peligrosa 2

Muestra: LP2A1NE5.1

Clase artefactual: Desecho de Talla.

Descripción macroscópica: Textura de "clastos" y matriz homogénea, color blanco rosado con inclusiones.

Descripción petrográfica: agregado de granos subesferoidales principalmente de ópalo y en menor medida de calcedonia. Entre los granos, e incluso rellenando varios de ellos, se dispone calcedonia fibrosa. Los orificios más grandes están rellenos por cuarzo en el sector central. Se presentan, aislados, cristaloclastos de cuarzo de hasta $0,5 \mathrm{~mm}$ (Figura A1.16).

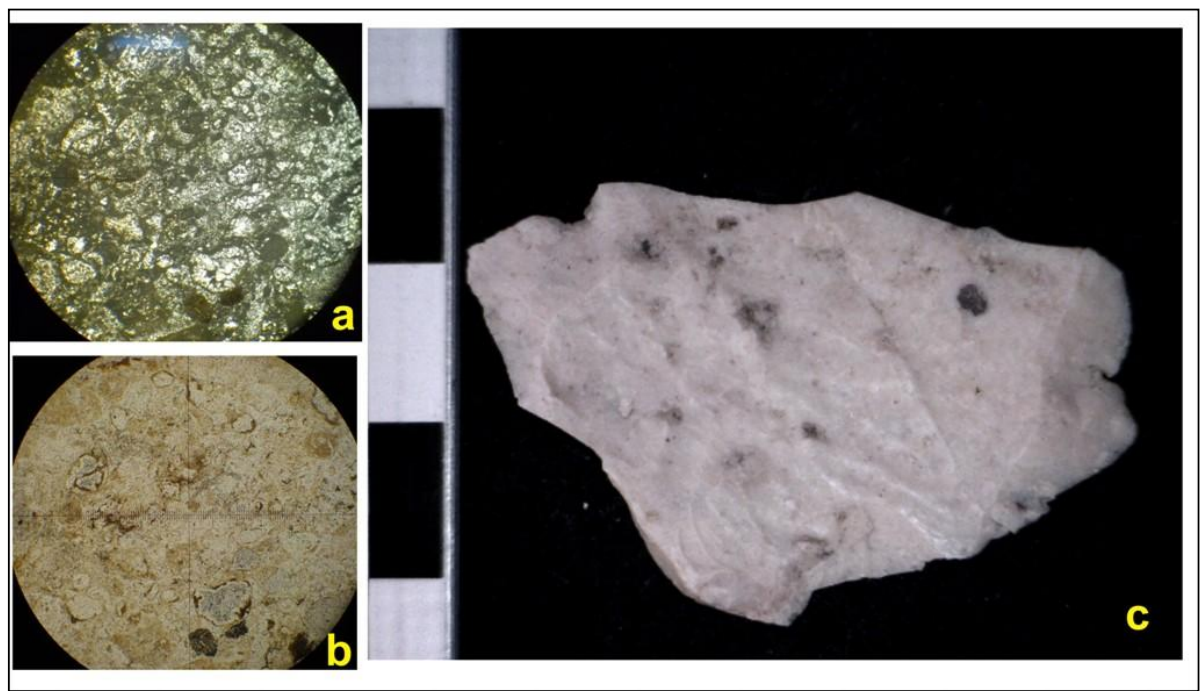


Figura A1.16. LP2A1NE5.1. microfotografía con luz polarizada(a) y natural (b), 63x. Detalle de muestra de mano (c).

\subsection{LOCALIDAD CARMONINA (CAR)}

\subsubsection{Sitio Carmonina 1 (CAR1)}

\section{Muestra CAR1S1-6}

Sitio: Carmonina 1

Muestra: CAR1S1-6

Clase artefactual: Desecho de Talla.

Descripción macroscópica: Textura de brecha, color gris translucida.

Descripción petrográfica: clastos redondeados de calcedonia de grano muy fino cementados por calcedonia de grano más grueso (grano de hasta $0,03 \mathrm{~mm}$ ). Tanto en los granos de calcedonia más fina como en el "cemento" calcedónico se desarrollaron espacios huecos elongados (en algunos casos contorneados por minerales opacos) y de contornos redondeados rellenos con cuarzo microcristalino anhedral y escasos cristales de cuarzo de mayor tamaño más calcita (secundaria). Todo el conjunto es atravesado por venillas aproximadamente paralelas rellenas por calcedonia en bandas (costriforme), los cristales forman textura en peine y en las venillas más finas textura en diente de perro por crecimiento enfrentado. Las venillas son tres, la más fina tiene hasta $0,11 \mathrm{~mm}$ de ancho, las otras dos son paralelas y están unidas en sectores con un ancho máximo de 0,17mm. En una porción del corte se observan pequeños clastos de calcedonia fina englobados por el "cemento" calcedónico y en otra parte predomina la calcedonia fina (Figura A1.17).

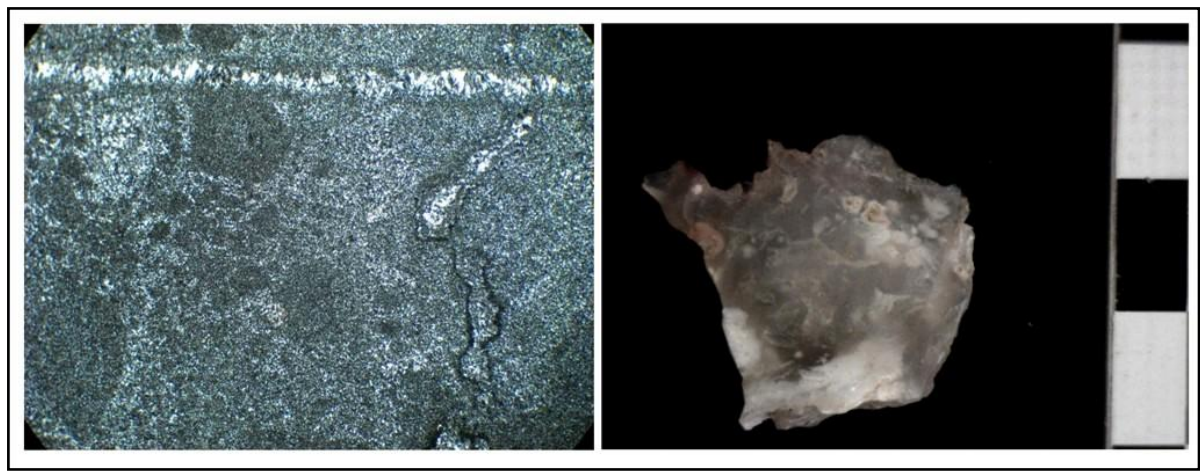

Figura A1.17. CAR1S1-6. Referencias: izquierda: microfotografía con luz polarizada, 63x. Derecha: muestra de mano.

Muestra CAR1S1-1.2 
Sitio: Carmonina 1

Muestra: CAR1S1-1.2

Clase artefactual: Desecho de Talla

Descripción macroscópica: Calcedonia masiva, color gris.

Descripción petrográfica: existen variaciones en el tamaño de grano de la calcedonia y en la morfología desarrollándose en algunos sectores cristales fibrosos. Se observan escasos clastos formados por calcedonia de grano más fino (Figura A1.18).

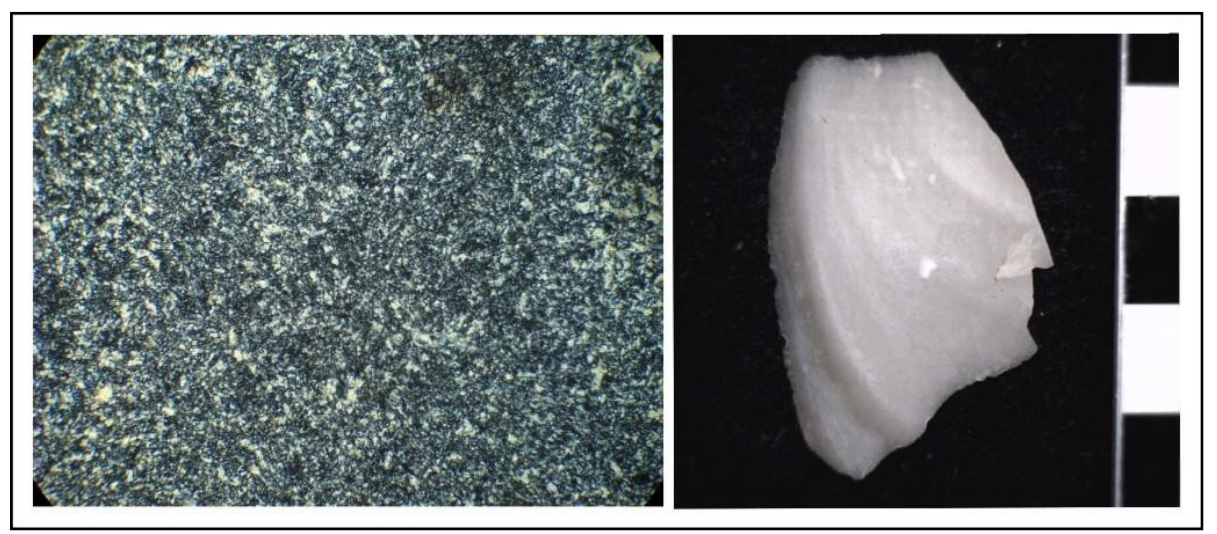

Figura A1.18. CAR1S1-1.2. Referencia: izquierda: microfotografía con luz polarizada, 63x. Derecha: muestra de mano.

\section{Muestra CAR1S1-1.1}

Sitio: Carmonina 1

Muestra: CARS1-1.1

Clase artefactual: Desecho de Talla.

Descripción macroscópica: Calcedonia masiva, color gris.

Descripción petrográfica: Calcedonia masiva de grano muy fino $(<0,03 \mathrm{~mm})$ cortada por venillas rellenas con calcedonia de grano más grueso.

\section{Muestra: CAR1S1-3}

Sitio: Carmonina1

Muestra: CAR1S1-3

Clase artefactual: Desecho de Talla.

Descripción macroscópica: Calcedonia masiva

Descripción petrográfica: Calcedonia casi completamente masiva con cristales anhedrales de hasta $0,1 \mathrm{~mm}$. Se observan pequeñas fracturas redondeadas en los márgenes rellenas con cuarzo de grano más fino y minerales opacos dispersos de grano muy fino (Figura A1.19). 


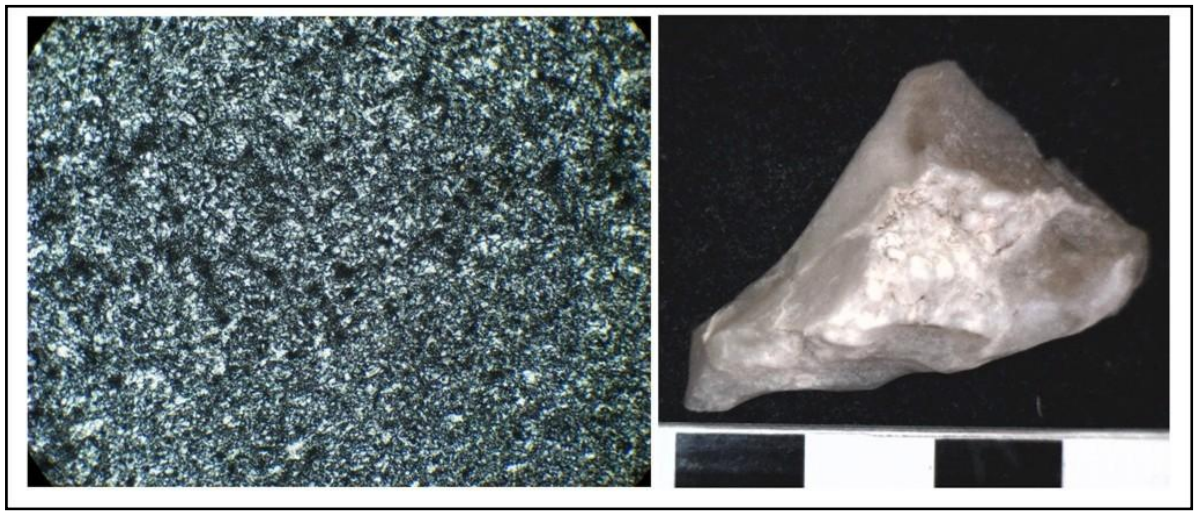

Figura A1.19. CARS1-3. Referencia: izquierda: microfotografía con luz polarizada, 63x. Derecha: muestra de mano.

\section{Muestra: CAR1S1-0}

Sitio: Carmonina 1

Muestra: CARS1-0

Clase artefactual: Desecho de Talla

Descripción macroscópica: Calcedonia masiva, color gris y blanco.

Descripción petrográfica: Calcedonia masiva con cristales de hasta $0,02 \mathrm{~mm}$ y pequeñas variaciones de tamaño. Se presenta un orificio subcircular relleno con grano algo más grueso de hasta $0,06 \mathrm{~mm}$. Se observan débiles bandeamientos (Figura A1.20).

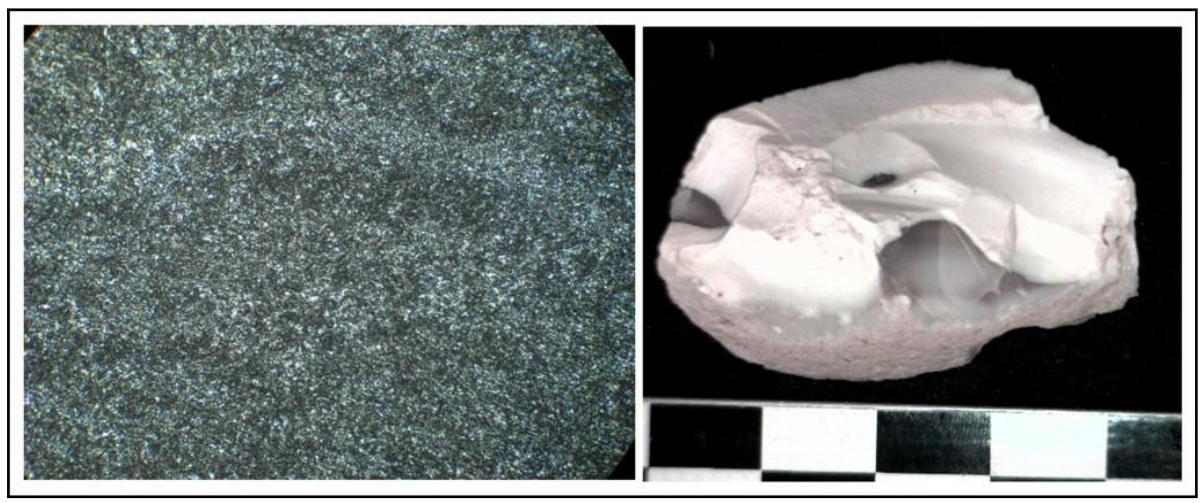

Figura A1.20. CAR1S1-0. Referencia: izquierda: microfotografía con luz polarizada, 63x. Derecha: muestra de mano.

\subsubsection{Sitio Pista}


Sitio: Pista

Muestra: PistaTR2-3.6

Clase artefactual: Núcleo.

Descripción macroscópica: Textura de brecha, color pardo y negro.

Descripción petrográfica: Calcedonia con brechamiento en algunos sectores y cementada por ópalo. Todo cortado por escasas venillas de hasta $0,04 \mathrm{~mm}$ de ancho rellenas con cristales de cuarzo anhedrales del mismo tamaño que las venillas $(0,04 \mathrm{~mm})$._Presencia de granos de hasta $0,16 \mathrm{~mm}$ de hematita (reemplazando pseudomórficamente a ¿pirita?) (Figura A1.21).

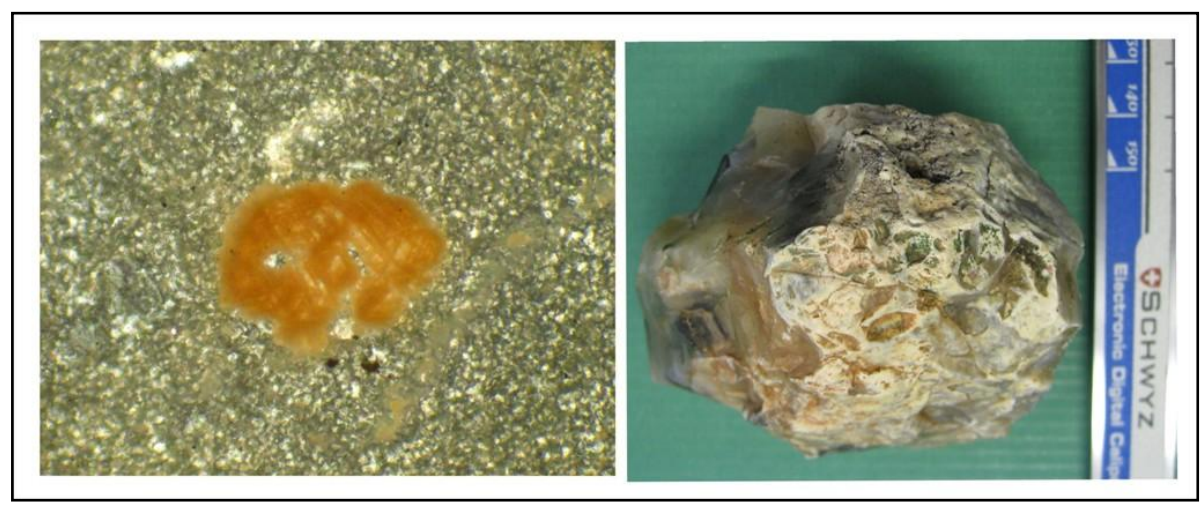

Figura A1.21. PistaTR2-3.6. Referencia: izquierda: microfotografía con luz polarizada, 63x. Derecha: muestra de mano.

\section{Muestra: PistaTR2-3.2}

Sitio: Pista

Muestra: PistaTR2-3.2

Clase artefactual: Nódulo natural.

Descripción macroscópica: Calcedonia masiva, color negro.

Descripción petrográfica: Calcedonia masiva incolora la que en sectores muestra color pardo claro. Está atravesada por escasas venillas rellenas de calcedonia de grano algo más grueso y límpida (incolora). Se presentan escasos minerales opacos con el margen oxidado de hasta $0,2 \mathrm{~mm}$ y minerales opacos menores a $0,02 \mathrm{~mm}$ dentro de las venillas (Figura A1.22). 


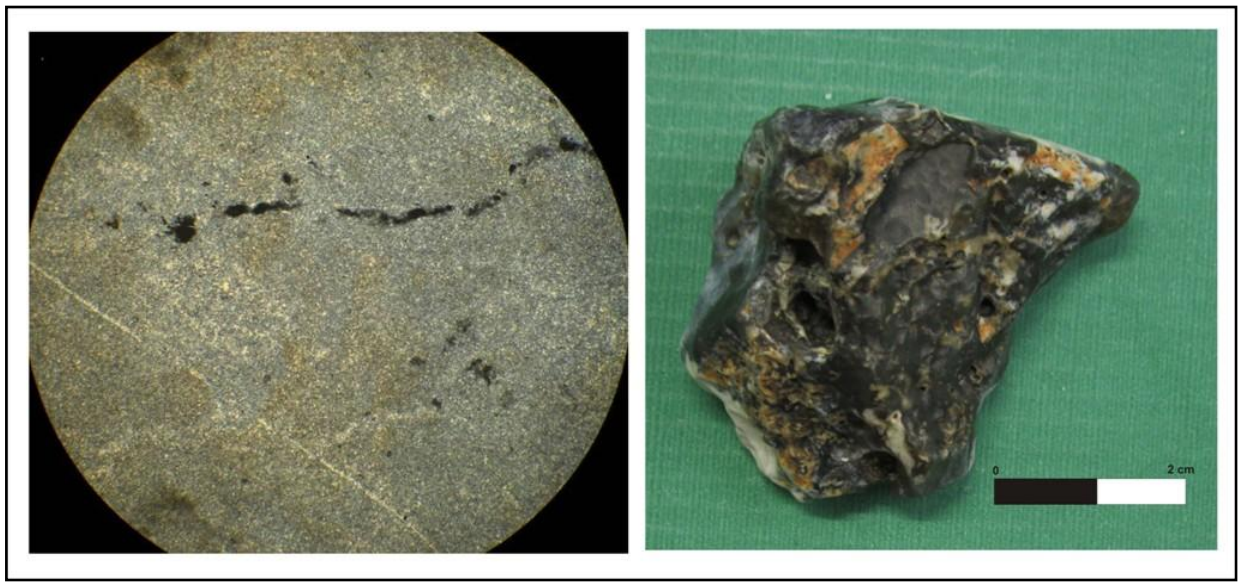

Figura A1.22. PistaTR2-3.2. Referencia: izquierda: microfotografía con luz polarizada, 63x. Derecha: muestra de mano.

\section{Muestra: PistaTR2-3.4}

Sitio: Pista

Muestra: PistaTR2-3.4

Clase artefactual: Fragmento natural.

Descripción macroscópica: Textura bandeada, color blanco y gris.

Descripción petrográfica: Este bandeamiento es visible al microscopio sin analizador. Con analizador se observa calcedonia en mosaico. En algunas bandas se desarrolla un agregado de granos esferoidales contorneados por "impurezas" similar a la textura "Moss", la cual indica precipitación a partir de un gel silíceo (Figura 6.18).

\section{Muestra: PistaTR2-2.3}

Sitio: Pista

Muestra: PistaTR2-2.3

Clase artefactual:

Descripción macroscópica: Calcedonia fibrosa, color pardo.

Descripción petrográfica: Es frecuente la textura microplumosa y en algunos sectores se desarrolla textura costriforme/coloforme (Figura A1.23). 


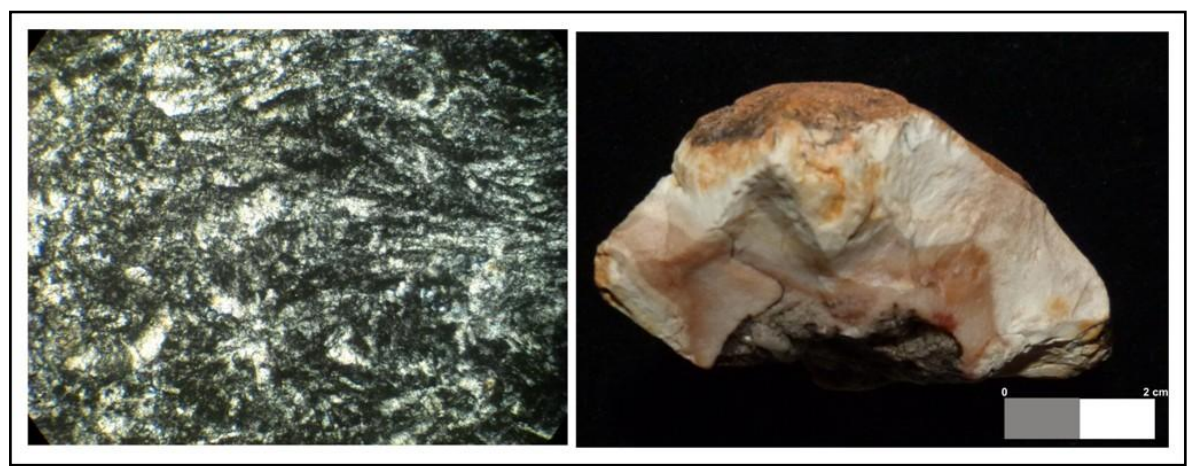

Figura A1.23. PistaTR2-2.3. Referencia: izquierda: microfotografía con luz polarizada, 63x. Derecha: muestra de mano.

2.3 LOCALIDAD AGUA DE PÉREZ (APE)

2.3.1 Sitio Agua de Pérez 1 (APE-1)

Muestra: APE1-2

Sitio: APE-1

Muestra: APE1-2

Clase artefactual: Desecho de Talla.

Descripción macroscópica: Calcedonia masiva.

Descripción petrográfica: Con luz natural se observa un bandeamiento muy débil.

Escasos minerales opacos aislados de hasta 0,15mm (Figura A1.24).

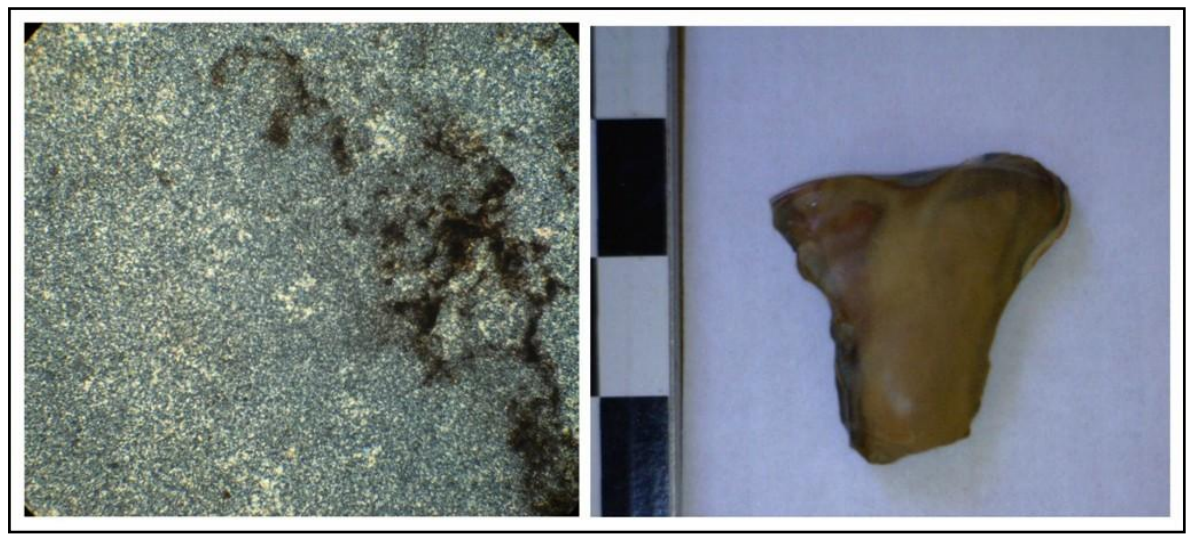

Figura A1.24. APE1-2. Referencia: izquierda: microfotografía con luz polarizada, 63x. Derecha: muestra de mano. 
Sitio: APE-1

Muestra: APE1-3

Clase artefactual: Desecho de Talla.

Descripción macroscópica: Calcedonia masiva, color blanco con bandas grises.

Descripción petrográfica: Clastos subredondeados de calcedonia (cristales de $<0.08 \mathrm{~mm}$ ) cementados por venillas de ópalo. Estas venillas tienen un ancho de 0,2 a $0,6 \mathrm{~mm}$, las mayores tienen relleno de ópalo en bordes y calcedonia en el sector central._Algunos clastos de calcedonia están formados por un agregado de granos delimitados por opacos/arcilla, estos granos tienen relleno de calcedonia con extinción radiada formando textura esferulítica, la cual resulta de la desvitrificación o recristalización de un gel (Figura A1.25).

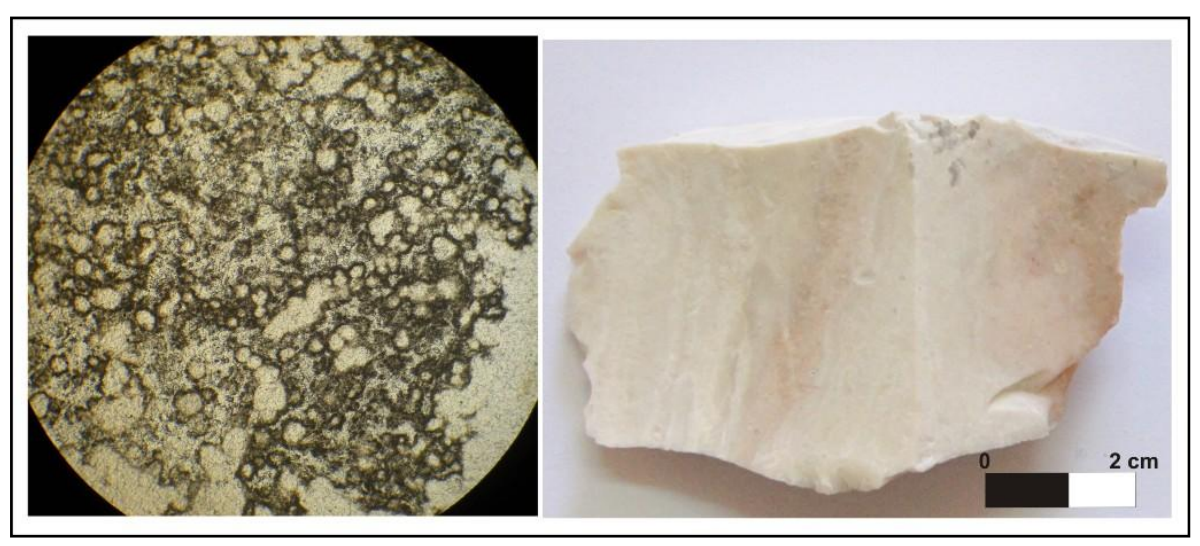

Figura A1.25. APE1-3. Referencia: izquierda: microfotografía con luz natural, 63x. Agregado de granos delimitados por opacos/arcilla con relleno de calcedonia con extinción radiada, textura esferulítica. Derecha: muestra de mano.

\subsection{DESCRIPCIÓN GENERAL DE LAS MUESTRAS}

En general la silicificación afectó rocas sedimentarias (p. ej. Muestra con trozos de equinodermos) más volcaniclásticas (p.ej. Muestras con cristaloclastos de cuarzo y clastos o minerales reemplazados). 


\section{ANEXO 2}

\section{ANÁLISIS GEOQUÍMICOS}

\section{Resultados de los análisis geoquímicos de artefactos de obsidiana de La Payunia.}

\begin{tabular}{|c|c|c|c|c|c|c|c|c|c|c|c|c|c|c|c|}
\hline Sitio & Código & Contexto & $\begin{array}{c}\text { Clase } \\
\text { Artefactual } \\
\end{array}$ & Procedencia & $\mathrm{K}$ & $\mathrm{Ti}$ & $\mathrm{Mn}$ & $\mathrm{Fe}$ & $\mathrm{Zn}$ & Ga & $\mathbf{R b}$ & $\mathrm{Sr}$ & $\mathrm{Y}$ & $\mathrm{Zr}$ & $\mathbf{N b}$ \\
\hline Alpa Este & MMPA06 & Superficial & AF Unifacial & $\begin{array}{c}\text { Cueva del } \\
\text { Huenul }\end{array}$ & 30862,0 & $\begin{array}{l}769 \\
9\end{array}$ & $\begin{array}{l}627 \\
8\end{array}$ & $\begin{array}{l}5253, \\
8\end{array}$ & $\begin{array}{l}29 \\
3\end{array}$ & $\begin{array}{l}11 \\
3\end{array}$ & $\begin{array}{l}102 \\
, 1\end{array}$ & $\begin{array}{l}105 \\
, 7\end{array}$ & $\begin{array}{l}15, \\
8\end{array}$ & $\begin{array}{l}55, \\
1\end{array}$ & $\begin{array}{l}7 \\
6\end{array}$ \\
\hline Alpa Este & MMPA07 & Superficial & DT & $\begin{array}{c}\text { Cueva del } \\
\text { Huenul }\end{array}$ & 32310,1 & $\begin{array}{l}789 \\
7\end{array}$ & $\begin{array}{l}590 \\
7\end{array}$ & $\begin{array}{l}5411, \\
4\end{array}$ & $\begin{array}{l}26, \\
0\end{array}$ & \begin{tabular}{|l|}
12 \\
1
\end{tabular} & $\begin{array}{l}100 \\
, 2\end{array}$ & $\begin{array}{l}114 \\
, 7\end{array}$ & $\begin{array}{l}15, \\
2\end{array}$ & $\begin{array}{l}58, \\
8\end{array}$ & $\begin{array}{l}9 \\
4\end{array}$ \\
\hline Alpa Este & MMPA08 & Superficial & DT & $\begin{array}{c}\text { Laguna del } \\
\text { Maule-1 }\end{array}$ & 34867,5 & $\begin{array}{l}113 \\
5,3\end{array}$ & $\begin{array}{l}539 \\
2\end{array}$ & $\begin{array}{l}7750, \\
7\end{array}$ & $\begin{array}{l}64, \\
0\end{array}$ & $\begin{array}{l}13 \\
9\end{array}$ & $\begin{array}{l}161 \\
8\end{array}$ & \begin{tabular}{l|}
120 \\
, 7
\end{tabular} & $\begin{array}{l}24, \\
5\end{array}$ & $\begin{array}{l}186 \\
, 6\end{array}$ & $\begin{array}{l}13 \\
4\end{array}$ \\
\hline Alpa Este & MMPA09 & Superficial & AF Unifacial & Unassigned & 38037,6 & $\begin{array}{l}321 \\
9,8 \\
\end{array}$ & $\begin{array}{l}796, \\
5\end{array}$ & $\begin{array}{l}1836 \\
7,5 \\
\end{array}$ & \begin{tabular}{l|}
191 \\
0
\end{tabular} & 4,8 & $\begin{array}{l}134 \\
, 2\end{array}$ & $\begin{array}{l}486 \\
, 5\end{array}$ & $\begin{array}{l}27, \\
1\end{array}$ & $\begin{array}{l}667 \\
, 9\end{array}$ & $\begin{array}{l}18 \\
, 3\end{array}$ \\
\hline Alpa Este & MAEA01 & Superficial & DT & $\begin{array}{l}\text { Laguna del } \\
\text { Maule }\end{array}$ & 35875,0 & $\begin{array}{l}964 \\
8\end{array}$ & $\begin{array}{l}294 \\
5\end{array}$ & $\begin{array}{l}6637, \\
9\end{array}$ & $\begin{array}{l}34 \\
7\end{array}$ & $\begin{array}{l}13 \\
1\end{array}$ & $\begin{array}{l}172 \\
, 7\end{array}$ & $\begin{array}{l}95 \\
8\end{array}$ & $\begin{array}{l}18, \\
4\end{array}$ & $\begin{array}{l}136 \\
, 3\end{array}$ & $\begin{array}{l}9 \\
2 \\
\end{array}$ \\
\hline Alpa Este & MAEA02 & Superficial & DT & $\begin{array}{c}\text { Cueva del } \\
\text { Huenul }\end{array}$ & 36306,2 & $\begin{array}{l}927, \\
3\end{array}$ & $\begin{array}{l}579 \\
1\end{array}$ & $\begin{array}{l}6504, \\
3\end{array}$ & $\begin{array}{l}30 \\
6\end{array}$ & \begin{tabular}{l|}
15 \\
6
\end{tabular} & $\begin{array}{l}126 \\
3\end{array}$ & $\begin{array}{l}107 \\
, 3\end{array}$ & $\begin{array}{l}10, \\
1\end{array}$ & $\begin{array}{l}84, \\
9\end{array}$ & $\begin{array}{l}12 \\
, 7\end{array}$ \\
\hline Alpa Este & MAEA03 & Superficial & DT & unknown & 40933,9 & \begin{tabular}{|l|}
131 \\
8,4 \\
\end{tabular} & $\begin{array}{l}846 \\
8 \\
\end{array}$ & \begin{tabular}{|l}
8814, \\
4 \\
\end{tabular} & \begin{tabular}{|l}
53, \\
2 \\
\end{tabular} & \begin{tabular}{|l|}
20 \\
5 \\
\end{tabular} & $\begin{array}{l}152 \\
, 0 \\
\end{array}$ & \begin{tabular}{|l|}
121 \\
1 \\
\end{tabular} & $\begin{array}{l}13, \\
6 \\
\end{array}$ & $\begin{array}{l}109 \\
, 4 \\
\end{array}$ & $\begin{array}{l}16 \\
7 \\
\end{array}$ \\
\hline Alpa Este & MAET01 & Superficial & DT & $\begin{array}{l}\text { Laguna del } \\
\text { Maule }\end{array}$ & 39554,8 & $\begin{array}{l}112 \\
2,1\end{array}$ & $\begin{array}{l}338 \\
8\end{array}$ & \begin{tabular}{|l}
8274 \\
6 \\
\end{tabular} & $\begin{array}{l}37 \\
2 \\
\end{array}$ & $\begin{array}{l}16, \\
2\end{array}$ & $\begin{array}{l}193 \\
1\end{array}$ & $\begin{array}{l}105 \\
, 5 \\
\end{array}$ & $\begin{array}{l}20, \\
7\end{array}$ & $\begin{array}{l}154 \\
, 0\end{array}$ & $\begin{array}{l}11 \\
6 \\
\end{array}$ \\
\hline Alpa Este & MAET02 & Superficial & DT & Cerro Huenul & 30977,1 & \begin{tabular}{|l}
540, \\
0 \\
\end{tabular} & $\begin{array}{l}458, \\
3 \\
\end{array}$ & \begin{tabular}{|l}
5044, \\
5 \\
\end{tabular} & $\begin{array}{l}28, \\
0 \\
\end{array}$ & \begin{tabular}{l|}
11, \\
6 \\
\end{tabular} & $\begin{array}{l}105 \\
, 5 \\
\end{array}$ & $\begin{array}{l}101 \\
0 \\
\end{array}$ & 9,9 & $\begin{array}{l}73, \\
1 \\
\end{array}$ & $\begin{array}{l}10 \\
, 5 \\
\end{array}$ \\
\hline Alpa Este & MAET03 & Superficial & DT & Cerro Huenul & 32750,8 & $\begin{array}{l}592 \\
4\end{array}$ & $\begin{array}{l}423 \\
8 \\
\end{array}$ & $\begin{array}{l}5234, \\
8 \\
\end{array}$ & $\begin{array}{l}25, \\
9 \\
\end{array}$ & \begin{tabular}{|l|}
13 \\
2 \\
\end{tabular} & $\begin{array}{l}107 \\
6\end{array}$ & $\begin{array}{l}108 \\
1 \\
\end{array}$ & $\begin{array}{l}12, \\
9\end{array}$ & $\begin{array}{l}78, \\
1\end{array}$ & $\begin{array}{l}14 \\
0 \\
\end{array}$ \\
\hline Alpa Este & MAET04 & Superficial & DT & $\begin{array}{c}\text { Laguna del } \\
\text { Maule }\end{array}$ & 33799,6 & \begin{tabular}{|l|}
960 \\
8 \\
\end{tabular} & $\begin{array}{l}443 \\
3 \\
\end{array}$ & \begin{tabular}{|l}
7381, \\
7 \\
\end{tabular} & $\begin{array}{l}46, \\
6 \\
\end{array}$ & \begin{tabular}{|l|}
14, \\
0 \\
\end{tabular} & $\begin{array}{l}168 \\
, 2\end{array}$ & \begin{tabular}{|l|}
116 \\
6 \\
\end{tabular} & $\begin{array}{l}20, \\
7\end{array}$ & $\begin{array}{l}185 \\
, 1\end{array}$ & $\begin{array}{l}11 \\
0 \\
\end{array}$ \\
\hline Alpa Este & MAET05 & Superficial & DT & Cerro Huenul & 34739,8 & \begin{tabular}{|l|}
889 \\
8 \\
\end{tabular} & $\begin{array}{l}488 \\
3 \\
\end{array}$ & $\begin{array}{l}5906, \\
8 \\
\end{array}$ & \begin{tabular}{|l|}
29 \\
7 \\
\end{tabular} & $\begin{array}{l}14, \\
2\end{array}$ & $\begin{array}{l}114 \\
, 6\end{array}$ & $\begin{array}{l}112 \\
, 3\end{array}$ & $\begin{array}{l}12, \\
3\end{array}$ & $\begin{array}{l}83, \\
4\end{array}$ & $\begin{array}{l}17 \\
0\end{array}$ \\
\hline Alpa Este & MAET06 & Superficial & DT & Cerro Huenul & 31688,4 & $\begin{array}{l}850 \\
0\end{array}$ & $\begin{array}{l}538 \\
1\end{array}$ & \begin{tabular}{|l}
5560, \\
1 \\
\end{tabular} & $\begin{array}{l}27, \\
3\end{array}$ & \begin{tabular}{|l|}
12 \\
4
\end{tabular} & $\begin{array}{l}112 \\
, 7\end{array}$ & $\begin{array}{l}107 \\
, 7\end{array}$ & $\begin{array}{l}16, \\
2\end{array}$ & $\begin{array}{l}94, \\
2\end{array}$ & $\begin{array}{l}18 \\
, 7\end{array}$ \\
\hline Alpa Este & MAET07 & Superficial & DT & Cerro Huenul & 39572,0 & $\begin{array}{l}147 \\
2,2 \\
\end{array}$ & $\begin{array}{l}700, \\
2 \\
\end{array}$ & \begin{tabular}{|l}
9493, \\
2 \\
\end{tabular} & \begin{tabular}{|l}
39 \\
3 \\
\end{tabular} & \begin{tabular}{|l|}
18 \\
3 \\
\end{tabular} & $\begin{array}{l}137 \\
, 4 \\
\end{array}$ & \begin{tabular}{|l|}
124 \\
, 4 \\
\end{tabular} & $\begin{array}{l}11, \\
8\end{array}$ & $\begin{array}{l}99, \\
4 \\
\end{array}$ & $\begin{array}{l}16 \\
, 5 \\
\end{array}$ \\
\hline Alpa Este & MAEJ02 & Superficial & AF Bifacial & $\begin{array}{l}\text { Laguna del } \\
\text { Maule }\end{array}$ & 33999,5 & \begin{tabular}{|l|}
865 \\
5 \\
\end{tabular} & $\begin{array}{l}336 \\
8 \\
\end{array}$ & \begin{tabular}{|l}
6504, \\
2 \\
\end{tabular} & \begin{tabular}{|l|}
37, \\
0 \\
\end{tabular} & \begin{tabular}{|l|}
12 \\
3 \\
\end{tabular} & $\begin{array}{l}145 \\
1\end{array}$ & $\begin{array}{l}81 \\
7 \\
\end{array}$ & $\begin{array}{l}16, \\
9\end{array}$ & $\begin{array}{l}143 \\
, 6\end{array}$ & $\begin{array}{l}9 \\
5 \\
\end{array}$ \\
\hline Alpa Este & MALE01 & Superficial & AF Bifacial & Las Cargas & 31110,3 & \begin{tabular}{|l}
768 \\
8 \\
\end{tabular} & $\begin{array}{l}609 \\
7 \\
\end{array}$ & \begin{tabular}{|l}
8732, \\
8 \\
\end{tabular} & \begin{tabular}{|l}
38 \\
4 \\
\end{tabular} & \begin{tabular}{|l|}
14 \\
3 \\
\end{tabular} & $\begin{array}{l}114 \\
, 1 \\
\end{array}$ & $\begin{array}{l}215 \\
6 \\
\end{array}$ & $\begin{array}{l}15, \\
0\end{array}$ & $\begin{array}{l}140 \\
, 8\end{array}$ & $\begin{array}{l}10 \\
7 \\
\end{array}$ \\
\hline Alpa Este & MAEJ01 & Superficial & AF Bifacial & $\begin{array}{c}\text { Laguna del } \\
\text { Maule }\end{array}$ & 35589,7 & $\begin{array}{l}841 \\
5\end{array}$ & $\begin{array}{l}349 \\
5\end{array}$ & $\begin{array}{l}6915, \\
4\end{array}$ & $\begin{array}{l}39, \\
2\end{array}$ & \begin{tabular}{l|}
14 \\
4
\end{tabular} & $\begin{array}{l}163 \\
, 0\end{array}$ & $\begin{array}{l}93 \\
5\end{array}$ & $\begin{array}{l}18, \\
8\end{array}$ & $\begin{array}{l}156 \\
, 6\end{array}$ & $\begin{array}{l}10 \\
0\end{array}$ \\
\hline $\begin{array}{c}\text { Cueva } \\
\text { Delerma }\end{array}$ & MMPA01 & $\begin{array}{c}\text { Estratigráfi } \\
\text { co }\end{array}$ & DT & $\begin{array}{c}\text { Laguna del } \\
\text { Maule-2 }\end{array}$ & 37465,8 & \begin{tabular}{|l|}
928 \\
6 \\
\end{tabular} & \begin{tabular}{|l}
471 \\
4 \\
\end{tabular} & \begin{tabular}{|l}
6690, \\
7 \\
\end{tabular} & \begin{tabular}{|l}
36 \\
3 \\
\end{tabular} & \begin{tabular}{|l|}
16 \\
3 \\
\end{tabular} & $\begin{array}{l}174 \\
, 5 \\
\end{array}$ & \begin{tabular}{|l|}
93 \\
2 \\
\end{tabular} & $\begin{array}{l}23, \\
4 \\
\end{array}$ & $\begin{array}{l}133 \\
, 0\end{array}$ & $\begin{array}{l}12 \\
0 \\
\end{array}$ \\
\hline $\begin{array}{c}\text { La } \\
\text { Carmonin } \\
a\end{array}$ & MLAC01 & $\begin{array}{c}\text { Estratigráfi } \\
\text { co }\end{array}$ & DT & $\begin{array}{l}\text { Laguna del } \\
\text { Maule }\end{array}$ & 36473,1 & $\begin{array}{l}781 \\
8\end{array}$ & $\begin{array}{l}303 \\
3\end{array}$ & $\begin{array}{l}6751 \\
1\end{array}$ & $\begin{array}{l}32 \\
4\end{array}$ & $\begin{array}{l}14, \\
7\end{array}$ & $\begin{array}{l}173 \\
, 4\end{array}$ & $\begin{array}{l}95, \\
0\end{array}$ & $\begin{array}{l}18, \\
9\end{array}$ & $\begin{array}{l}139 \\
, 3\end{array}$ & $\begin{array}{l}10 \\
9\end{array}$ \\
\hline $\begin{array}{c}\text { La } \\
\text { Peligrosa }\end{array}$ & MMPA03 & $\begin{array}{c}\text { Estratigráfi } \\
\text { co }\end{array}$ & DT & $\begin{array}{c}\text { Laguna del } \\
\text { Maule-1 }\end{array}$ & 33274,9 & $\begin{array}{l}106 \\
4,0\end{array}$ & $\begin{array}{l}512 \\
3\end{array}$ & \begin{tabular}{|l}
7206, \\
7 \\
\end{tabular} & $\begin{array}{l}63, \\
0\end{array}$ & $\begin{array}{l}13 \\
2\end{array}$ & $\begin{array}{l}158 \\
, 1\end{array}$ & $\begin{array}{l}105 \\
, 2\end{array}$ & $\begin{array}{l}22, \\
4\end{array}$ & $\begin{array}{l}163 \\
, 3\end{array}$ & $\begin{array}{l}13 \\
6 \\
\end{array}$ \\
\hline $\begin{array}{c}\text { La } \\
\text { Peligrosa }\end{array}$ & MMPA04 & $\begin{array}{c}\text { Estratigráfi } \\
\text { co }\end{array}$ & AF Bifacial & $\begin{array}{c}\text { Laguna del } \\
\text { Maule-1 }\end{array}$ & 33812,1 & \begin{tabular}{|l|}
107 \\
4,6 \\
\end{tabular} & $\begin{array}{l}527 \\
4 \\
\end{array}$ & \begin{tabular}{|l}
7299, \\
5 \\
\end{tabular} & \begin{tabular}{|l|}
62 \\
1 \\
\end{tabular} & \begin{tabular}{|l|}
13 \\
4
\end{tabular} & $\begin{array}{l}155 \\
8\end{array}$ & $\begin{array}{l}109 \\
, 3 \\
\end{array}$ & $\begin{array}{l}21, \\
2\end{array}$ & $\begin{array}{l}165 \\
, 5\end{array}$ & $\begin{array}{l}12 \\
, 3 \\
\end{array}$ \\
\hline $\begin{array}{c}\text { La } \\
\text { Peligrosa }\end{array}$ & MMPA05 & $\begin{array}{c}\text { Estratigráfi } \\
\text { co }\end{array}$ & AF Bifacial & $\begin{array}{c}\text { Laguna del } \\
\text { Maule-1 }\end{array}$ & 35227,9 & \begin{tabular}{|l|}
124 \\
3,7 \\
\end{tabular} & $\begin{array}{l}554 \\
3 \\
\end{array}$ & \begin{tabular}{|l}
8493, \\
9 \\
\end{tabular} & \begin{tabular}{|l|}
73, \\
0 \\
\end{tabular} & 13 & $\begin{array}{l}165 \\
, 6\end{array}$ & \begin{tabular}{|l|}
133 \\
4 \\
\end{tabular} & $\begin{array}{l}24, \\
5\end{array}$ & $\begin{array}{l}200 \\
, 5\end{array}$ & $\begin{array}{l}13 \\
, 2 \\
\end{array}$ \\
\hline $\begin{array}{c}\text { La } \\
\text { Peligrosa } \\
\end{array}$ & MLPE01 & $\begin{array}{c}\text { Estratigráfi } \\
\text { co }\end{array}$ & DT & El Peceno-2 & 34410,6 & \begin{tabular}{|l|}
218 \\
2,1 \\
\end{tabular} & $\begin{array}{l}872 \\
7 \\
\end{array}$ & \begin{tabular}{|l}
7109, \\
0 \\
\end{tabular} & \begin{tabular}{|l|}
67 \\
5 \\
\end{tabular} & $\begin{array}{l}20, \\
7 \\
\end{array}$ & $\begin{array}{l}273 \\
, 5 \\
\end{array}$ & \begin{tabular}{|l|}
336 \\
6 \\
\end{tabular} & $\begin{array}{l}10, \\
0\end{array}$ & $\begin{array}{l}173 \\
, 9\end{array}$ & $\begin{array}{l}21 \\
2 \\
\end{array}$ \\
\hline $\begin{array}{c}\text { La } \\
\text { Peligrosa }\end{array}$ & MLPE02 & $\begin{array}{c}\text { Estratigráfi } \\
\text { co }\end{array}$ & DT & El Peceno-2 & 41019,3 & \begin{tabular}{|l|}
263 \\
5,1
\end{tabular} & $\begin{array}{l}119 \\
1,0\end{array}$ & \begin{tabular}{|l}
9842, \\
7 \\
\end{tabular} & $\begin{array}{l}90 \\
9 \\
\end{array}$ & \begin{tabular}{|l|}
30, \\
2
\end{tabular} & $\begin{array}{l}308 \\
, 4\end{array}$ & \begin{tabular}{|l|}
373 \\
, 7
\end{tabular} & $\begin{array}{l}10, \\
4\end{array}$ & $\begin{array}{l}210 \\
, 7\end{array}$ & $\begin{array}{l}26 \\
, 5\end{array}$ \\
\hline
\end{tabular}




\begin{tabular}{|c|c|c|c|c|c|c|c|c|c|c|c|c|c|c|c|}
\hline $\begin{array}{c}\text { La } \\
\text { Peligrosa }\end{array}$ & MLPE03 & $\begin{array}{c}\text { Estratigráfi } \\
\text { co }\end{array}$ & DT & $\begin{array}{c}\text { Laguna del } \\
\text { Maule }\end{array}$ & 35541,2 & $\begin{array}{l}112 \\
6,7\end{array}$ & $\begin{array}{l}573, \\
9\end{array}$ & \begin{tabular}{|l}
8687, \\
4
\end{tabular} & \begin{tabular}{|l|}
50 \\
1 \\
\end{tabular} & \begin{tabular}{|l|}
15 \\
9
\end{tabular} & \begin{tabular}{|l|}
178 \\
, 2 \\
\end{tabular} & \begin{tabular}{|l|}
119 \\
, 2 \\
\end{tabular} & \begin{tabular}{|l|}
23 \\
0
\end{tabular} & \begin{tabular}{|l|}
206 \\
0 \\
\end{tabular} & $\begin{array}{l}17 \\
, 5 \\
\end{array}$ \\
\hline $\begin{array}{c}\text { La } \\
\text { Peligrosa }\end{array}$ & MMPA02 & $\begin{array}{c}\text { Estratigrafí } \\
a\end{array}$ & DT & Desconocida-A & 29881,9 & $\begin{array}{l}126 \\
2,6\end{array}$ & $\begin{array}{l}400, \\
5\end{array}$ & $\begin{array}{l}8255, \\
6\end{array}$ & $\begin{array}{l}74, \\
2\end{array}$ & 8,3 & $\begin{array}{l}136 \\
7\end{array}$ & \begin{tabular}{|l|}
190 \\
, 1
\end{tabular} & $\begin{array}{l}18 \\
3\end{array}$ & \begin{tabular}{|l|}
178 \\
8
\end{tabular} & $\begin{array}{l}10 \\
2\end{array}$ \\
\hline $\begin{array}{c}\text { La } \\
\text { Peligrosa }\end{array}$ & MLPE04 & \begin{tabular}{|c|}
$\begin{array}{c}\text { Estratigráfi } \\
\text { co }\end{array}$ \\
\end{tabular} & DT & El Peceno-2 & 34475,3 & \begin{tabular}{|l|}
175 \\
7,6 \\
\end{tabular} & \begin{tabular}{|l}
748, \\
3 \\
\end{tabular} & \begin{tabular}{|l}
6556, \\
9 \\
\end{tabular} & \begin{tabular}{|l|}
61, \\
2 \\
\end{tabular} & \begin{tabular}{|l|}
20 \\
0 \\
\end{tabular} & \begin{tabular}{|l|}
248 \\
0 \\
\end{tabular} & \begin{tabular}{|l|}
318 \\
, 6 \\
\end{tabular} & 9,8 & \begin{tabular}{|l|}
159 \\
, 7 \\
\end{tabular} & \begin{tabular}{|l|}
18 \\
9 \\
\end{tabular} \\
\hline $\begin{array}{l}\text { Loma } \\
\text { Alta }\end{array}$ & MLOA02 & Superficial & DT & $\begin{array}{c}\text { Laguna del } \\
\text { Maule }\end{array}$ & 36667,9 & \begin{tabular}{|l|}
981, \\
7 \\
\end{tabular} & \begin{tabular}{|l}
384, \\
0 \\
\end{tabular} & \begin{tabular}{|l|}
7643, \\
2 \\
\end{tabular} & \begin{tabular}{|l|}
44, \\
4 \\
\end{tabular} & $\begin{array}{l}15 \\
8 \\
\end{array}$ & \begin{tabular}{|l|}
160 \\
, 4 \\
\end{tabular} & \begin{tabular}{|l|}
106 \\
, 1 \\
\end{tabular} & \begin{tabular}{|l|}
22, \\
0 \\
\end{tabular} & \begin{tabular}{|l|}
177 \\
, 6 \\
\end{tabular} & \begin{tabular}{|l|}
13 \\
8 \\
\end{tabular} \\
\hline $\begin{array}{l}\text { Loma } \\
\text { Alta }\end{array}$ & MLOA03 & Superficial & DT & $\begin{array}{c}\text { Laguna del } \\
\text { Maule }\end{array}$ & 32825,5 & $\begin{array}{l}827, \\
8\end{array}$ & $\begin{array}{l}214, \\
7\end{array}$ & \begin{tabular}{|l}
6214, \\
2 \\
\end{tabular} & $\begin{array}{l}38 \\
2 \\
\end{array}$ & \begin{tabular}{|l}
11 \\
7
\end{tabular} & $\begin{array}{l}151 \\
, 5\end{array}$ & \begin{tabular}{|l}
87 \\
2 \\
\end{tabular} & $\begin{array}{l}20 \\
8\end{array}$ & \begin{tabular}{|l|}
149 \\
, 1 \\
\end{tabular} & $\begin{array}{l}12 \\
, 6 \\
\end{array}$ \\
\hline $\begin{array}{l}\text { Loma } \\
\text { Alta }\end{array}$ & MLOA05 & Superficial & DT & $\begin{array}{c}\text { Laguna del } \\
\text { Maule }\end{array}$ & 35361,0 & $\begin{array}{l}101 \\
6,0\end{array}$ & $\begin{array}{l}421, \\
4\end{array}$ & \begin{tabular}{|l|}
7464, \\
5
\end{tabular} & $\begin{array}{l}45, \\
0\end{array}$ & $\begin{array}{l}14, \\
6\end{array}$ & $\begin{array}{l}173 \\
, 0\end{array}$ & \begin{tabular}{|l|}
100 \\
, 1
\end{tabular} & $\begin{array}{l}23 \\
3\end{array}$ & \begin{tabular}{|l|}
186 \\
6 \\
\end{tabular} & $\begin{array}{l}15 \\
1\end{array}$ \\
\hline $\begin{array}{l}\text { Loma } \\
\text { Alta }\end{array}$ & MLOA06 & Superficial & AF Bifacial & $\begin{array}{c}\text { Laguna del } \\
\text { Maule }\end{array}$ & 35491,1 & $\begin{array}{l}939, \\
8\end{array}$ & $\begin{array}{l}405, \\
3\end{array}$ & \begin{tabular}{|l}
7166, \\
7
\end{tabular} & $\begin{array}{l}44, \\
0\end{array}$ & \begin{tabular}{|l}
14 \\
3
\end{tabular} & $\begin{array}{l}160 \\
8\end{array}$ & $\begin{array}{l}95, \\
3\end{array}$ & $\begin{array}{l}20 \\
8\end{array}$ & \begin{tabular}{|l|}
164 \\
, 2 \\
\end{tabular} & $\begin{array}{l}16 \\
0\end{array}$ \\
\hline $\begin{array}{c}\text { Loma } \\
\text { Alta }\end{array}$ & MLOA07 & Superficial & DT & $\begin{array}{l}\text { Laguna del } \\
\text { Maule }\end{array}$ & 34065,3 & $\begin{array}{l}930, \\
7\end{array}$ & $\begin{array}{l}373, \\
7\end{array}$ & $\begin{array}{l}7152, \\
9\end{array}$ & $\begin{array}{l}39 \\
2\end{array}$ & \begin{tabular}{|l|}
13 \\
2 \\
\end{tabular} & $\begin{array}{l}156 \\
4\end{array}$ & $\begin{array}{l}101 \\
, 1 \\
\end{array}$ & \begin{tabular}{|l|}
19 \\
1
\end{tabular} & \begin{tabular}{|l|}
164 \\
, 3 \\
\end{tabular} & $\begin{array}{l}9 \\
7\end{array}$ \\
\hline $\begin{array}{c}\text { Loma } \\
\text { Alta }\end{array}$ & MLOA09 & Superficial & DT & $\begin{array}{c}\text { Laguna del } \\
\text { Maule }\end{array}$ & 35942,6 & $\begin{array}{l}920, \\
3 \\
\end{array}$ & $\begin{array}{l}412, \\
5\end{array}$ & $\begin{array}{l}7069, \\
3 \\
\end{array}$ & $\begin{array}{l}44 \\
4\end{array}$ & \begin{tabular}{|l}
15 \\
1 \\
\end{tabular} & $\begin{array}{l}162 \\
, 5 \\
\end{array}$ & $\begin{array}{l}95 \\
4\end{array}$ & \begin{tabular}{|l|}
21 \\
1
\end{tabular} & \begin{tabular}{|l|}
179 \\
, 4 \\
\end{tabular} & $\begin{array}{l}16 \\
, 4 \\
\end{array}$ \\
\hline $\begin{array}{l}\text { Loma } \\
\text { Alta }\end{array}$ & MLOA12 & Superficial & DT & $\begin{array}{c}\text { Laguna del } \\
\text { Maule }\end{array}$ & 36267,2 & $\begin{array}{l}111 \\
5,9\end{array}$ & $\begin{array}{l}425, \\
7\end{array}$ & \begin{tabular}{|l}
7931, \\
5
\end{tabular} & $\begin{array}{l}39 \\
3\end{array}$ & \begin{tabular}{|l}
15 \\
6
\end{tabular} & $\begin{array}{l}163 \\
2 \\
\end{array}$ & \begin{tabular}{|l|}
115 \\
, 6 \\
\end{tabular} & \begin{tabular}{|l|}
21 \\
1
\end{tabular} & \begin{tabular}{|l|}
191 \\
8 \\
\end{tabular} & $\begin{array}{l}12 \\
4 \\
\end{array}$ \\
\hline $\begin{array}{c}\text { Loma } \\
\text { Alta }\end{array}$ & MLOA04 & Superficial & DT & Las Cargas & 31282,4 & $\begin{array}{l}758, \\
7 \\
\end{array}$ & $\begin{array}{l}602, \\
5 \\
\end{array}$ & \begin{tabular}{|l}
8706, \\
4 \\
\end{tabular} & $\begin{array}{l}37, \\
2 \\
\end{array}$ & \begin{tabular}{|l}
15 \\
4 \\
\end{tabular} & \begin{tabular}{|l}
112 \\
, 6 \\
\end{tabular} & \begin{tabular}{|l|}
226 \\
, 3 \\
\end{tabular} & \begin{tabular}{|l}
18 \\
5 \\
\end{tabular} & \begin{tabular}{|l|}
147 \\
, 6 \\
\end{tabular} & $\begin{array}{l}11 \\
5 \\
\end{array}$ \\
\hline $\begin{array}{c}\text { Loma } \\
\text { Alta }\end{array}$ & MLOA08 & Superficial & DT & Las Cargas & 33634,5 & $\begin{array}{l}107 \\
0,7 \\
\end{array}$ & $\begin{array}{l}631, \\
8\end{array}$ & \begin{tabular}{|l}
8826, \\
7 \\
\end{tabular} & $\begin{array}{l}35 \\
2 \\
\end{array}$ & \begin{tabular}{|l}
16 \\
6 \\
\end{tabular} & $\begin{array}{l}114 \\
0 \\
\end{array}$ & $\begin{array}{l}214 \\
, 9 \\
\end{array}$ & $\begin{array}{l}16 \\
1 \\
\end{array}$ & \begin{tabular}{|l|}
140 \\
, 3 \\
\end{tabular} & $\begin{array}{l}16 \\
5 \\
\end{array}$ \\
\hline $\begin{array}{c}\text { Loma } \\
\text { Alta }\end{array}$ & MLOA10 & Superficial & AF Bifacial & Las Cargas & 30612,7 & $\begin{array}{l}946, \\
4\end{array}$ & $\begin{array}{l}372, \\
3\end{array}$ & $\begin{array}{l}7712, \\
7\end{array}$ & $\begin{array}{l}29 \\
9\end{array}$ & $\begin{array}{l}13 \\
9 \\
\end{array}$ & $\begin{array}{l}115 \\
, 6 \\
\end{array}$ & \begin{tabular}{|l|}
223 \\
, 4 \\
\end{tabular} & $\begin{array}{l}16 \\
4\end{array}$ & \begin{tabular}{|l|}
135 \\
, 5 \\
\end{tabular} & $\begin{array}{l}6 \\
9 \\
\end{array}$ \\
\hline $\begin{array}{c}\text { Loma } \\
\text { Alta } \\
\end{array}$ & MLOA11 & Superficial & DT & Las Cargas & 32385,0 & $\begin{array}{l}954, \\
5 \\
\end{array}$ & $\begin{array}{l}406, \\
8\end{array}$ & \begin{tabular}{|l}
8021, \\
5 \\
\end{tabular} & $\begin{array}{l}35 \\
9 \\
\end{array}$ & \begin{tabular}{|l}
15, \\
2 \\
\end{tabular} & $\begin{array}{l}109 \\
, 7 \\
\end{array}$ & \begin{tabular}{|l|}
221 \\
, 0 \\
\end{tabular} & $\begin{array}{l}13 \\
8 \\
\end{array}$ & \begin{tabular}{|l|}
128 \\
, 0 \\
\end{tabular} & $\begin{array}{l}8, \\
7 \\
\end{array}$ \\
\hline $\begin{array}{l}\text { Loma } \\
\text { Alta }\end{array}$ & MLOA14 & Superficial & DT & Las Cargas & 33744,8 & $\begin{array}{l}775 \\
7\end{array}$ & $\begin{array}{l}441, \\
8\end{array}$ & \begin{tabular}{|l}
8941, \\
1
\end{tabular} & $\begin{array}{l}36 \\
9\end{array}$ & $\begin{array}{l}17 \\
5\end{array}$ & $\begin{array}{l}127 \\
9\end{array}$ & \begin{tabular}{|l|}
240 \\
, 2 \\
\end{tabular} & $\begin{array}{l}18 \\
9\end{array}$ & \begin{tabular}{|l|}
143 \\
8 \\
\end{tabular} & $\begin{array}{l}5, \\
3\end{array}$ \\
\hline $\begin{array}{c}\text { Loma } \\
\text { Alta }\end{array}$ & MLOA01 & Superficial & DT & unknown & 37429,7 & $\begin{array}{l}793, \\
9\end{array}$ & $\begin{array}{l}250, \\
9\end{array}$ & \begin{tabular}{|l}
6581, \\
8 \\
\end{tabular} & $\begin{array}{l}33, \\
1 \\
\end{array}$ & \begin{tabular}{|l}
14 \\
4
\end{tabular} & $\begin{array}{l}181 \\
, 7 \\
\end{array}$ & $\begin{array}{l}79 \\
3\end{array}$ & $\begin{array}{l}19 \\
8\end{array}$ & \begin{tabular}{|l|}
126 \\
, 0 \\
\end{tabular} & $\begin{array}{l}8 \\
3 \\
\end{array}$ \\
\hline $\begin{array}{c}\text { Loma } \\
\text { Alta }\end{array}$ & MLOA15 & Superficial & DT & $\begin{array}{c}\text { Laguna del } \\
\text { Maule }\end{array}$ & 34492,8 & $\begin{array}{l}704, \\
1 \\
\end{array}$ & $\begin{array}{l}318, \\
8\end{array}$ & \begin{tabular}{|l}
6650, \\
7 \\
\end{tabular} & $\begin{array}{l}34 \\
7 \\
\end{array}$ & \begin{tabular}{|l}
14, \\
0 \\
\end{tabular} & $\begin{array}{l}155 \\
, 2 \\
\end{array}$ & \begin{tabular}{|l}
92, \\
0 \\
\end{tabular} & $\begin{array}{l}24, \\
6 \\
\end{array}$ & \begin{tabular}{|l|}
164 \\
, 7 \\
\end{tabular} & $\begin{array}{l}8 \\
2 \\
\end{array}$ \\
\hline $\begin{array}{l}\text { Loma } \\
\text { Alta }\end{array}$ & MLOA16 & Superficial & DT & $\begin{array}{c}\text { Laguna del } \\
\text { Maule }\end{array}$ & 36118,7 & $\begin{array}{l}879, \\
1\end{array}$ & $\begin{array}{l}258, \\
4\end{array}$ & \begin{tabular}{|l|}
7533, \\
6
\end{tabular} & $\begin{array}{l}46 \\
6\end{array}$ & \begin{tabular}{|l|}
15 \\
2
\end{tabular} & $\begin{array}{l}174 \\
8\end{array}$ & \begin{tabular}{|l|}
121 \\
, 5
\end{tabular} & $\begin{array}{l}20 \\
7\end{array}$ & \begin{tabular}{|l|}
178 \\
5 \\
\end{tabular} & $\begin{array}{l}9 \\
7\end{array}$ \\
\hline $\begin{array}{c}\text { Loma } \\
\text { Alta } \\
\end{array}$ & MLOA18 & Superficial & AF Unifacial & $\begin{array}{c}\text { Laguna del } \\
\text { Maule }\end{array}$ & 34807,8 & \begin{tabular}{|l}
857, \\
8 \\
\end{tabular} & $\begin{array}{l}276, \\
5 \\
\end{array}$ & \begin{tabular}{|l}
6294, \\
9 \\
\end{tabular} & \begin{tabular}{|l|}
34, \\
6 \\
\end{tabular} & \begin{tabular}{|l|}
12 \\
8 \\
\end{tabular} & \begin{tabular}{|l|l}
147 \\
, 5 \\
\end{tabular} & \begin{tabular}{|l|}
88, \\
1 \\
\end{tabular} & $\begin{array}{l}19, \\
5\end{array}$ & \begin{tabular}{|l|}
136 \\
, 1 \\
\end{tabular} & \begin{tabular}{|l}
6 \\
9 \\
\end{tabular} \\
\hline $\begin{array}{l}\text { Loma } \\
\text { Alta }\end{array}$ & MLOA19 & Superficial & DT & $\begin{array}{c}\text { Laguna del } \\
\text { Maule }\end{array}$ & 36295,0 & $\begin{array}{l}101 \\
6,8\end{array}$ & $\begin{array}{l}331, \\
4\end{array}$ & $\begin{array}{l}7492, \\
4 \\
\end{array}$ & $\begin{array}{l}39 \\
0\end{array}$ & \begin{tabular}{|l}
15 \\
3
\end{tabular} & $\begin{array}{l}164 \\
, 1\end{array}$ & \begin{tabular}{|l|}
118 \\
, 7
\end{tabular} & $\begin{array}{l}19, \\
2\end{array}$ & \begin{tabular}{|l|}
178 \\
, 9 \\
\end{tabular} & $\begin{array}{l}10 \\
8\end{array}$ \\
\hline $\begin{array}{c}\text { Loma } \\
\text { Alta }\end{array}$ & MLOA21 & Superficial & DT & $\begin{array}{c}\text { Laguna del } \\
\text { Maule }\end{array}$ & 36256,9 & $\begin{array}{l}110 \\
2,2 \\
\end{array}$ & $\begin{array}{l}398, \\
0\end{array}$ & \begin{tabular}{|l}
7799, \\
1 \\
\end{tabular} & $\begin{array}{l}42, \\
3 \\
\end{array}$ & \begin{tabular}{|l}
15 \\
3 \\
\end{tabular} & $\begin{array}{l}169 \\
0 \\
\end{array}$ & \begin{tabular}{|l|}
120 \\
, 5 \\
\end{tabular} & $\begin{array}{l}21, \\
8\end{array}$ & \begin{tabular}{|l|}
180 \\
, 0 \\
\end{tabular} & $\begin{array}{l}10 \\
, 2 \\
\end{array}$ \\
\hline $\begin{array}{c}\text { Loma } \\
\text { Alta }\end{array}$ & MLOA22 & Superficial & DT & $\begin{array}{c}\text { Laguna del } \\
\text { Maule }\end{array}$ & 35716,7 & \begin{tabular}{|l}
981, \\
7 \\
\end{tabular} & $\begin{array}{l}311, \\
2\end{array}$ & \begin{tabular}{|l}
7128, \\
2 \\
\end{tabular} & \begin{tabular}{|l}
42, \\
1 \\
\end{tabular} & \begin{tabular}{|l}
13 \\
7 \\
\end{tabular} & $\begin{array}{l}171 \\
, 7 \\
\end{array}$ & \begin{tabular}{|l|}
101 \\
, 2 \\
\end{tabular} & $\begin{array}{l}18, \\
5\end{array}$ & \begin{tabular}{|l|}
156 \\
, 4 \\
\end{tabular} & $\begin{array}{l}11 \\
, 0 \\
\end{array}$ \\
\hline $\begin{array}{c}\text { Loma } \\
\text { Alta } \\
\end{array}$ & MLOA23 & Superficial & DT & $\begin{array}{c}\text { Laguna del } \\
\text { Maule }\end{array}$ & 32961,0 & \begin{tabular}{|l}
896, \\
8 \\
\end{tabular} & $\begin{array}{l}409, \\
2 \\
\end{array}$ & \begin{tabular}{|l|}
7043, \\
8 \\
\end{tabular} & \begin{tabular}{|l}
41, \\
2 \\
\end{tabular} & \begin{tabular}{|l}
13 \\
0 \\
\end{tabular} & $\begin{array}{l}163 \\
, 3 \\
\end{array}$ & $\begin{array}{l}95 \\
8 \\
\end{array}$ & $\begin{array}{l}23, \\
0 \\
\end{array}$ & \begin{tabular}{|l|}
174 \\
, 3 \\
\end{tabular} & $\begin{array}{l}16 \\
9 \\
\end{array}$ \\
\hline $\begin{array}{c}\text { Loma } \\
\text { Alta }\end{array}$ & MLOA24 & Superficial & DT & $\begin{array}{c}\text { Laguna del } \\
\text { Maule }\end{array}$ & 34238,5 & $\begin{array}{l}839, \\
1 \\
\end{array}$ & $\begin{array}{l}131, \\
0\end{array}$ & \begin{tabular}{|l}
6823, \\
8 \\
\end{tabular} & $\begin{array}{l}39 \\
9 \\
\end{array}$ & \begin{tabular}{|l}
13 \\
4 \\
\end{tabular} & $\begin{array}{l}158 \\
, 6 \\
\end{array}$ & \begin{tabular}{|l|}
117 \\
, 8 \\
\end{tabular} & $\begin{array}{l}20, \\
5\end{array}$ & \begin{tabular}{|l|}
164 \\
, 1 \\
\end{tabular} & $\begin{array}{l}9, \\
1 \\
\end{array}$ \\
\hline $\begin{array}{l}\text { Loma } \\
\text { Alta }\end{array}$ & MLOA25 & Superficial & DT & $\begin{array}{c}\text { Laguna del } \\
\text { Maule }\end{array}$ & 35224,3 & $\begin{array}{l}935, \\
1\end{array}$ & $\begin{array}{l}231, \\
5\end{array}$ & \begin{tabular}{|l}
6925, \\
3 \\
\end{tabular} & $\begin{array}{l}36 \\
9\end{array}$ & \begin{tabular}{|l|}
14 \\
1
\end{tabular} & $\begin{array}{l}171 \\
, 3\end{array}$ & \begin{tabular}{|l|}
112 \\
, 5 \\
\end{tabular} & $\begin{array}{l}21, \\
7\end{array}$ & \begin{tabular}{|l|}
163 \\
, 2 \\
\end{tabular} & $\begin{array}{l}10 \\
6 \\
\end{array}$ \\
\hline $\begin{array}{c}\text { Loma } \\
\text { Alta }\end{array}$ & MLOA17 & Superficial & AF Bifacial & Las Cargas & 32841,4 & $\begin{array}{l}766, \\
2 \\
\end{array}$ & $\begin{array}{l}435, \\
9\end{array}$ & \begin{tabular}{|l}
8583, \\
9 \\
\end{tabular} & $\begin{array}{l}37 \\
4 \\
\end{array}$ & \begin{tabular}{|l}
15 \\
8 \\
\end{tabular} & $\begin{array}{l}116 \\
, 8 \\
\end{array}$ & \begin{tabular}{|l|}
224 \\
, 5 \\
\end{tabular} & $\begin{array}{l}17, \\
7\end{array}$ & \begin{tabular}{|l|}
132 \\
, 8 \\
\end{tabular} & \begin{tabular}{|l}
6 \\
1 \\
\end{tabular} \\
\hline $\begin{array}{c}\text { Loma } \\
\text { Alta }\end{array}$ & MLOA20 & Superficial & DT & Las Cargas & 32588,0 & $\begin{array}{l}804, \\
7 \\
\end{array}$ & $\begin{array}{l}500, \\
6 \\
\end{array}$ & \begin{tabular}{|l}
9150, \\
1 \\
\end{tabular} & $\begin{array}{l}42, \\
7 \\
\end{array}$ & \begin{tabular}{|l}
17 \\
0 \\
\end{tabular} & $\begin{array}{l}135 \\
, 5 \\
\end{array}$ & \begin{tabular}{|l|}
252 \\
, 5 \\
\end{tabular} & $\begin{array}{l}19, \\
2\end{array}$ & \begin{tabular}{|l|}
146 \\
, 9 \\
\end{tabular} & $\begin{array}{l}6, \\
3 \\
\end{array}$ \\
\hline $\begin{array}{c}\text { Loma } \\
\text { Alta } \\
\end{array}$ & MLOA26 & Superficial & AF Unifacial & Las Cargas & 33191,3 & $\begin{array}{l}114 \\
7,4 \\
\end{array}$ & $\begin{array}{l}692, \\
7 \\
\end{array}$ & \begin{tabular}{|l|}
1007 \\
0,4 \\
\end{tabular} & \begin{tabular}{|l}
40 \\
5 \\
\end{tabular} & \begin{tabular}{|l}
18 \\
5 \\
\end{tabular} & \begin{tabular}{|l}
132 \\
, 6 \\
\end{tabular} & \begin{tabular}{|l|}
239 \\
, 5 \\
\end{tabular} & $\begin{array}{l}20, \\
3\end{array}$ & \begin{tabular}{|l|}
161 \\
, 7 \\
\end{tabular} & \begin{tabular}{|l}
13 \\
, 3 \\
\end{tabular} \\
\hline $\begin{array}{c}\text { Loma } \\
\text { Alta }\end{array}$ & MLOA27 & Superficial & DT & Las Cargas & 31189,0 & $\begin{array}{l}819, \\
2 \\
\end{array}$ & $\begin{array}{l}511, \\
2\end{array}$ & \begin{tabular}{|l}
8646, \\
7 \\
\end{tabular} & $\begin{array}{l}36 \\
3\end{array}$ & $\begin{array}{l}15 \\
2 \\
\end{array}$ & $\begin{array}{l}116 \\
, 6 \\
\end{array}$ & \begin{tabular}{|l|}
218 \\
, 3 \\
\end{tabular} & $\begin{array}{l}19, \\
4\end{array}$ & \begin{tabular}{|l|}
142 \\
, 6 \\
\end{tabular} & $\begin{array}{l}7, \\
2 \\
\end{array}$ \\
\hline $\begin{array}{l}\text { Payún } \\
\text { Liso }\end{array}$ & LSAL01 & Superficial & $\begin{array}{c}\text { Muestra de } \\
\text { mano }\end{array}$ & Cerro Huenul & 36318 & 688 & 509 & 4576 & 21 & 14 & 90 & 106 & 12 & 65 & 11 \\
\hline $\begin{array}{l}\text { Payún } \\
\text { Matrú }\end{array}$ & SAL02 & Superficial & $\begin{array}{c}\text { Muestra de } \\
\text { mano }\end{array}$ & Cerro Huenul & 37401 & 734 & 539 & 5566 & 26 & 14 & 96 & 107 & 14 & 70 & 12 \\
\hline $\begin{array}{l}\text { Payún } \\
\text { Matrú }\end{array}$ & SAL03 & Superficial & $\begin{array}{c}\text { Muestra de } \\
\text { mano }\end{array}$ & unknown & 38363 & 878 & 428 & 5088 & 28 & 15 & 153 & 79 & 17 & 122 & 12 \\
\hline
\end{tabular}




\begin{tabular}{|c|c|c|c|c|c|c|c|c|c|c|c|c|c|c|c|}
\hline APE & MPSU01 & Superficial & DT & Cerro Huenul & 33162,1 & $\begin{array}{l}759 \\
7\end{array}$ & $\begin{array}{l}558 \\
8\end{array}$ & $\begin{array}{l}5443, \\
8\end{array}$ & $\begin{array}{l}25, \\
6\end{array}$ & $\begin{array}{l}13, \\
2\end{array}$ & $\begin{array}{l}107 \\
1\end{array}$ & $\begin{array}{l}103 \\
, 6\end{array}$ & $\begin{array}{l}13 \\
5\end{array}$ & $\begin{array}{l}86, \\
5\end{array}$ & $\begin{array}{l}16 \\
6\end{array}$ \\
\hline APE & MAPE01 & Superficial & DT & $\begin{array}{l}\text { Laguna del } \\
\text { Maule }\end{array}$ & 32442,0 & $\begin{array}{l}851 \\
4\end{array}$ & $\begin{array}{l}444 \\
6\end{array}$ & $\begin{array}{l}6889 \\
8\end{array}$ & $\begin{array}{l}43, \\
8\end{array}$ & $\begin{array}{l}12 \\
6\end{array}$ & $\begin{array}{l}160 \\
6\end{array}$ & $\begin{array}{l}92 \\
4\end{array}$ & $\begin{array}{l}23, \\
3\end{array}$ & $\begin{array}{l}174 \\
, 2\end{array}$ & $\begin{array}{l}16 \\
6\end{array}$ \\
\hline APE & MAPE02 & Superficial & ASF RC & Cerro Huenul & 32451,2 & $\begin{array}{l}791, \\
8\end{array}$ & $\begin{array}{l}434 \\
9\end{array}$ & $\begin{array}{l}5229, \\
9\end{array}$ & $\begin{array}{l}24, \\
1\end{array}$ & $\begin{array}{l}12, \\
2\end{array}$ & $\begin{array}{l}103 \\
6\end{array}$ & $\begin{array}{l}101 \\
, 4\end{array}$ & 9,8 & $\begin{array}{l}73, \\
1\end{array}$ & $\begin{array}{l}12 \\
1\end{array}$ \\
\hline PRC & MPRC06 & Superficial & Núcleo & Cerro Huenul & 33531,0 & $\begin{array}{l}850 \\
9 \\
\end{array}$ & $\begin{array}{l}485 \\
3 \\
\end{array}$ & $\begin{array}{l}5649, \\
5\end{array}$ & $\begin{array}{l}33, \\
6\end{array}$ & $\begin{array}{l}13, \\
1\end{array}$ & $\begin{array}{l}103 \\
9 \\
\end{array}$ & $\begin{array}{l}108 \\
, 6 \\
\end{array}$ & - & - & - \\
\hline PRC & MPRC07 & Superficial & AF Unifacial & $\begin{array}{c}\text { Laguna del } \\
\text { Maule }\end{array}$ & 34185,2 & $\begin{array}{l}678, \\
0 \\
\end{array}$ & $\begin{array}{l}410, \\
2 \\
\end{array}$ & $\begin{array}{l}6331, \\
7 \\
\end{array}$ & $\begin{array}{l}33, \\
6\end{array}$ & $\begin{array}{l}13, \\
2 \\
\end{array}$ & $\begin{array}{l}170 \\
7 \\
\end{array}$ & $\begin{array}{l}89 \\
9 \\
\end{array}$ & \begin{tabular}{|l|}
18 \\
7 \\
\end{tabular} & $\begin{array}{l}144 \\
9 \\
\end{array}$ & $\begin{array}{l}11 \\
, 7\end{array}$ \\
\hline PRC & MPRC08 & Superficial & DT & $\begin{array}{c}\text { Laguna del } \\
\text { Maule }\end{array}$ & 37635,2 & $\begin{array}{l}100 \\
1,5\end{array}$ & $\begin{array}{l}335 \\
0\end{array}$ & $\begin{array}{l}7133, \\
7\end{array}$ & $\begin{array}{l}33, \\
6\end{array}$ & $\begin{array}{l}15, \\
0\end{array}$ & $\begin{array}{l}173 \\
4\end{array}$ & $\begin{array}{l}94, \\
9\end{array}$ & $\begin{array}{l}17 \\
3 \\
\end{array}$ & $\begin{array}{l}145 \\
9\end{array}$ & $\begin{array}{l}14 \\
3\end{array}$ \\
\hline PRC & MPRC09 & Superficial & DT & $\begin{array}{l}\text { Laguna del } \\
\text { Maule }\end{array}$ & 35639,2 & $\begin{array}{l}824 \\
2\end{array}$ & $\begin{array}{l}372 \\
7\end{array}$ & $\begin{array}{l}6519 \\
7\end{array}$ & $\begin{array}{l}32 \\
9\end{array}$ & $\begin{array}{l}14 \\
7\end{array}$ & $\begin{array}{l}167 \\
0\end{array}$ & $\begin{array}{l}92 \\
9\end{array}$ & \begin{tabular}{|l|}
23 \\
1
\end{tabular} & $\begin{array}{l}149 \\
, 7\end{array}$ & $\begin{array}{l}15 \\
5\end{array}$ \\
\hline PRC & MPRC10 & Superficial & DT & $\begin{array}{c}\text { Laguna del } \\
\text { Maule }\end{array}$ & 35446,0 & $\begin{array}{l}814, \\
7 \\
\end{array}$ & $\begin{array}{l}413, \\
2 \\
\end{array}$ & $\begin{array}{l}6877, \\
2 \\
\end{array}$ & $\begin{array}{l}34, \\
3\end{array}$ & $\begin{array}{l}14, \\
2\end{array}$ & $\begin{array}{l}173 \\
, 0 \\
\end{array}$ & $\begin{array}{l}91 \\
6 \\
\end{array}$ & \begin{tabular}{|l|}
21 \\
5 \\
\end{tabular} & $\begin{array}{l}155 \\
3 \\
\end{array}$ & $\begin{array}{l}15 \\
5\end{array}$ \\
\hline PRC & MPRC11 & Superficial & DT & $\begin{array}{c}\text { Laguna del } \\
\text { Maule }\end{array}$ & 36086,6 & $\begin{array}{l}885 \\
7 \\
\end{array}$ & $\begin{array}{l}362 \\
5 \\
\end{array}$ & $\begin{array}{l}7058, \\
4\end{array}$ & $\begin{array}{l}38, \\
2\end{array}$ & $\begin{array}{l}15, \\
0\end{array}$ & $\begin{array}{l}186 \\
1 \\
\end{array}$ & $\begin{array}{l}106 \\
1 \\
\end{array}$ & \begin{tabular}{|l|}
21 \\
9 \\
\end{tabular} & $\begin{array}{l}161 \\
, 7 \\
\end{array}$ & $\begin{array}{l}17 \\
4\end{array}$ \\
\hline PRC Tren & MPRC01 & Superficial & DT & $\begin{array}{c}\text { Laguna del } \\
\text { Maule }\end{array}$ & 35895,8 & \begin{tabular}{|l|}
933, \\
2 \\
\end{tabular} & $\begin{array}{l}337, \\
1 \\
\end{array}$ & $\begin{array}{l}7062, \\
1 \\
\end{array}$ & $\begin{array}{l}36, \\
3\end{array}$ & $\begin{array}{l}13, \\
6 \\
\end{array}$ & $\begin{array}{l}166 \\
1 \\
\end{array}$ & $\begin{array}{l}89 \\
3 \\
\end{array}$ & - & $\begin{array}{l}132 \\
5 \\
\end{array}$ & $\begin{array}{l}14 \\
0 \\
\end{array}$ \\
\hline PRC Tren & MPRC02 & Superficial & DT & $\begin{array}{c}\text { Laguna del } \\
\text { Maule }\end{array}$ & 33958,7 & $\begin{array}{l}842 \\
0\end{array}$ & $\begin{array}{l}287 \\
7\end{array}$ & $\begin{array}{l}6311, \\
9\end{array}$ & $\begin{array}{l}34, \\
5\end{array}$ & $\begin{array}{l}12, \\
1\end{array}$ & $\begin{array}{l}157 \\
, 2\end{array}$ & $\begin{array}{l}87 \\
8\end{array}$ & $\begin{array}{l}17 \\
3\end{array}$ & $\begin{array}{l}130 \\
, 3\end{array}$ & $\begin{array}{l}15 \\
0\end{array}$ \\
\hline PRC Tren & MPRC03 & Superficial & DT & $\begin{array}{l}\text { Laguna del } \\
\text { Maule }\end{array}$ & 34977,6 & $\begin{array}{l}752 \\
3\end{array}$ & $\begin{array}{l}357, \\
3\end{array}$ & $\begin{array}{l}6752, \\
6\end{array}$ & $\begin{array}{l}37, \\
9\end{array}$ & $\begin{array}{l}13 \\
7\end{array}$ & $\begin{array}{l}174 \\
, 7\end{array}$ & $\begin{array}{l}92 \\
9\end{array}$ & \begin{tabular}{|l|}
15 \\
7
\end{tabular} & $\begin{array}{l}142 \\
3\end{array}$ & $\begin{array}{l}15 \\
5\end{array}$ \\
\hline PRC Tren & MPRC04 & Superficial & DT & Cerro Huenul & 30938,8 & $\begin{array}{l}802 \\
0\end{array}$ & $\begin{array}{l}580, \\
0\end{array}$ & $\begin{array}{l}5247 \\
3\end{array}$ & $\begin{array}{l}30, \\
4\end{array}$ & $\begin{array}{l}11, \\
2\end{array}$ & $\begin{array}{l}102 \\
9\end{array}$ & $\begin{array}{l}101 \\
99\end{array}$ & $\begin{array}{l}13 \\
8\end{array}$ & $\begin{array}{l}88, \\
7\end{array}$ & $\begin{array}{l}19 \\
, 3\end{array}$ \\
\hline PRC Tren & MPRC05 & Superficial & ASF RC & $\begin{array}{l}\text { Laguna del } \\
\text { Maule }\end{array}$ & 32172,3 & $\begin{array}{l}766, \\
4\end{array}$ & $\begin{array}{l}340, \\
1\end{array}$ & $\begin{array}{l}6010, \\
1\end{array}$ & $\begin{array}{l}35 \\
8\end{array}$ & $\begin{array}{l}11, \\
2\end{array}$ & $\begin{array}{l}161 \\
9\end{array}$ & $\begin{array}{l}87 \\
1\end{array}$ & - & - & - \\
\hline $\begin{array}{c}\text { Puesto } \\
\text { Mira }\end{array}$ & LSAL01 & Superficial & AF Bifacial & Cerro Huenul & 36318 & 688 & 509 & 4576 & 21 & 14 & 90 & 106 & 12 & 65 & 11 \\
\hline $\begin{array}{c}\text { Puesto } \\
\text { Mira }\end{array}$ & LSAL02 & Superficial & DT & Cerro Huenul & 37401 & 734 & 539 & 5566 & 26 & 14 & 96 & 107 & 14 & 70 & 12 \\
\hline $\begin{array}{c}\text { Puesto } \\
\text { Mira }\end{array}$ & LSAL03 & Superficial & Núcleo & unknown & 38363 & 878 & 428 & 5088 & 28 & 15 & 153 & 79 & 17 & 122 & 12 \\
\hline $\begin{array}{l}\text { Rincón } \\
\text { Blanco }\end{array}$ & MRBP17 & Superficial & AF Bifacial & Cerro Huenul & 38317,4 & $\begin{array}{l}113 \\
2,9\end{array}$ & $\begin{array}{l}635 \\
6 \\
\end{array}$ & $\begin{array}{l}7066, \\
7\end{array}$ & $\begin{array}{l}33 \\
4\end{array}$ & $\begin{array}{l}17, \\
5\end{array}$ & $\begin{array}{l}135 \\
9\end{array}$ & $\begin{array}{l}117 \\
7\end{array}$ & \begin{tabular}{|l|}
13 \\
3
\end{tabular} & $\begin{array}{l}99 \\
4\end{array}$ & $\begin{array}{l}15 \\
3\end{array}$ \\
\hline $\begin{array}{l}\text { Rincón } \\
\text { Blanco }\end{array}$ & MRBP01 & Superficial & DT & $\begin{array}{c}\text { Laguna del } \\
\text { Maule }\end{array}$ & 36871,1 & $\begin{array}{l}973, \\
5 \\
\end{array}$ & $\begin{array}{l}434, \\
1 \\
\end{array}$ & $\begin{array}{l}7117, \\
7\end{array}$ & $\begin{array}{l}42, \\
3\end{array}$ & $\begin{array}{l}14, \\
5\end{array}$ & $\begin{array}{l}180 \\
1 \\
\end{array}$ & $\begin{array}{l}93, \\
5\end{array}$ & $\begin{array}{l}19 \\
4 \\
\end{array}$ & $\begin{array}{l}150 \\
, 7 \\
\end{array}$ & $\begin{array}{l}16 \\
4\end{array}$ \\
\hline $\begin{array}{l}\text { Rincón } \\
\text { Blanco }\end{array}$ & MRBP02 & Superficial & AF Bifacial & $\begin{array}{c}\text { Laguna del } \\
\text { Maule }\end{array}$ & 35185,4 & \begin{tabular}{|l|}
934, \\
7 \\
\end{tabular} & $\begin{array}{l}393 \\
6 \\
\end{array}$ & $\begin{array}{l}6811, \\
2 \\
\end{array}$ & $\begin{array}{l}34, \\
8 \\
\end{array}$ & $\begin{array}{l}13, \\
8 \\
\end{array}$ & $\begin{array}{l}171 \\
8 \\
\end{array}$ & $\begin{array}{l}93 \\
9 \\
\end{array}$ & \begin{tabular}{|l|}
21 \\
2 \\
\end{tabular} & $\begin{array}{l}153 \\
9 \\
\end{array}$ & $\begin{array}{l}18 \\
6 \\
\end{array}$ \\
\hline $\begin{array}{l}\text { Rincón } \\
\text { Blanco }\end{array}$ & MRBP03 & Superficial & AF Bifacial & $\begin{array}{c}\text { Laguna del } \\
\text { Maule }\end{array}$ & 35878,1 & $\begin{array}{l}826 \\
4\end{array}$ & $\begin{array}{l}294, \\
3 \\
\end{array}$ & $\begin{array}{l}6629, \\
9\end{array}$ & $\begin{array}{l}30, \\
2\end{array}$ & $\begin{array}{l}13, \\
7\end{array}$ & $\begin{array}{l}175 \\
8\end{array}$ & $\begin{array}{l}98, \\
4\end{array}$ & \begin{tabular}{|l|}
16 \\
4
\end{tabular} & $\begin{array}{l}136 \\
1\end{array}$ & $\begin{array}{l}8, \\
8\end{array}$ \\
\hline $\begin{array}{l}\text { Rincón } \\
\text { Blanco }\end{array}$ & MRBP04 & Superficial & AF Unifacial & $\begin{array}{c}\text { Laguna del } \\
\text { Maule }\end{array}$ & 34200,0 & \begin{tabular}{|l|}
913, \\
1 \\
\end{tabular} & $\begin{array}{l}325 \\
9 \\
\end{array}$ & $\begin{array}{l}6947, \\
3 \\
\end{array}$ & $\begin{array}{l}32, \\
3\end{array}$ & $\begin{array}{l}12, \\
5\end{array}$ & $\begin{array}{l}165 \\
4 \\
\end{array}$ & $\begin{array}{l}94 \\
8 \\
\end{array}$ & \begin{tabular}{|l|}
19, \\
1
\end{tabular} & $\begin{array}{l}135 \\
1 \\
\end{array}$ & $\begin{array}{l}12 \\
5 \\
\end{array}$ \\
\hline $\begin{array}{l}\text { Rincón } \\
\text { Blanco }\end{array}$ & MRBP05 & Superficial & DT & $\begin{array}{c}\text { Laguna del } \\
\text { Maule }\end{array}$ & 36431,8 & $\begin{array}{l}810 \\
8 \\
\end{array}$ & $\begin{array}{l}239 \\
5 \\
\end{array}$ & $\begin{array}{l}6593, \\
0\end{array}$ & $\begin{array}{l}31, \\
4\end{array}$ & $\begin{array}{l}14, \\
5\end{array}$ & $\begin{array}{l}174 \\
2 \\
\end{array}$ & $\begin{array}{l}99, \\
2 \\
\end{array}$ & $\begin{array}{l}19 \\
9 \\
\end{array}$ & $\begin{array}{l}135 \\
, 7 \\
\end{array}$ & $\begin{array}{l}9, \\
4\end{array}$ \\
\hline $\begin{array}{l}\text { Rincón } \\
\text { Blanco }\end{array}$ & MRBP06 & Superficial & AF Unifacial & $\begin{array}{c}\text { Laguna del } \\
\text { Maule }\end{array}$ & 35865,4 & $\begin{array}{l}780, \\
4 \\
\end{array}$ & $\begin{array}{l}357, \\
9 \\
\end{array}$ & $\begin{array}{l}6563, \\
7 \\
\end{array}$ & $\begin{array}{l}34, \\
9\end{array}$ & $\begin{array}{l}14, \\
1 \\
\end{array}$ & $\begin{array}{l}175 \\
2 \\
\end{array}$ & $\begin{array}{l}96 \\
6 \\
\end{array}$ & \begin{tabular}{|l|}
20 \\
5 \\
\end{tabular} & $\begin{array}{l}145 \\
, 0\end{array}$ & $\begin{array}{l}10 \\
1 \\
\end{array}$ \\
\hline $\begin{array}{l}\text { Rincón } \\
\text { Blanco }\end{array}$ & MRBP07 & Superficial & DT & $\begin{array}{c}\text { Laguna del } \\
\text { Maule }\end{array}$ & 35703,9 & \begin{tabular}{|l|}
871 \\
8 \\
\end{tabular} & $\begin{array}{l}249, \\
2 \\
\end{array}$ & $\begin{array}{l}6328, \\
9 \\
\end{array}$ & $\begin{array}{l}29, \\
9\end{array}$ & $\begin{array}{l}13, \\
1\end{array}$ & $\begin{array}{l}170 \\
, 4 \\
\end{array}$ & $\begin{array}{l}93 \\
8 \\
\end{array}$ & \begin{tabular}{|l|}
15 \\
3 \\
\end{tabular} & $\begin{array}{l}130 \\
6 \\
\end{array}$ & $\begin{array}{l}7 \\
9 \\
\end{array}$ \\
\hline $\begin{array}{l}\text { Rincón } \\
\text { Blanco }\end{array}$ & MRBP08 & Superficial & Núcleo & $\begin{array}{c}\text { Laguna del } \\
\text { Maule }\end{array}$ & 35521,2 & \begin{tabular}{|l|}
790, \\
6 \\
\end{tabular} & $\begin{array}{l}245, \\
0 \\
\end{array}$ & $\begin{array}{l}6285, \\
0 \\
\end{array}$ & $\begin{array}{l}27, \\
8 \\
\end{array}$ & $\begin{array}{l}13, \\
5\end{array}$ & $\begin{array}{l}163 \\
1 \\
\end{array}$ & $\begin{array}{l}90 \\
3 \\
\end{array}$ & \begin{tabular}{|l|}
19, \\
9 \\
\end{tabular} & $\begin{array}{l}127 \\
3 \\
\end{array}$ & $\begin{array}{l}7, \\
1\end{array}$ \\
\hline $\begin{array}{l}\text { Rincón } \\
\text { Blanco }\end{array}$ & MRBP09 & Superficial & AF Unifacial & $\begin{array}{c}\text { Laguna del } \\
\text { Maule }\end{array}$ & 35289,1 & \begin{tabular}{|l|}
964, \\
8 \\
\end{tabular} & $\begin{array}{l}381, \\
5 \\
\end{array}$ & $\begin{array}{l}6764, \\
8 \\
\end{array}$ & $\begin{array}{l}32, \\
7 \\
\end{array}$ & $\begin{array}{l}13, \\
6\end{array}$ & $\begin{array}{l}175 \\
1 \\
\end{array}$ & $\begin{array}{l}97 \\
6 \\
\end{array}$ & \begin{tabular}{|l|}
18 \\
9 \\
\end{tabular} & $\begin{array}{l}150 \\
, 2 \\
\end{array}$ & $\begin{array}{l}17 \\
, 0\end{array}$ \\
\hline $\begin{array}{l}\text { Rincón } \\
\text { Blanco }\end{array}$ & MRBP10 & Superficial & DT & $\begin{array}{c}\text { Laguna del } \\
\text { Maule }\end{array}$ & 35519,3 & $\begin{array}{l}834, \\
3\end{array}$ & $\begin{array}{l}418 \\
9\end{array}$ & $\begin{array}{l}6982, \\
3\end{array}$ & $\begin{array}{l}38, \\
4\end{array}$ & $\begin{array}{l}14, \\
4\end{array}$ & $\begin{array}{l}174 \\
8\end{array}$ & $\begin{array}{l}94, \\
0\end{array}$ & $\begin{array}{l}20 \\
1 \\
\end{array}$ & $\begin{array}{l}160 \\
0\end{array}$ & $\begin{array}{c}18 \\
5\end{array}$ \\
\hline $\begin{array}{l}\text { Rincón } \\
\text { Blanco }\end{array}$ & MRBP12 & Superficial & AF Bifacial & $\begin{array}{c}\text { Laguna del } \\
\text { Maule }\end{array}$ & 34391,8 & $\begin{array}{l}823 \\
4\end{array}$ & $\begin{array}{l}413, \\
4\end{array}$ & $\begin{array}{l}6645, \\
9\end{array}$ & $\begin{array}{l}36, \\
5\end{array}$ & $\begin{array}{l}13 \\
7\end{array}$ & $\begin{array}{l}168 \\
, 7\end{array}$ & $\begin{array}{l}94, \\
9\end{array}$ & $\begin{array}{l}20 \\
4 \\
\end{array}$ & $\begin{array}{l}156 \\
5\end{array}$ & $\begin{array}{l}19 \\
, 7\end{array}$ \\
\hline $\begin{array}{l}\text { Rincón } \\
\text { Blanco }\end{array}$ & MRBP13 & Superficial & DT & $\begin{array}{c}\text { Laguna del } \\
\text { Maule }\end{array}$ & 33153,2 & \begin{tabular}{|l|}
829 \\
8 \\
\end{tabular} & $\begin{array}{l}345, \\
0 \\
\end{array}$ & $\begin{array}{l}6123, \\
1 \\
\end{array}$ & $\begin{array}{l}37, \\
8 \\
\end{array}$ & $\begin{array}{l}11, \\
9\end{array}$ & $\begin{array}{l}158 \\
5 \\
\end{array}$ & $\begin{array}{l}87 \\
0 \\
\end{array}$ & \begin{tabular}{|l|}
17 \\
9 \\
\end{tabular} & $\begin{array}{l}143 \\
1 \\
\end{array}$ & $\begin{array}{l}18 \\
0 \\
\end{array}$ \\
\hline $\begin{array}{l}\text { Rincón } \\
\text { Blanco }\end{array}$ & MRBP14 & Superficial & DT & $\begin{array}{c}\text { Laguna del } \\
\text { Maule }\end{array}$ & 34794,9 & \begin{tabular}{|l|}
829 \\
9 \\
\end{tabular} & $\begin{array}{l}311 \\
8 \\
\end{array}$ & $\begin{array}{l}6323, \\
9 \\
\end{array}$ & $\begin{array}{l}30, \\
9\end{array}$ & $\begin{array}{l}13, \\
0\end{array}$ & $\begin{array}{l}157 \\
6 \\
\end{array}$ & $\begin{array}{l}88 \\
9 \\
\end{array}$ & \begin{tabular}{|l|}
18 \\
3 \\
\end{tabular} & $\begin{array}{l}130 \\
4 \\
\end{array}$ & $\begin{array}{c}11 \\
9 \\
\end{array}$ \\
\hline $\begin{array}{l}\text { Rincón } \\
\text { Blanco }\end{array}$ & MRBP15 & Superficial & DT & $\begin{array}{c}\text { Laguna del } \\
\text { Maule }\end{array}$ & 37720,3 & $\begin{array}{l}100 \\
2,5 \\
\end{array}$ & $\begin{array}{l}293 \\
3 \\
\end{array}$ & $\begin{array}{l}7286, \\
1 \\
\end{array}$ & $\begin{array}{l}43, \\
0\end{array}$ & $\begin{array}{l}14, \\
3\end{array}$ & $\begin{array}{l}174 \\
1 \\
\end{array}$ & $\begin{array}{l}94, \\
5 \\
\end{array}$ & \begin{tabular}{|l|}
16 \\
0 \\
\end{tabular} & $\begin{array}{l}131 \\
9 \\
\end{array}$ & $\begin{array}{l}10 \\
8 \\
\end{array}$ \\
\hline Rincón & MRBP16 & Superficial & AF Unifacial & Laguna del & 34808,7 & $\begin{array}{l}800 \\
1 \\
\end{array}$ & $\begin{array}{l}215 \\
9\end{array}$ & $\begin{array}{l}6434, \\
9\end{array}$ & $\begin{array}{l}26, \\
4\end{array}$ & $\begin{array}{l}12, \\
3\end{array}$ & $\begin{array}{l}170 \\
4\end{array}$ & $\begin{array}{l}94 \\
5\end{array}$ & \begin{tabular}{|l|}
19 \\
4
\end{tabular} & $\begin{array}{l}128 \\
, 2\end{array}$ & $\begin{array}{l}5, \\
6\end{array}$ \\
\hline
\end{tabular}




\begin{tabular}{|c|c|c|c|c|c|c|c|c|c|c|c|c|c|c|c|}
\hline Blanco & & & & Maule & & & & & & & & & & & \\
\hline $\begin{array}{l}\text { Rincón } \\
\text { Blanco }\end{array}$ & MRBP18 & Superficial & AF Bifacial & $\begin{array}{c}\text { Laguna del } \\
\text { Maule }\end{array}$ & 35851,7 & $\begin{array}{l}897, \\
4\end{array}$ & $\begin{array}{l}377, \\
4\end{array}$ & $\begin{array}{l}6601, \\
8\end{array}$ & $\begin{array}{l}35 \\
6\end{array}$ & $\begin{array}{l}13, \\
9\end{array}$ & $\begin{array}{l}176 \\
, 7\end{array}$ & $\begin{array}{l}92 \\
4\end{array}$ & $\begin{array}{l}20, \\
2\end{array}$ & $\begin{array}{l}150 \\
, 7\end{array}$ & $\begin{array}{l}14 \\
8\end{array}$ \\
\hline $\begin{array}{l}\text { Rincón } \\
\text { Blanco }\end{array}$ & MRBP19 & Superficial & ASF RC & $\begin{array}{l}\text { Laguna del } \\
\text { Maule }\end{array}$ & 36491,9 & $\begin{array}{l}808, \\
9\end{array}$ & $\begin{array}{l}286, \\
1\end{array}$ & $\begin{array}{l}6598, \\
5\end{array}$ & $\begin{array}{l}34, \\
2\end{array}$ & $\begin{array}{l}14, \\
6\end{array}$ & $\begin{array}{l}174 \\
1\end{array}$ & $\begin{array}{l}95 \\
6\end{array}$ & $\begin{array}{l}20, \\
0\end{array}$ & $\begin{array}{l}137 \\
4\end{array}$ & $\begin{array}{l}10 \\
8\end{array}$ \\
\hline $\begin{array}{l}\text { Rincón } \\
\text { Blanco }\end{array}$ & MRBP20 & Superficial & AF Bifacial & $\begin{array}{l}\text { Laguna del } \\
\text { Maule }\end{array}$ & 36439,0 & $\begin{array}{l}907, \\
4\end{array}$ & $\begin{array}{l}280 \\
7\end{array}$ & $\begin{array}{l}6918, \\
1\end{array}$ & $\begin{array}{l}33, \\
4\end{array}$ & $\begin{array}{l}14, \\
3\end{array}$ & $\begin{array}{l}180 \\
, 4\end{array}$ & $\begin{array}{l}97, \\
5\end{array}$ & $\begin{array}{l}19, \\
4\end{array}$ & $\begin{array}{l}141 \\
6\end{array}$ & $\begin{array}{l}11 \\
8\end{array}$ \\
\hline $\begin{array}{l}\text { Rincón } \\
\text { Blanco }\end{array}$ & MRBP21 & Superficial & DT & $\begin{array}{c}\text { Laguna del } \\
\text { Maule }\end{array}$ & 38029,4 & $\begin{array}{l}949 \\
7\end{array}$ & $\begin{array}{l}412, \\
2\end{array}$ & $\begin{array}{l}7470, \\
0\end{array}$ & $\begin{array}{l}37, \\
9\end{array}$ & $\begin{array}{l}16, \\
2\end{array}$ & $\begin{array}{l}193 \\
, 3 \\
\end{array}$ & $\begin{array}{l}108 \\
4 \\
\end{array}$ & $\begin{array}{l}20, \\
5\end{array}$ & $\begin{array}{l}164 \\
6 \\
\end{array}$ & $\begin{array}{l}18 \\
, 3 \\
\end{array}$ \\
\hline $\begin{array}{l}\text { Rincón } \\
\text { Blanco }\end{array}$ & MRBP22 & Superficial & AF Unifacial & $\begin{array}{c}\text { Laguna del } \\
\text { Maule }\end{array}$ & 37913,1 & $\begin{array}{l}893, \\
2\end{array}$ & $\begin{array}{l}256, \\
6\end{array}$ & $\begin{array}{l}6937, \\
4\end{array}$ & $\begin{array}{l}34, \\
5\end{array}$ & $\begin{array}{l}15, \\
2\end{array}$ & $\begin{array}{l}171 \\
1 \\
\end{array}$ & $\begin{array}{l}95 \\
7 \\
\end{array}$ & $\begin{array}{l}17, \\
0\end{array}$ & $\begin{array}{l}131 \\
, 2 \\
\end{array}$ & $\begin{array}{l}11 \\
, 2\end{array}$ \\
\hline $\begin{array}{l}\text { Rincón } \\
\text { Blanco }\end{array}$ & MRBP23 & Superficial & DT & $\begin{array}{c}\text { Laguna del } \\
\text { Maule }\end{array}$ & 36752,0 & $\begin{array}{l}865, \\
6\end{array}$ & $\begin{array}{l}271, \\
2\end{array}$ & $\begin{array}{l}6674, \\
9\end{array}$ & $\begin{array}{l}30, \\
5\end{array}$ & $\begin{array}{l}14, \\
3\end{array}$ & $\begin{array}{l}167 \\
, 5\end{array}$ & $\begin{array}{l}91 \\
9\end{array}$ & $\begin{array}{l}19, \\
0\end{array}$ & $\begin{array}{l}135 \\
9\end{array}$ & $\begin{array}{l}9, \\
0\end{array}$ \\
\hline $\begin{array}{l}\text { Rincón } \\
\text { Blanco }\end{array}$ & MRBP24 & Superficial & AF Bifacial & $\begin{array}{l}\text { Laguna del } \\
\text { Maule }\end{array}$ & 37734,7 & $\begin{array}{l}998, \\
0\end{array}$ & $\begin{array}{l}252, \\
0\end{array}$ & $\begin{array}{l}6899 \\
6\end{array}$ & $\begin{array}{l}30, \\
6\end{array}$ & $\begin{array}{l}14, \\
4\end{array}$ & $\begin{array}{l}178 \\
, 2\end{array}$ & $\begin{array}{l}102 \\
, 2 \\
\end{array}$ & $\begin{array}{l}16, \\
9\end{array}$ & $\begin{array}{l}133 \\
, 7\end{array}$ & $\begin{array}{l}8, \\
6\end{array}$ \\
\hline $\begin{array}{l}\text { Rincón } \\
\text { Blanco }\end{array}$ & MRBP25 & Superficial & DT & $\begin{array}{l}\text { Laguna del } \\
\text { Maule }\end{array}$ & 37259,5 & $\begin{array}{l}939, \\
3\end{array}$ & $\begin{array}{l}270, \\
2\end{array}$ & $\begin{array}{l}6915, \\
8\end{array}$ & $\begin{array}{l}34, \\
0\end{array}$ & $\begin{array}{l}14, \\
6\end{array}$ & $\begin{array}{l}184 \\
0\end{array}$ & $\begin{array}{l}104 \\
1\end{array}$ & $\begin{array}{l}17 \\
9\end{array}$ & $\begin{array}{l}139 \\
0\end{array}$ & $\begin{array}{l}10 \\
2\end{array}$ \\
\hline $\begin{array}{l}\text { Rincón } \\
\text { Blanco }\end{array}$ & MRBP26 & Superficial & DT & $\begin{array}{c}\text { Laguna del } \\
\text { Maule }\end{array}$ & 37839,3 & $\begin{array}{l}953, \\
4\end{array}$ & $\begin{array}{l}323, \\
6 \\
\end{array}$ & $\begin{array}{l}7281 \\
8 \\
\end{array}$ & $\begin{array}{l}32, \\
1 \\
\end{array}$ & $\begin{array}{l}15, \\
1 \\
\end{array}$ & $\begin{array}{l}183 \\
, 3 \\
\end{array}$ & $\begin{array}{l}98 \\
4 \\
\end{array}$ & $\begin{array}{l}17, \\
7 \\
\end{array}$ & $\begin{array}{l}141 \\
, 7 \\
\end{array}$ & $\begin{array}{l}9, \\
9 \\
\end{array}$ \\
\hline $\begin{array}{l}\text { Rincón } \\
\text { Blanco }\end{array}$ & MRBP27 & Superficial & DT & $\begin{array}{c}\text { Laguna del } \\
\text { Maule }\end{array}$ & 41363,1 & $\begin{array}{l}965, \\
4\end{array}$ & $\begin{array}{l}366, \\
1\end{array}$ & $\begin{array}{l}8106, \\
0\end{array}$ & $\begin{array}{l}40, \\
8\end{array}$ & $\begin{array}{l}18, \\
2\end{array}$ & $\begin{array}{l}190 \\
0\end{array}$ & $\begin{array}{l}102 \\
7\end{array}$ & $\begin{array}{l}19, \\
3\end{array}$ & $\begin{array}{l}145 \\
1\end{array}$ & $\begin{array}{l}10 \\
5\end{array}$ \\
\hline $\begin{array}{l}\text { Rincón } \\
\text { Blanco }\end{array}$ & MRBP28 & Superficial & DT & $\begin{array}{c}\text { Laguna del } \\
\text { Maule }\end{array}$ & 34289,5 & $\begin{array}{l}101 \\
7,2 \\
\end{array}$ & $\begin{array}{l}356, \\
0\end{array}$ & $\begin{array}{l}6915, \\
6\end{array}$ & $\begin{array}{l}30, \\
8\end{array}$ & $\begin{array}{l}12, \\
5\end{array}$ & $\begin{array}{l}180 \\
, 2 \\
\end{array}$ & $\begin{array}{l}110 \\
2 \\
\end{array}$ & $\begin{array}{l}18, \\
4\end{array}$ & $\begin{array}{l}152 \\
1 \\
\end{array}$ & $\begin{array}{l}9, \\
3\end{array}$ \\
\hline $\begin{array}{l}\text { Rincón } \\
\text { Blanco }\end{array}$ & MRBP11 & Superficial & DT & Desconocida & 35201,1 & $\begin{array}{l}128 \\
8,7\end{array}$ & $\begin{array}{l}386, \\
9\end{array}$ & $\begin{array}{l}8132 \\
9\end{array}$ & $\begin{array}{l}41 \\
4\end{array}$ & $\begin{array}{l}14, \\
9\end{array}$ & $\begin{array}{l}170 \\
6\end{array}$ & $\begin{array}{l}170 \\
, 4\end{array}$ & $\begin{array}{l}15 \\
6\end{array}$ & $\begin{array}{l}205 \\
, 5\end{array}$ & $\begin{array}{l}10 \\
1\end{array}$ \\
\hline
\end{tabular}




\section{BIBLIOGRAFÍA}

ABRAHAM, M. E.

-2000. Geomorfología de la Provincia de Mendoza. En: ARGENTINA. Recursos y problemas ambientales de la zona árida. Provincias de Mendoza, San Juan y La Rioja. Tomo I, Caracterización ambiental. E.M. Abraham y F.R Martínez (eds.), pp.: 29-48.

AGÜERO BLANCH, V.

-1965. El tembetá: tipos y áreas de dispersión en el departamento de Malargüe, (Mendoza). Anales de Arqueología y Etnología, 20, Mendoza.

-1971. Malargüe, pueblo trashumante. Anales de Arqueología y Etnología, XXIV-XXV: 209-223.

AMICK, D. S.

-1994. Technological organization and the structure of inference in lithic analysis: an examination of Folsom hunting behavior in the American Southwest. En: The organization of North American prehistoric chipped stone tools technologies, P. Carr (ed.), pp. 9-34.

AMICK, D. y R. MAULDIN (Eds.).

-1989. Experiments in Lithic Technology. BAR International Series 528.

ANDREFSKY, W.

-1991. Inferring trends in prehistoric settlement behavior from lithic production technology in the southern plains. North American Archaeology 12(2): 129-144.

-1994. Raw-material availability and the organization of technology. American Antiquity 59 (1): 21-34.

-1998. Lithics. Macroscopic approaches to analysis. Cambridge University Press.

ARAGÓN, E. y N. FRANCO

-1997. Características de rocas para la talla por percusión y propiedades petrográficas. Anales del Instituto de la Patagonia, Vol. 25: 187-199.

ASCHERO, C.

-1975. Ensayo para una clasificación morfológica de artefactos líticos aplicados a estudios tipológicos comparativos. Informe a CONICET. Ms.

-1983 Ensayo para una clasificación morfológica de artefactos líticos aplicada a estudios tecnológicos comparativos. Apéndice A-C. Revisión 1983. Cátedra de Ergología y Tecnología. Facultad de Filosofía y Letras. Universidad de Buenos Aires. Ms.

-1988. De punta a punta: Producción, mantenimiento y diseño en puntas de proyectil precerámicas de la Puna argentina. Actas del IX Congreso Nacional de Arqueología Argentina, pp. 219-229, Buenos Aires.

-1993. Ensayo para una clasificación morfológica de artefactos líticos aplicados a estudios tipológicos comparativos. Apéndices A-C. Revisión. Cátedra de Ergología y Tecnología, FFyL-UBA. Buenos Aires, MS.

ASCHERO C., y S. HOCSMAN. 
-2004. Revisando cuestiones tipológicas en torno a la clasificación de artefactos bifaciales. Temas de Arqueología, Análisis Lítico. A. Acosta, D. Loponte y M. Ramos (eds), pp.: 7-26. Buenos Aires.

BABOT, M. P.

-2004. Tecnología y utilización de artefactos de molienda en el Noroeste Prehispánico. Tesis de Doctorado en Arqueología, Facultad de Ciencias Naturales e Instituto Miguel Lillo, Universidad Nacional de Tucumán. San Miguel de Tucumán.

-2006. El papel de la molienda en la transición hacia la producción agropastoril: un análisis desde la Puna meridional Argentina. Estudios Atacameños, 32: 75-92.

BAMFORTH, D. B.

-1986. Technological efficiency and tool curation. American Antiquity 51 (1): 38-50.

-1991. Technological organization and hunter-gatherer land use. American Antiquity 56: 216-235.

-1992. Quarries in Context: a regional perspective on lithic procurement. Perspectives in California Archaeology 2: 132-151.

BARBERENA, R.

-2008. Arqueología y Biogeografía Humana en Patagonia Meridional. Colección Tesis Doctorales de la SAA, Buenos Aires.

BARBERENA, R.,A. HAJDUK; A. F GIL, G. A NEME, V. A DURÁN, M. D GLASCOCK, M. GIESSO, K. BORRAZZO M. P. POMPEI; M L SALGÁN, V. CORTEGOSO, G. VILLAROSA y A. A RUGHINI.

-2011. Obsidians in the south-central Andes: geological, geochemical, and archaeological assessment of north Patagonian sources (Argentina).Quaternary International 245(1):25-36.

BARROS, M. P. y P. G. MESSINEO

-2004. Identificación y aprovisionamiento de ftanita o chert en la cuenca superior del Arroyo Tapalqué (Partido de Olavarría, Provincia de Buenos Aires, Argentina). Estudios Atacameños 28: 87-103.

BARTON, $\mathrm{H}$.

-2008. Expedient technologies and curated tools within a system of high residential mobility: An example using mass analysis of flakes from the Simpson desert, central Australia. Lithic Technology 33(1): 51-71.

BAYÓN, C. y N. FLEGENHEIMER

-2004. Cambio de planes a través del tiempo para el traslado de roca en la pampa bonaerense. Estudios Atacameños 28: 59-70.

BAYÓN, C., N. FLEGENHEIMER, M. VALENTE y A. PUPIO

-1999. Dime cómo eres y te diré de dónde vienes: procedencia de rocas cuarcíticas en la Región Pampeana. Relaciones de la Sociedad Argentina de Antropología XXIV: 187-217.

BAYÓN C., N. FLEGENHEIMER y A. PUPIO

-2006. Planes sociales en el abastecimiento y traslado de roca en la Pampa bonaerense en el Holoceno temprano y tardío. Relaciones de la Sociedad Argentina de Antropología XXXI: 19-27.

BECK KELLY, R.

-2008 Transport, distances and debitage assemblage diversity: an application of the field 
processing model to southern Utah toolstone procurement sites, American Antiquity 73 (4): 759- 780.

BECK, C., A.K. TAYLOR, G. T. JONES, C.M. FADEM, C. R. COOK y S. A. MILLWARD

-2002. Rocks are heavy: transport costs and Paleoarchaic quarry behaviour in the Great Basin. Journal of Anthropological Archaeology 21: 481-507.

BELARDI, J. B.

-2005. Paisajes arqueológicos: un estudio comparativo de diferentes ambientes patagónicos. Oxford, British Archaeological Reports 1390.

BELARDI, J. B. y L. A. BORRERO

-1999. El paisaje arqueológico de la margen norte del lago Argentino (Provincia de Santa Cruz, Argentina). Prehistoria 3: 35-64.

BELARDI, J. B.; L. A. BORRERO; P. A. CAMPAN; F. CARBALLO MARINA; N. V. FRANCO; M. F. GARCÍA; V. D. HORWITZ; J. L. LANATA; F. M. MARTIN; F. E. MUÑOZ; A. S. MUÑOZ y F. SAVANTI

-1992. Intensive archaeological survey in the Upper Santa Cruz basin, Southern

Patagonia. Current Anthropology 33: 451-454.

BELARDI, J. B., P. TIBERI, C. STERN y A. SÚNICO.

-2006. Al este del Cerro Pampa: ampliación del área de disponibilidad de la Pampa del Asador (Provincia de Santa Cruz). Intersecciones en Antropología 7: 27-36.

BELLELLI, C., F. X. PEREYRA y M. CARBALLIDO

-2006. Obsidian localization and circulation in northwestern Patagonia (Argentina): sources and archaeological record. En: Geomaterials in Cultural Heritage, M. Maggetti y B. Messiga (eds.), pp.: 241-255. Geological Society, Special Publications, Londres.

BERMÚDEZ, A. y D. DELPINO

-1990. La provincia basáltica andino cuyana. Revista de la Asociación Geológica Argentina XLIV (1-4) (1989): 35-55.

BERMÚDEZ, A., D. DELPINO, F. FREY Y A. SAAL

-1993. Los basaltos de retroarco extraandinos. En: Geología y Recursos Naturales de Mendoza. Relatorio, V. Ramos (ed.), pp.: 161-172. XII Congreso Geológico Argentino, Buenos Aires.

BERÓN, M.

-2004. Dinámica Poblacional y Estrategias de Subsistencia de Poblaciones Prehispánicas de la Cuenca Atuel-Salado-Chadileuvú-Curacó, Provincia de La Pampa. Tesis Doctoral Inédita. Facultad de Filosofía y Letras, UBA, Buenos Aires.

-2006. Base regional de recursos minerales en el occidente pampeano: procedencia y estrategias de aprovisionamiento. Relaciones de la Sociedad Argentina de Antropología № 31: 47-88.

-2010. Circuitos regionales y conflictos intergrupales prehispánicos. Evidencias arqueológicas de violencia y guerra en La Pampa occidental argentina. En: Actas del XVII Congreso Nacional de Arqueología Chilena, pp.: 493-502.

BERÓN, MÓNICA; CURTONI, RAFAEL 
-1998. Investigaciones arqueológicas en Pampa Seca, Cuenca del río Curacó, provincia de La Pampa. Intersecciones en Antropología, Vol. II pp.: 5-30.

-2002. Propuestas metodológicas para la caracterización arqueológica de canteras y talleres de la Meseta del Fresco (La Pampa, Argentina). En: Del Mar a los Salitrales. 10.000 de Historia Pampeana en el Umbral del Tercer Milenio. Mazzanti, D., M. Berón y F. Oliva (eds.), pp.: 171-184.

BERTOTTO, G.W.

-2000. Cerro Agua Poca, un cono basáltico cuaternario portador de xenolitos ultramáficos, en el oeste de la provincia de La Pampa, Argentina. Revista de la Asociación Geológica Argentina, 55(1-2): 59-71.

-2012. Descripción de muestras arqueológicas de La Payunia. Ms

BERTOTTO, G.W., C.A. CINGOLANI y E.A. BJERG

-2009. Geochemical variations in Cenozoic back-arc basalts at the border of La Pampa and Mendoza provinces, Argentina. Journal of South American Earth Sciences 28: 360-373.

BERTOTTO, G.WALTER; GARRIDO, MIRTA

-2010. Estudios petrográficos de muestras arqueológicas procedentes de la Provincia de Mendoza. Ms

BETTINI, F.H., POMBO, R.A., MOMBRÚ, C.A. y M.A. ULIANA

-1979. Consideraciones sobre el diastrofismo andino en la vertiente oriental de la Cordillera Principal, entre los $34^{\circ} 30^{\prime}$ y los $37^{\circ}$ Lat. Sur. : $7^{\circ}$ Congreso Geológico Argentino (Neuquén, 1978). Asociación Geológica Argentina, Vol. 1., pp.: 161-172.

BETTINGER, R.

1989. The Archaeology of Pynion House, Two Eagles, and Crater Middens: Three Residential Sites in Owen Valley, Eastern California. American Museum of Natural History, Anthropological Papers $\mathrm{N}^{\circ} 67$. New York.

-1991. Hunter Gatherers: Archaeological and Evolutionary Theory.Plenum, New York.

-2001 Holocene Hunter-Gatherers. En: Archaeology atthe Millennium, G. Feinman y D. Price (ed.), pp.: 137-186. Nueva York.

BETTINGER R. y M. BAUMHOFF

-1982. The Numic spread: Great Basin Cultures in Competition. American Antiquity 47 (3): 485-503.

BETTINGER, R, WINTERHALDER, $B$, MCELREATH, $R$

-2006. A simple model of technological intensification. Journal of Archaeological Science 33:538-545.

BINFORD, L. R.

-1973. Interassemblage Variability: The Mousterian and the 'Functional Argument'. En: The Explanation of Culture Change: Models in Prehistory. C. Renfrew (ed.), pp. 227-254. Londres.

-1975. Sampling, Judgment, and the Archaeological Record. En: Sampling in Archaeology. James W. Mueller, (ed.) University of Arizona Press, Tucson, pp. 251-257.

-1977. Forty-seven trips: A case study in the character of archaeological formation process. En: Stone Tools as Cultural Markers. R. Wright (ed.), pp.: 24-36. Australian Institute of Aboriginal Studies, Camberra.

-1978. Nunamiut Ethnoarchaeology. New York, Academic Press.

-1979. Organization and formation processes: looking at curated technologies. Journal of Anthropological Research 35 (3): 255-273. 
-1980. Willow smoke and dog's tails: hunter-gatherer settlement system and archaeological site formation. American Antiquity 45 (1): 4-20.

-1988. En Busca del Pasado. Editorial Critics, Barcelona, España.

-2001. Frames of Reference. University of California, Berkeley.

BINFORD, L. y G. I. QUIMBY

-1963. Indian Sites and Chippcd Stone Materials in the Northern Lake Michigan Area. En: An Archaeological Perspective, L. Binford (ed.). New York. Academic Press.

BINFORD, L. Y N. STONE

-1985. "Righteous rocks" and Richard Gould: some observations on misguided "debate". American Antiquity 50(1): 151-153.

BIRD D. y J. O'CONNELL

-2006. Behavioral Ecology and Archaeology. Journal of Archaeological Research 14: 143-188.

BLEED, $P$.

-1986. The Optimal Design of Hunting Weapons: Maintainability or Reliability. American Antiquity Vol. 51 (4): 737-747.

-1997. Content as variability, result as selection: A behavioral model for the study of technology. En: Rediscovering Darwin: Evolutionary theory and archaeological explanation. Archaeological Papers of the American Anthropological Association, American Anthropological Association. C. Barton \& G. Clark (eds.). N 7, pp.: 95-106. Washington.

BONNAT, G. F.

-2009. Estrategias de Abastecimiento y Producción Lítica Durante el Holoceno Tardío en el Sitio Valle Hermoso 1 (Malargüe, Mendoza). Tesis de licenciatura. Universidad del Centro de la Provincia de Buenos Aires, Facultad de Ciencias Sociales.

-2011. Abastecimiento y producción lítica en el sitio Valle Hermoso I (Malargüe, Mendoza). Interseccionesen Antropología 12: 121-134.

BONOMO, M.

-2005. Costeando Las Llanuras. Arqueología del Litoral marítimo pampeano. Sociedad Argentina de Antropología. Buenos Aires.

BONOMO, M. y L. PRATES

-2006. La explotación de depósitos secundarios de rodados en el curso medio del Río Negro y el litoral marítimo pampeano. En: Artefactos Líticos, Movilidad y Funcionalidad de Sitios en Sudamérica: Problemas y Perspectivas. Escola, P. y S. Hocsman (eds.), Oxford, BAR International Series. En Prensa.

BORRAZO, $\mathrm{K}$

-2010. Arqueología de los esteparios Fueguinos: Tecnología y Tafonomía Lítica en el Norte de Tierra del Fuego. Tesis doctoral, Universidad de Buenos Aires.

BORRERO, L.A.

-1989-1990. Evolución cultural divergente en la Patagonia austral. Anales del Instituto de la Patagonia; Serie Ciencias Sociales 19:133-140. Punta Arenas, Chile. 
-1991. Los “modelos de situaciones excepcionales" y el estudio de sociedades de cazadores y recolectores. Comechingonia 8 (7): 109-127

-1993. Site Formation Processes in Patagonia: Depositional Rates and the Properties of the Archaeological Record. En: Explotación de recursos faunísticos en sistemas adaptativos americanos. Arqueología Contemporánea 4 (1993): 107-122. Editado por: J. L. Lanata.-1994-95. Arqueología de la Patagonia. Palimpsesto 4: 9-69.

-1999. Human Dispersal and climatic conditions during Late Pleistocene times in Fuego- Patagonia. Quaternary International 53-54: 93-99.

-2002. Arqueología y biogeografía humana en el sur de Mendoza (Comentario crítico). En: Entre Montañas y Desiertos: Arqueología del sur de Mendoza, A. F. Gil y G. A. Neme (eds.), pp.: 195-202. Sociedad Argentina de Antropología. Buenos Aires.

-2004. The Archaeozoology of Andean 'Dead Ends' in Patagonia: Living near the Continental Ice Cap. En: Colonisation, Migration and Marginal Areas. A Zooarchaeological approach. M. S. Mondini; A. S. Muñoz y S. Wickler (ed.), pp. 55-61. Oakville, Oxbow Books.

BORRERO, L. A. y R. BARBERENA.

-2006. Hunter-Gatherer Home Ranges and Marine Resources. AnArchaeological Case from Southern Patagonia. Current Anthropology 47 (5): 855-867.

BORRERO, L.A y H. NAMI

-1996. Algunas Hipótesis y Propuestas de trabajo para una arqueología regional. Praehistoria 2: 35-41.

BORRERO, L. A.; J. L. LANATA y B. N. VENTURA.

-1992. Distribuciones de hallazgos aislados en Piedra del Águila. En: Análisis espacial en la arqueología patagónica. L. A.Borrero y J. L. Lanata (comp.), pp.: 9-20. Ediciones Ayllu, Buenos Aires.

BOUSMAN, C. B.

-1993. Hunter-Gatherer Adaptations, Economic Risk and Tool Design. Lithic Technology 18 (1/2): 59-86.

-2005. Coping with risk: Later stone age technological strategies at Blydefontein Rock Shelder, South Africa. Journal of Anthropological Archaeology 24: 193-226.

BRADBURY, A. Y P. CARR

-1995. Flake typologies and alternative approaches: an experimental assesment. Lithic Technology 20 (2): 100-115.

-1999. Examining Stage and Continuum Models of Flake Debris Analysis: An Experimental Approach. Journal of Archaeological Science 26: 105-116.

BRANTINGHAM, P. J.

-2003. A neutral model of stone raw material procurement. American Antiquity 68 (3): 487-509.

-2006. Measuring Forager mobility. Current Anthropology 47 (3): 435-459.

BRANTINGHAM P. J. AND KUHN S. L.

-2001. Constraints on Levallois Core Technology: A Mathematical Model. Journal of Archaeological Science 28: 747-761.

BUCHANAN L.J. 
-1981. Precious metal deposits associated with volcanic environments in the southwest. En: Relations of tectonics to ore deposits in the southern cordillera, Dickinson, W. R y Payne, W.D. (eds). Arizona Geological, Society Digest, 14: 237-269.

CABRERA, A.

-1976. Regiones fitogeográficas argentinas. En: Enciclopedia Argentina de Agricultura y Jardinería; Tomo II. ACME. Buenos Aires.

CAMPOS, G., CORTEGOSO V. Y MAZZANTI, C.

-2006. Estrategias tecnológicas y cambios en el uso de los Recursos Líticos. Caverna de las Brujas, Malargüe, Mendoza. En: Arqueología y ambiente de áreas naturales protegidas de la provincia de Mendoza. Durán V. y V, Cortegoso (eds.). Anales de Arqueología y Etnología. Vol. especial № 61: 33-52.

CANALS FRAU

-1956. Algunos aspectos de la cultura de Agrelo. En: Anales de Arqueología y Etnología. 12: 9-18. Universidad Nacional de Cuyo.

CANDIA, R.; A. PUIG; A. DALMASSO; F. VIDELA y E. MARTINEZ CARRETERO

-1993. Diseño del Plan de Manejo para la Reserva Provincial de La Payunia. Multiequina 2: 5-87. Mendoza.

CAPITANELLI, R.

-1972. Geomorfología y Clima de la provincia de Mendoza. Geología, Geomorfología, Climatología, Fitogeografía y Zoología de la provincia de Mendoza, Vol. XIII boletín de la Sociedad Argentina de Botánica. Ministerio de Mendoza.

-2005. Climatología de Mendoza. Ed. Facsimilar. Facultad de Filosofía y Letras. Universidad Nacional de Cuyo.

CARDILLO, M. Y J. CHARLIN

-2007. Tendencias observadas en la variabilidad de los raspadores de Norte y Sur de Patagonia. Explorando las interrelaciones entre forma, tamaño e historia de vida. Trabajo presentado en el 20 Congreso Argentino y 1o Latinoamericano de Arqueometría, Buenos Aires.

CARR, P.

-1994. The organization of technology: impact and potential. En: The Organization of North American Prehistoric Chipped Stone Toll Technologies, P. Carr (ed.), pp. :1-8. International Monographs in Prehistory, Archaeological Series 7.

CARR, D. y R. BOSZHARDT

-2010. Silver Mound, Wisconsin: Source of Hixton Silicified Sandstone. Midcontinental Journal of Archaeology, Vol. 35 (1), pp.: 5.

CARRETERO, E. M

-2006. Payunia, Reserva Natural y Provincia Fitogeográfica. En: Arqueología y Ambiente de Áreas Naturales Protegidas de la Provincia de Mendoza, Vol. especial N 61, Anales de Arqueología y Etnología. Duran V. y V. Cortegoso (eds.), Mendoza.

CATTÁNEO, R. 
-2004. Desarrollo metodológico para el estudio de fuentes de aprovisionamiento lítico en la meseta central santacruceña, Patagonia argentina. Estudios Atacameños 28: 105-119.

CHARLIN, J.

-2007. Una perspectiva espacial de la intensidad de uso de las materias primas líticas en el campo volcánico Pali Aike (Prov. Santa Cruz, Argentina). En: Arqueología de Fuego-Patagonia. Levantando piedras, desenterrando huesos... y develando arcanos. F., M. Carballo, A. Martinic, Prieto, y G. Bahamonde (eds.), pp.: 129-150. CEQUA. Punta Arenas, Chile.

-2009. Aprovisionamiento, explotación y circulación de obsidianas durante el Holoceno tardío en Pali Aike (Provincia de Santa Cruz). Relaciones de la Sociedad Argentina de Antropología XXXIV: 53-73.

CHARNOV E.L.

-1976. Optimal foraging, the marginal value theorem. Theoretical Population Biology 9: 129-136.

$\mathrm{CHURCH}, \mathrm{T}$.

1994. Terms in lithic resource studies. Lithic resource studies: a source for archaeologist. Lithic Technology 3: 9-25.

CIVALERO, M. T. y N. FRANCO.

2003. Early Human Occupations in Western Santa Cruz Province, Southernmost South America. Quaternary International 109-110: 77-86.

CLARKSON, C.

-2002. An index of invasiveness for the measurement of unifacial and bifacial retouch: a theoretical, experimental and archaeological verification. Journal of Archaeological Science 29: 65-75.

COLLINS, M

-1975. Lithic Technology as a Means of Processual Inference, En: Lithic Technology: Making and Using Stone Tools, E. Swanson (ed.): 15-34, Mouton, The Hague.

CORTEGOSO, $\mathrm{V}$.

-2005. Aproximaciones teóricas y metodológicas para el estudio tecnológico: variables sincrónicas y diacrónicas en el análisis lítico. Anales de Arqueología y Etnología 59/60: 107-148.

CORTEGOSO V., G. NEME, M. GIESSO, V. DURÁN y A. GIL

-2012. El uso de la obsidiana en el sur de Mendoza. En: Paleoecología humana en el sur de Mendoza, Gil A. y G. Neme (eds.). Sociedad Argentina de Antropología. En Prensa.

CUSTER J., J. CAVALLO Y M. STEWART

-1983. Lithic Procurement an Paleo-Indian Settlement Patterns on the Middle Atlantic Coastal Plain. North American Archaeologist 4: 263-275.

DALMASSO, A. D.

-2010. Revegetación de áreas degradadas con especies nativas. Boletín de la Sociedad Argentina Botánica 45 (1-2): 149-171.

DAVID, N. y C. KRAMER.

-2001. Ethnoarchaeology in Action. Cambridge, Cambridge World Archaeology. 
DIBBLE, H. L.

-1984. Interpreting typological variation of Middle Paleolithic scraperss: function, style, or sequence of reduction? Journal of Field Archaeology 11: 431-436.

-1987. The interpretation of Middle Paleolithic Scraper Morfology. American Antiquity 52 (1): 109-117.

-1991. Rebuttal to Close. Journal of Field Archaeology 18: 264-267.

-1997. Platform variability and flake morphology: a comparison of experimental and archaeological data and implications for interpreting prehistoric lithic technological strategies. Lithic Technology 22 (2): 150-170.

-1998. Comment on Quantifying lithic curation: an experimental test of Dibble and Pelcin's original flaketool mass predictor, by Zachary J. Davis and John J. Shea. Journal of Archaeological Science 25: 611-613.

DIBBLE, H. Y A. PELCIN

-1995. The effect of hammer mass and velocity on flake mass. Journal of Archaeological Science 22: 429.439 .

DELENDATTI, G.L.

-2005. The La Cabeza Gold-Silver Deposit: A Low-Sulphidation Epithermal System in the Bloque de San Rafael, Mendoza, Argentina. VIII Congreso Argentino de Geología Económica: 199-206. Buenos Aires.

DE FRANCESCO, A., DURÁN, V., BLOISE, A. Y G.NEME.

-2006. Caracterización y procedencia de obsidianas de sitios arqueológicos del área natural protegida Laguna del Diamante (Mendoza, Argentina) con metodología no destructiva por fluorescencia de rayos (XRF). Anales de Arqueología y Etnología 61: 53-67.

DINCAUZE, D.

-2000. Environmental Archaeological Principles and Practice. Cambridge University Press, Cambridge.

DUNNELL, R. Y W. DANCEY

-1983. The siteless survey: a regional scale data collection strategy. Advances in Archaeological Method and Theory 6: 267-287.

DURÁN, V.

-1992. Estudios Arqueológicos en el Curso Medio del Valle del Río Grande (Malargüe, Mendoza). Manuscrito. Informe final beca de formación superior. CONICET. Buenos Aires.

-1997. Arqueología del Valle del Río Grande, Malargüe, Mendoza. Tesis Doctoral. Facultad de Ciencias Naturales y Museo, Universidad Nacional de la Plata.

-2000. Poblaciones Indígenas de Malargüe. Su arqueología e historia, Universidad Nacional de Cuyo, Facultad de Filosofía y Letras, CEIDER, $N^{\circ} 1$, Mendoza.

-2002. Nuevas consideraciones sobre la problemática arqueológica del valle del río Grande (Malargüe, Mendoza). En: Entre Montañas y Desiertos: arqueología del sur de Mendoza. A. Gil y G. Neme (eds.), Sociedad Argentina de Antropología, Buenos Aires.

DURÁN V. y M. ALTAMIRA

-2001. Estudios Arqueológicos en la Reserva Natural Caverna de las Brujas (Malargüe, Mza). Actas de las III Jornadas de Arqueología de la Patagonia. Buenos Aires. 
DURÁN V., Y R. MIKKAN

-2009. Impacto Del volcanismo holocénico sobre el poblamiento humano del sur de Mendoza (Argentina). Intersecciones en Antropología 10, pp.: 295-310.

DURÁN V., M. GIESSO, M. GLASCOCK, G. NEME, A. GIL y L. SANHUEZA

2004. Estudios de fuentes de aprovisionamiento y redes de distribución de obsidiana durante el Holoceno Tardío en el sur de Mendoza (Argentina). Estudios Atacameños 28: 25-43.

ECHAVARRÍA, L. E.

1997. Texturas de cuarzo del depósito epitermal El Dorado-Monserrat, Provincia de Santa Cruz: descripción e implicancias genéticas. Asociación Geológica Argentina, Vol. 52 (4): 491-502.

ELÍAS, A. M.

2007. Tecnología lítica entre las sociedades de ca. 1000 años AP en Antofagasta de la Sierra (Prov. de Catamarca, Puna Meridional Argentina). Estudios Atacameños 33: 59-85.

ELÍAS, A., P. ESCOLA y P. TCHILINGUIRIAN,

2007. ¿Cómo dos gotas de agua?: Análisis petrográfico de recursos líticos de la microrregión Antofagasta de la Sierra (prov. de Catamarca, Puna Meridional argentina). Resúmenes del 2o Congreso Argentino y 10 Latinoamericano de Arqueometría, T. Palacios (ed.), pp. 84-85. Comisión Nacional de Energía Atómica, Centro Atómico Constituyentes, Buenos Aires.

ELÍAS, A. M. y ESCOLA, P. S.

2010. Viejos y Nuevos Horizontes: Obsidianas entre Sociedades Agrícolas-Pastoriles del Período Tardío en Antofagasta de la Sierra (Prov. de Catamarca, Puna Meridional Argentina). Revista Española de Antropología Americana, Vol. 40 p. 9 - 29

ELSTON, R. G.

1986. Prehistory of the Western Area. En Great Basin, editado por W. L. d'Azevedo. Handbook of North American Indians, Vol. 11, pp.: 135-148. Smithsonian institution, Washington D.C.

1989. The Tosawihi Quarries: An Archaeologicla Testing Program. Intermontain Research Reports, Reno, Nevada.

1992. Modeling the economics and organization of lithic procurement. En: Archaeological Investigations at Tosawhi, a great basin quarry, R. G. Elston y R. C. Raven (eds.), II Vol. Roport, Intermountain Research.

EREN, METIN I., MANUEL DOMINGUEZ-RODRIGO, IAN LE, DANIEL S. ADLER, STEVEN L. KUHN, AND OFER BAR-YOSEF.

-2005. Defining and measuring reduction in unifacial scrapers. Journal of Archaeological Science 32: 11901201.

ERICSON, J. E.

-1984. Toward the analysis of lithic production system. En: Prehistoric Quarries and Lithic Production, J. E. Ericson y B. Purdy (eds.), pp.: 1-9.Cambridge University Press.

EERKENS, J.W. Y C.P. LIPO 
2007. Cultural transmission theory and the archaeological record: providing context to understanding variation and temporal changes in material culture. Journal of Archaeological Research15:239-274.

ESCOLA, P. S.

-2000.Tecnología Lítica y Sociedades Agro-pastoriles Tempranas. Tesis Doctoral Inédita, Facultad de Filosofía y Letras, UBA.

-2003 Disponibilidad de recursos líticos y fuentes de aprovisionamiento en un sector de la Puna meridional. Mundo de Antes 3: 65-86. Revista del Instituto de Arqueología y Museo. Facultad de Ciencias Naturales e I.M.L. Universidad Nacional de Tucumán.

-2004. La expeditividad y el registro arqueológico. Chúngara; vol. Especial, pp.: 49-60.

ESCOLA, P. Y S. HOCSMAN.

-2007. Procedencia de artefactos de obsidiana de contextos arqueológicos de Antofagasta de la Sierra (ca. 4500-3500 AP). Comechingonia, 10: 49-62.

FALABELLA, F. Y R. STEHBERG

-1989. Los inicios del desarrollo agrícola y alfarero: zona central (330 a.C. a 900 d.C.). En: Culturas de Chile. Prehistoria, J. Hidalgo, V. Schiappacasse, H. Niesmeyer, C. Aldunate e I.Solimano (Eds.); pp.: 295311. Editorial Andrés Bello. Chile.

FERNÁNDEZ, F.J.

-2012. Microvertebrados del Holoceno de sitios arqueológicos en el sur de Mendoza (República Argentina): aspectos tafonómicos y sus implicancias en la subsistencia humana. Tesis Doctoral inédita. Facultad de Ciencias Naturales y Museo, Universidad Nacional de La Plata.

FLEGENHEIMER N, S. KAIN, M. ZÁRATE Y A. BARNA

-1996. Aprovisionamiento de rocas cuarcíticas en Tandilia. Las canteras del Arroyo Diamante. Arqueología 6: 117- 143, Revista de la Sección Prehistoria, ICA-UBA, Buenos Aires.

FLEGENHEIMER, N. Y C. BAYÓN

-1999. Abastecimiento de rocas en sitios pampeanos tempranos. Recolectando colores.

En: Los Tres Reinos: Prácticas de Recolección en el Cono Sur de América, C. Aschero, A. Korstanje y P.M. Vuoto (eds.), pp.: 95-107. Magna Publicaciones. Tucumán.

FLEGENHEIMER, N. Y C. BELLELLI

-2007. La arqueología y las piedras, un recorrido por los estudios líticos en Argentina.

Relaciones de la Sociedad Argentina de Antropología XXXII: 141-168.

FOLEY, R.

-1981a. Off-Site Archaeology and Human Adaptation in Eastern Africa. An Analysis of Regional Artefact Density in the Amboseli, Southern Kenia. Cambridge Monographs in African Archaeology 3. BAR International Series 97. Oxford.

-1981b. Off Site Archaeology: an Alternative Approach for the Short Sited. En: Pattern in the Past: Essays in Honour of David Clarke, I. Hodder; N. Hammond y G. Isaac (eds.), pp. 157-183. Cambridge University Press, Cambridge.

1985. Optimality Theory in Anthropology. Man 20: 222-242.

FOLGUERA, A., G. BOTTESI, T. ZAPATA y V.A.RAMOS 
-2008. Crustal collapse in the Andean backarcsince 2 Ma: Tromen volcanic plateau, Southern Central Andes (3640"-37³0"S). Tectonophysics 459: 140-160.

FRANCO, V. N.

-1994. Maximización en el aprovechamiento de los recursos líticos. Un caso analizado en el Área Interserrana Bonaerense. En: Arqueología de cazadores recolectores. Límites, casos y aperturas. J. L. Lanata y L. A. Borrero (comp), pp.: 75-88. Arqueología contemporánea 5. Edición Especial.

-2002a. Estrategias de utilización de recursos líticos en la cuenca superior del río Santa Cruz. Tesis doctoral inédita. Universidad de Buenos Aires.

-2002b. ¿Es posible diferenciar los conjuntos líticos atribuidos a la exploración de un espacio de los correspondientes a otras etapas del poblamiento? Revista Werken 3: 119-132. Santiago de Chile, Chile.

-2004. La organización tecnológica y el uso de las escalas espaciales amplias. El caso del sur y oeste de Lago Argentino. Temas de Arqueología, Análisis Lítico A. Acosta, D. Loponte y M. Ramos (eds.), pp.:101-144, Buenos Aires.

-2007. Lithic Artifacts and the Information about Human Utilization of Large Areas. En: Artefactos Líticos, Movilidad y Funcionalidad de Sitios: Problemas y Perspectivas, P. Escola y S. Hocsman (eds.), British Archaeological Reports, John and Erica Hedge Ltd., Oxford, United Kingdom: En prensa.

FRANCO, N. V. y E. ARAGÓN.

-2002. Muestreo de fuentes potenciales de aprovisionamiento lítico: un caso de estudio. En: Del Mar a los Salitrales. Diez mil Años de Historia Pampeana en el Umbral del Tercer Milenio, D. Mazzanti, M. Berón y F. Oliva, pp.: 243 - 250. Universidad Nacional de Mar del Plata y Sociedad Argentina de Antropología, Mar del Plata.

FRANCO V. N. y L. A. BORRERO

-1999. Metodología de análisis de la estructura regional de recursos líticos. En: En los tres reinos de recolección. Cono Sur de América, Aschero C., Kostanje y Vuoto (eds.), pp.: 27-37. Instituto de Arqueología y Museo, Tucumán.

FRISON, G. C., AND B. A. BRADLEY

-1980 Folsom Tools and Technology at the Hanson Site, Wyoming. University of New Mexico Press, Albuquerque.

FRISON, G. Y D. J. STANFORD

-1982. The Agate Basin Components. En: G. Frison y D. Stanford (eds.). The Agate Basin Site: 76-142, New York, Academic Press.

GAMBIER, M.

-1976 Ecología y Arqueología de los Andes Centrales Argentino-Chilenos, Actas y Memorias, IV Congreso Nacional de Arqueología Argentina, Tomo III (1/4): 185-199, San Rafael.

-1979. Investigaciones arqueológicas en la región del Alto río Diamante, Provincia de Mendoza. Publicaciones del Instituto de Investigaciones Arqueológicas y Museo 5. San Juan.

-1980. Excavaciones en la Gruta de El Manzano, Río Grande-Mendoza. Boletín del Museo de Ciencias Naturales y Antropológicas Juan Cornelio Moyano 1: 45-55.Mendoza.

-1985. La Cultura de los Morrillos. Instituto de Investigaciones Arqueológicas y Museo. Facultad de Filosofía, Humanidades y Artes. Universidad Nacional de San Juan, San Juan. 
-1987. Excavaciones arqueológicas en la Gruta El Manzano. En: 1ras Jornadas de Arqueología de la Patagonia-Comunicaciones. Gobierno de la Provincia de Chubut. Serie Humanidades 2: 123. Chubut.

GAMBLE, C.

-1990. El Poblamiento Paleolítico de Europa. Editorial Crítica, España.

-1993. Exchange, foraging and local hominid networks. En: Trade and Exchange in Prehistoric Europe, C. Scarre y F. Healy (eds.), pp.: 35-44. Oxbow Books. Oxford.

-1993. Exchange, foraging and local hominid network. En: Trade and exchange in prehistoric Europe, Scarre C.y F. Healy (eds.), pp.: 35-44, Oxbow Books, Oxford.

GARGIULO, M. F., N. RUBINSTEIN, F. CARPIO y J. SALVARREDI

-2007. Caracterización de lo zona de alteración Central II, Bloque San Rafael, provincia de Mendoza. Revista de la Asociación Geológica Argentina 62(3): 387-395.

GARVEY R.

-2008. A Behavioural Ecological Approach to a Proposed Middle Holocene Occupational Gap. Before Farming 2008 (2):1-14.

2008b. A model of lithic raw material procurement. En: Strangers no more: method and theory in flaked stone studies C. Berg y C. Ward (eds.), Alabama, University of Alabama Press. En prensa.

GENESTE J-M.

-1988 Systemes d'approvionnement en matières premières lithiques au Paléolithique Moyen et au Paléolithique Superieur en Aquitaine. L'Homme de Néandertal 8: 61-70 La Mutation. Liège.

-1991. Développement des systèmes de production lithique au cours du Paléolithique Moyen en Aquitaine Septentrionale. Mémoirs du Musée de Préhistorique d'lle-de-France 3: 203-213.

GERMA, A., QUIDELLEUR, X., GILLOT, P.Y. Y TCHILINGUIRIAN, P.

-2010. Volcanic evolution of the back-arc Pleistocene Payún Matrú Volcanic Field (Argentina). Journal of South American Earth Sciences 29: 717-730.

GIARDINA, M.

-2010. El aprovechamiento de la avifauna entre las sociedades cazadoras-recolectoras del sur de Mendoza: un enfoque arqueozoológico. Tesis doctoral inédita. Facultad de Ciencias Naturales y Museo. Universidad Nacional de La Plata. La Plata.

-2012. Intensificación en el sur de Mendoza. Un enfoque avifaunístico. Archaeofauna. En prensa.

GIESSO M., M. D. GLASCOCK, V. DURÁN, V. CORTEGOSO, A. GIL, G. NEME Y L. SANHUEZA

-2008. Tendencias temporales y espaciales en el uso de la obsidiana en los andes meridionales. MS.

GIESSO, M., DURÁN, V., NEME, G.A., GLASCOCK, M.D., CORTEGOSO, V., GIL, A.F. Y L. SANHUEZA

-2011a. Application of a Portable XRF to Study Obsidian Use in the Central Andes region of Argentina and Chile.Archaeometry 53 (1): 1-21.

GIESSO, M., V. DURÁN, V. CORTEGOSO Y M. D. GLASCOCK 
-2011b. Circulación de obsidiana y redes de interacción inter-regionales en el extremo norte de la Patagonia argentina. Trabajo presentado en las VII Jornadas de Arqueología de la Patagonia, Libro de Resúmenes: 38. Malargüe, Mendoza

GIL, A. F.

-1997-1998. El significado de los cultígenos prehispánicos registrados en el sur mendocino. Discusiones en torno al límite meridional de la agricultura andina. Relaciones de la Sociedad Argentina de Antropología XXII-XXIII: 295-318.

-2000. Arqueología de La Payunia; Sur de Mendoza. Tesis Doctoral. Facultad de Ciencias Naturales y Museo. Universidad Nacional de La Plata. La Plata.

-2002. El registro arqueológico y la ocupación humana en La Payunia. En: Entre Montañas y el Desierto: Aportes a la Arqueología del Sur Mendocino, A. Gil y G. Neme (eds), pp.: 103-118. Sociedad Argentina de Antropología, Serie Libros, Buenos Aires.

-2006. Arqueología de la Payunia (Mendoza, Argentina). El poblamiento humano en los márgenes de la agricultura. BAR International Series 1477, Inglaterra.

GIL, A. y G. NEME.

-2002. Entre Montañas y el Desierto: Aportes a la Arqueología del Sur Mendocino: 103-118. Ed. A. Gil y G. Neme. Sociedad Argentina de Antropología, Serie Libros.

-2005. Aportes para la discusión del intercambio en el sur de Mendoza. Actas XVI Congreso Nacional de Arqueología

Chilena. http//www.arqueologiamendoza.com.ar/secciones/publicaciones/publicaciones.html

-2006. Distribuciones arqueológicas superficiales en Payunia-Llancanelo. Anales de Arqueología y Etnología 61: 163-184.

-2010 Registro arqueológico en la cuenca media del Atuel: viejos y nuevos problemas; viejos y nuevos datos. En Condiciones Paleoambientales y ocupaciones humanas durante la transición PleistocenoHoloceno de Mendoza, M. Zárate, A. Gil y Gustavo Neme (eds.), pp.: 239-275. Publicaciones de la Sociedad Argentina de Antropología, Buenos Aires.

GIL, A., M. ZÁRATE Y G. NEME.

-2005. Mid-Holocene Paleoenvironments and the archaeological record of southern Mendoza, Argentina. Quaternary International 132: 81-94.

GIL, A., R. H. TYKOT, G. NEME, Y N. R. SHELNUT

-2006. Maize on the Frontier. Isotopic and Macrobotanical Data from Central-Western Argentina. En Histories of Maize, J. Staller, R. Tykot y B. Benz (eds.), pp. 199-214. Academic Press, London.

GIL, A., G. NEME, V. DURÁN, M. GIARDINA, P. NOVELLINO, L. DE SANTIS Y D. MIGUELISSI.

-2007. Exploraciones arqueológicas en Laguna Llancanelo (Mendoza, Argentina). En: Arqueología de Fuego Patagonia. Levantando piedras, desenterrando huesos...y develando arcanos, pp.: 453-465.

GIL, A., L. SALGÁN y G. NEME

2011. Obsidian Sources Explotation in the La Payunia Volcanic Field (Mendoza Province, Argentina). Trabajo presentado en el $78^{\circ}$ Annual Meeting of SAA. Sacramento, USA.

GIL, A., G. NEME, A. UGAN Y R. H. TYKOT

-2011. Oxygen Isotopes and Human Residential Mobility in Central Western Argentina. International Journal of Osteoarchaeology. En Prensa. 
GLASCOCK, M. D.

-2010. Comparison and contrast between XRF and NAA: Used for characterization of obsidian sources in Central Mexico. En: X Ray Fluorescence Spectrometry (XRF) in Geoarchaeology, M.S. Shackley (ed.), pp.: 161-192. Springer: NewYork.

-1998. A systematic approach to obsidian source characterization. En: Archaeological obsidian studies: Method and theory, Advances in archaeological and museum science, Vol. 3: 15-65, MS. Shackley (ed.). Plenum Press, Nueva York.

-2011. X-ray Fluorescence Analysis of Obsidian from Argentina. Archaeometry Laboratory. Ms.

GÓMEZ OTERO, J. Y CH. STERN.

-2005. Circulación, intercambio y uso de obsidianas en la costa de la provincia del Chubut (Patagonia argentina), durante el Holoceno tardío. Intersecciones en Antropología 6: 93-108.

GOULD, R.A

-1968. Living Archaeology: The Ngatatjara of Western Australia. Southwestern Journal of Anthropology, Vol. 24 (2), pp.: 101-122.

-1971. The Archaeologist as Ethnographer: A Case from the Western Desert of Australia. World Archaeology, Vol. 3 (2), pp.: 143-177.

-1977. The Archaeologist as Ethnographer. En: Horizons of Anthropology, S. Tax y L. G. Freemen (eds.), pp.: 151-170. Aldine, Chicago.

-1978. The anthropology of human residues. American Anthropologist 80: 815-835.

-1979. Exotic Stones and Battered Bones. Archaeology, Vol. 32 (2) pp.: 28-37.

-1980 Living Archaeology.Cambridge: Cambridge University Press.

-1991. Arid-land foraging as seen from Australia: adaptative models and behavioral realities. Oceania 62: 12-33.

GOULD, R. y S. SAGGERS.

-1985. Lithic procurement in Central Australia: a closer look at Binford's idea ofembeddedness in archaeology. American Antiquity 50 (1): 117-136.

GONZÁLEZ DÍAZ, E.

-1972. Descripción Geológica de la Hoja 30e, Agua Escondida. Boletín 135. Servicio Geológico Nacional. Buenos Aires.

-1979. Descripción Geológica de la Hoja 31d, La Matancilla. Boletín 173. Servicio Geológico Nacional. Buenos Aires.

GONZÁLES DÍAZ E. Y L. FAUQUÉ.

-1993. Geomorfología. XII Congreso Geológico Argentino y II Congreso de Exploración de Hidrocarburos, pp.: 217-224. Geología y Recursos Naturales de Mendoza, Mendoza.

GOTELLI, N. Y G. GRAVES

-1996. Null models in ecology. Smithsonian Institution Press, Washington y London.

GRAYSON, D. K.

-1989 Bone transport, bone destruction, and reverse utility Curves. Journal of archaeological Science, 16, pp. 643-652. 
GRAYSON, D.K. Y DELPECH, F.

1998. Changing diet Breadth in the early Upper Paleolithic of southwestern France. Journal of archaeological Science 25, PP.:360-401.

GROEBER, P.

-1926. Toponimia Araucana. Sociedad Argentina de Estudios Geográficos, Anales 2 (1), Buenos Aires.

-1933. Confluencia de los ríos Grande y Barrancas (Mendoza y Neuquén). Descripción de la hoja 31c del mapa geológico general de la República Argentina. Dirección de Minas y Geología, Boletín 38, Buenos Aires.

-1937. Descripción geológica de la Hoja 30c, Puntilla de Huincán, provinciade Mendoza. Dirección Nacional de Geología y Mineria (Inédito), Buenos Aires

-1946. Observaciones geológicas a lo largo del meridiano 70. 1. Hoja Chos Malal. Revista de la Asociación Geológica Argentina I (3), 177-211.

-1947. Observaciones geológicas a lo largo del meridiano $70^{\circ} .2$ Hojas Sosneado y Maipo. Sociedad Geológica Argentina, Revista 2(2): 141-176. Asociación Geológica Argentina, Serie C, Reimpresiones 1: 1-174, Buenos Aires.

-1980. Reimpreso en Asociación Geológica Argentina, Serie C, Reimpresiones 1: 1-174, Buenos Aires.

GUDNASON J. , H.P. MARTIN, SØAGER, NINA, LLAMBÍAS, EDUARDO J.

-2012. Geochronology of the late Pliocene to recent volcanic activity in the Payenia back-arc volcanic province, Mendoza Argentina. Journal of South American Earth Sciences 37, pp.: 191-201.

HALLER, M. Y C. RISSO.

-2011. La erupción del volcán Peteroa (35015’S, 7018'O) del 4 de septiembre de 2010. Revista de la Asociación Geológica Argentina 68(2): 295 - 305.

HAMMER, Ø., HARPER, D.A.T., AND P. D. RYAN,

-2001. PAST: Paleontological Statistics Software Package for Education and Data Analysis. Palaeontologia Electronica 4(1): 9pp. http://palaeoelectronica. org/2001_1/past/issue1_01.htm.

HAMMER, $\varnothing .$, HARPER, D. Y P. RYAN

-2004. PAST - PAlaeontological STatistics, versión. 1.21.http://folk.uio.no/ohammer/past

HAURY, C. E.

-1995. Defining Lithic Procurement Technology. En: Lithic Resource Studies: A Sourcebook for Archaelogists, T. Church (ed.), pp.: 26-31. Lithic Technology, Special Publication 3. Department of Anthropology, University of Tulsa.Tulsa, Oklahoma.

HAYDEN, B

-1979. Palaeolithic reflections. Lithic technology and ethnographic excavations among Australian Aborigines. Australian Institute of Aboriginal Studies, Canberra, Australia. Humanities Press Inc., New Jersey, U.S.A.

-1980. Confusion in the bipolar world: bashed pebbles and splinter pieces. Lithic Technology IX(1):2-7.

-1998 [1977]. Stone tool functions in the Western Desert. En: Archaeology of Aboriginal Australia: A reader, T. Murray (ed.), pp.: 266-284. Sydney. Unwin and Allen.

-1979. Palaeolithic reflections. Lithic technology and ethnographic excavations among Australian Aborigines. Australian Institute of Aboriginal Studies, Canberra, Australia. Humanities Press Inc., New Jersey, U.S.A. 
-1989. From chopper to celt: the evolution of resharpening techniques. En Time, energy and stone tools, ed. por R. Torrence, pp. 7-16. Cambridge University Press, Cambridge.

HAYDEN B. y S.HUTCHINGW

-1989: "Whither the Billet Flake?" En: Experiments in Lithic Tecnology. B.A.R. London. pp 235-258.

HENRY, D. O.

-1989. Correlations between reduction strategies and settlement patterns. Archaeological Papers of the American Anthropological Association. Special Issue: Alternative Approaches to Lithic Analysis 1(1): 139-155.

HERMO, D.O.

-2008. Los cambios en la circulación de las materias primas líticas en ambientes mesetarios de Patagonia. Tesis Doctoral. Facultad de Ciencias Naturales. Universidad Nacional de La Plata. 2 tomos. La Plata.

HERNANDO, I., LLAMBIAS, E. J. Y GONZALEZ, P.D.

-2008. Historia eruptiva y formación de la caldera del volcán Payún Matrú, retroarco andino del sureste de Mendoza. En: $17^{\circ}$ Congreso Geológico Argentino, Actas: 1361-1362, Jujuy.

HERNANDO, IRENE R; LLAMBIAS, EDUARDO J; GONZALEZ, PABLO D Y SATO, KEI.

-2012 Volcanic stratigraphy and evidence of magma mixing in the Quaternary Payún Matrú volcano, andean backarc in western Argentina. Andean Geology 2012, Vol. 39 (1), pp.: 158-179.

HISCOCK, P.

-2001. Looking the other way. A materialist/technological approach to classifying tools and implements, cores and retouched flakes. En: Tools or cores? The identification and study of alternative core technology in lithic assemblages, S. McPherron y J. Lindley (eds.). University of Pennsylvania Museum.

-1994. Technological responses to risk in Holocene Australia. Journal of World Prehistory 8 (3): 267- 292.

-2002. Quantifying the size of artifact assemblages. Journal of Archaeological Science 29: 251-258.

HISCOCK, P. y V. ATTENBROW

-2002. Morphological and reduction continuums in Eastern Australia: Measurement and implications at Capertee 3. Tempus 7: 167-174.

-2003. Early Australian implement variation: a reduction model. Journal of Achaeological Science 30: 239249.2005 Australia's Eastern Regional Sequence revisited: Technology and change at Capertee 3. British Archaeological Reports. International Monograph Series 1397. Oxford: Archaeo press.

HISCOCK, P. Y C. CLARKSON

-2005a. Measuring artefact reduction. An examination of Kuhn's geometric index of reduction. En: Lithics "Down Under". Recent Australian Approches to lithic reduction, use and classification. C. Clarkson y L. Lamb eds. British Archaeological Reports International Monograph series. Oxford: Archaeopress.

-2005b. Experimental evaluation of Kuhn's geometric index of reduction and the flat-flake problem. Journal of Achaeological Science 32: 1015-1022. 
HOARD, R J; J R BOZELL; S R HOLEN; M D GLASCOCK; H NEFF Y J M ELAM

-1993. Source Determination of White River Group Silicates from Two Archaeological a Sites in the Great Plains, American Antiquity 58 (4): 698-710.

HURLBUT D.

-1960. Manual de mineralogía. Ed. Reverté, Barcelona.

INGBAR, E.

-1994. Lithic Material Selection and Technological Organization. En: The organization of North American prehistoric chipped stone Technologies, P. Carr (ed.), pp.: 45-56. International Monographs in Prehistory. Archaeological Series 7. Michigan.

INGBAR M. Y RISSO C.

-2001. Holocene yardangs in volcanic terrains in the Southern Andes, Argentina. Earth Surface Processes and Landforms 26, pp.: 657-666.

INGBAR, E., M. LARSON y B. BRADLEY

-1989 A Nontypological Approach to Debitage Análisis, En: DS. Amick y R.P Mauldin (eds.) Experiments in Lithic Technology, pp.: 67-99, BAR International Series 528, Oxford.

INGOLD, T

-2000. The Perception of the Environment: Essays in Livelihood, Dwelling and Skill, Routledge, New York.

IRIARTE, J.

1995. Afinando la puntería: tamaño, forma y rejuvenecimiento en las puntas de proyectil pedunculadas del Uruguay. En: Arqueología en el Uruguay. VII Congreso Nacional de Arqueología Uruguaya, M. Consens, J. M. López Mass y M. C. Curbelo (ed.).

JESKE, R. J.

-1989. Economics in raw material use by prehistoric hunter-gatherer. En: Time, energy and stone tools, Torrance Robin (ed.), pp.: 34-56. Cambridge University Press. Cambridge.

-1992. Energetic Efficiency and Lithic Technology: An Upper Mississippian Example. American Antiquity, Vol 57 (3): 467-481.

JOCHIM, M.

1981. Strategies for Survival, Cultural Behavior in an Ecological Context. Academic Press.

JOHNSON, J.K.,

1984. Measuring Prehistoric Quarry Site Activity in Northeastern Mississippi. En: Butler, B.M., May, E.E. (Eds.), Prehistoric Chert Exploitation: Studies from the Midcontinent. Center for Archaeological Investigations Occasional Paper No. 2. Southern Illinois University at Carbondale, pp. 225-235.

-1989. The Utility of Production Trajectory Modeling as a framework for regional analysis. En: Alternative Approaches to Lithic Analysis Archaeological Papers of the American Anthropological Association 1, Henry, D.O., Odell, G.H. (Eds.), pp.: 119-133.

JONES, G. Y R. LEONARD

1989. The concept of diversity: an introduction. En: Quantifying Diversity in Archaeology, R. Leonard y G. Jones (eds), pp.: 1-3. Cambridge University Press, Cambridge. 
JONES, G.T., BECK, C., JONES, E.E., HUGHES, R.E.,

-2003. Lithic Source Use and Paleoarchaic Foraging Territories in the Great Basin. American Antiquity 68 (1): 5-38.

JONES G.T, L. M. FONTES, R. A. HOROWITZ, C. BECK, y D. G. BAILEY

2012. Reconsidering Paleoarchaic Mobility in the Central Great Basin . En: American Antiquity, Vol. 77 (2): 351-368.

JUNGERS, W. L.; A. B. FALSETTI y C. E. WALL

1995 Shape, relative size, and size-adjustments in morphometrics. En: Yearbook of Physical Anthropology 38: 137-161.

KAY, S.M., GORRING, M. Y RAMOS, V.A.

-2004. Magmatic sources, setting and causes of Eocene to Recent Patagonian plateau magmatism $\left(36^{\circ} \mathrm{S}\right.$ to 52º S latitude). Revista de la Asociación Geológica Argentina 59(4): 556568.

KAY, S.M., BURNS, W.M., COPELAND, P., MANCILLA, O.,

-2006. Upper Cretaceous to Holocene magmatism and evidence for transient Miocene shallowing of the Andean subduction zone under the northern Neuquén Basin. En: Evolution of an Andean margin. A tectonic and magmatic view from the Andes to the Neuquén Basin (35-39 S. lat). Kay, S., Ramos, V. (eds.), Geological Society of America Special Paper 07, pp.: 19-60.

KELLY, R. L.

-1983. Hunter-Gatherer Mobility Strategies. Journal of Anthropological Research 39:277-306.

-1994 Some Thoughts on Future Directions in the Study of Stone Tool Organization, in The Organization of North American Prehistoric Chipped Stone Tool Technology, edited by P. Carr. International Monographs in Prehistory 7:132-136. -1988. The three sides of a biface. American Antiquity 53 (4): 717-734.

-1992. Mobility/Sedentism: Concepts, Archaeological Measures, and Effects. Annual Review of Anthropology 21:43-66. -1995. The foraging spectrum. Diversity in hunter-gatherer life way. Smithsonian Institution Press. Washington D. C.

KELLY, R.L. AND LAWRENCE C. TODD.

-1988. Coming into the Country: Early Paleoindian Hunting and Mobility. American Antiquity 53:231-244.

KINTIGH, K.W.

-1989. Sample size, significance, and measures of diversity. Quantifying diversity in archaeology 25-36.

KOLDEHOFF, B.

-1987 The Cahokia flake tool industry: socioeconomic implications for Late Prehistory in the Central Mississippi Valley. En The Organization of Core Technology, editado por J.K. Johnson y C.A. Morrow, pp. 151-185. Westview Press, Boulder.

KREBS, C.J.

-1989. Ecological Methodology. Harper and Row Publishers, New York. 654 pp.

KREBS J.R 
-1994. A formal approach to the design and assembly of mobile toolkits. American Antiquity vol. 59 (3): 426-442.

-1995. Technology, foraging and land use: a strategic approach. En: Mousterian Lithic Technology and Ecological.19-37 y 125-156. Perspective. University Press, New Jersey.

KUHN, S.

-1989. Hunter-gatherer foraging organization and strategies of artifact replacement and discard. En D. S. Amick y R. P. Mauldin (eds.), Experiments in Lithic Technology: 33-47. Oxford, BAR International Series 528.

-1990. A geometric index of reduction for unifacial stone tools. Jounal of Achaeological Science 17: 583593.

-1994. A formal approach to the design and assembly of mobile toolkits. American Antiquity 59 (3): $426-$ 442.

-2004. Upper Paleolithic raw material economies at Ücagizli cave, Tuckey. Jounal of Anthropological Archaeology 23: 431-448.

LAGIGLIA, H.

-1968. Secuencias culturales del centro-oeste argentino: Valles del Atuel y el Diamante, Revista Científica de Investigaciones del Museo de Historia Natural de San Rafael (Mendoza), 1 (4): 159-176, San Rafael.

-1970a. Primer diagrama polínico de la estratigrafía arqueológica argentina. Notas del Museo N 11. Museo de Historia Natural de San Rafael, Mendoza

-1970b. Informe preliminar de las excavaciones arqueológicas del Atuel. En: Actas y Trabajos del 1er. Congreso de Arqueología Argentina; pp.: 97-101.

-1970c. Presencia del "Phaseolus vulgaris, var. OblongusAlef." En las excavaciones arqueológicas del Rincón del Atuel, Depto. de San Rafael (Mendoza), Argentina.Addenda et Corrigenda sobre el poroto prehispánico del Atuel. Notas del Museo 6. San Rafael. Mendoza.

-1974 Síntesis cronológico cultural del Centro Oeste Argentino con especial referencia a los valles del Atuel y Diamante. Revista del Museo de Historia Natural de San Rafael 2(3): 83-101, San Rafael.

-1975. Prehistoria del Centro Oeste Argentino. En: Revista del Museo de Historia Natural de San Rafael. 15: 15-22.

-1977a. Arqueología y Ambiente Natural de los Valles del Atuel y Diamante. Tesis Doctoral. 2 Tomos. Facultad de Ciencias Naturales y Museo. Universidad Nacional de La Plata. La Plata.

-1977b. Dinámica cultural en el Centro Oeste y sus relaciones con áreas aledañas argentinas y chilenas. Actas del VII Congreso de Arqueología Chilena; Tomo II: 531-560. Chile.

-1997a Arqueología de Cazadores- Recolectores Cordilleranos de Altura. Ediciones Ciencia y Arte. Instituto de Ciencias Naturales de San Rafael, Museo Municipal de Historia Natural, San Rafael.

-1997b. Arqueología Prehistórica del Atuel y Diamante. Revista del Centro de Investigación Territorial (CINTER) N² pp.29-46 Mendoza.

-1999. Las ocupaciones tempranas del Atuel (nuevos estudios en la Gruta del Indio). Actas XII Congreso Nacional de Arqueología Argentina, III: 251-255.

-2002. Arqueología y Prehistoria del sur mendocino y sus relaciones con el Centro Oeste Argentino, En: Entre Montañas y Desiertos. Arqueología del sur de Mendoza, Gil, A y G. Neme (eds.) 43-64, Sociedad Argentina de Antropología, Buenos Aires.

LANATA, J. 
1996. Cambios para evolucionar: las propiedades del registro arqueológico y la evolución de los grupos humanos en Patagonia y Tierra del Fuego. En: J. Gómez Otero (Ed.). Arqueología. Sólo Patagonia; pp.: 99-106. Puerto Madryn. Chubut.

LANATA, J. L., Y L. A. BORRERO

-1994 Riesgo y Arqueología. En: Arqueología de Cazadores-Recolectores. Límites, Casos y Aperturas. J.L. Lanata y L.A Borrero (comp.), pp.: 129-143, Arqueología Contemporánea 5. Bs.As.

LANE, $P$.

-2008 The use of ethnography in landscape archaeology. En: The Handbook of Landscape Archaeology, B.

David and J. Thomas (eds.). Left Coast Press: Walnut Creek, CA. WAC Research Handbook Series, pp.: 237-44.

LEMONIER, P.

-1992 Elements for an Anthropology of Technology. Anthropological Paper 88. Ann Arbor: Museum of Anthropology, University of Michigan, 1992.

LEÓN R J C., D. BRAN, M. COLLANTES, J.M. PARUELO AND A.SORIANO.

-1998. Grandes Unidades de vegetación en la Patagonia. Ecologia Austral 8 123-141

LINARES E. y GONZÁLEZ R.R.

-1990. Catálogo de edades radimétricas de la República Argentina 1957-1987. Asociación Geológica Argentina Publicaciones Especiales B-19,pp.: 628 Buenos Aires.

LLAMBÍAS, E. J.

-1966. Geología y petrología del volcán Payún Matrú. Acta Geológica Lilloana, 8: 265-310.

-2003. Geología de los cuerpos ígneos. Asociación Geológica Argentina, Serie B, Didáctica y Complementaria 27, Instituto Superior de Correlación Geológica, Serie Correlación Geológica 15, 182 p., Buenos Aires

-2008. El distrito volcánico de La Payunia. Un paisaje lunar en nuestro planeta. Colección SEGEMAR.

-2009. Volcanes. Nacimiento. Estructura. Dinámica. Ed. Vázquez Mazzini. Buenos Aires

LLAMBÍAS, E.J., BERTOTTO, G.W., RISSO, C. y I. R HERNANDO.

-2010. El volcanismo cuaternario en el retroarco de Payenia: una revisión. Revista de la asociación Geológica Argentina 67 (2): 278-300.

LLANO, C. L

-2008 El registro arqueobotánico en el sitio Arroyo Malo 3, alto valle del Atuel, Mendoza, Argentina. Intersecciones en Antropología 9; pp. 133-143

- 2011. Aprovechamiento de los Recursos vegetales entre las sociedades cazadoras-recolectores del Sur de Mendoza. Tesis Doctoral inédita, Universidad Nacional del COMAHUE.

LÓPEZ L., A. PÉREZ y C. R. STERN

-2009 Fuentes de aprovisionamiento y distribución de obsidianas en la provincia del Neuquén, noroeste de la Patagonia, Argentina. Intersecciones en Antropología 10: 75-80

LUEDTKE, B. E.

-1979. The Identification of Sources of Chert Artifacts. American Antiquity 44: 744-756. 
LURIE, R.

-1989. Lithic technology and mobility strategies: the Koster Site Middle Archaic. En: Time, Energy and Stone Tools. New directions in Archaeology, R. Torrence (ed.), pp.: 46-56. Cambridge University Press, Cambridge.

LYONS W. H., M. D. GLASCOCK y P. J. MEHRINGER JR

-2003. Silica from sources to site: ultraviolet fluorescence and trace elements identify cherts from Lost Dune, southeastern Oregon, USA, Journal of Archaeological Science 30: 1139-1159.

MANDRYK, C.

-1993. Hunter-gatherer social costs and the nonviability of submarginal environments. Journal of Anthropological Research 49: 39-70.

MARCHETTI, D.W., CERLING, T.E., EVENSON, E.B., GOSSE, J.C. y O. MARTÍNEZ

-2006. Cosmogenic exposures ages of lava flows that temporarily dammed the Río Grande and Río Salado, Mendoza province, Geological Society of America Meeting Backbone of the Americas,

Paper 5-39: 66, Mendoza.

MARKGRAFF, V.

-1983. Late and postglacial vegetational and paleoclimatic changes in subantartic temperate, and arid environments in Argentina. Palynology 7:43-70.

MARES, M. J. MORELLO y G. GOLDSTEIN

-1985. The monte desert and other subtropical semi-arid biomes of Argentina, with comments on their relation to North America arid areas. En: Hot Desert and Arid Shrublands; M. Evenari et al. (Eds.) pp.: 203-237. Elsevier Science Publishers. Amsterdam.

MCANANY, P.A.

-1988 The effects of lithic procurement strategies on tool curation and recycling. Lithic Technology 17:311.

MELCHOR, R. y S. CASADÍO

-1999. Hoja Geologica 3766-III La Reforma, provincia de La Pampa. Servicio Geológico Minero Argentino, Boletín 295, p. 63, Buenos Aires.

MELTZER, D.

-1989. Was Stone Exchange Among Eastern North American Paleoindians? En: Eastern Paleoindian lithic resource use, C. Ellis y J. Lothrop (ed.), pp.11-39. Westview Press, Boulder.

METCALFE D Y K.R. BARLOW

-1992. A model for exploring the optimal trade off between field processing and transport. American Anthropologist 94:340-356.

-1995. Clocking the First Americans. Annual Review of Anthropology, Vol. 24: 21-45.

MITHEN, S.

-1998. Introduction: The archaeological study of human creativity. Creativity in human evolution and prehistory. S. Mithen (ed.). Routledge. London. 
MONDINI, M Y S. MUÑOZ

-2004. Behavioural Variability in the So-Called Marginal Areas from a Zooarchaeological Perspective: An Introduction. En: Colonisation, Migration, and Marginal Areas. A Zooarchaeological Approach, pp.: 42-45 Oxbow Books. UK.

MORRISON, K. D.

-1994. The intensification of production: archaeological approaches. Journal of archaeological Method and Theory 1(2):111-159.

MORRISON, K.D.

-1995, Fields of Victory: Vijayanagara and the Course of Intensification, Contributions of the University of California Archaeological Research Facility, No. 53, Berkeley.

MORROW, C. y R. JEFFERIES

-1989. Trade or embedded procurement?: a test case from southern Illinois. En: Time, Energy and Stone Tools, R. Torrence (ed.): 27-33. Cambridge, Cambridge University Press

MUGAS LOBOS, A.; MÁRQUEZ-ZAVALÍA, M. y M. GALLINSKI

-2010. Petrografía y geoquímica de las rocas gondwánicas del proyecto minero Don Sixto, Mendoza. Revista Asociación Geológica Argentina Vol.67 (3): 392-402.

NAMI, $\mathrm{H}$.

-1986. Experimentos para el estudio de la tecnología bifacial de las ocupaciones tardías en el extremo sur de Patagonia Continental. PREP: Informes de Investigación 5:1-120.

-1992. El subsistema tecnológico de la confección de instrumentos líticos y la explotación de los recursos del ambiente: una nueva vía de aproximación. Shincal 2 :33-53.

2003. Experimentos para explorar la secuencia de reducción Fell de la Patagonia Austral. Magallania 31: 107-138.

NARANJO, J.A.; HALLER, M.J.; OSTERA, H.A.; PESCE, A.H.; SRUOGA, P.

-1999. Geología y peligros del Complejo Volcánico Planchón-Peteroa, Andes del Sur (35¹5'S), Región del Maule, Chile-Provincia de Mendoza, Argentina. Servicio Nacional de Geología y Minería, Boletín, No. 52,55 p.

NARCISO, V., G. SANTAMARÍA Y J. C. ZANETTINI.

-2001a. Hoja Geológica 3769-I Barrancas. Provincias de Mendoza y Neuquén. Instituto de Geología y Recursos Minerales, Servicio Geológico Minero Argentino. Boletín 253, Buenos Aires.

NARCISO, V., J. M. ZANETTINI Y E. SEPULVEDA.

-2001b. Hoja Geológica 3769-II Agua Escondida. Provincias de Mendoza y La Pampa. Instituto de Geología y Recursos Minerales, Servicio Geológico Minero Argentino. Boletín 300, Buenos Aires

NELSON, M.

-1991. The Study of Technological Organization. Archaeological Method and Theory, M. Schiffer (ed.): 5799. Tucson University of Arizona Press.

NEME, G. 
2002a. Arqueología del Alto Valle del Atuel (Provincia de Mendoza).Tesis Doctoral. Facultad de -Ciencias Naturales. Universidad Nacional de La Plata. 2 tomos. La Plata.

-2002b. Arqueología del alto valle del río Atuel: modelos, problemas y perspectivas en el estudio arqueológico de las regiones de altura del sur de Mendoza. En: Entre Montañas y Desiertos: Arqueología del Sur de Mendoza, A. Gil y G. Neme (eds.), pp.: 65-84. Sociedad Argentina de Antropología, Serie Libros, Buenos Aires.

-2007. Cazadores-recolectores de altura en los Andes meridionales: el alto valle del río Atuel. British Archaeological Reports International Series: 1591. Reino Unido.

-2009. Un enfoque regional en cazadores-recolectores del oeste argentino: el potencial de la ecología humana. En: Perspectivas actuales en Arqueología Argentina, Por R. Barberena, K. Borrazo y L.A. Borrero (eds.). CONICET, IMICIHU, Bs.As.

NEME G. y A. GIL.

-2008. Biogeografía humana en los andes meridionales: tendencias arqueológicas en el sur de Mendoza. Chungara, Revista de Antropología Chilena 40 (1):5-18.

-2009 Human occupation and increasing Mid-Holocene Aridity. Current Anthropology Vol. 50(1), pp.: 149163.

-2012. El registro Arqueológico del sur de Mendoza en Perspectiva Biogeográfica. En: Paleoecología humana en el sur de Mendoza, Gil A. y G. Neme (eds.). Sociedad Argentina de Antropología. En Prensa.

NEME, G., D. NAVARRO, D. ANDREONI, C. LLANO, M. GIARDINA, C. OTAOLA, F. FERNANDEZ, C. WHITLOCK, A. GIL.

-2011 Human subsistence changes during the late Holocene: resource over exploitation or climate change in the upper Atuel river valley, Argentina. Poster presentado en el XVIII INQUA, Berna Suiza.

NOVELLINO P.

-2002. Bioarqueología del Sur de Mendoza. En: Gil, A y G Neme (eds.) Entre Montañas y Desiertos. Arqueología del sur de Mendoza, pp. 119-139 Sociedad Argentina de Antropología, Buenos Aires.

NOVELLINO, P. y A. GIL

2007. Estrés nutricional, hipoplasia y explotación de recursos en el centro sur de Mendoza (Argentina) Intersecciones en Antropología 8: 17-29.

NOVELLINO P., A. GIL, G. NEME y V. DURÁN.

2004. El consumo de maíz en el Holoceno tardío del oesteargentino: isótopos estables y caries. Revista Española de Antropología Americana 34: 85-110.

NULLO, F.E., STEPHENS, G., COMBINA, A., DIMIERI, L., BALDAUF, P. Y PABLO BOUZA.

-2005. Hoja Geológica 3569-III / 3572-IV Malargüe, Provincia de Mendoza. Instituto de Geología y Recursos Minerales, Servicio Geológico Minero Argentino, Boletín 346:85, Buenos Aires.

ODELL, G. H.

-1996. Economizing Behavior and the Concept of "Curation". En Stone Tools Theoretical Insights into Human Prehistory, ed. G. H. Odell, pp. 51-80. Plenum Press, New York.

-2003. Lithic Analysis (Manuals in Archaeological Method, Theory and Technique). Serie editors: Orser C. E y Shiffer M. B. Springer. U.S.A. 
O'CONNELL, J. F. Y HAWKES

-1998. Hadza Hunting, Butchering and bone transport and their archaeological implication. Journal of archaeological research, 44: 2; 113-161

O'CONNELL, J., Y F. MARSHALL

-1989. Analysis of Kangaroo Body Part Transport Among the Alyawara of Central Australia. Journal of Archaeological Science 16:393-405.

OTAOLA, C

2012. Zooarqueología en la Cordillera del Sur de Mendoza: un Enfoque Tafonómico. Tesis doctoral inédita. Universidad de Buenos Aires.

PÁEZ, M. M., D. NAVARRO, L.D. ROJO y A. GUERCI

2010. Vegetación y Paleoambientes durante el Holoceno en Mendoza. En: Condiciones paleoambientales y ocupaciones humanas durante la transición Pleistoceno-Holoceno en Mendoza M. Zárate, A. Gil y G. Neme (Comp) , pp.:175-212. Sociedad Argentina de Antropología, Buenos Aires.

PARRY, W. Y R. KELLY

1987. Expedient core technology and sedentism. En: The organization of core technology, J. Johnson y C. Morrow (ed.), pp.: 285-304. Westview Press, Colorado.

PASQUARE, G., BISTACCHI, A., FRANCALANCI, L., BERTOTTO, G., BOARI, E., MASSIRONI, M. Y ROSSOTTI, A. -2008. Very long pahoehoe basaltic lava flows in the Payenia volcanic province (Mendoza and La Pampa), Argentina. Revista de la Asociación Geológica Argentina 63 (1): 131-149.

PAULIDES, L. S.

2011. Organización de la tecnología lítica en el curso superior del Río Salado (Mendoza): el Sitio Puesto Jaque 2. Trabajo presentado en XVII Congreso Nacional de Arqueología Argentina. Mendoza.

PÁEZ, M. M., D. NAVARRO, L.D. ROJO, A. GUERCI

2010. Vegetación y Paleoambientes durante el Holoceno en Mendoza. En: Condiciones paleoambientales y ocupaciones humanas durante la transición Pleistoceno-Holoceno en Mendoza, M. Zárate, A. Gil y G. Neme (Comp), pp.:175-212. Sociedad Argentina de Antropología, Buenos Aires.

PELCIN, A.

-1998. The threshold effect of platform width: a reply to Davis and Shea. Journal of Archaeological Science 25: 615-620.

PÉREZ WINTER, C.

-2008. Organización Tecnológica durante el Holoceno Medio en el Alto Valle del Río Atuel, Sur de Mendoza. Caso: Arroyo Malo 3. Tesis de Lic. Fac. de Filosofía y Letras, UBA, Buenos Aires.

-2009a. Cambios climáticos y estrategias tecnológicas: caso arqueológico Arroyo Malo 3, sur de Mendoza, Argentina. Socidade \& Natureza 21(3): 289-304.

-2009b. Estructuración de los recursos líticos en el sur de la provincia de Mendoza, Argentina: una perspectiva arqueológica. Caminhos de Geografia Uberlândia 10(30): 1-12.

-2010. Tendencias del registro lítico durante el Holoceno medio: sitio Arroyo Malo 3, alto valle del río Atuel, sur de Mendoza. Intersecciones en Antropología 11: 159-172. 
POLANSKI, J.

-1954. Rasgos geomorfológicos del territorio de la provincia de Mendoza. Ministerio de Economía, Instituto de investigaciones Económicas y tecnológicas. Cuaderno de investigaciones y Estudios 4.

POLITIS, G.

-1988. Paradigmas, modelos y métodos en la Arqueología de la Pampa Bonaerense. En: Arqueología

Contemporánea Argentina. Ediciones Búsqueda. Buenos Aires.

PRATES, L.

2008. Arqueología del valle medio del Río Negro. Sociedad Argentina de Antropología, Colección tesis de doctorado, Buenos Aires.

QUIDELLEUR, X., J. CARLUT, P.TCHILINGUIRIAN, A. GERMA y P. GILLOT,

-2009. Paleomagnetic directions from mid-latitude sites in the southern hemisphere (Argentina): Contribution to time averaged field models. Physics of the Earth and Planetary Interiors 172: 199209.

RAMOS, V.A.

-2009. Anatomy and global context of the Andes: Main geologic features and the Andean orogenic cycle. En Kay, S.M., Ramos, V.A. y Dickinson, W. (eds.) Backbone of the Americas: Shallow Subduction, Plateau Uplift, and Ridge and Terrane Collision, Geological Society of America, Memoir 204: 31-65.

RAMOS, V.A., FOLGUERA, A.

-2005. Tectonic evolution of the Andes of Neuquén: constraints derived from the magmatic arc and foreland deformation. In: Veiga, G., et al. (Ed.), The Neuquén Basin: a case study in sequence stratigraphy and basin dynamics: The Geological Society, Special Publication, 252, pp. 15-35

-2011. Payenia volcanic province in the Southern Andes: An appraisal of an exceptional Quaternary tectonic setting. Journal of Volcanology and Geothermal Research 201: 53-64.

RAMOS, V.A. y S.M. KAY

2006. Overview of the Tectonic Evolution of the Southern Central Andes of Mendoza and Neuquén $\left(35^{\circ}\right.$ $39^{\circ} \mathrm{S}$ Latitude). En: Evolution of an Andean margin: A tectonic and magmatic view from the Andes

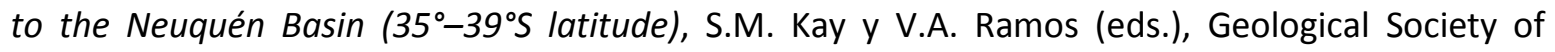
America, Special Paper 407: 1-18.

RAFFERTY, J.

1985 The archaeological record on sedentarines: recognition, development and implications. En Advances in Archaeological Theory and Methods, M. Schiffer (ed), pp. 113-148. Academic Press, New York.

RATHJE, W. L., Y M. B. SCHIFFER

1982. Archaeology. Harcourt Brace Jovanovich, New York.

RENFREW, C.

-1977. Alternative models for exchange and spatial distribution. En: Exchange Systems in Prehistory, T. Earle y J. Ericson (ed.), pp. 71-90. Academic Press, New York.

RISSO, C., K., NÉMETH, A.M., COMBINA, F. NULLO y M. DROSINA, 
2008. The role of phreatomagmatism in a Plio-Pleistocene highdensity scoria cone field: Llancanelo Volcanic Field (Mendoza), Argentina. Journal of Volcanology and Geothermal Research 169: 61-86.

ROIG F. A.

-1972 Bosquejo fisionómico de la vegetación de la provincia de Mendoza. Boletín de la Sociedad Argentina de Botánica pp.: 49-80. X Jornadas Argentinas de Botánica. Mendoza.

ROIG F.A., E. MARTÍNEZ CARRETERO Y E. MÉNDEZ

-2000. Vegetación de la Provincia de Mendoza. En: ARGENTINA. Recursos y problemas ambientales de la zona árida. Provincias de Mendoza, San Juan y La Rioja. Tomo I, Caracterización ambiental.E.M. Abraham y F.R Martínez (eds.), pp.: 63-70.

RUBINSTEIN, N.,

-2005. Informe petrográfico - mineralógico, Hoja Minero-metalogenética Agua Escondida, Minas de Mo Elsiren y Germán. Informe interno, SEGEMAR, 16 pp.

RUBINSTEIN, N. y M. F. GARGIULO

-2005. Análisis textural de cuarzo hidrotermal del depósito El Pantanito, provincia de Mendoza: nuevos aportes sobre su génesis. Revista de la Asociación Geológica Argentina 60 (1): 96-103

RUSCONI, C.

-1961-62. Poblaciones pre y posthispánicas de Mendoza, Arqueología, Imprenta Oficial, Mendoza. 4 tomos.

SALGÁN, M. L.

-2007. Biogeografía humana y organización tecnológica en el sur de la Provincia de Mendoza. En: ICES-3, Malargüe. Mendoza.

-2009. Fuentes de aprovisionamiento y disponibilidad de recursos líticos en La Payunia: Avances y Perspectivas. IV Jornadas Arqueológicas Cuyanas. INCIHUSA-CONICET. Mendoza, pp.: 74.

-2010. Análisis petrográfico y fuentes primarias de rocas silíceas. Avances y perspectivas en el estudio de la organización tecnológica de poblaciones cazadoras y recolectoras de La Payunia (Mendoza, Argentina). Trabajo presentado en XVII Congreso Nacional de Arqueología Argentina. Mendoza.

-2011. Obsidianas en el campo volcánico de La Payunia: aprovisionamiento, patrones de distribución e implicancias para la ocupación regional. Trabajo presentado en VIII Jornadas de Arqueología de la Patagonia. Libro de Resúmenes: 71. Malargüe, Mendoza

SALGÁN, L. Y C. PÉREZ WINTER.

-2008-09. Fuentes primarias y secundarias en ambientes de altura y áridos del sur de Mendocino. Anales en Antropología y Etnología 63-64:247-275. Universidad Nacional de Cuyo. Mendoza.

SALGÁN, M. L., A. GIL y G. NEME

-2012. Obsidianas en La Payunia (sur de Mendoza, Argentina): patrones de distribución e implicancias en la ocupación regional. Revista Magallania, Vol.40(1): 263-277.

SANTAMARÍA, G. R.,

1997. Determinaciones petrográficas de la Hoja 3769-I, Barrancas, provincias de Mendoza y Neuquén. Secretaría de Minería. Delegación Mendoza, 5 págs., (Informe inédito). Mendoza. 
SARIO, G.

2010. Poblamiento humano en la provincia de San Luis: una perspectiva arqueológica a través del caso de la organización de la tecnología en la Ea. La Suiza. Tesis doctoral. Universidad Nacional de Córdoba.

SASSAMAN, $\mathrm{K}$

1994. Production for Exchange in the Mid-Holocene Southeast: A Savannah River Valley Example. Lithic Technology, Vol. 19 (1): 42-51.

SEELENFREUND, A., C. REES, R. BIRD, G. BAILEY, R. BÁRCENA, V. DURÁN

-1996. Trace-Element Analysis of Obsidian Sources and Artifacts of Central Chile (Maule River Basin) and Western Argentina (Colorado River).En Latin American Antiquity, Vol. 7, No. 1, pp. 7-20

SEMPER, J., y H. LAGIGLIA

1968. Excavaciones arqueológicas en el Rincón del Atuel. Revista Científica de Investigaciones 1 (4): 89158. San Rafael. Mendoza.

SHACKLEY, M.S.

-1998 Archaeological Obsidian Studies: Method and Theory. En: Advances in Archaeological and Museum Sciences Series 3, New York: Springer / Plenum Publishing.

-2005. Obsidian: Geology and Archaeology in the North American Southwest. Tucson, The University of Arizona Press.

-2007. Archaeological Petrology and the Archaeometry of Lithic Materials. $50^{\text {th }}$ Anniversary Volume, edited by A.M. Pollard. Archaeometry 50: 194-215.

SCHEINSOHN, V.

-2002 En el país de los ciegos el tuerto es rey. Visibilidad arqueológica y paisaje en la localidad Cholila. En: Contra viento y marea. Arqueología de Patagonia, M. T. Civalero, P. M. Fernández y A. G. Guráieb (eds.). Instituto Nacional de Antropología y Sociedad Argentina de Antropología. Buenos Aires.

SCHIFFER, M.B.

-1972 Archaeological Context and Systemic Context. American Antiquity 37:156-165.

-1976 Behavioral Archeology. Academic Press, New York.

SHIFFER, M. B. y J.M. SKIBO

-1987. Theory and experiment in the study of technological change. En: Current Anthropology, 28: 595-622.

SCHOBINGER J.

-1975. Prehistoria y protohistoria de la Región Cuyana. Museo de Ciencias Naturales y Antropológicas "Juan Cornelio Moyano", Mendoza.

-1978. Nuevos lugares con arte rupestre en el extremo sur de la provincia de Mendoza, Relaciones de la Sociedad Argentina de Antropología, T. XII, pp. 175-182, Buenos Aires.

SHOTT, M.

-1986. Technological organization and settlement mobility: an ethnographic examination. Journal of Anthropological Research 4 (2): 15-51. 
1989. Diversity, organization, and behavior in the material record. Ethnographic and archaeological examples. Current Anthropology 30: 283-315.

-1994. Size and form in the analysis of flake debris: review and recent approaches. Journal of Archaeological Method and Theory 1: 69-110.

-2003. Chaı^ne ope'ratoire and reduction sequence. Lithic Technology 28: 95-105.

SMITH, E. A.

-2000. Three Styles in the Evolutionary Analysis of Human Behaviour. En: Adaptation and Human Behaviour. Ed. Por L. Conk, N. Chagnon and W. Irons. New York: Aldine de Gruyter, pp.27-46.

SPIELMANN, K.

-1986. Interdependence among egalitarian societies. Journal of Anthropological Archaeology 5: 279-312.

SRUOGA, P.; P. GUERSTEIN Y A. BERMUDEZ

-1993. Riesgo volcánico. En: V. Ramos (Ed.) Geología y Recursos Naturales de Mendoza. Relatorio del XII Congreso Geológico Argentino 1: 659-667. Mendoza.

STERN, C.

-1994. The implications of time-averaging for reconstructing the land-use patterns of early tool-using hominids. En: Early Hominid Behavourial Ecology. Editado por: J. Oliver, N. Sikes y

K. M. Steart, pp. 89-105. Orlando, Academic Press.

-2004. Obsidian in southern Patagonia: Review of the current information. Contra viento y marea. Arqueología de Patagonia, (M. T. Civalero, P. M. Fernández y A. G. Guráieb Comp.), Instituto Nacional de Antropología y Pensamiento Latinoamericano y Sociedad Argentina de Antropología, Buenos Aires: 168-176.

STERN, C. Y N. FRANCO

-2000. Obsidiana gris verdosa veteada en la cuenca superior del río Santa Cruz, extremo sur de Patagonia. Anales del Instituto de la Patagonia, Serie Ciencias Humanas 28: 265-273.

STERN, C.R., F.A. FREY, K. FUTA R.E. ZARTMAN, PENG, Z. y T.K. KYSER,

-1990. Trace element and $\mathrm{Sr}, \mathrm{Nd}, \mathrm{Pb}$ and $\mathrm{O}$ isotopic composition of Pliocene and Quaternary alkali basalts of the Patagonian plateau lavas of southernmost South America.Contributions to Mineralogy and Petrology, Vol. 104, p. 294-308.

STOUT, D.

-2002. Skill and cognition in stone tool production. Current Anthropology 43 (5): 693-722.

SUGRAÑES, N.

-2009. Entre fragmentos y vasijas: Análisis cerámico del sitio Valle Hermoso 1 (Malargüe, Mendoza). Tesis de licenciatura inédita. Facultad de Humanidades y Artes. Universidad Nacional de Rosario.

-2011. Tecnología Cerámica y Estrategias de Movilidad entre Cazadores Recolectores de Altura. El caso del sitio Valle Hermoso 1 (Malargüe, Mendoza). Intersecciones en Antropología 12: 155-166.

SULLIVAN, A. III y K. ROZEN

-1985. Debitage Analysis and Archaeological Interpretation. American Antiquity 50(4):755-779 
SUROVELL, T. A.

-2009. Toward a Behavioral Ecology of Lithic Technology: Cases from Paleoindian Archaeology. University of Arizona Press, Tucson.

TARBUCK, E.J., y F.K. LUTGENS

-1992. The Earth:An Introduction to Physical Geology, 4th ed. New York: Macmillan.

THOMAS, D. H.

-1975. Nonsite Sampling in Archaeology. Up the Creek Without a Site? Sampling in Archaeology. Ed. J. E Mueller, pp. 67-81. The University of Arizona Press, Tucson.

TORRENCE, R.

-1989. Tools as optimal solutions. En Time, energy and stone tools, R. Torrence (ed), pp. 1-6. Cambridge University Press. Cambridge.

-1994. Strategies for moving on in lithic studies. The organization of North American Prehistory Chipped Stone Tool Technology, Carr (ed.). International Monographs in Prehistory Archaeological Series 7: 123-136.

TRIPALDI, A.

-2010 Campos de dunas en la planicie sanrafaelina: patrones de dunas e inferencias paleoclimáticas durante el Pleistoceno tardío-Holoceno. En: Condiciones paleoambientales y ocupaciones humanas durante la transición Pleistoceno.Holoceno y Holoceno de Mendoza, pp.65-94Zárate et al compiladores. Sociedad Argentina de Antropología, Buenos Aires.

TUCKER, H., A. RISI Y R. BANDIERA

-2011. Identification of astronomical objects in ancient engravings: Malargüe, Mendoza, Argentina. Methodological contributions in archaeoastronomy. "Oxford IX" International Symposium on Archaeoastronomy Proceedings IAU Symposium No. 278, Clive L. N. Ruggles, ed.: 118-127.

TAYLOR, W.

1964. Thethered nomadism and water territoriality hypothesis. En: Acts of the $5^{\text {th }}$ Congress of Americanist: 197-203.

UGAN, A. G. NEME, A. GIL, J. COLTRAIN, R. P. TYKOT y P. NOVELLINO

-2012. Geographic variation in bone carbonate and water $18 \mathrm{O}$ values in Mendoza, Argentina and their relationship to prehistoric economy and settlement. Journal of Archaeological Science 39:27522763.

UGAN, A., J. BRIGHT, y A. ROGERS

-2003 When Is Technology Worth the Trouble? Journal of Archaeological Science 30:1315-1329.

VETH. P. M.

-1993. Islands in the Interior. The Dynamics of Prehistoric Adaptations within the Arid Zone of Australia. Ann Arbor, International Monographs in Prehistory, Archaeological Series 3.

VIOLANTE, R., OSELLA, A., VEGA, M., DE LA ROVERE, E., OSTERRIETH, M.,

-2010. Paleoenvironmental reconstruction in the western lacustrine plain of Llancanelo Lake, Mendoza, Argentina. Journal of South American Earth Sciences 29 (3), 650-664. 
WHALLON, R.

-2006. Social networks and information: Non - "utilitarian" mobility among huntergatherers. Journal of Anthropological Archaeology 25: 259-270.

WILSON, L.

-2007. Understanding Prehistoric Lithic Raw Material Selection: Application of a Gravity Model J Archaeology Method Theory (2007) 14:388-411.

WINTERHALDER, B., y E. A. SMITH,

-1981. Hunter-Gatherer Foraging Strategies: Ethnographic and Archaeological Analyses. Chicago: University of Chicago Press

-1992. Evolutionary ecology and the social sciences. En: Evolutionary Ecology and Human Behavior.Ed. E.A.Smith y B.Winterhalder, capítulo 1. Aldine de Gruyter, New York.

-2000. Analyzing adaptive strategies: Human behavioral ecology at twenty-five. Evolutionary Anthropology 9 (2): $51-72$.

YELLEN, J.

-1977. Long Term Hunter-Gatherer Adaptation to Desert Environments: A Biogeographical Perspective. World Archaeology 8:262-274.

ZÁRATE, M.

-2002. Los ambientes del tardiglacial y Holoceno en Mendoza. En: Gil, A., Neme, G. (Eds.), Entre Montañas y Desiertos: Arqueología del Sur de Mendoza. Sociedad Argentina de Antropología, Buenos Aires, pp. 9-42.

ZÁRATE, M. A. GIL y G. NEME

-2010. Integrando los registros: generalizaciones, alcances y limitaciones. En: Condiciones paleoambientales y ocupaciones humanas durante la transición Pleistoceno-Holoceno y Holoceno de Mendoza, M. Zárate, A. GIL y G. NEME (comp), pp.309-330. Sociedad Argentina de Antropología, Buenos Aires. 